\title{
Deployment of Solar-Assisted and Non-Solar Electric Vehicle Charging Stations in the State of Tennessee FINAL REPORT
}

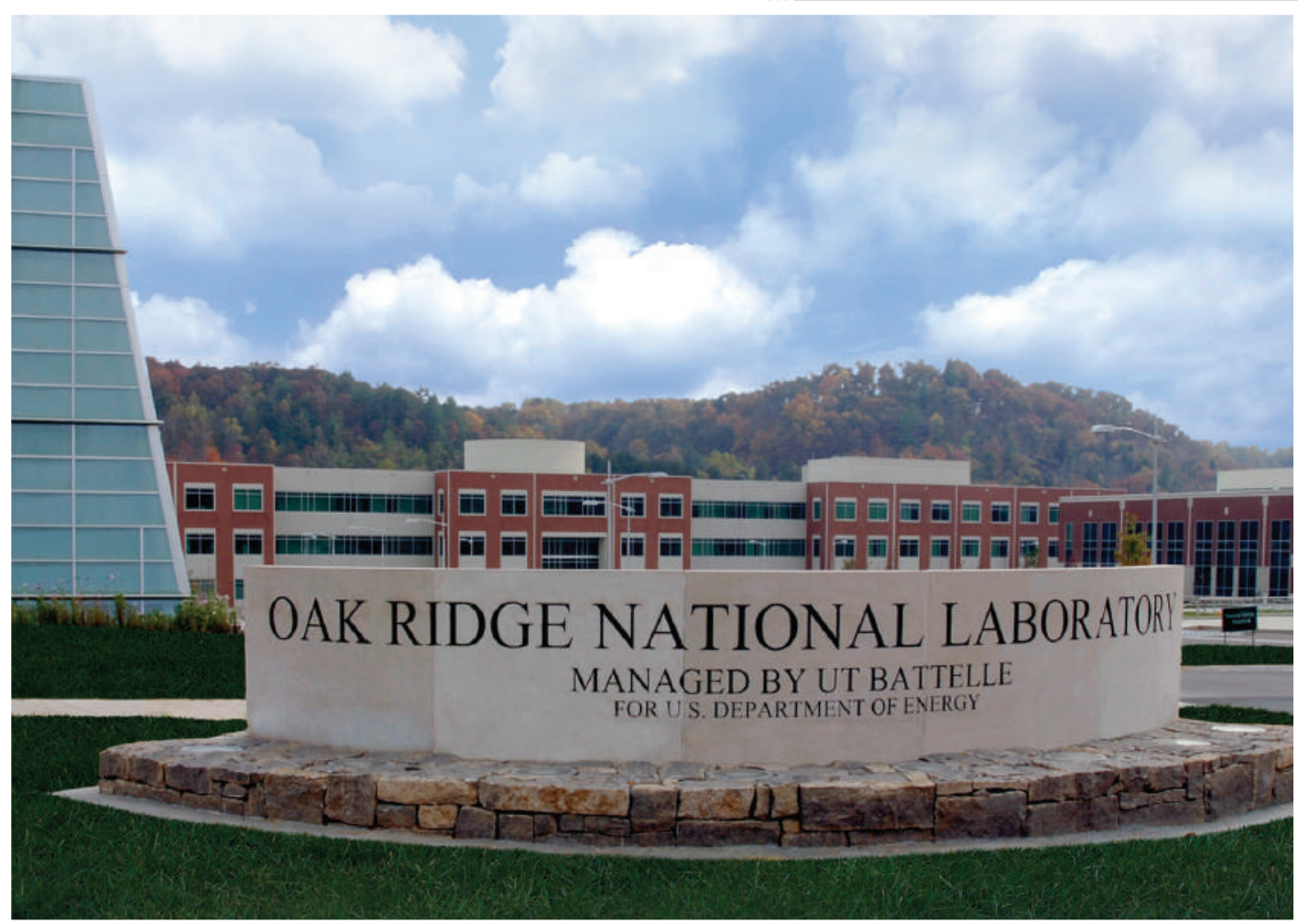

Approved for public release. Distribution is unlimited.
Norm Durfee

Rick Goeltz

Tim LaClair Melissa Lapsa Curt Maxey Randy Overbey

September 2014 


\section{DOCUMENT AVAILABILITY}

Reports produced after January 1, 1996, are generally available free via US Department of Energy (DOE) SciTech Connect.

Website http://www.osti.gov/scitech/

Reports produced before January 1, 1996, may be purchased by members of the public from the following source:

National Technical Information Service

5285 Port Royal Road

Springfield, VA 22161

Telephone 703-605-6000 (1-800-553-6847)

TDD 703-487-4639

Fax 703-605-6900

E-mail info@ntis.gov

Website http://www.ntis.gov/help/ordermethods.aspx

Reports are available to DOE employees, DOE contractors, Energy Technology Data Exchange representatives, and International Nuclear Information System representatives from the following source:

Office of Scientific and Technical Information

PO Box 62

Oak Ridge, TN 37831

Telephone 865-576-8401

Fax 865-576-5728

E-mail reports@osti.gov

Website http://www.osti.gov/contact.html

This report was prepared as an account of work sponsored by an agency of the United States Government. Neither the United States Government nor any agency thereof, nor any of their employees, makes any warranty, express or implied, or assumes any legal liability or responsibility for the accuracy, completeness, or usefulness of any information, apparatus, product, or process disclosed, or represents that its use would not infringe privately owned rights. Reference herein to any specific commercial product, process, or service by trade name, trademark, manufacturer, or otherwise, does not necessarily constitute or imply its endorsement, recommendation, or favoring by the United States Government or any agency thereof. The views and opinions of authors expressed herein do not necessarily state or reflect those of the United States Government or any agency thereof. 
Energy and Environmental Sciences Division

\title{
DEPLOYMENT OF SOLAR-ASSISTED AND NON-SOLAR ELECTRIC VEHICLE CHARGING STATIONS IN THE STATE OF TENNESSEE
}

\section{FINAL REPORT}

\author{
Norm Durfee \\ Rick Goeltz \\ Tim LaClair \\ Melissa Lapsa \\ Curt Maxey \\ Randy Overbey \\ Partners
}

Tennessee Valley Authority

Electric Power Research Institute

Nissan, North America.

State of Tennessee

Site Hosts

Date Published: September 2014

Prepared by

OAK RIDGE NATIONAL LABORATORY

Oak Ridge, Tennessee 37831-6283

managed by

UT-BATTELLE, LLC

for the

US DEPARTMENT OF ENERGY

under contract DE-AC05-00OR22725 



\section{CONTENTS}

Page

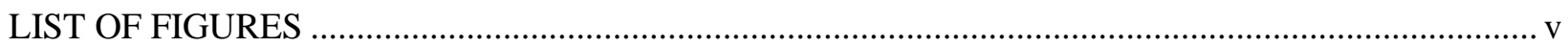

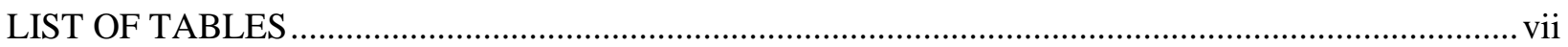

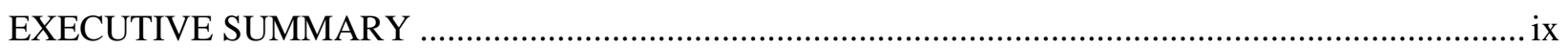

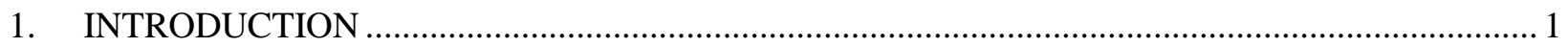

1.1 OVERVIEW OF THE ELECTRIC VEHICLE PROJECT …........................................... 1

1.2 US POLICY REGARDING EVS AND THE EV PROJECT AT THE NATIONAL

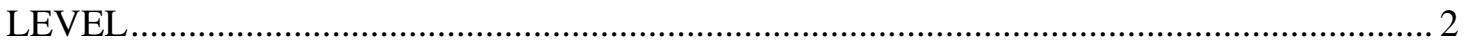

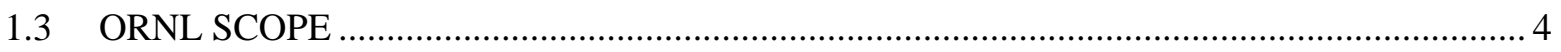

1.3.1 Phase 1 Installations-Solar-Assisted Level 2 EV Charging Stations .......................... 4

1.3.2 Phase 2 Installations-Level 2 and DCFC EV Charging Stations on the ORNL

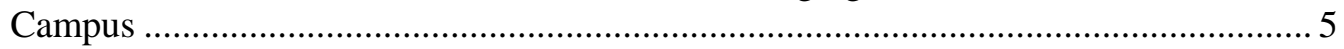

1.4 STATE OF THE TECHNOLOGY FOR EV CHARGING …....................................... 5

1.5 OVERVIEW OF THE SPECIFIC TECHNOLOGIES DEPLOYED IN THE ORNL

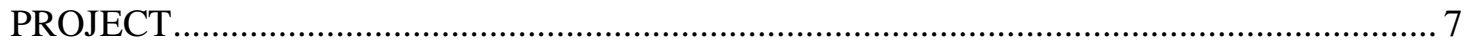

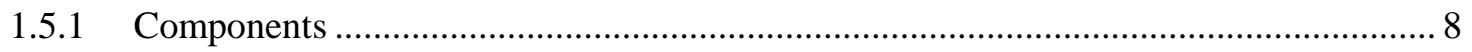

1.6 SUMMARY OF EV CHARGING STATIONS INSTALLED DURING THIS

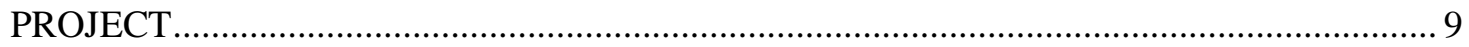

2. PHASE 1 INSTALLATIONS-SOLAR-ASSISTED CHARGING STATIONS INSTALLED

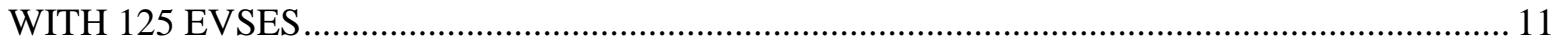

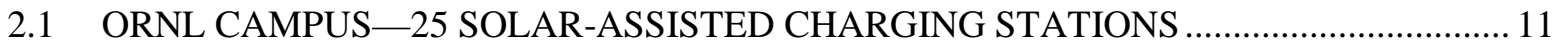

2.2 EPRI, KNOXVILLE-SIX SOLAR-ASSISTED CHARGING STATIONS ........................ 15

2.3 SMYRNA, NISSAN ADMINISTRATION BUILDING-NINE SOLAR-ASSISTED

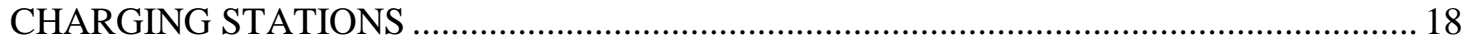

2.4 SMYRNA, NISSAN BATTERY PLANT—THREE SOLAR-ASSISTED CHARGING

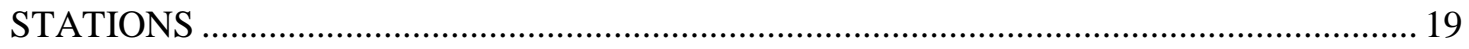

2.5 FRANKLIN, NISSAN HEADQUARTERS-EIGHTEEN SOLAR-ASSISTED

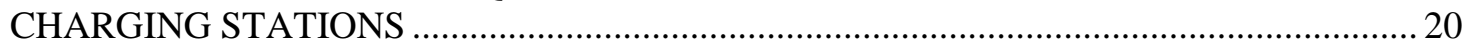

2.6 CITY OF KNOXVILLE-TEN SOLAR-ASSISTED CHARGING STATIONS ................. 22

2.7 UNIVERSITY OF TENNESSEE-KNOXVILLE-TWELVE SOLAR-ASSISTED

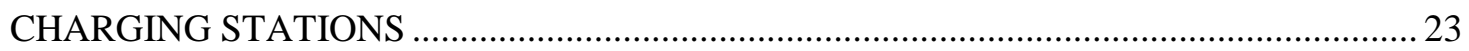

2.8 NASHVILLE, LP FIELD_EIGHT SOLAR-ASSISTED CHARGING STATIONS ............. 24

2.9 STATE OF TENNESSEE EMPLOYEE PARKING LOT-FOUR SOLAR-ASSISTED

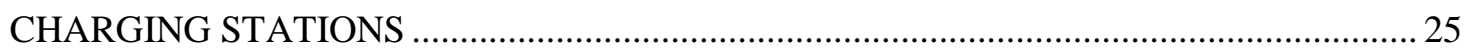

2.10 NASHVILLE, VANDERBILT-10 SOLAR-ASSISTED CHARGING STATIONS ........... 26

2.11 CHATTANOOGA-TEN SOLAR-ASSISTED CHARGING STATIONS ........................... 26

2.12 MEMPHIS, SHELBY FARMS-TEN SOLAR-ASSISTED CHARGING STATIONS ........ 27

3. PHASE 2 INSTALLATIONS-NON-SOLAR LEVEL 2 EVSES AND DCFC ON THE

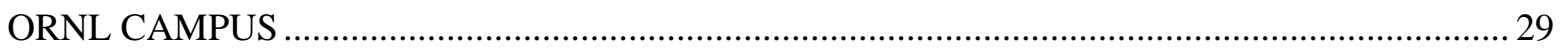

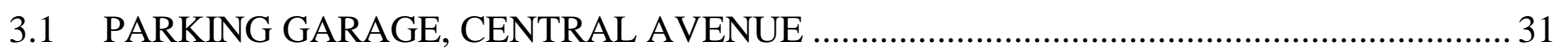

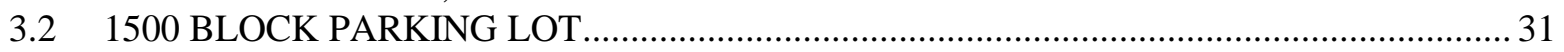

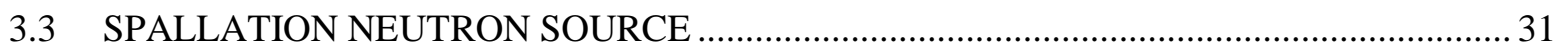

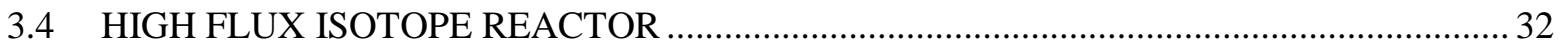

3.5 NATIONAL TRANSPORTATION RESEARCH CENTER …........................................... 32

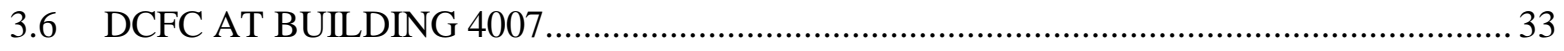

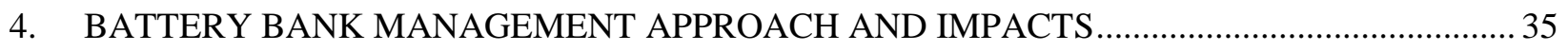

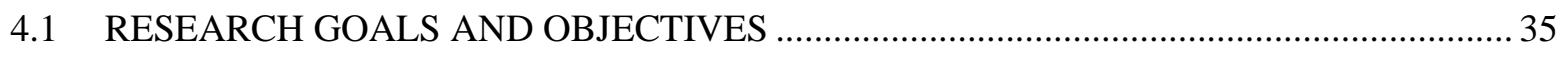




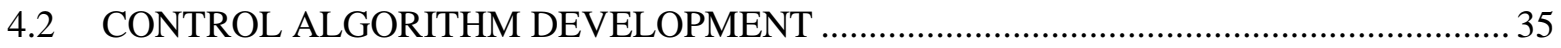

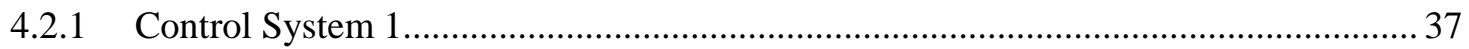

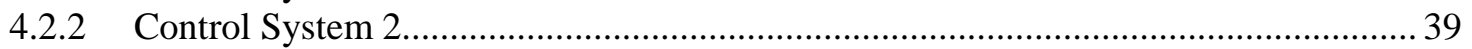

4.2.3 Control System 3 ........................................................................................... 40

4.3 EVALUATION OF THE BATTERY MANAGEMENT CONTROL SCHEMES ................ 41

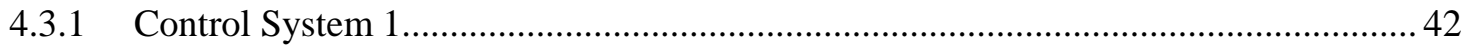

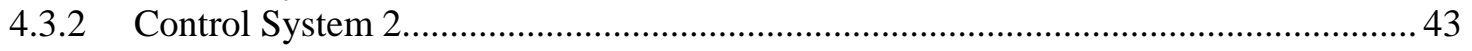

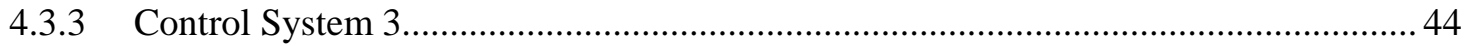

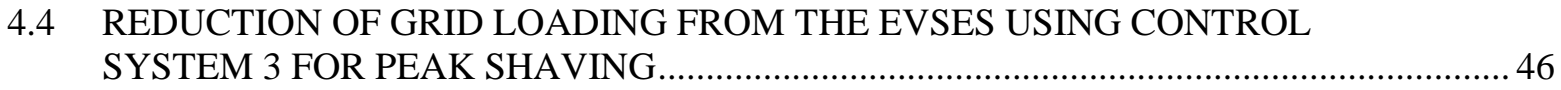

4.5 FINAL IMPLEMENTATION OF THE CONTROL ALGORITHM AND

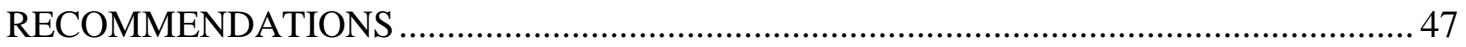

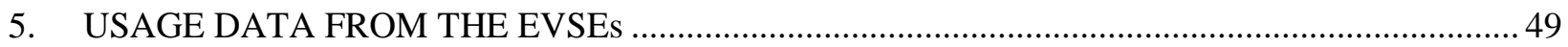

5.1 DATA PROCESSING AND INFRASTRUCTURE SUMMARY REPORT

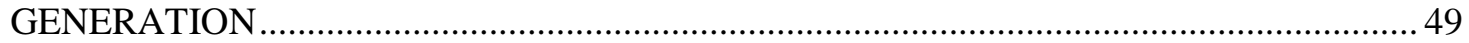

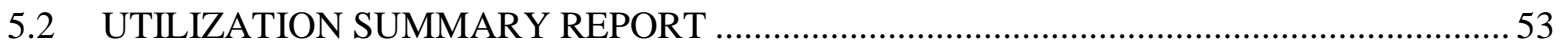

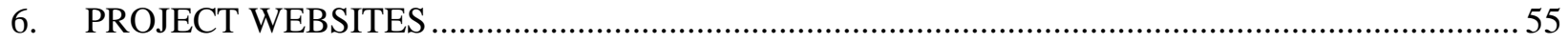

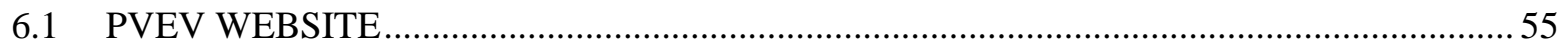

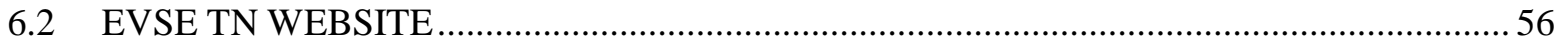

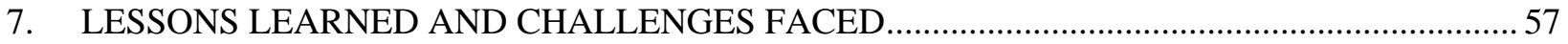

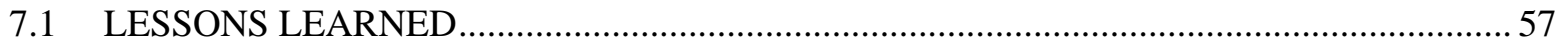

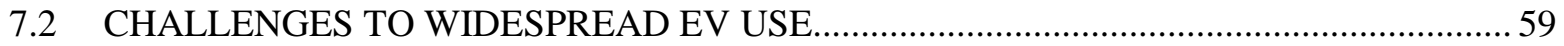

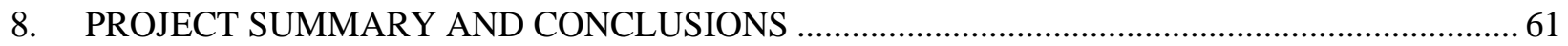

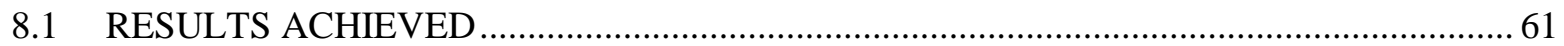

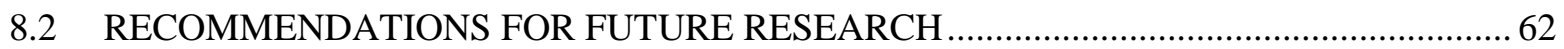

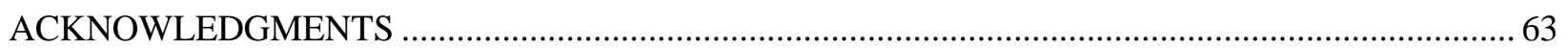

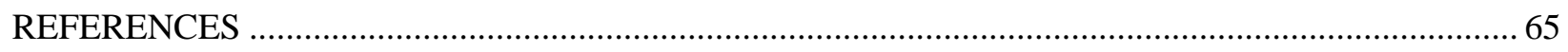

APPENDIX A. ORNL EV PROJECT ELECTRIC VEHICLE CHARGING INFRASTRUCTURE

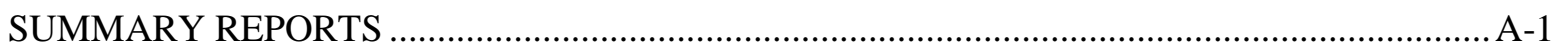

APPENDIX B. UTILIZATION SUMMARY REPORTS ........................................................ B-1 


\section{LIST OF FIGURES}

Figures $\quad$ Page

Figure 1. Map of EV infrastructure deployment for The EV Project. ...................................................... 2

Figure 2. PEV sales for December 2010 through November 2012 and HEV sales for December

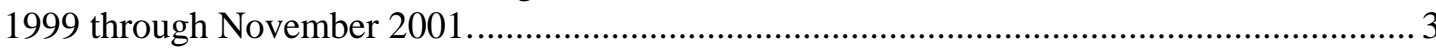

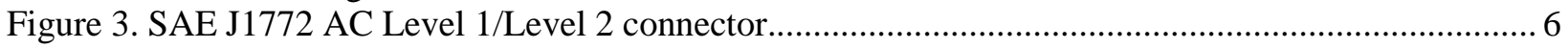

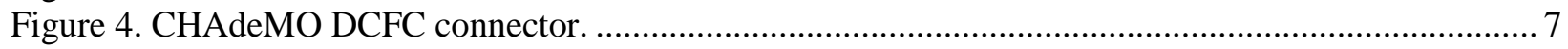

Figure 5. The SAE J1772 combo connector, which enables Level 1 and Level 2 AC charging or DC

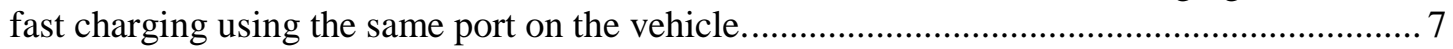

Figure 6. Solar-assisted EV charging station general system configuration............................................. 8

Figure 7. DOE Vehicle Systems program manager Lee Slezak, speaking at the ORNL ribbon

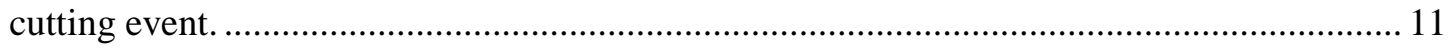

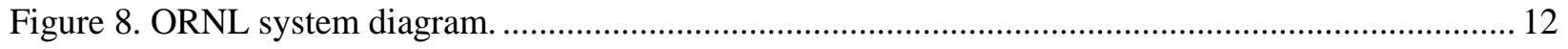

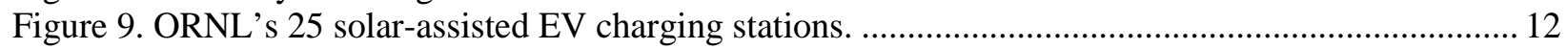

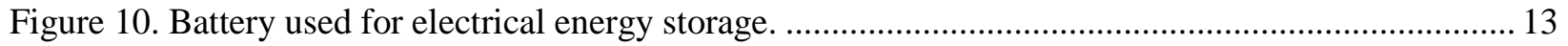

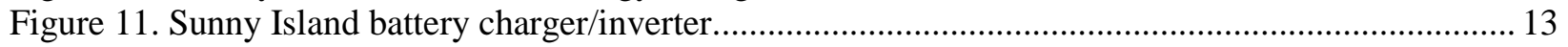

Figure 12. Blink wall-mounted ESVEs installed at the ORNL solar-assisted charging station. ................ 13

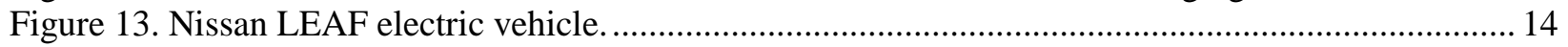

Figure 14. Chevrolet Volt extended-range electric vehicle. ............................................................. 14

Figure 15. Website showing live data from the solar-assisted EV charging station................................ 15

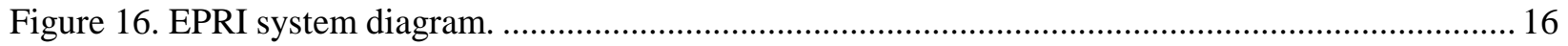

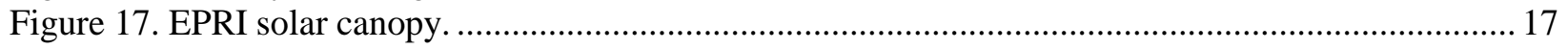

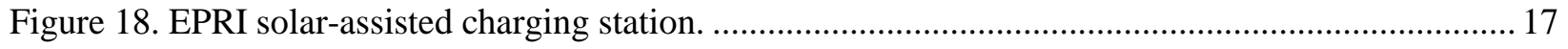

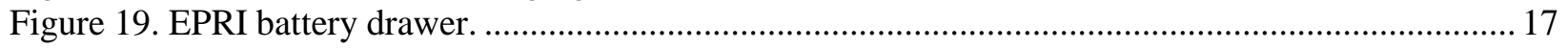

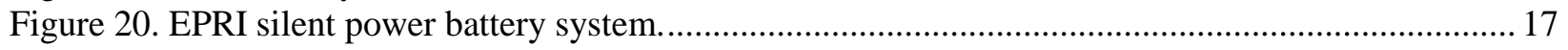

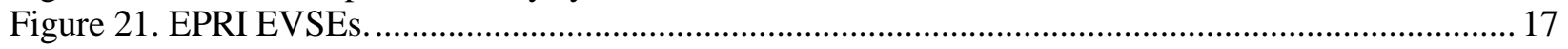

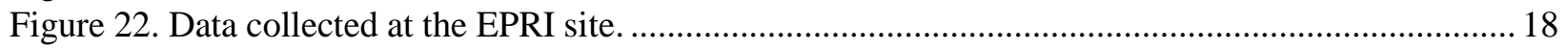

Figure 23. Nissan Smyrna Administration Building solar canopy.................................................... 18

Figure 24. Nine charging stations at the Nissan Administration Building, Smyrna............................... 19

Figure 25. Solar charging station at Nissan's Smyrna Battery Plant. ..................................................20

Figure 26. Franklin Nissan Headquarters with solar canopy.........................................................20

Figure 27. 18 Solar-assisted charging stations at Nissan Headquarters, Franklin, Tennessee................... 21

Figure 28. Franklin Nissan headquarters utility room for solar station. .................................................. 21

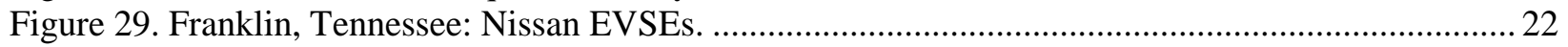

Figure 30. Solar panels for Coliseum EV charging stations. .......................................................... 22

Figure 31. Solar panel location at the Market Square garage. .............................................................. 22

Figure 32. Ribbon cutting ceremony for the Civic Coliseum charging stations. ...................................... 23

Figure 33. One of the charging stations at the Market Square garage .............................................2 23

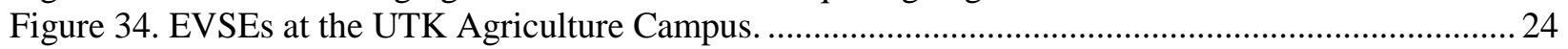

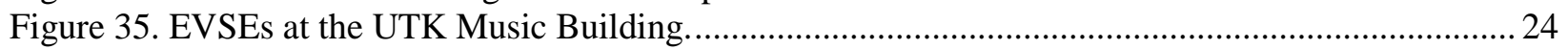

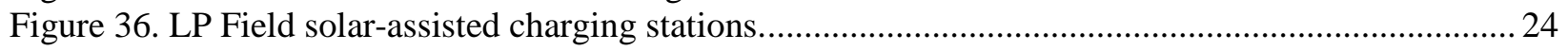

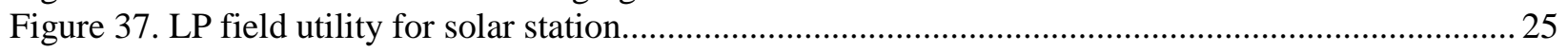

Figure 38. State of Tennessee Employee Parking Lot site solar-assisted charging stations......................25

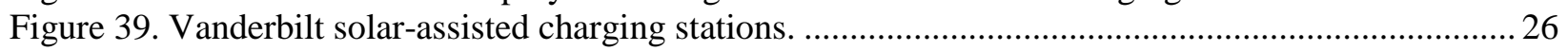

Figure 40. Chattanooga Theatre solar-assisted charging stations. .......................................................26

Figure 41. Shelby Farms solar-assisted charging stations. ............................................................... 27

Figure 42. Map of all charging station locations on the ORNL campus............................................... 30

Figure 43. Charging station at the ORNL parking garage (two of four EVSEs are shown)...................... 31 


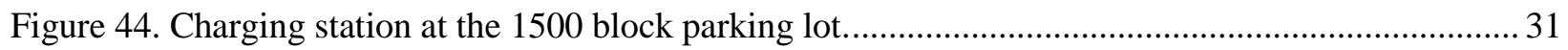

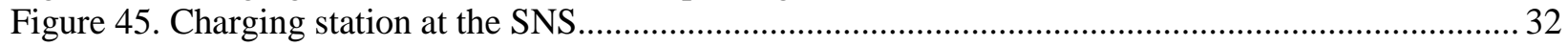

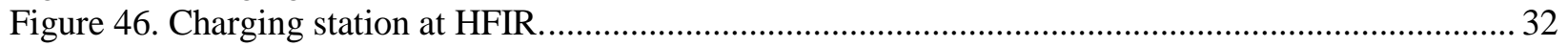

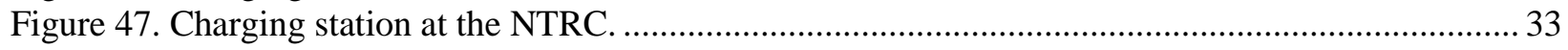

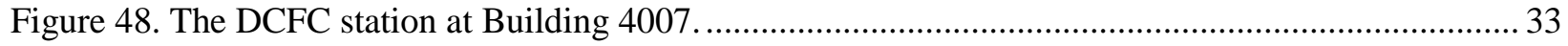

Figure 49. High-level system diagram for each solar-assisted EV site .................................................. 36

Figure 50. Start and stop times for charge events at the ORNL and State of Tennessee Employee Parking Lot sites during 2013 Q3 (July 1-September 30, 2013)......................................... 38

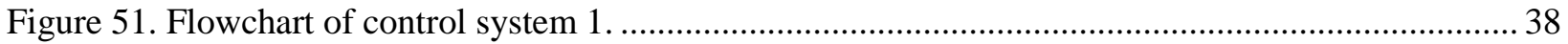

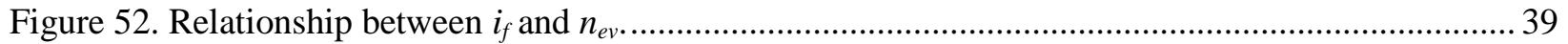

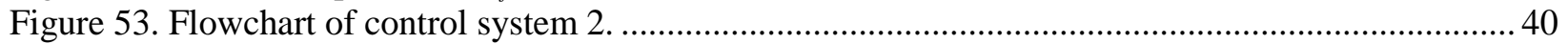

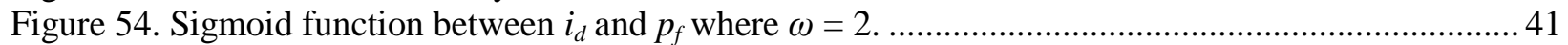

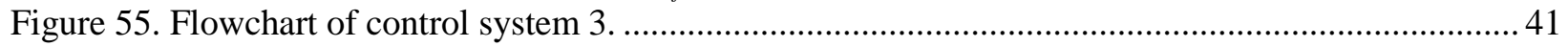

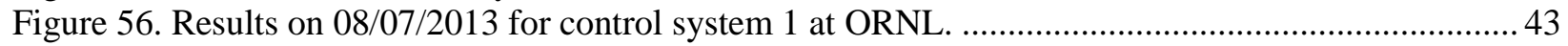

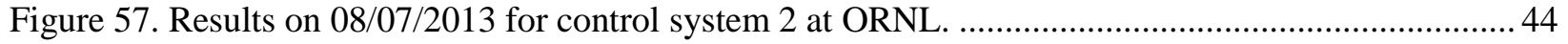

Figure 58. Results on 08/07/2013 for control system 3 at ORNL. ...................................................... 45

Figure 59. Sigmoid function for $\omega=2,3,4,5$, and 10. The box lists the actual/potential shaving percentages per $\omega$ value for the State of Tennessee Employee Parking Lot site..................... 46

Figure 60. Time of day distribution graphs in the summary reports for the ORNL solar-assisted site

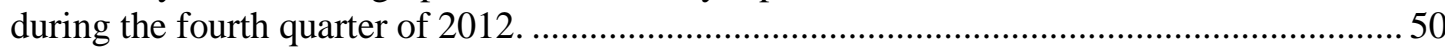

Figure 61. Duration distribution graphs in the summary reports for the ORNL solar-assisted site

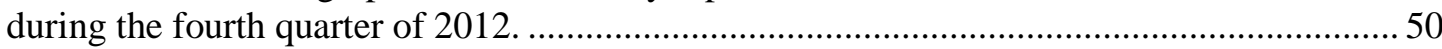

Figure 62. Vehicle charging analysis graphs included in the summary reports for the ORNL solar-

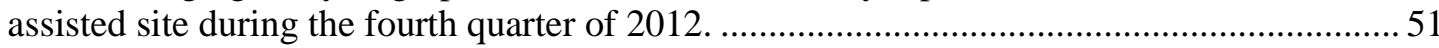

Figure 63. Energy consumption analysis graphs included in the summary reports for the ORNL solar-assisted site during the fourth quarter of 2012.

Figure 64. EVSE analysis graphs included in the summary reports for the ORNL solar-assisted site

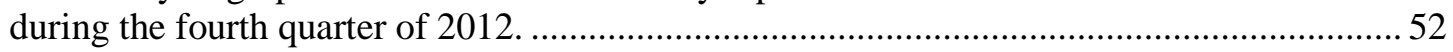

Figure 65. EVSE load and PV array power generation profiles from the summary report for the ORNL solar-assisted site during the fourth quarter of 2012. .......................................... 52

Figure 66. Utilization summary graphs for the set of all ORNL EVSEs through the second quarter

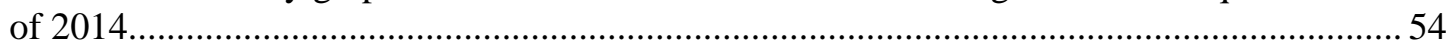

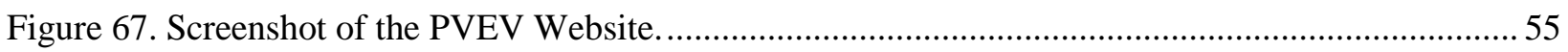

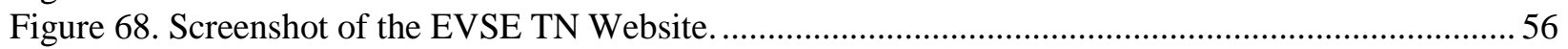




\section{LIST OF TABLES}

\section{Tables}

Page

Table 1. Phase 1 installation sites and number of EVSEs at each location................................................ 4

Table 2. Phase 2 installation locations at the ORNL campus ............................................................ 5

Table 3. Components installed at the Knoxville, Nashville, Chattanooga, and Memphis solar-

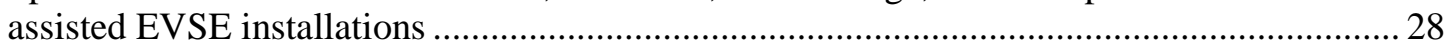

Table 4. List of variables used for battery control systems............................................................. 37

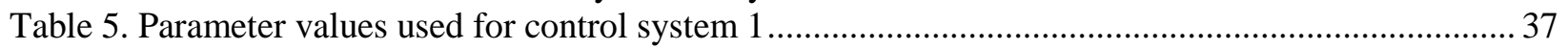

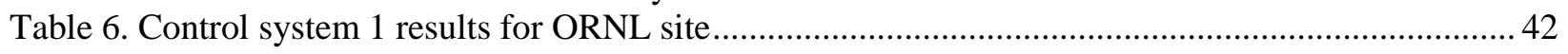

Table 7. Control system 1 results for the State of Tennessee Employee Parking Lot site......................... 43

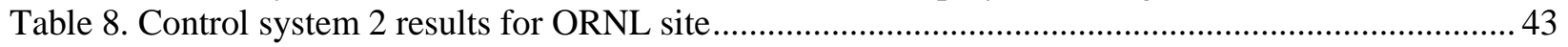

Table 9. Control system 2 results for the State of Tennessee Employee Parking Lot site......................... 44

Table 10. Control system 3, results for ORNL site .............................................................................. 44

Table 11. Control system 3, results for the State of Tennessee Employee Parking Lot site...................... 45

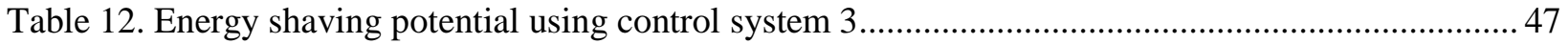

Table 13. Locations of the EV charging stations deployed in the ORNL EV Project ............................... 62 



\section{EXECUTIVE SUMMARY}

The Oak Ridge National Laboratory (ORNL) EV Project was part of a DOE-funded electric vehicle (EV) charging infrastructure demonstration called "The EV Project," which started in 2009 and was led by ECOtality. The ORNL project scope included specific goals that differentiated it from the national project. In particular, ORNL and its project partners developed a solar-assisted EV charging station design that integrates a solar PV array, a battery bank, and EV supply equipment (EVSE) using a gridconnected configuration for all of the components.

Listed below are highlights of the project:

1. Successfully installed, with regional partners, 125 solar-assisted charging stations and 19 non-solar stations in four Tennessee cities and at the Oak Ridge National Laboratory.

2. Completed the project within the allotted budget while slightly expanding the scope (with approval).

3. Enjoyed great regional support from project partners, including the Tennessee Valley Authority, Nissan North America, the Electric Power Research Institute, the State of Tennessee, and site hosts for the installed equipment.

4. Developed and tested a demand response algorithm merging solar production, electric vehicle supply equipment demand, and external battery state of charge in order to maximize peak power offset.

5. Collected and analyzed data from all stations and found that workplace EVs (at Oak Ridge National Laboratory) average $8.36 \mathrm{kWh}$ per charge event which, at residential local rates of $\$ 0.10$ per $\mathrm{kWh}$, is a cost of $\$ 0.836$ (83.6 cents). This average charge supports approximately 28.4 miles of driving and equates to approximately 2.94 cents/mile for fuel, based on an average efficiency for EVs of 3.4 miles/kWh.

6. Found that EV drivers in the public setting (Market Square Garage in Knoxville) averaged $8.85 \mathrm{kWh}$ per charge, at a cost for the electricity of about 88.5 cents. This level of charging provides approximately 30.1 miles per charge event.

7. Established, with regional partners, the Tennessee EV Advisory Council, which helps guide EV adoption and charger installation planning.

8. Established two web sites, one for monitoring the solar-assisted station at ORNL and one for collecting data from stations external to ORNL.

9. Linked the Oak Ridge National Laboratory on-site stations to ORNL's Central Energy Data System.

10. Agreed with the State of Tennessee to implement a state-funded project for additional charging infrastructure, to be carried out in FYs 2015 and 2016. 



\section{INTRODUCTION}

\subsection{OVERVIEW OF THE ELECTRIC VEHICLE PROJECT}

The US Department of Energy (DOE) awarded ECOtality North America a grant to lead a large-scale electric vehicle (EV) charging infrastructure demonstration called "The EV Project"

(http://theevproject.com/). The national project was officially launched on October 1, 2009, and ended at the end of 2013, whereas a part of The EV Project being conducted by the Oak Ridge National Laboratory (ORNL) continued through September 2014. Funding from DOE, made available through the American Recovery and Reinvestment Act (ARRA), totaled \$114.8 million. With additional cost-share contributions and funding from project partners, the total value of the project was approximately $\$ 230$ million. ECOtality partnered with Nissan North America, General Motors, the Idaho National Laboratory (INL), ORNL, and others to deploy and collect data from more than 8,000 Nissan LEAF, Chevrolet Volt, and Smart Fortwo ${ }^{\mathrm{TM}}$ electric drive vehicles and more than 12,000 charging systems across the United States, including both AC Level 2 charging units and DC fast chargers (DCFCs). The EV Project deployed EV charging infrastructure in 21 major cities and metropolitan areas in 9 states and Washington, D.C. The states are Arizona, California, Georgia, Illinois, Oregon, Pennsylvania, Tennessee, Texas, and Washington. The EV Project is the largest deployment of EVs and charging infrastructure in history, and it has paved the way for the successful rollout of electric transportation across many parts of America.

Over the course of the project, charging infrastructure was deployed in the following major population areas: San Francisco, Los Angeles, and San Diego, California; Portland, Eugene, Corvallis, and Salem, Oregon; Seattle, Washington., Phoenix and Tucson, Arizona; Dallas, Fort Worth, and Houston, Texas; Nashville, Knoxville, Chattanooga, and Memphis, Tennessee; Chicago, Illinois; Philadelphia, Pennsylvania; Atlanta, Georgia; and Washington, D.C. These deployment regions are shown in Fig. 1. The Nissan LEAF became available to consumers and commercial fleets in these areas in early 2011, and the Chevy Volt was officially included in the project beginning in June 2010. In the state of Tennessee, Nissan made 1,000 LEAF EVs available for purchase under The EV Project starting in 2011, and ECOtality's plans included the installation of 2,350 Level 2 charging stations in the state. The State of Tennessee offered a \$2,500 rebate for up to 1,000 qualifying EVs (including the Chevrolet Volt and the Nissan LEAF with DC Fast Charge capabilities).

Because a significant percentage of EV charging takes place at EV drivers' residences, a portion of The EV Project funding was used to support home charging units installed by ECOtality. Each participant received a set of home electric vehicle supply equipment (EVSE; also often referred to as an EV charging station). The term "EVSE" refers in a general sense to all of the equipment used to supply electricity to an EV. The EVSEs were provided, typically at no cost, in exchange for allowing the collection of vehicle and charge information from their home chargers and from publicly available EVSEs. EV participants in the project were qualified based on home electrical power capabilities. A total of 7,937 Nissan LEAF, Chevrolet Volt, and Smart Fortwo electric drive vehicles participated in The EV Project for collection of usage data.

The EV Project also installed a significant number of publicly available EVSEs. ECOtality and EV Project partners coordinated with local communities in planning the placement and deployment of these units. Both Level 2 and DCFC EVSEs were provided. 


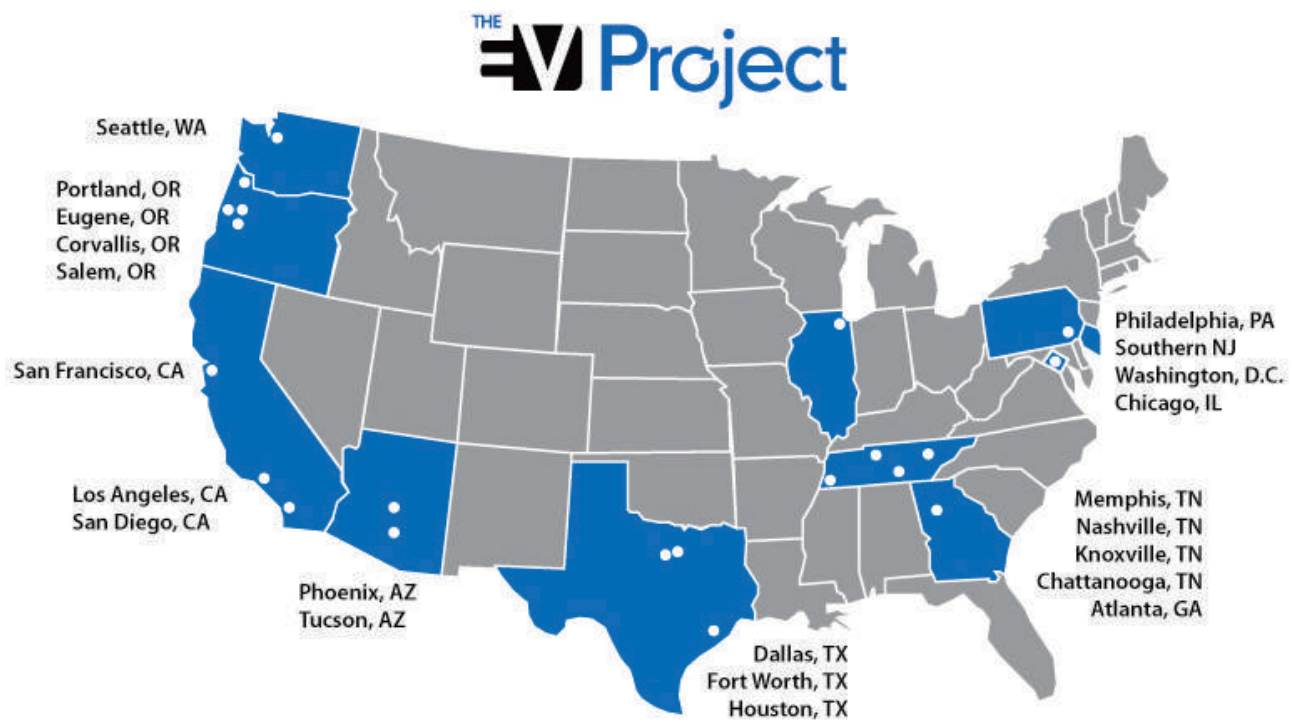

Figure 1. Map of EV infrastructure deployment for The EV Project.

Objectives for The EV Project (http://theevproject.com) included the collection and analysis of data from plug-in EVs (including Nissan LEAF and Chevrolet Volt electric drive vehicles) to characterize EV usage in diverse topographic and climatic conditions, evaluation of component reliability and the effectiveness of the charging infrastructure, assessment of the impact of EVs on the electric grid, and trials of various revenue systems for commercial and public charging infrastructure. The ultimate goal of the project was to use the lessons learned from the deployment of these first EVs, and the charging infrastructure supporting them, to enable the streamlined deployment of the next five million EVs.

\subsection{US POLICY REGARDING EVS AND THE EV PROJECT AT THE NATIONAL LEVEL}

The deployment of EV technology provides a means to reduce US dependence on imported petroleum and reduce greenhouse gas emissions while employing a high-efficiency, low-operating-cost means of transportation. The EV Project is one of several programs in a larger DOE initiative and represents an important part of current US energy policy.

The Energy Improvement and Extension Act of 2008, and subsequently the American Clean Energy and Security Act of 2009, authorized federal tax credits for new qualified plug-in EVs (PEVs). The ARRA also authorized federal tax credits of up to a maximum of $\$ 4,000$ for plug-in electric drive conversion kits, although this credit was allowed to expire at the beginning of 2012. The federal tax credit for new PEVs was set to $\$ 2,500$, plus $\$ 417$ for each kilowatt-hour of battery capacity over $5 \mathrm{kWh}$ up to $\$ 5,000$. The maximum credit allowed for each new PEV is therefore $\$ 7,500$, and the credit is permitted only for the first 200,000 PEVs sold by each manufacturer. As of July 2014, these credits remain available for vehicles from all EV manufacturers. Several state and regional incentives and tax exemptions have also been established for PEVs, in addition to other non-monetary incentives.

As part of the ARRA, the United States made a substantial financial commitment to build US manufacturing capacity in advanced lithium-ion batteries and secure a position as a global leader in this enabling technology. This investment included a pledge of $\$ 2$ billion in federal funding to support the development of next-generation electric cars and batteries, in addition to $\$ 400$ million in funding for transportation electrification demonstration and deployment projects. Two separate funding opportunity announcements were issued for these activities, and The EV Project was funded as one of the demonstration and deployment projects. Additionally, $\$ 3.1$ billion in loans designed to stimulate the development and production of advanced fuel-efficient vehicles were provided to automakers. In total, the 
Congressional Budget Office estimates that $\$ 7.5$ billion will be spent to accelerate EV adoption in the United States through 2019 [1].

In his 2011 State of the Union address, President Barack Obama set the goal for the United States to become the first country to have 1 million EVs on the road by 2015. This goal was established based on forecasts made by DOE, using manufacturer announcements and media reports regarding production capacities of PEV models to enter the US market through 2015. DOE estimated a cumulative potential production of 1,222,200 PEVS by 2015 based on manufacturer announcements and media reports of production capacity for a number of different EV models. PEV sales have actually increased more rapidly than hybrid EV (HEV) sales in the first 2 years they were available, although the total number of PEV sales has not reached the levels initially expected. Figure 2 shows a comparison of HEV and PEV sales during the first 24 months after each technology was released.

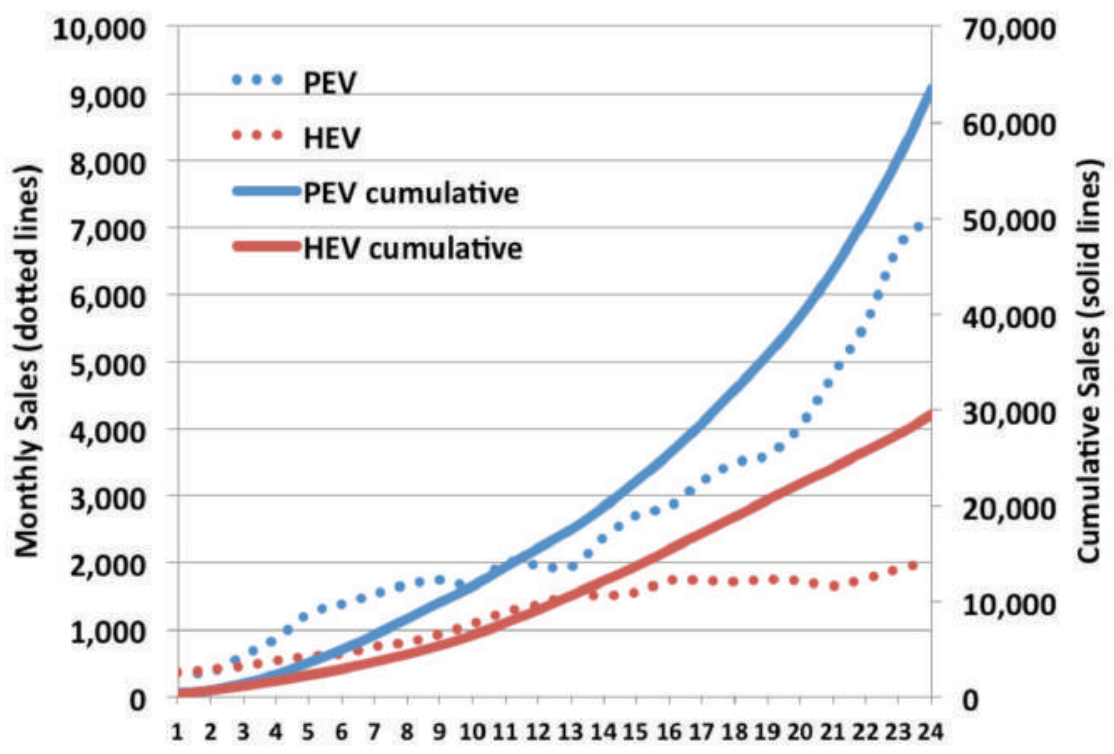

Figure 2. PEV sales for December 2010 through November 2012 and HEV sales for December 1999 through November 2001. (From [2])

In March 2012, President Obama announced the EV Everywhere Grand Challenge, which aims to enable American innovators to rapidly develop and commercialize the next generation of technologies to achieve the sufficient PEV cost, range, and charging infrastructure necessary for widespread deployment. The EV Everywhere Challenge has the goal of advancing EV technologies so that by 2022 the United States will be producing a five-passenger EV that will offer a payback time of less than 5 years and a recharging speed fast enough to provide enough range for the typical American driver. In January 2013, Energy Secretary Steven Chu announced the Workplace Charging Challenge as a part of the EV Everywhere Challenge. The Workplace Charging Challenge aims to increase the convenience of PEV ownership by expanding access to EV charging stations by increasing the number of US employers offering charging by a factor of 10 over the next 5 years. At the same time that the Workplace Charging Challenge was announced, DOE released the EV Everywhere Blueprint, which outlines goals for EV technologies.

ECOtality began installing its Blink Level 2 wall-mount charging stations in EV Project regions nationwide in December 2010 and has since installed more than 12,000 commercial and residential chargers. In the state of Tennessee, the company installed over 1,800 Level 2 and DCFC stations during the project.

By the end of the fourth quarter of 2013, more than 8,200 vehicles had participated in The EV Project, 12,248 EVSEs has been installed, and data had been collected from both vehicles and EVSEs. More than 4.1 million charging events were recorded, representing over 34,000 MWh of energy delivered to EV project vehicles and a reduction in gasoline consumption of over 4.1 million gallons of gasoline. 
The EVSE installations included both residential $(8,250)$ and commercial $(3,998$, including publicly available, workplace and fleet) units. The residential EVSEs typically were installed ahead of a LEAF delivery but concurrent with a Volt delivery. EV Project vehicles have accumulated approximately 109 million miles over the course of the project.

\subsection{ORNL SCOPE}

ORNL's role in The EV Project—in collaboration with project team partners including the Tennessee Valley Authority (TVA), Electric Power Research Institute (EPRI), State of Tennessee, Nissan, and the site hosts - consisted of the installation and data collection from $144 \mathrm{EV}$ charging stations across Tennessee. The installations include 125 solar-assisted charging stations equipped with Level 2 EVSEs with battery storage systems at 15 sites across the state, in addition to 18 non-solar Level 2 EVSEs and 1 DCFC at the ORNL campus. This effort provides valuable field experience with grid- and solar-based recharge of PEVs and offers a platform for studying critical issues in vehicle-grid interactions.

ORNL was awarded \$6.8 million in ARRA funds (part of the original \$99.8 million), and regional partners provided matching funds that effectively enabled completion of twice the number of EVSE installations. The completion date for the ORNL project is September 30, 2014. As part of the project, ORNL has collected data on EVSE use at the installation sites and data on the systems' performance, component reliability, and so on; and it has performed data reduction and analysis to derive deployment feedback for DOE. An optimal control scheme was also developed to discharge a battery bank integrated with the solar-assisted EV charging station sites and the electric grid; this control system offsets power demand from the EVSEs to minimize the impact of EV charging on the grid.

Locations for the publicly available charging stations were selected using a variety of factors, including traffic patterns and the locations of employment centers, regional attractions, and retail hubs, as well as input from many regional partners and stakeholders. In Tennessee, the information collected has been used to lay the groundwork for a rich charging infrastructure in four major cities-Nashville, Knoxville, Chattanooga, and Memphis—as well as the critical routes connecting them.

\subsubsection{Phase 1 Installations-Solar-Assisted Level 2 EV Charging Stations}

The first installations completed were 125 solar-assisted Level 2 charging stations located at 15 separate installation sites across the state of Tennessee. Table 1 shows the locations and the number of EVSEs installed at each site.

Table 1. Phase 1 installation sites and number of EVSEs at each location

\begin{tabular}{llr}
\hline \multicolumn{3}{c}{ Solar-assisted Level 2 EVSE installations } \\
\hline ORNL Central Campus & Oak Ridge & 25 \\
EPRI Knoxville Laboratory & Knoxville & 6 \\
Civic Coliseum Garage & Knoxville & 6 \\
Market Square Garage & Knoxville & 4 \\
University of Tennessee Agriculture Campus & Knoxville & 6 \\
University of Tennessee Music Building & Knoxville & 6 \\
Vanderbilt University, parking near Broadway Ave. & Nashville & 10 \\
LP Field & Nashville & 8 \\
State of Tennessee Employee Parking Lot site & Nashville & 4 \\
Shelby Farms Park & Memphis & 10 \\
Theatre Centre & Chattanooga & 6 \\
TVA Advanced Vehicle Test Facility & Chattanooga & 4 \\
Nissan Battery Plant & Smyrna & 3 \\
Nissan Administrative Building & Smyrna & 9 \\
Nissan Headquarters & Franklin & 18 \\
\hline
\end{tabular}


All sites include a grid-connected photovoltaic (PV) array as well as battery energy storage that can be used to further offset the energy consumption from the EVSEs and address the issue of peak electrical power demand. These phase 1 installations were completed in late 2012.

\subsubsection{Phase 2 Installations-Level 2 and DCFC EV Charging Stations on the ORNL Campus}

The ORNL campus was equipped with 18 additional non-solar Level 2 EVSEs to provide charging infrastructure to charge employees' or visitors' EVs during the workday at multiple facilities around the campus. In addition, one DCFC was installed at ORNL to enable rapid charging for EV drivers when needed. The non-solar Level 2 installations were completed at five sites on the ORNL campus and the DCFC was placed at a sixth location. The ORNL campus site locations are summarized in Table 2. All phase 2 installations were final by April 2013.

Table 2. Phase 2 installation locations at the ORNL campus

\begin{tabular}{cccccc}
\hline $\begin{array}{c}\text { High Flux Isotope } \\
\text { Reactor }\end{array}$ & $\begin{array}{c}\text { Central Ave } \\
\text { Parking Garage }\end{array}$ & Building 1520 & $\begin{array}{c}\text { Spallation } \\
\text { Neutron } \\
\text { Source }\end{array}$ & $\begin{array}{c}\text { National } \\
\text { Transportation } \\
\text { Research Center }\end{array}$ & $\begin{array}{c}\text { Building 4007 } \\
\text { (DCFC) }\end{array}$ \\
\hline 4 & 4 & 4 & 4 & 2 & 1 \\
\hline
\end{tabular}

\subsection{STATE OF THE TECHNOLOGY FOR EV CHARGING}

EV charging is performed by connecting the vehicle to an EVSE. The 1996 National Electrical Code and California Article 625 defined EVSE as

The conductors, including the ungrounded, grounded, and equipment grounding conductors, the electric vehicle connectors, attachment plugs, and all other fittings, devices, power outlets or apparatuses installed specifically for the purpose of delivering energy from the premises wiring to the electric vehicle.

Although these devices are commonly referred to as charging stations, modern EVs such as the Chevy Volt and Nissan LEAF contain electronics on board the car that can convert the alternating current (AC) supplied from the electrical grid to the direct current (DC) needed to charge the battery. The EV also manages the rate of charge for optimal battery performance and monitors the state of charge (SOC) so that charging is stopped when the battery is full. In this sense, the vehicle contains its own charger, and the EVSE simply supplies the electricity and facilitates the power transfer according to standards developed for this function. The primary function of the EVSE is therefore to communicate with the EV to coordinate the transfer of electrical energy in a safe manner and allow the electricity to flow to the vehicle.

EVSEs enhance safety by enabling two-way communication between the charging station and the EV. These communications between the EVSE and the vehicle ensure that the current passed to the vehicle is both below the limits of the power source and also below the limits of what the car can receive. There are additional safety features such as a safety lock-out to prevent current from flowing if the plug is not connected to the EV.

Different types of EVSEs exist for connection to different power sources with a range of power capabilities. Most EVs today use AC charging systems that are based on the SAE J1772 standard. All EVs in the US market today are supplied with a portable Level 1 EVSE (commonly referred to as a charging cord) that can be connected to a standard 120 volt (V) AC outlet. Level 1 EVSEs are capable of transferring 12-16 amps (A) of current, which limits the power transfer to about $1.9 \mathrm{~kW}$. Unfortunately, charging an EV at this power level is quite slow. For a Nissan LEAF, about 18 hours would be required to fully charge the vehicle using a Level 1 EVSE. 
Level 2 chargers allow for a faster charge, but they require 208 to $240 \mathrm{~V}$ AC power. The current is limited by the $\mathrm{J} 1772$ connector to a maximum of 80 A for Level 2 AC EVSEs, which corresponds to a maximum power of $19 \mathrm{~kW}$. The current and power that can be transferred may actually be less than the maximum that the $\mathrm{J} 1772$ standard permits, depending on the rating of the particular circuit to which the EVSE is connected. The higher power allows EVs to be charged in a matter of several hours with a Level 2 EVSE; Level 2 chargers are the most common type of EVSE in use today. Level 1 and Level 2 AC chargers use the same SAE J1772 connector (Fig. 3).

For even faster charging, EVSEs that output DC power directly to the vehicle at relatively high voltage can be used. These EVSEs are frequently referred to as DCFCs or DC quick chargers. Not all EVs are equipped with DC charge capability. The Nissan LEAF, for example, offers DC fast charging as an option, whereas the Chevrolet Volt (with a smaller battery capacity than the LEAF) does not have DC fast charge capability. DCFC EVSEs require a high-voltage, 3-phase AC power supply, which is typically only available in commercial settings. There are two separate standards in existence today, and the most recent SAE J1772 standard defines two levels of DC charging. Charging with DCFCs can reduce the charge time of EVs to less than 30 minutes.

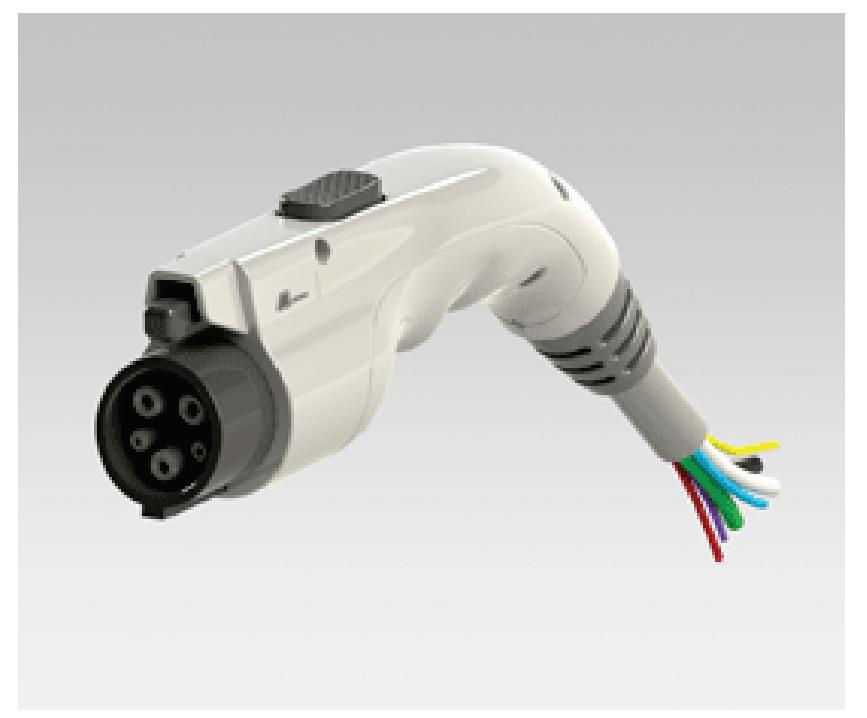

Figure 3. SAE J1772 AC Level 1/Level 2 connector.

The Japan Electric Vehicle Standard (JEVS) G105-1993, developed by the Japan Automobile Research Institute, was the first DC fast charging standard to be implemented commercially and is the only standard currently in widespread use at the time of this report. Both the standard and the corresponding electrical connector are normally referred to as "CHAdeMO," the trade name for the highvoltage fast charging method. A CHAdeMO charging connector is shown in Fig. 4. EVSEs that follow the CHAdeMO standard can provide DC power of up to $500 \mathrm{~V}$ with a current of up to $125 \mathrm{~A}$, corresponding to power of up to $62.5 \mathrm{~kW}$.

The SAE J1772 standard was updated in October 2012 to include provisions for DC fast charging. This most recent standard includes specifications for a new charge connector that adds two new electrical contacts for high-power DC charging to the Level 1/Level 2 AC connector. The female receptacle, located on the EV, will therefore accept both the original Level 1/Level $2 \mathrm{AC}$ charge connector and the DC-charge enabled connector so that a single port can be used for either AC or DC charging. The "combo connector" for the new SAE standard is shown in Fig. 5. The development of the SAE J1772 DC charging standard has met with a fair amount of controversy because vehicles and EVSEs using the CHAdeMO standard are already on the market; the new standard will result in incompatible EVs and charging systems as new vehicles and chargers using J1772 DC fast charging become available. Note that 
for the ORNL EV Project, no vehicles or chargers were available using the J1772 DCFC connectors. Therefore, all of the DCFC EVSEs installed are based on the CHAdeMO standard.

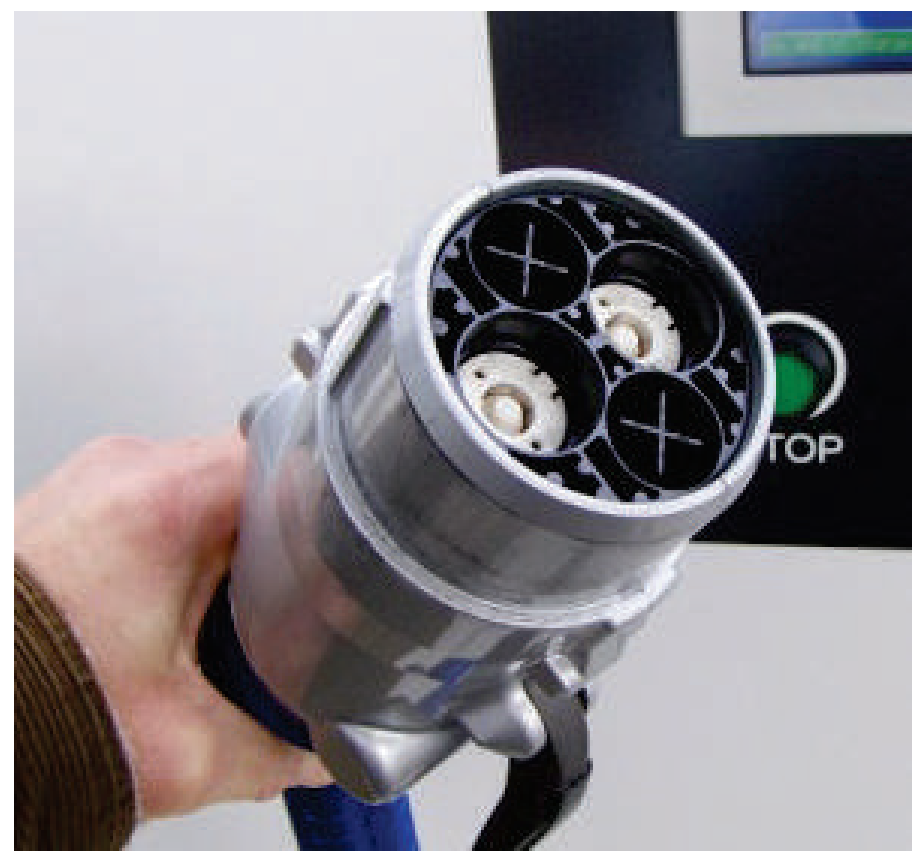

Figure 4. CHAdeMO DCFC connector.
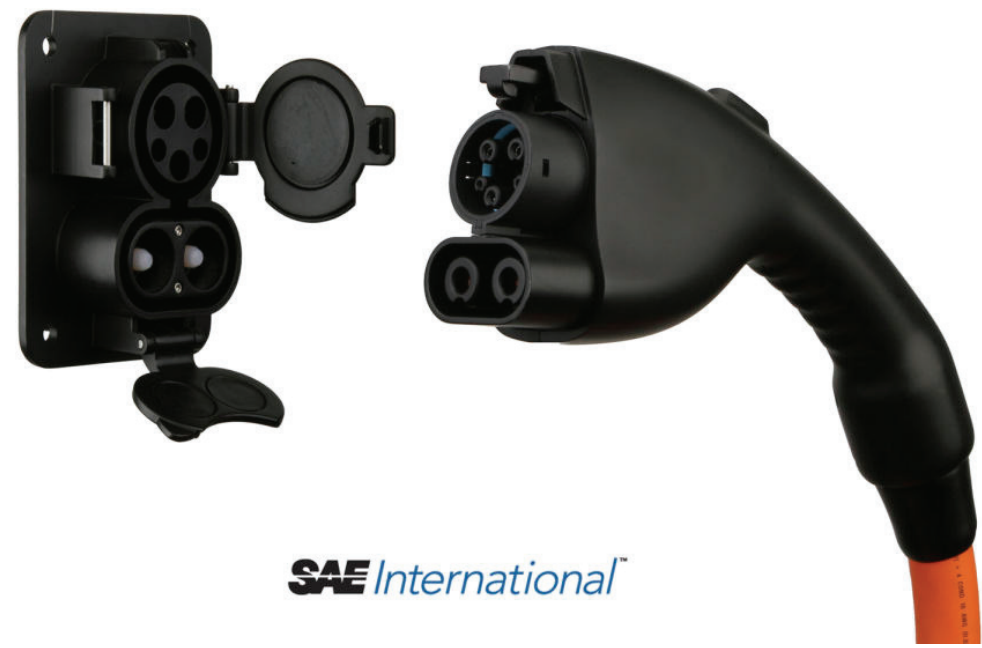

Figure 5. The SAE J1772 combo connector, which enables Level 1 and Level 2 AC charging or DC fast charging using the same port on the vehicle.

\subsection{OVERVIEW OF THE SPECIFIC TECHNOLOGIES DEPLOYED IN THE ORNL PROJECT}

1. Level 2 and DCFC EVSE Station Design (Including Solar-Assisted)

Solar-assisted charging stations use solar photovoltaic (PV) arrays to generate electricity to replenish the electricity used to charge the EVs. For the 25 solar-assisted EV charging stations at ORNL, the solar energy generated over the course of the year for each solar-assisted charging space is sufficient to offset 
the energy required to drive a vehicle such as the Nissan LEAF almost 10,000 miles, thus reducing fossil fuel usage and greenhouse gas generation. Each solar-assisted charging installation is also equipped with a battery bank. The purpose of the battery bank is to store electrical energy from the grid and discharge the stored energy during periods of peak charging demand. This will suppress surge demand on the grid and mitigate the impact on local grid infrastructure, possibly avoiding the need to expand electrical infrastructure to meet EV charging needs. This reduction in power consumption could also prevent electric peak usage fees that may be generated by high power demands from the EV charging stations. Figure 6 shows the system configuration for the solar-assisted EV charging station design.

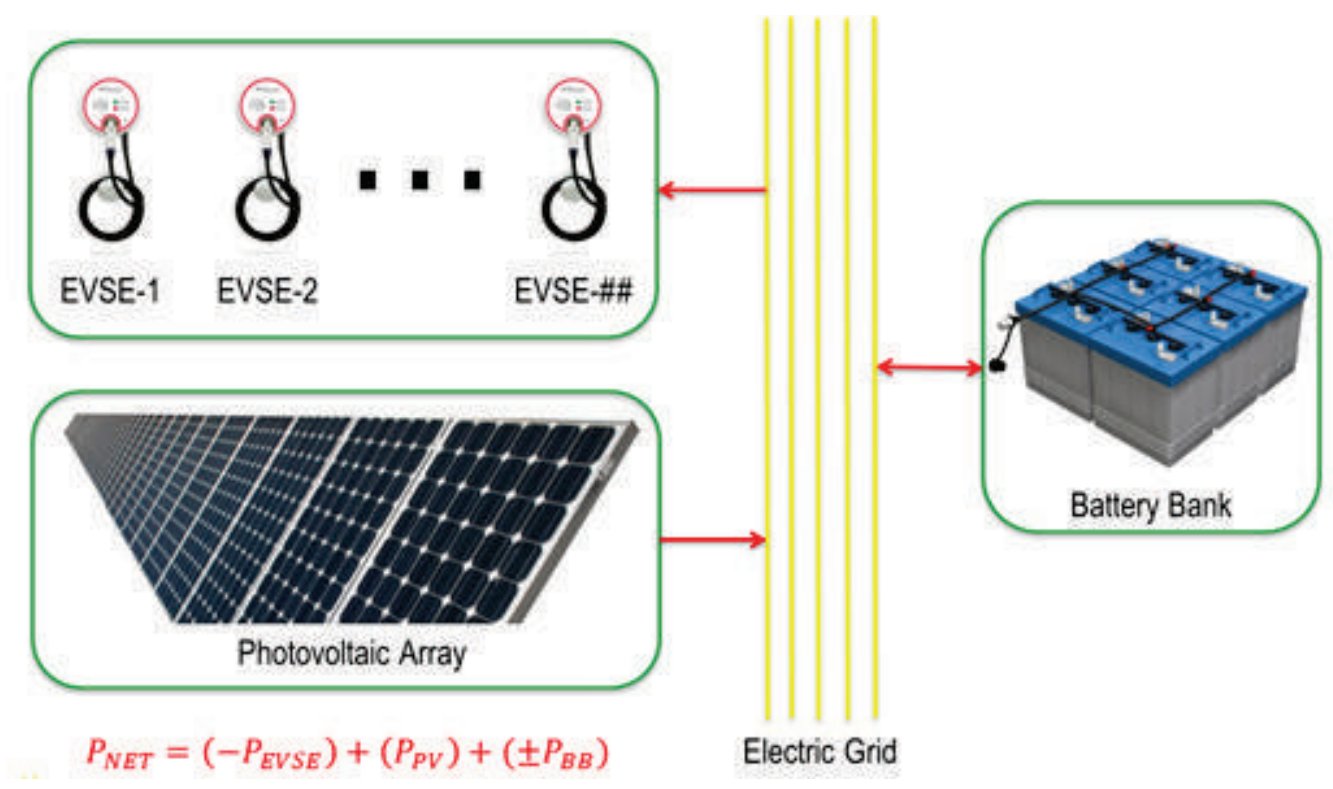

Figure 6. Solar-assisted EV charging station general system configuration.

\subsubsection{Components}

- Solar canopy: Wherever practical, the PV solar array is mounted on a canopy above the solar-assisted EVSE parking spaces. In addition to providing a mounting structure for the solar PV array, the canopy provides shade and some protection from the elements, thereby keeping the vehicle and its battery cooler during hot weather. The canopy solar PV modules are electrically connected in a parallel/series arrangement to supply the optimal DC voltage to an inverter. The inverter converts DC power from the array to $\mathrm{AC}$ to feed to the power grid through a transformer. The canopy area over each charger space can support solar modules having a total capacity of about $2 \mathrm{~kW}$, which are expected to produce enough electricity in a year to offset an EV's typical annual electricity usage.

- Battery bank and associated electronics to mitigate peak usage charges: Electrical utility companies supplying power for the charging stations, whether solar-assisted or not, are concerned about surge loads on the grid from vehicle charging. The purpose of the battery banks is to store energy on site, charging the batteries during periods of low charging demand and discharging them into the electrical grid during high demand to minimize the surge load on the grid. The battery bank is equipped with an Internet-connected charger/inverter unit. The charger/inverter can charge the batteries using power from the grid, rectifying $\mathrm{AC}$ to $\mathrm{DC}$, and it can reverse flow to feed power back into the grid by converting $48 \mathrm{~V}$ DC battery power to $\mathrm{AC}$ at the proper voltage. The charge/discharge cycles can be programmed to optimize performance in offsetting surge demand, and the charger/inverter can be controlled remotely via the Internet. 
- Level 2 EVSE: Level 2 chargers provide currents of up to $30 \mathrm{~A}$ at 208 to $240 \mathrm{~V}$ AC. Rectification to DC is accomplished within the vehicle via the onboard battery management system. Level 2 EVSEs can charge a fully depleted vehicle in approximately 6-8 hours. The EVSEs are equipped with SAE J1772 connectors, the standard for Level 2 chargers. The EVSEs and J1772 connectors are compliant with the National Electric Code and have a number of important safety features:

- They interlock with the EV drive system so the vehicle cannot be driven while connected to the charger.

- They de-energize if the cable or connector is subjected to strain.

- They provide a charge current interrupting device with automatic test for personal protection.

- They de-energize connector parts until the connector is properly latched into the vehicle socket. The connector is automatically de-energized before being unplugged from the vehicle.

ORNL EVSEs are activated by a radio frequency identification card (RFID), similar to a credit card, which is assigned to each user. Since the ORNL EVSEs are programmed as "fleet" chargers, Blink does not require that a credit card be associated with a user RFID card.

- A DCFC EVSE provides DC power to the vehicle at up to $500 \mathrm{~V}$ and $125 \mathrm{~A}$. This is a higher power than can be accepted from an AC EVSE, which allows for more energy to be transferred in a shorter period of time. DCFC technology can charge a Nissan LEAF to $80 \%$ capacity in about 30 minutes, which is particularly desirable for charging commuters' EVs. One DCFC was installed at the ORNL campus during the phase 2 installations.

- Data and communications: The EVSEs, solar PV inverters, and battery charger/inverter units are all Internet-connected. During the research portion of the project, EVSE usage data for each charging event were collected and sent to INL for analysis and interpretation with regard to vehicle performance, maintenance, and operational issues. The collection of electronic data from all charging stations is to characterize EV use, evaluate the component reliability and effectiveness of charge infrastructure, and assess the impact of EVs on the electric grid.

\subsection{SUMMARY OF EV CHARGING STATIONS INSTALLED DURING THIS PROJECT}

The primary objective of the ORNL EV Project, with its statewide partners, was to install solarassisted EV charging stations across Knoxville, Nashville, Chattanooga, and Memphis; additional charging stations with Level 2 EVSEs and a DCFC were installed at ORNL. The 125 solar-assisted EVSEs were completed in late 2012 at 15 different sites. A second phase of installations, with 18 Level 2 EVSEs and one DCFC EVSE at 6 additional sites on the ORNL campus, was completed in April 2013. These stations are all fully operational and data collection for EVSE usage continues from all of the installation sites. 



\section{PHASE 1 INSTALLATIONS-SOLAR-ASSISTED CHARGING STATIONS INSTALLED WITH 125 EVSES}

\subsection{ORNL CAMPUS-25 SOLAR-ASSISTED CHARGING STATIONS}

A 25-space solar-assisted charging station was opened on the North Parking Lot of ORNL's main campus in March 2011. A formal dedication and ribbon cutting was held on May 25, 2011, and was attended by the DOE sponsor and numerous regional partners including TVA, Nissan, EPRI, ECOtality, the State of Tennessee, and the news media (Fig. 7). Initially, two types of employee-owned EVs used the charging station, the Nissan LEAF and the Chevrolet Volt; but the user base at ORNL has increased and employees have purchased other EVs as they have become available. As of the publication of this report, there are 37 ORNL EV drivers, with PEV models now including the Toyota Prius plug-in, Ford Fusion Energi, Ford C-Max Energi, and Smart Fortwo electric, in addition to the LEAF and Volt.

A $47 \mathrm{~kW}$ solar PV array is installed on a canopy over the parking spaces. The PV array regularly supplies more energy during the day than the existing number of EVs consume at ORNL. The canopy design also provides shade to the EVs during charging. The charging station is equipped with a battery bank with a usable capacity of $30 \mathrm{kWh}$ (the total specified capacity is approximately $60 \mathrm{kWh}$ ) to enable buffering of the power consumed and produced. As documented later in this report, optimization studies have been conducted to determine the most effective charge/discharge protocol to minimize surge loads on the grid caused by EV charging.

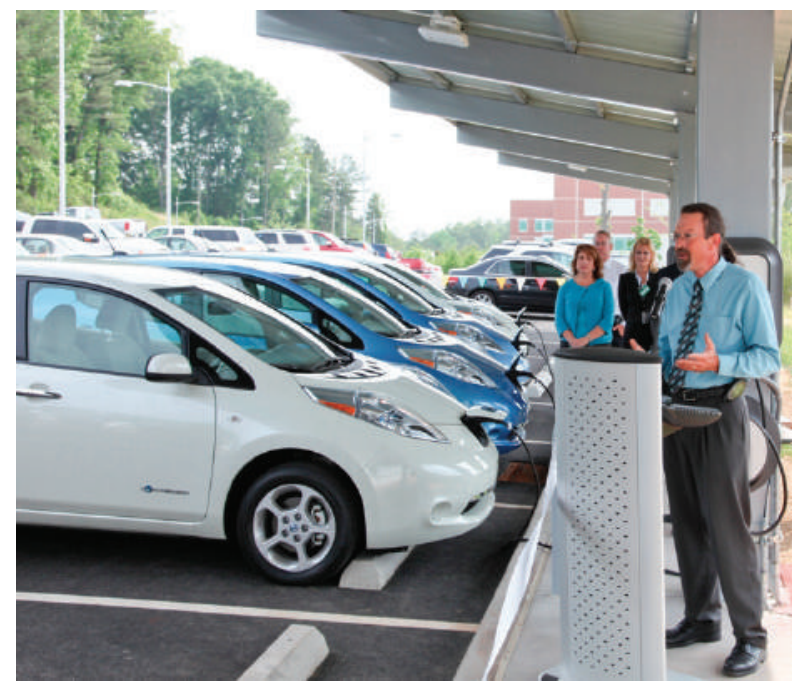

Figure 7. DOE Vehicle Systems program manager Lee Slezak, speaking at the ORNL ribbon cutting event.

Throughout the duration of The EV Project, charging data from the solar-assisted charging station were transmitted to ECOtality and then collected and analyzed by INL. ORNL also conducted analysis of the EVSE usage and solar power generation data collected for all charging stations installed by ORNL. To avoid any privacy concerns, no personal information was used in analysis of the data. The reduced data collected to date are presented later in this report. Figure 8 shows a schematic of the ORNL system.

Solar: The $47 \mathrm{~kW}$ ORNL solar canopy is outfitted with 210 Sharp ND-224UC1 PV modules rated at $224 \mathrm{~W}$ each. The modules are composed of multi-crystalline silicon solar cells with a module efficiency of $13.74 \%$. The solar canopy measures approximately 235 by $20 \mathrm{ft}$ in plan and is tilted $10^{\circ}$ toward the south. The structure is a moment-resisting frame constructed of rectangular hollow structural sections (Fig. 9).

Fourteen single-column frames spaced at $18 \mathrm{ft}$ support tubular steel purlins and the standing seam metal roof to which the solar PV modules are attached. The solar PV modules are electrically connected in series strings of 14 modules each to produce $600 \mathrm{~V} \mathrm{DC}$ for optimum performance with the DC-to-AC inverter. Fifteen such series strings are connected in parallel at three circuit combiners manufactured by SolarBOS to produce $75 \mathrm{~A}$ at full nameplate rating.

The three combiners feed a PV Powered $50 \mathrm{~kW}$ inverter manufactured by Advanced Energy. The inverter converts the $600 \mathrm{VDC}$ to $208 \mathrm{VAC} 3$-phase power at $96 \%$ efficiency. The AC voltage is increased by a transformer and feeds onto the ORNL power grid. 


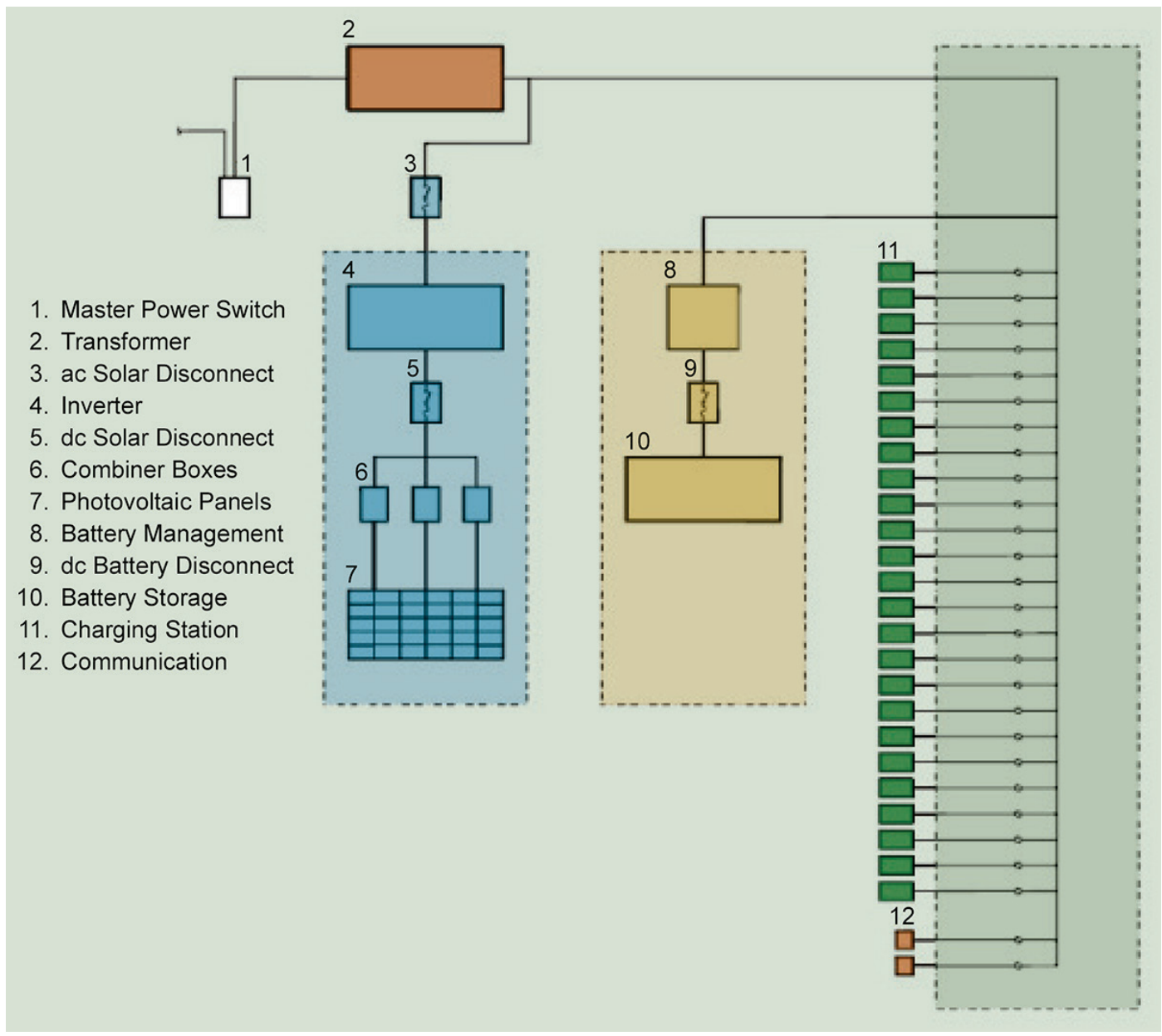

Figure 8. ORNL system diagram.

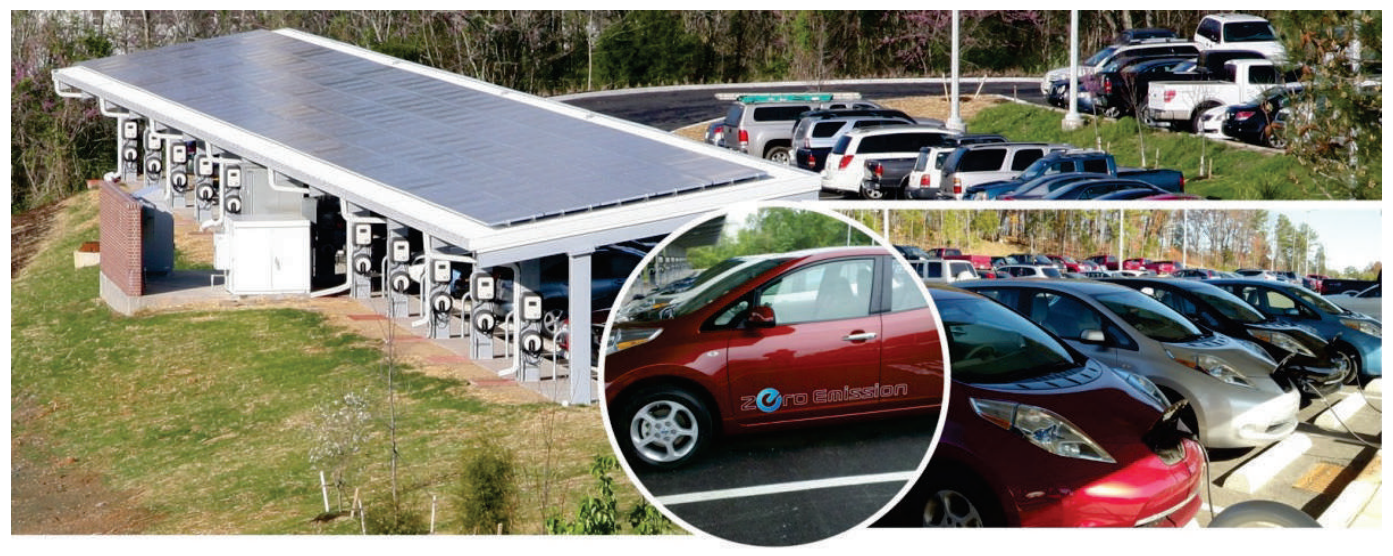

Figure 9. ORNL's 25 solar-assisted EV charging stations.

The solar-assisted charging station uses the solar PV arrays to generate electricity to offset the electricity used to charge the EVs. Each parking space is covered by approximately $2 \mathrm{~kW}$ of solar PV modules. Over the course of a year, $2 \mathrm{~kW}$ of PV will generate about 3,090 kWh of grid-connected electricity. At 3.5 miles per kWh (conservatively estimated based on an assumed range of 85 miles per 
full charge), the modules produce enough energy to drive a Nissan LEAF about 10,000 miles, thus reducing fossil fuel usage and greenhouse gas generation.

Battery: The ORNL solar-assisted EV charging station is equipped with a battery bank consisting of $40 \mathrm{C} \& \mathrm{D}$ Technologies model VRS $12-175 \mathrm{~F}$ batteries (Fig. 10). The usable storage capacity is $30 \mathrm{kWh}$ (total battery capacity is approximately $60 \mathrm{kWh}$ ), and the batteries are able to discharge at a peak rate exceeding $12 \mathrm{~kW}$. The purpose of the battery bank is to store electrical energy from the grid and discharge the stored energy during periods of peak charging demand, thus suppressing surge demand on the grid and mitigating the impact on local grid infrastructure. It also may avoid the need to expand infrastructure to meet vehicle charging needs. The battery bank is enclosed in an air-conditioned steel cabinet.

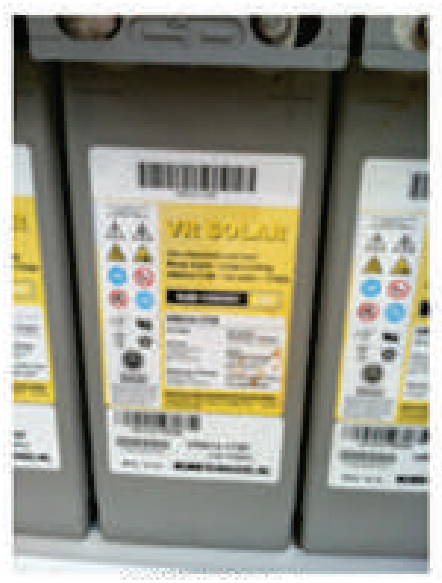

Figure 10. Battery used for electrical energy storage.

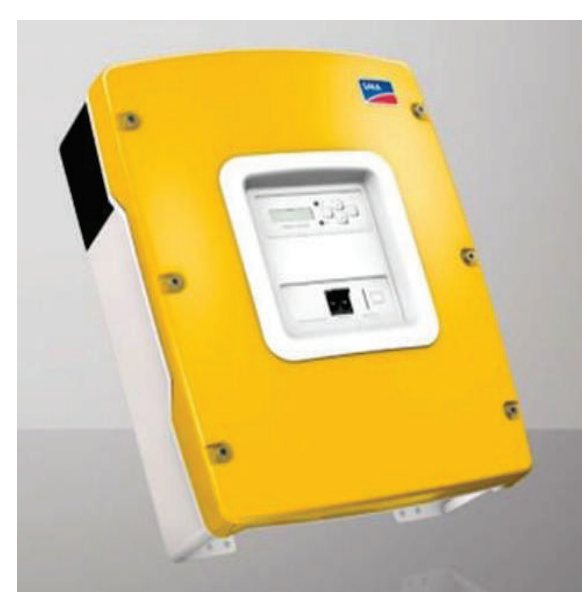

Figure 11. Sunny Island battery charger/inverter.

The battery bank is charged and discharged by an SMA Technologies AG Sunny Island 5048 inverter/charger (Fig. 11). The Sunny Island is a bidirectional inverter, meaning that it is both an inverter and a battery charger, and it is also tied to the grid. The inverter converts AC line voltage to DC for battery charging. The charge profile can be customized to match the specific batteries to maximize battery life, and it can perform an equalization charge to balance the individual cells. The Sunny Island inverter is also capable of discharging energy stored in the battery bank to the power grid to help offset load surges from EV charging. The inverter's rated continuous $\mathrm{AC}$ output is $5 \mathrm{~kW}$ at $25^{\circ} \mathrm{C}$. The discharge profile can be customized to maximize battery life, to maximize energy to the grid, or to compromise between the two objectives.

EVSEs: The ORNL solar-assisted charging station includes 25 Blink EVSEs manufactured by ECOtality (Fig. 12). The Blink EVSEs include all the primary EVSE features described plus Internet connectivity. They can be configured to transmit and receive data using Wi-Fi, hardwire Ethernet, or CDMA (a cell phone protocol).

EVs: In 2010 the automaker Nissan brought the world's first modern mass-production EV, the Nissan LEAF, onto the market (Fig. 13). The LEAF, a 5 passenger zero-emission hatchback powered by advanced lithium-ion batteries, is the most common EV driven at ORNL. It is equipped with a $24 \mathrm{kWh}$ lithium-ion battery that powers an $80 \mathrm{~kW}$ AC motor. The battery is housed in a triple-protection structure system, and in the event of an accident, an impact-sensor will cut off the high-voltage power supply to protect cabin occupants. The 2013 LEAF has an official range of 75 miles from a full charge, according to the Environmental Protection Agency (EPA). To charge a fully depleted LEAF to full battery capacity would require 6-8 hours

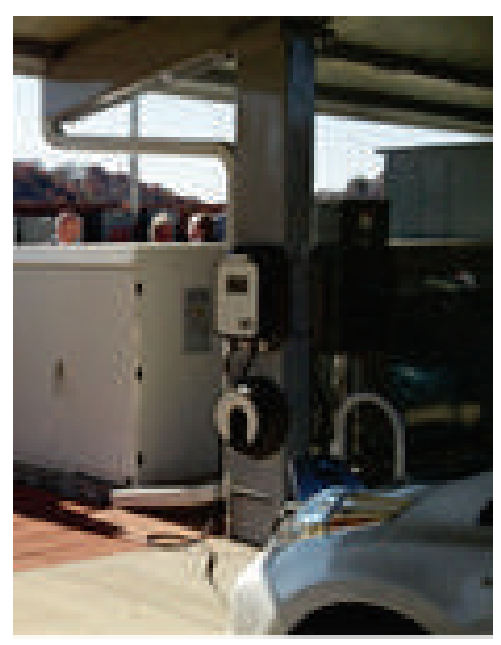

Figure 12. Blink wall-mounted ESVEs installed at the ORNL solarassisted charging station. 
using a Level 2 EVSE. At ORNL, the average miles per charge based on measured EVSE data is approximately 32.3 miles and the average total charge time is 2 hours and 24 minutes.

The Chevrolet Volt is the second most common EV driven at ORNL and was included in the detailed vehicle data collection for The EV Project (Fig. 14). The Volt is unique among EVs in that it runs on electricity stored in its battery but can also generate its own electricity using the vehicle's gasoline engine to power the electric motor in case the battery becomes depleted. The Volt's $16 \mathrm{kWh}$ lithium-ion battery pack will allow it to travel an EPA-estimated 35 miles without operating the engine. A Level 2 EVSE can fully charge the Volt's battery in approximately 4 hours, and a $120 \mathrm{~V}$ charging kit (Level 1) allows it to plug into a conventional electrical outlet and fully charge the battery in about 10 hours, depending on climate. With a full tank of gas, the total driving range is up to 375 miles.

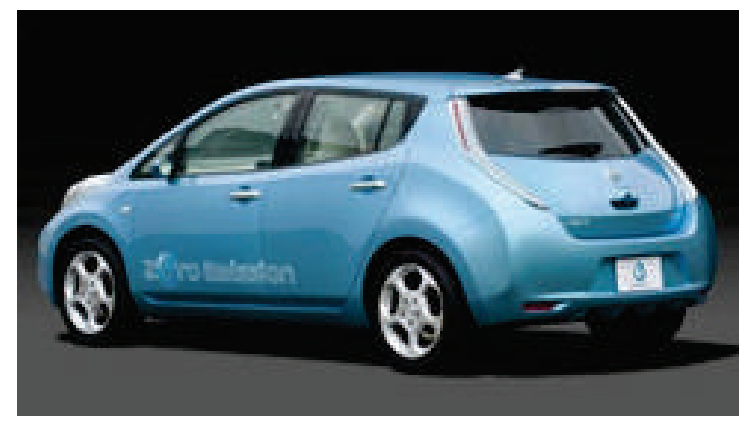

Figure 13. Nissan LEAF electric vehicle.

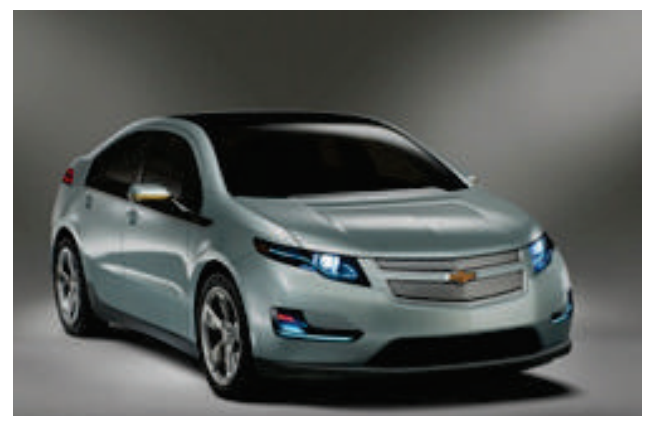

Figure 14. Chevrolet Volt extendedrange electric vehicle.

Data and Communication: As was shown in Fig. 6, three independent systems are "grid-tied" to the electric utility grid - the EVSEs, the battery bank, and the PV solar cells-and each system is also Internet-connected. Power is supplied to the EVSEs directly from the grid, but stored energy in the battery bank can also be returned to the grid to fully or partially offset the EVSE demand. Additionally, power is generated from the solar array on the roof of the charging station, and this power is transferred to the grid whether or not power is required for EVSE operation. This configuration provides flexibility in the operation of the systems, but communication between the systems is necessary to make control decisions for charging and discharging the battery bank.

The Internet connectivity of each of these systems enables convenient data extraction and remote access to monitor and control the operation of each device. Data from each system can be obtained by performing web queries from the vendor servers and by direct communication with the devices using application programming interfaces (APIs). Redundancy of the power data for the solar and battery inverters is provided by local data storage, which serves as a backup in the event of a communication failure. The power to each EVSE is also measured using current transformers that are connected to each EVSE circuit, and these data are logged to an ORNL database.

A website was created to show the amount of energy being stored, used, and produced by the battery bank, EV charging station, and PV solar cells in real time, and a web application is used to control the battery power transfers (Fig. 15). The data from the EVSEs, battery bank, and solar array were of primary interest for the research portion of the project; data from these systems were collected and analyzed by ORNL, as presented later in this report. 


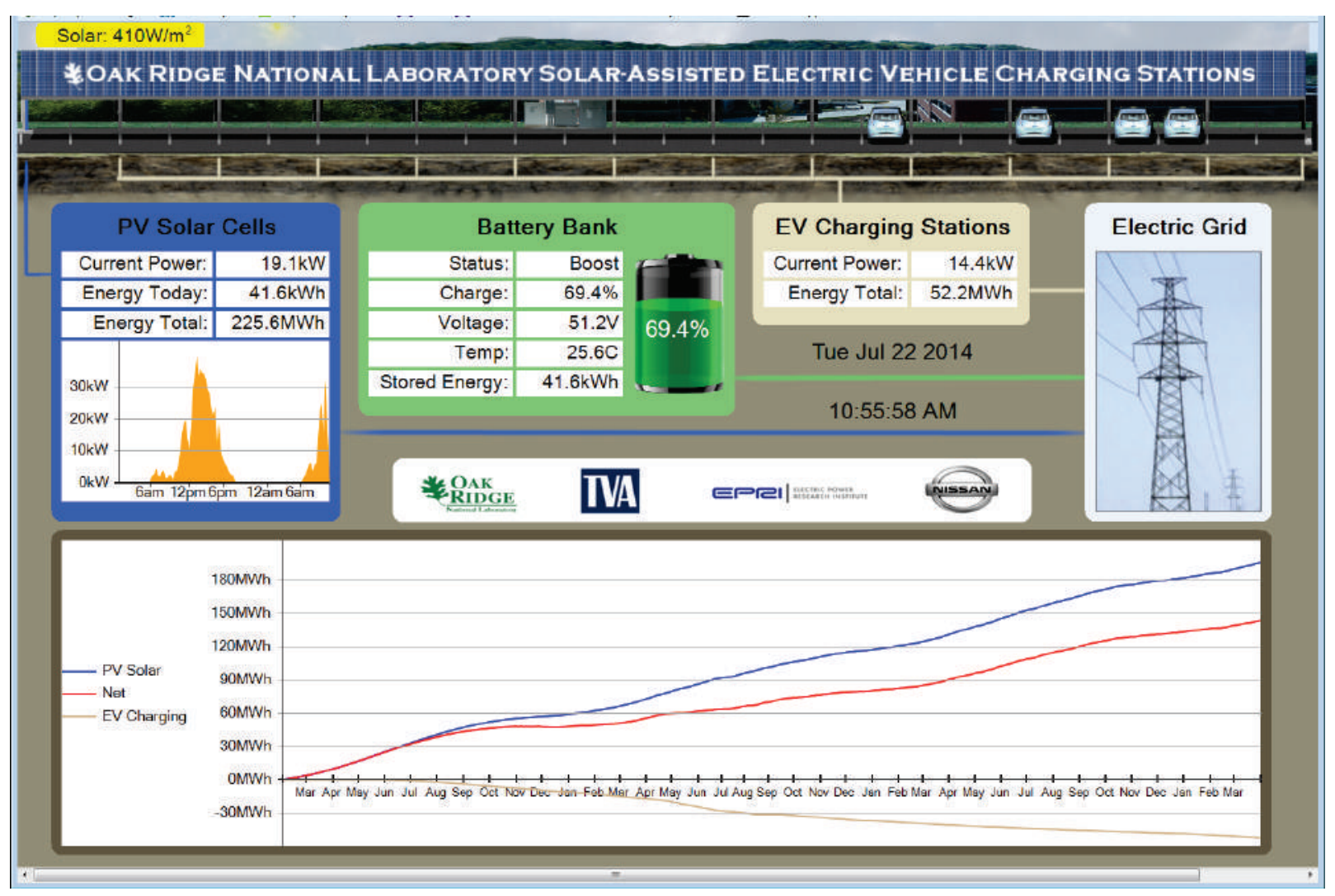

Figure 15. Website showing live data from the solar-assisted EV charging station.

\subsection{EPRI, KNOXVILLE-SIX SOLAR-ASSISTED CHARGING STATIONS}

TVA and EPRI held a ribbon cutting ceremony on January 25, 2011 for six solar-assisted charging stations installed at EPRI's Knoxville laboratory. The event was well attended and received significant coverage from media outlets, including the New York Times. TVA arranged to have a LEAF, a Volt, and two Mitsubishi i-MiEVs on site, and test drives of the EVs were made available. The overall system configuration is shown in Fig. 16, and the following sections provide details of the system design. 


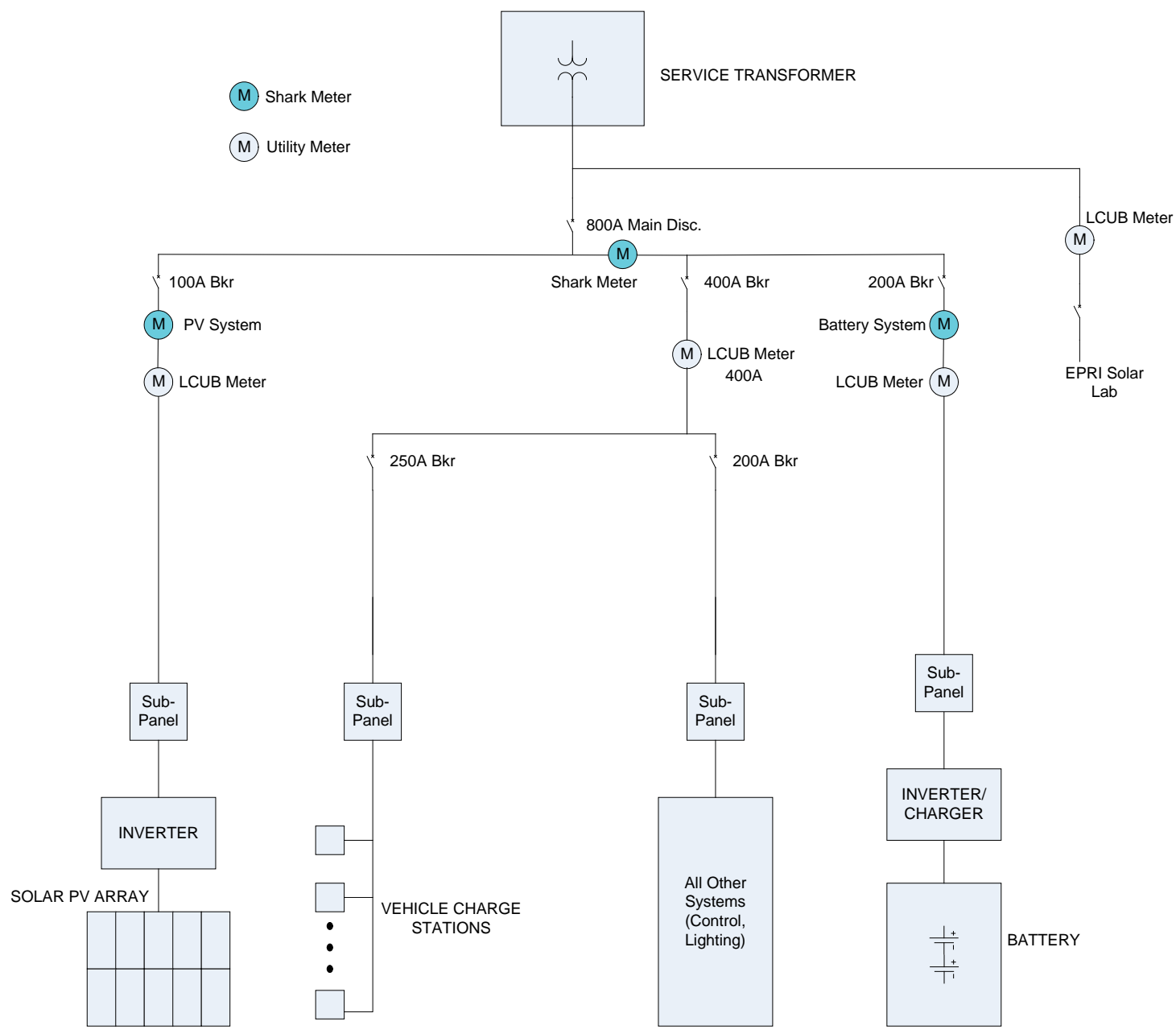

Figure 16. EPRI system diagram.

Solar: The $12 \mathrm{~kW}$ system at the EPRI Knoxville facility is outfitted with 60 REC Solar AE210-USA modules rated at $210 \mathrm{~W}$ each. The modules are composed of multi-crystalline silicon solar cells with a module efficiency of 12.7\%. Each solar module is connected to an Enphase M190-72-240-S12 microinverter. The solar canopy measures approximately 63 by $20 \mathrm{ft}$ in plan and is tilted $3^{\circ}$ toward the south (Figs. 17 and 18). The structure is a moment-resisting frame constructed of rectangular hollow structural sections. Three single-column frames spaced at $23 \mathrm{ft}$ support tubular steel purlins to which the solar PV modules are attached. A standing seam metal roof is attached to the underside of the purlins to ensure that the canopy is drip-tight. The outputs of the micro-inverters are electrically connected in parallel strings of 15 modules each to produce $240 \mathrm{~V}$ AC. Four such parallel strings are connected, each via an AC disconnect, in parallel to provide the full system capacity. 


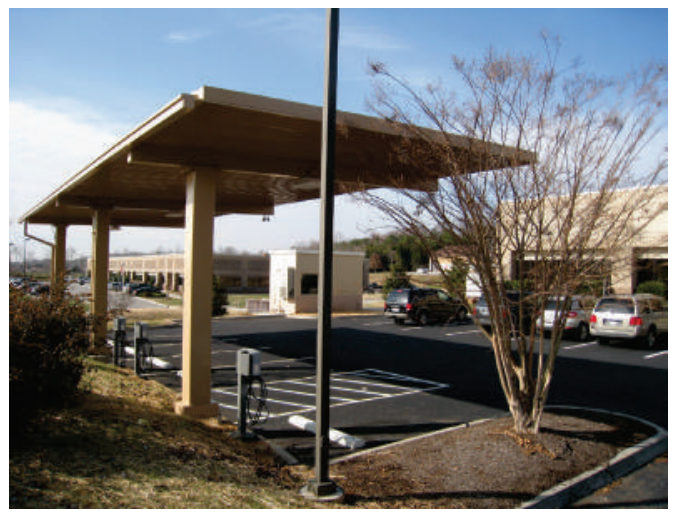

Figure 17. EPRI solar canopy.

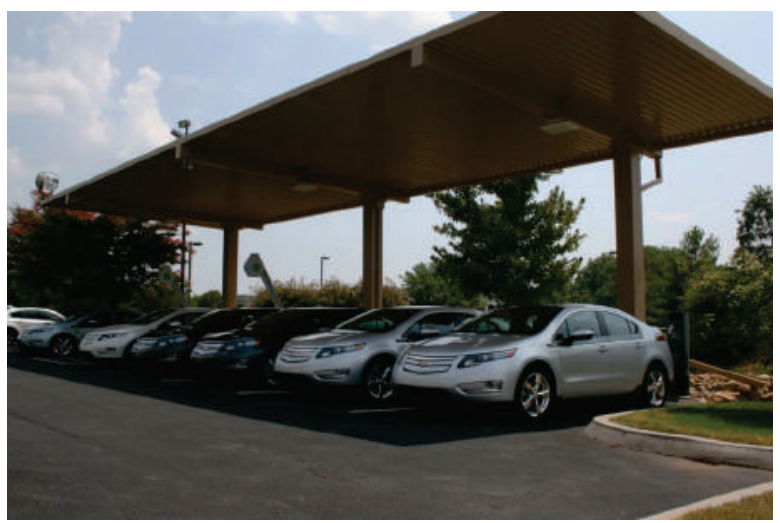

Figure 18. EPRI solar-assisted charging station.

Battery: The EPRI TVA SMART TM Station battery storage system consists of three Silent Power Model 10000 battery cabinets that are installed indoors. Each cabinet provides up to $9.2 \mathrm{~kW}$ of peak output power with a usable storage capacity of $10 \mathrm{kWh}$ (total battery capacity is approximately $15 \mathrm{kWh}$ ) for a total of $27.6 \mathrm{~kW}$ of peak power output with a $30 \mathrm{kWh}$ usable capacity for all three systems. The battery system in each cabinet consists of 48 GS Yuasa SLC70-4 advanced lead acid batteries wired in series/parallel strings to form a nominal 48 V DC bus (Fig. 19). The Silent Power units have a built-in battery charging system with a $3 \mathrm{~kW}$ rating per cabinet (Fig. 20).

EVSEs: EPRI completed its initial Knoxville installation with Clipper Creek DS-100 EVSEs. During 2011, four of the original EVSEs were replaced with two EVSE LLC Model 3722 overhead cable units and two Eaton SBR3BX00000 pedestal EVSEs. EPRI evaluated other EVSEs over the duration of the project. The two remaining Clipper Creek units were retrofitted with Liberty plug-in access control keypads during 2011. The EVSEs are shown in Fig. 21.

Data and Communications: All data logged at the EPRI site were transmitted via cellular modem or Internet connection to a database system located in Knoxville. Data can be extracted from this database for external reporting. EPRI developed a data extractor program for providing project data to INL. Data collected at the EPRI site are shown in Fig. 22. Further details of the EPRI data are included in Appendix B.

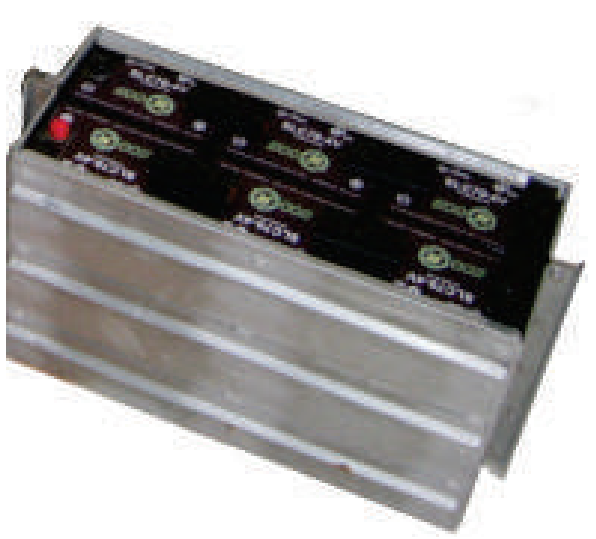

Figure 19. EPRI battery drawer.

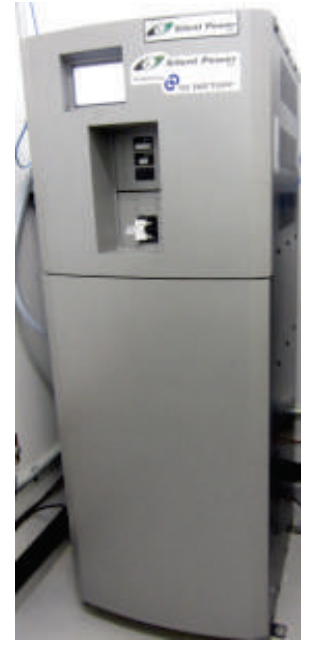

Figure 20. EPRI silent power battery system.

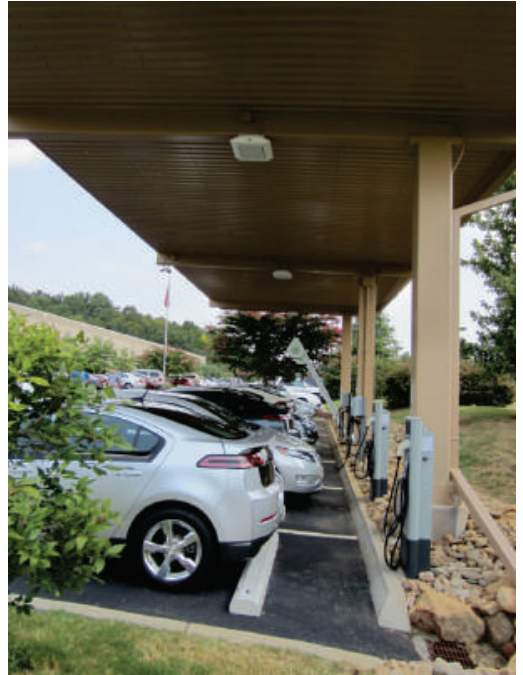

Figure 21. EPRI EVSEs. 


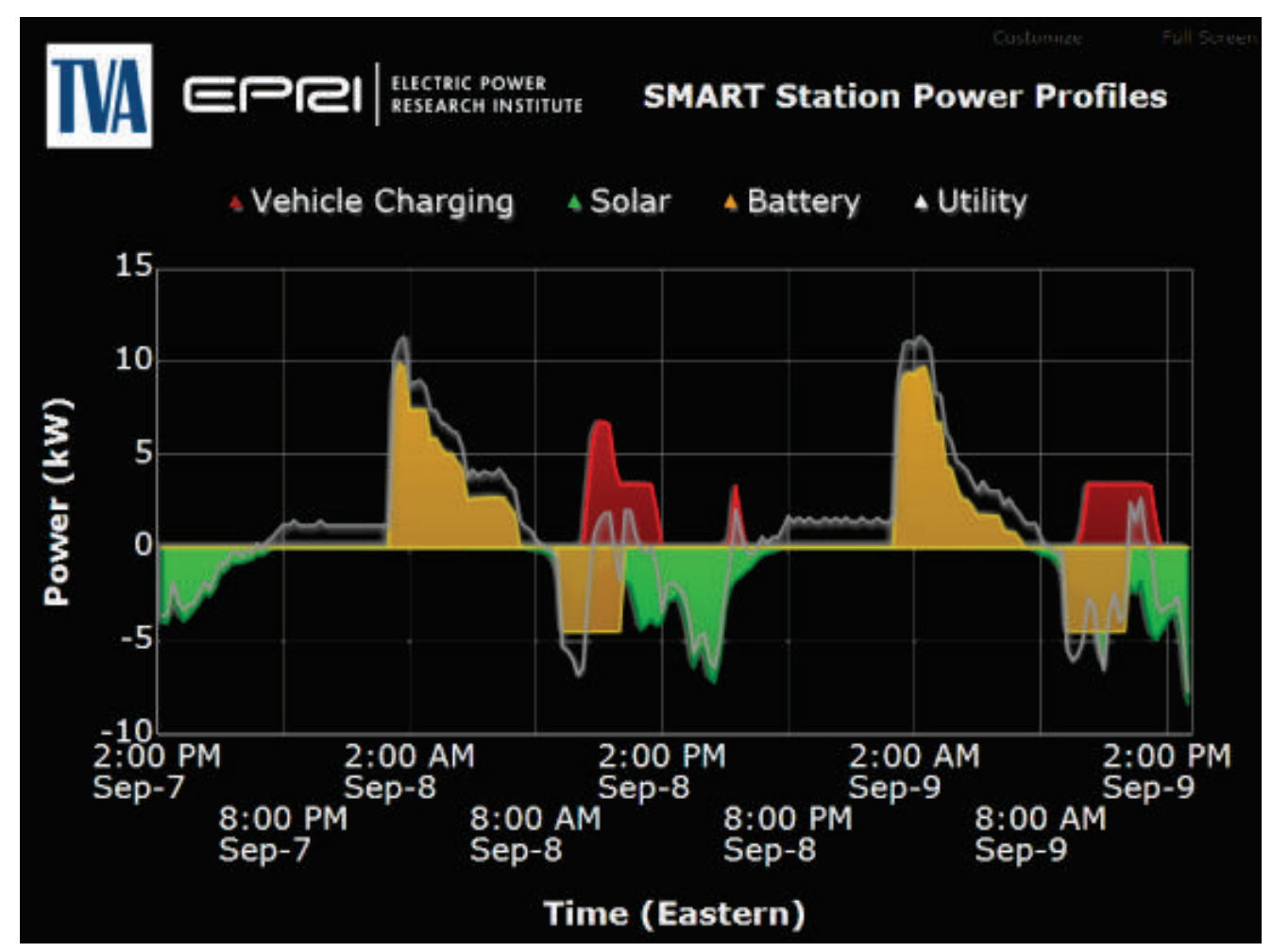

Figure 22. Data collected at the EPRI site.

\subsection{SMYRNA, NISSAN ADMINISTRATION BUILDING-NINE SOLAR-ASSISTED CHARGING STATIONS}

Nissan completed installation of nine solar-assisted charging stations at its Smyrna, Tennessee, assembly plant in September 2011 (Fig. 23).

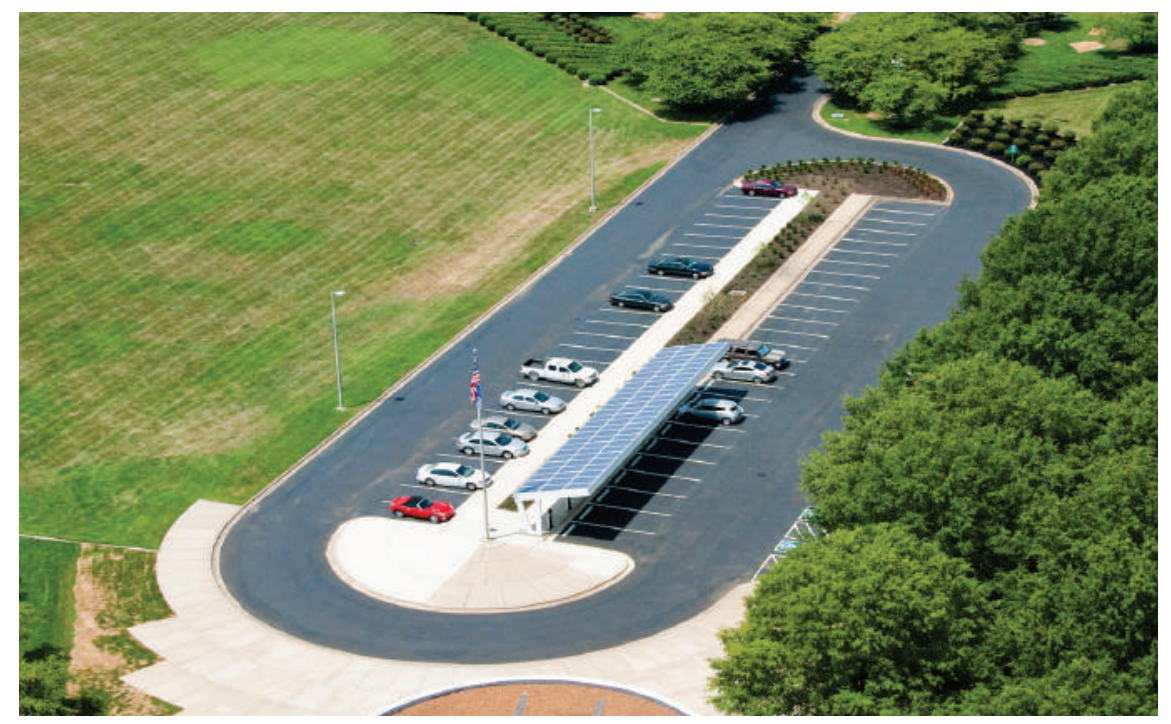

Figure 23. Nissan Smyrna Administration Building solar canopy. 
Solar: The $19 \mathrm{~kW}$ Nissan solar canopy covering nine EV charging spaces incorporates 72 Sharp NUU235F1 modules rated at $235 \mathrm{~W}$ each. The modules are composed of mono-crystalline silicon solar cells, with a module efficiency of $14.4 \%$. The solar canopy measures approximately 87 by 17 feet in plan and is tilted 10 degrees toward the south. The structure is a moment-resisting frame constructed of rectangular hollow structural sections with four single main columns. The PV array is mounted on top of the steel canopy with a Florian PV racking system that provides a weather-tight roof structure. The solar PV modules are electrically connected in series strings of nine modules each to provide DC voltage to a Xantrex GT30 DC to AC inverter. Eight such series strings are connected in parallel at two SolarBOS circuit combiners to form a bi-polar system, one negative combiner and one positive combiner.

Battery: The Nissan solar-assisted EV charging stations are equipped with a single lithium ion battery from a Nissan LEAF automobile. The battery is rated at $90 \mathrm{~kW}$, with $24 \mathrm{kWh}$ of capacity. The battery storage system is stored in a conditioned electrical equipment room and designed with a control system to shave electrical demand during peak charging periods. It is controlled by a special battery management system designed by Nissan, Schneider Electric, and Bonitron. The use of Nissan LEAF lithium batteries for energy storage will provide a second-life use for the EV batteries.

The battery is discharged to the utility grid using a Xantrex GT 100 grid-tied DC-to-AC inverter. The inverter is capable of discharging energy stored in the battery bank to the power grid to help offset load surges from EV charging. The discharge profile can be customized to maximize battery life, shave peak demands, discharge at predefined outputs, and maximize energy to the grid.

EVSEs: Nissan has nine Blink EVSEs, manufactured by ECOtality, at its administration building (Fig. 24). The Blink EVSEs include Internet connectivity and can be configured to use Wi-Fi, hardwired Ethernet, or CDMA.

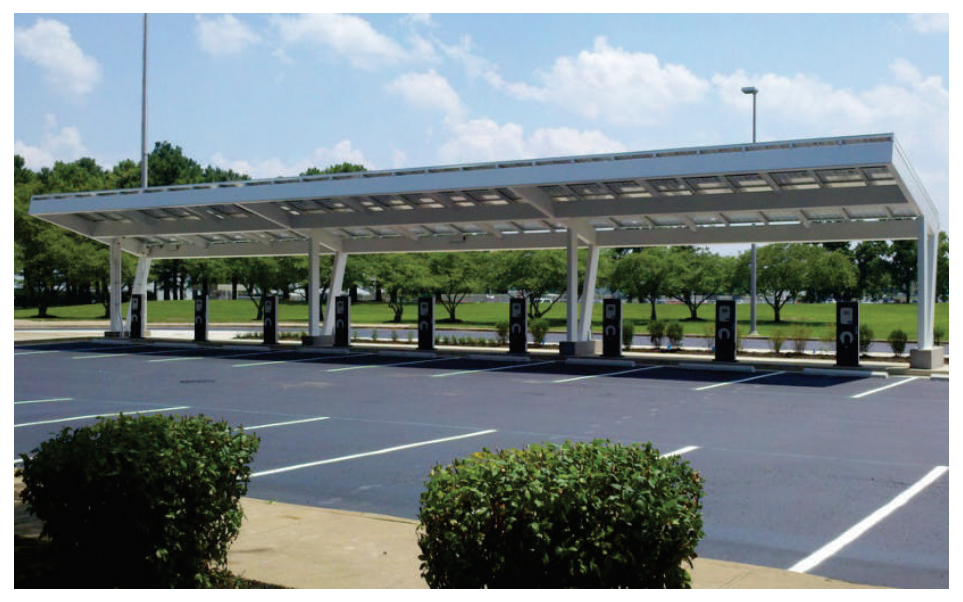

Figure 24. Nine charging stations at the Nissan Administration Building, Smyrna.

\subsection{SMYRNA, NISSAN BATTERY PLANT-THREE SOLAR-ASSISTED CHARGING STATIONS}

Nissan installed three solar-assisted charging stations at its lithium ion battery plant in Smyrna, Tennessee. Construction was completed in September 2011 (Fig. 25). 
Solar: The $6.5 \mathrm{~kW}$ Nissan solar canopy to cover three EV charging spaces (currently under construction) is designed with Sharp NU-U235F1 modules rated at $235 \mathrm{~W}$ each. The modules are composed of mono-crystalline silicon solar cells with a module efficiency of $14.4 \%$. The solar canopy measures approximately 30 by $17 \mathrm{ft}$ in plan and is tilted $10^{\circ}$ toward the south. The structure is a moment-resisting frame constructed of rectangular hollow structural sections with four main columns. The PV array is mounted on top with a Florian PV racking system that provides a weather-tight roof structure. The solar PV modules are electrically connected in series strings of nine modules each to provide DC voltage to a Xantrex GT30 DC-to-AC inverter. Four such series strings are connected in parallel at two SolarBOS circuit combiners to form

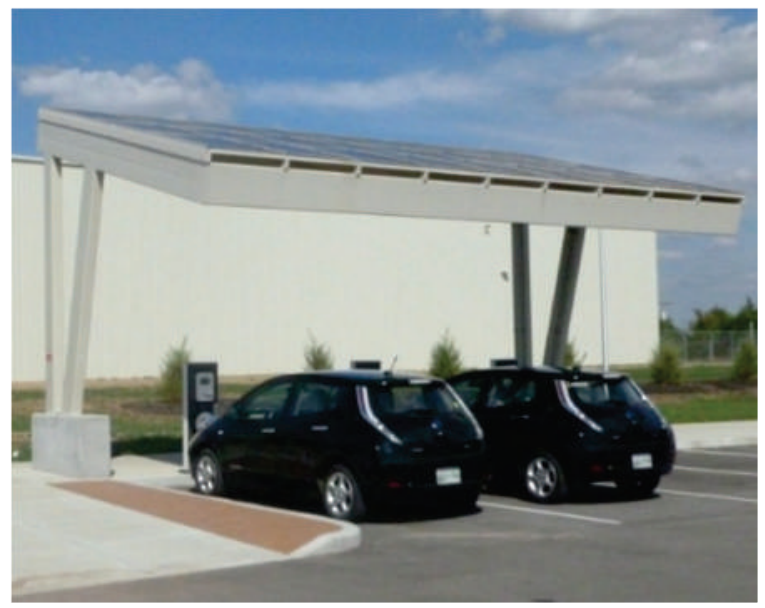

Figure 25. Solar charging station at Nissan's Smyrna Battery Plant. a bipolar system, one negative combiner and one positive combiner.

Battery: The Nissan solar-assisted EV charging stations are equipped with a single lithium ion battery from a Nissan LEAF automobile. The battery is rated at $90 \mathrm{~kW}$, with $24 \mathrm{kWh}$ of capacity. The battery storage system is stored in a conditioned electrical equipment room and designed with a control system to shave electrical demand during peak charging periods. It is controlled by a special battery management system designed by Nissan, Schneider Electric, and Bonitron. The use of Nissan LEAF lithium batteries for energy storage will provide a second-life use for the EV batteries.

The battery is discharged to the utility grid using a Xantrex GT 100 DC-to-AC inverter. This inverter is capable of discharging energy stored in the battery bank to the power grid to help offset load surges from EV charging. The discharge profile can be customized to maximize battery life, shave peak demands, discharge at predefined outputs, and maximize energy to the grid.

EVSEs: Nissan has three Blink EVSEs, manufactured by ECOtality, at its battery plant. The Blink EVSEs include Internet connectivity and can be configured to use Wi-Fi, hardwire Ethernet, or CDMA (a cell phone protocol).

\subsection{FRANKLIN, NISSAN HEADQUARTERS-EIGHTEEN SOLAR-ASSISTED CHARGING STATIONS}

Nissan completed 18 solar-assisted charging stations at its Franklin, Tennessee, headquarters in August 2011 (Fig. 26).

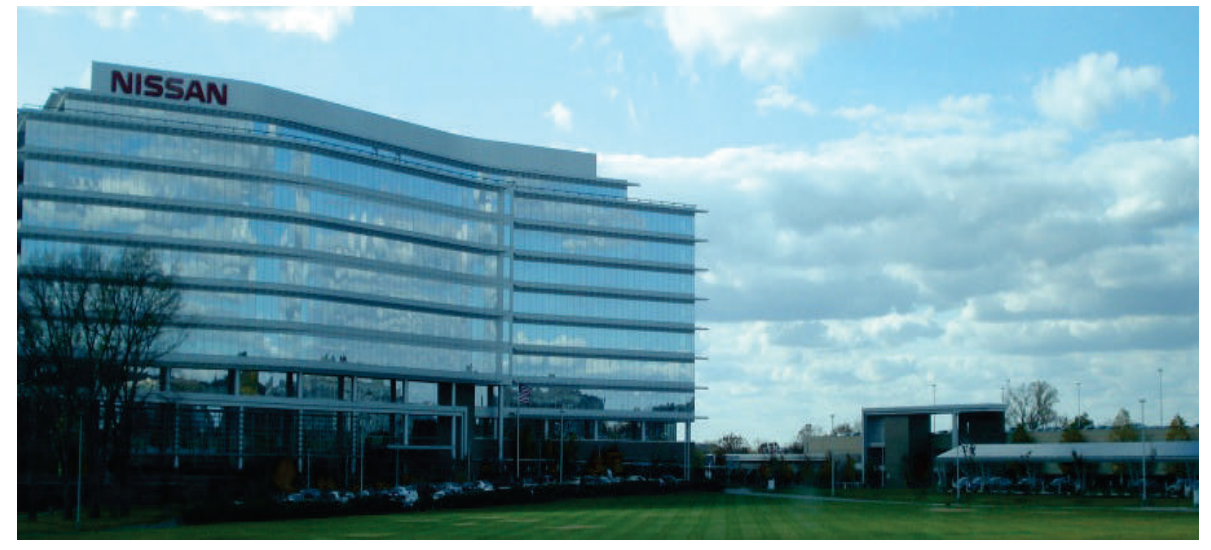

Figure 26. Franklin Nissan Headquarters with solar canopy. 
Solar: The $38 \mathrm{~kW}$ Nissan solar canopy covering $18 \mathrm{EV}$ charging spaces is designed with Sharp NU$\mathrm{U} 235 \mathrm{~F} 1$ modules rated at $235 \mathrm{~W}$ each. The modules are composed of mono-crystalline silicon solar cells with a module efficiency of $14.4 \%$. The solar canopy measures approximately 175 by $17 \mathrm{ft}$ in plan and is tilted $10^{\circ}$ toward the south (Fig. 27). The structure is a moment-resisting frame constructed of rectangular hollow structural sections with four single main columns. The PV array is mounted on top of the steel with a Florian PV racking system that provides a weather-tight roof structure. The solar PV modules are electrically connected in series strings of nine modules each to provide DC voltage to a Xantrex GT30 DC-to-AC inverter. Sixteen such series strings are connected in parallel at two SolarBOS circuit combiners to form a bipolar system, one negative combiner and one positive combiner.

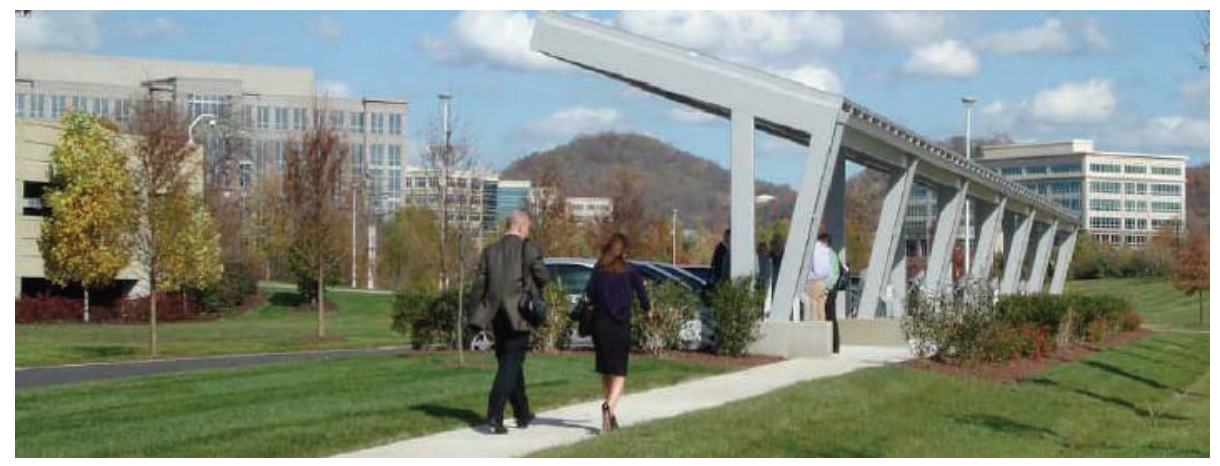

Figure 27. 18 Solar-assisted charging stations at Nissan Headquarters, Franklin, Tennessee.

Battery: The Nissan Headquarters solar-assisted EV charging stations are equipped with a single lithium ion battery from a Nissan LEAF automobile. The battery is rated at $90 \mathrm{~kW}$, with $24 \mathrm{kWh}$ of capacity. The battery storage system is stored in a conditioned electrical equipment room and designed with a control system to shave electrical demand during peak charging periods (Fig. 28). It is controlled by a special battery management system designed by Nissan, Schneider Electric, and Bonitron. The use of Nissan

LEAF lithium batteries for energy storage will provide a second-life use for the EV batteries.

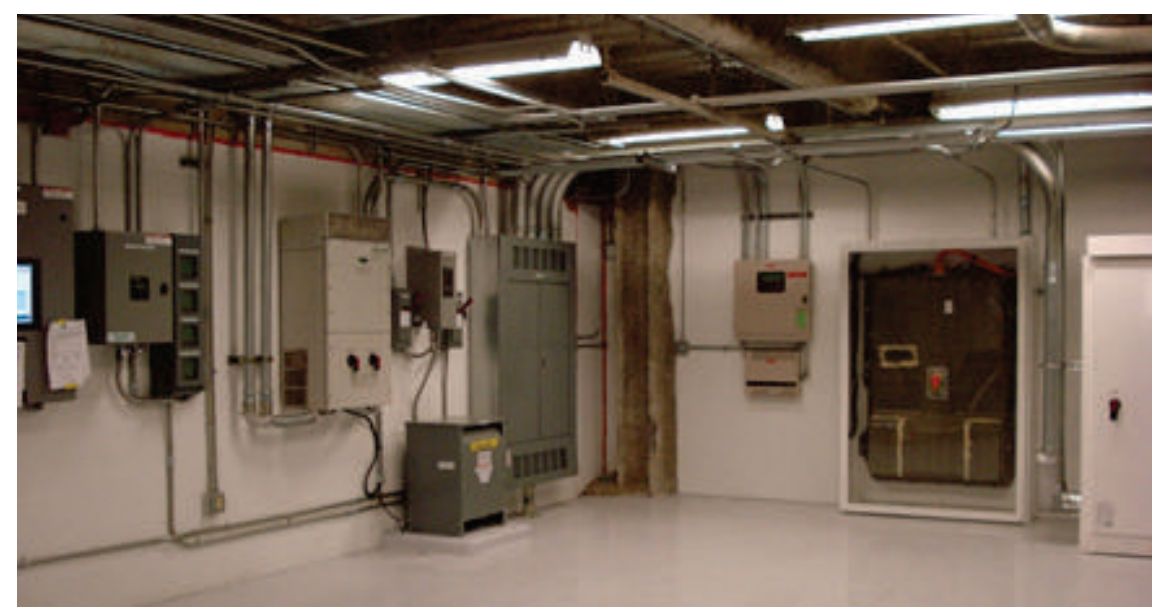

Figure 28. Franklin Nissan headquarters utility room for solar station.

The battery is discharged to the utility grid using a Xantrex GT 100 DC-to-AC inverter. This inverter is capable of discharging energy stored in the battery bank to the power grid to help offset load surges from EV charging. The discharge profile can be customized to maximize battery life, shave peak demands, discharge at predefined outputs, and maximize energy to the grid. 
EVSEs: Nissan has 18 EVSEs manufactured by AeroVironment, Inc. (AV) at its headquarters building (Fig. 29). The AV EVSEs have Internet connectivity and can be configured to use Wi-Fi, hardwire Ethernet, or CDMA (a cell phone protocol).

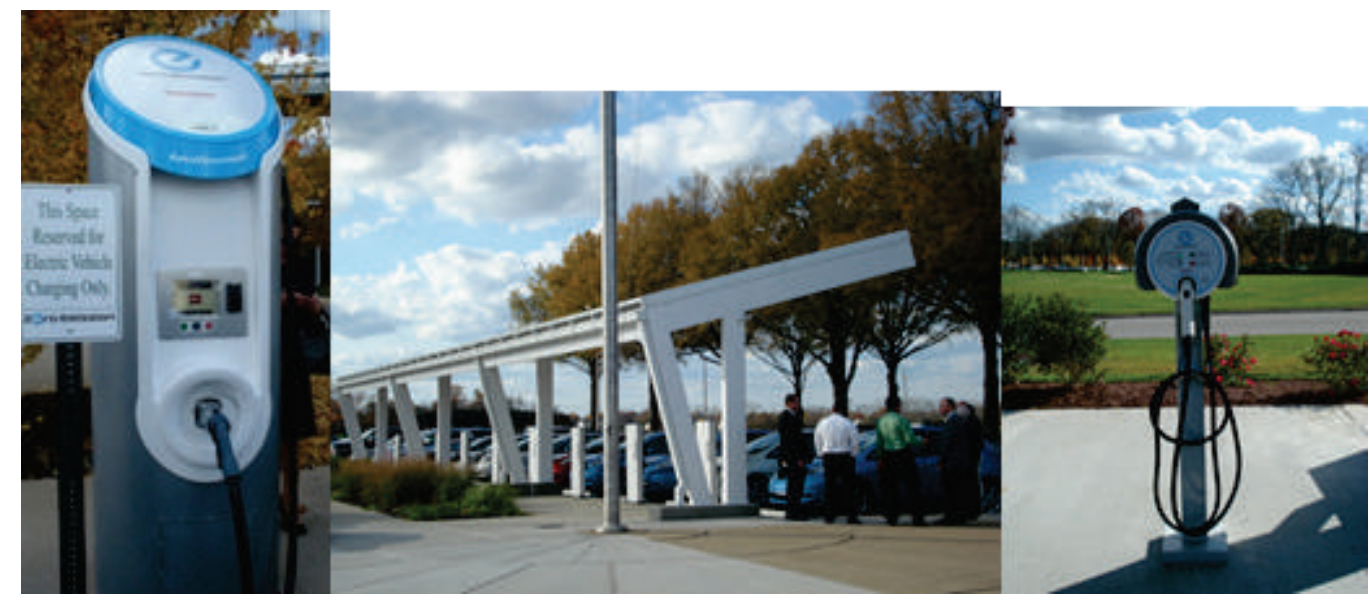

Figure 29. Franklin, Tennessee: Nissan EVSEs.

\subsection{CITY OF KNOXVILLE-TEN SOLAR-ASSISTED CHARGING STATIONS}

ORNL installed 10 solar-assisted charging spaces at two sites owned by the City of Knoxville. Four stations were constructed at the Market Street parking garage and six spaces were built at the Knoxville Civic Coliseum parking garage. The assets will be transferred to the city following completion of the research project in September 2014.

Solar: The Civic Coliseum solar panels are designed with Sharp ND-240QCJ modules rated at $14.4 \mathrm{~kW}$ total (Fig. 30). An Enphase system with 60 Model M215 micro-inverters is used to convert the $\mathrm{DC}$ voltage from the arrays to AC voltage that is connected to the grid. The Market Square garage solar panels are Sharp ND-240QCJ modules rated at $8.4 \mathrm{~kW}$ total (Fig. 31). An Enphase system with 36 Model M215 micro-inverters is used to convert the DC power to AC power. The Internet connectivity of each PV system is achieved using an Enphase Envoy Communications Gateway.

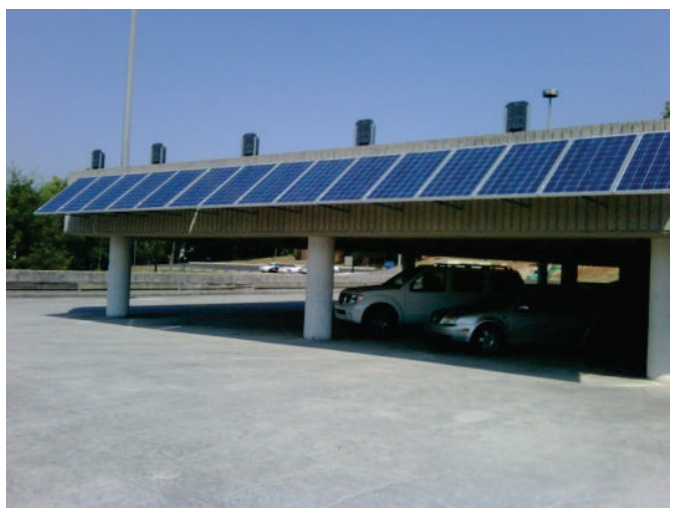

Figure 30. Solar panels for Coliseum EV charging stations.

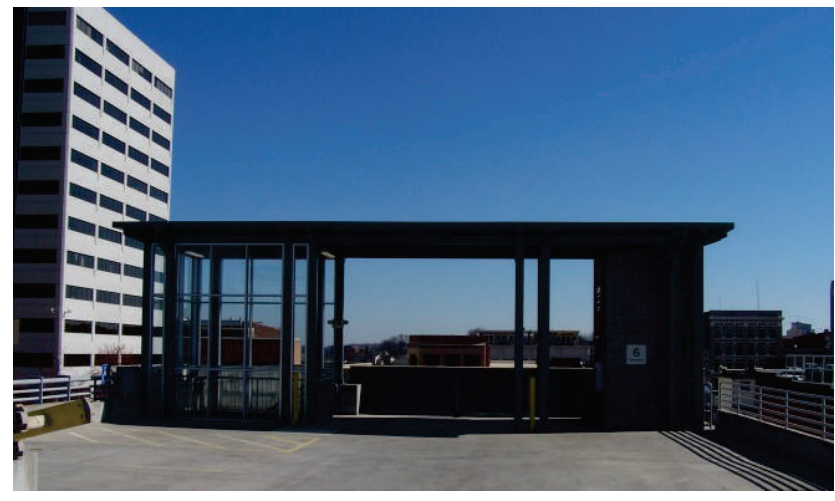

Figure 31. Solar panel location at the Market Square garage.

Battery: The Civic Coliseum battery bank contains GS SLC70-4V lead acid batteries with a total capacity of $6.7 \mathrm{kWh}$. The Market Square garage battery bank also uses GS lead acid batteries with a 
capacity of $10 \mathrm{kWh}$. Both batteries are controlled using a SMA Technologies AG Sunny Island 5048 inverter/charger.

EVSEs: The Coliseum garage has six and Market Square garage has four Blink EVSE charging stations (Figs. 32 and 33). All of the EVSEs have Internet connectivity.

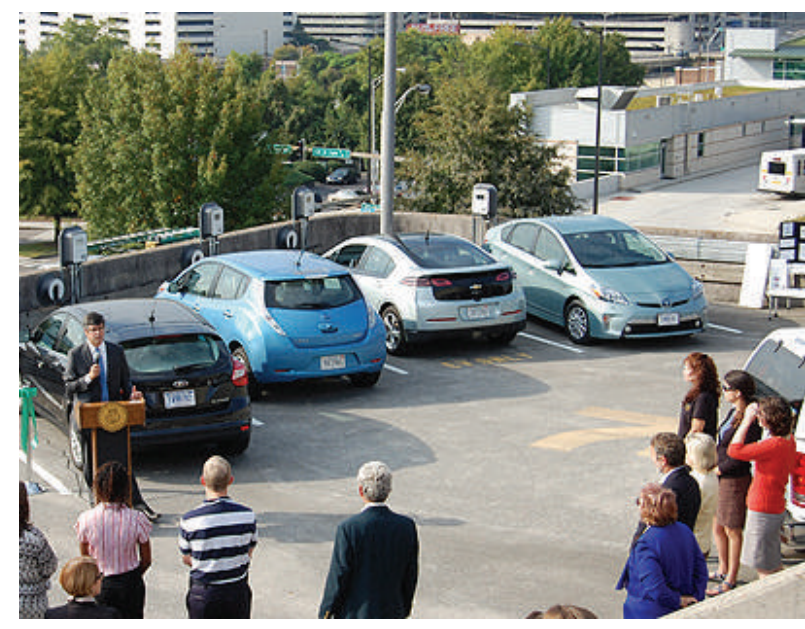

Figure 32. Ribbon cutting ceremony for the Civic Coliseum charging stations.

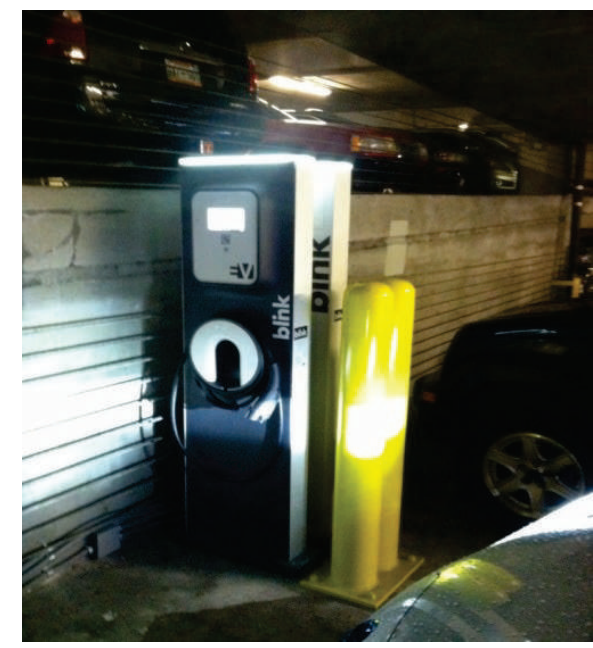

Figure 33. One of the charging stations at the Market Square garage.

Data and Communication: For both the Market Square and Civic Coliseum locations, there is Internet connectivity to the battery and solar inverters, in addition to each of the Blink EVSEs, which permits remote access to monitor and control each device. The solar and battery inverters also have local data storage on the device to provide data backup in case of communication failure. The power drawn by each EVSE is also measured using a dedicated current transformer that feeds power data to a Trendpoint Enersure branch circuit power analyzer with Internet access to transmit the data. The measured data were collected and logged to an ORNL database during the project.

\subsection{UNIVERSITY OF TENNESSEE-KNOXVILLE-TWELVE SOLAR-ASSISTED CHARGING STATIONS}

ORNL installed 12 solar-assisted charging spaces at two locations on the University of TennesseeKnoxville (UTK) campus (Figs. 34 and 35). The construction package included 12 charging stations: 6 spaces at the Agriculture Campus and 6 at the Music Building staff parking lot. The assets will be transferred to UTK following completion of the project. The UTK Music Building and Agriculture Campus designs are essentially equivalent. 


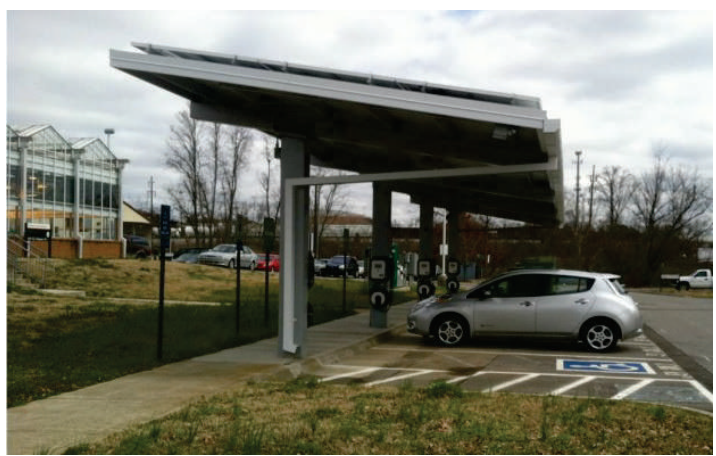

Figure 34. EVSEs at the UTK Agriculture Campus.

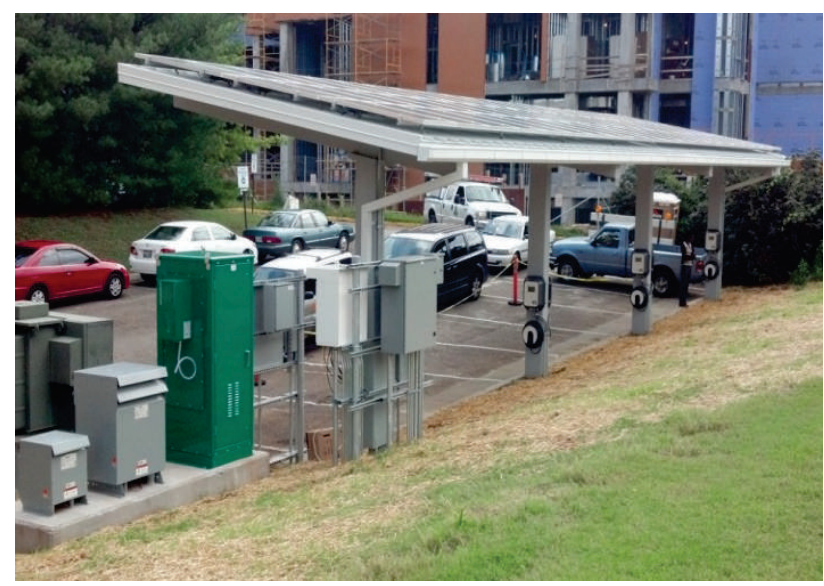

Figure 35. EVSEs at the UTK Music Building.

Solar: The UTK Music Building solar array and Agriculture Campus solar array each consist of 60 Sharp modules, with a total capacity at each location of $14.4 \mathrm{~kW}$. An Enphase inverter system with 60 Model M215 micro-inverters is used to convert the DC voltage from each array to AC voltage, and each system is equipped with an Enphase Envoy Communications Gateway to provide Internet connectivity.

Battery: The UTK Music Building and Agriculture Campus solar-assisted charging stations employ GS lead acid batteries with a total capacity of $10 \mathrm{kWh}$ for each battery bank. Each battery bank is controlled by an SMA Technologies AG Sunny Island 5048 inverter/charger.

EVSEs: Six Blink charging stations were installed at both the UTK Music Building and the Agriculture Campus.

Data and Communications: For both solar-assisted EV charging station locations, Internet connectivity is available to the battery and solar inverters, as well as each of the EVSEs, enabling remote access to monitor and control each device. The solar and battery inverters also have local data storage on the device to provide data backup in case of communications failure. The power drawn by each EVSE is measured using a current transformer, and the measured data were logged to an ORNL database during the project.

\subsection{NASHVILLE, LP FIELD—EIGHT SOLAR-ASSISTED CHARGING STATIONS}

ORNL installed eight solar-assisted charging spaces at LP Field in Nashville (Fig. 36). These stations will be turned over to the Metropolitan Government of Nashville and Davidson County at the end of the project.

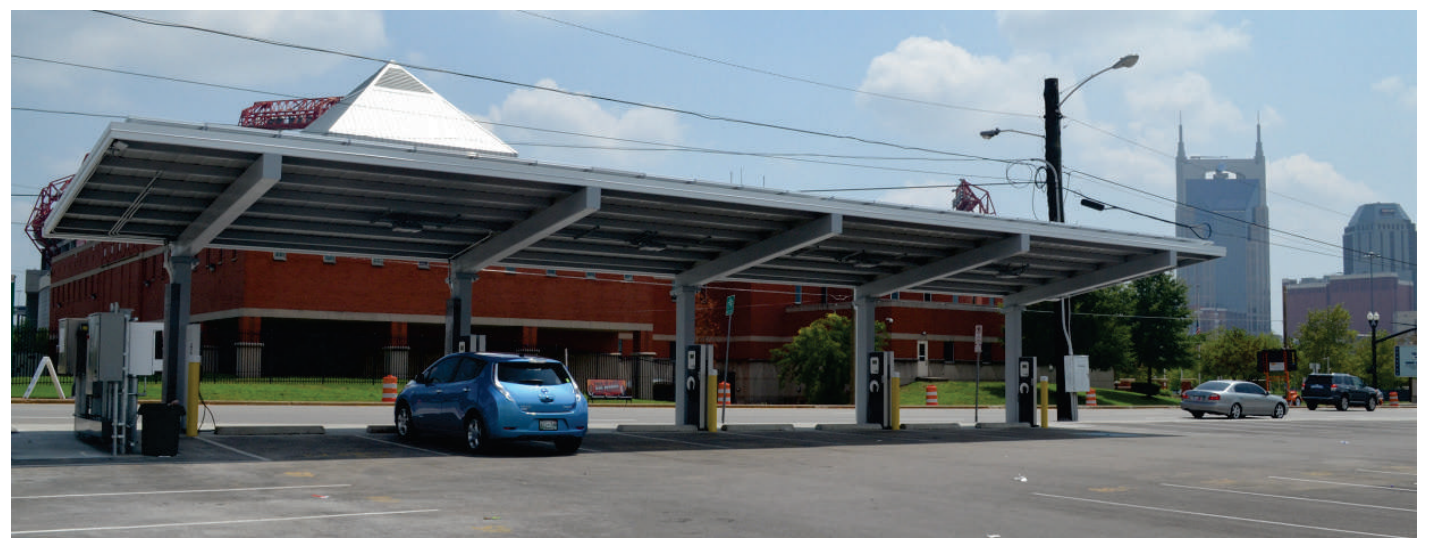

Figure 36. LP Field solar-assisted charging stations. 
Solar: The Nashville LP Field solar canopy covering eight $\mathrm{EV}$ charging spaces is designed with Sharp NU-U235F1 photovoltaic modules rated at a total capacity of $17.2 \mathrm{~kW}$. An Enphase inverter system with 72 Model M215 microinverters is used to convert the DC voltage from the array to AC voltage, and each system is equipped with an Enphase Envoy Communications Gateway to provide Internet connectivity.

Battery: The battery bank consists of GS lead acid batteries with a capacity of $13 \mathrm{kWh}$ and is controlled by a SMA Sunny Island charger/inverter.

EVSEs: Eight Blink EVSEs were installed at the LP Field solar-assisted charging station

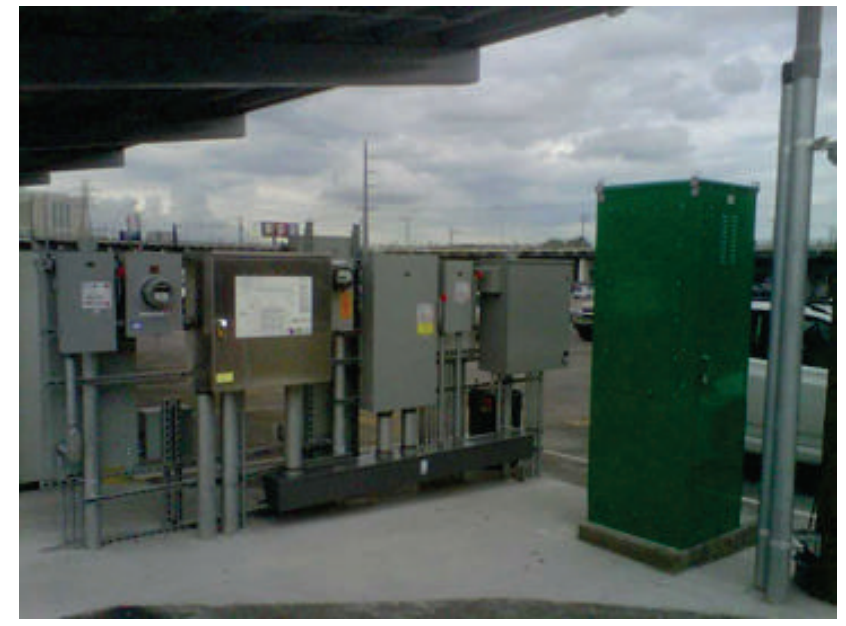

Figure 37. LP field utility for solar station. location.

Data and Communications: Internet connectivity is provided to the battery and solar inverters, as well as to each of the EVSEs. The solar and battery inverters also have local data storage on the device to provide data backup in case of communications failure. The power drawn by each EVSE is measured using a current transformer, and the measured data were logged to an ORNL database during the project.

\subsection{STATE OF TENNESSEE EMPLOYEE PARKING LOT-FOUR SOLAR-ASSISTED CHARGING STATIONS}

Four solar-assisted charging stations were installed at property owned by the State of Tennessee at the Bicentennial Mall in Nashville (Fig. 38). The station and associated equipment were dismantled and moved to storage in early April 2014 to make the area available for a new baseball field being built by the Metro Sports Authority. The station will be reinstalled at a later date. The assets will be transferred to the state at the end of the research project.

Solar: The State of Tennessee Employee Parking Lot site has a solar array consisting of Sharp ND-240QCJ modules with a total capacity of $8.6 \mathrm{~kW}$. An Enphase inverter system with 36 Model M215 micro-inverters is used to convert the DC voltage from the array to AC voltage, and each system is equipped with an Enphase Envoy Communications Gateway for Internet connectivity.

Battery: The battery bank consists of GS lead acid batteries with a capacity of $6.7 \mathrm{kWh}$ and is controlled by a SMA Technologies AG

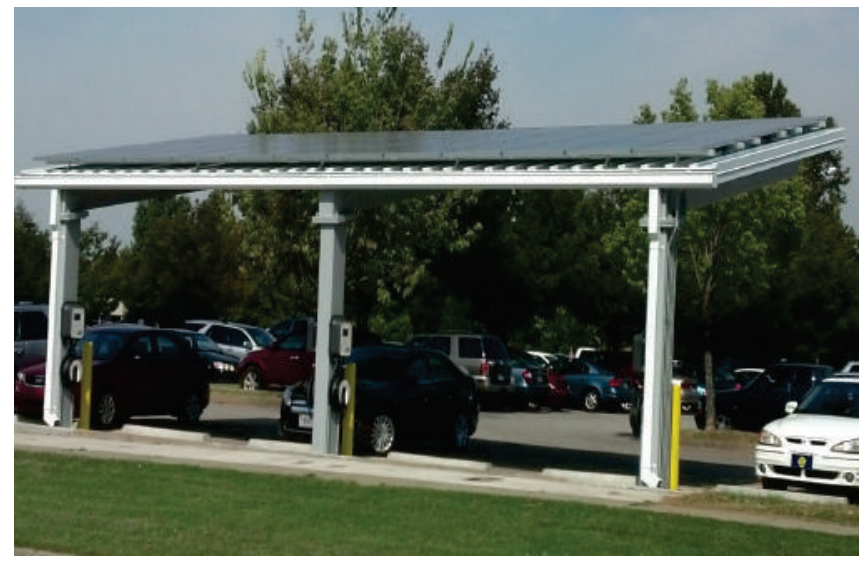

Figure 38. State of Tennessee Employee Parking Lot site solar-assisted charging stations. Sunny Island 5048 inverter/charger.

EVSEs: Four Blink EVSEs were installed on the Bicentennial Mall site.

Data and Communications: Internet connectivity was provided to the battery and solar inverters, as well as to each of the EVSEs. The solar and battery inverters also have local data storage on the device to provide data backup in case of communications failure. The power drawn by each EVSE was measured using a current transformer, and the measured data were logged to an ORNL database during the project. 


\subsection{NASHVILLE, VANDERBILT-10 SOLAR-ASSISTED CHARGING STATIONS}

TVA and EPRI collaborated on the installation of 10 solar-assisted charging stations on the Vanderbilt University campus in Nashville. These stations are located in a parking area near Broadway Avenue (Fig. 39). Installation was completed in September 2012.

Solar: The solar array consists of Enphase modules with a total capacity of $20 \mathrm{~kW}$.

Battery: The battery bank consists of GS lead acid batteries with a capacity of $3 \mathrm{kWh}$, controlled by a Schneider Electric (Xantrex) inverter.

EVSEs: Ten Model Eaton EVSEs were installed at the Vanderbilt site.

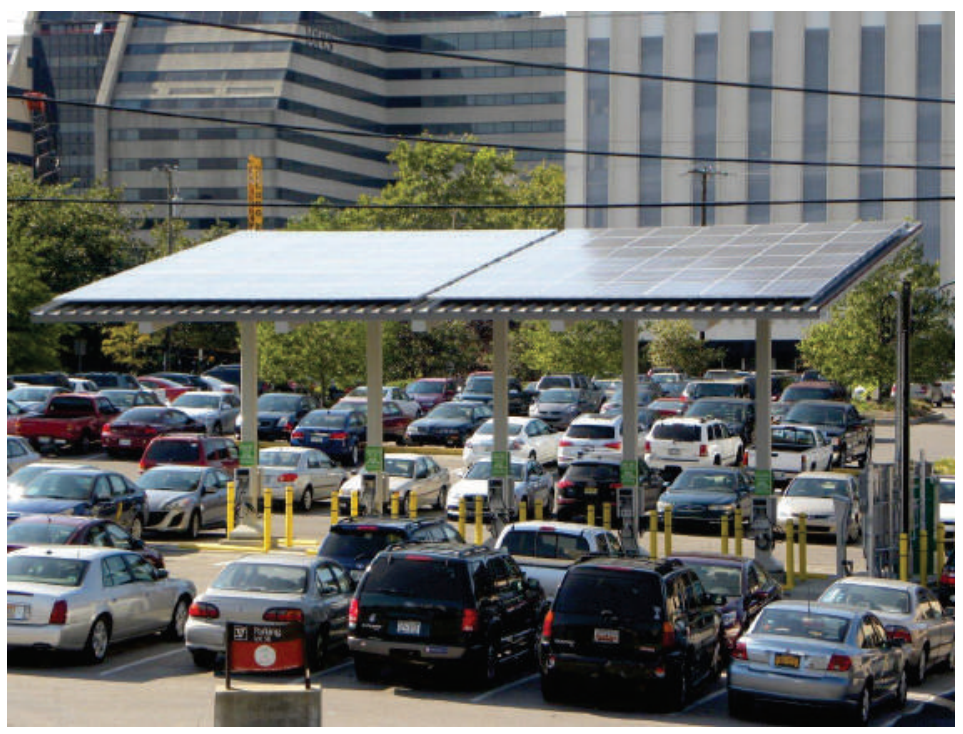

Figure 39. Vanderbilt solar-assisted charging stations.

\subsection{CHATTANOOGA-TEN SOLAR-ASSISTED CHARGING STATIONS}

TVA and EPRI managed the installation of ten solar-assisted charging stations in Chattanooga, Tennessee. Six of the spaces are located in a site near the downtown area at the Chattanooga Theatre Centre (Fig. 40). The remaining four spaces are located at the TVA Advanced Vehicle Test Facility on the north side of the city.

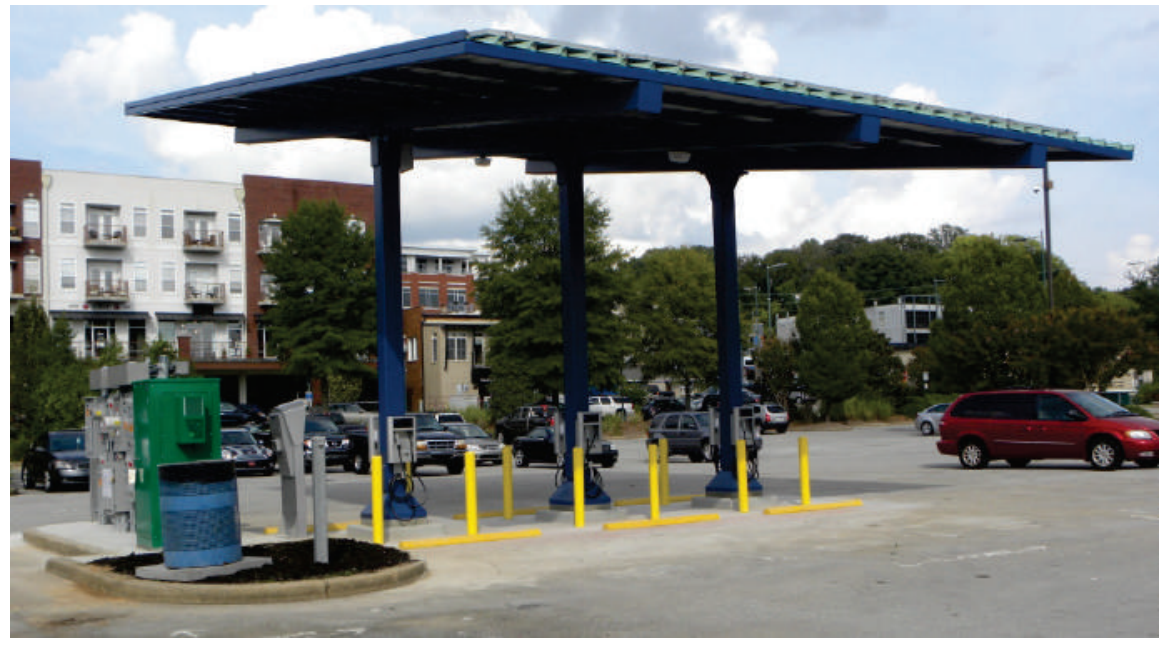

Figure 40. Chattanooga Theatre solar-assisted charging stations. 
Solar: The Theatre site uses Sharp ND-240QCJ photovoltaic modules and an Enphase inverter system incorporating an Enphase model M215 microinverter for each solar panel. The total output capacity is $12 \mathrm{~kW}$. The Vehicle Test Facility includes both an SMA and an Enphase system, each providing $50 \%$ of the rated power, for a total capacity of $8 \mathrm{~kW}$.

Battery: Each site has a battery bank consisting of GS lead acid batteries with a capacity of $3 \mathrm{kWh}$. Battery charging and discharging are controlled by a Schneider Electric (Xantrex) inverter/charger.

EVSEs: The Theatre location has six Eaton EVSEs and the Vehicle Test Facility has four EVSEs from four manufacturers: GE, Pass-Seymour, Clipper-Creek, and EVSE LLC.

\subsection{MEMPHIS, SHELBY FARMS-TEN SOLAR-ASSISTED CHARGING STATIONS}

TVA and EPRI also managed the installation of ten solar-assisted charging stations in Memphis, Tennessee. The site, completed in September 2012, is located at Shelby Farms Park near the main park office building (Fig. 41).

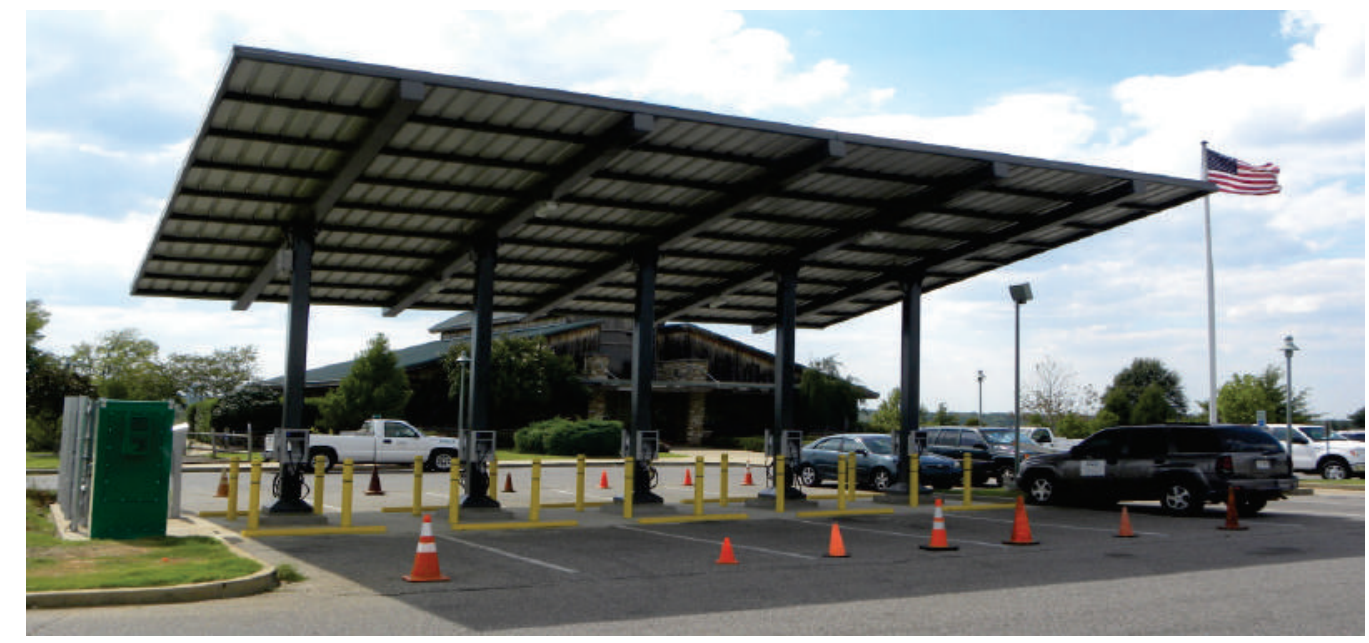

Figure 41. Shelby Farms solar-assisted charging stations.

Solar: The Shelby Farms solar array incorporates an Enphase system with a total capacity of $20 \mathrm{~kW}$.

Battery: The battery bank consists of GS lead acid batteries with a total capacity of $3 \mathrm{kWh}$ and is controlled by a Schneider Electric (Xantrex) inverter/charger.

EVSEs: Ten Eaton EVSEs were installed at the Memphis location.

Table 3 lists a comparison of the Knoxville, Nashville, Chattanooga, and Memphis EVSE installations. 
Table 3. Components installed at the Knoxville, Nashville, Chattanooga, and Memphis solar-assisted EVSE installations

\begin{tabular}{|c|c|c|c|c|c|c|c|}
\hline \multirow[t]{2}{*}{ Sites } & \multicolumn{2}{|c|}{ EVSE } & \multicolumn{2}{|c|}{ Solar } & \multicolumn{3}{|c|}{ Battery } \\
\hline & $\begin{array}{c}\text { No. of } \\
\text { Stations }\end{array}$ & Model & $\begin{array}{l}\text { Total Power } \\
(k W)\end{array}$ & Module & Type & $\begin{array}{c}\text { Capacity } \\
(k W h)\end{array}$ & Controller \\
\hline ORNL & 25 & Blink & 47.0 & $\begin{array}{l}\text { Sharp, with } \\
\text { PV Powered } \\
\text { Inverter }\end{array}$ & $\begin{array}{l}\text { C\&D } \\
\text { Technologies }\end{array}$ & 60.0 & $\begin{array}{l}\text { SMA Sunny } \\
\text { Island }\end{array}$ \\
\hline EPRI Knoxville & 6 & Blink & 12.0 & $\begin{array}{l}\text { REC Solar, } \\
\text { w/ Enphase } \\
\text { Inv }\end{array}$ & $\begin{array}{l}\text { GS battery- } \\
\text { lead acid }\end{array}$ & 30.0 & $\begin{array}{l}\text { SMA Sunny } \\
\text { Island }\end{array}$ \\
\hline $\begin{array}{l}\text { Nissan Admin, } \\
\text { Smyrna }\end{array}$ & 9 & Blink & 19.0 & $\begin{array}{l}\text { Sharp, with } \\
\text { Enphase Inv }\end{array}$ & $\begin{array}{l}\text { Nissan Leaf } \\
\text { battery }\end{array}$ & 24.0 & $\begin{array}{l}\text { Xantrex, Custom } \\
\text { charger }\end{array}$ \\
\hline $\begin{array}{l}\text { Nissan Battery } \\
\text { plant, Smyrna }\end{array}$ & 3 & Blink & 6.5 & $\begin{array}{l}\text { Sharp, with } \\
\text { Enphase Inv }\end{array}$ & $\begin{array}{l}\text { Nissan Leaf } \\
\text { battery }\end{array}$ & 24.0 & $\begin{array}{l}\text { Xantrex, Custom } \\
\text { charger }\end{array}$ \\
\hline $\begin{array}{l}\text { Nissan } \\
\text { Headquarters, } \\
\text { Franklin }\end{array}$ & 18 & $\begin{array}{l}\text { AeroViron } \\
\text { ment }\end{array}$ & 38.0 & $\begin{array}{l}\text { Sharp, with } \\
\text { Enphase Inv }\end{array}$ & $\begin{array}{l}\text { Nissan Leaf } \\
\text { battery }\end{array}$ & 24.0 & $\begin{array}{l}\text { Xantrex, Custom } \\
\text { charger }\end{array}$ \\
\hline $\begin{array}{l}\text { Knoxville } \\
\text { (Coliseum) }\end{array}$ & 6 & Blink & 14.4 & $\begin{array}{l}\text { Sharp, with } \\
\text { Enphase Inv }\end{array}$ & $\begin{array}{l}\text { GS battery- } \\
\text { lead acid }\end{array}$ & 6.7 & $\begin{array}{l}\text { SMA Sunny } \\
\text { Island }\end{array}$ \\
\hline $\begin{array}{l}\text { Knoxville } \\
\text { (Market Square) }\end{array}$ & 4 & Blink & 8.4 & $\begin{array}{l}\text { Sharp, with } \\
\text { Enphase Inv }\end{array}$ & $\begin{array}{l}\text { GS battery- } \\
\text { lead acid }\end{array}$ & 10.0 & $\begin{array}{l}\text { SMA Sunny } \\
\text { Island }\end{array}$ \\
\hline $\begin{array}{l}\text { UTK (Music } \\
\text { Building) }\end{array}$ & 6 & Blink & 14.4 & $\begin{array}{l}\text { Sharp, with } \\
\text { Enphase Inv }\end{array}$ & $\begin{array}{l}\text { GS battery- } \\
\text { lead acid }\end{array}$ & 10.0 & $\begin{array}{l}\text { SMA Sunny } \\
\text { Island }\end{array}$ \\
\hline $\begin{array}{l}\text { UTK (Ag } \\
\text { Campus) }\end{array}$ & 6 & Blink & 14.4 & $\begin{array}{l}\text { Sharp, with } \\
\text { Enphase Inv }\end{array}$ & $\begin{array}{l}\text { GS battery- } \\
\text { lead acid }\end{array}$ & 10.0 & $\begin{array}{l}\text { SMA Sunny } \\
\text { Island }\end{array}$ \\
\hline $\begin{array}{l}\text { Nashville (LP } \\
\text { Field) }\end{array}$ & 8 & Blink & 17.2 & $\begin{array}{l}\text { Sharp, with } \\
\text { Enphase Inv }\end{array}$ & $\begin{array}{l}\text { GS battery- } \\
\text { lead acid }\end{array}$ & 13.0 & $\begin{array}{l}\text { SMA Sunny } \\
\text { Island }\end{array}$ \\
\hline Nashville (State) & 4 & Blink & 8.6 & $\begin{array}{l}\text { Sharp, with } \\
\text { Enphase Inv }\end{array}$ & $\begin{array}{l}\text { GS battery- } \\
\text { lead acid }\end{array}$ & 6.7 & $\begin{array}{l}\text { SMA Sunny } \\
\text { Island }\end{array}$ \\
\hline $\begin{array}{l}\text { Nashville } \\
\text { (Vanderbilt) }\end{array}$ & 10 & Eaton & 20.0 & $\begin{array}{l}\text { Sharp, with } \\
\text { Enphase Inv }\end{array}$ & $\begin{array}{l}\text { GS battery- } \\
\text { lead acid }\end{array}$ & 3.0 & $\begin{array}{l}\text { Schneider } \\
\text { Electric } \\
\text { (Xantrex) }\end{array}$ \\
\hline $\begin{array}{l}\text { Chattanooga } \\
\text { (Advanced } \\
\text { Vehicle Test } \\
\text { Facility) }\end{array}$ & 4 & $\begin{array}{l}\text { GE; Pass- } \\
\text { Seymour; } \\
\text { Clipper- } \\
\text { Creek; } \\
\text { EVSE } \\
\text { LLC }\end{array}$ & 8.0 & $\begin{array}{l}\text { Sharp, with } \\
\text { Enphase } \\
\text { Inverter }\end{array}$ & $\begin{array}{l}\text { GS battery- } \\
\text { lead acid }\end{array}$ & 3.0 & $\begin{array}{l}\text { Schneider } \\
\text { Electric } \\
\text { (Xantrex) }\end{array}$ \\
\hline $\begin{array}{l}\text { Chattanooga } \\
\text { (Chattanooga } \\
\text { Theatre Centre) }\end{array}$ & 6 & Eaton & 12.0 & $\begin{array}{l}\text { Sharp, with } \\
\text { Enphase Inv }\end{array}$ & $\begin{array}{l}\text { GS battery- } \\
\text { lead acid }\end{array}$ & 3.0 & $\begin{array}{l}\text { Schneider } \\
\text { Electric } \\
\text { (Xantrex) }\end{array}$ \\
\hline $\begin{array}{l}\text { Memphis (Shelby } \\
\text { Farms Park) }\end{array}$ & 10 & Eaton & 20.0 & $\begin{array}{l}\text { Sharp, with } \\
\text { Enphase Inv }\end{array}$ & $\begin{array}{l}\text { GS battery- } \\
\text { lead acid }\end{array}$ & 3.0 & $\begin{array}{l}\text { Schneider } \\
\text { Electric } \\
\text { (Xantrex) }\end{array}$ \\
\hline
\end{tabular}




\section{PHASE 2 INSTALLATIONS-NON-SOLAR LEVEL 2 EVSES AND DCFC ON THE ORNL CAMPUS}

Following the completion of the solar-assisted charging stations at ORNL, a second phase of EVSE installations was initiated at multiple sites around the campus. As the number of EV owners at ORNL grew, it was evident that the single location for EV charging stations did not meet the need for the many EV drivers located in different buildings across campus. New locations were selected to address the increasing demand and anticipated future needs for EV charging for both employees and visitors to ORNL. Sites were selected for parking areas at prominent and convenient locations across ORNL's 4,470-acre main campus and at the National Transportation Research Center (NTRC), an ORNL research facility located about 12 miles from the primary ORNL campus.

During 2012 and 2013, the additional 19 EVSEs were installed at 6 different locations at ORNL. Eighteen of the installed chargers are Blink Level 2 EVSEs and the other unit is a Blink DCFC installed to provide a rapid charging capability. All of the EVSEs, manufactured by ECOtality, have Internet connectivity. The power to each EVSE is also measured using current transformers connected to each EVSE circuit, and these data are logged to an ORNL database.

As with the solar-assisted installations, the EVSE charging data were collected on the Blink network and subsequently downloaded to ORNL for analysis. To avoid privacy concerns, no personal information was used in analysis of the data. The usage data collected to date were processed and are presented later in this report. Figure 42 shows a map of the ORNL campus with the charging station locations indicated. The numbers shown inside each circle indicate the number of EVSEs at each site. Additional information about each charging station site and photos of the installation are provided in the following sections. 


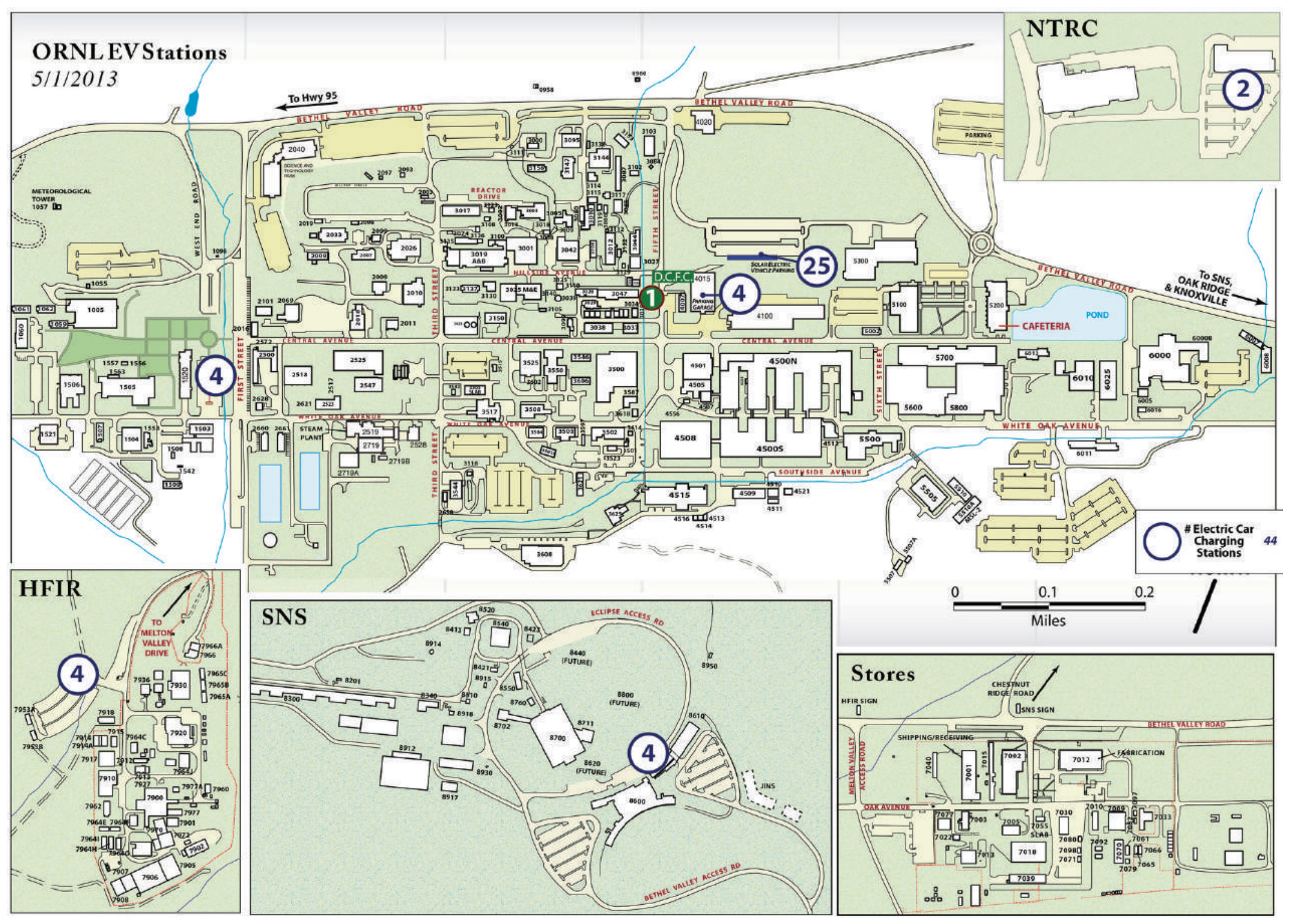

Figure 42. Map of all charging station locations on the ORNL campus. 


\subsection{PARKING GARAGE, CENTRAL AVENUE}

Four Level 2 Blink EVSEs were installed at the parking garage on Central Avenue near the intersection at Fifth Street (Fig. 43). Network connectivity to each EVSE and the current transformers is available via a network switch with a wireless bridge connection to the Central Energy Data System.

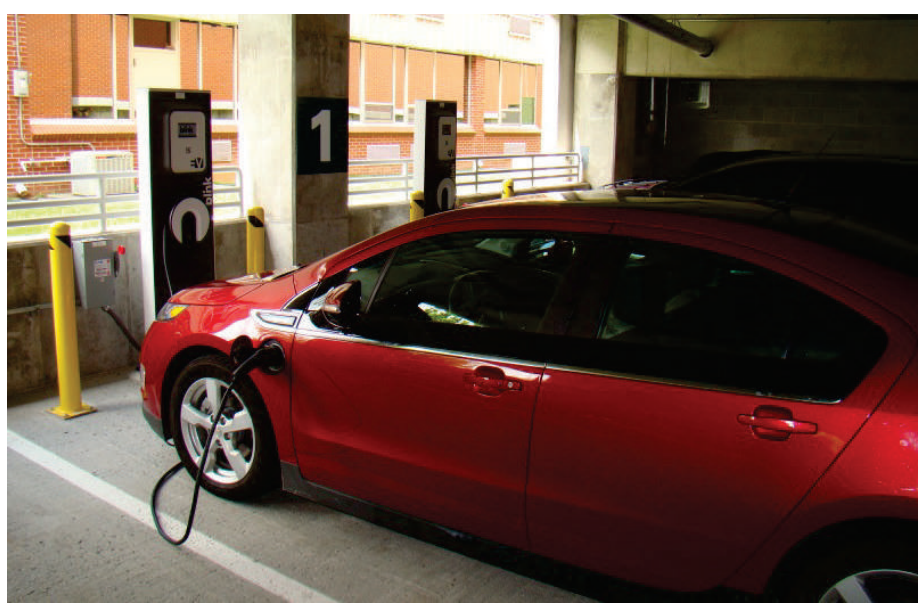

Figure 43. Charging station at the ORNL parking garage (two of four EVSEs are shown).

\subsection{BLOCK PARKING LOT}

Four Level 2 Blink EVSEs were installed at the 1500 block parking lot located near the western end of the main campus on White Oak Avenue near its intersection with First Street (Fig. 44). They provide EV charging access for the 1500 block of buildings. Network connectivity to each EVSE and the current transformers is available via a network switch with a wireless bridge connection to the Central Energy Data System.

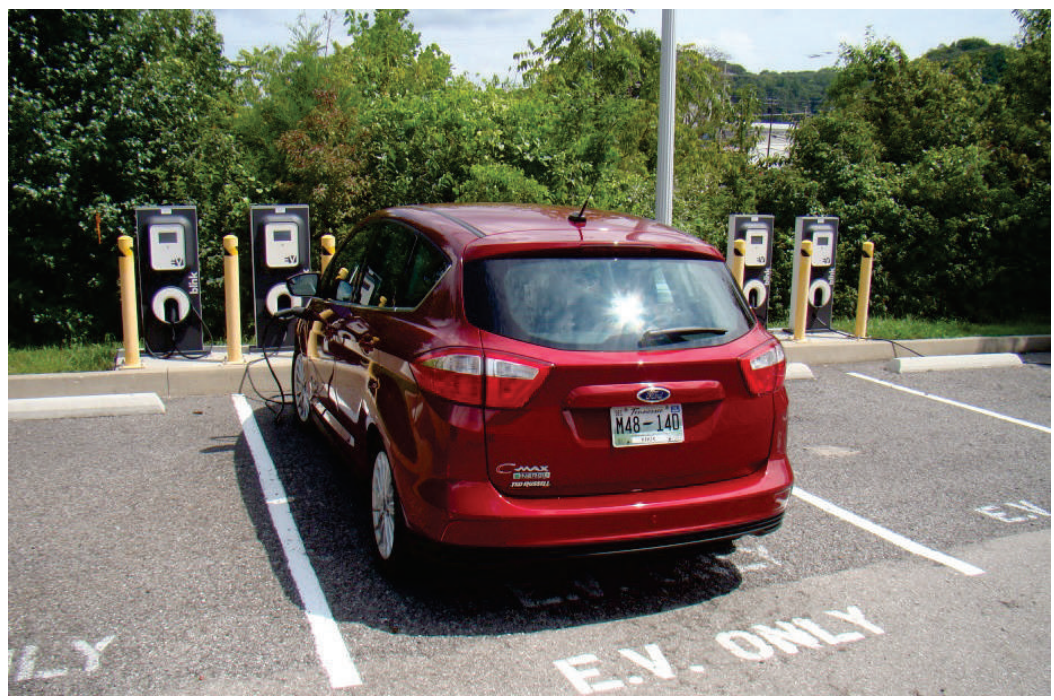

Figure 44. Charging station at the 1500 block parking lot.

\subsection{SPALLATION NEUTRON SOURCE}

Four Level 2 Blink EVSEs were installed in a parking area adjacent to the Spallation Neutron Source (SNS) (Fig. 45) located on Chestnut Ridge near the east end of the ORNL campus. Network connectivity 
to each EVSE and the current transformers is available via a network switch with a wireless bridge connection to the Central Energy Data System.

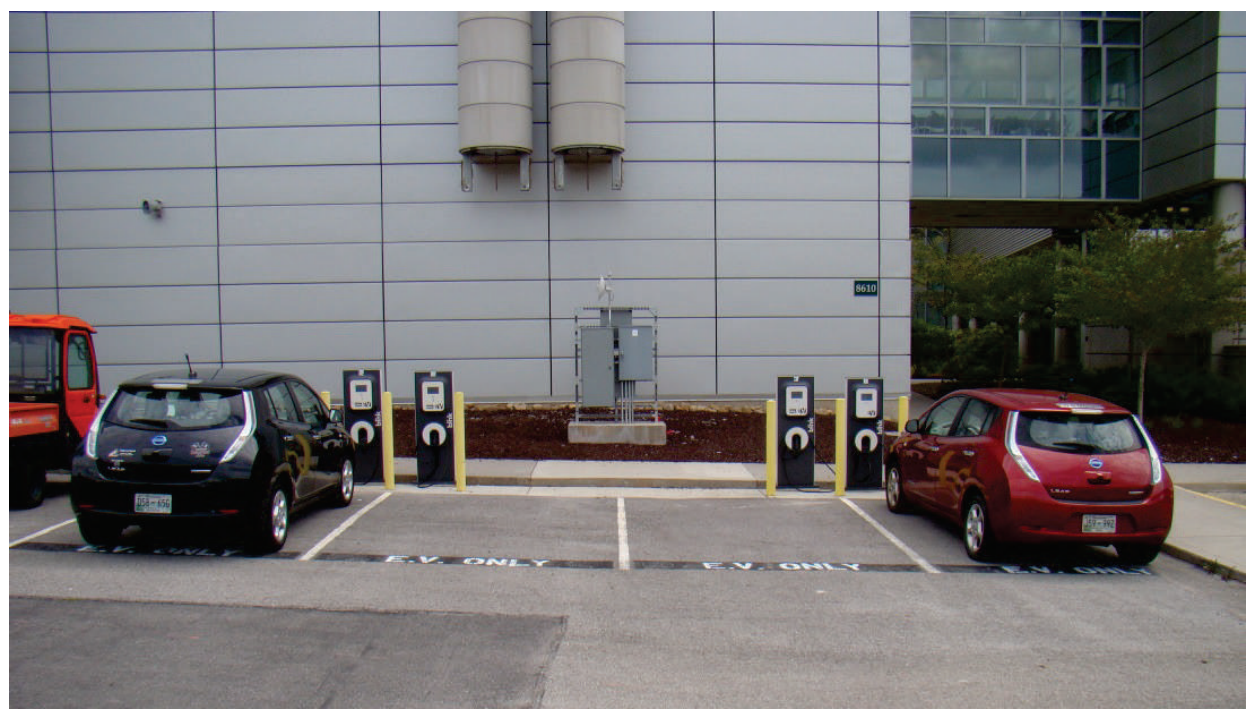

Figure 45. Charging station at the SNS.

\subsection{HIGH FLUX ISOTOPE REACTOR}

Four Level 2 Blink EVSEs were installed in the parking lot accessing the High Flux Isotope Reactor (HFIR) facility (Fig. 46) located off of Melton Valley Drive. Network connectivity to each EVSE and the current transformers is available via a network switch with a wireless bridge connection to the Central Energy Data System.

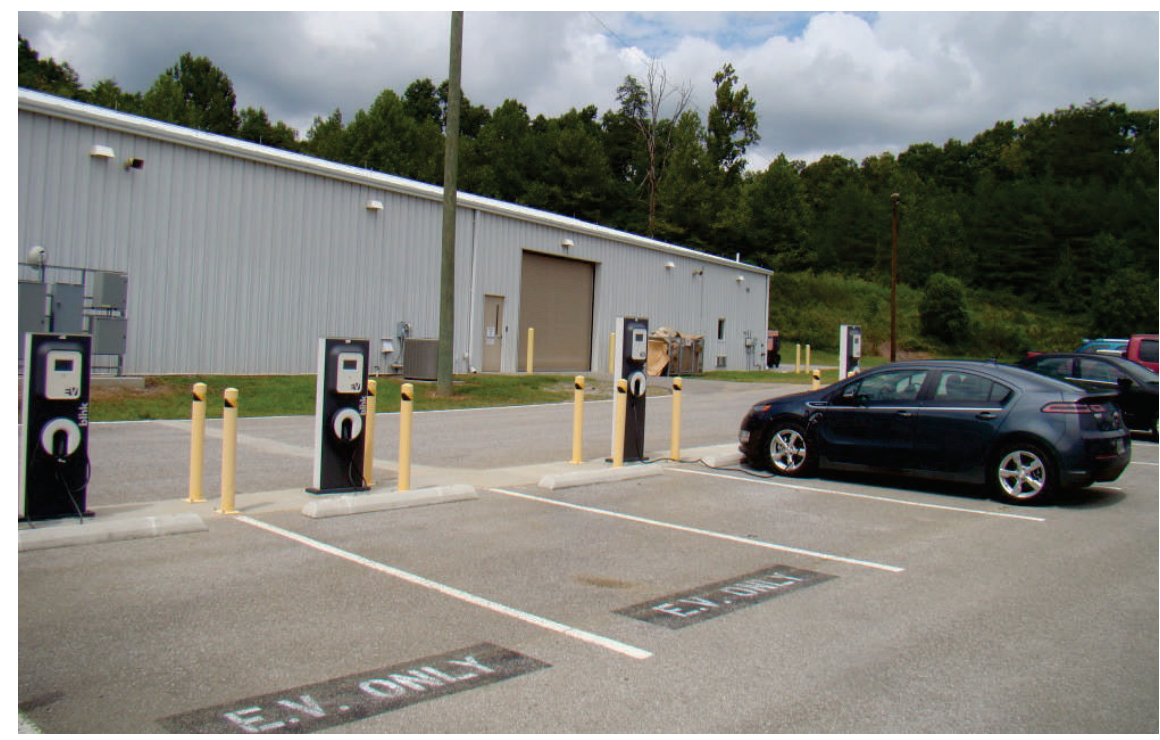

Figure 46. Charging station at HFIR.

\subsection{NATIONAL TRANSPORTATION RESEARCH CENTER}

Two Level 2 Blink EVSEs were installed in the parking lot of the NTRC campus located off Hardin Valley Road near Knoxville (Fig. 47). Network connectivity to each EVSE and the current transformers is available via an internet router with a wireless bridge connection to the Central Energy Data System. 


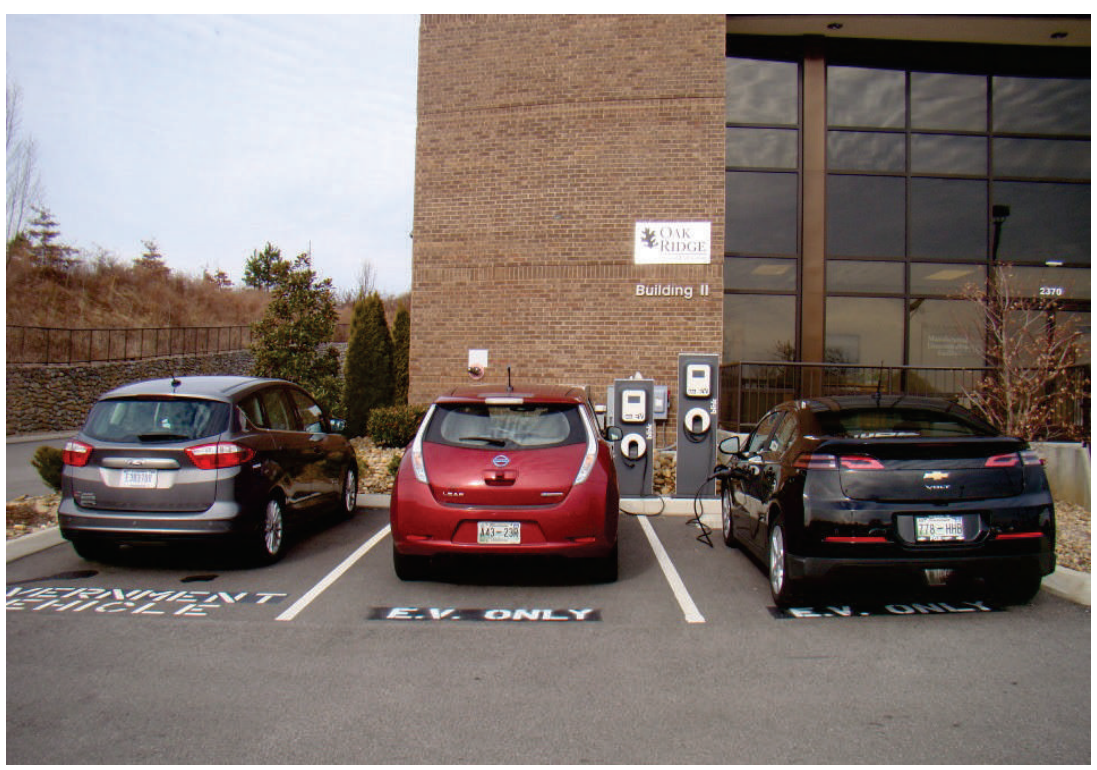

Figure 47. Charging station at the NTRC.

\subsection{DCFC AT BUILDING 4007}

A Blink DCFC was installed next to Building 4007, accessible from Fifth Street near Central Avenue (Fig. 48). Network connectivity to each EVSE and the current transformers is available via a network switch with a wireless bridge connection to the Central Energy Data System. An emergency power disconnect is located next to the DCFC.

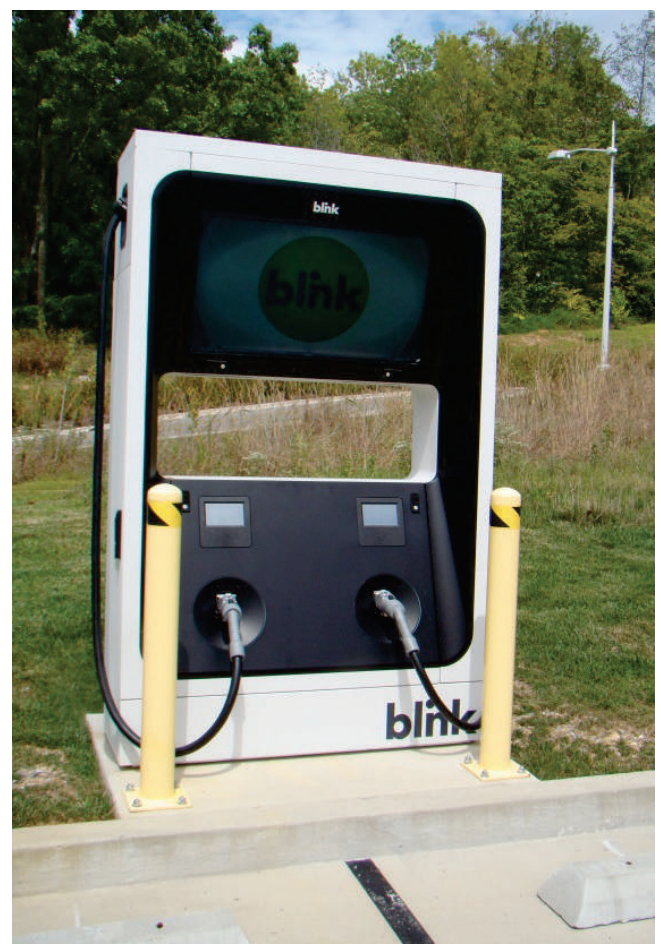

Figure 48. The DCFC station at Building 4007. 



\section{BATTERY BANK MANAGEMENT APPROACH AND IMPACTS}

The addition of EV charging systems to the electric grid to meet the growing demand of EV owners will have a significant effect on electric utilities and consumers. Electrical infrastructure may be required to meet the growing load demand from a large number of EVSEs in the future. Furthermore, the use of EV charging infrastructure could increase consumer demand charges from utilities. Distributed generation (DG) technologies can be used to minimize this additional load from EVSEs. DG technologies use renewables and energy storage with on-demand schedule dispatch strategies to mitigate the grid impact from EVSEs.

There has been much research dealing with DG technologies using renewables and local storage to mitigate the load on the electric grid:

- Chen and Gooi [3] developed a real-time dynamic scheduling algorithm for solar and battery systems. Control was based on the battery charge and discharge characteristics and current and temperature dependence of the capacity.

- Research by Nottrott et al. [4] used a linear programming routine to optimize charging and discharging of a grid-tied solar and battery system.

- Lu and Shahidehpour [5] used the Lagrangian relaxation-based optimization algorithm for short-term scheduling of battery charge and discharge.

- Costanzo et al. [6] developed a framework for peak-load shaving in smart homes. An online scheduling algorithm was developed to schedule the operation of appliances.

ORNL reviewed these DG technologies before developing the approach used for The EV Project.

\subsection{RESEARCH GOALS AND OBJECTIVES}

As part of The EV Project, ORNL developed three separate control methodologies to minimize EVSE load on the electric grid using a solar PV array and battery bank, and the three control systems were compared with one another to determine which approach yielded the best performance for overall load reduction and power shaving. These evaluations were performed for both a private and a public site, the usage characteristics being rather different between the two locations. The first control system discharges the battery bank at a constant rate during specific times of the day based on historical data. The second discharges the battery bank based on the number of EVs charging (linear) and the amount of solar energy being generated. The third discharges the battery bank based on a sigmoid function (nonlinear), also taking into consideration the amount of renewable energy being generated. The third control system recharges the battery bank at night but also during times of the day when there is an excess of solar power. For these evaluations, ORNL investigated two different types of environments where EVSEs are located: private and public. Both the first and second control systems recharge the battery bank at night when demand charges are lowest.

The primary objectives of this research were to evaluate the use of renewable energy (e.g., solar) and local storage (e.g., battery bank) to mitigate the load from EV charging, to analyzed the impact of EV charging on the electric grid and to study equipment reliability.

\subsection{CONTROL ALGORITHM DEVELOPMENT}

Data used for the experiments were collected from two sites: ORNL and the State of Tennessee Employee Parking Lot site at 408 Harrison Street in Nashville. The ORNL site represents a private site used by employees and visitors of ORNL. The state site in Nashville represents a site used by state employees during weekdays and business hours. The public is able to use these EVSEs at night and 
during the weekends. The ORNL site has 25 Blink Level 2 EVSEs, a 47kW solar PV array, and a $60 \mathrm{kWh}$ battery bank. The PV array is made of 210 Sharp ND-224UC1 modules rated at 224W each and measures 235 x $20 \mathrm{ft}$ with a 50kW PV Powered inverter. The battery bank, with a usable capacity of $30 \mathrm{kWh}$, is made of 40 valve-regulated lead acid deep cycle batteries from C\&D Technologies. A $5 \mathrm{~kW}$ inverter/charger from SMA (Sunny Island 5048U) is used to discharge and charge the battery bank to and from the electric grid, respectively. The State of Tennessee Employee Parking Lot site has four EVSE units, an $8.6 \mathrm{~kW}$ solar PV array, and a $6.7 \mathrm{kWh}$ battery bank. The EVSE, battery bank equipment, and solar PV array are the same models as described for the ORNL site. The main difference is the solar inverter, consisting of an Enlighten microinverter (M215-60-2LL) and an Envoy communication gateway (ENV-120-01), produced by Enphase Energy. Additional details for the sites are provided in Section 2.

Data corresponding to 2 weeks of operation at each site during July-August 2013 were used to determine the electrical load mitigation resulting from the implementation of each of the three control systems. EVSE load data were obtained from the Blink Network website [7] for this analysis, and solar generation data for the ORNL and Nashville sites were taken from the Advanced Energy and Enphase websites [8,9], respectively. For actual implementation of the control systems, the relevant data from all sources are uploaded to the Internet via communications links on the devices and are available for use in the control algorithms, effectively in real time. All of these data are configured for 15 minute time resolution. Each control system algorithm evaluated using historical data was also implemented in software to actively control the battery charge and discharge cycles at ORNL's solar-assisted charging station during a period of at least several days. This allowed verification that the actual performance using real-time data from the hardware was the same as that modeled. No discrepancies were found between the measured and modeled behaviors for the control systems.

Figure 49 shows the primary components of the solar-assisted charging stations connected to the electrical grid. This design uses the grid as both a source and a sink for electrical power transfers and provides a high level of flexibility for the interactions among the components of the solar-assisted EV charging stations.

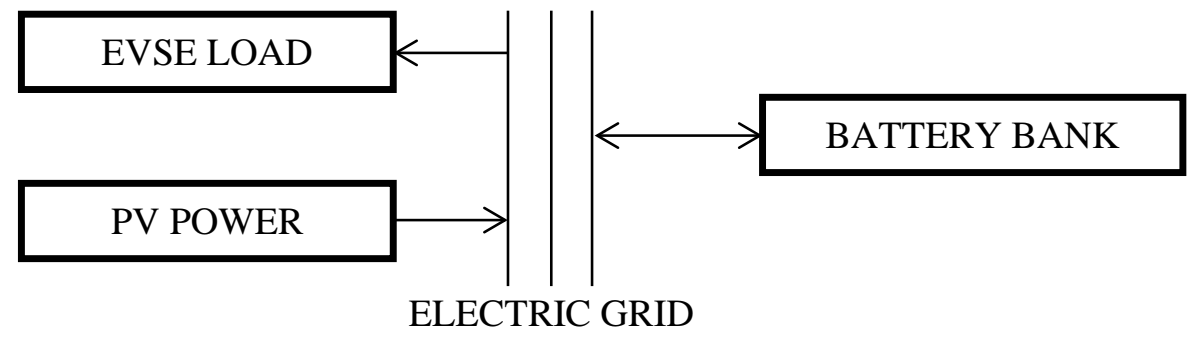

Figure 49. High-level system diagram for each solar-assisted EV site.

The following discussion addresses the three battery bank control systems in order from simplest to most complex. Variables used in all three control systems are listed in Table 4. The variable $t$ represents the time-step, and $t_{s d}, t_{e d}, t_{s c}$, and $t_{e c}$ represent the start $(s)$ and end $(e)$ times for charging $(c)$ and discharging $(d)$. The power variables $p_{f}, p_{p v}, p_{e v s e}, p_{d}, p_{m}$, and $p_{l}$ signify the feed power to the electric grid, power generated from the PV array, total power consumption by the EVSEs, difference between $p_{\text {evse }}$ and $p_{p v}$, makeup power (Eq. [1]), and power limit, respectively. The current variables $i_{f}, i_{d}, i_{m}, i_{l}$, and $i_{n e v}$ symbolize the feed current of the inverter, the current corresponding to the power difference $p_{d}$, the makeup current, total current limit, and current limit for each EV, respectively. All of the current values indicated are AC currents. The variable $n_{e v}$ is the number of charging EVs and $\omega$ is a calibration variable for the sigmoid function that changes the slope of the function over time.

$$
\left.\mathrm{p}_{\mathrm{m}}=\mathrm{i}_{\mathrm{m}} * 120 \mathrm{~V}=\min \left(\mathrm{p}_{\mathrm{ev}} * \mathrm{i}_{\text {evse }}, \mathrm{i}_{\mathrm{l}}\right) * 120 \mathrm{~V}\right)
$$


Table 4. List of variables used for battery control systems

\begin{tabular}{cl}
\hline Variable & \multicolumn{1}{c}{ Definition } \\
\hline$t$ & current time \\
$t_{s d}$ & start time for discharge \\
$t_{e d}$ & end time for discharge \\
$t_{s c}$ & start time for charge \\
$t_{e c}$ & end time for charge \\
$p_{f}$ & feed power of inverter \\
$p_{p v}$ & power of PV array \\
$p_{e v s e}$ & total power of EVSE units \\
$p_{d}$ & difference in power between $p_{e v s e}$ and $p_{p v}$ \\
$p_{m}$ & makeup power \\
$p_{l}$ & power limit \\
$i_{f}$ & feed current of inverter \\
$i_{d}$ & current of $p_{d}$ \\
$i_{m}$ & makeup current \\
$i_{l}$ & total current limit \\
$i_{n e v}$ & current limit for each EV \\
$n_{e v}$ & number of charging EVs \\
$\omega$ & calibration variable for sigmoid function
\end{tabular}

\subsubsection{Control System 1}

The concept behind control system 1 is to use charge and discharge current values $\left(i_{f}\right)$ based solely on the time of day $(t)$. This capability is present in the SMA Sunny Island 5048U inverter/charger. Start charge and discharge times, end charge and discharge times, and discharge rates for the ORNL and the State of Tennessee Employee Parking Lot sites are shown in Table 5. If it is nighttime ( $t$ between $t_{s c}=$ 20:00 and $t_{e c}=6: 00$ ), then $i_{f}=-41.7 \mathrm{~A}$ (maximum charge rate of $5 \mathrm{~kW}$ at $120 \mathrm{~V}$ ) for both sites. The State of Tennessee Employee Parking Lot site has 1/5 the maximum discharge rate because the battery bank is only $6.7 \mathrm{kWh}$. The charge times were chosen during the night because night hours are off-peak hours. The discharge times were chosen based on historical user data (shown in Fig. 50). At ORNL, discharging the battery bank for 6 hours at $5 \mathrm{~kW}$ was chosen to completely use the batteries to a 50\% depth-of-discharge (DOD). This DOD was chosen to protect the life of the batteries. The same approach was used for the State of Tennessee Employee Parking Lot site, discharging the batteries for 3 hours at $1 \mathrm{~kW}$ to obtain a 50\% DOD. A flowchart of control system 1 is shown in Fig. 51.

Table 5. Parameter values used for control system 1

\begin{tabular}{ccc}
\hline Variable & ORNL & $\begin{array}{c}\text { State of Tennessee Employee } \\
\text { Parking Lot site }\end{array}$ \\
\hline$t_{s d}$ & $7: 00$ & $8: 00$ \\
$t_{e d}$ & $13: 00$ & $11: 00$ \\
$t_{s c}$ & $20: 00$ & $20: 00$ \\
$t_{e c}$ & $6: 00$ & $6: 00$ \\
$i_{l}$ & $41.7 \mathrm{~A}$ & $8.34 \mathrm{~A}$ \\
\hline
\end{tabular}



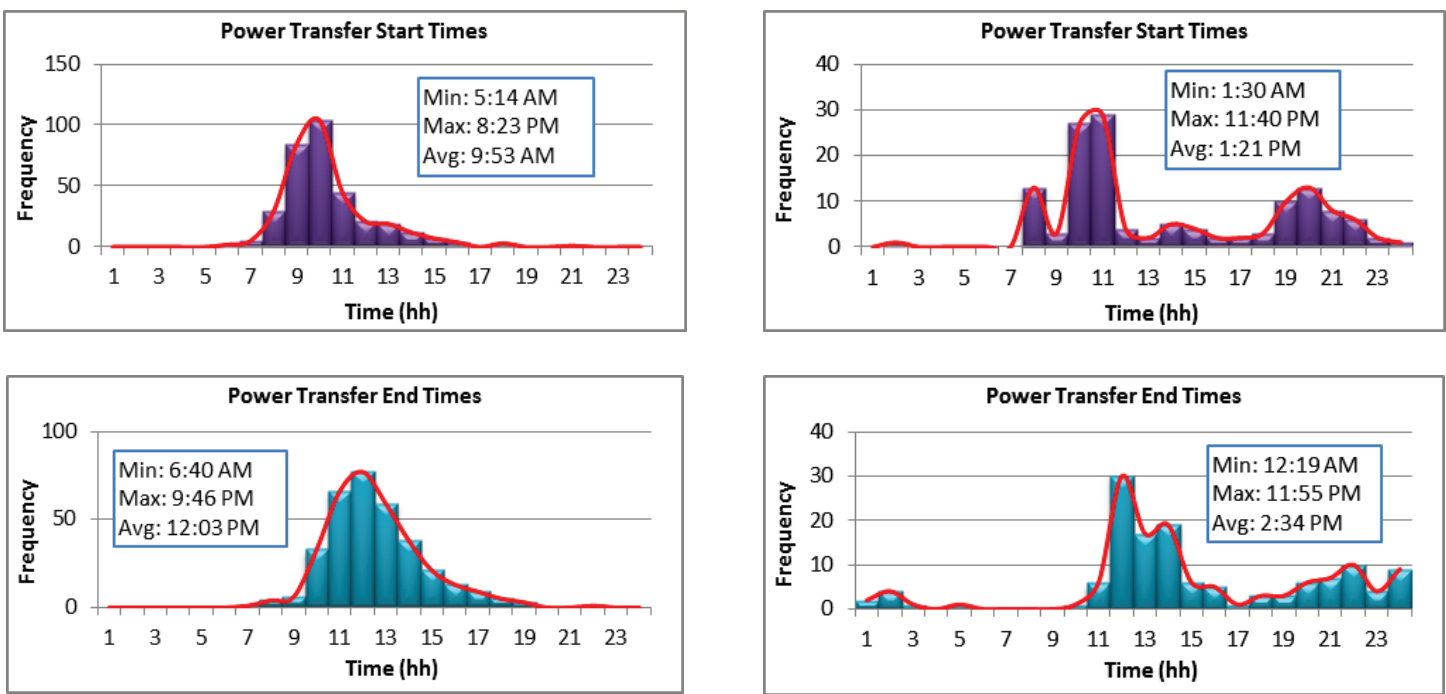

(a) ORNL

(b) State of Tennessee Employee Parking Lot Site

Figure 50. Start and stop times for charge events at the ORNL and State of Tennessee Employee Parking Lot sites during 2013 Q3 (July 1-September 30, 2013).

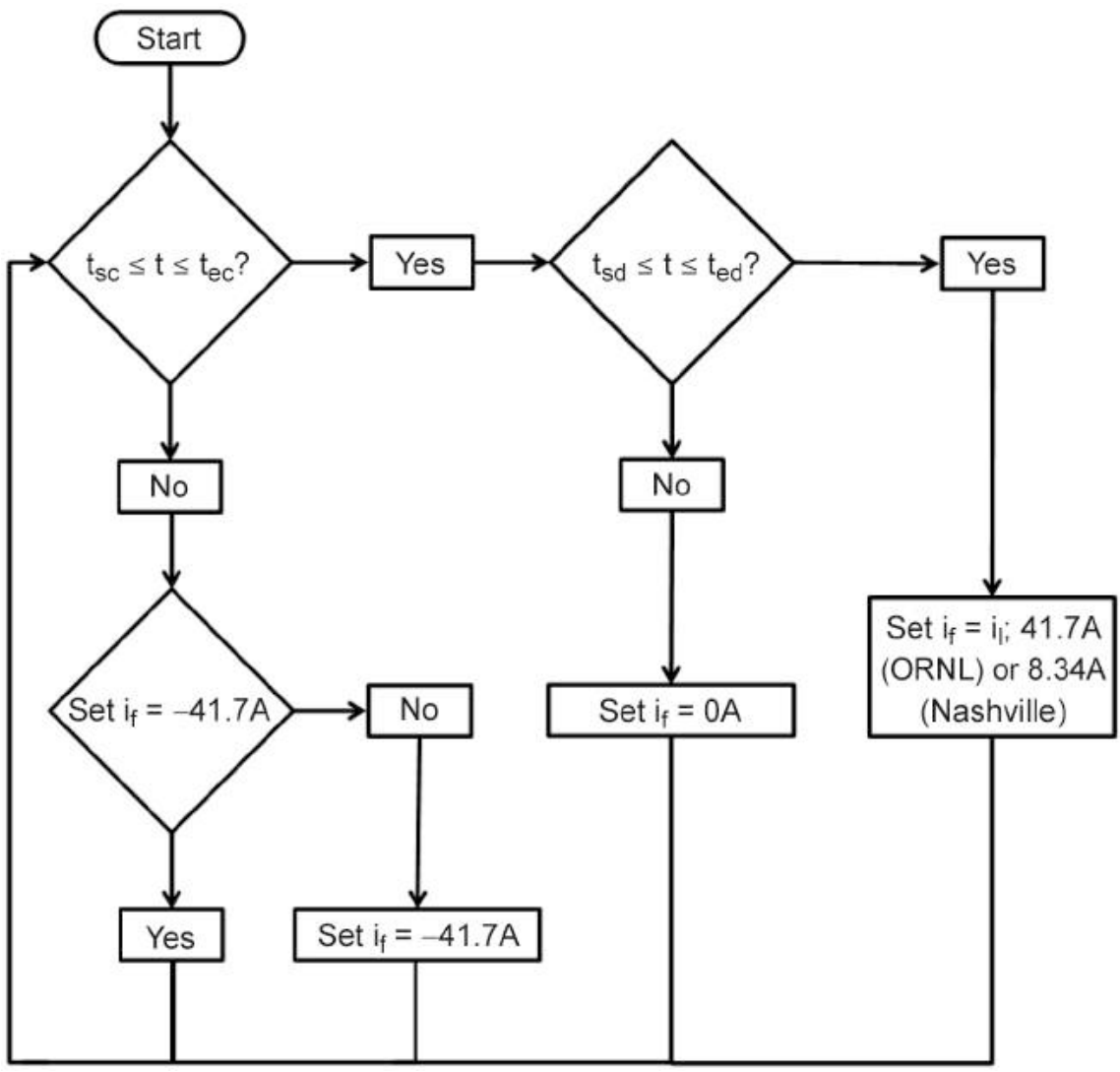

Figure 51. Flowchart of control system 1. 


\subsubsection{Control System 2}

Control system 2 is a closed-loop system that uses external variables to determine the discharge rate (controlled by $i_{f}$ ). External variables include power being produced by the PV array $\left(p_{p v}\right)$, total power consumption by the EVSE $\left(p_{\text {evse }}\right)$, and the number of EVs charging $\left(n_{e v}\right)$. The rate of discharge is determined using the number of charging $\mathrm{EVs}\left(n_{e v}\right)$ and multiplying by a constant current value of $i_{\text {nev }}=$ 27.5A (ORNL). This amount was determined by the maximum charge rate of the Blink Level 2 EVSE, which is $3.3 \mathrm{~kW}$. The State of Tennessee Employee Parking Lot site uses $i_{\text {nev }}=5.5 \mathrm{~A}(1 / 5$ of $27.5 \mathrm{~A})$ because the battery bank is $6.7 \mathrm{kWh}$. The relationship between variables $i_{f}$ and $n_{e v}$ is shown in Fig. 52 . This control system ensures the amount being discharged to the electric grid is no more than is needed. There is a 15 minute delay because of the limited time resolution. A flowchart for control system 2 is shown in Fig. 53.

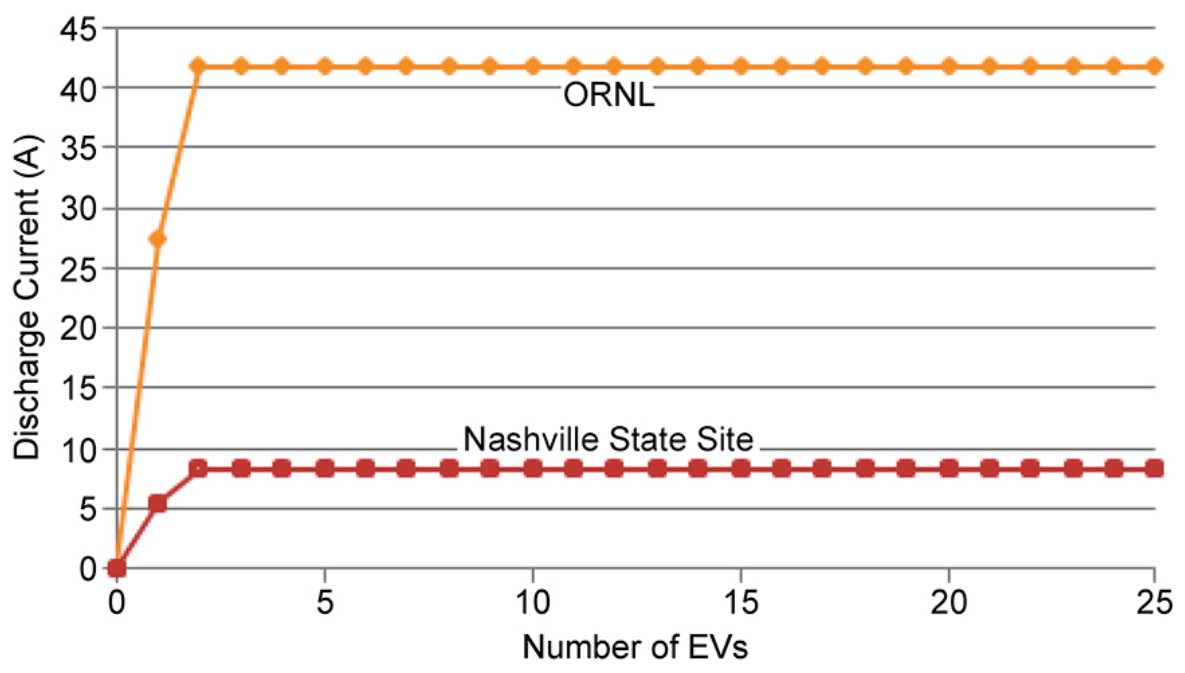

Figure 52. Relationship between $i_{f}$ and $n_{e v}$. 


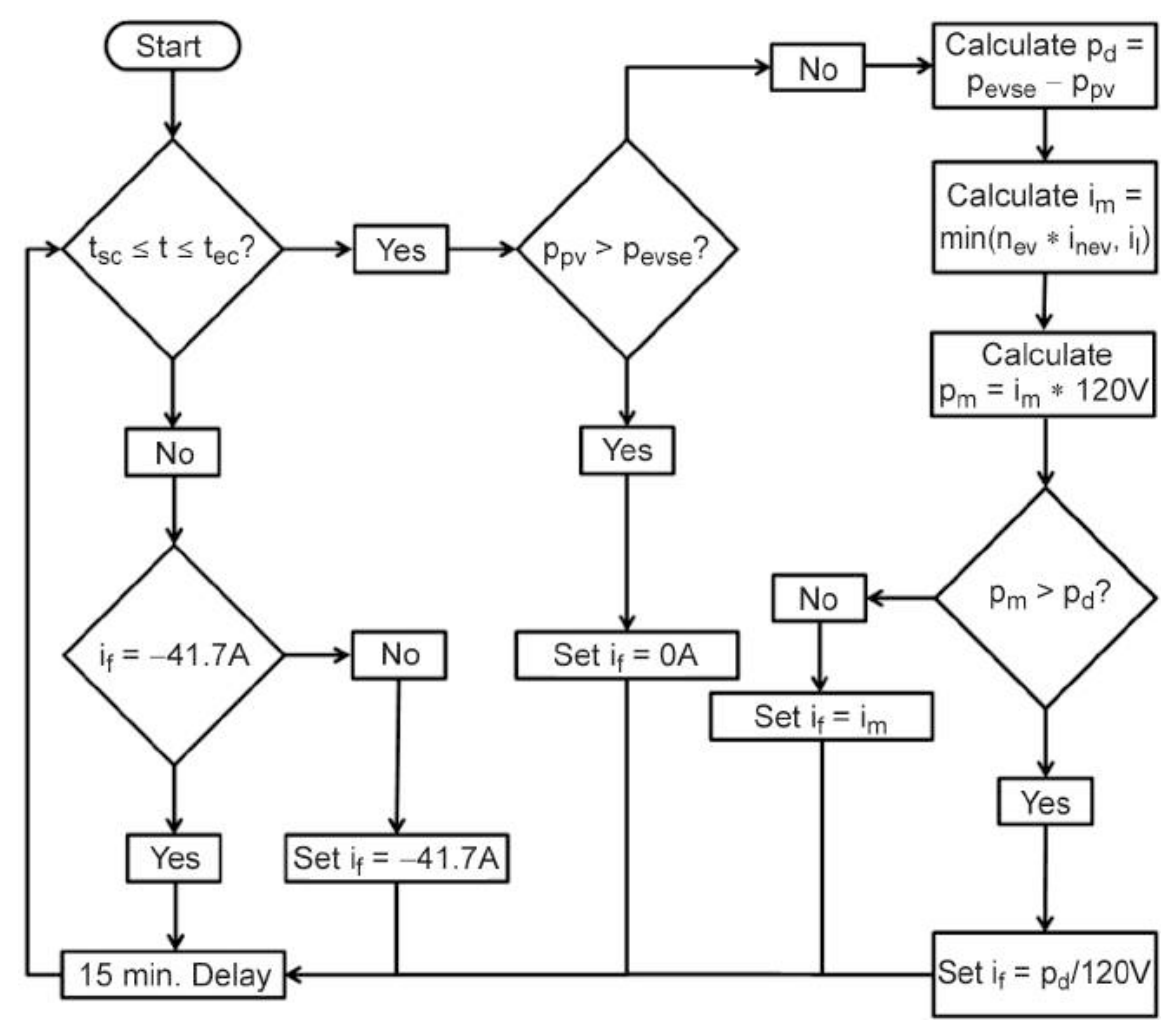

Figure 53. Flowchart of control system 2.

\subsubsection{Control System 3}

The concept for control system 3 is similar to that for 2 . However, instead of using the relationship shown in Fig. 52 between variables $i_{f}$ and $n_{e v}$, a sigmoid function (Eq. [2] and Fig. 54) is used to help limit the amount of power discharged to the electric grid $\left(p_{f}\right)$ by applying a control strategy based on the difference current $\left(i_{d}\right)$. This helps prevent the battery bank from discharging all of its energy too quickly, leaving no energy for later in the day. The power limit, $p_{l}$, is set to $5 \mathrm{~kW}$ for ORNL and $1 \mathrm{~kW}$ for the State of Tennessee Employee Parking Lot site. These values correspond to the maximum inverter and battery capabilities at each site. It was found that for recent EVSE usage profiles, the maximum discharge rate can be employed without using more energy than is available from 50\% DOD. Changes to the power limit can be made based on observation of EVSE usage. The parameter $\omega$ adjusts the steepness of the sigmoid curve and allows the research team to control how quickly the inverter output power $p_{f}$ responds to the difference current $i_{d}$.

$$
\mathrm{P}_{\mathrm{f}}\left(\mathrm{i}_{\mathrm{d}}\right)=\mathrm{p}_{\mathrm{l}}\left(\frac{2}{1+\mathrm{e}^{-\omega\left(\mathrm{i}_{\mathrm{d}} / \mathrm{i}_{\mathrm{l}}\right)}}-1\right)
$$




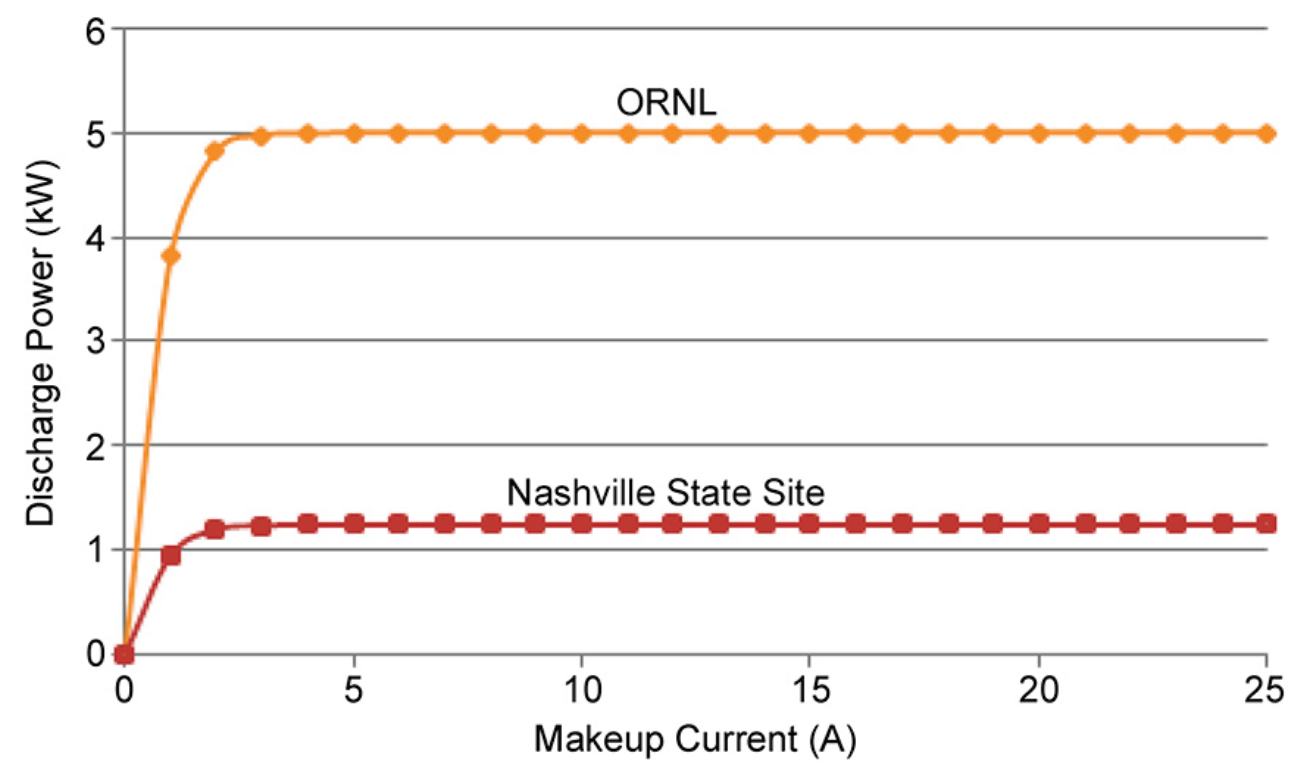

Figure 54. Sigmoid function between $i_{d}$ and $p_{f}$ where $\omega=2$.

Another difference from control system 2 is that during the daytime (8:00 - 20:00), excess power from the PV array $\left(p_{p v}\right)$ can be used to charge the battery bank. There is a 15 minute delay because of the time resolution of the electrical meters. A flowchart of control system 3 is shown in Fig. 55.

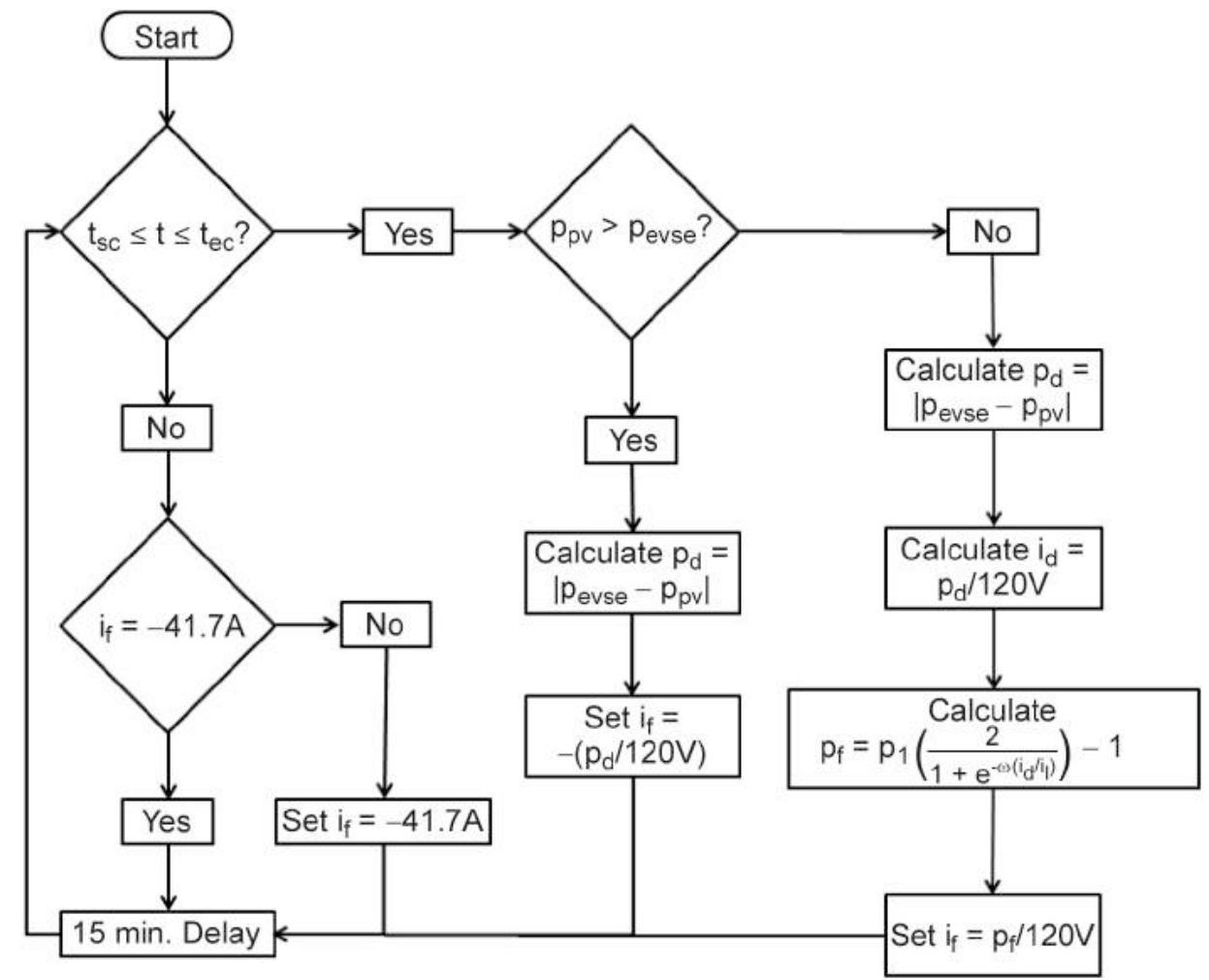

Figure 55. Flowchart of control system 3.

\subsection{EVALUATION OF THE BATTERY MANAGEMENT CONTROL SCHEMES}

This section presents the results from all three control system simulations for the ORNL and State of the Tennessee Employee Parking Lot sites. Note that the results are expressed in energy values 
corresponding to 15 minute time increments. There are two metrics used to express performance: battery shaving efficiency $\left(\eta_{b s}\right)$ and actual-to-potential shaving efficiency $\left(\eta_{a p}\right)$, shown in Eqs. (3) and (4), respectively. The battery shaving efficiency is the ratio of energy discharged from the battery bank that goes toward shaving the net daytime energy consumption from EV charging $\left(E_{s}\right)$, to the total energy discharged from the battery bank $\left(E_{b}\right)$. The actual-to-potential shaving efficiency is the ratio of actual energy from EV charging that has been shaved by discharging the battery bank to the electric grid $\left(E_{s}\right)$, to the energy from EV charging that has the potential to be shaved $\left(E_{p}\right)$. In the results shown in Figs. 56 through 58 (see following sections), positive energy values indicate energy supplied to the electric grid and negative values indicate energy consumption from the electric grid.

$$
\begin{aligned}
& \eta_{\mathrm{bs}}=\frac{E_{s}}{E_{b}} * 100 \% \\
& \eta_{\text {ap }}=\frac{E_{s}}{E_{p}} * 100 \%
\end{aligned}
$$

\subsubsection{Control System 1}

The implementation of control system 1 at ORNL was found to provide a battery shaving efficiency $\left(\eta_{b s}\right)$ of $13.74 \%$ and an actual-to-potential shaving efficiency $\left(\eta_{a p}\right)$ of $58.18 \%$. The State of Tennessee Employee Parking Lot site produced results of 5.29\% battery shaving efficiency and an actual-to-potential shaving efficiency of $2.11 \%$. Summary results of the energy usage ( 2 week time period) under control system 1 for ORNL and the State of Tennessee Employee Parking Lot site are found in Tables 6 and 7 , respectively. The battery shaving efficiency for both sites shows a major disadvantage of control system 1. Any percentage below $100 \%$ indicates that the battery bank is being discharged during times of the day when mitigation of the EVSE load is not needed. This is shown in Fig. 56 (between the dashed vertical orange lines). When the grid consumption with battery plot (purple) is positive, this indicates that the EVSE load is completely offset by the solar production (red). The mode (light blue) shows whether the system is charging (+1), neutral (0), or discharging ( -1$)$. However, the difference between the purple and the green (grid consumption without battery bank) plots indicates that the battery bank is still discharging to the electric grid even though it is not needed. The consumption from the electric grid during the nighttime indicates that the battery bank is charging (during a low-demand period) as expected.

Because of the nature of control system 1, discharging at a static rate throughout a specified time period wastes much of the energy discharged from the battery bank to the electric grid. The efficiency metrics would be higher with increased utilization, but this would not guarantee $100 \%$ battery shaving efficiency.

Tables 6 and 7 show solar production is much larger than the EVSE load for the ORNL $(\times 8.09)$ and State of Tennessee Employee Parking Lot $(\times 2.37)$ sites. Even though solar production is significantly larger than the EVSE load, a battery shaving efficiency of less than $100 \%$ can be due not only to the control system but also to a lack of sufficiently large local energy storage capacity and a limited discharge rate from the local storage inverter.

Table 6. Control system 1 results for ORNL site

\begin{tabular}{lc}
\hline \multicolumn{1}{c}{ Measurement } & Energy $(\mathrm{kWh})$ \\
\hline EVSE & -322.36 \\
Solar & 2775.66 \\
Shaved energy $\left(E_{s}\right)$ & 60.00 \\
Potential for energy shaving $\left(E_{p}\right)$ & 103.13 \\
Energy from battery $\left(E_{b}\right)$ & 390.00 \\
\hline
\end{tabular}


Table 7. Control system 1 results for the State of Tennessee Employee Parking Lot site

\begin{tabular}{lc}
\hline \multicolumn{1}{c}{ Measurement } & Energy $(\mathrm{kWh})$ \\
\hline EVSE & -185.47 \\
Solar & 475.82 \\
Shaved energy $\left(E_{s}\right)$ & 2.06 \\
Potential for energy shaving $\left(E_{p}\right)$ & 41.80 \\
Energy from battery $\left(E_{b}\right)$ & 39.00 \\
\hline
\end{tabular}

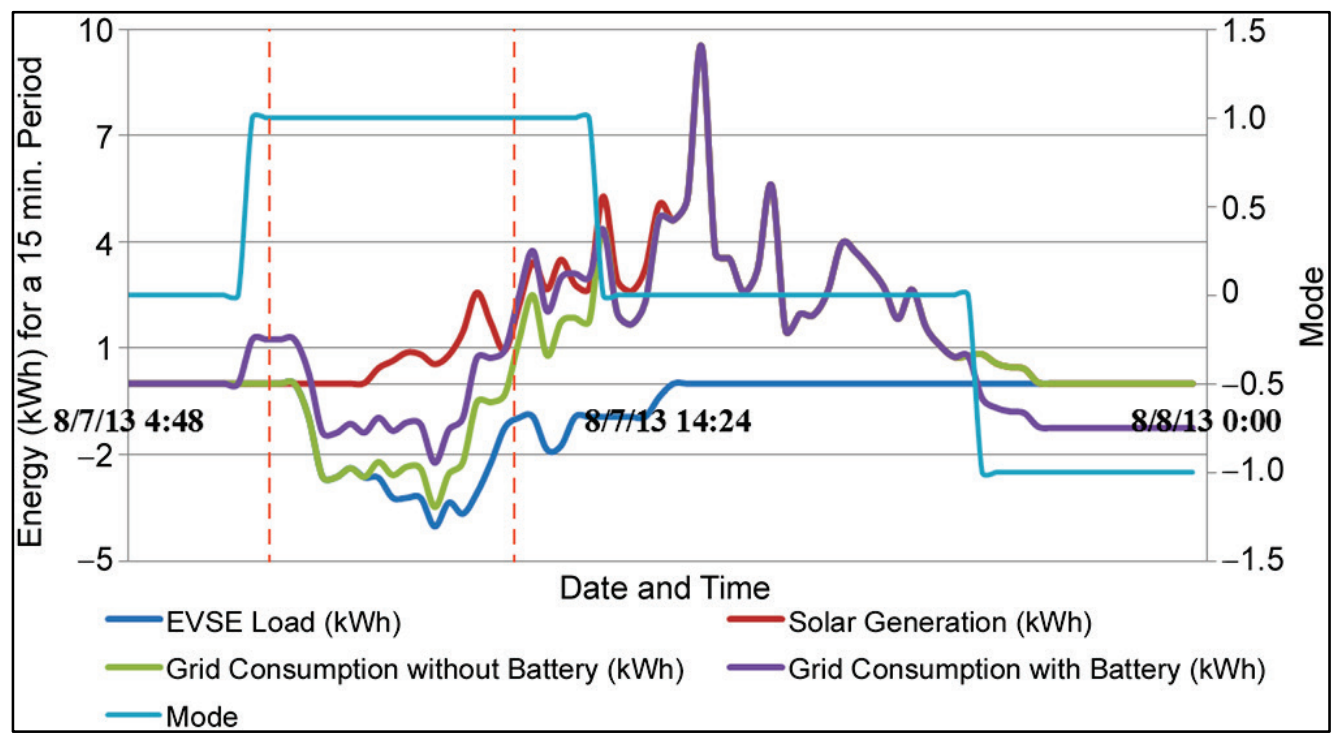

Figure 56. Results on 08/07/2013 for control system 1 at ORNL.

\subsubsection{Control System 2}

The implementation of control system 2 at ORNL yielded a $100 \%$ battery shaving efficiency and an actual-to-potential shaving efficiency of $60.61 \%$. The State of Tennessee Employee Parking Lot site also produced a result of $100 \%$ battery shaving efficiency and an actual-to-potential shaving efficiency of $38.59 \%$. The complete results for ORNL and the State of Tennessee Employee Parking Lot site are found in Tables 8 and 9, respectively. The battery shaving efficiency for both sites indicates that all discharged energy from the battery bank is being used to mitigate load from the EVSE. This is shown in Fig. 57 (between the dashed vertical orange lines). There is no difference between the grid consumption with battery plot (purple) and grid consumption without battery bank plot (green) after the purple plot goes positive, which indicates that the battery bank discharges to the electric grid only when needed. The consumption from the electric grid during the night time indicates the battery bank is charging as expected.

Table 8. Control system 2 results for ORNL site

\begin{tabular}{lc}
\hline \multicolumn{1}{c}{ Measurement } & Energy $(\mathrm{kWh})$ \\
\hline EVSE & -322.36 \\
Solar & 2775.66 \\
Shaved energy $\left(E_{s}\right)$ & 62.50 \\
Potential for energy shaving $\left(E_{p}\right)$ & 103.13 \\
Energy from battery $\left(E_{b}\right)$ & 62.50 \\
\hline
\end{tabular}


Table 9. Control system 2 results for the State of Tennessee Employee Parking Lot site

\begin{tabular}{lc}
\hline \multicolumn{1}{c}{ Measurement } & Energy $(\mathrm{kWh})$ \\
\hline EVSE & -185.47 \\
Solar & 475.82 \\
Shaved energy $\left(E_{s}\right)$ & 25.00 \\
Potential for energy shaving $\left(E_{p}\right)$ & 41.80 \\
Energy from battery $\left(E_{b}\right)$ & 25.00 \\
\hline
\end{tabular}

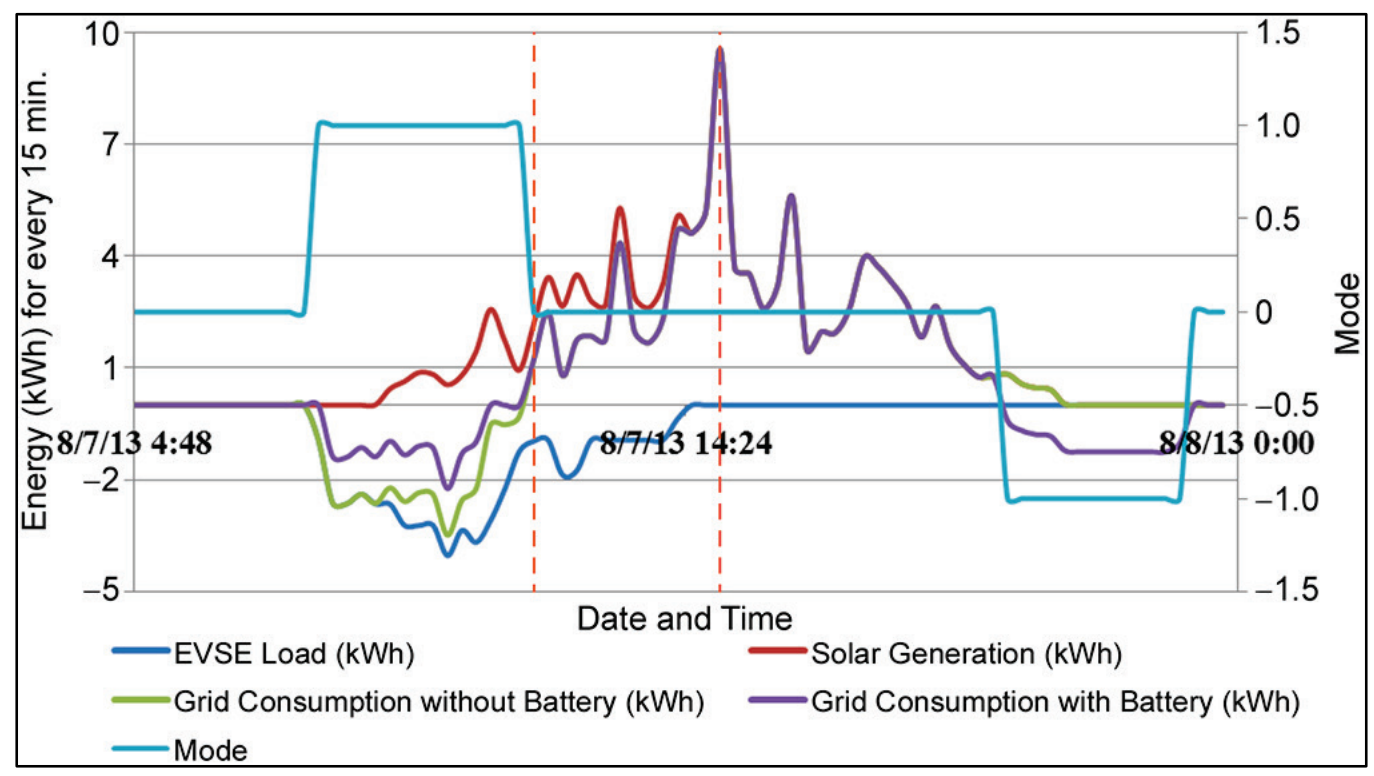

Figure 57. Results on 08/07/2013 for control system 2 at ORNL.

\subsubsection{Control System 3}

The implementation for control system 3 at ORNL produced a $91.78 \%$ battery shaving efficiency, and the actual-to-potential shaving efficiency was $60.31 \%$. The State of Tennessee Employee Parking Lot site produced a result of $74.33 \%$ battery shaving efficiency and an actual-to-potential shaving efficiency of 74.16\%. The complete results for ORNL and the State of Tennessee Employee Parking Lot site are found in Tables 10 and 11. The resulting plots showing the solar, EVSE, and battery energy flows for control system 3 at ORNL are shown in Fig. 58. There is little or no consumption from the electric grid during the nighttime because the battery bank is charged during the day when there is excess solar power available. Depending on total power usage and electricity pricing at different times of the day, it may or may not be preferable to charge the battery at night; but recharging the battery bank with the excess solar power does provide additional energy that can be discharged to the EVSE during the day if needed, which is responsible for the improved performance of control system 3 at the State of Tennessee Employee Parking Lot site.

Table 10. Control system 3, results for ORNL site

\begin{tabular}{lc}
\hline \multicolumn{1}{c}{ Measurement } & Energy $(\mathrm{kWh})$ \\
\hline EVSE & -322.36 \\
Solar & 2775.66 \\
Shaved energy $\left(E_{s}\right)$ & 62.20 \\
Potential for energy shaving $\left(E_{p}\right)$ & 103.13 \\
Energy from battery $\left(E_{b}\right)$ & 67.77 \\
\hline
\end{tabular}


Table 11. Control system 3, results for the State of Tennessee Employee Parking Lot site

\begin{tabular}{lc}
\hline \multicolumn{1}{c}{ Measurement } & Energy $(\mathrm{kWh})$ \\
\hline EVSE & -185.47 \\
Solar & 475.82 \\
Shaved energy $\left(E_{s}\right)$ & 31.00 \\
Potential for energy shaving $\left(E_{p}\right)$ & 41.80 \\
Energy from battery $\left(E_{b}\right)$ & 41.70 \\
\hline
\end{tabular}

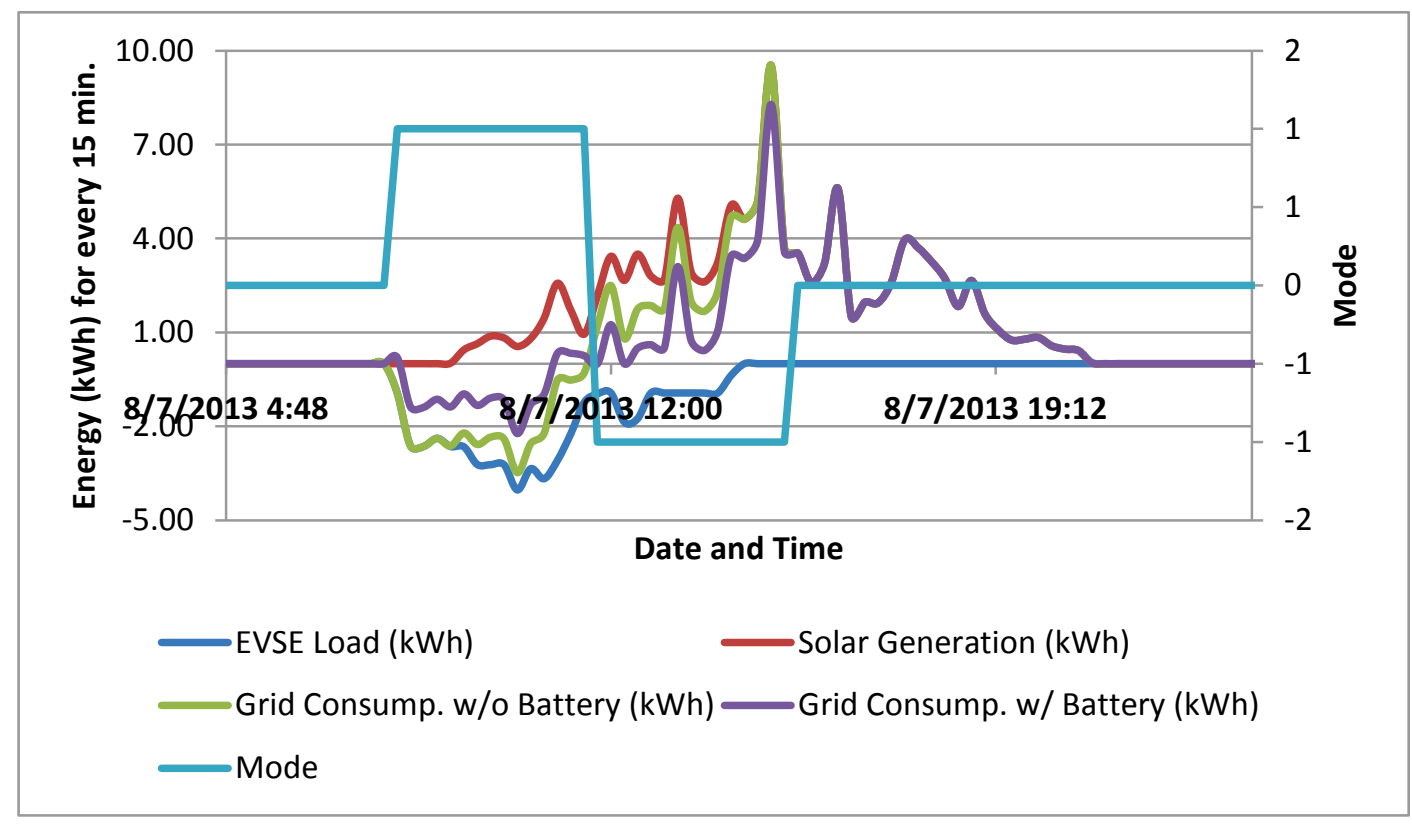

Figure 58. Results on 08/07/2013 for control system 3 at ORNL.

The $\omega$ variable was set to 4 for both the ORNL and the State of Tennessee Employee Parking Lot sites, although it could be set to any positive value. This value of $\omega$ was chosen because it yielded the best overall result for the actual-to-potential shaving. For the ORNL site, the shaved energy was within $0.3 \%$ of the value obtained using control system 2 , and the same shaving could be achieved with a value of $\omega$ optimized specifically for the ORNL site. At the State of Tennessee Employee Parking Lot site, on the other hand, the shaved energy with control system 3 increased by over $20 \%$ relative to control system 2 . The performance using different $\omega$ values is shown in Fig. 59 for the State of Tennessee Employee Parking Lot site. It is noted that a slightly higher actual/potential shaving was obtained for the ORNL site with an increased value of $\omega$ (with a maximum actual/potential shaving of $60.61 \%$ for $\omega=10$, as compared with the $60.31 \%$ for $\omega=4$ ); but a value in the range of 3-4 provided more balanced results when considering both locations.

The rationale for using a smaller $\omega$ is to taper discharging of the battery to ensure energy is available for mitigating EVSE load later in the day. The better results achieved with moderate values of $\omega$ at the State of Tennessee Employee Parking Lot site indicates that the battery discharging does need to be limited to maximize the energy shaving at that location, while for the ORNL solar-assisted site there is enough battery capacity for the given usage to permit using higher $\omega$ values. Nonetheless, the intermediate value provides a good compromise at both sites. A higher utilization of the EVSEs at both the ORNL and the State of Tennessee Employee Parking Lot site or a reduction in solar generation would result in lower $\omega$ values to achieve optimal shaving performance. Hence this parameter can be adjusted as a function of actual usage rates to provide the optimal performance. 


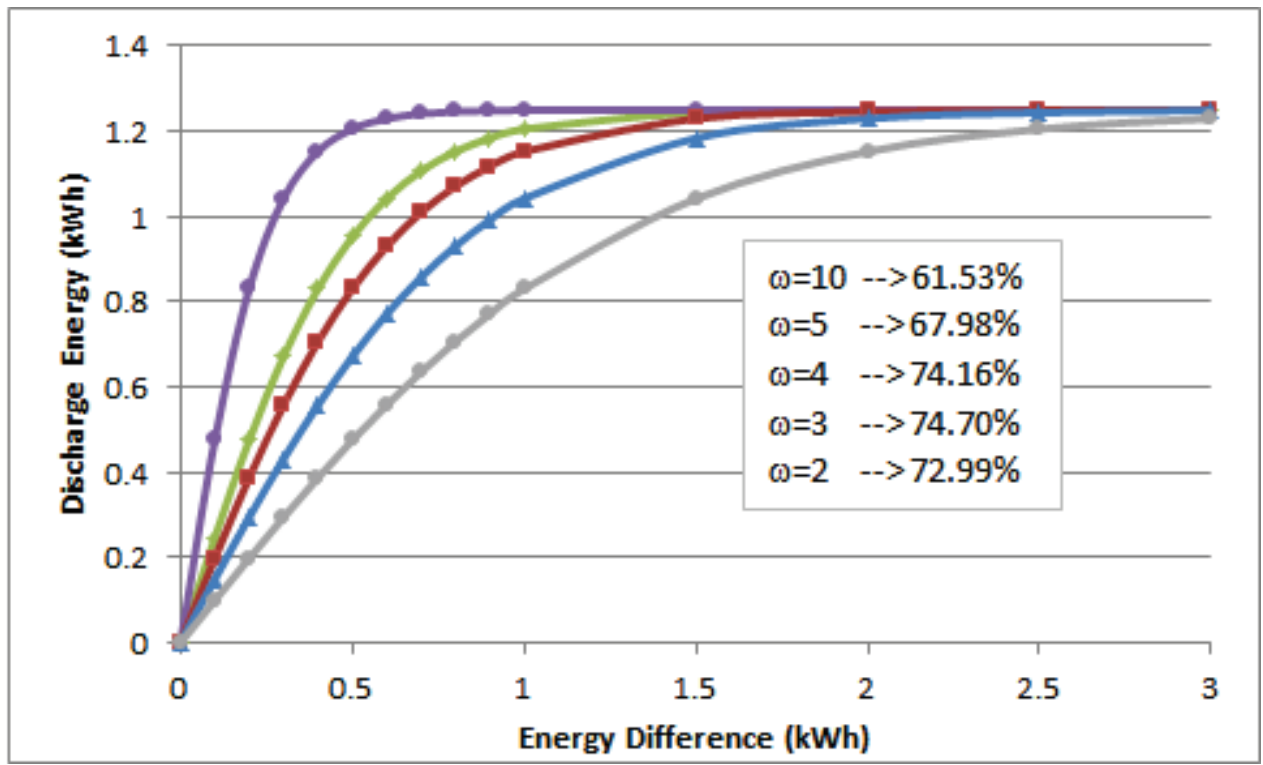

Figure 59. Sigmoid function for $\omega=2,3,4,5$, and 10 . The box lists the actual/potential shaving percentages per $\omega$ value for the State of Tennessee Employee Parking Lot site.

\subsection{REDUCTION OF GRID LOADING FROM THE EVSES USING CONTROL SYSTEM 3 FOR PEAK SHAVING}

The analysis presented above indicated that the nonlinear sigmoid function employed in control system 3 provides the greatest opportunity to reduce grid loading from the EVSEs, as reported previously in $[10,11]$. Further analysis was performed to quantify the energy shaving opportunities using control system 3 at five additional solar-assisted charging station locations during the period from July 25 to August 9, 2013. The analysis was completed for LP Field, Market Square, the UT Music Building, the Nissan Battery Plant, and the Nissan Administration Building sites, in addition to the ORNL and State of Tennessee Employee Parking Lot sites presented previously. These sites had a level of usage that was sufficient to provide a meaningful evaluation of the peak shaving algorithm, and there are enough differences in the design parameters and usage among these sites that the evaluations provide a good comparison of performance based on component sizing. Table 12 presents the energy shaving that can be achieved using the peak shaving algorithm for different values of $\omega$. The last column in the table shows the average energy shaved during each charge event, which is a measure of the effectiveness of the battery bank. The data do not show a clear trend of the energy shaved as a function of battery size or other characteristics of the charging station, which suggests that the EVSE usage profile plays a relatively strong role in the actual energy shaving that can be achieved. 
Table 12. Energy shaving potential using control system 3 The highlighted cells indicate the $\omega$ value that would yield the greatest energy shaving at each site.

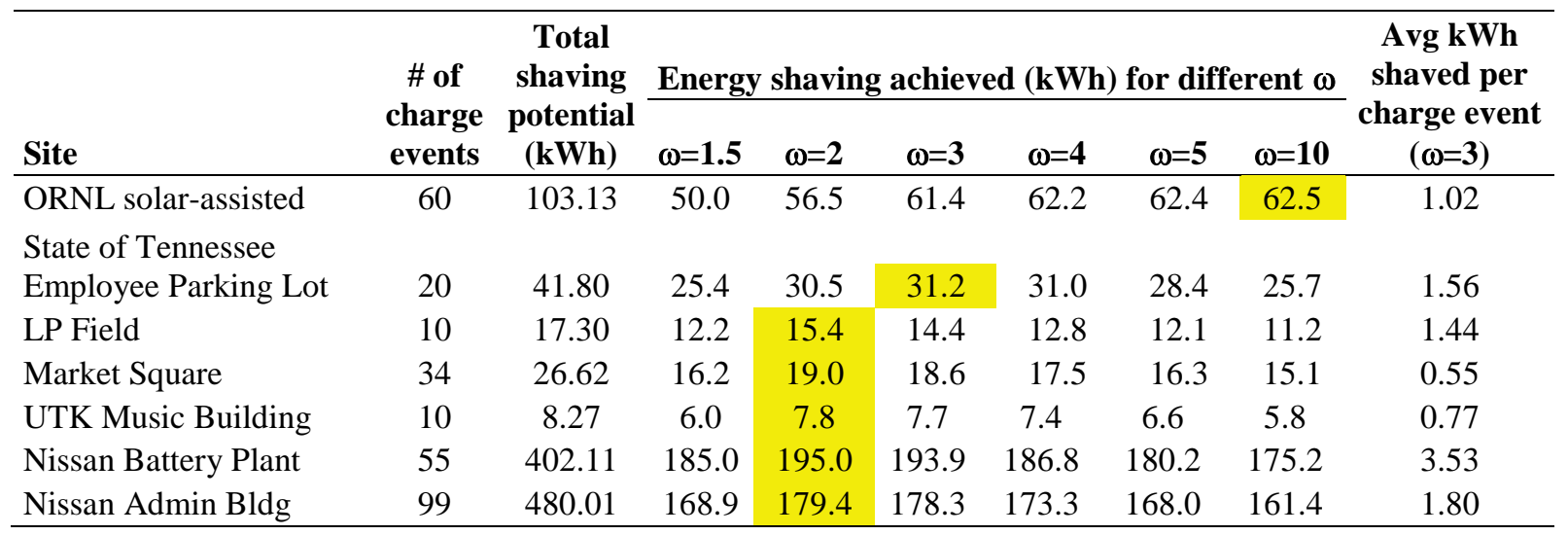

The inclusion of energy storage in EV charging station design can provide significant peak power shaving, particularly for solar-assisted EV charging stations. Power shaving holds the potential to scale to a large number of EVs by increasing the battery energy storage, which can help mitigate the load EVs have on the electric grid as their numbers increase. The magnitude of the peak shaving is dependent on several factors, including the sizing of the battery bank and its associated inverter and charger, whether a solar power generation is present and the size of the solar array, and the number of chargers present and the usage profile. Further research is needed to optimize the sizing of the components in the solar-assisted EV charging station for optimal peak shaving performance. Nonetheless, this research has demonstrated the ability of solar-assisted EV charging stations to minimize the load on the electric grid, and based on the research it can be expected that power shaving on the order of 0.6 to over $3 \mathrm{kWh}$ per EVSE charge can be realized.

\subsection{FINAL IMPLEMENTATION OF THE CONTROL ALGORITHM AND RECOMMENDATIONS}

This research investigated three control systems to mitigate load from EVSE on the electric grid using renewable energy (e.g., solar) and local storage (e.g., battery bank).

Experiments were conducted using data from two sites: the ORNL solar-assisted charging stations, which include 25 solar-assisted EVSEs, and the public State of Tennessee Employee Parking Lot charging station, which consists of 4 solar-assisted charging stations. Results indicate control system 3 having better performance, with battery operation negating up to $70.74 \%$ of the EVSE load on the grid compared with control system 2 (negating up to $60.61 \%$ of the load) and control system 1 (negating up to $58.18 \%$ ). Based on these results, control system 3 was implemented at the ORNL solar-assisted EV charging station site for everyday use. This control system was found to provide good results for the peak shaving at all sites evaluated using a value of $\omega=4$, although improvements can be made in most cases by optimizing $\omega$ using actual usage data to determine the value providing the greatest peak shaving benefit. 



\section{USAGE DATA FROM THE EVSES}

One of the primary objectives of The EV Project was to make available data regarding the usage of EVSEs and conduct analysis to characterize the charging behaviors of EV drivers using publicly available EV charging stations and workplace charging stations. These data are useful to researchers as well as to policy makers and planners to help determine the number of EVSEs necessary to accommodate a given set of EVs at specific locations, select the locations of charging stations to best meet demand, and design and size charging stations that use energy storage and/or alternative energy to minimize the impact of EV charging on the electrical grid. Additionally, electric utilities can use the data to better understand the impact that EVs will have on grid demand, which will help them plan for future infrastructure development. The data collected as part of The EV Project will therefore serve in planning and designing future EV charging station deployments.

All of the EVSEs installed as part of The EV Project include network connectivity. Detailed data for the power transfers and connection and charging times from the EVSEs are automatically stored on the EVSE manufacturer's website, which can be queried for further analysis. Furthermore, for the solarassisted charging stations, data from the solar array and battery storage systems were also recorded and are easily accessible as a result of the data connectivity. The data obtained from the EVSEs, PV arrays, and battery banks were evaluated to provide information about the power demands from EV charging and the power generation and storage of the solar-assisted EV charging stations.

\subsection{DATA PROCESSING AND INFRASTRUCTURE SUMMARY REPORT GENERATION}

The EVSE charging data available from the Blink database includes the following data signals: connect and disconnect times, power transfer start and end times, energy transfer during each 15 minute segment, maximum power transferred during each segment, and EVSE identification information. These data were processed to develop graphs and data summaries of the usage of EVSEs at each location, and quarterly infrastructure summary reports were developed as a means to provide regular status reports and to identify trends.

Since the Blink data and battery and solar array data are available as .csv files, ORNL developed a program using a Visual Basic for Applications (VBA) implementation in Microsoft Excel to automate the generation of each summary report using input files with data from a selected time period. The program allows the user to define and select sets of EVSEs for processing, and the data are then parsed and processed to generate all of the graphs for the summary report. The program exports the graphs and summary data to a file in a uniform format that is intended to be easy to read and provides data of interest to the EVSE research and user community. The following provides a description of the information included in the summary reports.

The distributions for the times when EVs are connected to the EVSEs and when power transfers occur provide information about the charging behavior of EV drivers, the utilization of the charging stations, and the load on the grid. The distribution is presented in the form of a histogram of the time series data for the corresponding time. Each hourly segment shown in the distribution graphs represents the time period ending at the corresponding hour of the day, based on 24 hour time. For example, in Fig. 60, the peak occurrence for the connection time distribution is shown to occur during the 1 hour period before 09:00, indicating that more connections occur between 8:00 and 9:00 a.m. than at any other time of day. 

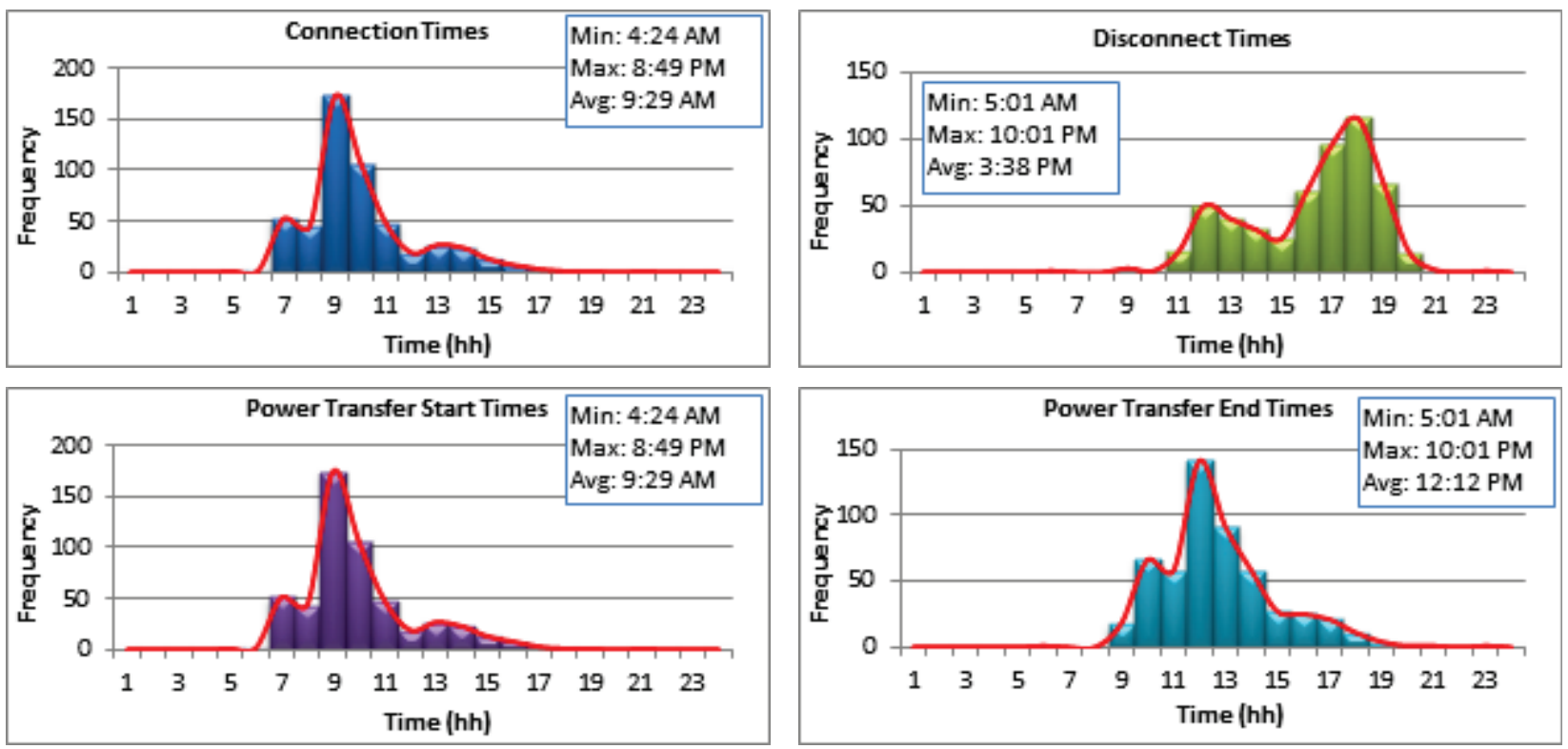

Figure 60. Time of day distribution graphs in the summary reports for the ORNL solar-assisted site during the fourth quarter of 2012.

Similarly, the distributions for durations of connection and power transfer (Fig. 61) show that EVs often remain connected for 8-9 hours, but charging ends most frequently after a duration of only 2-3 hours at the ORNL site. This is because the EV battery, which often maintains a significant partial charge when the vehicle connects, is charged completely during a few hours, but the car remains connected to the EVSE throughout the workday if the driver does not disconnect at some point.
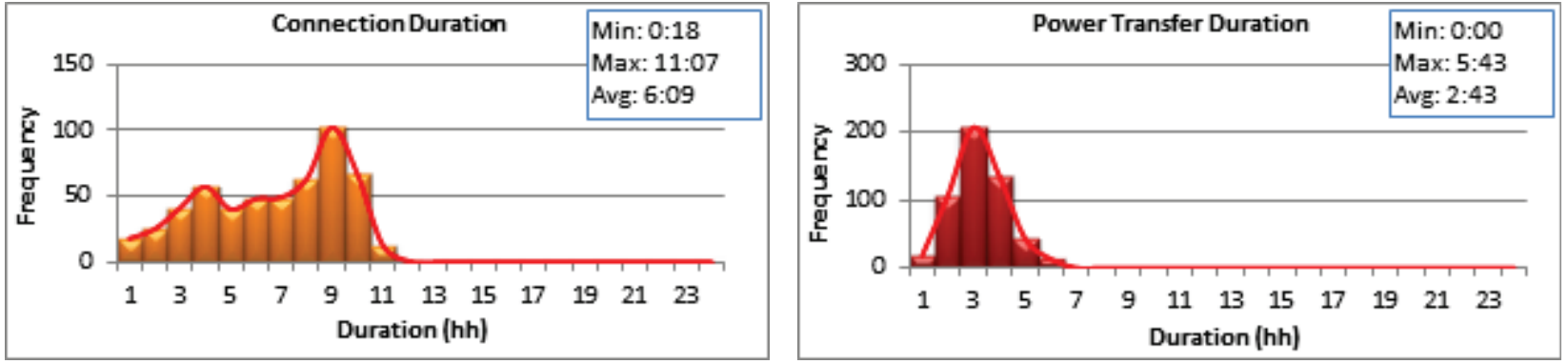

Figure 61. Duration distribution graphs in the summary reports for the ORNL solar-assisted site during the fourth quarter of 2012.

The distribution of the energy consumption per charge and the approximate distributions for the additional miles available from each charge event and the percentage of battery filled per charge are also included in the summary report (Fig. 62). The latter two values for each charge event are calculated values based on (1) the total energy consumption for the charge event, (2) an average initial value of the miles per kilowatt-hour for the Nissan LEAF (2.94 mi/kWh) and the Chevrolet Volt ( $2.78 \mathrm{mi} / \mathrm{kWh})$, and (3) the original vehicle battery size for the LEAF ( $24 \mathrm{kWh})$ and Volt $(16 \mathrm{kWh})$. 
Charging Analysis
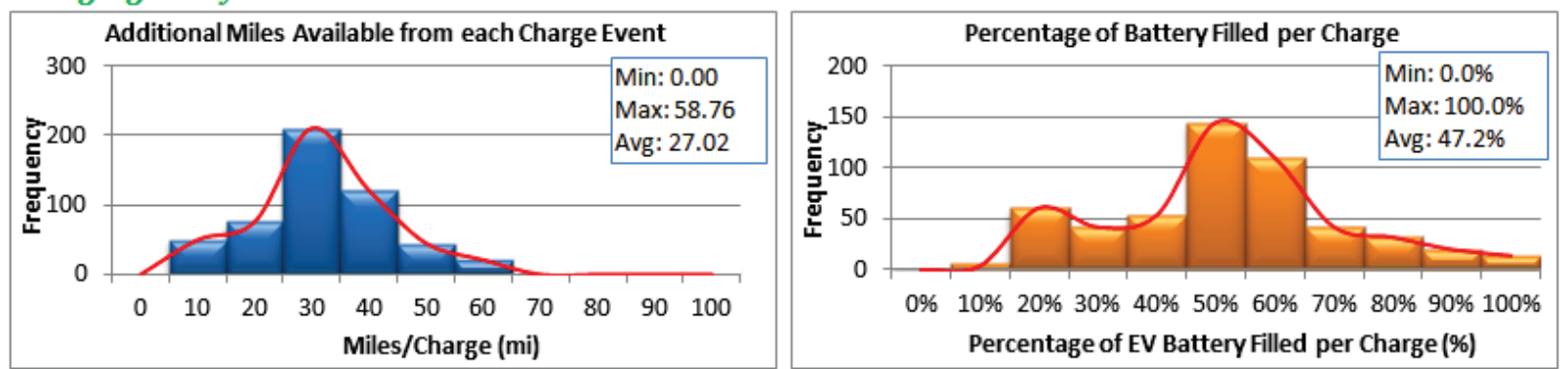

Figure 62. Vehicle charging analysis graphs included in the summary reports for the ORNL solar-assisted site during the fourth quarter of 2012.

The energy consumption is evaluated in several different ways in the summary report. In addition to the distribution information discussed, the total daily energy consumption is presented for each day during the quarter. The energy usage percentages by day of week are also shown in a pie chart (Fig. 63), in which the sector corresponding to the day with the greatest utilization is highlighted by being separated from the other days' data. Average daily energy use by day of week and the average number of charge events by day of week are also presented.
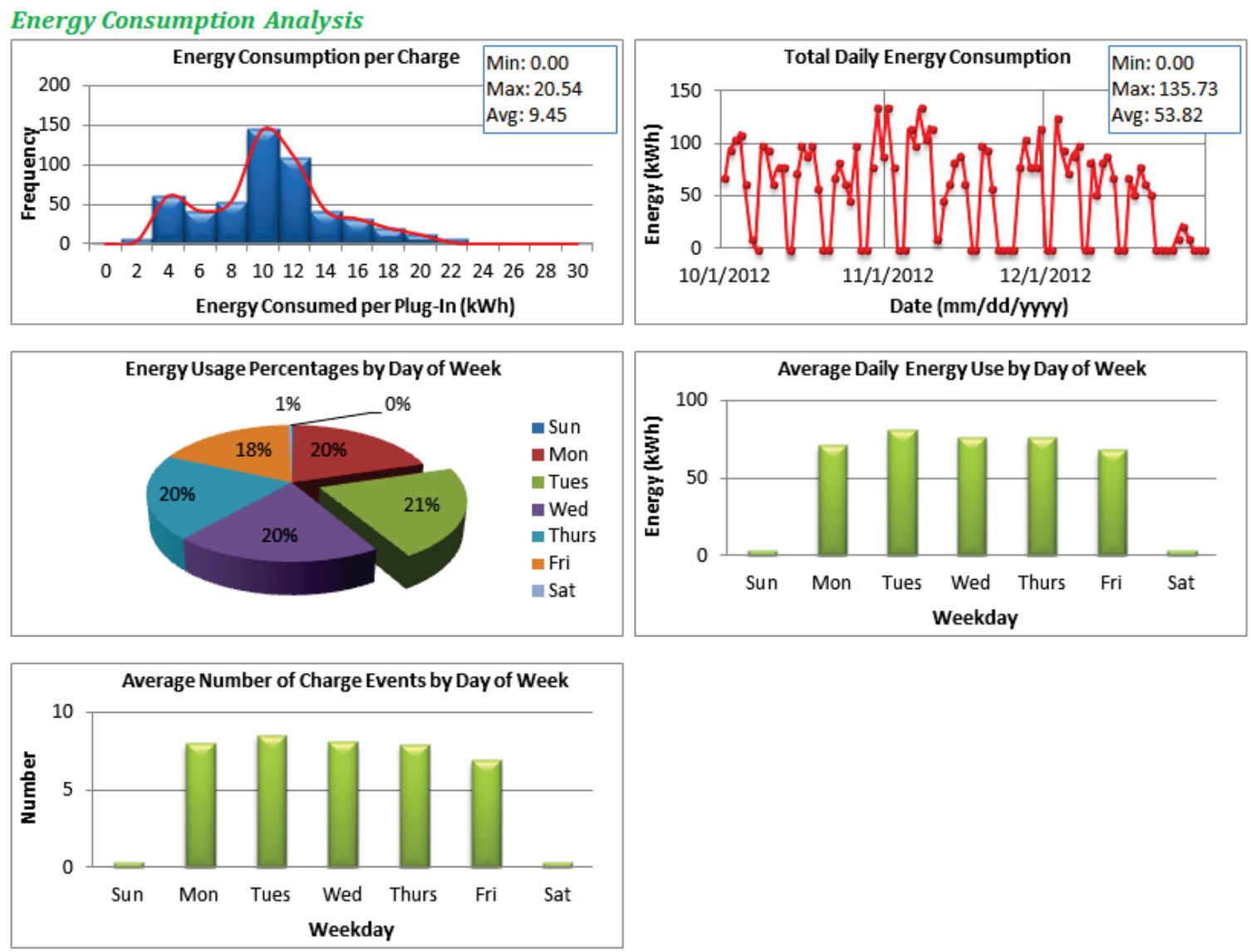

Figure 63. Energy consumption analysis graphs included in the summary reports for the ORNL solarassisted site during the fourth quarter of 2012. 
Data showing the percentages of time EVs are connected to each EVSE at the charger site and the actual times vehicles are charging at each EVSE are also shown in the report in two graphs under the heading "EVSE Analysis" (Fig. 64). These are intended to indicate the relative usage among all of the EVSEs at the site and allow a rapid means evaluation of whether there was any down time for specific EVSEs. In locations with excess capacity or relatively low utilization, however, some EVSEs may receive little usage if, for example, one space is used regularly by the same EV driver or is located closer to the building entrance.
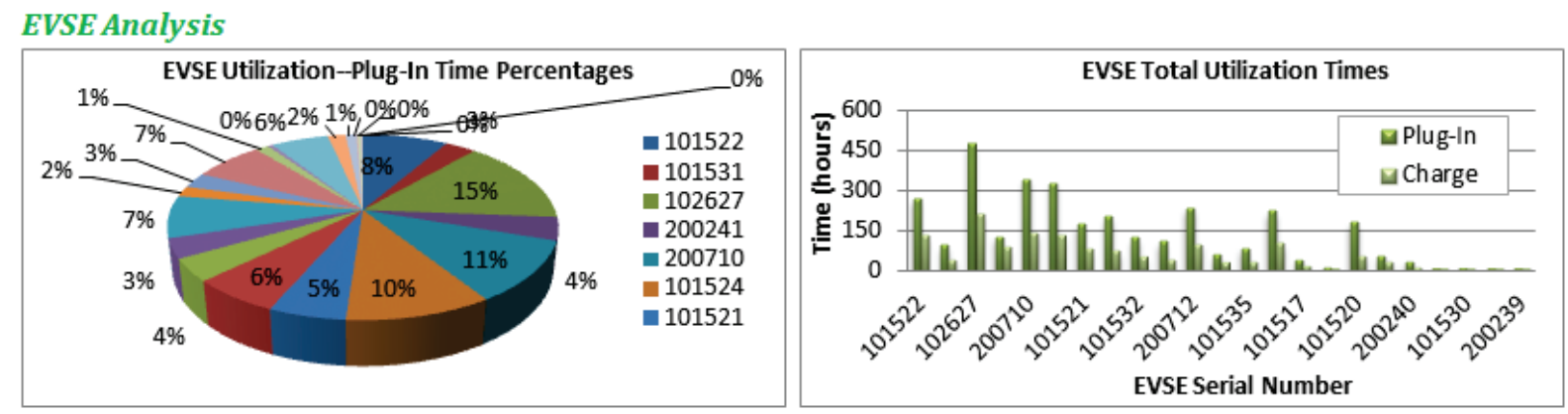

Figure 64. EVSE analysis graphs included in the summary reports for the ORNL solar-assisted site during the fourth quarter of 2012.

The final two graphs in the summary report are the EVSE load profile and the PV array power generation profile (for the solar-assisted charging stations), which show the energy usage by the EVSEs and the solar energy generation, both as totals by date (Fig. 65). The two graphs together indicate the charging station load on the electrical grid and the extent to which solar energy production from solarassisted charging stations offsets the energy use of the EVSEs.
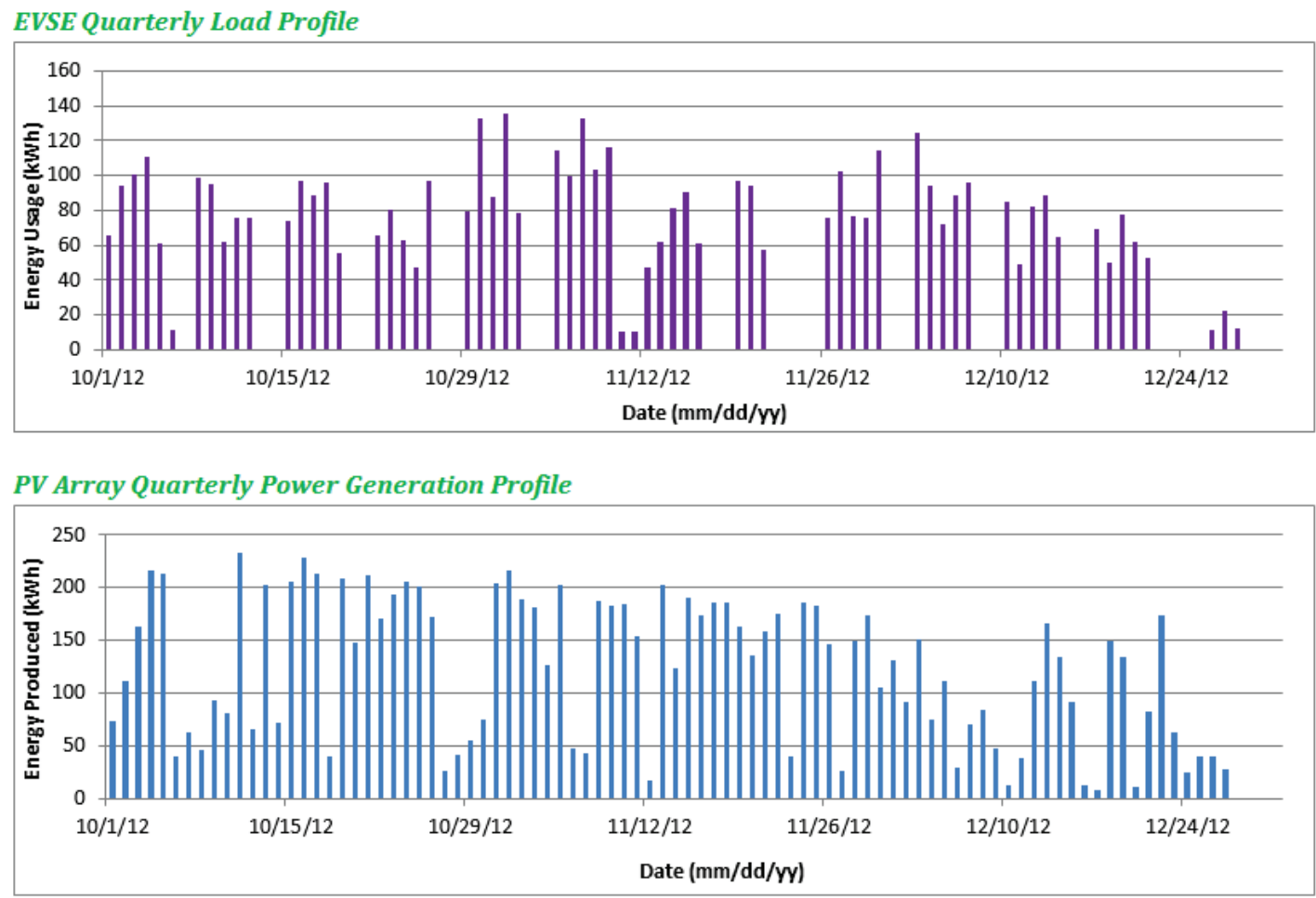

Figure 65. EVSE load and PV array power generation profiles from the summary report for the ORNL solar-assisted site during the fourth quarter of 2012. 
In addition to presenting the graphs described for each quarter in the summary report, a set of summary statistics showing (1) the number of charging events, (2) the percentage of time when EVs are connected, (3) the percentage of time when EVs are charging, (4) the average connection duration, (5) the average charge duration, (6) the average miles per charge, and (7) the average percentage of battery filled per charge event are listed for each quarter year-to-date. The installation statistics for the solar energy generation, energy consumed, net energy generation, and total distance traveled are also listed by quarter, and the total values for these statistics for the year are listed.

Appendix A contains a set of infrastructure summary reports with the information described for each charging station site. The reports cover the final quarter for which data are available in each calendar year from 2012-2014 during which the site was operational (up to 2014Q2, the last complete quarter of the project), and the summary statistics for all quarters are included. These reports provide a broad summary of the data accumulated in the ORNL EV Project.

\subsection{UTILIZATION SUMMARY REPORT}

A set of graphs were generated quarterly showing the overall usage of the EVSEs at each installation site and for multiple sites aggregated together in terms of the number of charge events. This information shows the growth of demand at each site and includes an indication of the overall percentage of usage. The "percent utilization" value is calculated by assuming that each EVSE has one charge opportunity per day for each weekday during the week for a total of 20 charge opportunities per month. This definition was intended for EVSEs located at a work location and is obviously not ideal in every situation, but it does provide a simple indication of the overall utilization that the EVSEs at each site achieved during the quarter. In addition to the quarterly totals, the number of charge events is shown by day of the week for each quarter. Figure 66 shows the utilization summary data for all ORNL EVSEs aggregated as an example. The complete set of utilization summary data is included in Appendix B. 

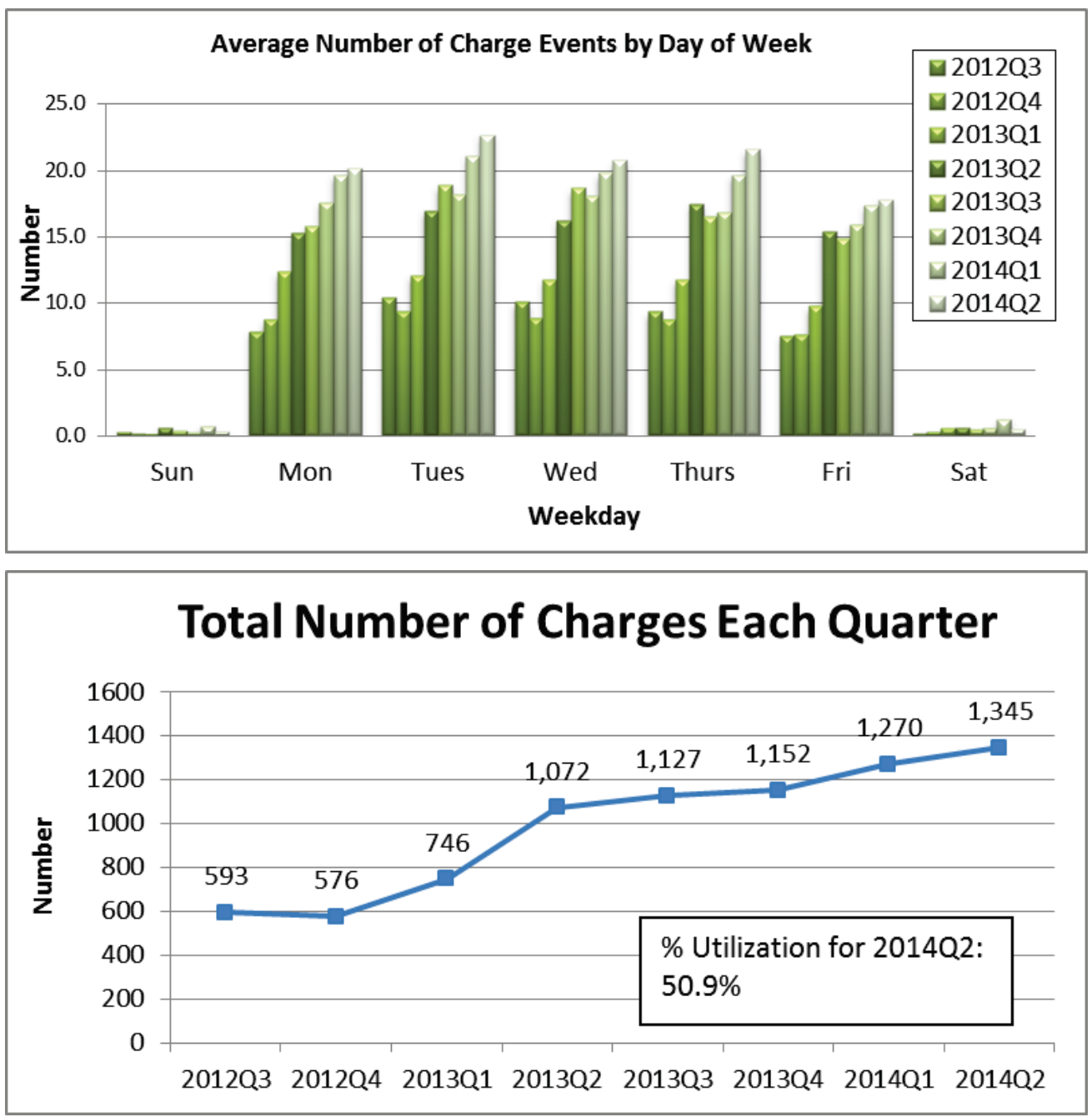

Figure 66. Utilization summary graphs for the set of all ORNL EVSEs through the second quarter of 2014. 


\section{PROJECT WEBSITES}

Two websites were created as part of the ORNL EV Project. The first site, known as the PVEV website, presents real-time and historical data for the operation of the solar-assisted charging station at the ORNL campus. The second website, EVSE TN, provides information on the utilization rates and energy usage from the EVSEs installed as part of the ORNL EV Project and makes available reports and data generated by the project. Both sites are intended to share information about the project with the public, to showcase ORNL's activities related to the deployment of and data collection from EV charging stations in the state of Tennessee, and to help promote the use of EVs.

\subsection{PVEV WEBSITE}

The PVEV website is located at https://extwebapps.ornl.gov/PVEV_ext. A screenshot of the webpage is shown in Fig. 67.

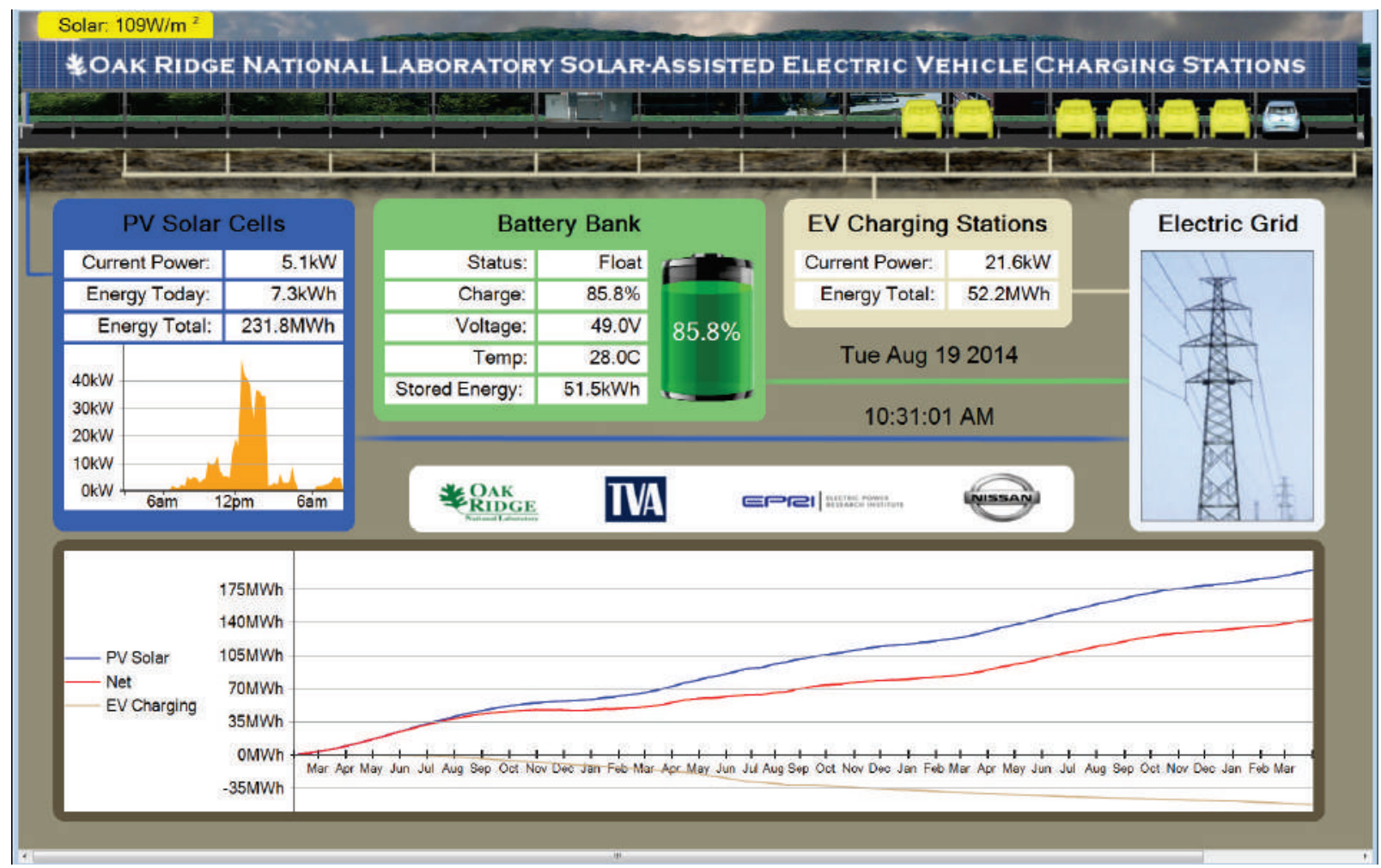

Figure 67. Screenshot of the PVEV Website.

The PVEV website shows the status of the various systems making up the ORNL solar-assisted charging station in a graphical format and presents the current power usage and power generation data from the EVSEs and the PV array, respectively. Near the top of the page below the title, the 25 parking spaces at the ORNL solar-assisted charging station are shown schematically. For each parking space at the physical site where an EV is parked and connected to an EVSE, the website shows an icon of an EV in the corresponding location. An icon for an EV that is currently charging will flash yellow, and an EV that is connected but not currently charging will remain solid blue.

Blocks for the PV solar cells, the battery bank, and the EV charging stations represent the actual hardware at the solar-assisted charging station, and the blocks include graphics and data that summarize the current operating state of these components of the charging station. For the PV solar cells, a graph also shows the solar power generation profile during the previous day of operation. The graph at the bottom of the page shows the cumulative electrical energy produced by the solar array (since the 
installation of the charging stations), the energy consumed by the EVSEs, and the net energy that has been returned to the electrical grid.

\subsection{EVSE TN WEBSITE}

The EVSE TN website is located at http://evse.ornl.gov. A screenshot of the website home page appears in Fig. 68.

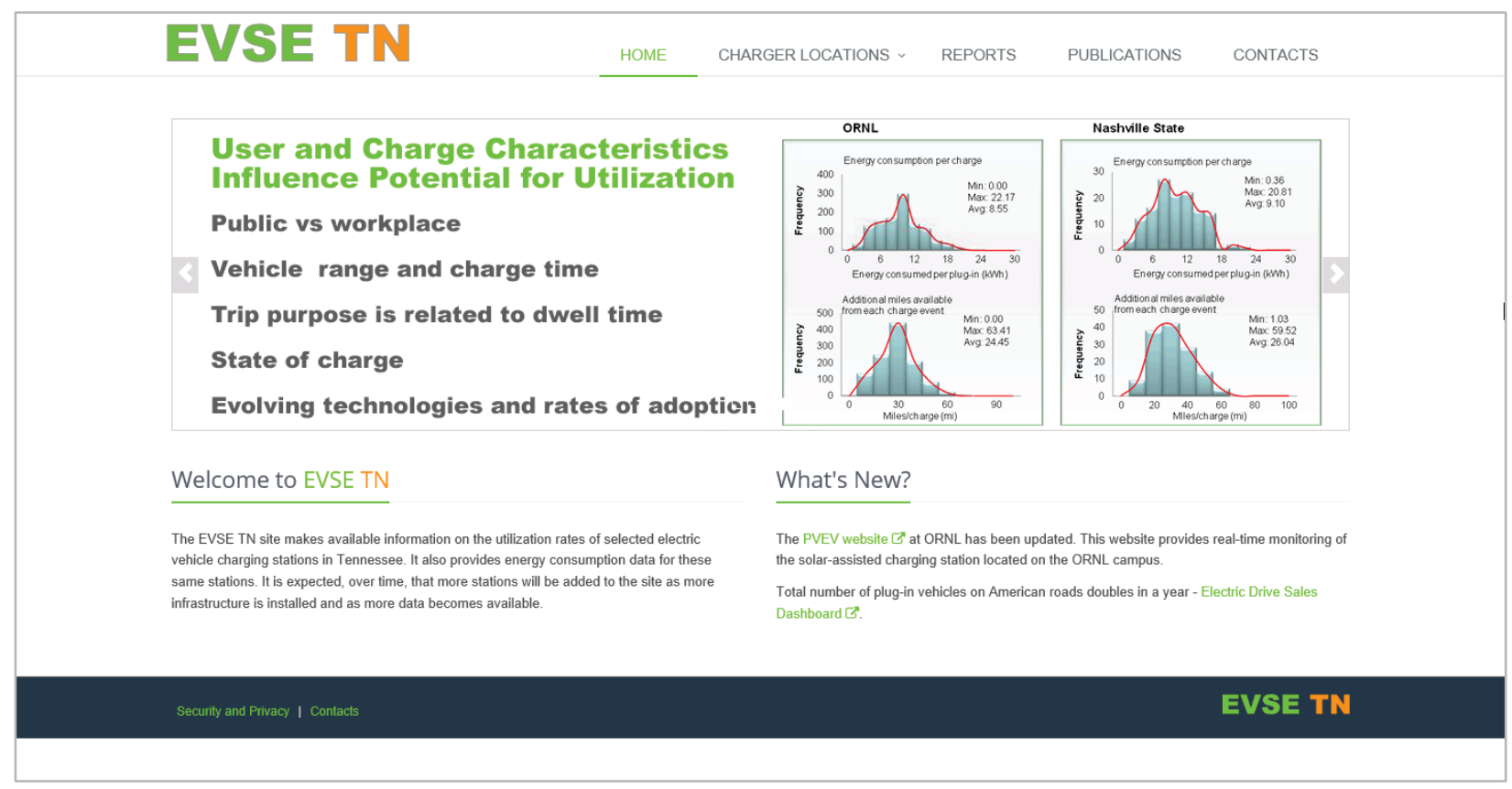

Figure 68. Screenshot of the EVSE TN Website.

In addition to providing data on the utilization rates of selected EV charging stations in Tennessee, the website includes information related to the ORNL EV Project. Links are available to reports and other research published during the project. The data contained in the website are currently limited to the charging stations installed as part of The EV Project, but the intention is to expand the data coverage in the future to include other charging stations in Tennessee. The website includes a map of the EVSE locations, photos, and data showing the utilization trends at each site. 


\section{LESSONS LEARNED AND CHALLENGES FACED}

This chapter discusses some of the challenges experienced by the project team in completing the tasks required to successfully plan and conduct the installation and maintenance of the EV charging stations and collect and process operational data from the equipment following installation. Developing a list of lessons learned requires consideration of the progress made and how it was achieved, along with the inevitable false starts and the obstacles that present themselves during the project. It is hoped that this discussion of experiences can help other groups who perform similar EVSE deployments in the future do so as efficiently as possible and avoid some of the pitfalls experienced during the ORNL EV project.

The following lessons learned are in no particular order, although they are categorized in terms of project coordination, planning and design, time considerations, and installation and operational issues.

\subsection{LESSONS LEARNED}

\section{Coordination with project partners, contractors, and other stakeholders}

1. Coordination and communication with site hosts is critical for a smooth installation. In some cases in which the host provided certain pieces of equipment or services, such as power supply equipment or Internet service, the project was delayed because the timing of the interface between the host and the installation subcontractor activities was not adequately communicated.

2. The project team must communicate expectations and plans for the hosts' usage requirements with the hosts. Different hosts have different requirements for use of the charging facilities. For example, UTK requires a permit to use the EVSEs and allows a maximum of 4 hours of charging time, whereas the City of Knoxville has no restrictions on the use of its EVSEs. Vanderbilt University was initially charging a fee for anyone to use the parking lot where its EVSEs were installed. Consequently, no one was using the EVSEs because it cost too much; but the reason they were not used was not understood until the ORNL team found out the university was charging to enter the lot. Once arrangements were made with the university to allow EV charging, the usage increased.

3. The Tennessee EV Advisory Council (TEVAC) was created as a direct result of the project and has been a beneficial coordinating body. Members include Nissan, ORNL, the State of Tennessee, TVA, EPRI, and the DOE Clean Cities Coalition. The team assisted the state with the parameters of its incentive program, tracked the adoption rate of EVs in Tennessee, and tracked the utilization rate of the solar-assisted stations across the state. Going forward, TEVAC will play a major role in determining the locations for additional EV charging infrastructure.

4. A multidisciplinary team approach at ORNL has worked well. Having weekly meetings either in person or by phone has kept the team working well together and moving forward.

5. The project enjoyed great support from its regional partners-Nissan, TVA, EPRI, the State of Tennessee, and all the site hosts. Building positive relationships with all partners helps the project move forward.

\section{Planning and design details}

1. The determination of siting details must account for accessibility to electrical power, traffic patterns, ease of accessibility, proximity to high-traffic areas and interstates, and accessibility to shopping and eating areas. 
2. It is helpful to have nontechnical, architectural-type renderings prepared for presentations to nontechnical stakeholders. Allow several weeks for review of preliminary plans before the completion of detailed design drawings.

3. Since the technology is still relatively new, address anything unique to EV charging, especially in conjunction with solar and/or supplemental battery systems, early in the design process. Doing so will keep costs down and eliminate delays in the bid and award times as well as construction time. For example, the method of independent grid connection for the separate systems is not familiar to many subcontractors. Also, metering requirements, data requirements, Internet interconnectivity, and battery system requirements and operation details need to be addressed in detail. There were many questions in these areas during the bid process that had to be answered, and lack of total system understanding on the part of the subcontractor caused construction delays.

4. Equipment and system performance warranty requirements must be identified in the bid package.

5. Numerous design issues must be considered for each site: vehicle profile with regard to solar canopy clearance, sidewalk requirements, curb height, Americans with Disabilities Act equipment location and height requirements, underground interferences, safety oversight, and Occupational Safety and Health Administration requirements must all be incorporated in the design process.

6. Construction design and specifications must be very specific in delineating scope of work requirements. There have been disputes over which parties (e.g., host, local utility, subcontractor) are responsible for scope after field work has started.

7. Some external installations have experienced very low usage and others have seen very high usage. Although this is part of the learning process, having a plan for relocating equipment and/or communicating about the location/availability/benefits of all the selected locations would be helpful in future projects.

8. Directly measuring all data needed for the project using ORNL-owned sensors was deemed to be important for consistency and control of the data. Data provided by Blink using online queries did not remain consistent throughout the project, and the team chose to install separate metering on the solarassisted stations installed by ORNL to ensure access to charging data without depending on a vendor website. Developing a backup data plan and procuring all needed hardware at the outset, eliminating reliance on external organizations, would have avoided the loss of data.

9. Ensure local power sources have adequate capacity, because upgrading equipment, such as transformers, can be costly. Ensure local metering requirements are identified and met.

\section{Time required for the bid/award process, approvals, permitting and performing of the installations}

1. In subcontracting the installation of the integrated system, ensure that enough time is allowed during the bid and award process for numerous questions and answers. We had almost 100 questions to answer during the bid process for the ORNL integrating contractor.

2. Allow time in the installation schedule for permitting by local utilities. All cities have somewhat different requirements and reviews, and it is imperative that the integrating contractor work closely with the local authorities where the systems are being installed.

3. Identify stakeholders that have oversight responsibilities and require prior review of details of the installation plans up front. Some only require a review, but others require both review and approval, which takes additional time. Areas of interest that have taken time to address include historical site 
reviews, beautification/esthetic reviews, environmental review committees, utilities, and other metro subcommittees.

\section{Installation and operational issues}

1. The grid-connected, integrated design concept (solar, external battery, and EVSE) worked well in the ORNL EV Project. The only serious problems were with purchased equipment (including the EVSEs) and Internet connections to solar inverters. Battery bank problems at ORNL were corrected by replacing a few bad batteries in the bank.

2. EVSEs are a new technology, so operating problems and failures should be expected. As much information as possible about reliability should be obtained prior to selecting hardware from a specific manufacturer, and it is necessary to budget for repair/replacement costs for the full period of operations. Even if repairs are covered under warranty, it still consumes project resources to have issues corrected. Overall, the performance of Blink EVSEs has been disappointing.

\subsection{CHALLENGES TO WIDESPREAD EV USE}

Although EV use has increased rapidly since EVs first became commercially available, there are a number of barriers to continued growth. Although the project scope did not address EV use specifically, the project team has identified specific issues that may impact EVSE and EV deployment. These do not fall under the lessons learned, but observations of the project team regarding implications of these issues warrant a discussion of barriers to EV adoption.

For EV use to continue to increase in the long term, it will be necessary that the EV charging network grow substantially so that it becomes convenient for EV drivers to charge their vehicles wherever and whenever needed. Therefore, accelerated deployment of EVSEs is needed so there will be enough infrastructure available to meet the demands of EV drivers everywhere. EVSE availability should be such that drivers can easily locate a charging station and charge the EV without delay. For encouraging EV use among daily commuters, workplace charging is a very clear advantage.

Since charging an EV battery currently takes longer than filling the gas tank of a conventional car, any inconvenience or delay in charging an EV may be perceived by consumers as a significant additional barrier. In the same light, EV and EVSE robustness are very important for convincing potential users that they will not be inconvenienced by problems with the charging infrastructure. The project team repeatedly experienced downtime and reliability issues with both the Blink Level 2 chargers and the DCFC; and the difficulties resulted in inconvenience for EV drivers at times, particularly at locations where the number of EVSEs was not much greater than the number of EV drivers. It is thought that developing new standards for EVSE performance and strict certification requirements may help to reduce such reliability concerns in the future.

The costs of EVs and the charging infrastructure are obvious barriers, but some unexpected cost issues seem to exist for EVSEs. It is generally believed that the cost of electricity makes the cost of operating an EV (after the initial purchase) favorable, but this may not be the case if owners must regularly use publicly available pay-per-charge EVSEs. When the cost to charge an EV is based on connection time and not on electricity use, as is often the case, it can be expensive on an energy basis to "top off" the battery to ensure that sufficient energy will be available for a given trip. If, for example, an EV driver plans to take a trip of 70 miles and has already driven 15-20 miles, then depending on the operating conditions it may be necessary to recharge the battery before departing. A cost of $\$ 3-7$ for a charging session that provides enough energy to travel $80-100$ miles is quite reasonable, but the same cost for only enough energy to travel 20 additional miles is more expensive than the gasoline needed for a conventional vehicle to travel the same distance.

Operating a private charging station (for workplace charging) may not be cost-effective for a potential site host or for employees, considering installation and maintenance fees. Maintenance fees for a single EVSE may exceed $\$ 1000$ annually. Depending on the number of users and how frequently each unit is 
used, the maintenance costs can eliminate any savings associated with energy use alone. These cost issues need to be carefully considered in planning for an EV charging station, and research should be conducted to identify approaches that can be applied to eliminate or minimize such cost barriers. 


\section{PROJECT SUMMARY AND CONCLUSIONS}

The ORNL EV Project was part of a DOE-funded EV charging infrastructure demonstration called "The EV Project," which started in 2009 and was led by ECOtality. The ORNL project included specific goals, however, that differentiated it from the national project. In particular, ORNL and its project partners developed a solar-assisted EV charging station design that integrates a solar PV array, a battery bank, and EVSEs using a grid-connected configuration for all of the components. This design is intended to minimize the electrical load imposed on the grid by EV charging. The design of the solar-assisted EV charging stations has been successfully demonstrated. The ORNL team and its project partners EPRI, TVA, Nissan, and the charging station site hosts deployed and collected data from the charging stations at sites across the state of Tennessee for at least 18 months at each location. The accomplishments of the ORNL EV Project contribute to the primary goal of laying the groundwork for future deployments of EV charging stations throughout the United States, and the solar-assisted EV charging station design specifically addresses concerns about mitigating the load from EVSEs on the electric grid.

\subsection{RESULTS ACHIEVED}

The ORNL project team and its partners successfully deployed 125 solar-assisted EV charging stations at 15 sites located in and around the four largest cities in the state of Tennessee (Memphis, Nashville, Knoxville, and Chattanooga) and met all project objectives. In addition to installing the solarassisted EV charging stations, ORNL installed 18 non-solar Level 2 Blink EVSEs and 1 DCFC at various locations around the ORNL campus. The locations for all charging stations are listed in Table 13. These locations include both public and private (workplace) sites, so usage data for both types of utilization were measured. The charging stations have been and continue to be used by EV drivers in Tennessee to charge their vehicles. Data from the EV charging stations were collected during their operation to provide information on charge utilization, energy consumption, energy production by the solar arrays, net energy use (or surplus) from the solar-assisted EV charging sites, and other statistics of EVSE usage. These usage and power data were analyzed for the EVSEs installed as part of the ORNL EV Project and provide valuable information about the utilization and power requirements of the EVSEs that will assist in the planning of future sites as EV use continues to increase in the United States.

The impact of EV charging on the electrical grid is an ongoing concern, since the energy requirements being satisfied by petroleum today must be met by an increased electric energy supply when EVs are more prevalent on American highways. Electric infrastructure may require upgrades to meet the growing load demand from a large number of EVSEs in the future. Furthermore, the use of EV charging infrastructure could increase consumer demand charges from utilities. As part of this project, ORNL developed three separate control methodologies to minimize EVSE load on the electric grid using a solar PV array and battery bank, and the three control systems were compared with one another to determine which approach yielded the best performance for overall load reduction and power shaving. A nonlinear control algorithm that discharges the battery bank when EVs draw more power than is produced by the solar array, and charges the battery bank during periods of excess solar production and during the night, was found to provide the best performance overall. This approach takes maximum advantage of the power from the solar array and excess power capacity provided by the battery bank storage to offset the grid loads from the EVSEs. Using the battery and the solar array together, this algorithm was found to offset the EVSE load on the grid by up to $70.7 \%$ during typical operating conditions at ORNL. This approach has been implemented using automated control software for everyday use at the ORNL solar-assisted charging station, and the algorithm has also been made available to the project partners for implementation at their solar-assisted charging station locations. 
Table 13. Locations of the EV charging stations deployed in the ORNL EV Project

\begin{tabular}{lcc}
\hline \multicolumn{1}{c}{ Site Location } & No. of EVSEs & Type \\
\hline ORNL campus & 25 & Solar-assisted, Level 2 \\
EPRI Knoxville & 6 & Solar-assisted, Level 2 \\
Nissan Administration Building, Smyrna & 9 & Solar-assisted, Level 2 \\
Nissan battery plant, Smyrna & 3 & Solar-assisted, Level 2 \\
Nissan Headquarters, Franklin & 18 & Solar-assisted, Level 2 \\
Knoxville (Civic Coliseum) & 6 & Solar-assisted, Level 2 \\
Knoxville (Market Square) & 4 & Solar-assisted, Level 2 \\
UT-Knoxville (Music Building) & 6 & Solar-assisted, Level 2 \\
UT-Knoxville (Ag Campus) & 6 & Solar-assisted, Level 2 \\
Nashville (LP Field) & 8 & Solar-assisted, Level 2 \\
Nashville (state) & 4 & Solar-assisted, Level 2 \\
Nashville (Vanderbilt) & 10 & Solar-assisted, Level 2 \\
Chattanooga (Advanced Vehicle Test Facility) & 4 & Solar-assisted, Level 2 \\
Chattanooga (Chattanooga Theatre Centre) & 6 & Solar-assisted, Level 2 \\
Memphis (Shelby Farms Park) & 10 & Solar-assisted, Level 2 \\
ORNL campus & 18 & non-solar, Level 2 \\
ORNL campus & 1 & non-solar, DCFC \\
\hline
\end{tabular}

\subsection{RECOMMENDATIONS FOR FUTURE RESEARCH}

Data collection at charging stations should be continued in order to monitor the growth of EVSE utilization, and detailed analysis of the demand on the electric grid will be necessary. To ensure the continued growth of EV deployment, data are needed that can assist in identifying optimal site locations for maximum use of the infrastructure and availability for EV drivers.

The project team recommends that research be conducted to better characterize the cost of EV ownership for different usage scenarios and to address the cost-effectiveness of EV charging outside the home. Incentives and other measures may be needed to make the cost of ownership attractive to potential buyers, and analysis should be conducted using realistic costs for both the EV owner and the EVSE site host.

Further research addressing the impact of EV charging on the electric grid is needed, as well as further study of the use of renewable energy and energy storage to help mitigate electrical grid load. Research should be pursued to optimize the sizing of the battery bank and the associated inverter/charger capacity for a given solar array in a system and to consider other configurations, including energy storage and/or renewable energy. Since EVs themselves can provide energy storage/buffering at different times of the day, research addressing benefits, control strategies, efficiencies, and other aspects of vehicle-to-grid systems is needed to develop the technology. 


\section{ACKNOWLEDGMENTS}

The authors appreciate the support of the US Department of Energy (DOE), particularly Lee Slezak and David Anderson of the Vehicle Technologies Program, Jason Conley of the National Energy Technology Laboratory, and Mary Rawlins of the DOE Oak Ridge Site Office. Thanks also to David Smith, Dave Mandl, Joel Poteat, and Betty Walker of ORNL; Charles Castello, formerly of ORNL; Jim Frankfort of Idaho National Laboratory; and James Ellis, formerly with TVA and Nissan. In the field, the team thanks Erin Gill and Jake Tisinger (City of Knoxville), Terry Ledford (University of Tennessee), Stacey Crain and Ken Srebnik (Nissan North America), John Halliwell (Electric Power Research Institute), Jay Harrison (Tennessee General Services Administration), Molly Cripps (Tennessee Department of Environment and Conservation), Andrew Frye (TVA), and Monica Fawknotson, Toby Compton, and the late Emmett Edwards (Sports Authority staff in Nashville). Without the support of these and many other contributors, success would not have been possible. 



\section{REFERENCES}

1. US Congressional Budget Office, Effects of Federal Tax Credits for the Purchase of Electric Vehicles, September 2012. Available at http://www.cbo.gov/sites/default/files/cbofiles/attachments/ElectricVehicles_One-Col.pdf, accessed $7 / 15 / 2014$.

2. US Department of Energy, EV Everywhere Grand Challenge Blueprint, Washington, D. C., January 2013.

3. S. X. Chen and H. B. Gooi, "Scheduling of energy storage in a grid-connected PV/battery system via SIMPLORER,” IEEE TENCON 2009, pp. 1-5, January 23-26, 2009.

4. A. Nottrott, J. Kleissl, and B. Washom, "Optimization routine for energy storage dispatch scheduling in grid-connected, combined photovoltaic-storage systems," International Conference on Electrical Energy Storage Applications and Technologies (EESAT 2011), San Diego, 2011.

5. B. Lu and M. Shahidehpour, "Short-term scheduling of battery in a grid-connected PV/battery system," IEEE Transactions on Power Systems 20(2), 1053-1061 (May 2005).

6. G. T. Costanzo, J. Kheir, and G. Zhu, "Peak-load shaving in smart homes via online scheduling," IEEE International Symposium on Industrial Electronics, pp. 1347-1352, June 27-30, 2011.

7. ECOtality, Inc., Blink Network, http://www.blinknetwork.com/. Accessed July 22, 2014.

8. Advanced Energy Industries, Inc., Advanced Energy, https://www.mypvpower.com/. Accessed July 22, 2014.

9. Enphase Energy Inc., Enlighten Manager, https://enlighten.enphaseenergy.com/. Accessed July 22, 2014.

10. T. Tesfaye and C. C. Castello, "Minimization of impact from electric vehicle supply equipment to the electric grid using a dynamically controlled battery bank for peak load shaving," IEEE Power Engineering Society (PES) Innovative Smart Grid Technologies (ISGT) Conference, Washington, D.C., February 24-27, 2013.

11. C. C. Castello, T. J. LaClair, and L. C. Maxey, "Control strategies for electric vehicle (EV) charging using renewables and local storage," IEEE Transportation and Electrification Conference and Expo (ITEC'14), Dearborn, Michigan, June 15-18, 2014. 



\section{APPENDIX A. ORNL EV PROJECT ELECTRIC VEHICLE CHARGING INFRASTRUCTURE SUMMARY REPORTS}





\section{APPENDIX A. ORNL EV PROJECT ELECTRIC VEHICLE CHARGING INFRASTRUCTURE SUMMARY REPORTS}

For each quarter of operation and at each charging station site, a summary report was created to provide statistics for the usage of the EVSEs, energy consumption, solar power generation at the solarassisted locations, and other information. Aggregated data for all charge events during the quarter were evaluated, and graphs were developed to characterize the utilization and electrical loads. Each summary report includes graphs that quantify the distribution of times when electric vehicles (EVs) were connected and power transfer occurred, the energy consumption per charge event by the electric vehicle supply equipment (EVSE), the level to which the EV batteries were charged, and the total energy usage and solar photovoltaic power generation profiles.

This appendix contains data from all of the EVSE installations, including those for which the installations were managed by Oak Ridge National Laboratory (ORNL), by the Electric Power Research Institute (EPRI), and by Nissan. The ORNL-managed installation sites for the EVSE charging stations include the ORNL campus solar-assisted site, the ORNL campus nonsolar installations (all sites combined), the Knoxville Civic Coliseum parking garage, the Knoxville Market Square parking garage, LP Field (Nashville), the Tennessee state lot at Fourth and Harrison (Nashville), the University of Tennessee-Knoxville (UKT) Music Building site (Knoxville), and the UTK Agriculture Campus location (Knoxville).

The EPRI-managed installation sites include EPRI's Knoxville laboratory, the Chattanooga Theatre Center site, the Tennessee Valley Authority (TVA) Advanced Vehicle Test Facility (Chattanooga), the Vanderbilt University location (Nashville), and the Shelby Farms Park site (Memphis).

The Nissan installations include the Nissan Headquarters in Franklin, Tennessee; the Nissan Administration Building (Smyrna, Tennessee); and the Smyrna Battery Plant. The complete results for the last quarter of each calendar year of operation at each site are presented, and statistical summaries for every quarter are listed in the corresponding report. The summary reports were generated through the second quarter of 2014, which was the last complete quarter during the project. Note that the format of data provided by the Blink Network changed in early 2014; detailed power transfer data, which had been available for charging events occurring in 2012 and 2013, were no longer provided by Blink. As a result, some of the graphs could not be generated in the reports for the final two quarters. 


\section{A.1 ORNL SOLAR-ASSISTED CHARGING STATIONS}

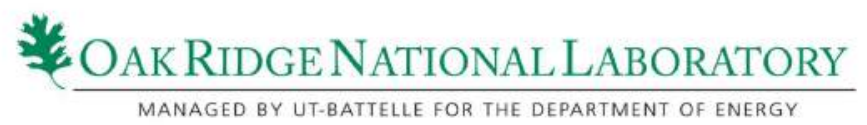

EV Project Solar-Assisted Charging Infrastructure Summary Report

EVSE Grouping/Region: ORNL solar-assisted

Report Period: October 1-December 31, 2012 (Quarter 4, 2012)

Number of EV Charging Stations: 25

$\exists \boldsymbol{\nabla}$ Project

\begin{tabular}{|c|c|c|c|c|c|}
\hline \multicolumn{2}{|l|}{ Usage Statistics } & Q1 & Q2 & Q3 & Q4 \\
\hline Number of charging events & & 695 & 749 & 593 & 524 \\
\hline Percent of time (connected vehicles) & & $12.3 \%$ & $11.9 \%$ & $7.0 \%$ & $5.8 \%$ \\
\hline Percent of time (charging vehicles) & & $3.3 \%$ & $3.4 \%$ & $2.9 \%$ & $2.6 \%$ \\
\hline Installation Statistics & Q1 & Q2 & Q3 & Q4 & 2012 Totals \\
\hline Solar-energy generated (MWh) & 9.03 & 12.19 & 15.84 & 10.83 & 47.89 \\
\hline Energy consumed (MWh) & 12.32 & 6.59 & 5.70 & 4.95 & 29.56 \\
\hline Net energy generation (MWh) & -3.28 & 5.60 & 10.13 & 5.88 & 18.33 \\
\hline Total distance traveled $(\mathrm{mi})^{\mathrm{i}}$ & 35233 & 18842 & 16310 & 14161 & 84546 \\
\hline
\end{tabular}

Time Series Analysis
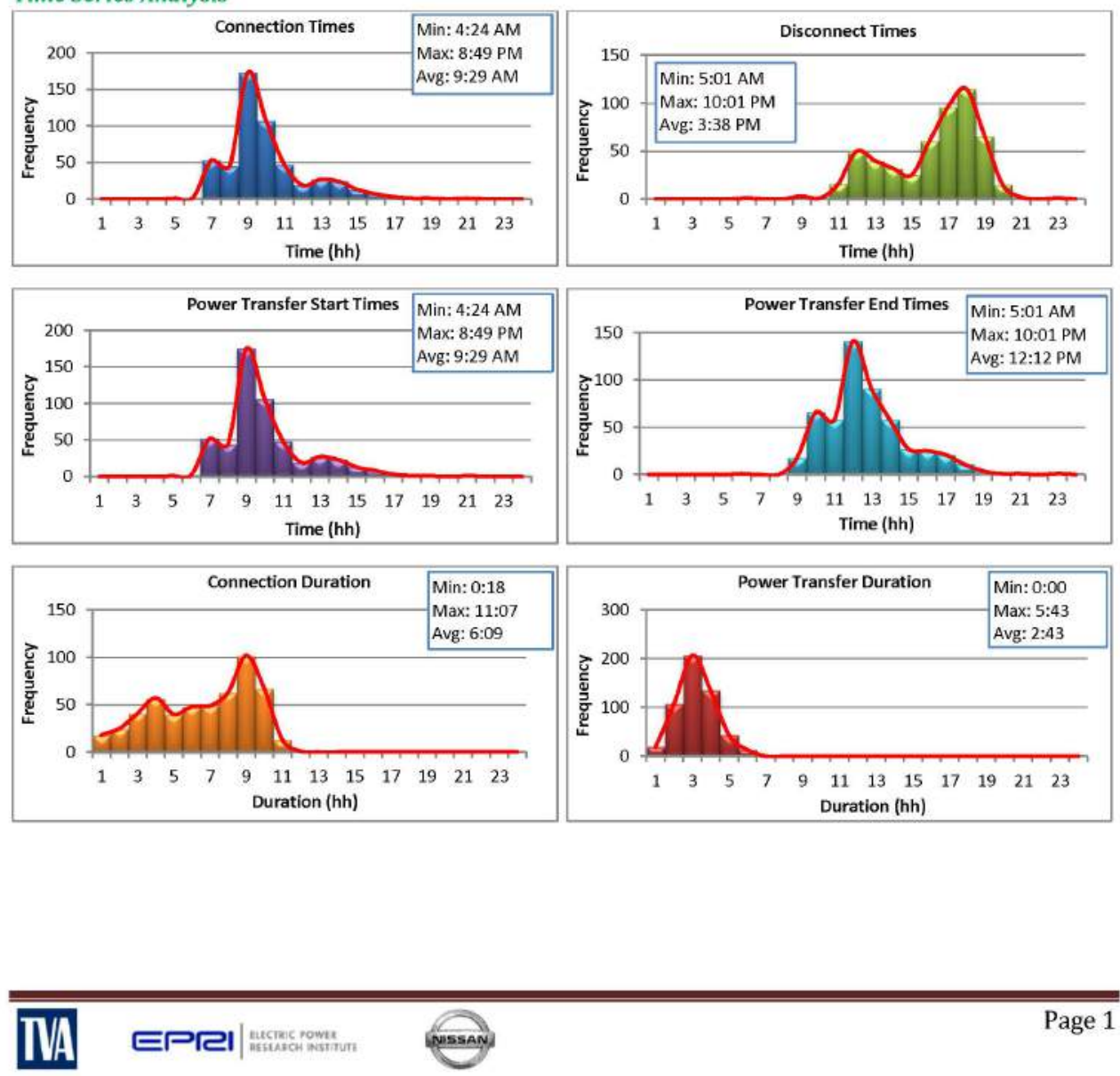


\section{OAK RIDGE NATIONAL LABORATORY}

Energy Consumption Analysis
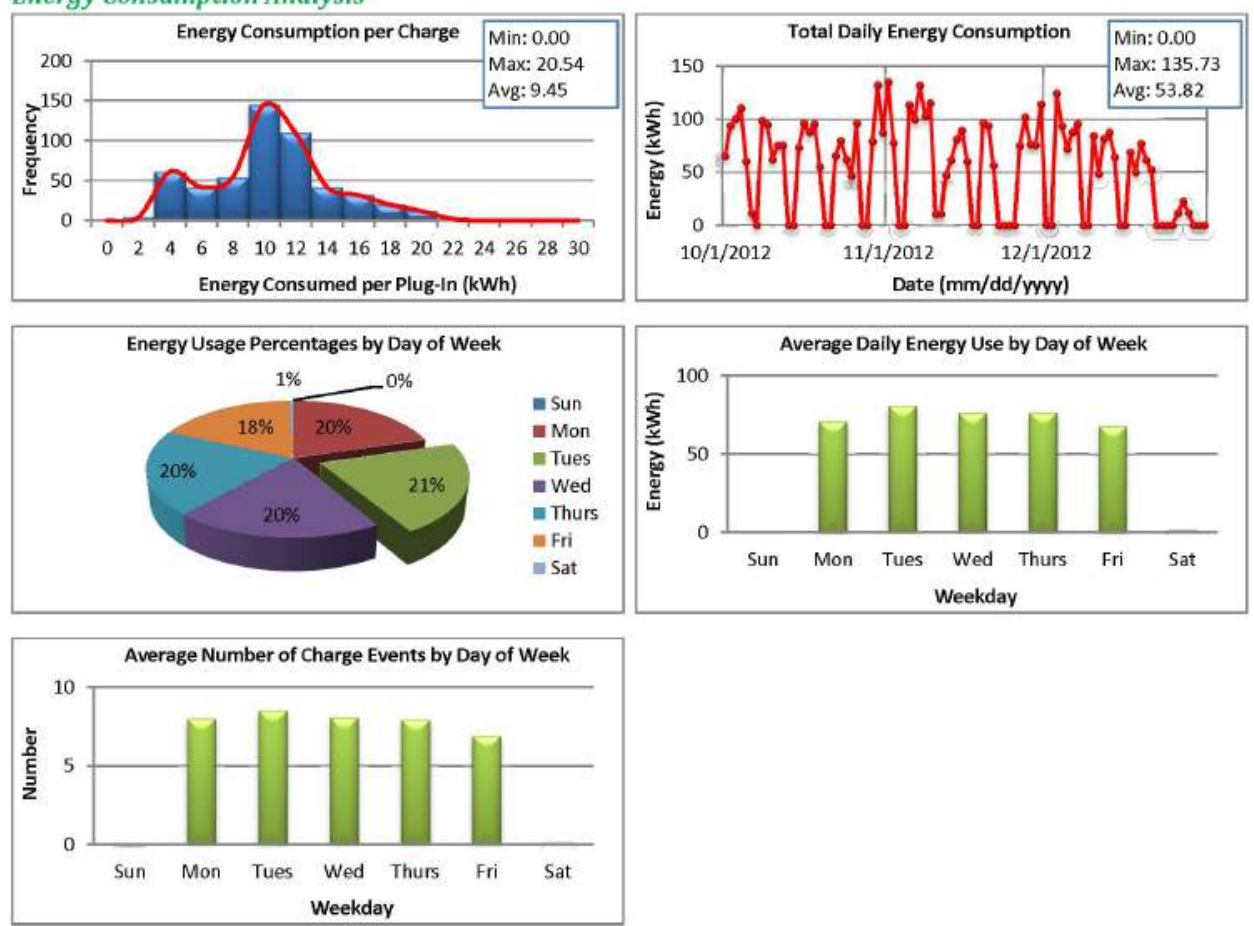

Charging Analysis
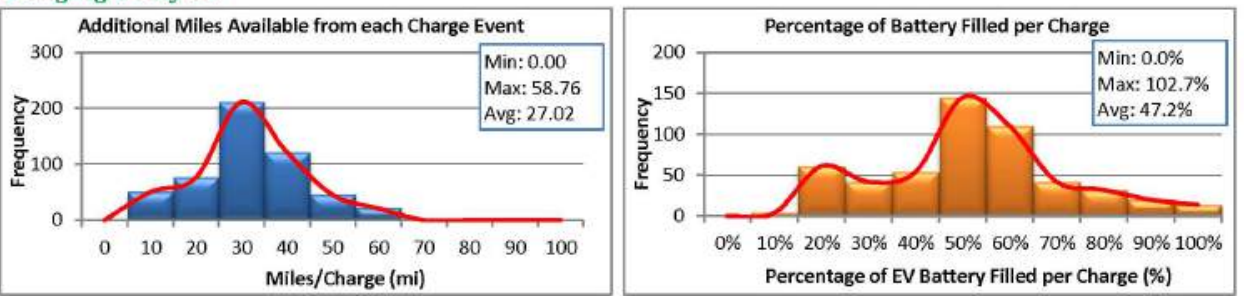

EVSE Analysis
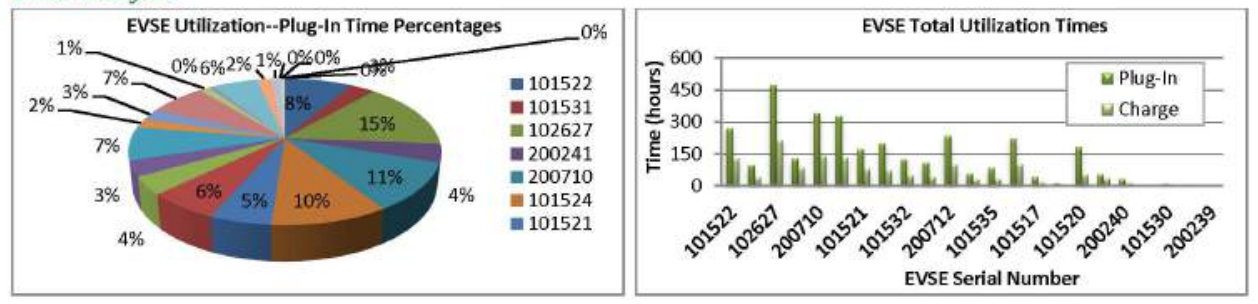

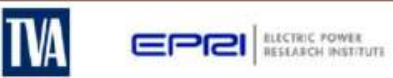

Page 2 


\section{OAK RIDGE NATIONAL LABORATORY}

\begin{tabular}{|c|c|c|c|c|}
\hline \multirow{5}{*}{$\begin{array}{l}\text { Average connection duration (hrs.) } \\
\text { Average charge duration (hrs.) } \\
\text { Average miles per charge } \\
\text { Average } \% \text { of battery filled per }\end{array}$} & Q1 & Q2 & Q3 & Q4 \\
\hline & 9.6 & 8.7 & 6.5 & 6.2 \\
\hline & 2.6 & 2.5 & 2.7 & 2.7 \\
\hline & 50.7 & 25.2 & 27.5 & 27.0 \\
\hline & $88.6 \%$ & $44.0 \%$ & $48.1 \%$ & $47.2 \%$ \\
\hline
\end{tabular}

EVSE Quarterly Load Profile

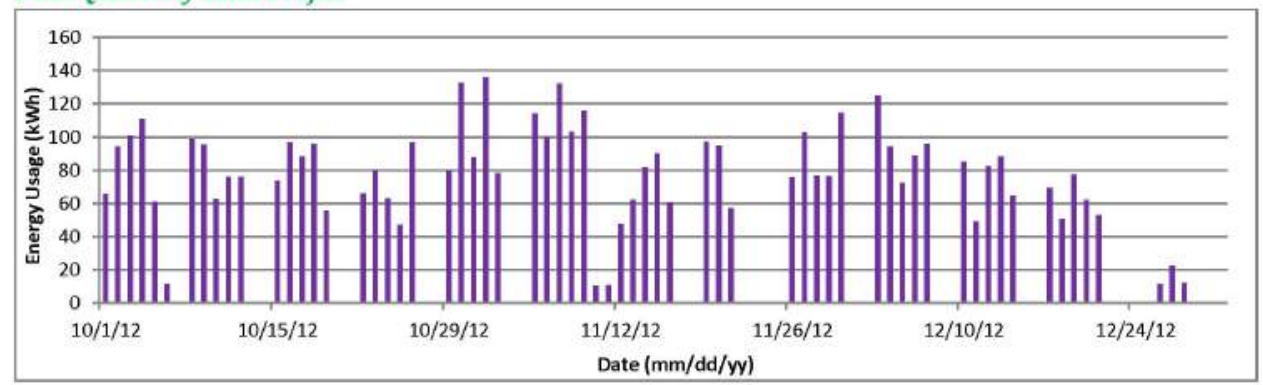

PV Array Quarterly Power Generation Profile

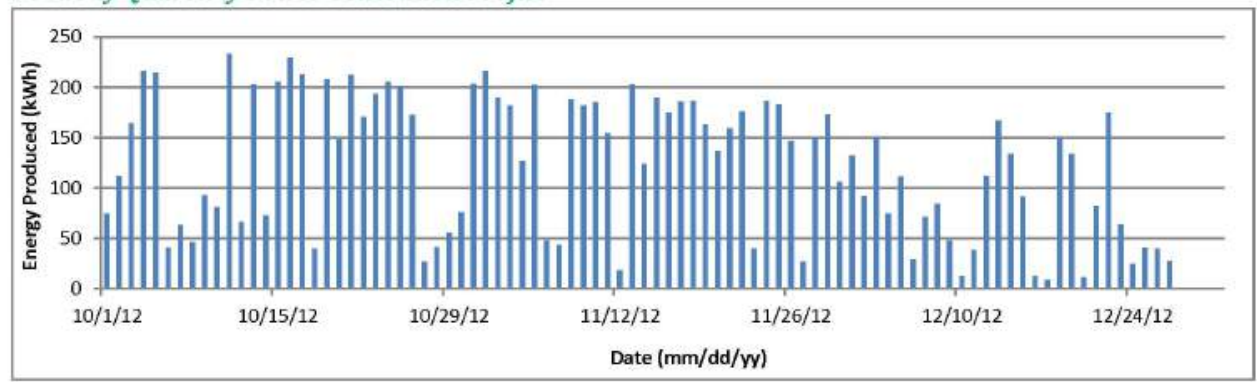

Based on the total energy consumption and an average of miles per $\mathrm{kWh}$ for the Nissan Leaf ( $2.94 \mathrm{mi} / \mathrm{kWh})$ and Chevy Volt $(2.78 \mathrm{mi} / \mathrm{kWh})$.

Values taken from http://www.fueleconomv.gov/.

"Based on energy consumption and size of battery for the Nissan Leaf ( $24 \mathrm{kWh}$ ) and Chevy Volt ( $16 \mathrm{kWh}$ ).

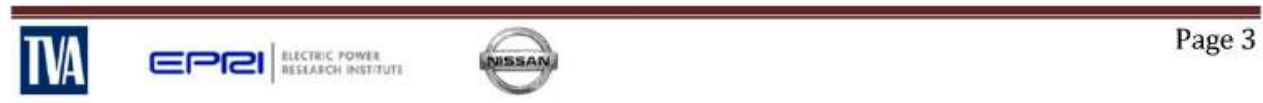




\section{Oak Ridge NaTiOnAL LabORATORY}

EV Project Solar-Assisted Charging Infrastructure Summary Report

EVSE Grouping/Region: ORNL solar-assisted

Report Period: October 1-December 31, 2013 (Quarter 4, 2013)

Number of EV Charging Stations: 25

$\exists \boldsymbol{F}$ Project

\begin{tabular}{|c|c|c|c|c|c|}
\hline Usage Statistics & & Q1 & Q2 & Q3 & Q4 \\
\hline \multirow{3}{*}{$\begin{array}{l}\text { Number of charging events } \\
\text { Percent of time (connected vehicles) } \\
\text { Percent of time (charging vehicles) }\end{array}$} & & 487 & 437 & 336 & 335 \\
\hline & & $5.7 \%$ & $5.4 \%$ & $4.0 \%$ & $4.0 \%$ \\
\hline & & $2.3 \%$ & $1.8 \%$ & $1.3 \%$ & $1.4 \%$ \\
\hline Installation Statistics & Q1 & Q2 & Q3 & Q4 & 2013 Totals \\
\hline \multirow{4}{*}{$\begin{array}{l}\text { Solar-energy generated (MWh) } \\
\text { Energy consumed (MWh) } \\
\text { Net energy generation (MWh) } \\
\text { Total distance traveled }(\mathrm{mi})^{\mathrm{i}}\end{array}$} & 1.36 & 11.77 & 24.21 & 21.55 & 58.89 \\
\hline & 4.21 & 3.20 & 2.41 & 2.57 & 12.39 \\
\hline & -2.85 & 8.57 & 21.80 & 18.98 & 46.5 \\
\hline & 12035 & 9153 & 6888 & 7339 & 35415 \\
\hline
\end{tabular}

Time Series Analysis
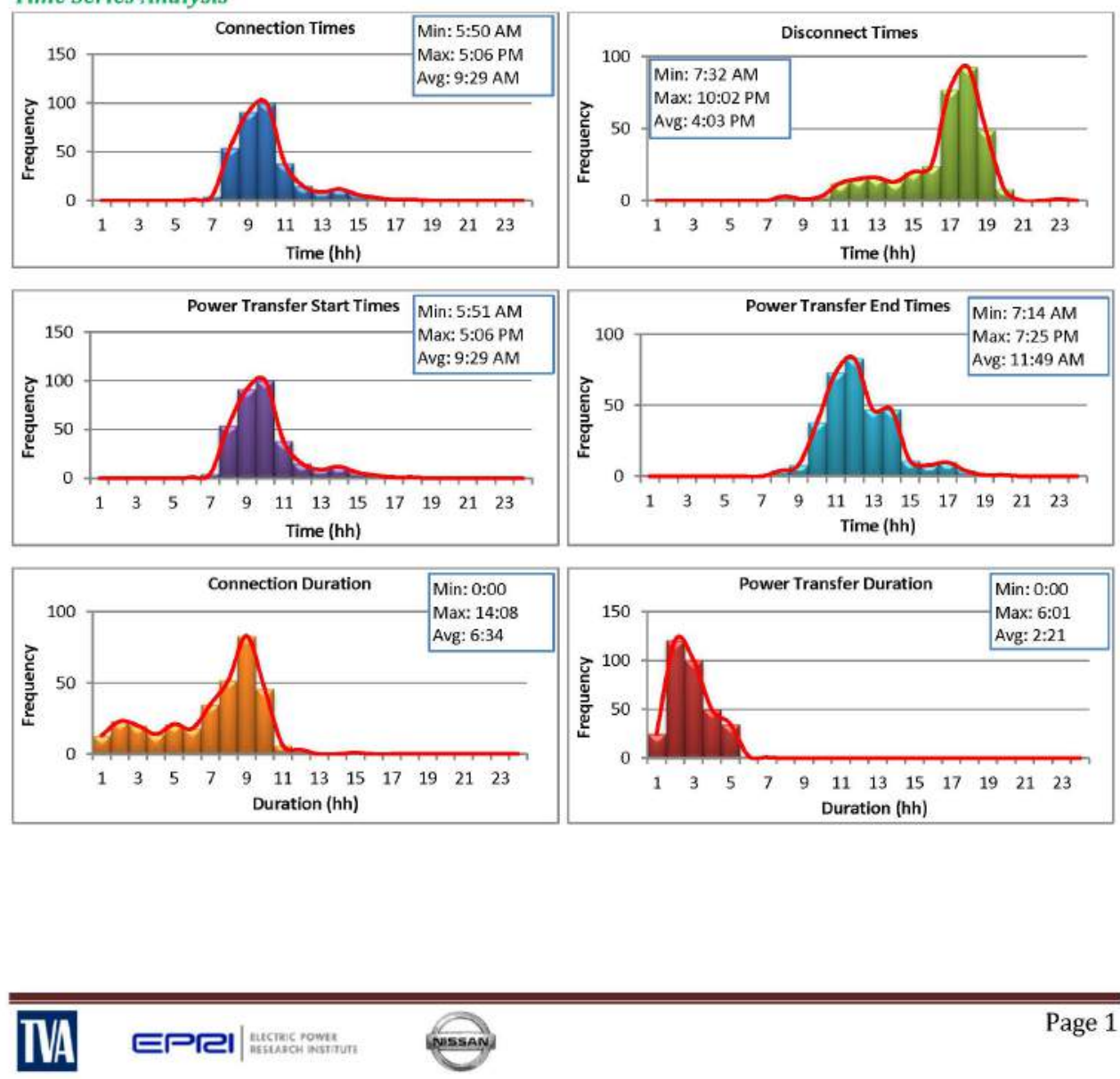


\section{OAK RIDGE NATIONAL LABORATORY}

Energy Consumption Analysis
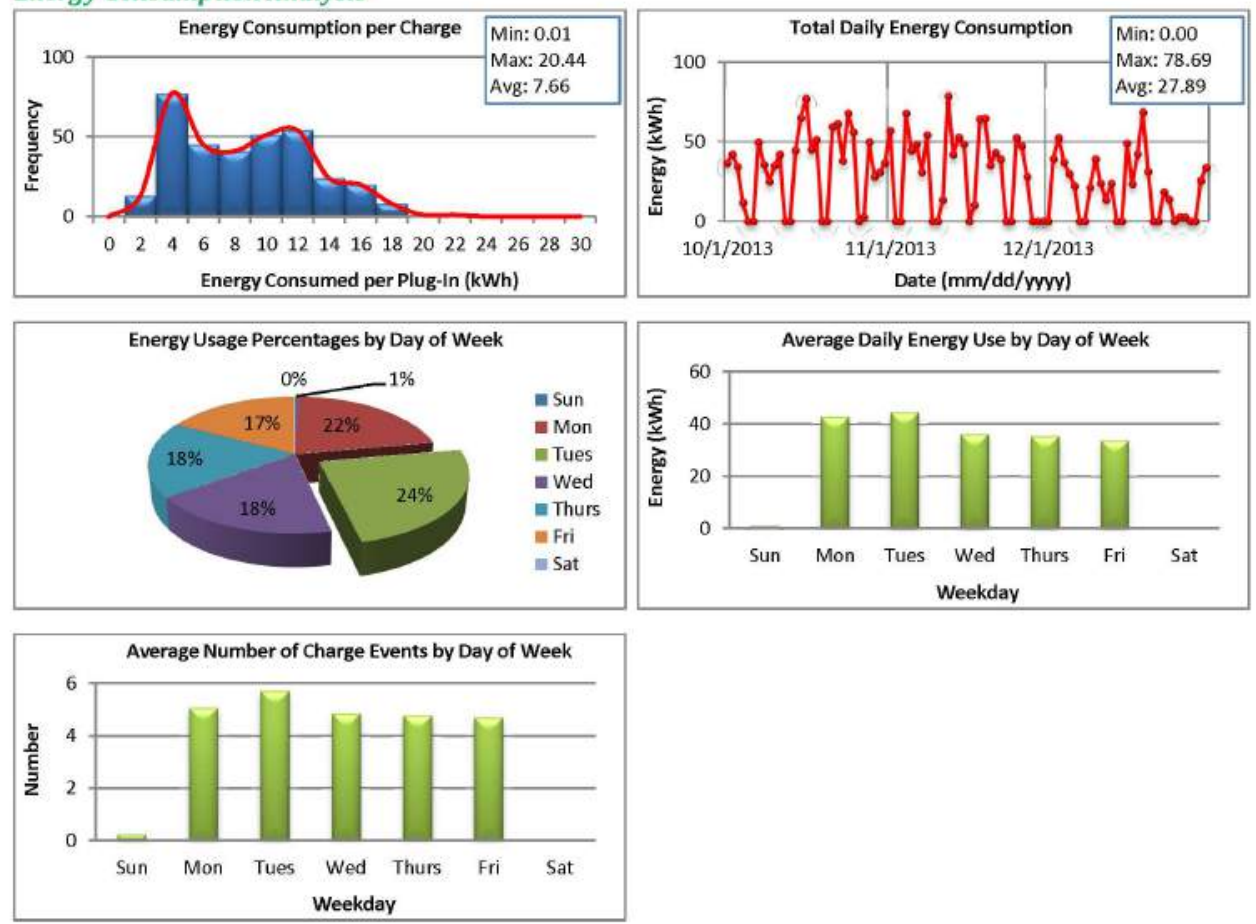

Charging Analysis
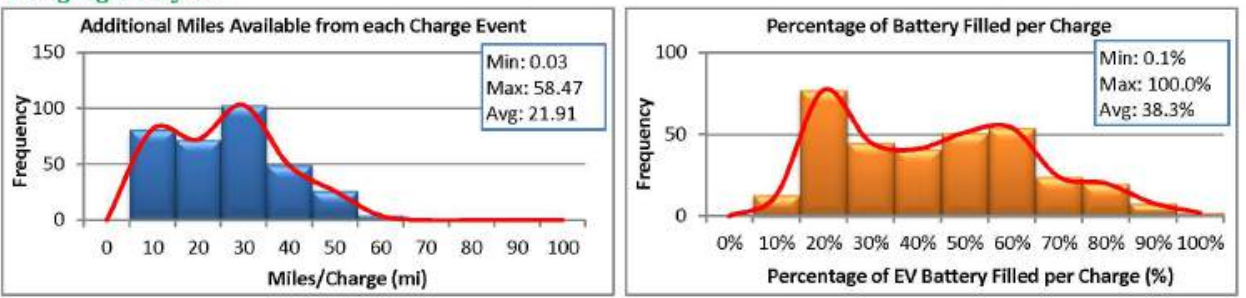

EVSE Analysis

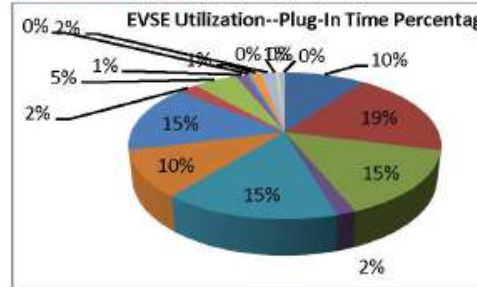

$=200238$
$=102627$
$=200712$
$=101522$
$=200710$
$=101516$
$=101517$
$=101521$
$=101524$
$=101525$

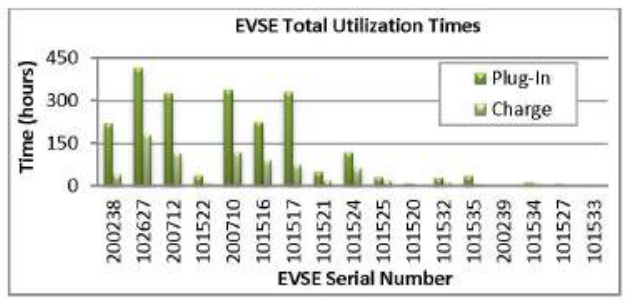

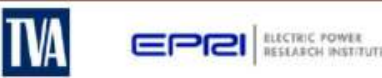

Page 2 


\section{OAK Ridge NATIONAL LABORATORY}

\begin{tabular}{|c|c|c|c|c|}
\hline \multirow{5}{*}{$\begin{array}{l}\text { Average connection duration (hrs.) } \\
\text { Average charge duration (hrs.) } \\
\text { Average miles per charge } \\
\text { Average } \% \text { of battery filled per }\end{array}$} & Q1 & Q2 & Q3 & Q4 \\
\hline & 6.3 & 6.7 & 6.5 & 6.6 \\
\hline & 2.6 & 2.2 & 2.2 & 2.4 \\
\hline & 24.7 & 20.9 & 20.5 & 21.9 \\
\hline & $43.2 \%$ & $36.6 \%$ & $35.8 \%$ & $38.3 \%$ \\
\hline
\end{tabular}

EVSE Quarterly Load Profile

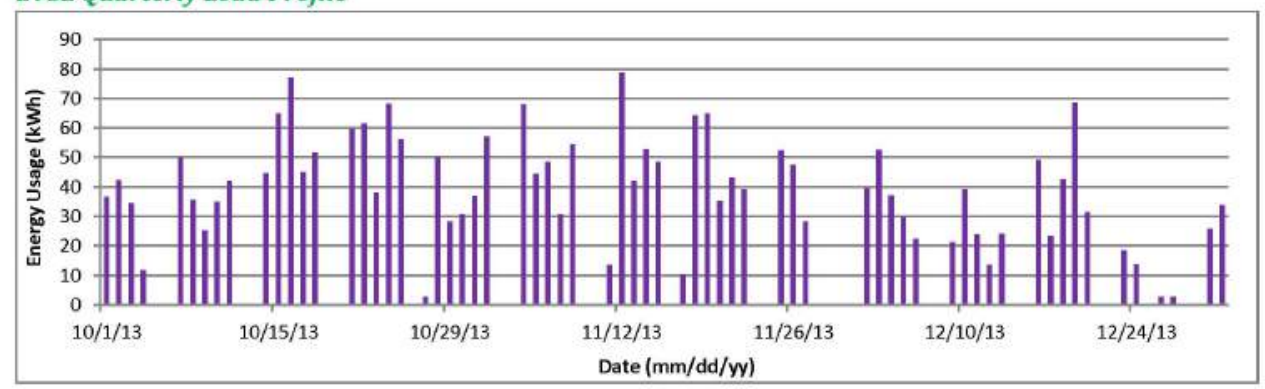

PV Array Quarterly Power Generation Profile

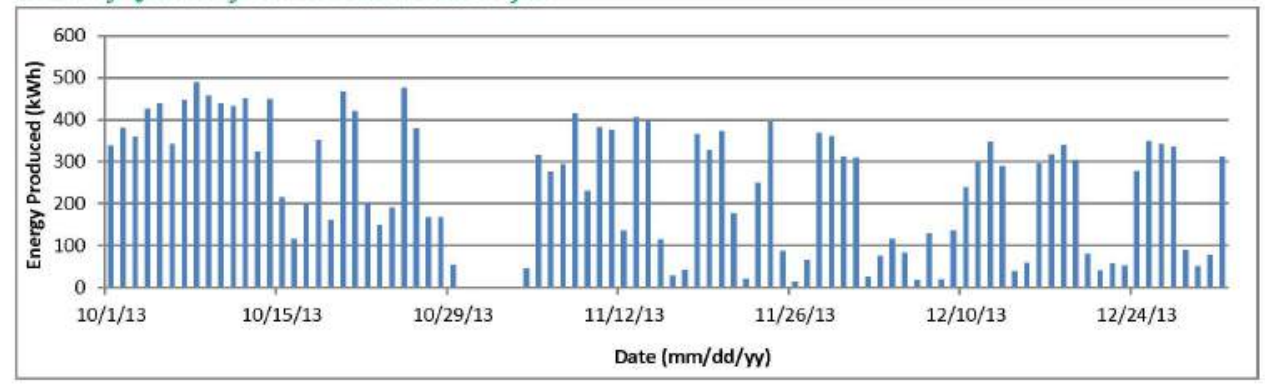

Based on the total energy consumption and an average of miles per $\mathrm{kWh}$ for the Nissan Leaf ( $2.94 \mathrm{mi} / \mathrm{kWh}$ ) and Chevy Volt ( $2.78 \mathrm{mi} / \mathrm{kWh}$ ).

Values taken from http://www.fueleconomv.gov/.

"Based on energy consumption and size of battery for the Nissan Leaf ( $24 \mathrm{kWh}$ ) and Chevy Volt ( $16 \mathrm{kWh}$ ).

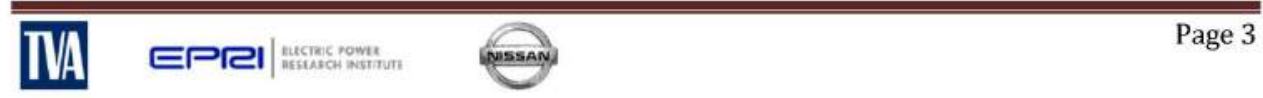




\section{Oak Ridge NaTiOnAL LabORATORY}

EV Project Solar-Assisted Charging Infrastructure Summary Report

EVSE Grouping/Region: ORNL solar-assisted

Report Period: April 1-June 30, 2014 (Quarter 2, 2014)

Number of EV Charging Stations: 25

$\exists \boldsymbol{F}$ Project

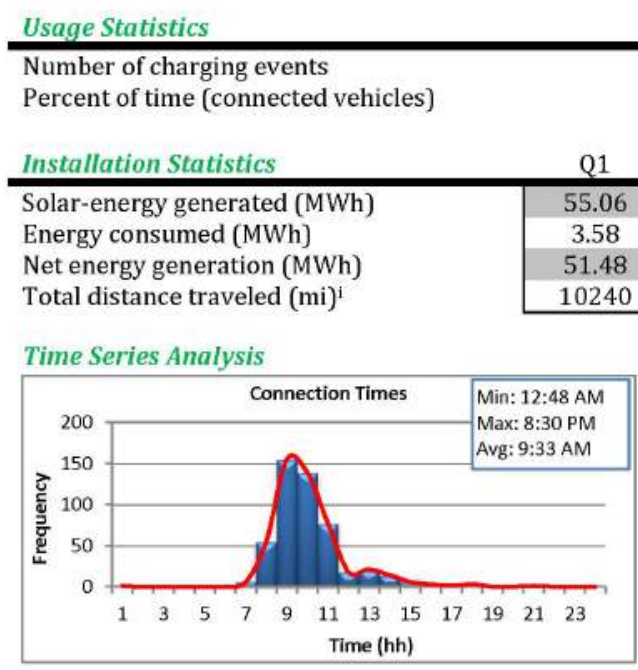

\begin{tabular}{cccc|} 
Q1 & Q2 & Q3 & Q4 \\
\hline 404 & 500 & - & - \\
$5.0 \%$ & $6.5 \%$ & - & - \\
\hline
\end{tabular}

\begin{tabular}{l|ccccc|} 
Installation Statistics & Q1 & Q2 & Q3 & Q4 & 2014 Totals \\
\hline Solar-energy generated (MWh) & 55.06 & 43.93 & - & - & 98.99 \\
Energy consumed (MWh) & 3.58 & 4.08 & - & - & 7.66 \\
Net energy generation (MWh) & 51.48 & 39.86 & - & - & 91.34 \\
Total distance traveled (mi) & 10240 & 11656 & - & - & 21896 \\
\hline
\end{tabular}

Time Series Analysis
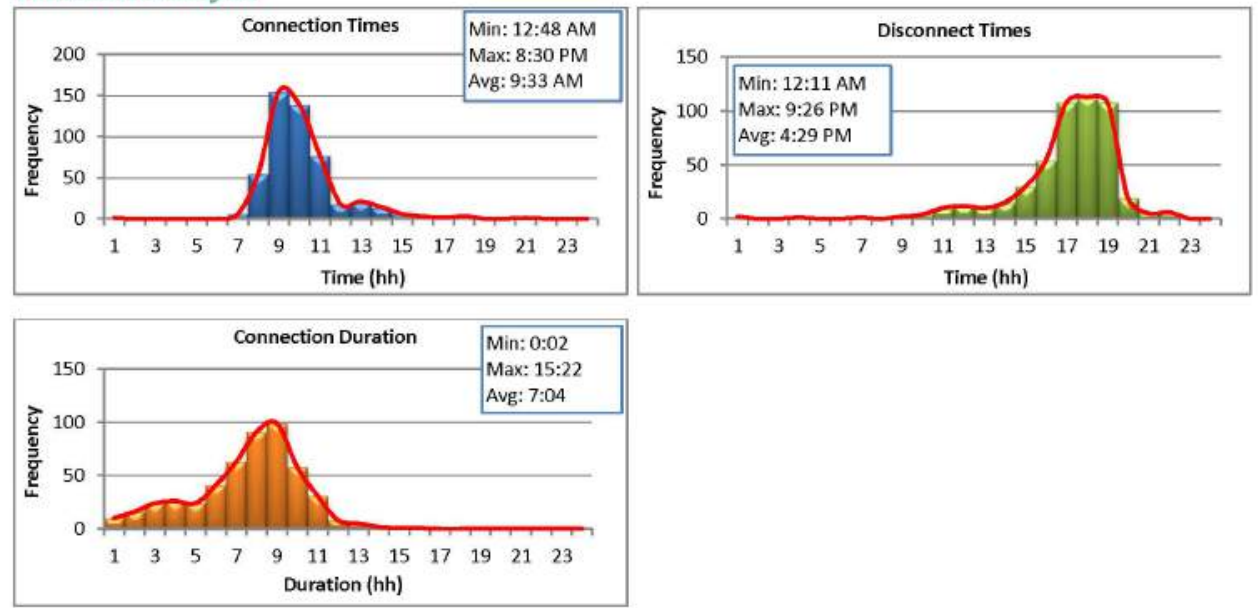

Page 1

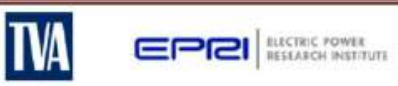




\section{OAK RIDGE NATIONAL LABORATORY}

Energy Consumption Analysis
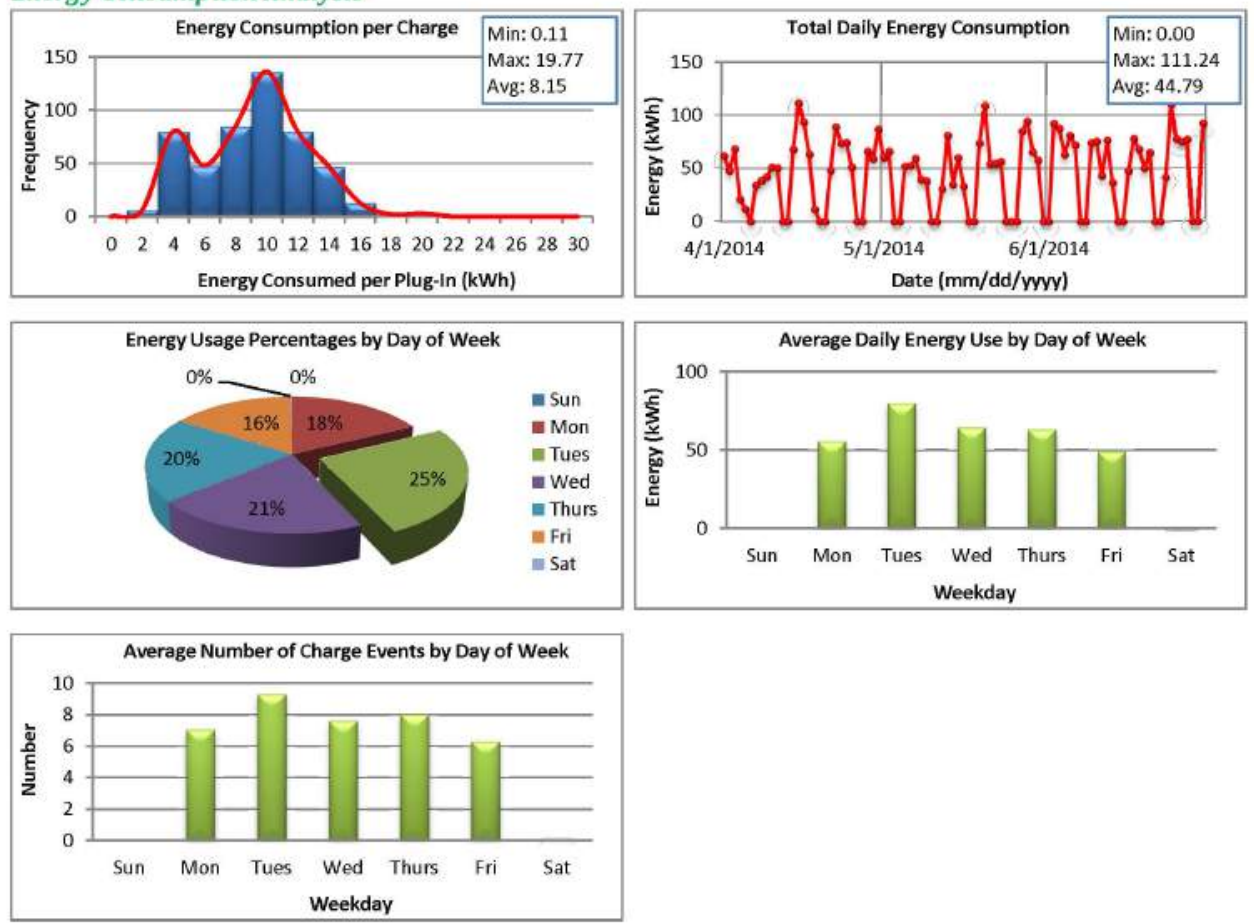

Charging Analysis
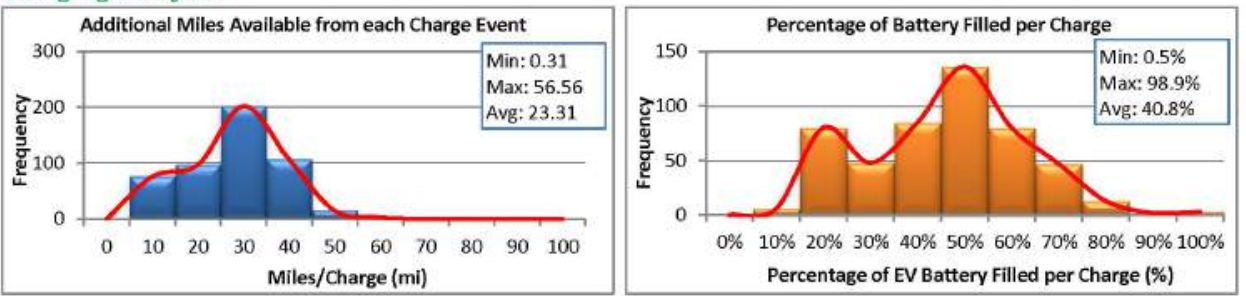

EVSE Analysis
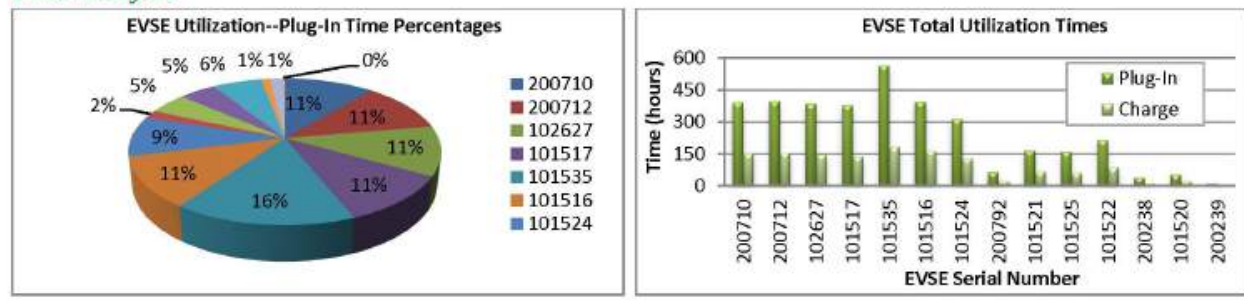

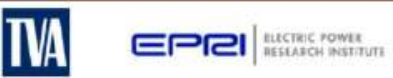

Page 2 


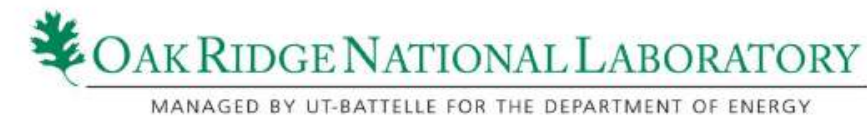

\begin{tabular}{|c|c|c|c|c|}
\hline Report Period Summary & Q1 & Q2 & Q3 & Q4 \\
\hline Average connection duration (hrs.) & 6.6 & 7.1 & - & - \\
\hline Average miles per charge ${ }^{i}$ & 25.3 & 23.3 & - & - \\
\hline $\begin{array}{l}\text { Average } \% \text { of battery filled per } \\
\text { charge event } \|\end{array}$ & $44.3 \%$ & $40.8 \%$ & - & - \\
\hline
\end{tabular}

EVSE Quarterly Load Profile

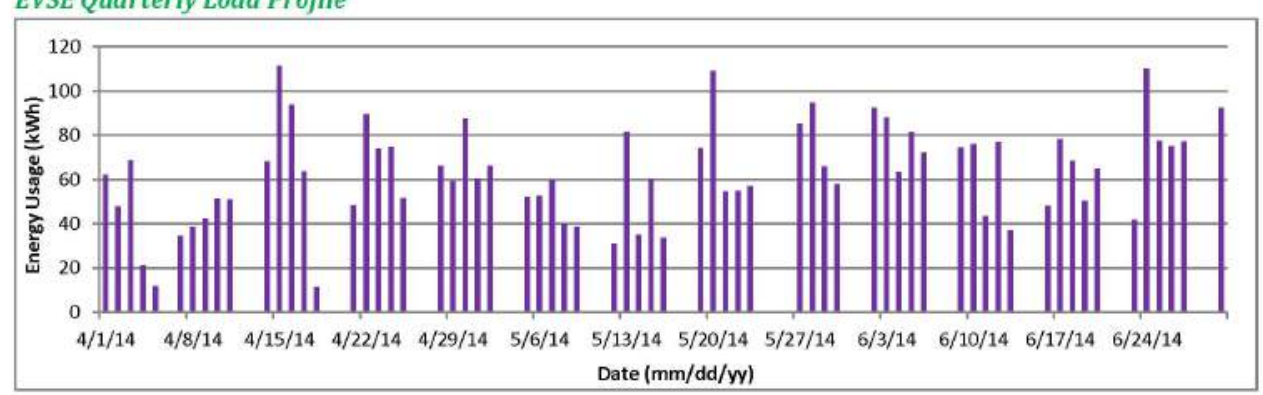

PV Array Quarterly Power Generation Profile

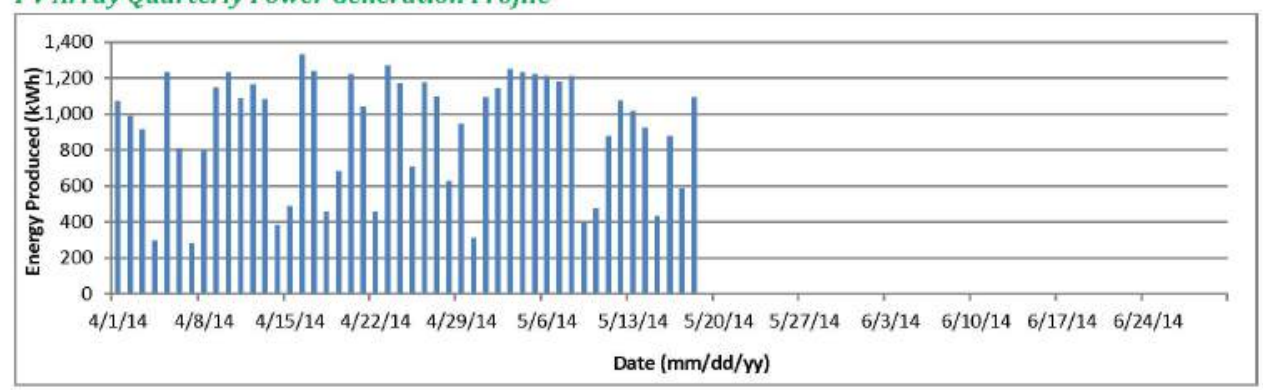

Based on the total energy consumption and an average of miles per $\mathrm{kWh}$ for the Nissan Leaf ( $2.94 \mathrm{mi} / \mathrm{kWh}$ ) and Chevy Volt ( $2.78 \mathrm{mi} / \mathrm{kWh}$ ).

Values taken from http://www.fueleconomy.gov/.

"Based on energy consumption and size of battery for the Nissan Leaf ( $24 \mathrm{kWh}$ ) and Chevy Volt (16 kWh).

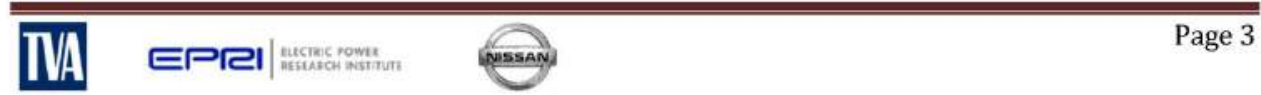




\section{A.2 ORNL Non-Solar Installations}

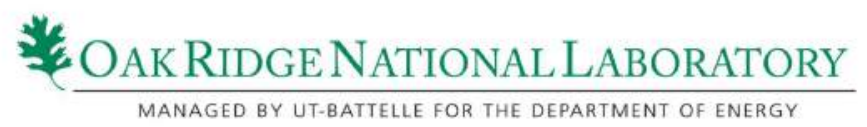

EV Project Solar-Assisted Charging Infrastructure Summary Report

EVSE Grouping/Region: ORNL non-solar

Report Period: October 1-December 31, 2012 (Quarter 4, 2012)

Number of EV Charging Stations: 19

$\exists \boldsymbol{A} /$ Project
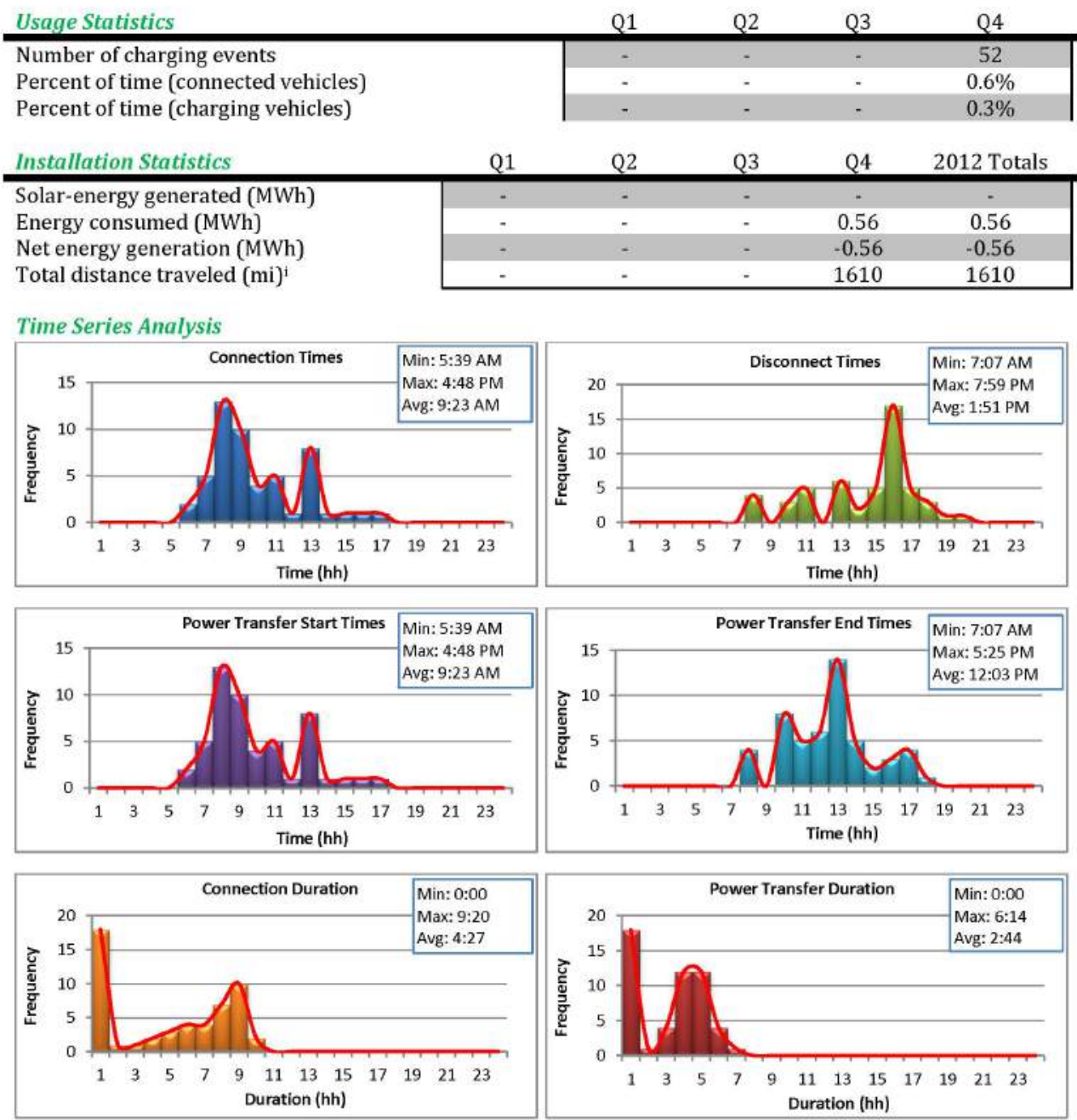

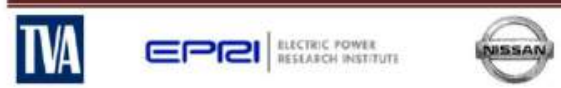

Page 1 


\section{OAK RIDGE NATIONAL LABORATORY}

Energy Consumption Analysis
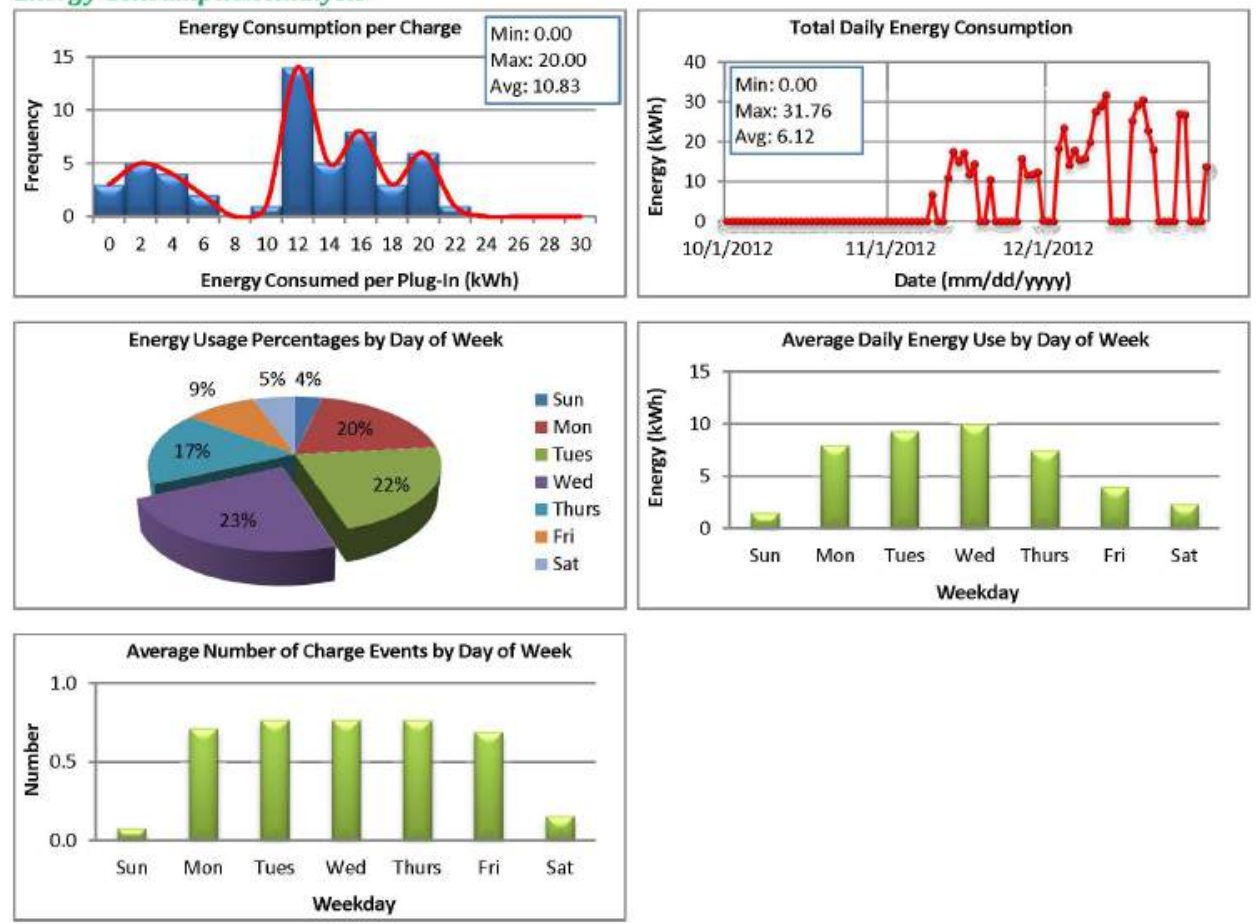

Charging Analysis
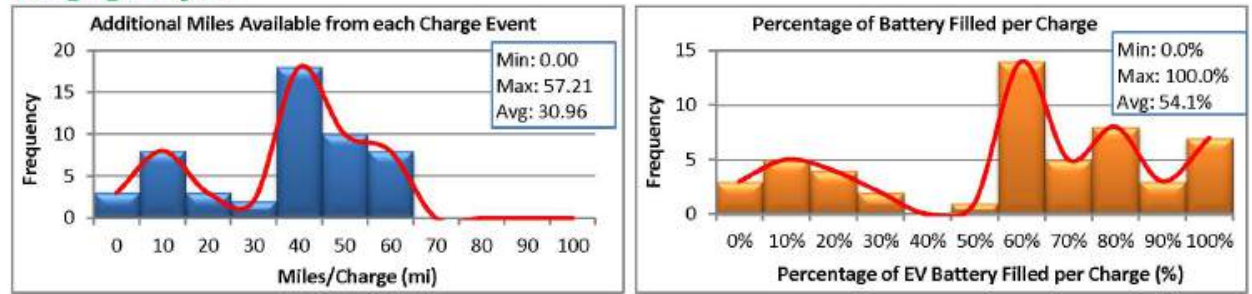

EVSE Analysis

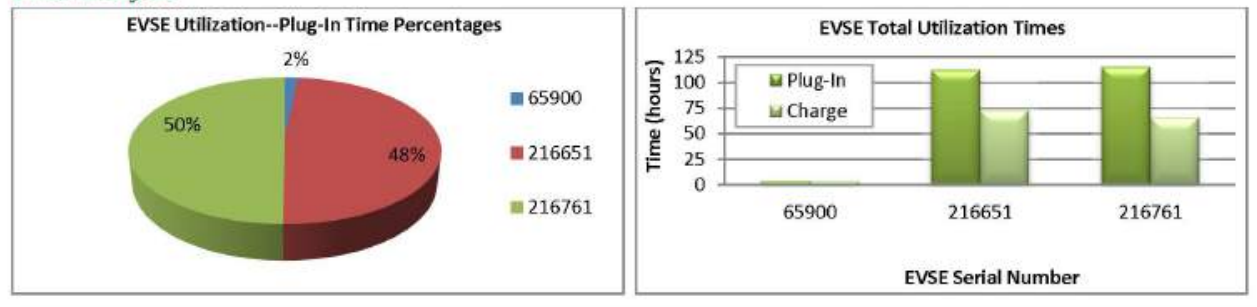

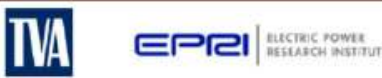

Page 2 


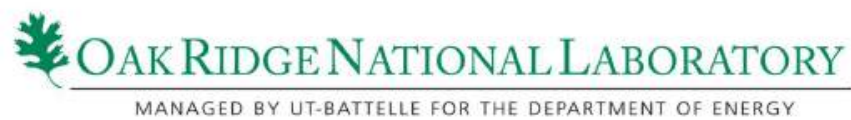

\begin{tabular}{|c|c|c|c|c|}
\hline Report Period Summary & Q1 & Q2 & Q3 & Q4 \\
\hline Average connection duration (hrs.) & - & - & - & 4.5 \\
\hline Average charge duration (hrs.) & - & - & - & 2.7 \\
\hline Average miles per charge & - & - & - & 31.0 \\
\hline $\begin{array}{l}\text { Average } \% \text { of battery filled per } \\
\text { charge event } t^{\mathrm{ii}}\end{array}$ & - & - & - & $54.1 \%$ \\
\hline
\end{tabular}

EVSE Quarterly Load Profile

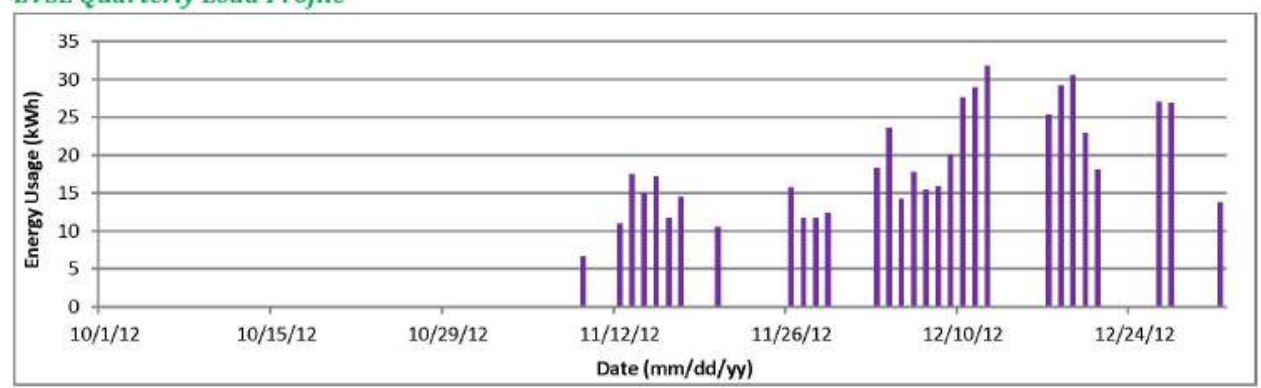

Based on the total energy consumption and an average of miles per $\mathrm{kWh}$ for the Nissan Leaf $(2.94 \mathrm{mi} / \mathrm{kWh})$ and Chevy Volt $(2.78 \mathrm{mi} / \mathrm{kWh})$ Values taken from http://www.fueleconomy.gov/.

Based on energy consumption and size of battery for the Nissan Leaf ( $24 \mathrm{kWh}$ ) and Chevy Volt ( $16 \mathrm{kWh}$ ).

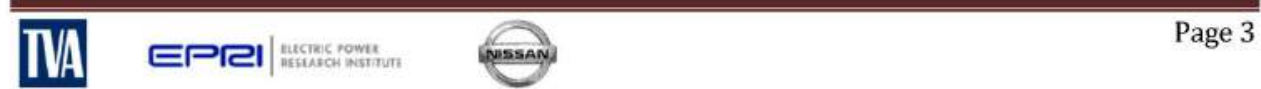




\section{Oak Ridge NaTiOnAL LabORATORY}

EV Project Solar-Assisted Charging Infrastructure Summary Report

EVSE Grouping/Region: ORNL non-solar

Report Period: October 1-December 31, 2013 (Quarter 4, 2013)

Number of EV Charging Stations: 19

F/y Project

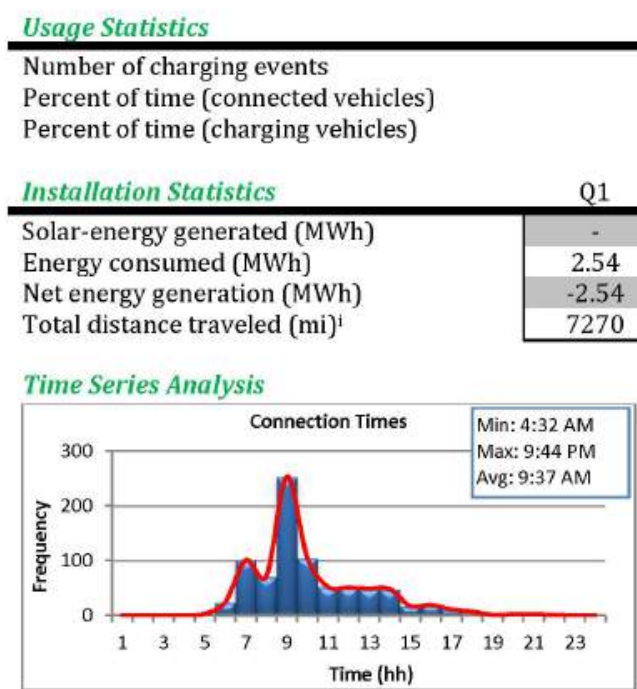

\begin{tabular}{cccc|} 
Q1 & Q2 & Q3 & Q4 \\
\hline 259 & 635 & 791 & 817 \\
$3.0 \%$ & $7.8 \%$ & $10.7 \%$ & $11.6 \%$ \\
$1.7 \%$ & $4.2 \%$ & $5.3 \%$ & $5.6 \%$
\end{tabular}
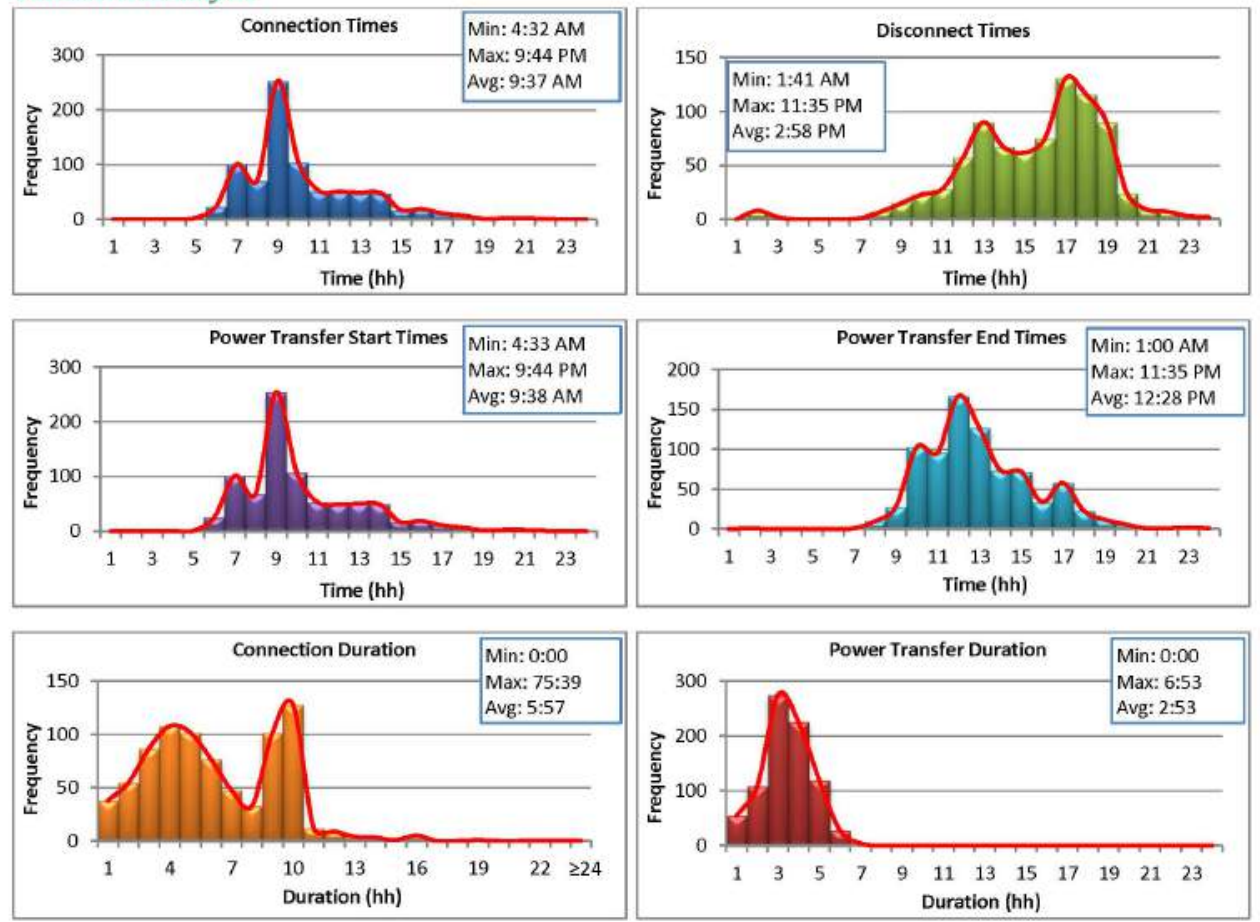

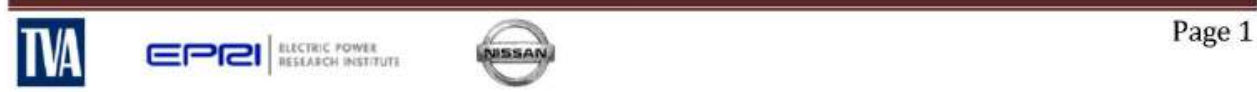




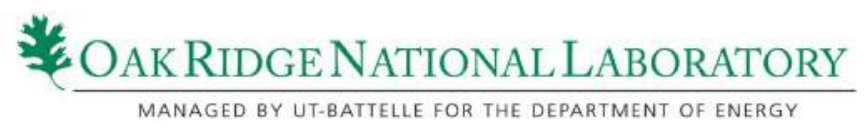

Energy Consumption Analysis
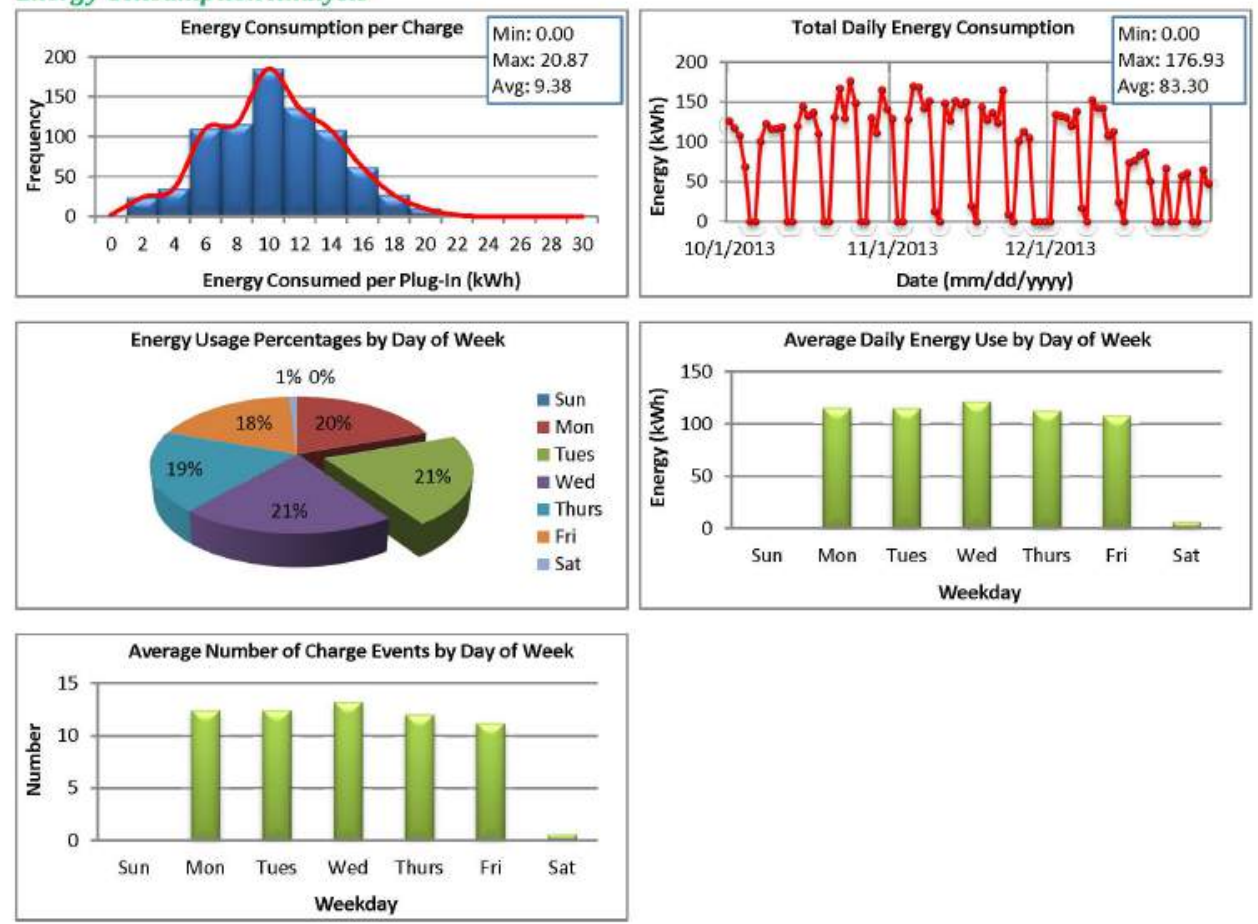

Charging Analysis
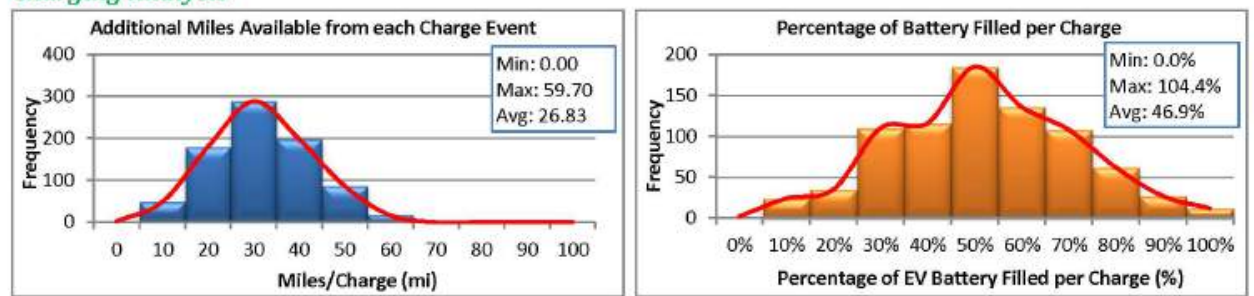

EVSE Analysis
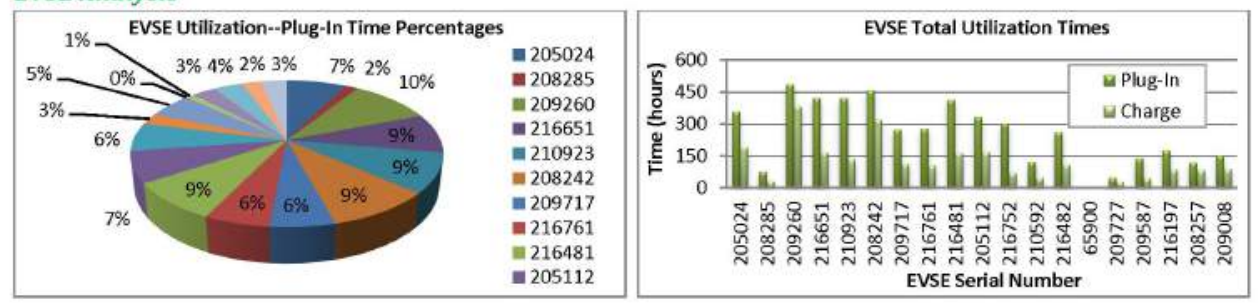

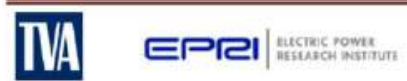

Page 2 


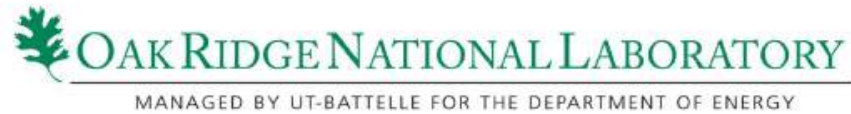

\begin{tabular}{|c|c|c|c|c|}
\hline Report Period Summary & Q1 & Q2 & Q3 & Q4 \\
\hline Average connection duration (hrs.) & 4.7 & 5.1 & 5.7 & 6.0 \\
\hline Average charge duration (hrs.) & 2.7 & 2.7 & 2.8 & 2.9 \\
\hline Average miles per charge & 28.1 & 26.5 & 26.1 & 26.8 \\
\hline $\begin{array}{l}\text { Average } \% \text { of battery filled per } \\
\text { charge event } t^{\mathrm{ii}}\end{array}$ & $49.1 \%$ & $46.3 \%$ & $45.7 \%$ & $46.9 \%$ \\
\hline
\end{tabular}

EVSE Quarterly Load Profile

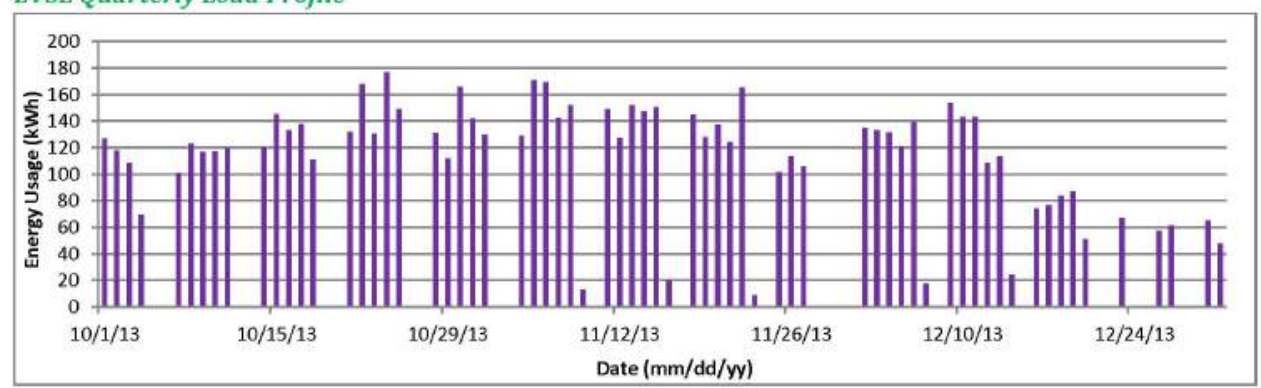

Based on the total energy consumption and an average of miles per $\mathrm{kWh}$ for the Nissan Leaf $(2.94 \mathrm{mi} / \mathrm{kWh})$ and Chevy Volt $(2.78 \mathrm{mi} / \mathrm{kWh})$ Values taken from http://www.fueleconomy.gov/.

Based on energy consumption and size of battery for the Nissan Leaf ( $24 \mathrm{kWh}$ ) and Chevy Volt ( $16 \mathrm{kWh})$.

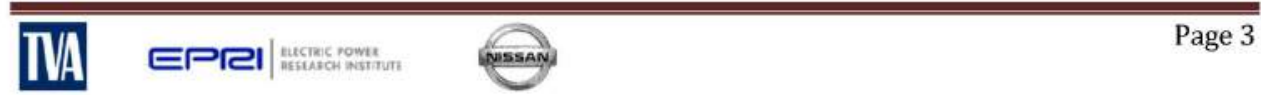




\section{Oak Ridge NaTiOnAL LabORATORY}

EV Project Solar-Assisted Charging Infrastructure Summary Report

EVSE Grouping/Region: ORNL non-solar

Report Period: April 1-June 30, 2014 (Quarter 2, 2014)

Number of EV Charging Stations: 19

$\exists \boldsymbol{F}$ Project

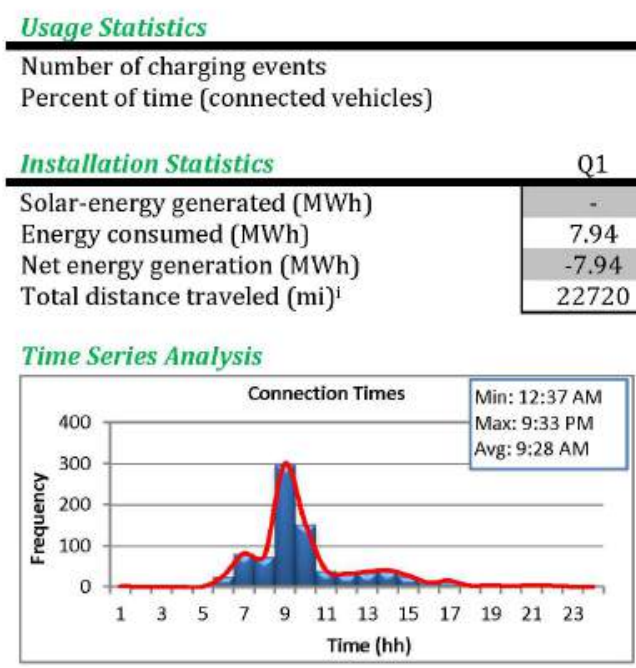

\begin{tabular}{cccc|} 
Q1 & Q2 & Q3 & Q4 \\
\hline 866 & 845 & - & - \\
$13.4 \%$ & $13.2 \%$ & - & - \\
\hline
\end{tabular}

Installation Statistics

Q1 Q2

Q2 Q3

3 Q4 2014 Totals

Energy consumed (MWh

Net energy generation (MWh)

$7.94 \quad 7.16$

$\begin{array}{llll}7.16 & - & - & 15.1\end{array}$

20485

$\begin{array}{rrr}- & - & 15.1 \\ - & - & -15.1\end{array}$

- $\quad 43205$

Time Series Analysis
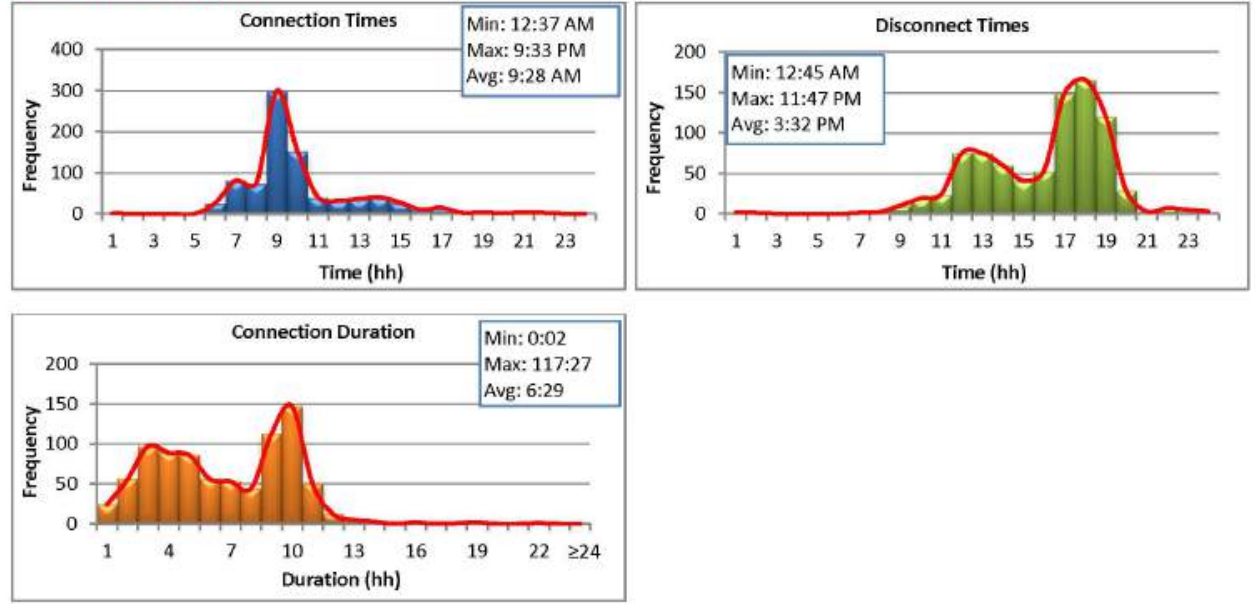


\section{OAK RIDGE NATIONAL LABORATORY}

Energy Consumption Analysis
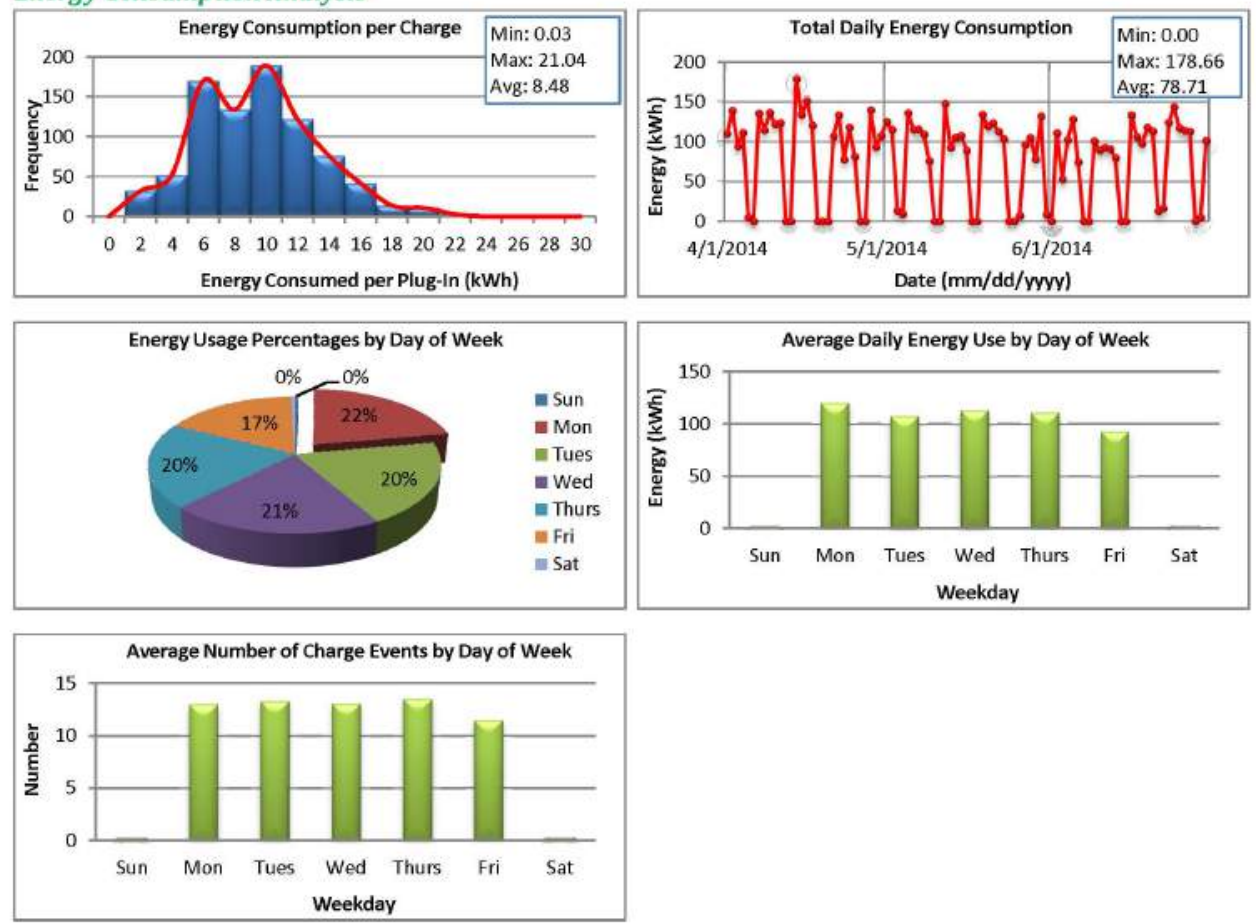

Charging Analysis
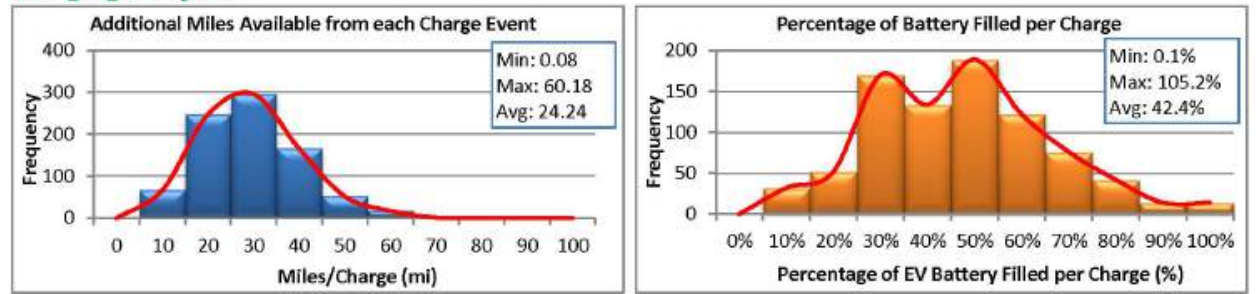

EVSE Analysis
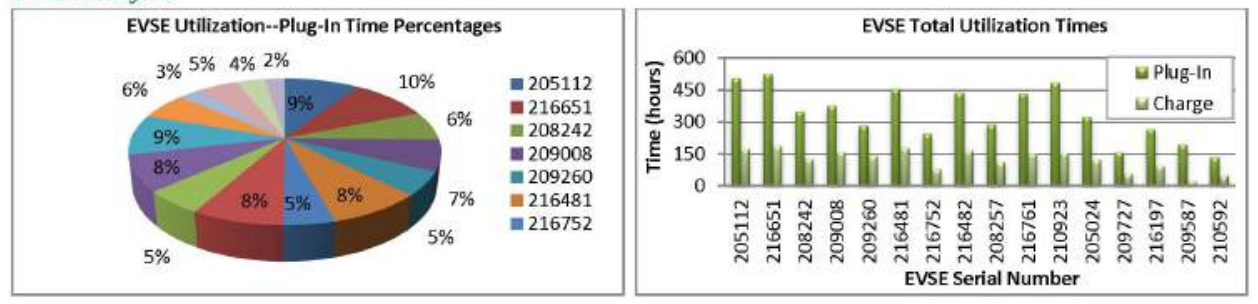

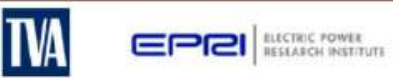

Page 2 


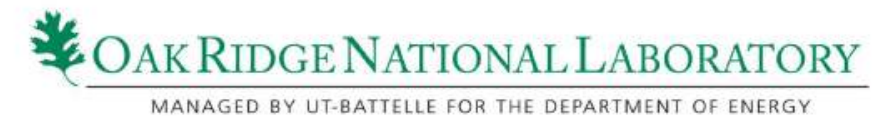

\begin{tabular}{l|cccc} 
Report Period Summary & Q1 & Q2 & Q3 & Q4 \\
\hline $\begin{array}{l}\text { Average connection duration (hrs.) } \\
\text { Average miles per charge }\end{array}$ & 6.3 & 6.5 & - & - \\
$\begin{array}{l}\text { Average \% of battery filled per } \\
\quad \text { charge event }\end{array}$ & 26.2 & $45.9 \%$ & $42.4 \%$ & -
\end{tabular}

EVSE Quarterly Load Profile

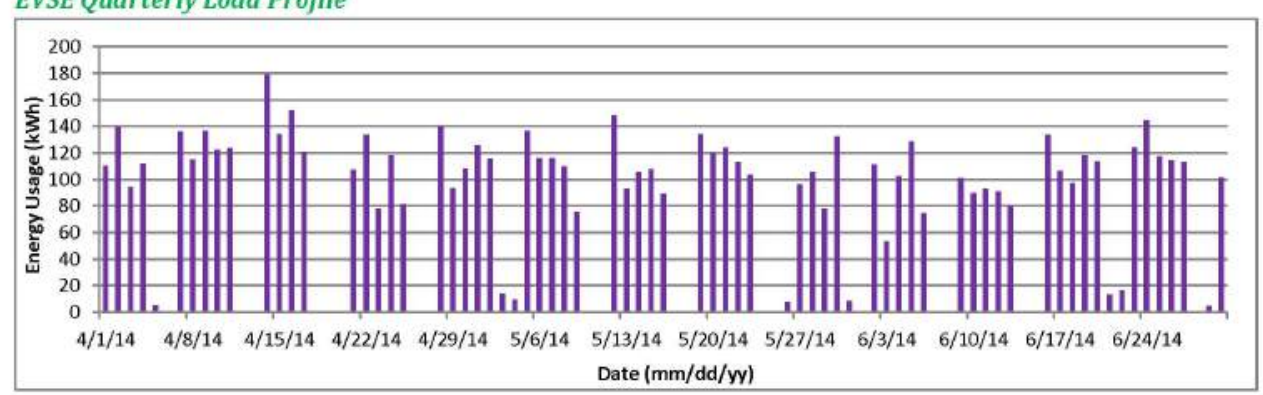

Based on the total energy consumption and an average of miles per $\mathrm{kWh}$ for the Nissan Leaf ( $2.94 \mathrm{mi} / \mathrm{kWh}$ ) and Chevy Volt ( $2.78 \mathrm{mi} / \mathrm{kWh}$ ). Values taken from http://www.fueleconomy.Rov/.

"Based on energy consumption and size of battery for the Nissan Leaf ( $24 \mathrm{kWh}$ ) and Chevy Volt (16 kWh).

D/A El| Page 3




\section{A.3 Knoxville Market Square Parking Garage}

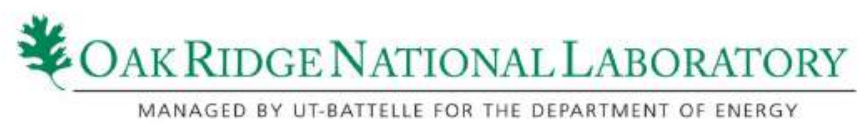

EV Project Solar-Assisted Charging Infrastructure Summary Report

EVSE Grouping/Region: Knoxville Market Square

Report Period: October 1-December 31, 2012 (Quarter 4, 2012

Number of EV Charging Stations: 4

$\exists \boldsymbol{A} /$ Project
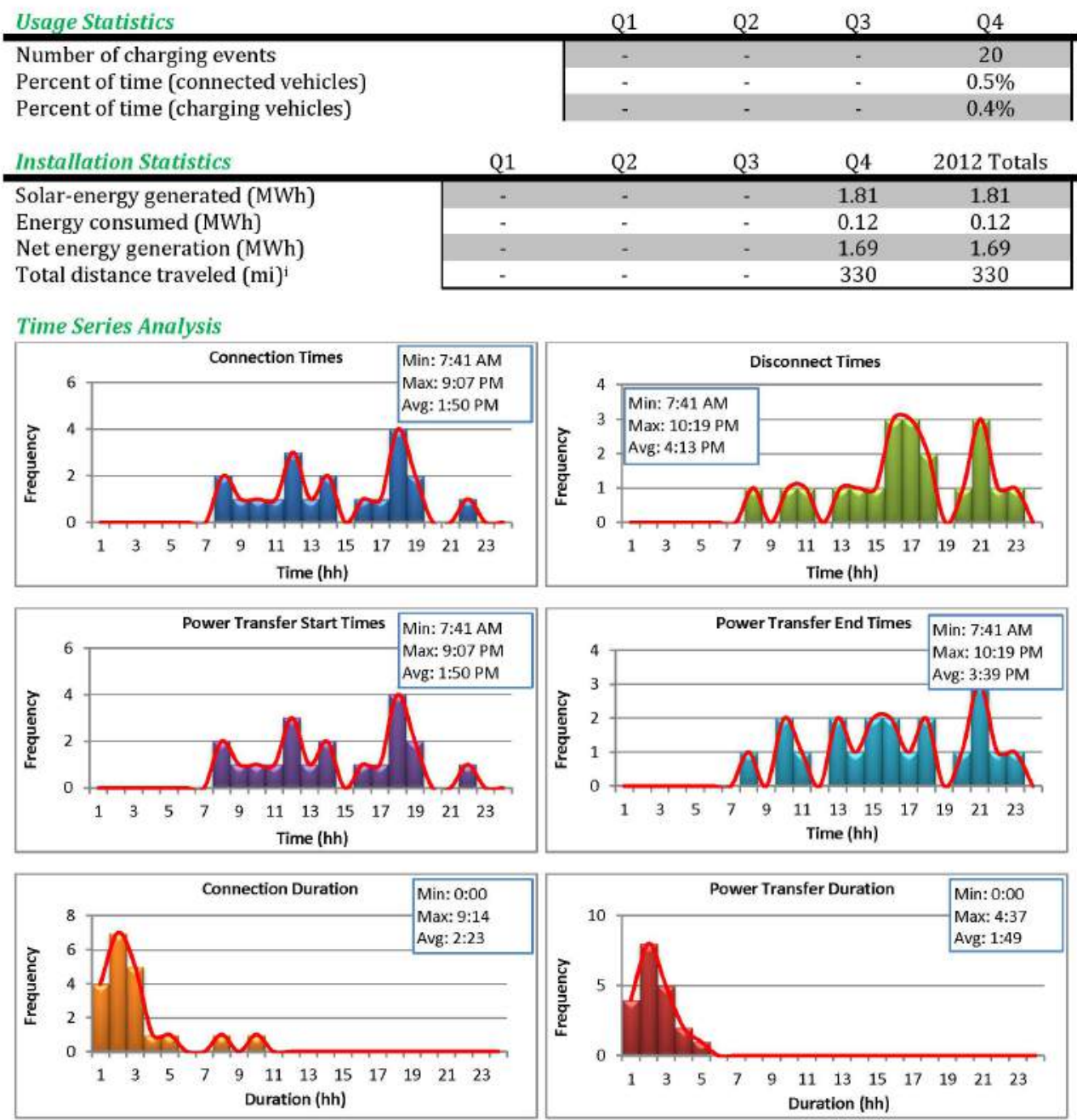

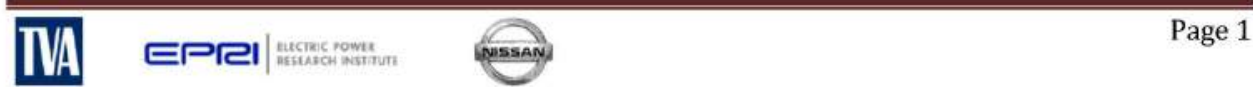




\section{OAK RIDGE NATIONAL LABORATORY}

Energy Consumption Analysis
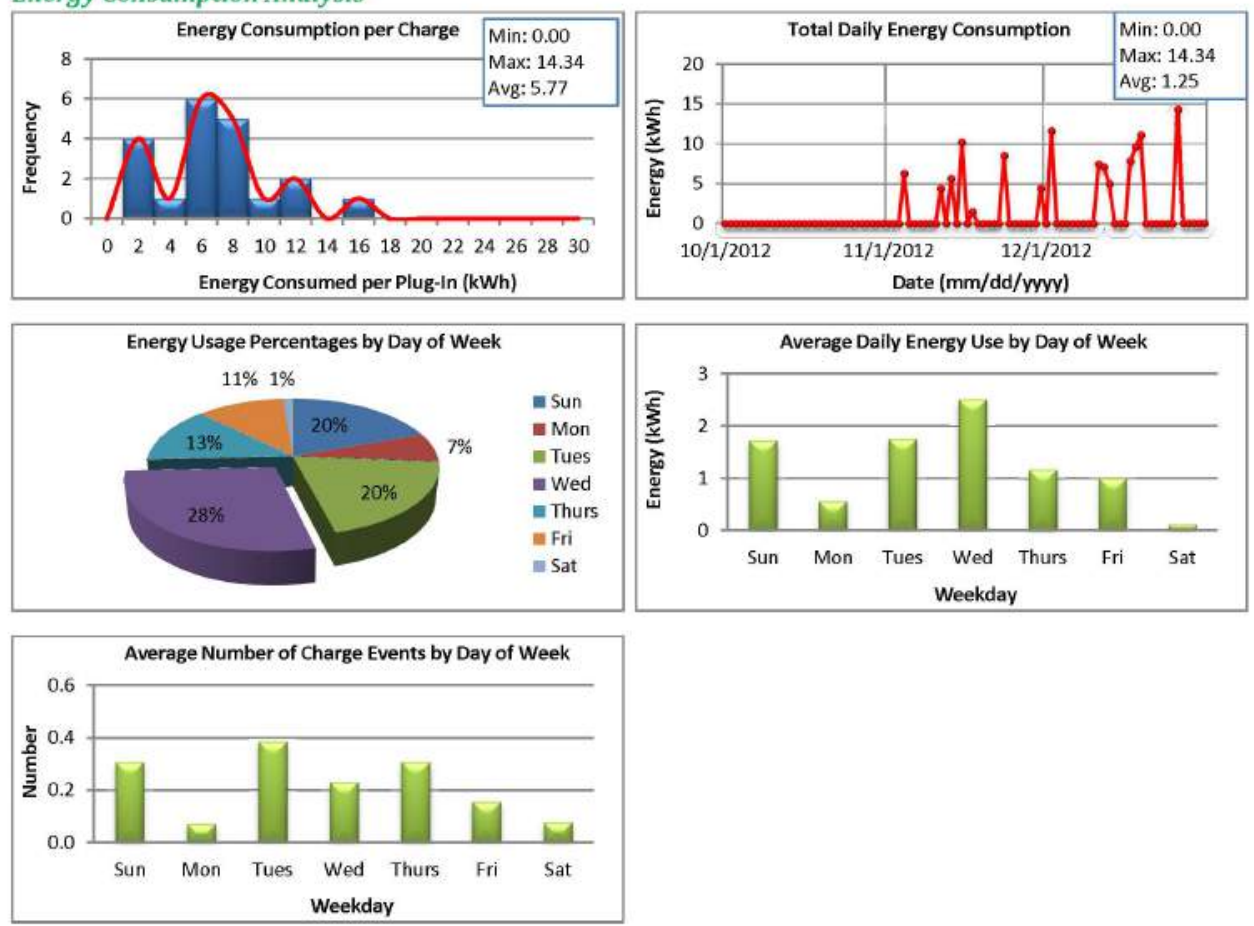

Charging Analysis
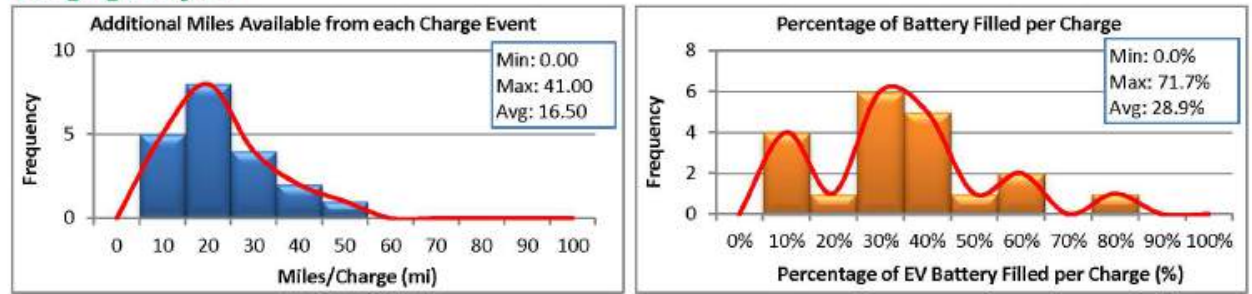

EVSE Analysís
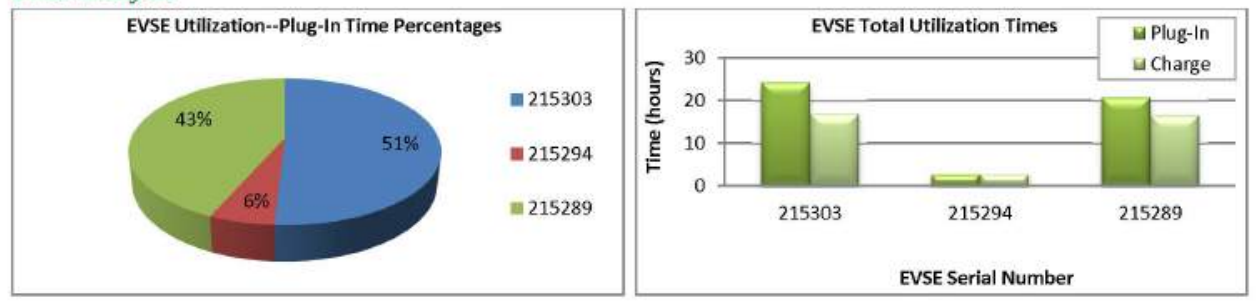

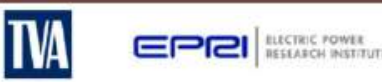

Page 2 


\section{OAK RIDGE NATIONAL LABORATORY}

\begin{tabular}{|c|c|c|c|c|}
\hline Report Period Summary & Q1 & Q2 & Q3 & Q4 \\
\hline Average connection duration (hrs.) & - & - & - & 2.4 \\
\hline Average charge duration (hrs.) & - & - & - & 1.8 \\
\hline Average miles per charge & - & - & - & 16.5 \\
\hline $\begin{array}{l}\text { Average } \% \text { of battery filled per } \\
\text { charge event } t^{\mathrm{ii}}\end{array}$ & - & - & - & $28.9 \%$ \\
\hline
\end{tabular}

\section{EVSE Quarterly Load Profile}

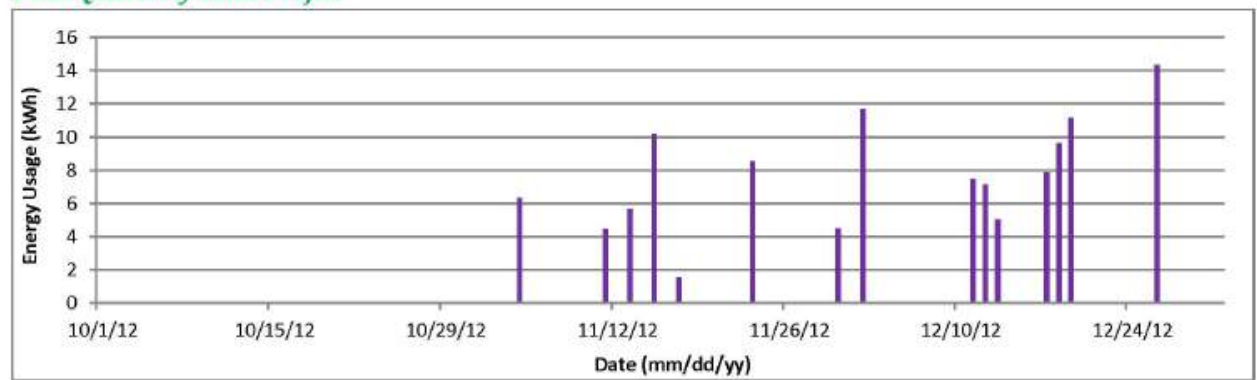

PV Array Quarterly Power Generation Profile

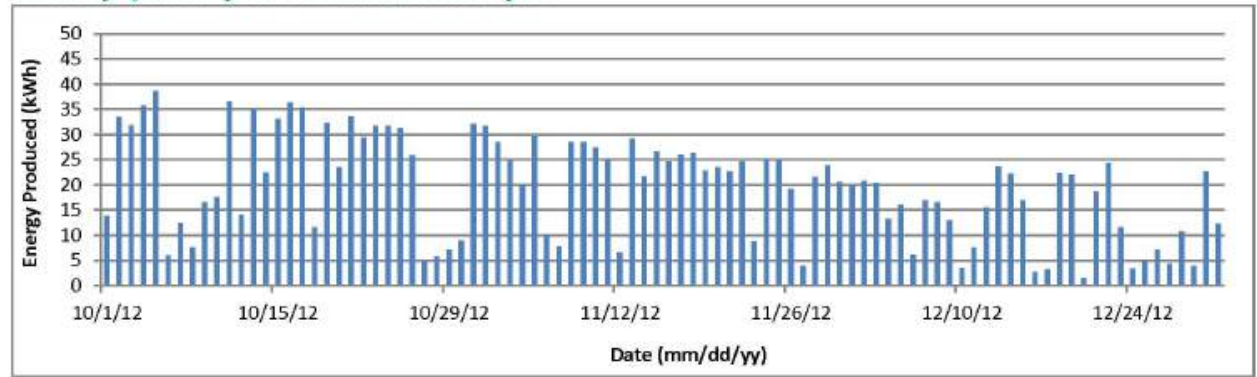

Based on the total energy consumption and an average of miles per $\mathrm{kWh}$ for the Nissan Leaf ( $2.94 \mathrm{mi} / \mathrm{kWh})$ and Chevy Volt $(2.78 \mathrm{mi} / \mathrm{kWh})$

Values taken from http://www.fueleconomv.gov/.

Based on energy consumption and size of battery for the Nissan Leaf ( $24 \mathrm{kWh}$ ) and Chevy Volt ( $16 \mathrm{kWh}$ ).

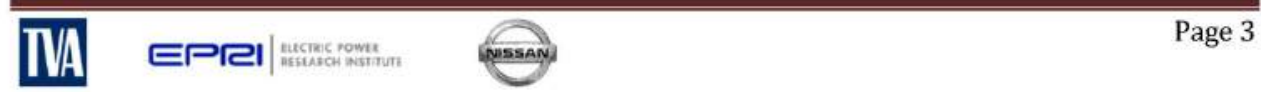




\section{Oak Ridge NaTiOnAL LabORATORY}

EV Project Solar-Assisted Charging Infrastructure Summary Report

EVSE Grouping/Region: Knoxville Market Square

Report Period: October 1-December 31, 2013 (Quarter 4, 2013)

Number of EV Charging Stations: 4

F/y Project

\begin{tabular}{|c|c|c|c|c|c|}
\hline \multicolumn{2}{|l|}{ Usage Statistics } & Q1 & Q2 & Q3 & Q4 \\
\hline \multirow{3}{*}{\multicolumn{2}{|c|}{$\begin{array}{l}\text { Number of charging events } \\
\text { Percent of time (connected vehicles) } \\
\text { Percent of time (charging vehicles) }\end{array}$}} & 30 & 112 & 221 & 222 \\
\hline & & $0.9 \%$ & $4.9 \%$ & $10.1 \%$ & $15.9 \%$ \\
\hline & & $0.6 \%$ & $2.1 \%$ & $4.8 \%$ & $5.1 \%$ \\
\hline Installation Statistics & Q1 & Q2 & Q3 & Q4 & 2013 Totals \\
\hline \multirow{4}{*}{$\begin{array}{l}\text { Solar-energy generated (MWh) } \\
\text { Energy consumed (MWh) } \\
\text { Net energy generation }(\mathrm{MWh}) \\
\text { Total distance traveled }(\mathrm{mi})^{\mathrm{i}}\end{array}$} & 1.90 & 3.76 & 3.24 & 1.80 & 10.7 \\
\hline & 0.19 & 0.61 & 1.43 & 1.49 & 3.72 \\
\hline & 1.71 & 3.15 & 1.82 & 0.31 & 6.99 \\
\hline & 550 & 1742 & 4085 & 4253 & 10630 \\
\hline
\end{tabular}

Time Series Analysis
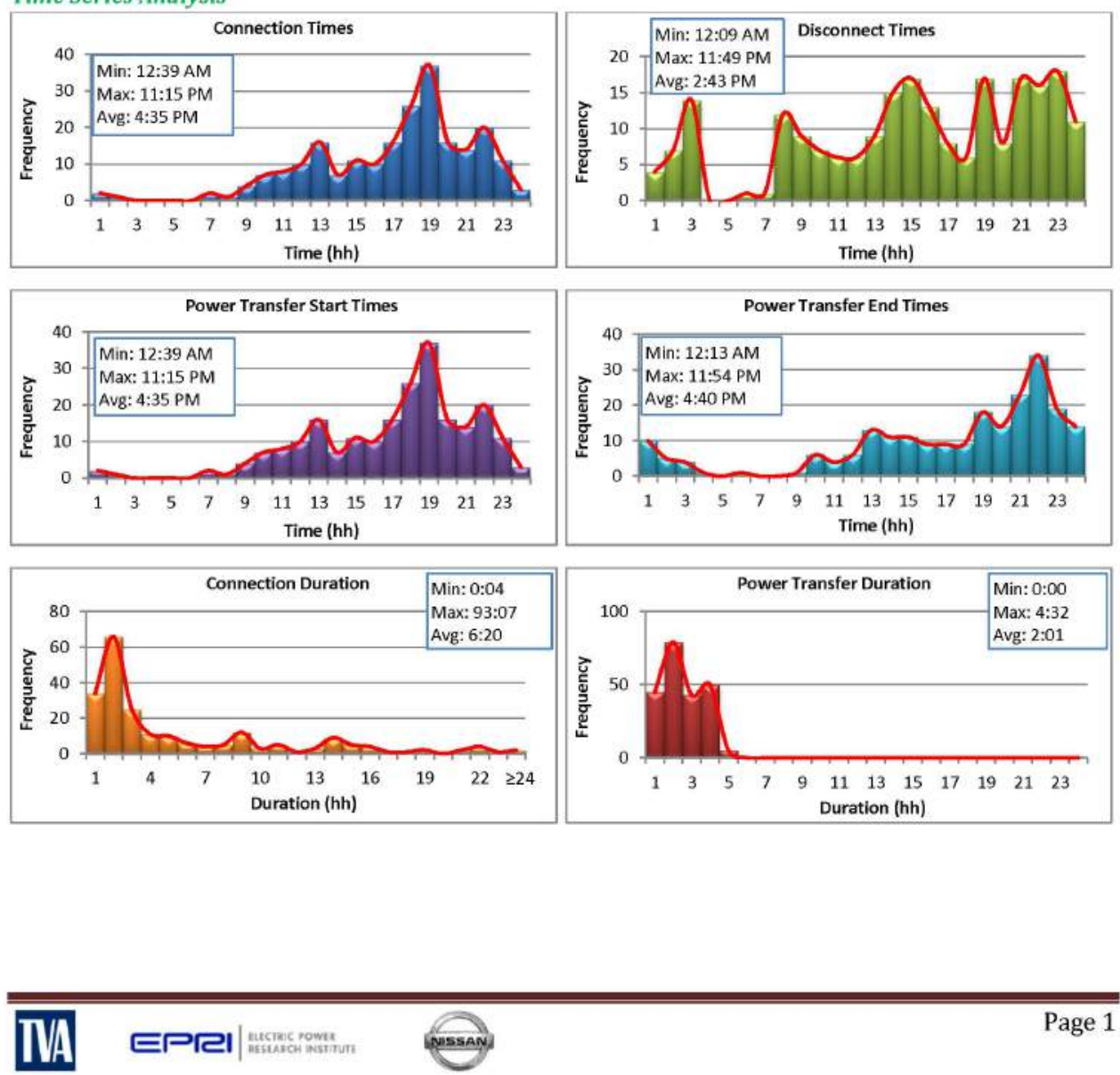


\section{OAK RIDGE NATIONAL LABORATORY}

Energy Consumption Analysis
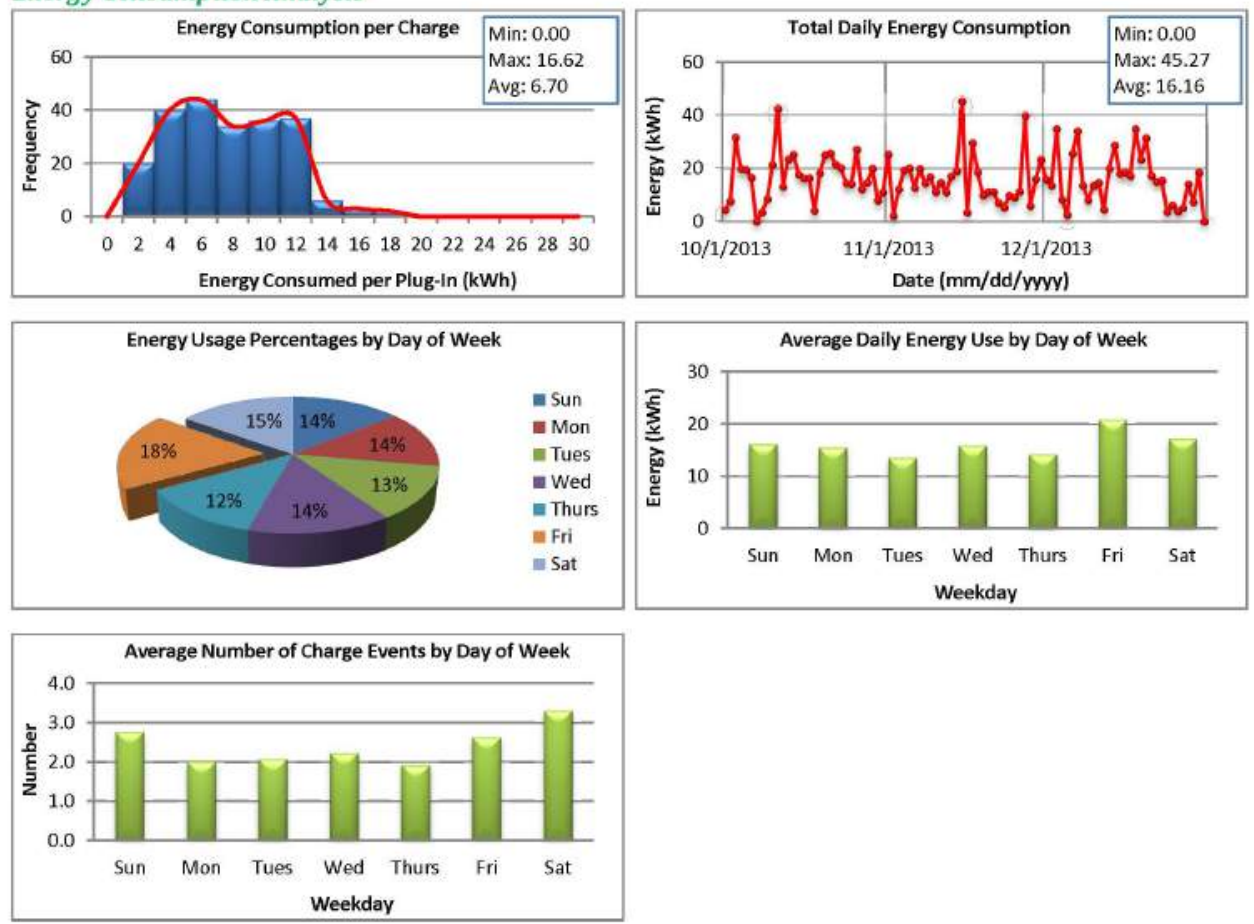

Charging Analysis
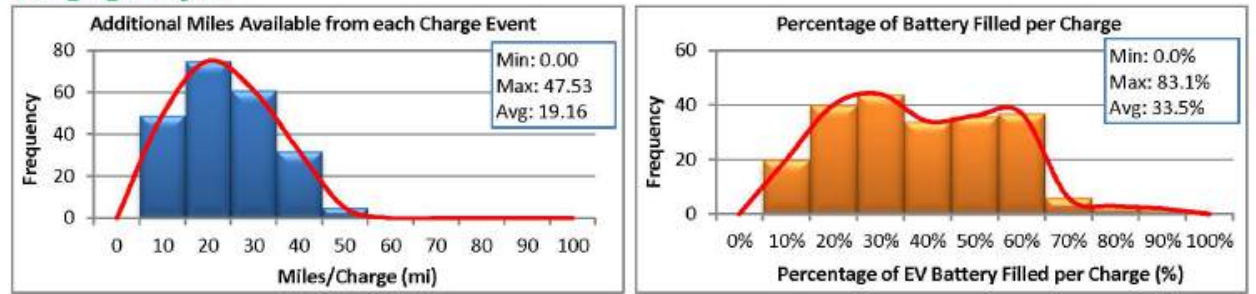

EVSE Analysis

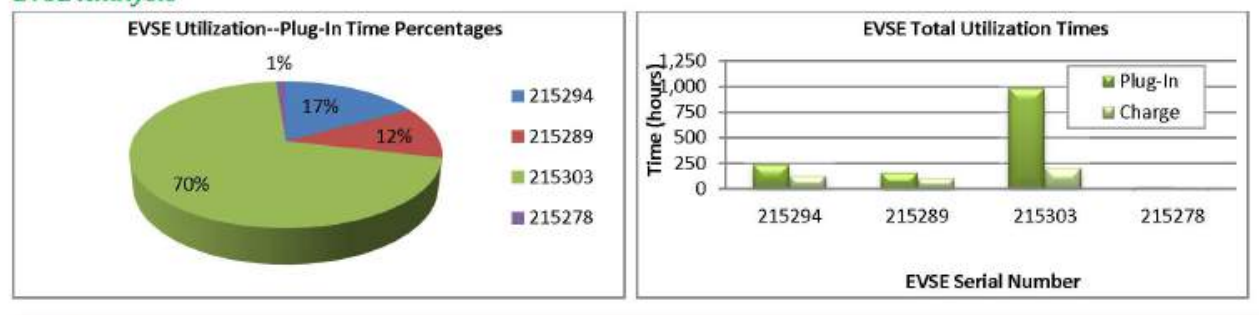

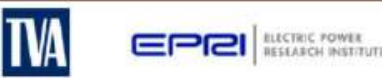

Page 2 


\section{OAK Ridge National Laboratory}

\begin{tabular}{|c|c|c|c|c|}
\hline \multirow{5}{*}{$\begin{array}{l}\text { Average connection duration (hrs.) } \\
\text { Average charge duration (hrs.) } \\
\text { Average miles per charge } \\
\text { Average } \% \text { of battery filled per }\end{array}$} & Q1 & Q2 & Q3 & Q4 \\
\hline & 2.5 & 3.8 & 4.0 & 6.3 \\
\hline & 1.7 & 1.6 & 1.9 & 2.0 \\
\hline & 18.3 & 15.6 & 18.5 & 19.2 \\
\hline & $32.1 \%$ & $27.2 \%$ & $32.3 \%$ & $33.5 \%$ \\
\hline
\end{tabular}

EVSE Quarterly Load Profile

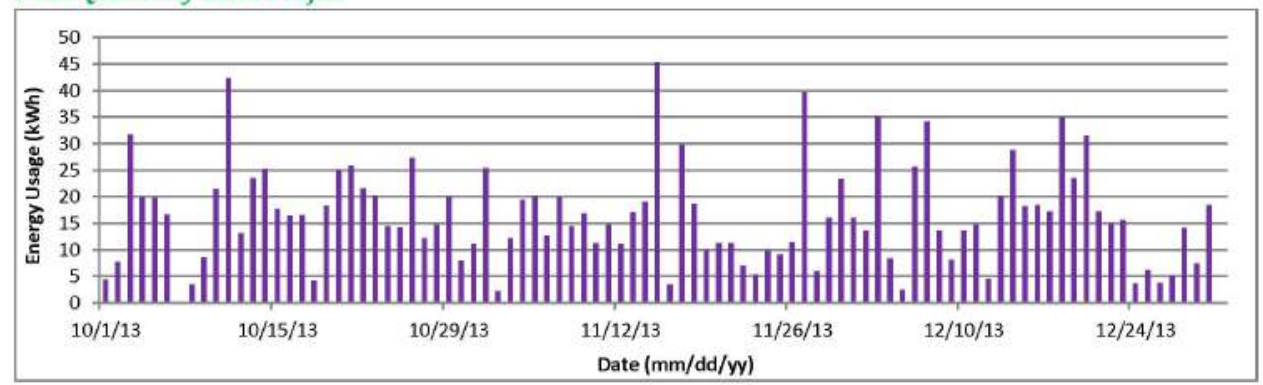

PV Array Quarterly Power Generation Profile

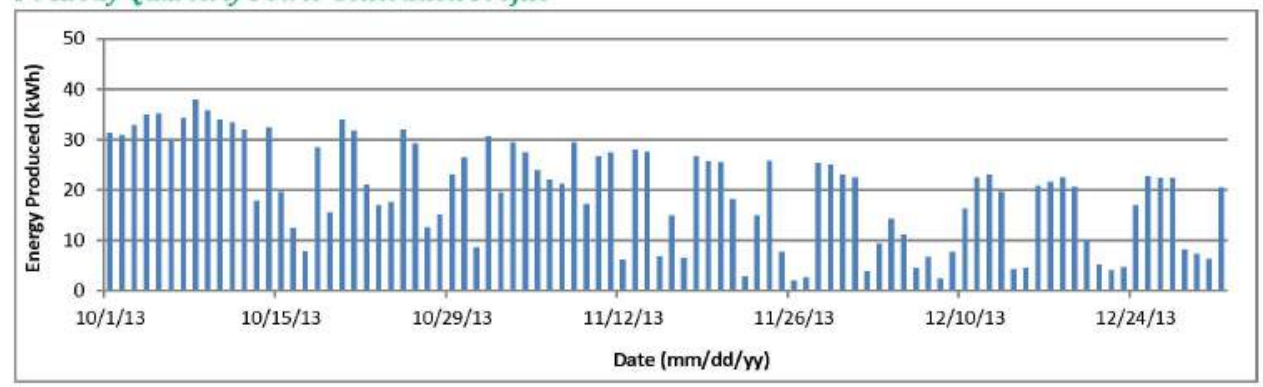

Based on the total energy consumption and an average of miles per $\mathrm{kWh}$ for the Nissan Leaf ( $2.94 \mathrm{mi} / \mathrm{kWh})$ and Chevy Volt ( $2.78 \mathrm{mi} / \mathrm{kWh})$.

Values taken from http://www.fueleconomv.gov/.

"Based on energy consumption and size of battery for the Nissan Leaf ( $24 \mathrm{kWh}$ ) and Chevy Volt (16 kWh).

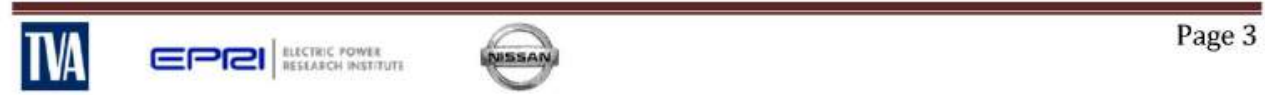




\section{Oak Ridge NaTiOnAL LabORATORY}

EV Project Solar-Assisted Charging Infrastructure Summary Report

EVSE Grouping/Region: Knoxville Market Square

Report Period: April 1-June 30, 2014 (Quarter 2, 2014)

Number of EV Charging Stations: 4

F/y Project

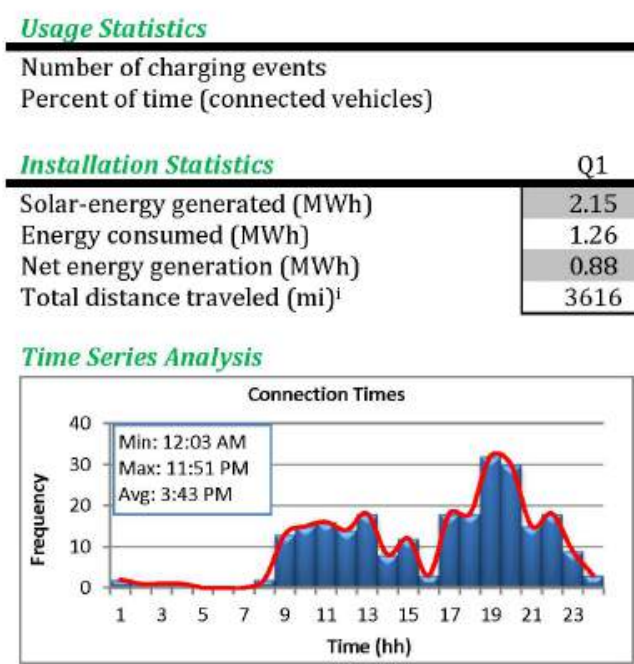

\begin{tabular}{cccc|} 
Q1 & Q2 & Q3 & Q4 \\
\hline 182 & 249 & - & - \\
$14.2 \%$ & $16.3 \%$ & - & - \\
\hline
\end{tabular}

Q1

$\begin{array}{llll}\text { Q2 } & \text { Q3 } & \text { Q4 } & \text { 2014 Totals }\end{array}$

3.57

1.62

1.95

4647

\begin{tabular}{ccc|}
- & - & 5.72 \\
- & - & 2.88 \\
- & - & 2.83 \\
- & - & 8263 \\
\hline
\end{tabular}
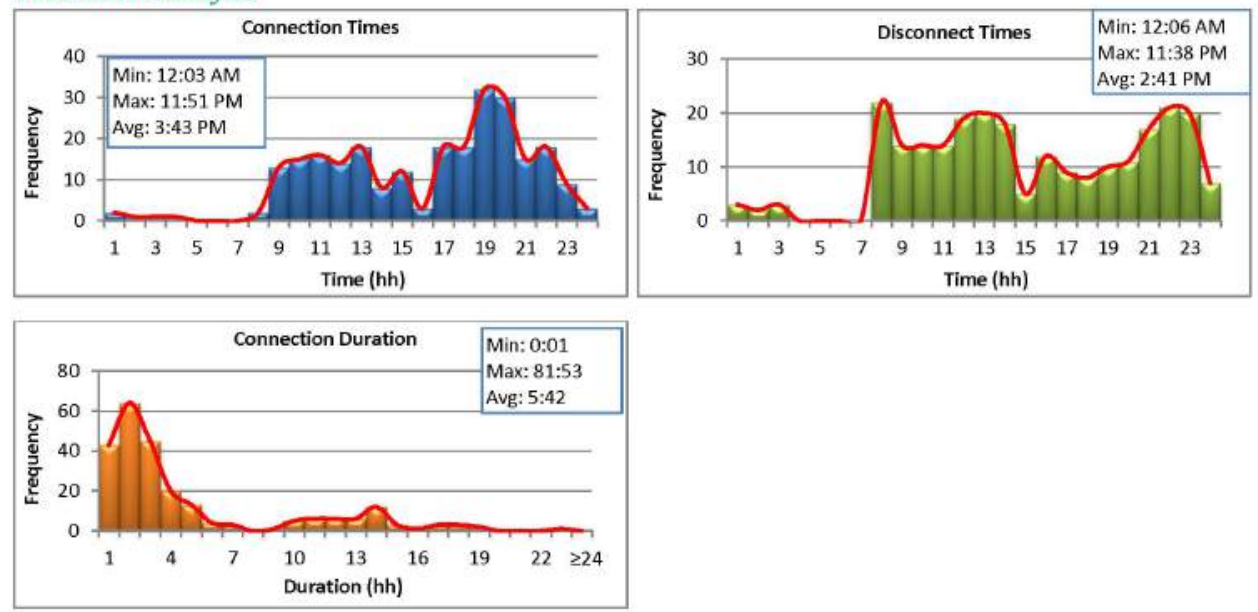


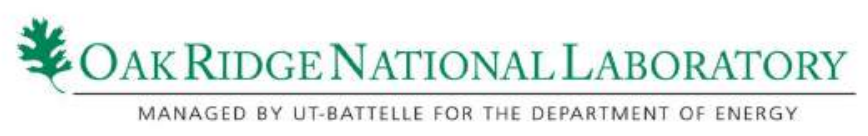

Energy Consumption Analysis
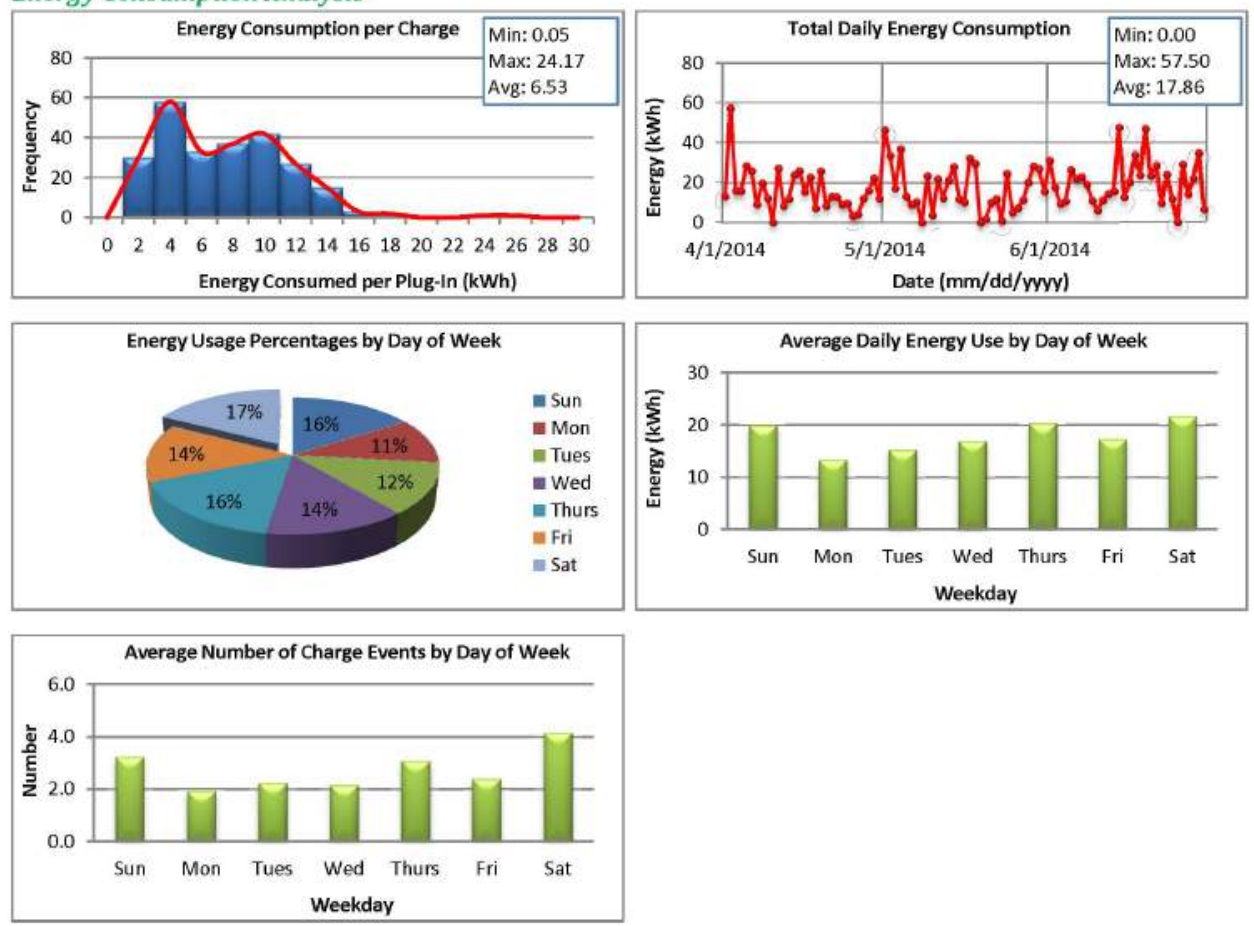

Charging Analysis
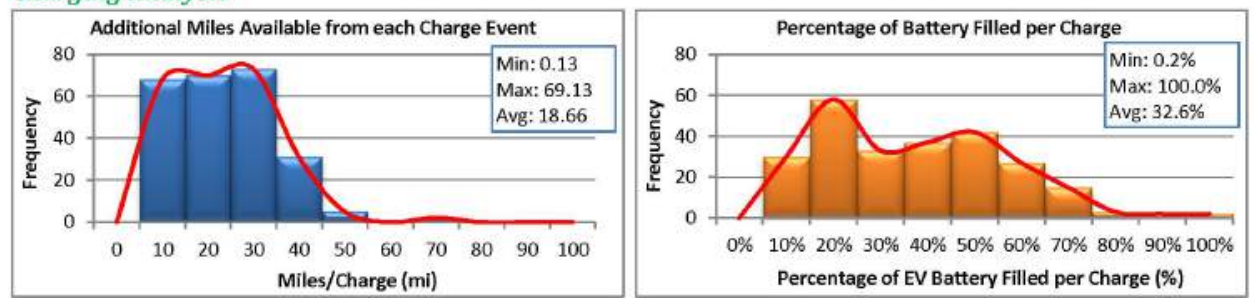

EVSE Analysis

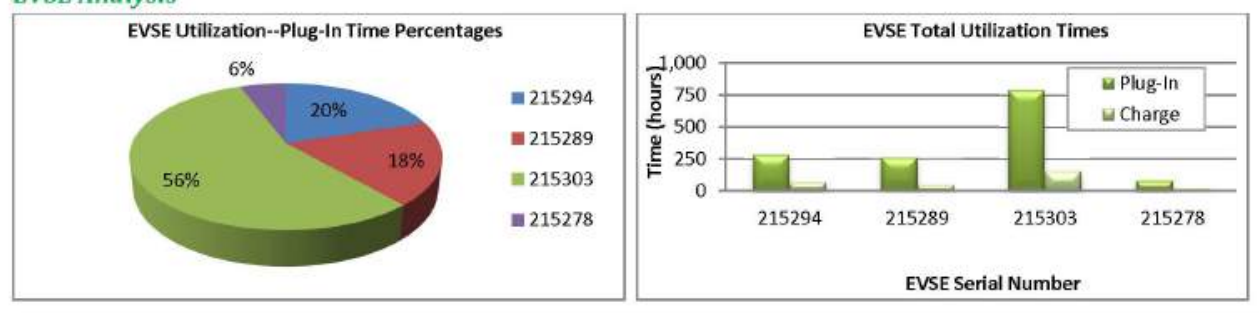

IVA EPR|

Page 2 


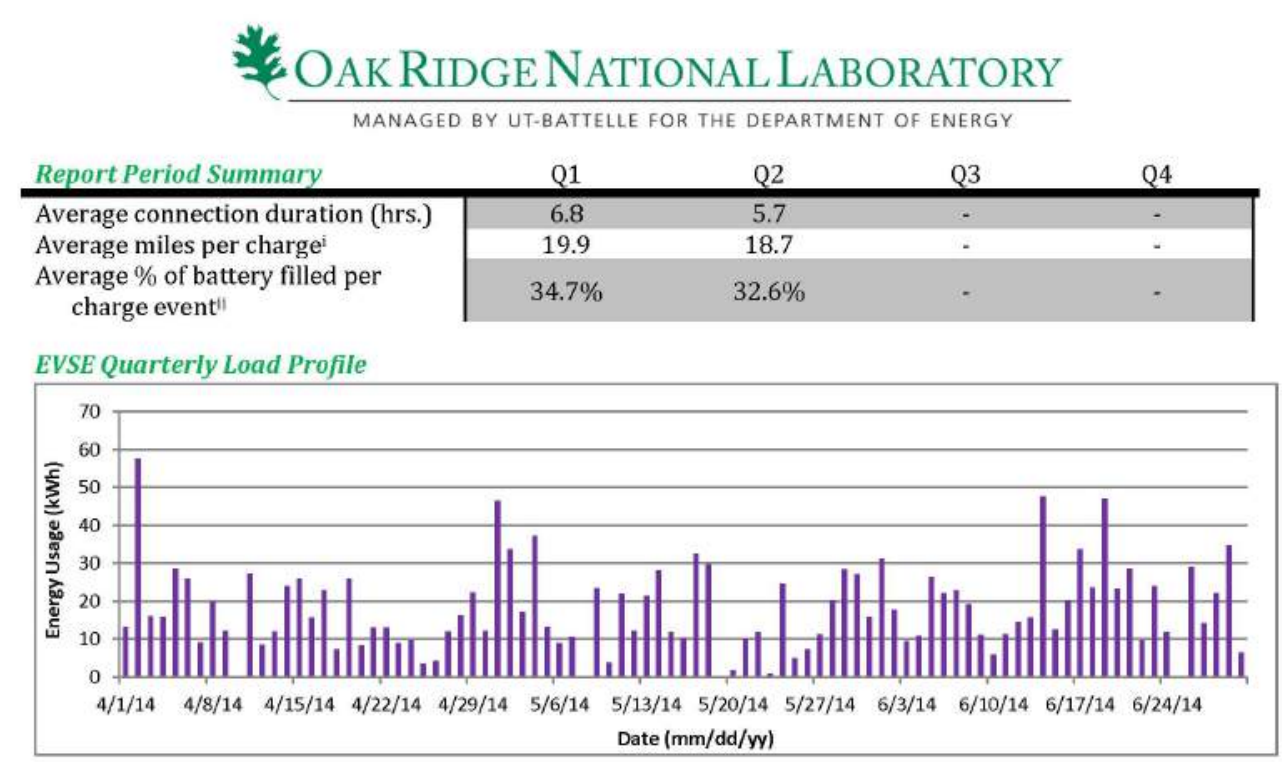

PV Array Quarterly Power Generation Profile

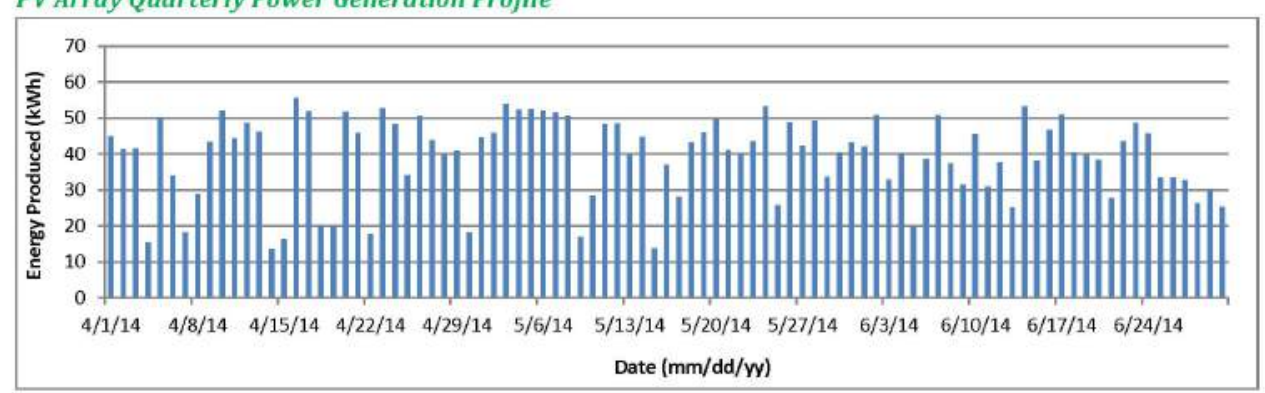

Based on the total energy consumption and an average of miles per $\mathrm{kWh}$ for the Nissan Leaf ( $2.94 \mathrm{mi} / \mathrm{kWh})$ and Chevy Volt $(2.78 \mathrm{mi} / \mathrm{kWh})$.

Values taken from http://www.fueleconomy.gov/.

"Based on energy consumption and size of battery for the Nissan Leaf ( $24 \mathrm{kWh}$ ) and Chevy Volt (16 kWh).

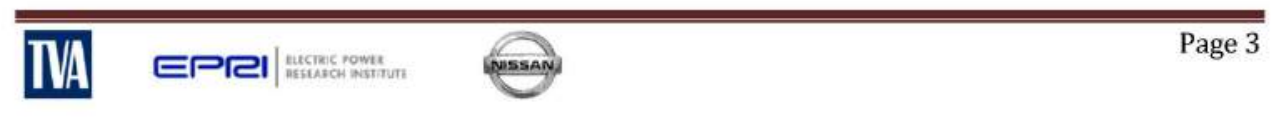




\section{A.4 Knoxville Civic Coliseum Parking Garage}

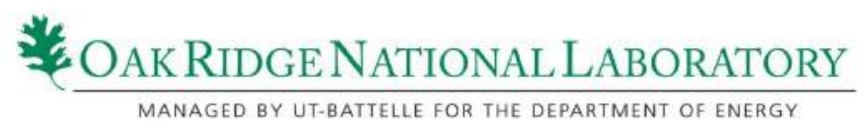

EV Project Solar-Assisted Charging Infrastructure Summary Report

EVSE Grouping/Region: Knoxville Coliseum

Report Period: October 1-December 31, 2012 (Quarter 4, 2012)

Number of EV Charging Stations: 6

$\exists \boldsymbol{A} /$ Project

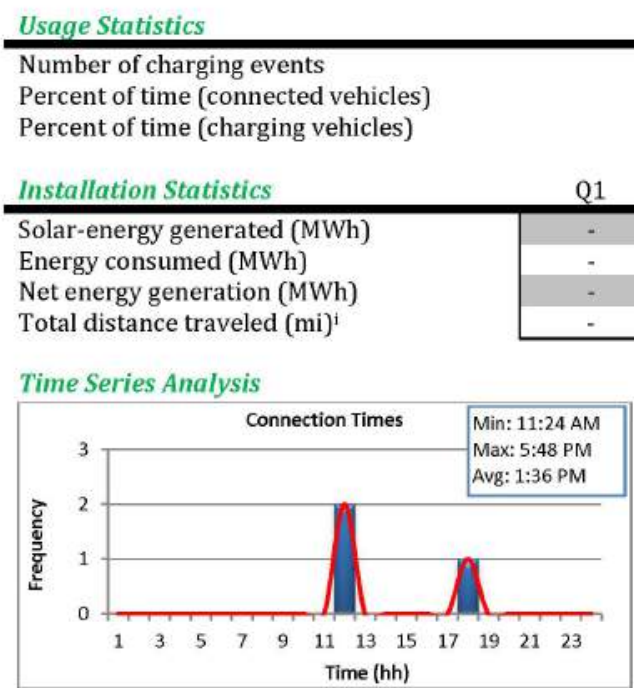

\begin{tabular}{|cccc|}
\hline Q1 & Q2 & Q3 & Q4 \\
\hline- & - & 4 & 3 \\
- & - & $0.0 \%$ & $0.0 \%$ \\
- & - & $0.0 \%$ & $0.0 \%$
\end{tabular}
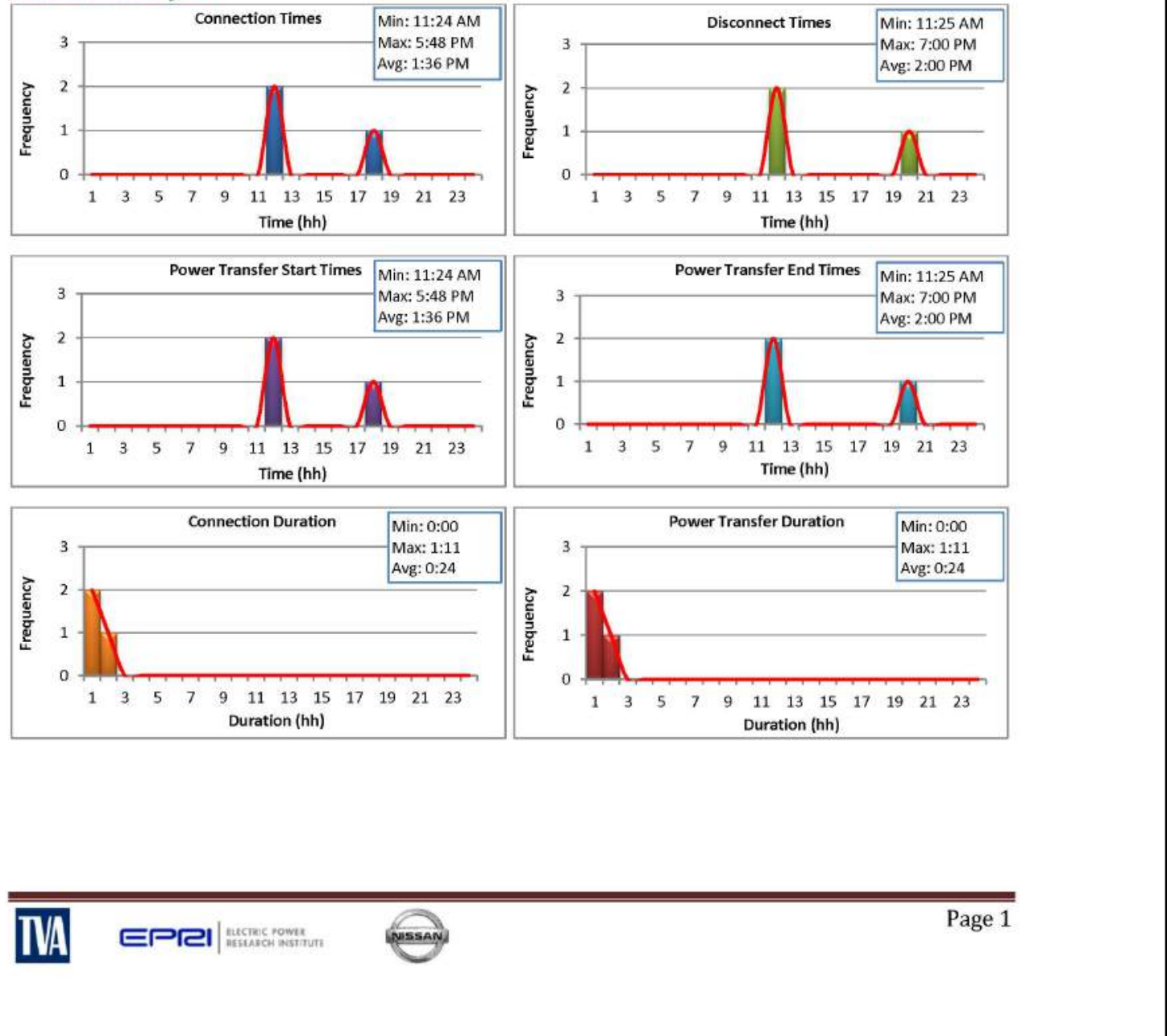


\section{OAK RIDGE NATIONAL LABORATORY}

Energy Consumption Analysis
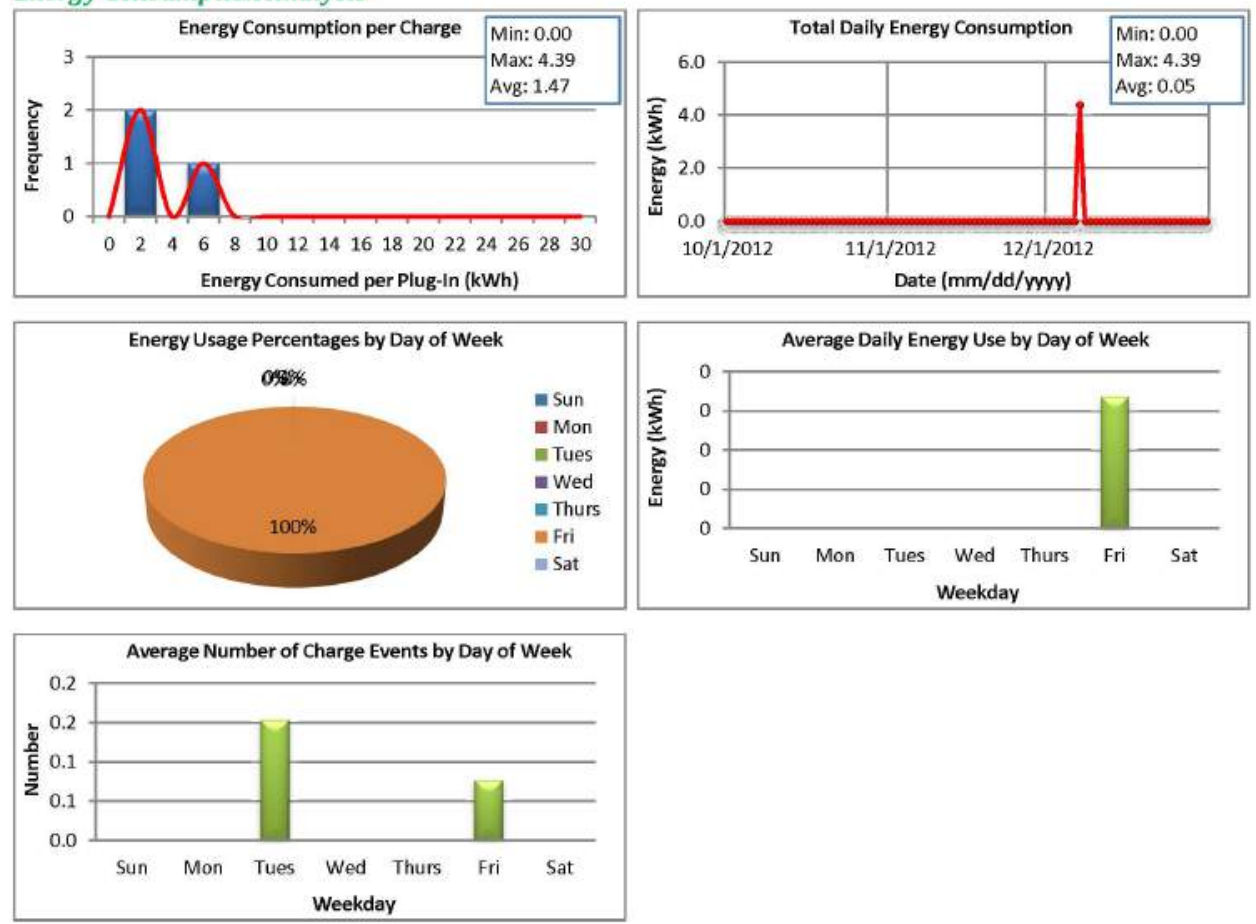

Charging Analysis
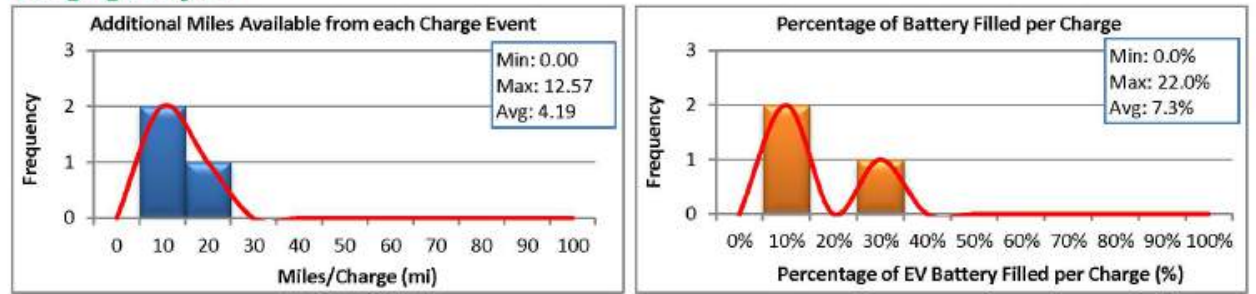

EVSE Analysis
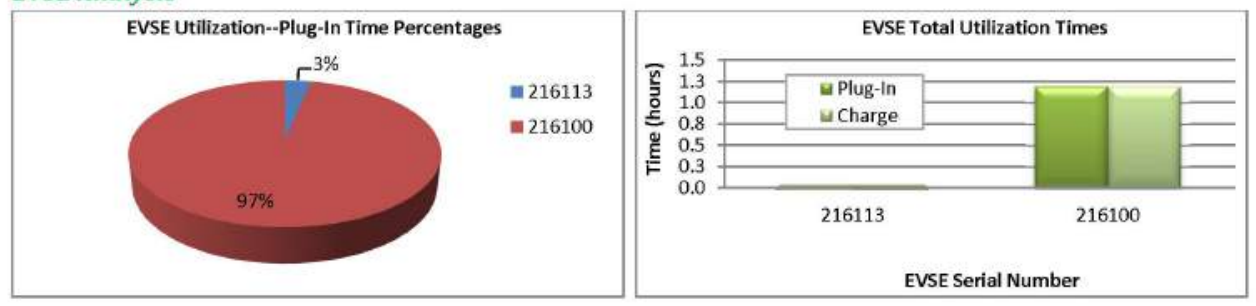

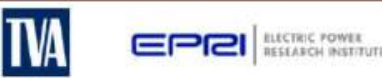

Page 2 


\section{$\frac{\text { OAK RidGE NATIONAL LABORATORY }}{\text { Managed By Ut-Battelle For the Department of ENERgy }}$}

\begin{tabular}{|c|c|c|c|c|}
\hline Report Period Summary & Q1 & Q2 & Q3 & Q4 \\
\hline Average connection duration (hrs.) & - & - & 1.0 & 0.4 \\
\hline Average charge duration (hrs.) & - & - & 0.7 & 0.4 \\
\hline Average miles per charge & - & - & 6.5 & 4.2 \\
\hline $\begin{array}{l}\text { Average } \% \text { of battery filled per } \\
\text { charge event } t^{\mathrm{ij}}\end{array}$ & - & - & $11.3 \%$ & $7.3 \%$ \\
\hline
\end{tabular}

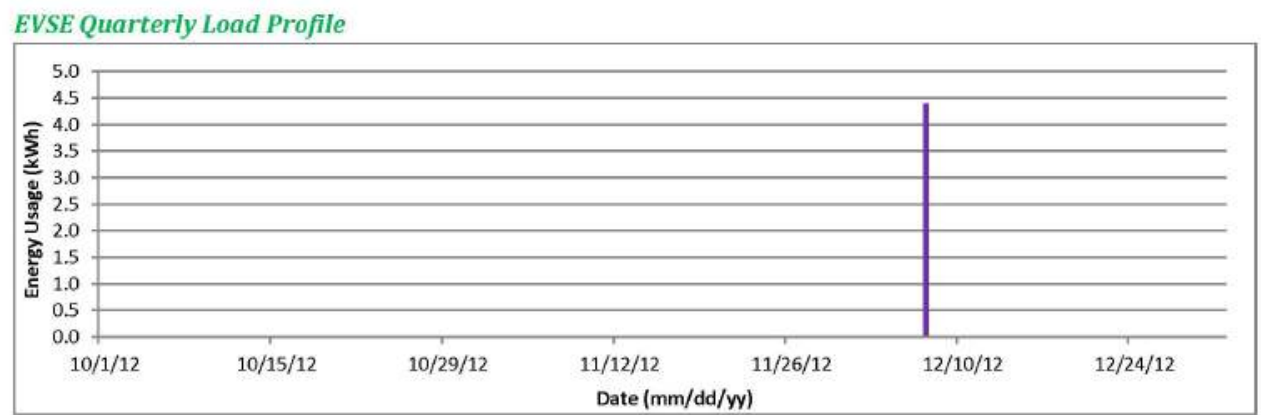

PV Array Quarterly Power Generation Profile

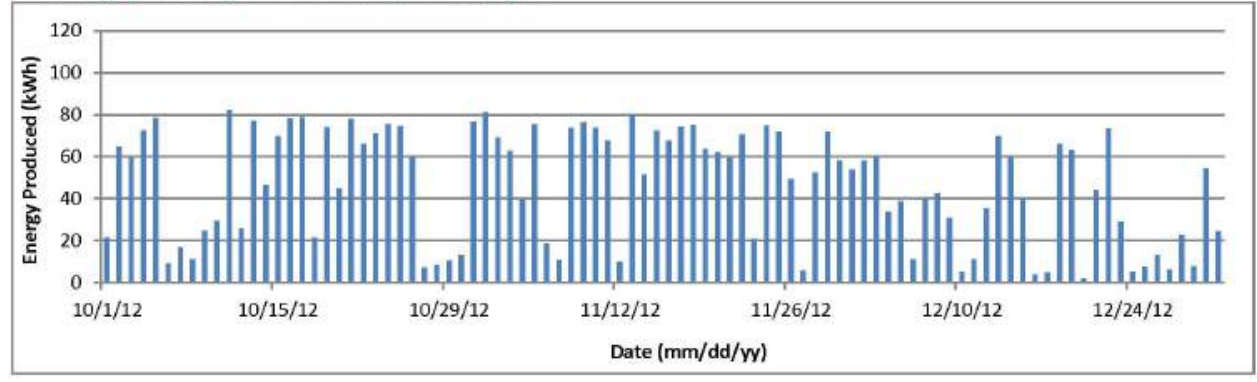

Based on the total energy consumption and an average of miles per $\mathrm{kWh}$ for the Nissan Leaf ( $2.94 \mathrm{mi} / \mathrm{kWh})$ and Chevy Volt $(2.78 \mathrm{mi} / \mathrm{kWh})$

Values taken from htto://www.fueleconomy.gov/.

Based on energy consumption and size of battery for the Nissan Leaf ( $24 \mathrm{kWh}$ ) and Chevy Volt (16 kWh).

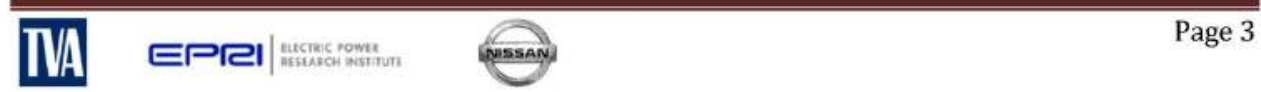




\section{OAK RIDGE NATIONAL LABORATORY}

EV Project Solar-Assisted Charging Infrastructure Summary Report

EVSE Grouping/Region: Knoxville Coliseum

Report Period: October 1-December 31, 2013 (Quarter 4, 2013)

Number of EV Charging Stations: 6

F/y Project

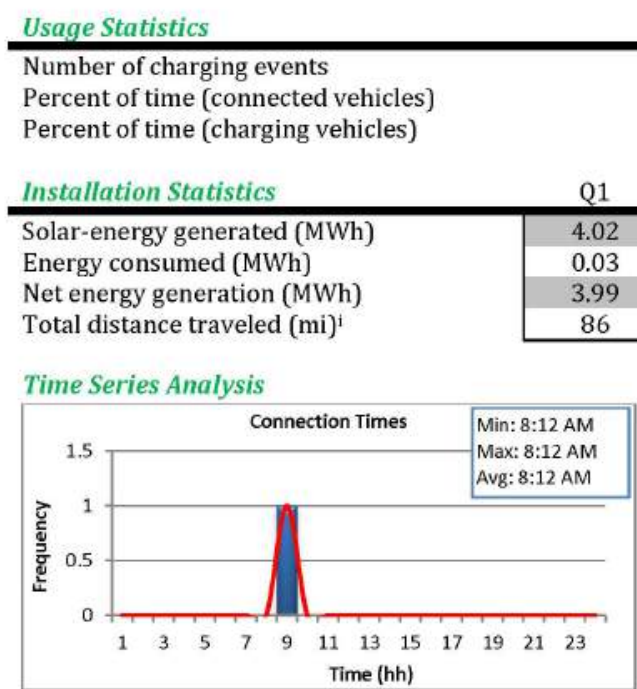

\begin{tabular}{cccc|} 
Q1 & Q2 & Q3 & Q4 \\
\hline 3 & 2 & 1 & 1 \\
$0.1 \%$ & $0.1 \%$ & $0.1 \%$ & $0.1 \%$ \\
$0.1 \%$ & $0.0 \%$ & $0.0 \%$ & $0.1 \%$
\end{tabular}
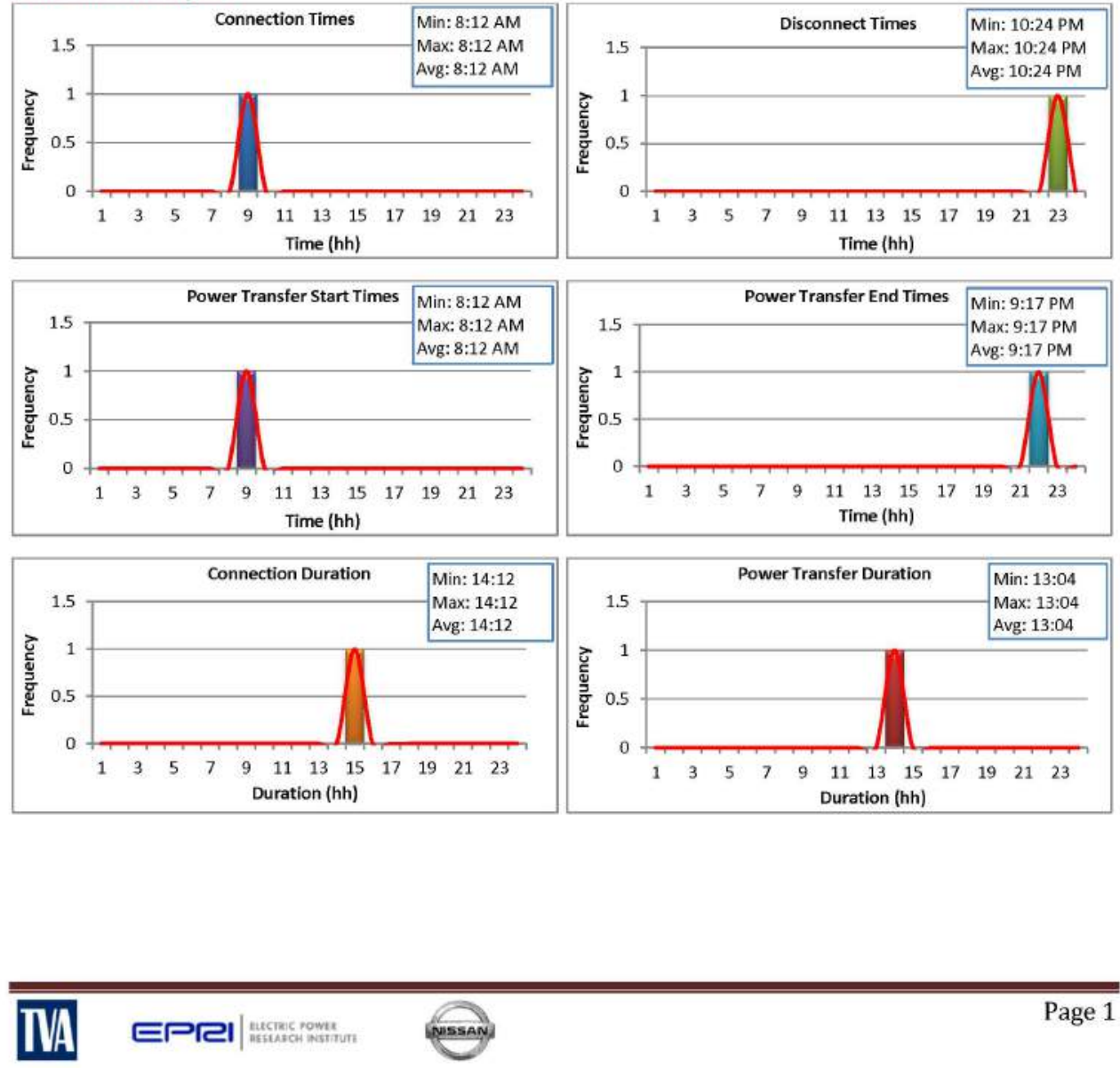


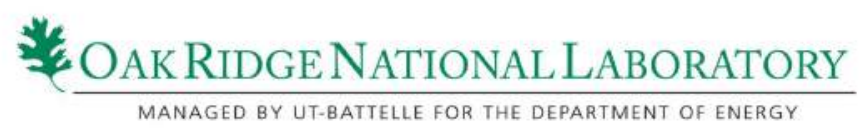

Energy Consumption Analysis
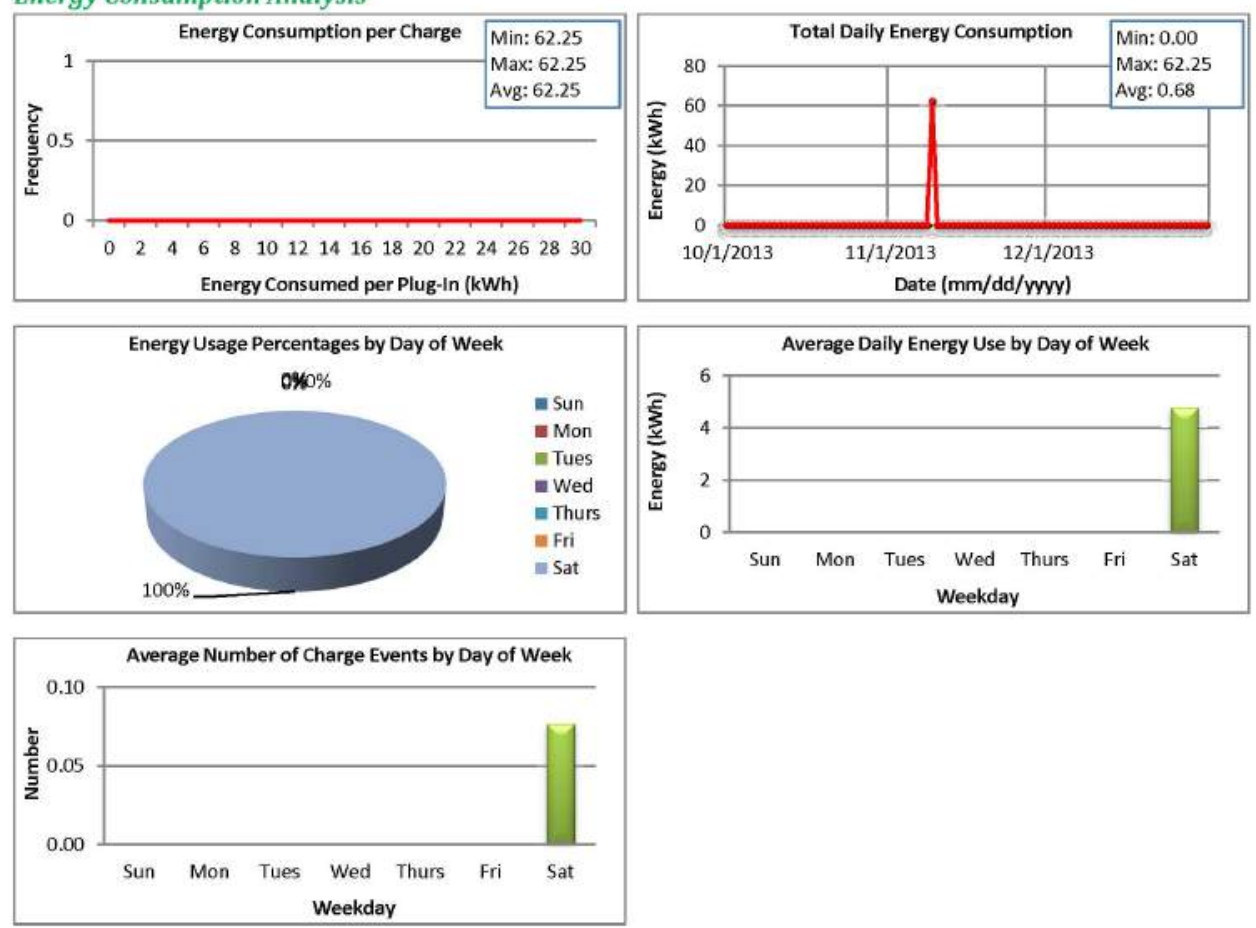

Charging Analysis
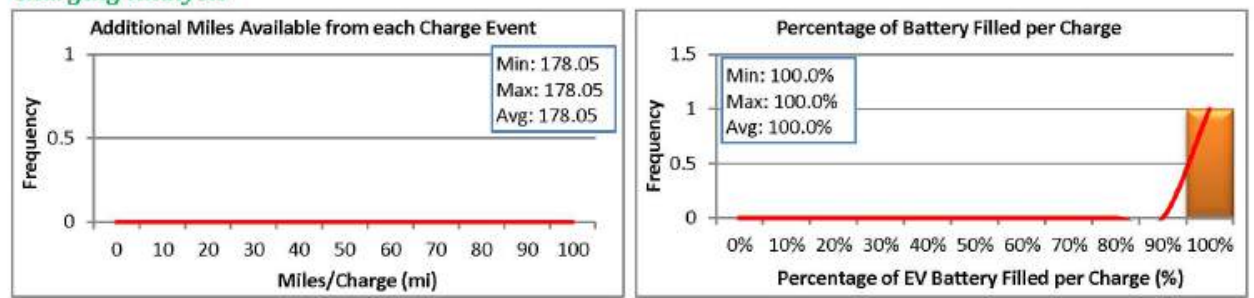

EVSE Analysís
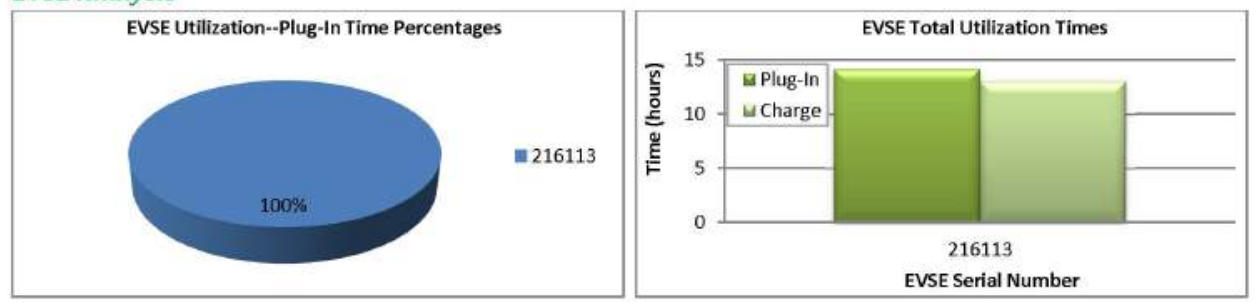

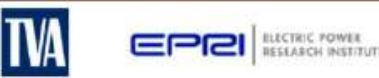

Page 2 


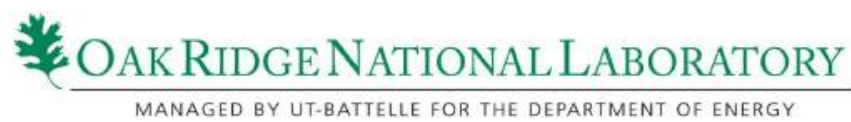

\begin{tabular}{|c|c|c|c|c|}
\hline \multirow{5}{*}{$\begin{array}{l}\text { Report Period Summary } \\
\text { Average connection duration (hrs.) } \\
\text { Average charge duration (hrs.) } \\
\text { Average miles per charge } \\
\text { Average } \% \text { of battery filled per }\end{array}$} & Q1 & Q2 & Q3 & Q4 \\
\hline & 3.5 & 3.6 & 7.1 & 14.2 \\
\hline & 2.7 & 2.1 & 4.1 & 13.1 \\
\hline & 28.6 & 20.3 & 33.4 & 178.0 \\
\hline & $50.1 \%$ & $35.5 \%$ & $58.5 \%$ & $100.0 \%$ \\
\hline
\end{tabular}

EVSE Quarterly Load Profile

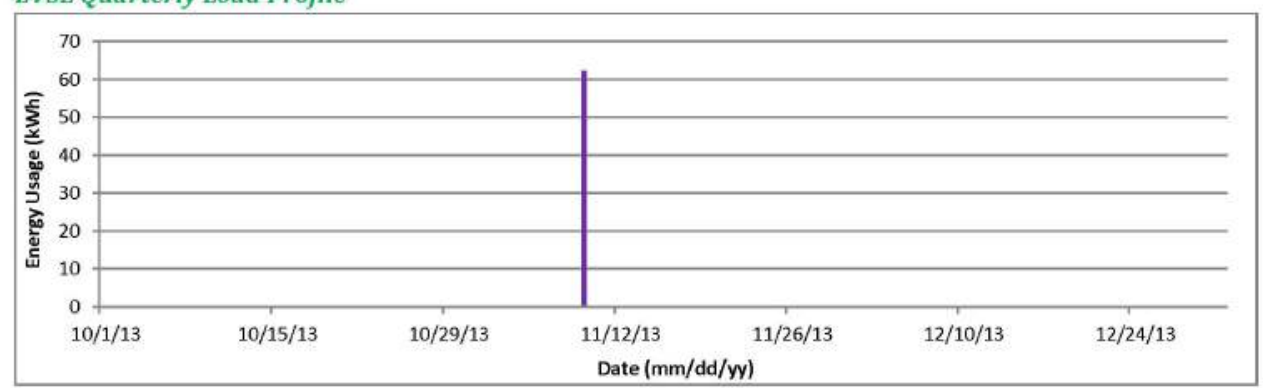

PV Array Quarterly Power Generation Profile

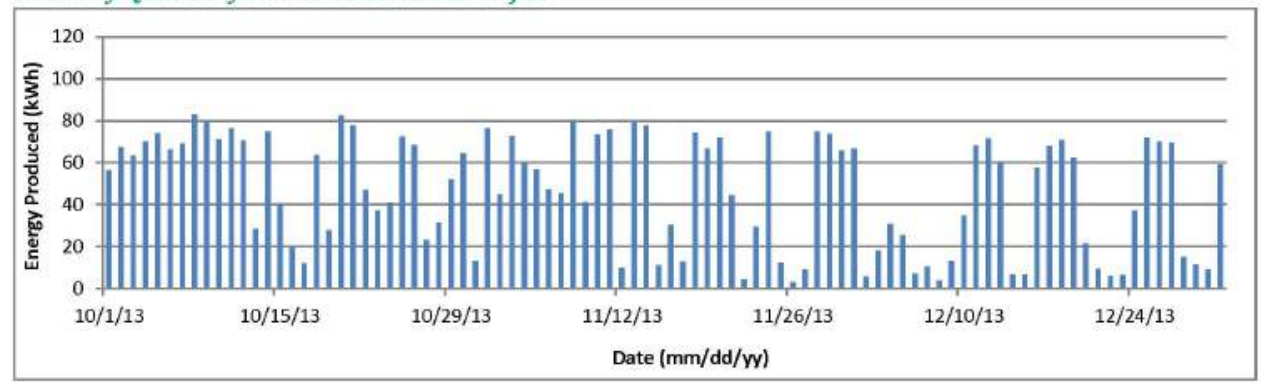

Based on the total energy consumption and an average of miles per $\mathrm{kWh}$ for the Nissan Leaf ( $2.94 \mathrm{mi} / \mathrm{kWh}$ ) and Chevy Volt ( $2.78 \mathrm{mi} / \mathrm{kWh}$ ).

Values taken from http://www.fueleconomv.gov/.

"Based on energy consumption and size of battery for the Nissan Leaf ( $24 \mathrm{kWh}$ ) and Chevy Volt (16 kWh).

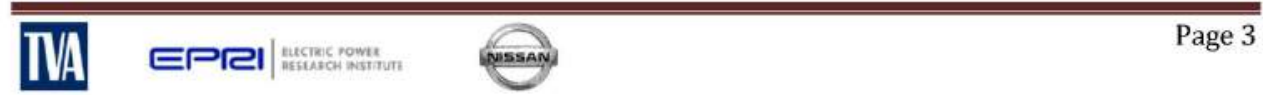




\section{Oak Ridge NaTiOnAL LabORATORY}

EV Project Solar-Assisted Charging Infrastructure Summary Report

EVSE Grouping/Region: Knoxville Coliseum

Report Period: April 1-June 30, 2014 (Quarter 2, 2014)

Number of EV Charging Stations: 6

$\exists \boldsymbol{F}$ Project

\begin{tabular}{|c|c|c|c|c|c|}
\hline Usage Statistics & & Q1 & Q2 & Q3 & Q4 \\
\hline Number of charging events & & 7 & 14 & - & - \\
\hline Percent of time (connected vehicles) & & $0.1 \%$ & $0.4 \%$ & - & - \\
\hline Installation Statistics & Q1 & Q2 & Q3 & Q4 & 2014 Totals \\
\hline Solar-energy generated (MWh) & 4.82 & 5.78 & - & - & 10.6 \\
\hline Energy consumed (MWh) & 0.04 & 0.09 & - & - & 0.13 \\
\hline Net energy generation (MWh) & 4.78 & 5.69 & - & - & 10.47 \\
\hline Total distance traveled $(\mathrm{mi})^{\mathrm{i}}$ & 114 & 271 & - & - & 385 \\
\hline
\end{tabular}

Time Series Analysis
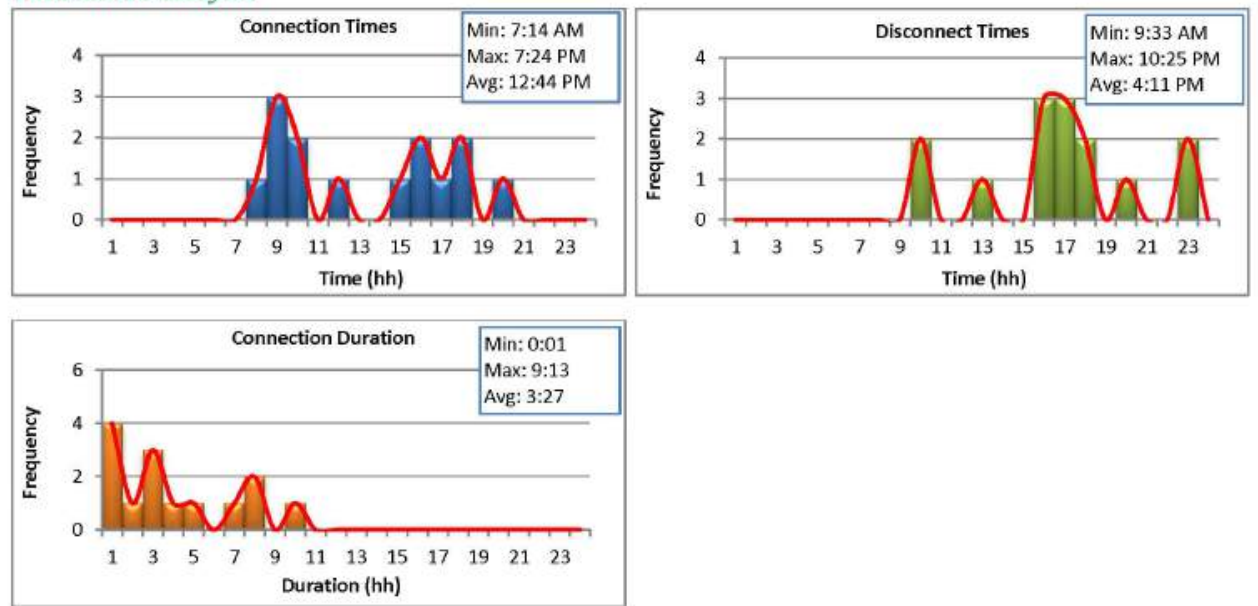

Page 1 


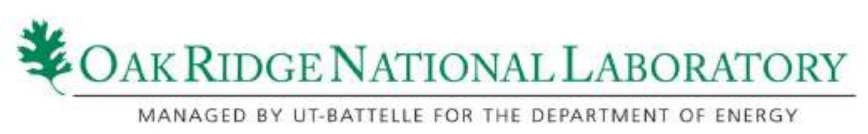

Energy Consumption Analysis
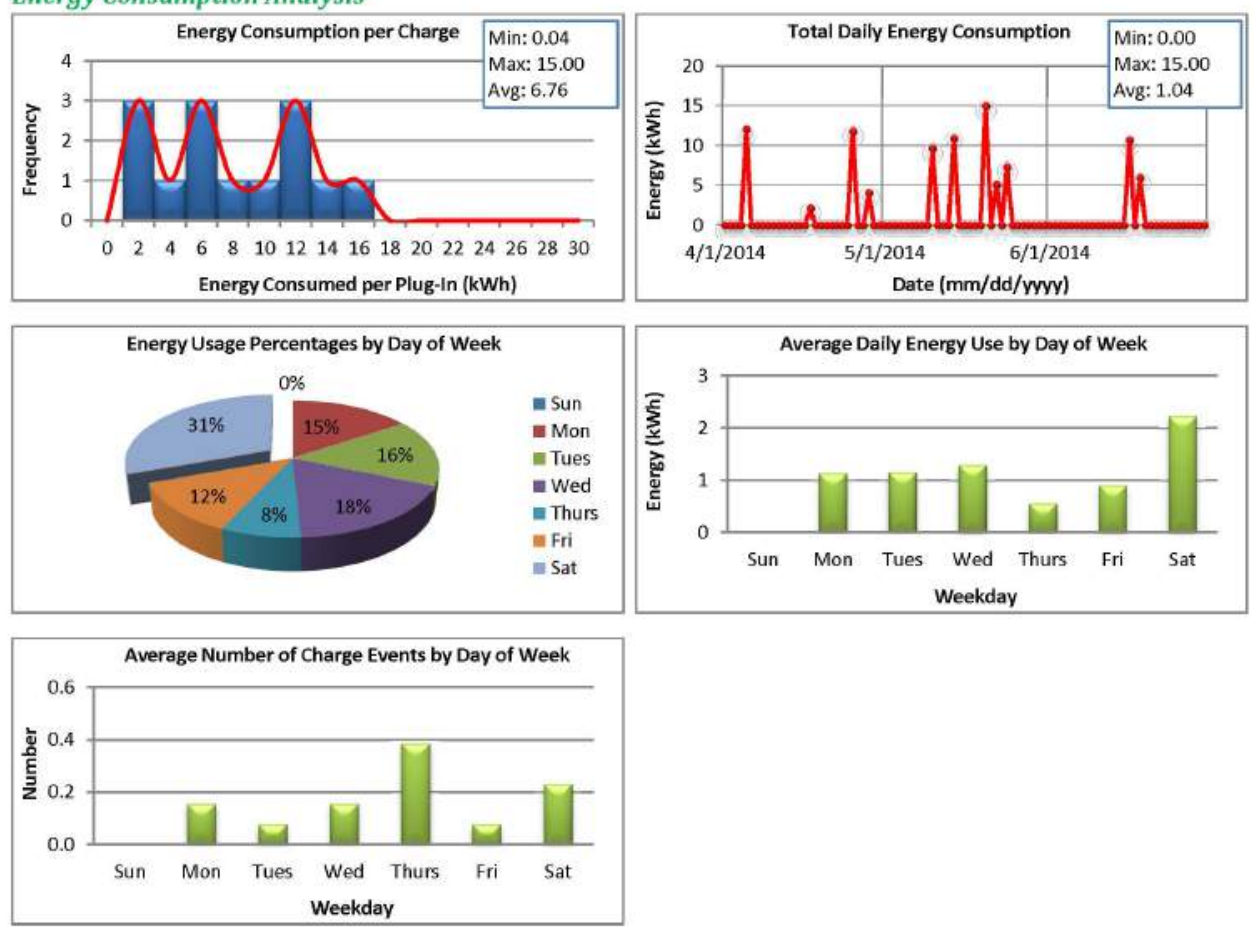

Charging Analysis
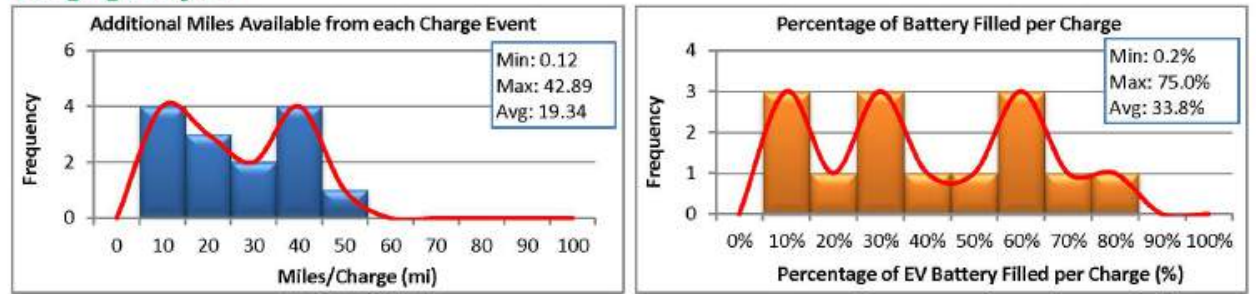

EVSE Analysis
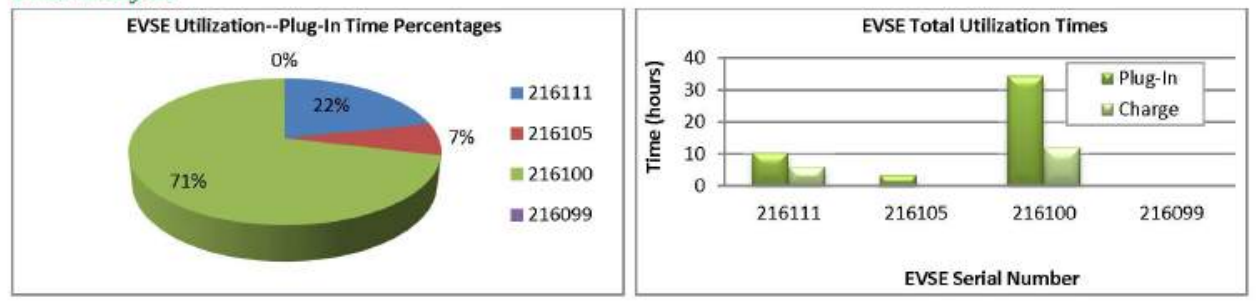

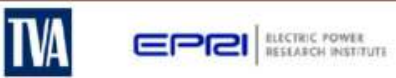

Page 2 


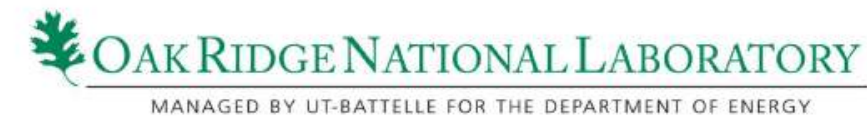

\begin{tabular}{l|cccc} 
Report Period Summary & Q1 & Q2 & Q3 & Q4 \\
\hline Average connection duration (hrs.) & 1.8 & 3.5 & - & - \\
\cline { 2 - 2 } & Average \% of battery filled per & 16.2 & 19.3 & - \\
$\quad \begin{array}{l}\text { Average event } \\
\quad \text { charge }\end{array}$ & $28.4 \%$ & $33.8 \%$ & -
\end{tabular}

EVSE Quarterly Load Profile

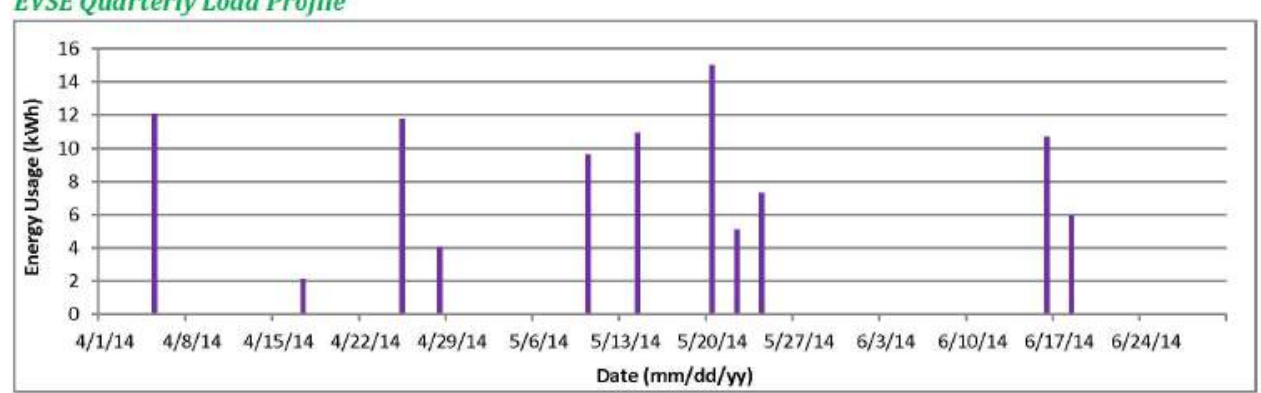

PV Array Quarterly Power Generation Profile

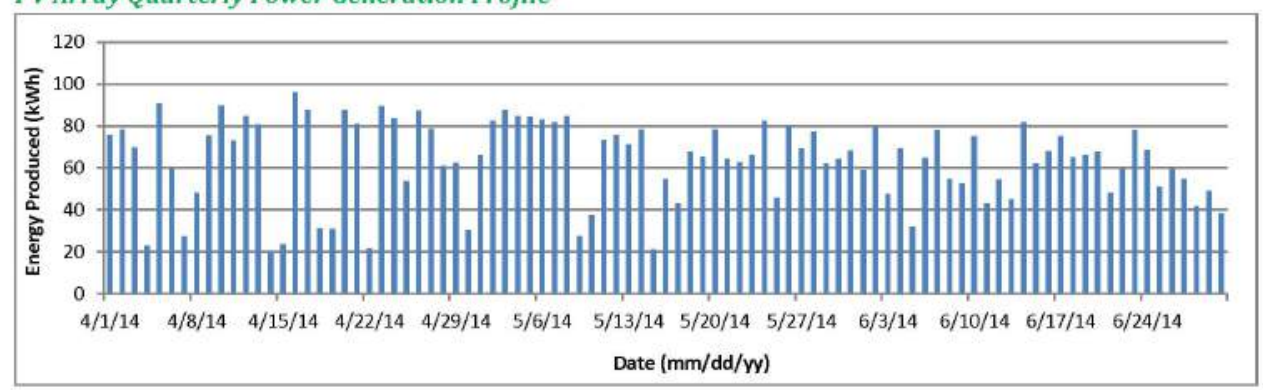

Based on the total energy consumption and an average of miles per $\mathrm{kWh}$ for the Nissan Leaf ( $2.94 \mathrm{mi} / \mathrm{kWh}$ ) and Chevy Volt ( $2.78 \mathrm{mi} / \mathrm{kWh}$ ).

Values taken from http://www.fueleconomy.gov/.

"Based on energy consumption and size of battery for the Nissan Leaf ( $24 \mathrm{kWh}$ ) and Chevy Volt (16 kWh).

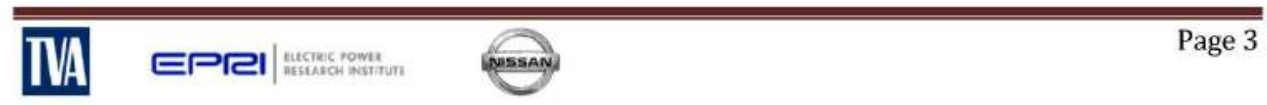




\section{A.6 University of Tennessee-Knoxville Agriculture Campus}

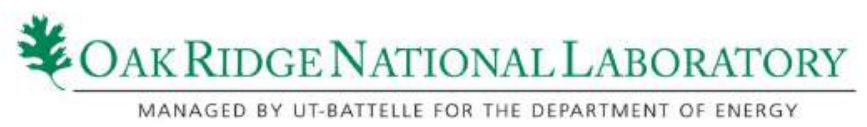

EV Project Solar-Assisted Charging Infrastructure Summary Report

EVSE Grouping/Region: UTK Agriculture

Report Period: October 1-December 31, 2012 (Quarter 4, 2012)

Number of EV Charging Stations: 8

$\exists \boldsymbol{Z} /$ Project
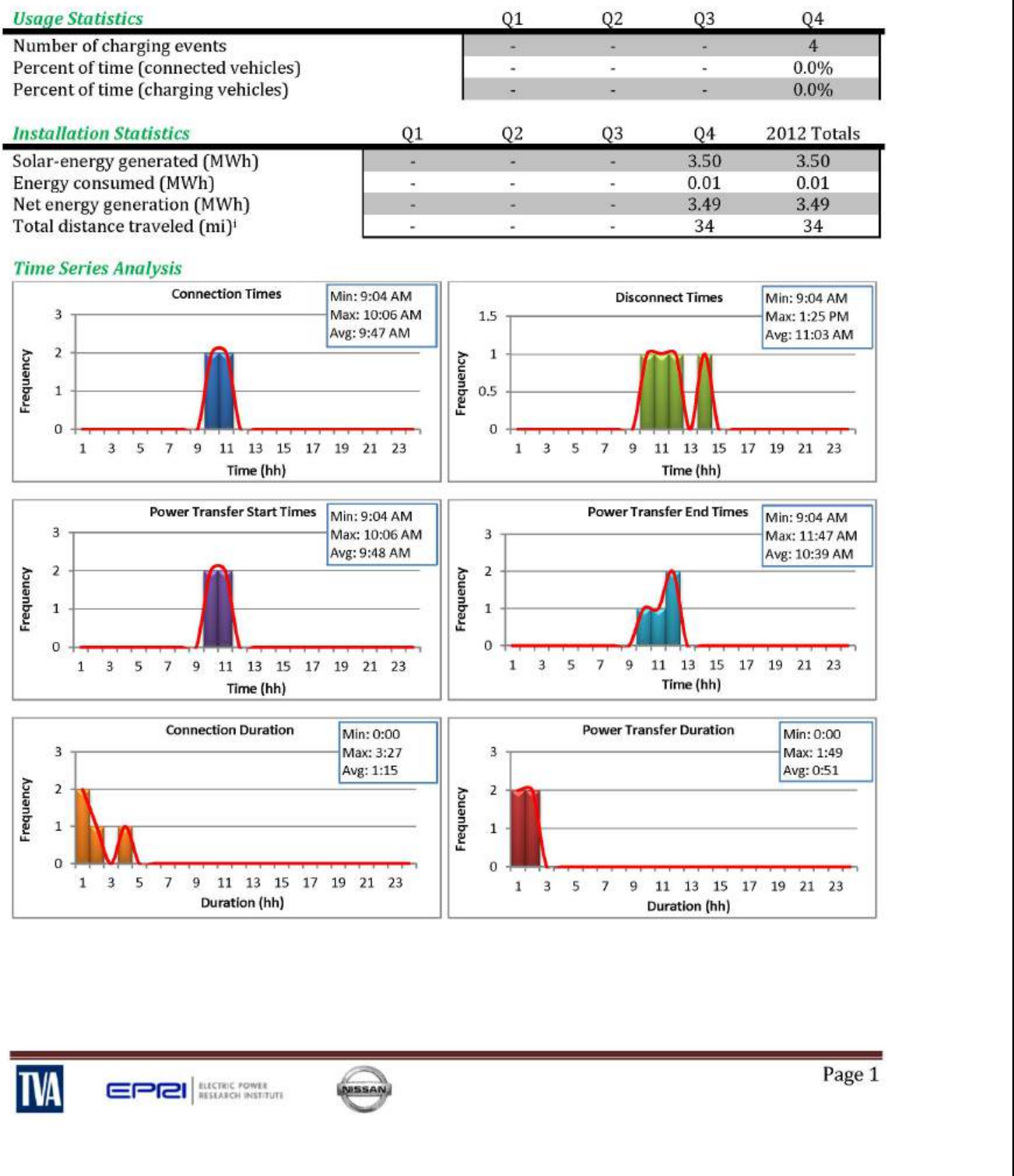


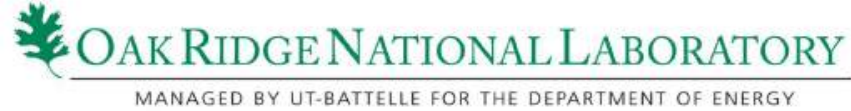

Energy Consumption Analysis
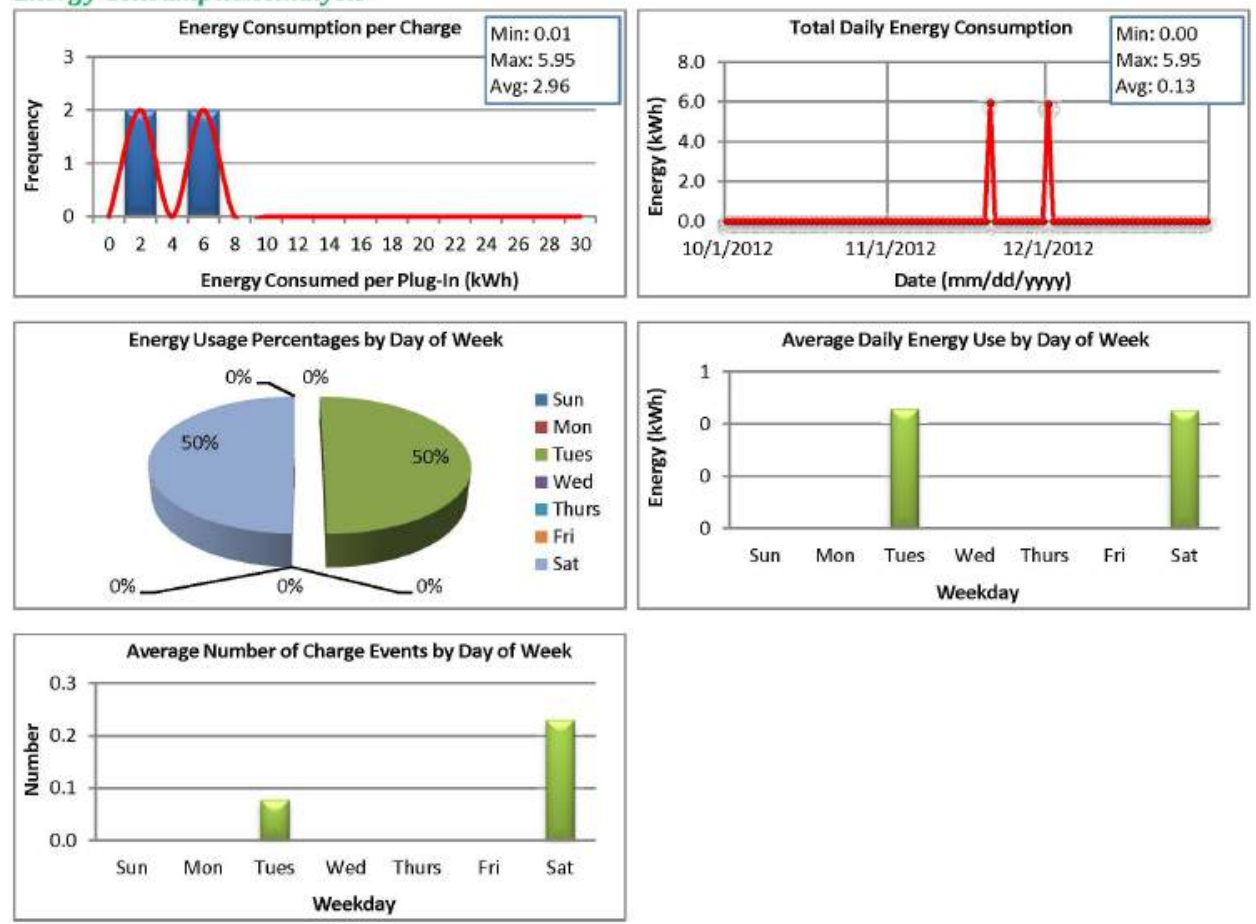

Charging Analysis
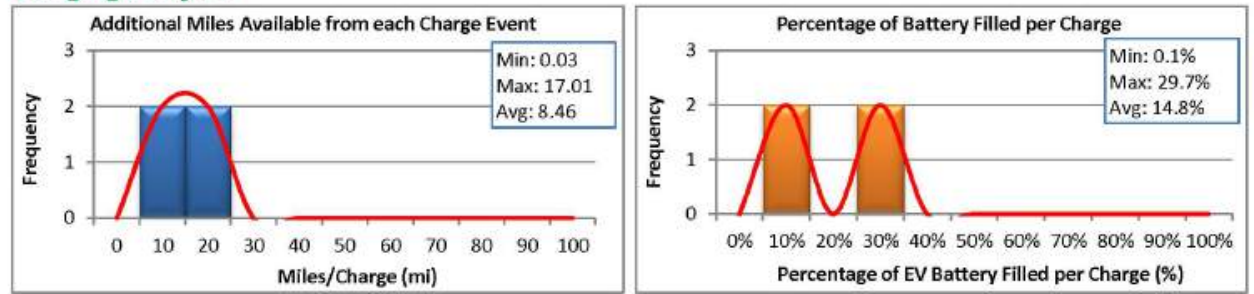

EVSE Analysís

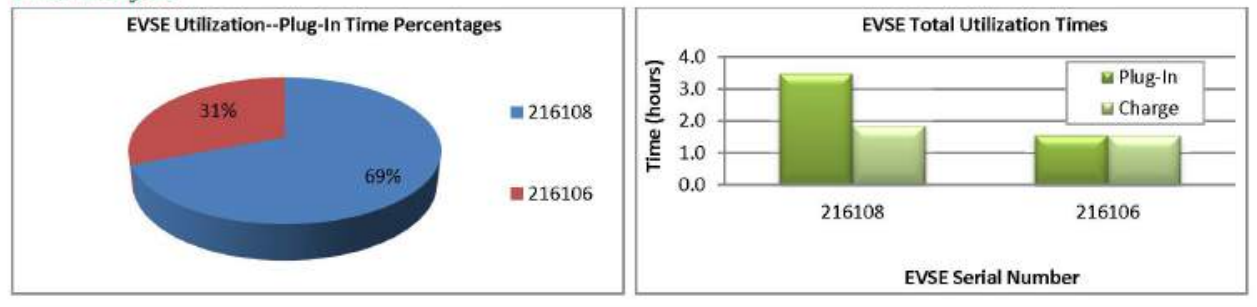

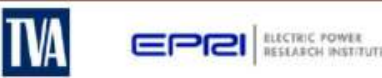

Page 2 


\section{$\frac{\text { OAK RidGE NATIONAL LABORATORY }}{\text { Managed By Ut-Battelle For the Department of ENERgy }}$}

Report Period Summary

Q1

Q2

Q3

Q4

Average connection duration (hrs.)

Average charge duration (hrs.)

Average miles per chargé

Average $\%$ of battery filled per charge event ${ }^{\mathrm{ii}}$

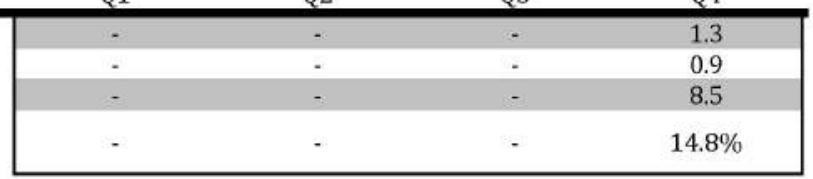

EVSE Quarterly Load Profile

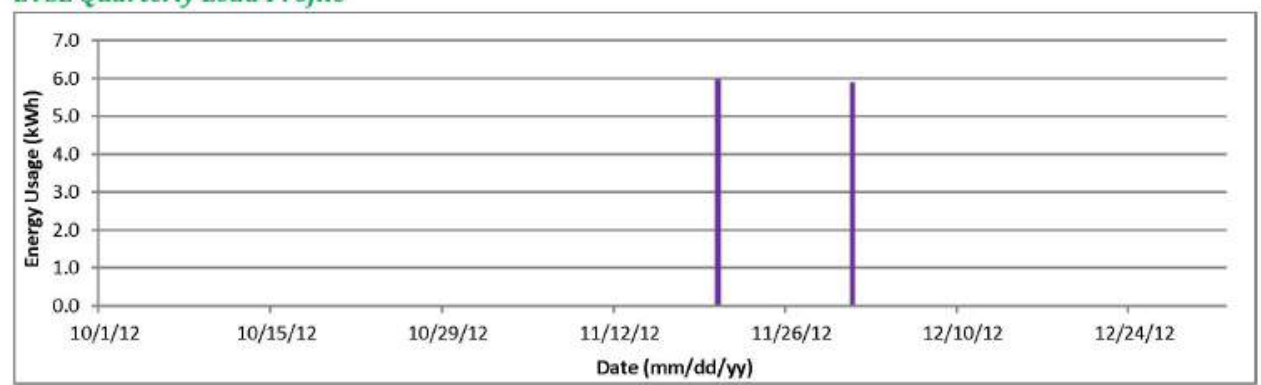

PV Array Quarterly Power Generation Profile

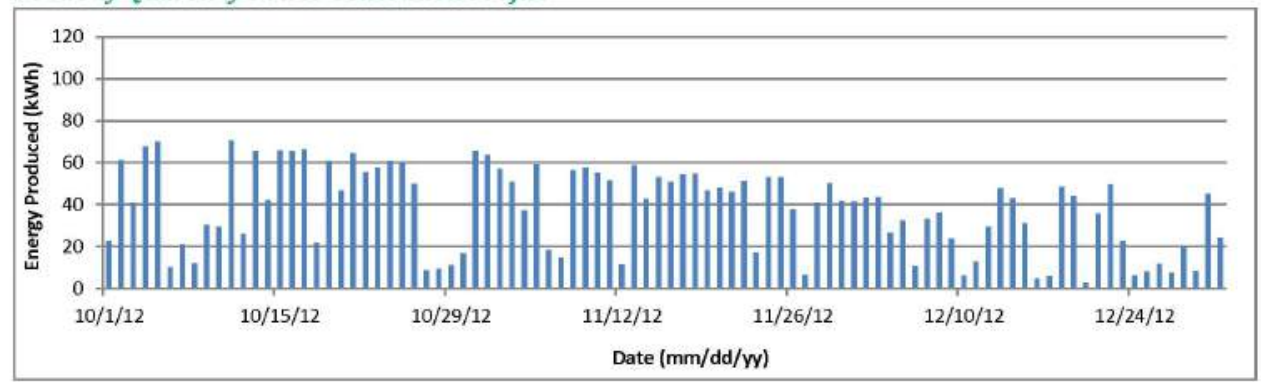

Based on the total energy consumption and an average of miles per $\mathrm{kWh}$ for the Nissan Leaf ( $2.94 \mathrm{mi} / \mathrm{kWh})$ and Chevy Volt $(2.78 \mathrm{mi} / \mathrm{kWh}$ ).

Values taken from http://www.fueleconomv.gov/.

"Based on energy consumption and size of battery for the Nissan Leaf ( $24 \mathrm{kWh}$ ) and Chevy Volt (16 kWh).

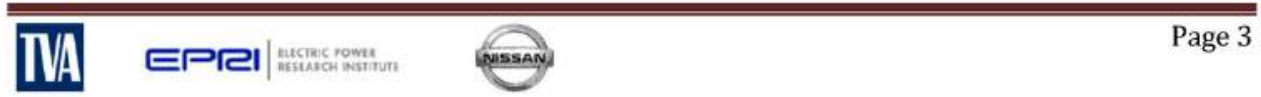




\section{Oak Ridge NaTiOnAL LabORATORY}

EV Project Solar-Assisted Charging Infrastructure Summary Report

EVSE Grouping/Region: UTK Agriculture

Report Period: October 1-December 31, 2013 (Quarter 4, 2013)

Number of EV Charging Stations: 8

$\exists \boldsymbol{F} /$ Project

\begin{tabular}{|c|c|c|c|c|c|}
\hline \multicolumn{2}{|l|}{ Usage Statistics } & Q1 & Q2 & Q3 & Q4 \\
\hline Number of charging events & & 10 & 15 & 15 & 32 \\
\hline Percent of time (connected vehicles) & & $0.1 \%$ & $0.1 \%$ & $0.1 \%$ & $0.2 \%$ \\
\hline Percent of time (charging vehicles) & & $0.1 \%$ & $0.1 \%$ & $0.1 \%$ & $0.2 \%$ \\
\hline Installation Statistics & Q1 & Q2 & Q3 & Q4 & 2013 Totals \\
\hline Solar-energy generated (MWh) & 3.52 & 6.44 & 5.79 & 3.50 & 19.25 \\
\hline Energy consumed (MWh) & 0.04 & 0.07 & 0.04 & 0.10 & 0.25 \\
\hline Net energy generation (MWh) & 3.48 & 6.38 & 5.75 & 3.40 & 19.01 \\
\hline Total distance traveled $(\mathrm{mi})^{i}$ & 128 & 188 & 114 & 292 & 722 \\
\hline
\end{tabular}

Time Series Analysis
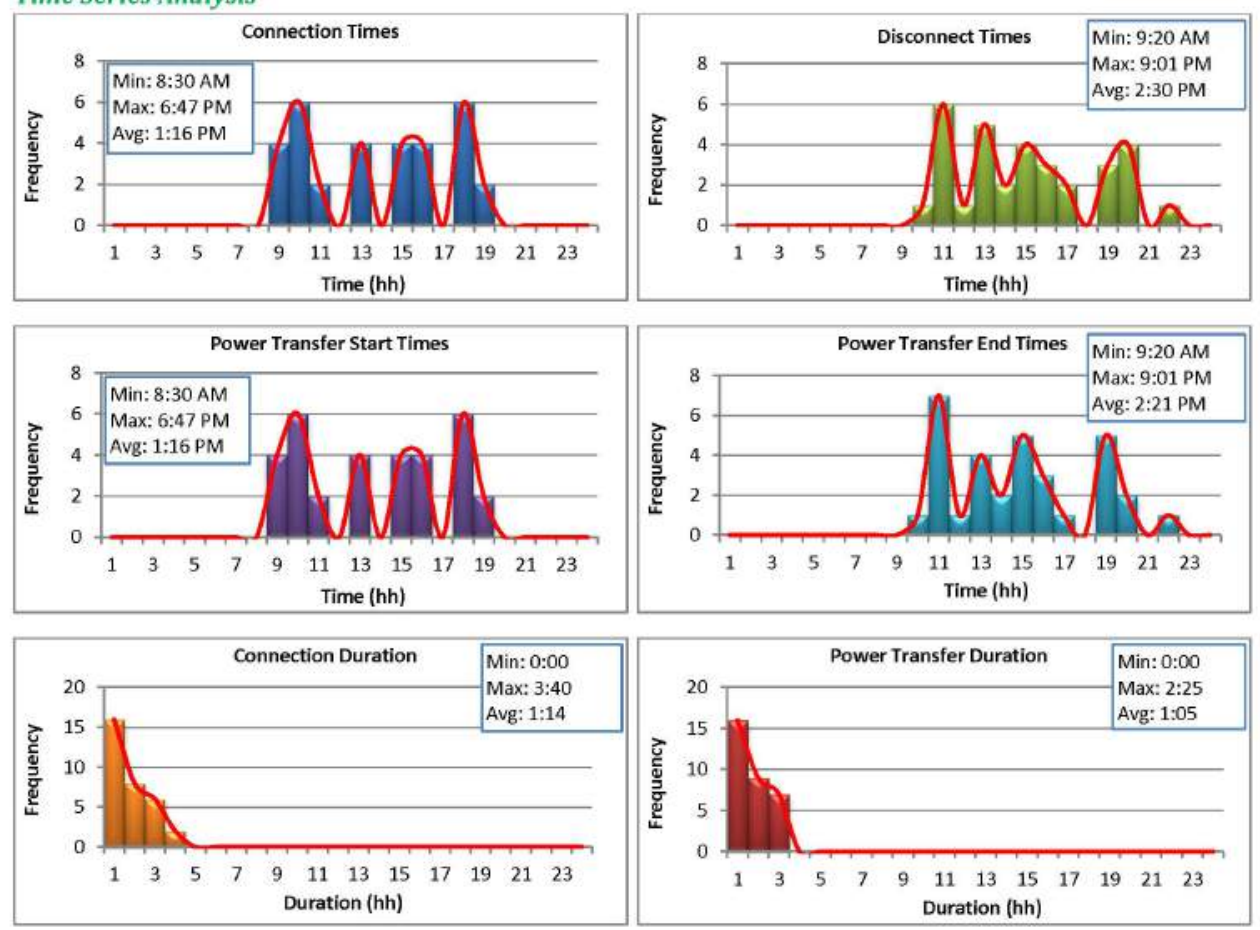

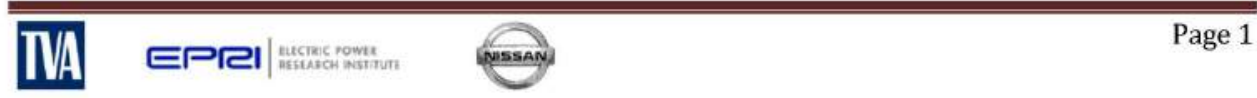




\section{OAK RIDGE NATIONAL LABORATORY}

Energy Consumption Analysis
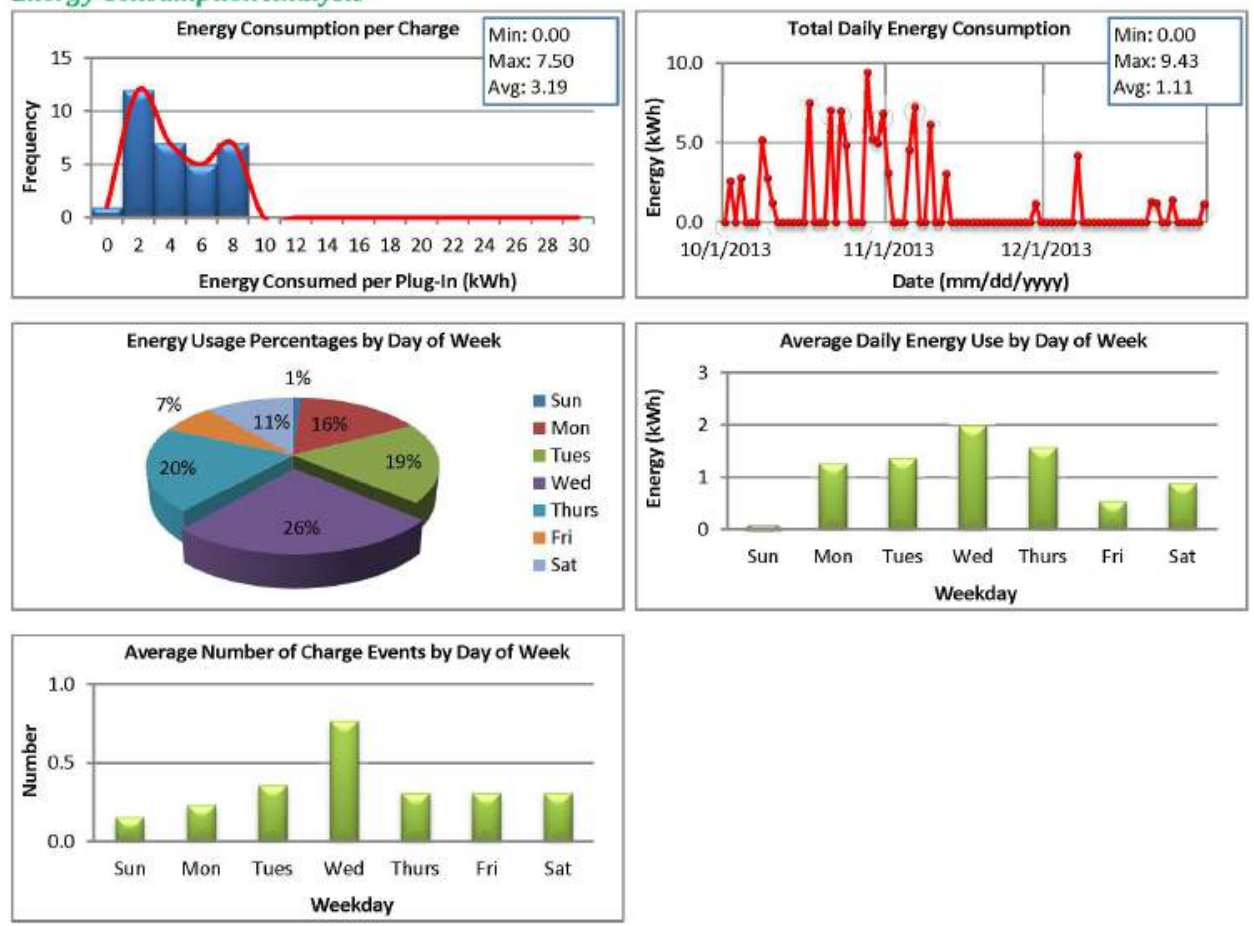

Charging Analysis
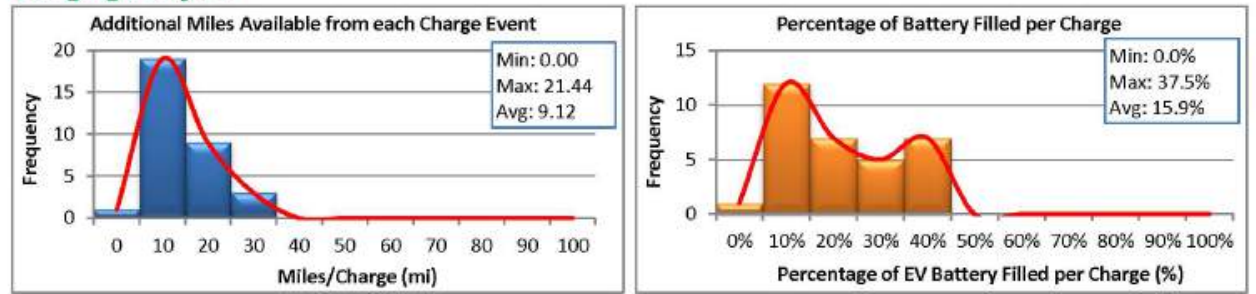

EVSE Analysis

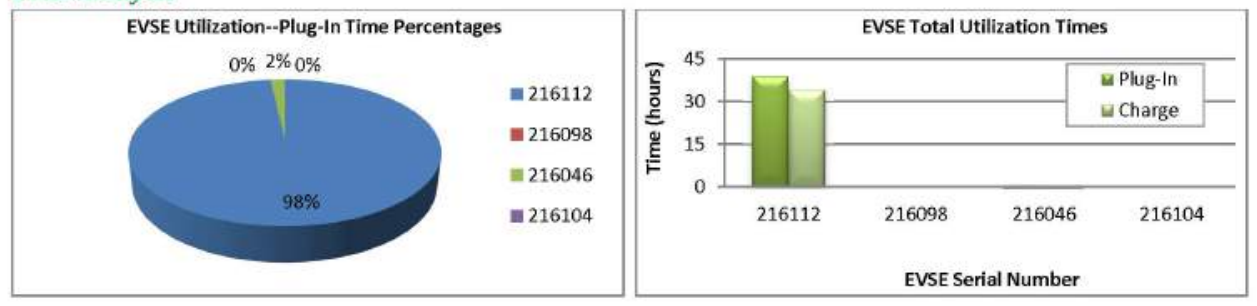

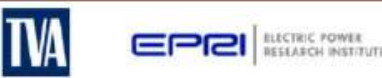

Page 2 


\section{soner}

\begin{tabular}{|c|c|c|c|c|}
\hline Report Period Summary & Q1 & Q2 & Q3 & Q4 \\
\hline Average connection duration (hrs.) & 1.9 & 1.6 & 0.9 & 1.2 \\
\hline Average charge duration (hrs.) & 1.2 & 1.3 & 0.8 & 1.1 \\
\hline Average miles per charge & 12.8 & 12.5 & 7.6 & 9.1 \\
\hline $\begin{array}{l}\text { Average } \% \text { of battery filled per } \\
\text { charge event } t^{\mathrm{ii}}\end{array}$ & $22.4 \%$ & $21.9 \%$ & $13.2 \%$ & $15.9 \%$ \\
\hline
\end{tabular}

EVSE Quarterly Load Profile

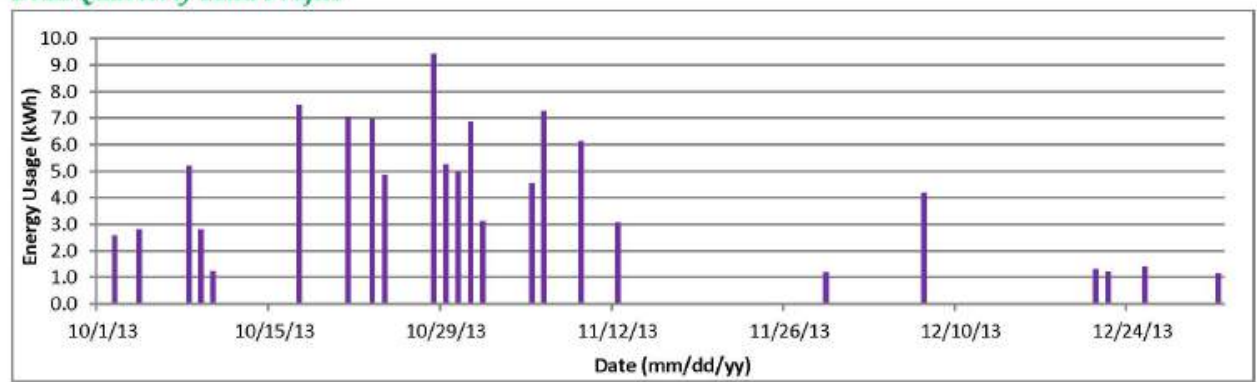

PV Array Quarterly Power Generation Profile

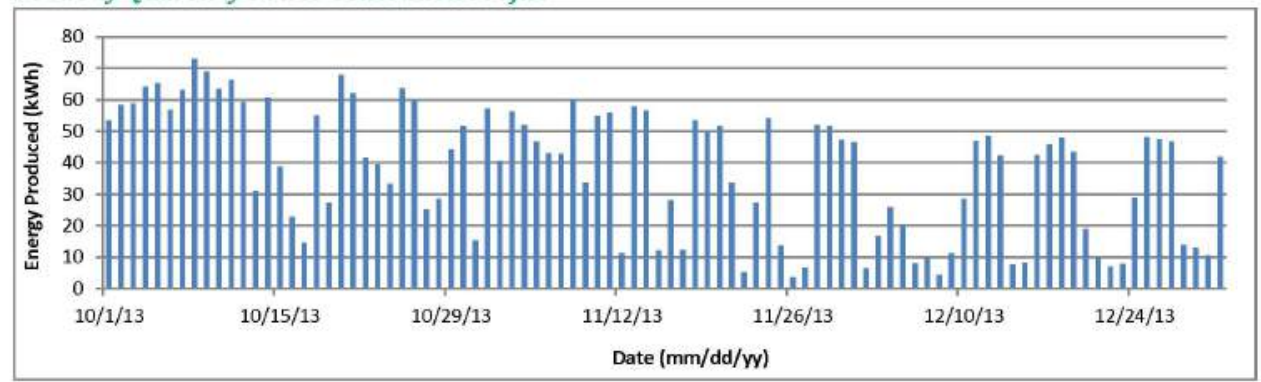

Based on the total energy consumption and an average of miles per $\mathrm{kWh}$ for the Nissan Leaf ( $2.94 \mathrm{mi} / \mathrm{kWh})$ and Chevy Volt $(2.78 \mathrm{mi} / \mathrm{kWh})$.

Values taken from htto://www.fueleconomy.gov/.

Based on energy consumption and size of battery for the Nissan Leaf ( $24 \mathrm{kWh})$ and Chevy Volt ( $16 \mathrm{kWh}$ ).

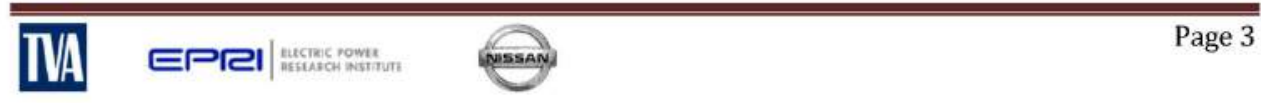




\section{Oak Ridge NaTiOnAL LabORATORY}

EV Project Solar-Assisted Charging Infrastructure Summary Report

EVSE Grouping/Region: UTK Agriculture

Report Period: April 1-June 30, 2014 (Quarter 2, 2014)

Number of EV Charging Stations: 8

$\exists \boldsymbol{F}$ Project

\begin{tabular}{|c|c|c|c|c|c|}
\hline Usage Statistics & & Q1 & Q2 & Q3 & Q4 \\
\hline Number of charging events & & 23 & 27 & - & - \\
\hline Percent of time (connected vehicles) & & $0.2 \%$ & $0.3 \%$ & - & - \\
\hline Installation Statistics & Q1 & Q2 & Q3 & Q4 & 2014 Totals \\
\hline Solar-energy generated (MWh) & 4.06 & 6.34 & - & - & 10.4 \\
\hline Energy consumed (MWh) & 0.06 & 0.09 & - & - & 0.15 \\
\hline Net energy generation (MWh) & 3.99 & 6.25 & - & - & 10.24 \\
\hline Total distance traveled $(\mathrm{mi})^{\mathrm{i}}$ & 181 & 245 & - & - & 426 \\
\hline
\end{tabular}

Time Series Analysis
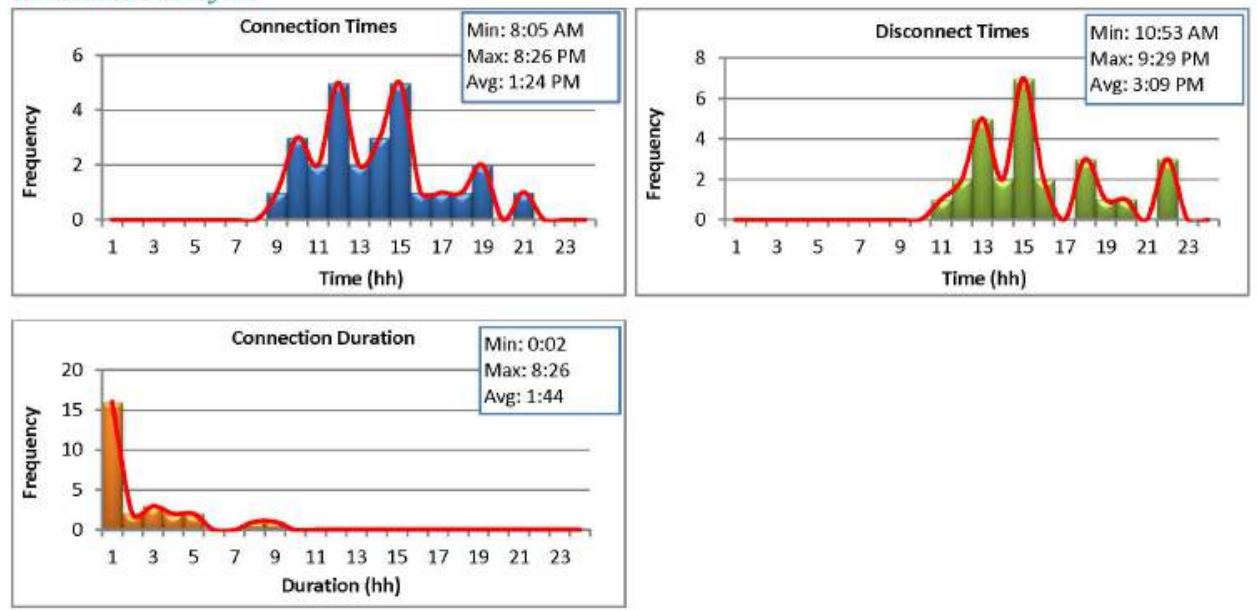

Page 1

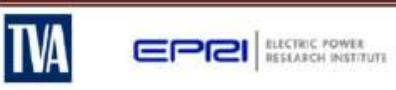




\section{OAK RIDGE NATIONAL LABORATORY}

Energy Consumption Analysis
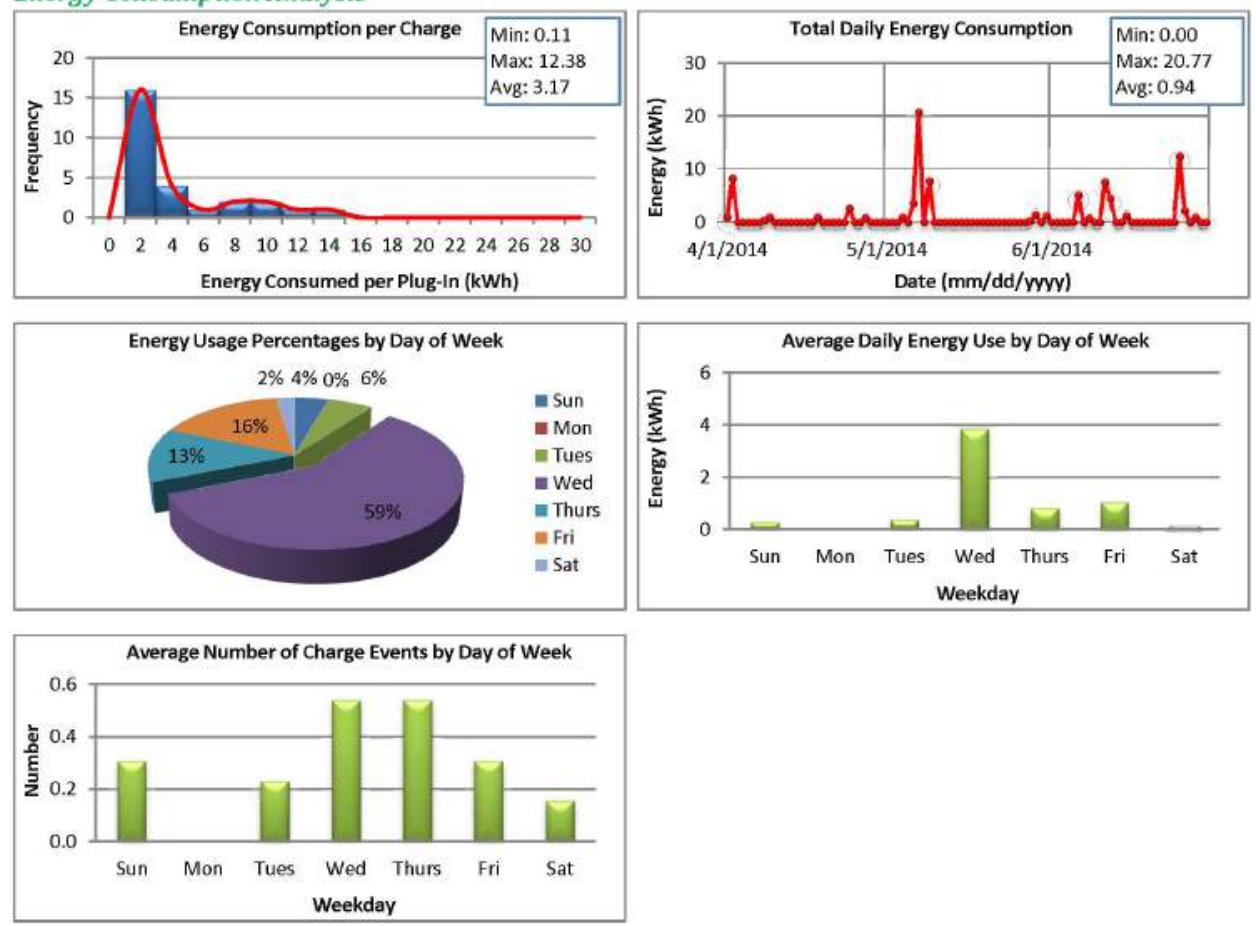

Charging Analysis
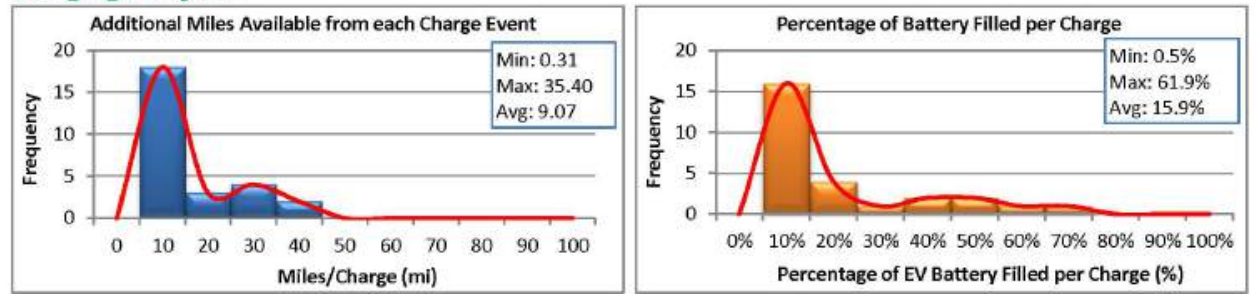

EVSE Analysís
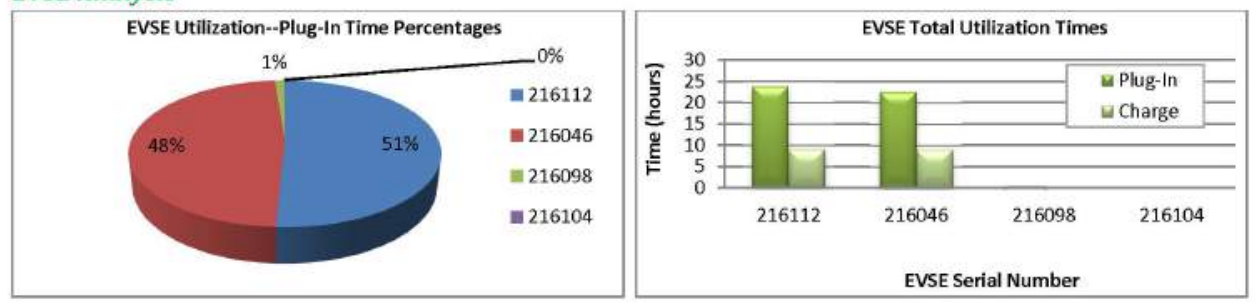

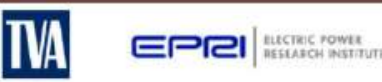

Page 2 


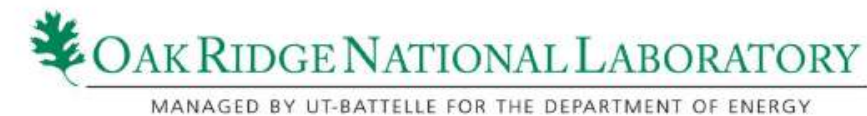

\begin{tabular}{|c|c|c|c|c|}
\hline Report Period Summary & Q1 & Q2 & Q3 & Q4 \\
\hline Average connection duration (hrs.) & 1.5 & 1.7 & - & - \\
\hline Average miles per charge ${ }^{i}$ & 7.9 & 9.1 & - & - \\
\hline $\begin{array}{l}\text { Average } \% \text { of battery filled per } \\
\text { charge event } \|\end{array}$ & $13.8 \%$ & $15.9 \%$ & - & - \\
\hline
\end{tabular}

EVSE Quarterly Load Profile

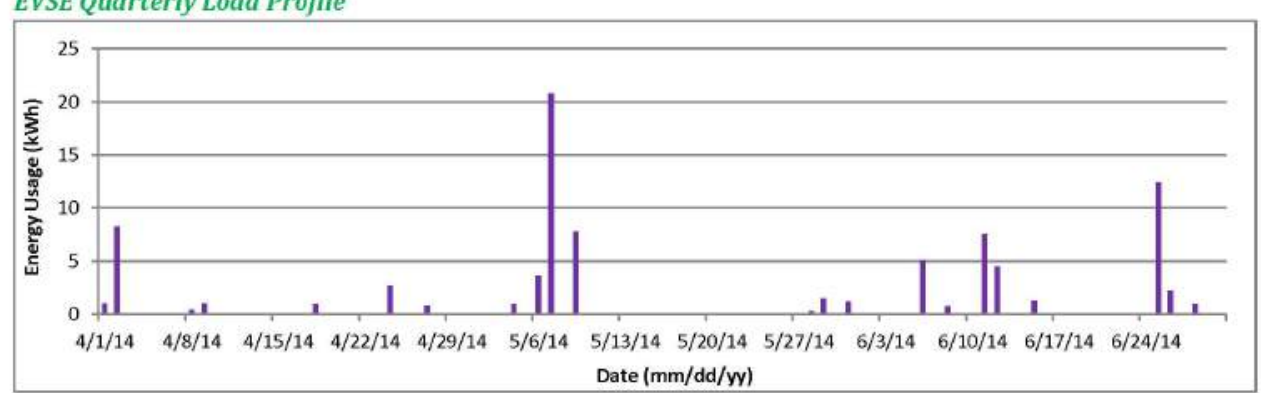

PV Array Quarterly Power Generation Profile

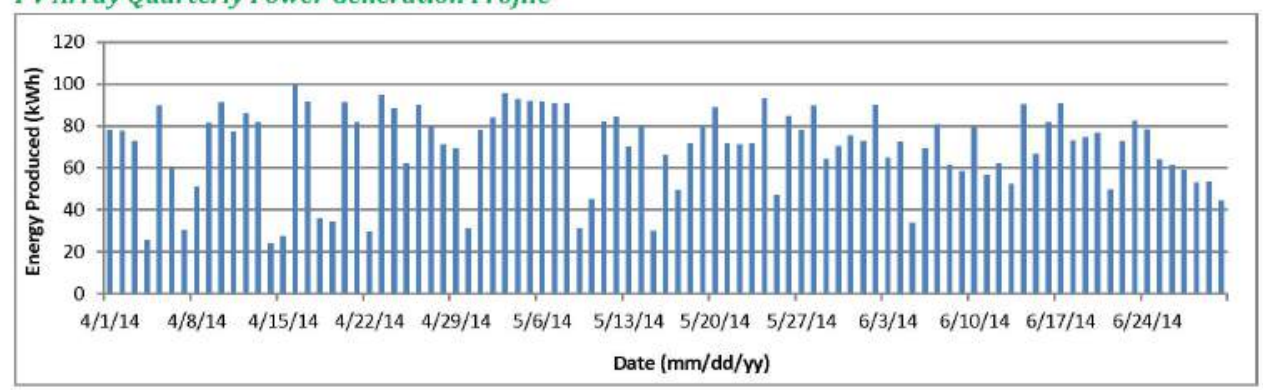

Based on the total energy consumption and an average of miles per $\mathrm{kWh}$ for the Nissan Leaf ( $2.94 \mathrm{mi} / \mathrm{kWh}$ ) and Chevy Volt ( $2.78 \mathrm{mi} / \mathrm{kWh}$ ).

Values taken from http://www.fueleconomy.gov/.

"Based on energy consumption and size of battery for the Nissan Leaf ( $24 \mathrm{kWh}$ ) and Chevy Volt (16 kWh).

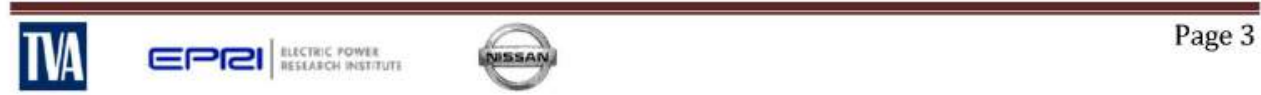




\section{A.7 University of Tennessee-Knoxville Music Building}

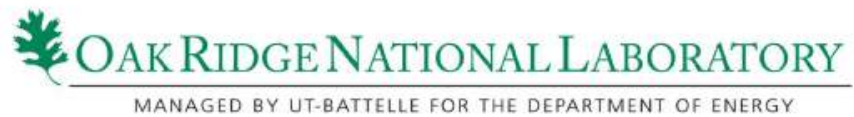

EV Project Solar-Assisted Charging Infrastructure Summary Report

EVSE Grouping/Region: UTK Music

Report Period: October 1-December 31, 2012 (Quarter 4, 2012)

Number of EV Charging Stations: 6

$=\mathbf{y}$ Project
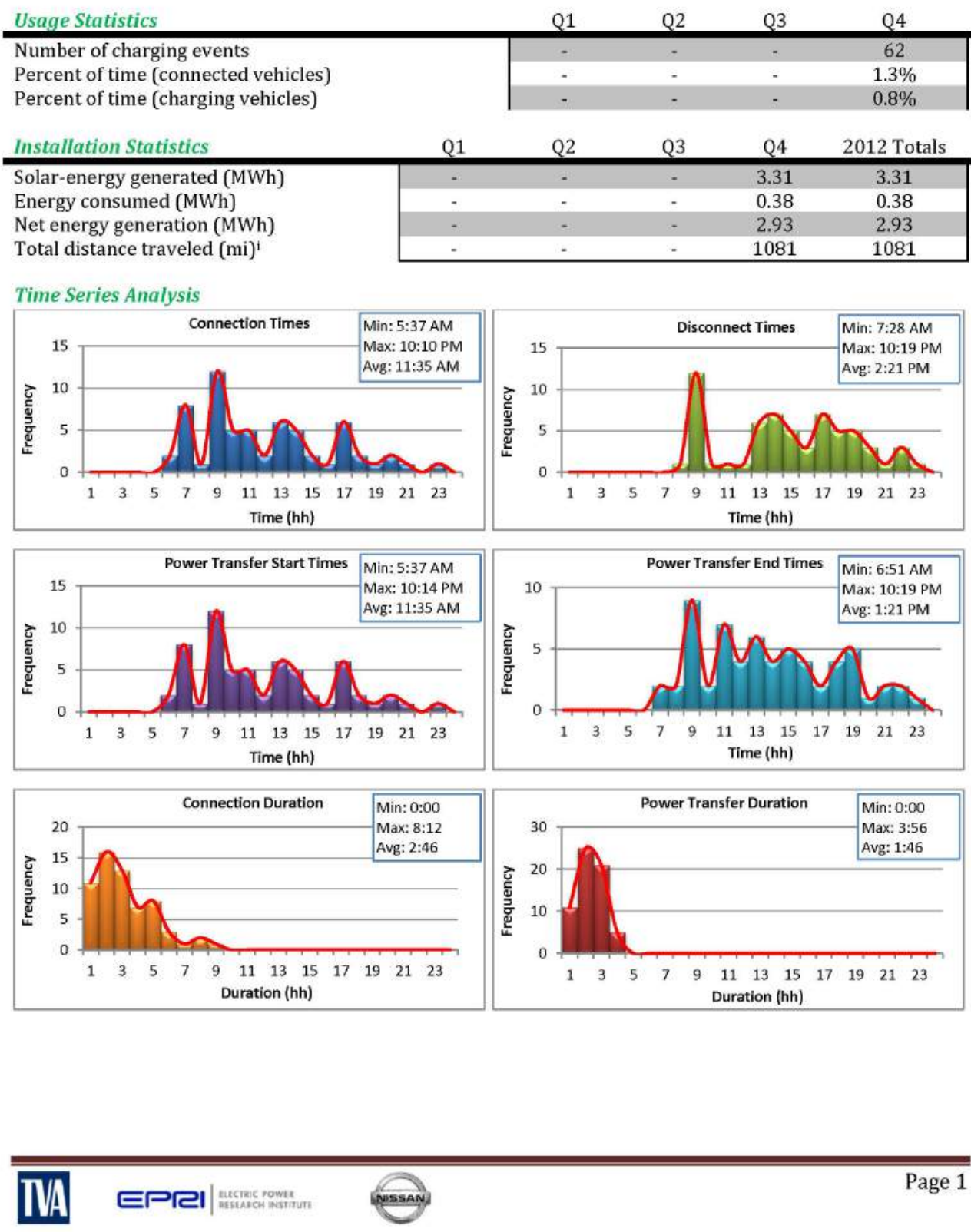


\section{OAK RIDGE NATIONAL LABORATORY}

Energy Consumption Analysis
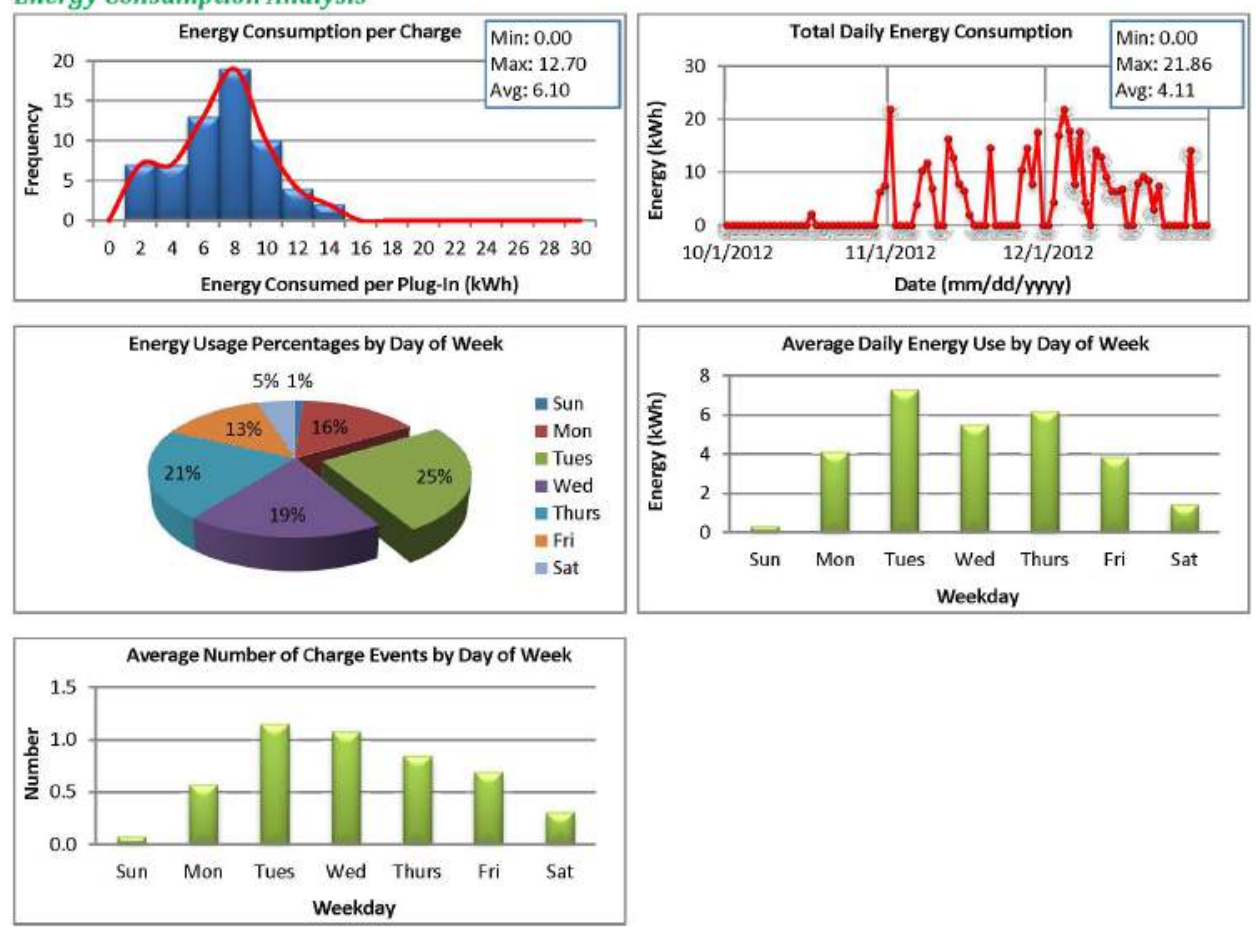

Charging Analysis
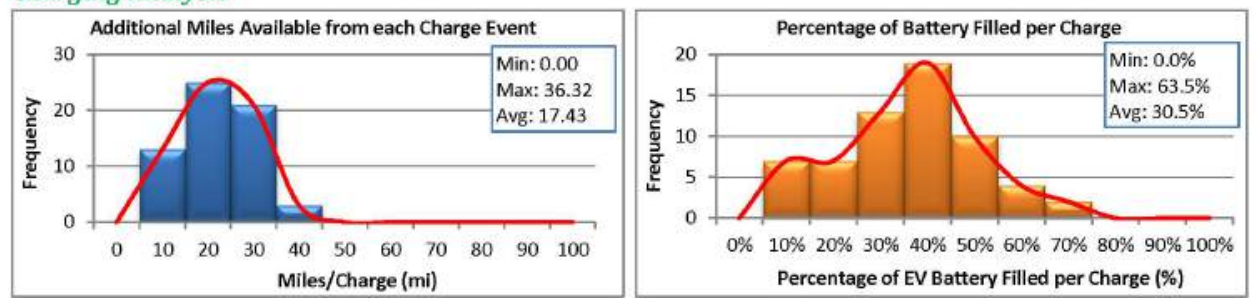

EVSE Analysis

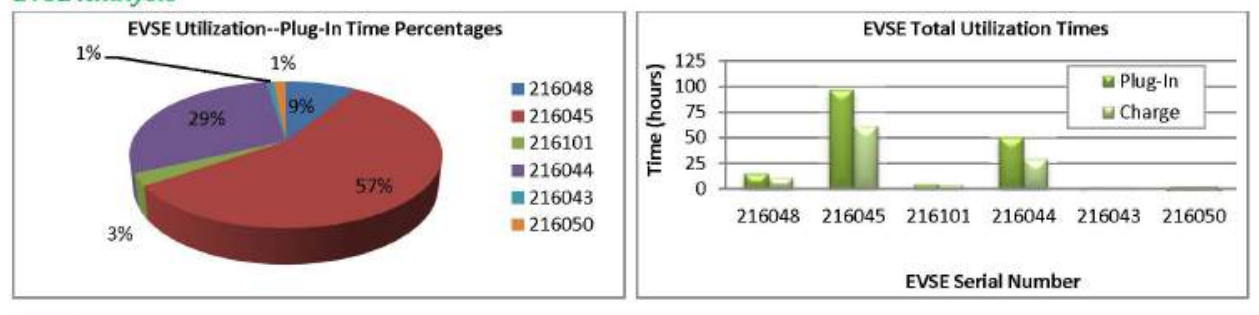

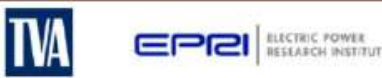

Page 2 


\section{OAK Ridge National LabORATORY}

\begin{tabular}{|c|c|c|c|c|}
\hline Report Period Summary & Q1 & Q2 & Q3 & Q4 \\
\hline Average connection duration (hrs.) & - & - & - & 2.8 \\
\hline Average charge duration (hrs.) & - & - & - & 1.8 \\
\hline Average miles per charge & - & - & - & 17.4 \\
\hline $\begin{array}{l}\text { Average } \% \text { of battery filled per } \\
\text { charge event } t^{\mathrm{ii}}\end{array}$ & - & - & - & $30.5 \%$ \\
\hline
\end{tabular}

EVSE Quarterly Load Profile

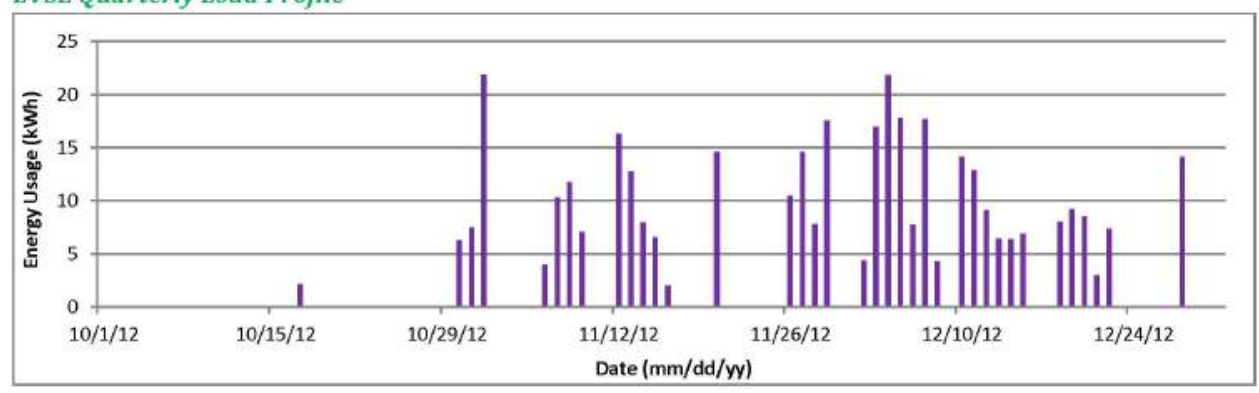

PV Array Quarterly Power Generation Profile

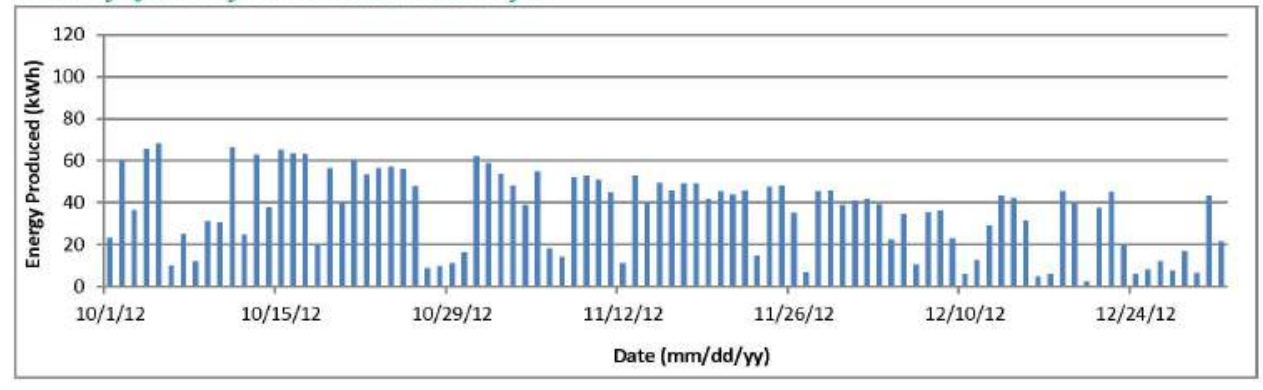

Based on the total energy consumption and an average of miles per $\mathrm{kWh}$ for the Nissan Leaf ( $2.94 \mathrm{mi} / \mathrm{kWh}$ ) and Chevy Volt ( $2.78 \mathrm{mi} / \mathrm{kWh}$.

Values taken from htto://www.fueleconomy.gov/.

"Based on energy consumption and size of battery for the Nissan Leaf ( $24 \mathrm{kWh}$ ) and Chevy Volt (16 kWh).

IVA EPRI|




\section{OAK RIDGE NATIONAL LABORATORY}

EV Project Solar-Assisted Charging Infrastructure Summary Report

EVSE Grouping/Region: UTK Music

Report Period: October 1-December 31, 2013 (Quarter 4, 2013)

Number of EV Charging Stations: 6

F/y Project

\begin{tabular}{|c|c|c|c|c|c|}
\hline \multicolumn{2}{|l|}{ Usage Statistics } & Q1 & Q2 & Q3 & Q4 \\
\hline \multirow{3}{*}{\multicolumn{2}{|c|}{$\begin{array}{l}\text { Number of charging events } \\
\text { Percent of time (connected vehicles) } \\
\text { Percent of time (charging vehicles) }\end{array}$}} & 105 & 131 & 107 & 166 \\
\hline & & $3.3 \%$ & $3.0 \%$ & $2.4 \%$ & $4.2 \%$ \\
\hline & & $2.0 \%$ & $2.0 \%$ & $1.5 \%$ & $2.5 \%$ \\
\hline Installation Statistics & Q1 & Q2 & Q3 & Q4 & 2013 Totals \\
\hline Solar-energy generated (MWh) & 3.34 & 6.34 & 5.63 & 3.29 & 18.6 \\
\hline Energy consumed (MWh) & 0.91 & 0.91 & 0.71 & 1.01 & 3.54 \\
\hline Net energy generation (MWh) & 2.43 & 5.42 & 4.92 & 2.28 & 15.05 \\
\hline Total distance traveled $(\mathrm{mi})^{i}$ & 2608 & 2615 & 2028 & 2890 & 10141 \\
\hline
\end{tabular}

Time Series Analysis
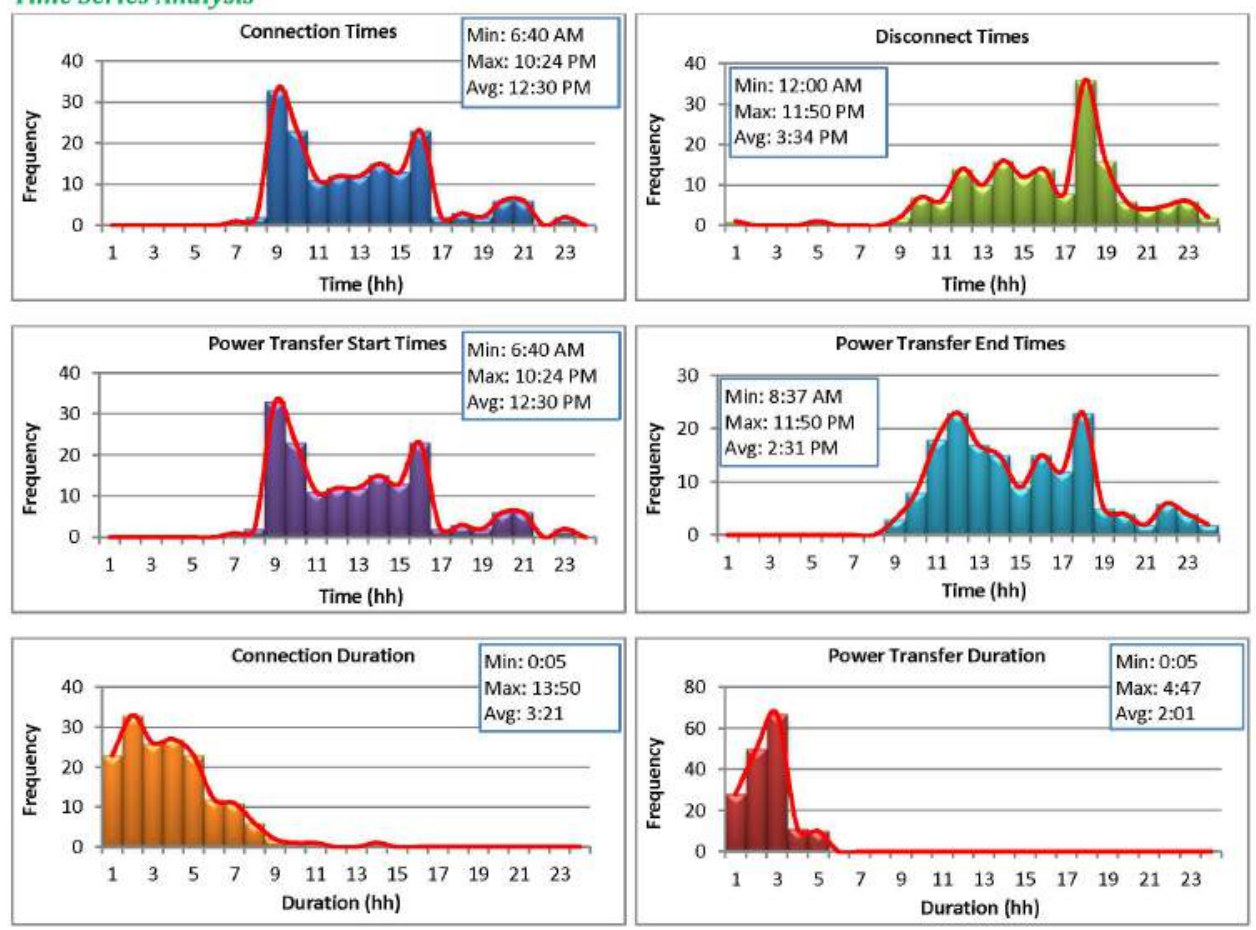

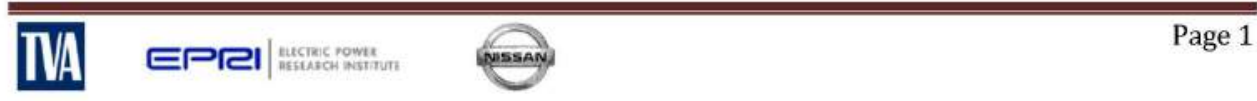




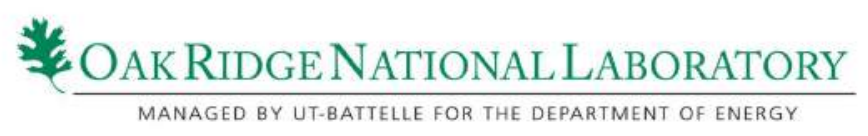

Energy Consumption Analysis
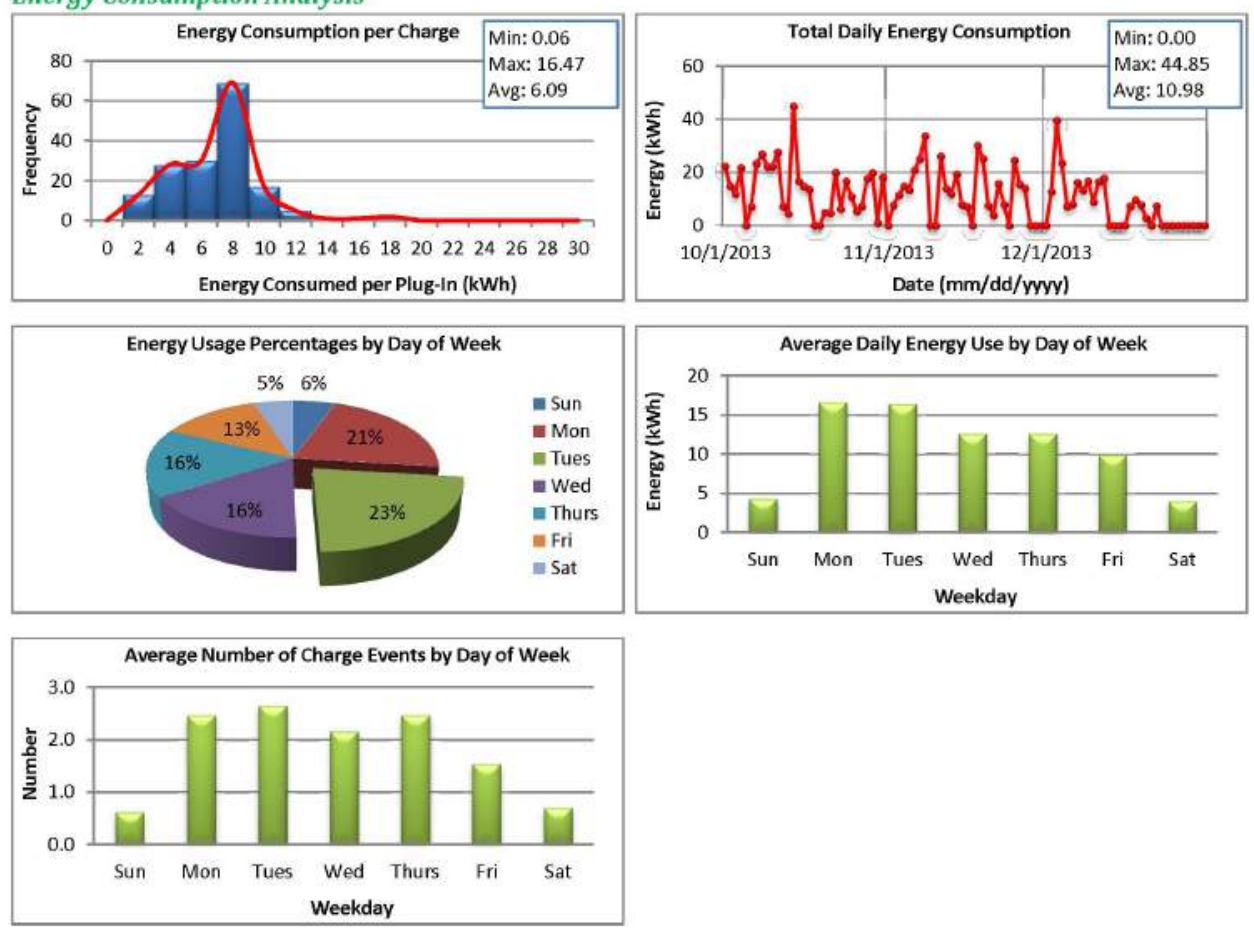

Charging Analysis
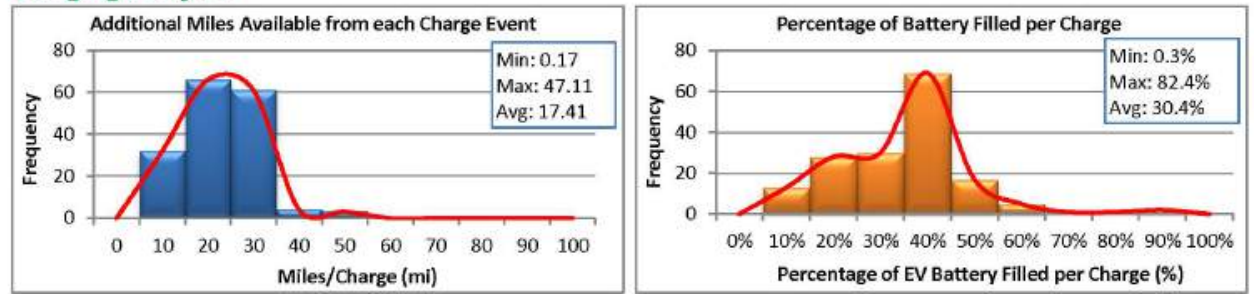

EVSE Analysís

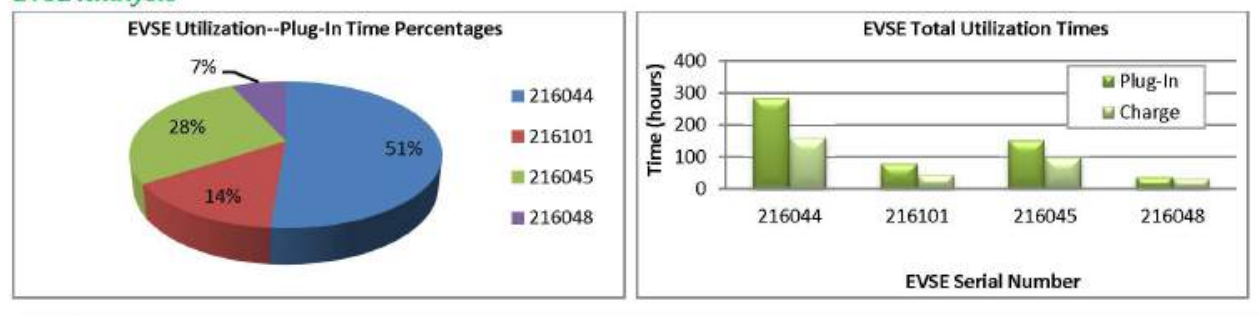

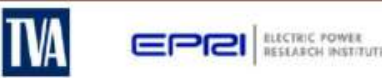

Page 2 


\section{soner}

\begin{tabular}{|c|c|c|c|c|}
\hline Report Period Summary & Q1 & Q2 & Q3 & Q4 \\
\hline Average connection duration (hrs.) & - & 3.0 & 3.0 & 3.4 \\
\hline Average charge duration (hrs.) & - & 2.0 & 1.9 & 2.0 \\
\hline Average miles per charge & - & 20.0 & 18.9 & 17.4 \\
\hline $\begin{array}{l}\text { Average } \% \text { of battery filled per } \\
\text { charge event }{ }^{\mathrm{ii}}\end{array}$ & - & $34.9 \%$ & $33.1 \%$ & $30.4 \%$ \\
\hline
\end{tabular}

EVSE Quarterly Load Profile

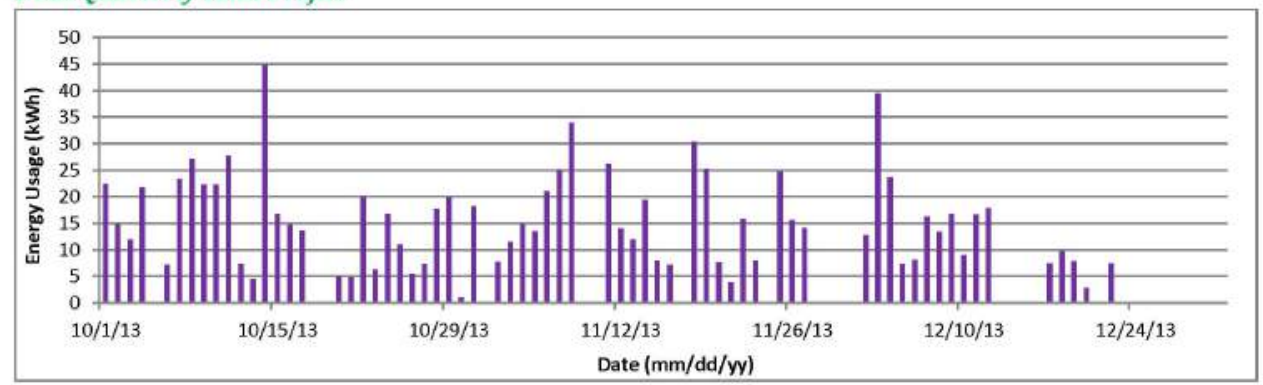

PV Array Quarterly Power Generation Profile

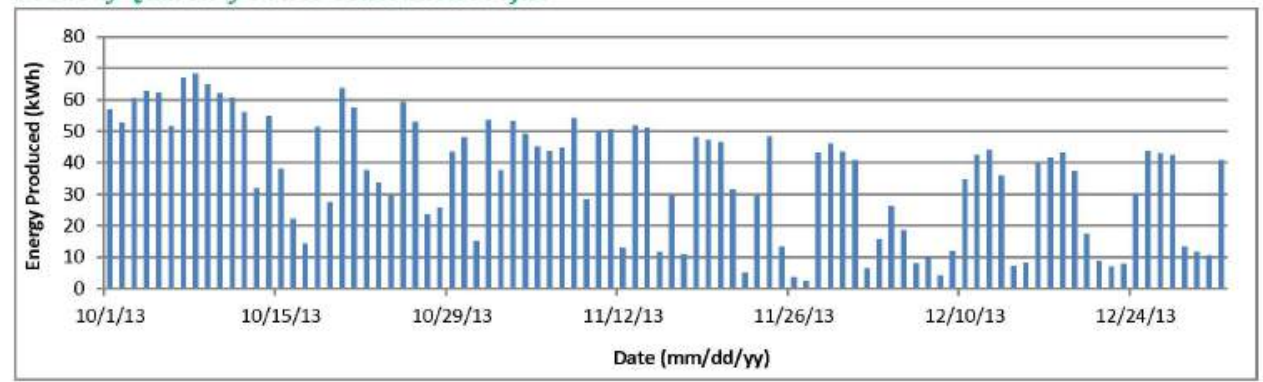

Based on the total energy consumption and an average of miles per kWh for the Nissan Leaf ( $2.94 \mathrm{mi} / \mathrm{kWh}$ ) and Chevy Volt $(2.78 \mathrm{mi} / \mathrm{kWh})$.

Values taken from http://www.fueleconomv.gov/.

"Based on energy consumption and size of battery for the Nissan Leaf ( $24 \mathrm{kWh}$ ) and Chevy Volt ( $16 \mathrm{kWh}$ ).

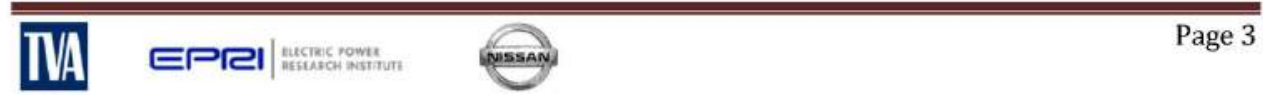




\section{Oak Ridge NaTiOnAL LabORATORY}

EV Project Solar-Assisted Charging Infrastructure Summary Report

EVSE Grouping/Region: UTK Music

Report Period: April 1-June 30, 2014 (Quarter 2, 2014)

Number of EV Charging Stations: 6

$\exists \boldsymbol{F}$ Project

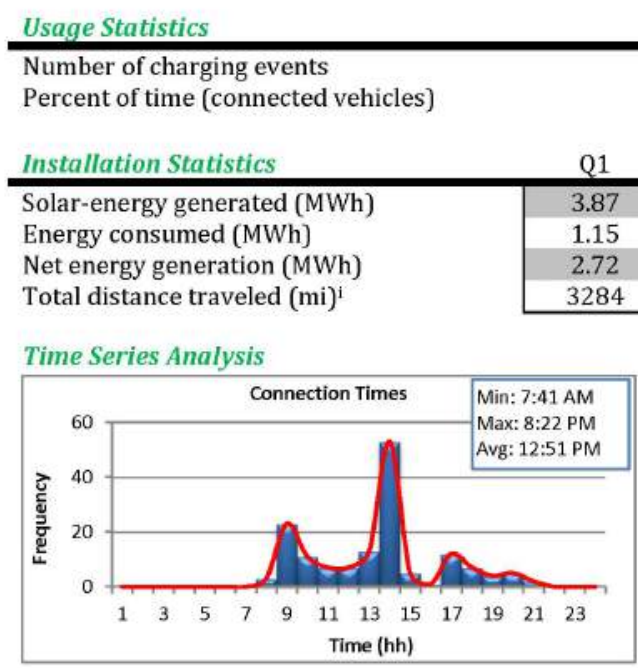

\begin{tabular}{cccc|} 
Q1 & Q2 & Q3 & Q4 \\
\hline 183 & 153 & - & - \\
$5.0 \%$ & $3.7 \%$ & - & - \\
\hline & & & \\
Q2 & Q3 & Q4 & 2014 Totals \\
\hline 6.23 & - & - & 10.1 \\
0.99 & - & - & 2.14 \\
5.24 & - & - & 7.96 \\
2845 & - & - & 6129 \\
\hline
\end{tabular}

Time Series Analysis
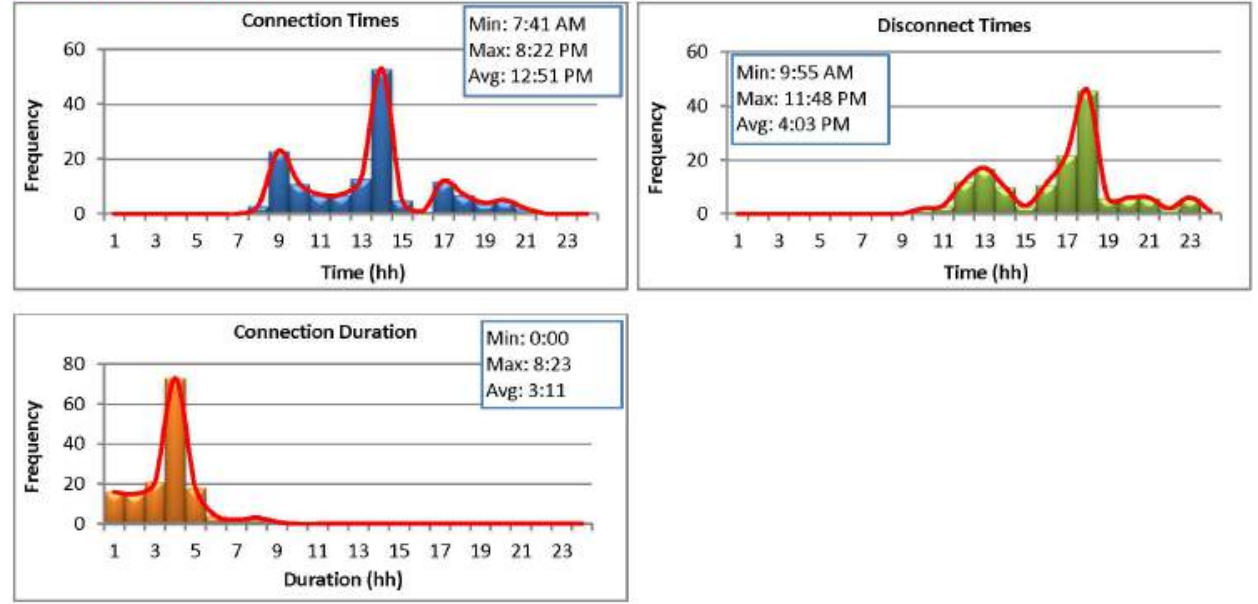

Page 1

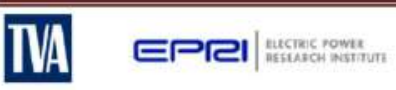




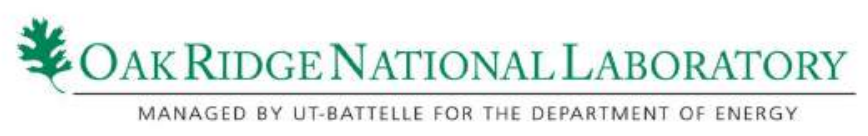

Energy Consumption Analysis
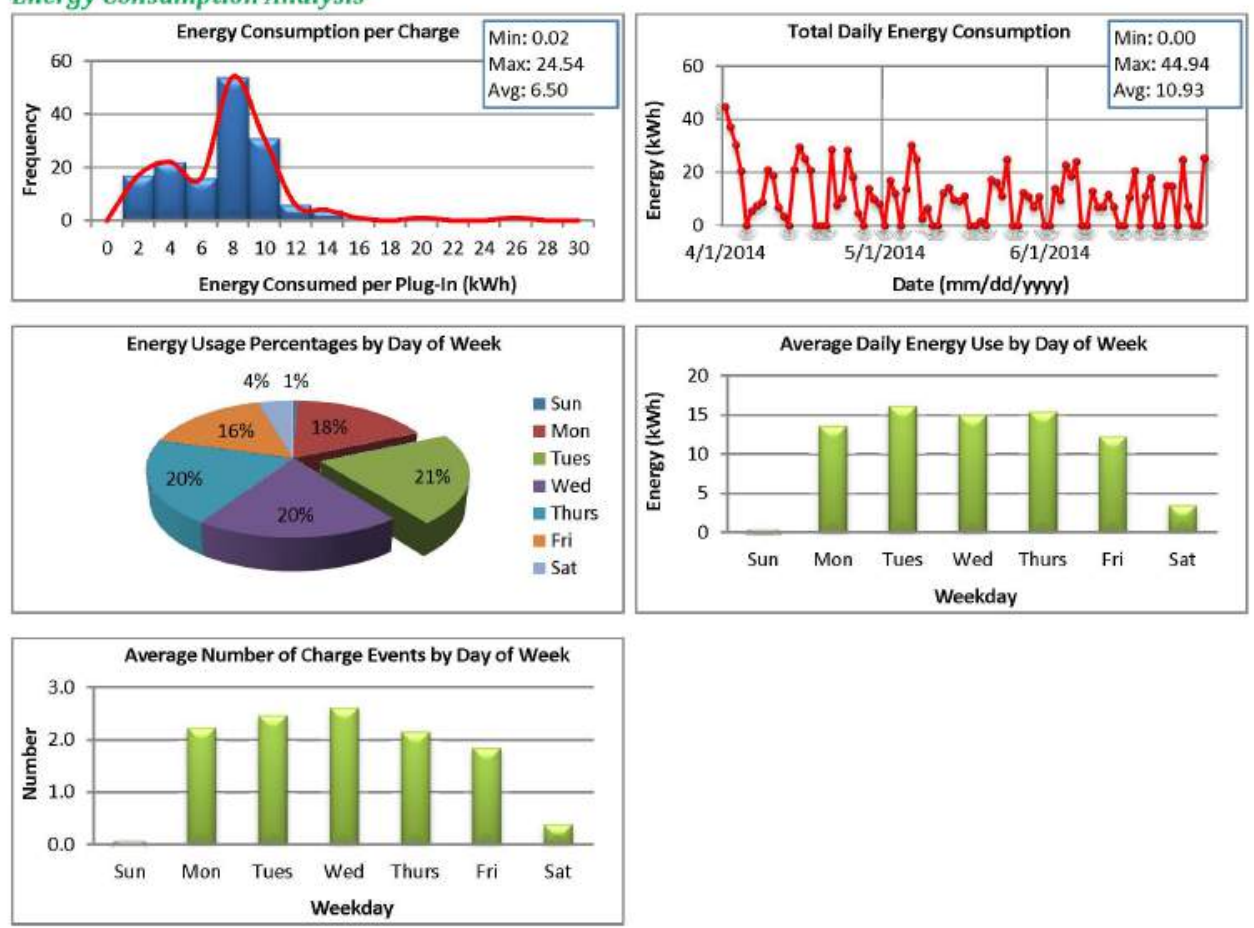

Charging Analysis
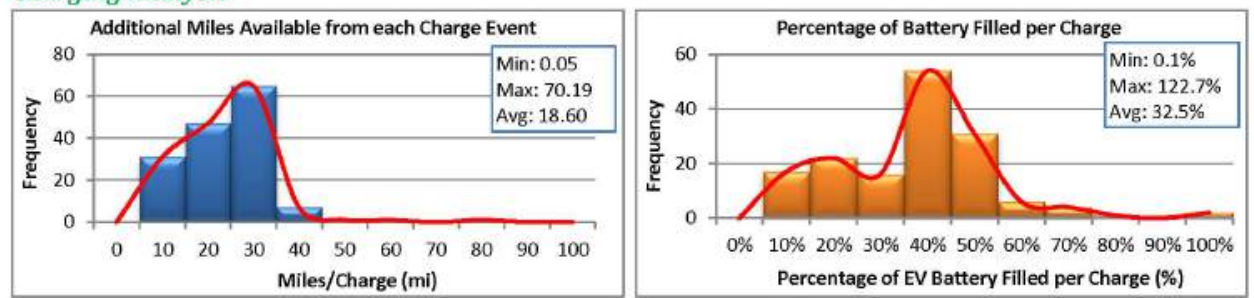

EVSE Analysís

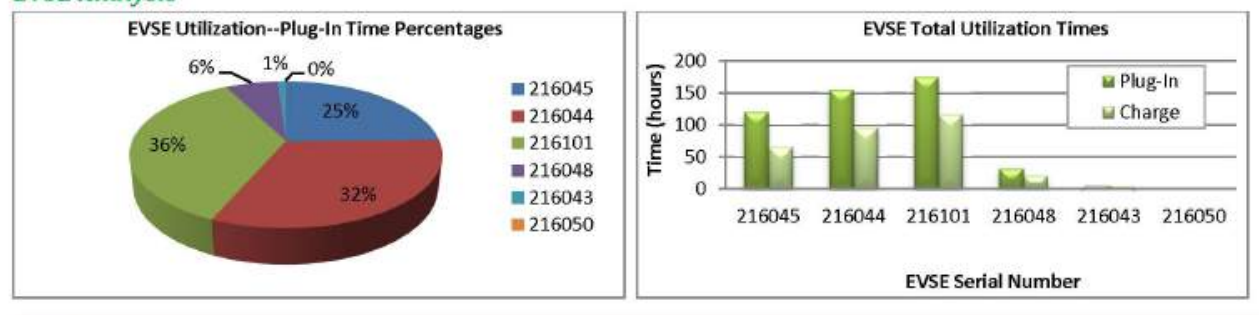

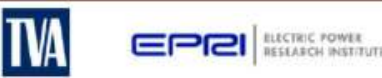

Page 2 


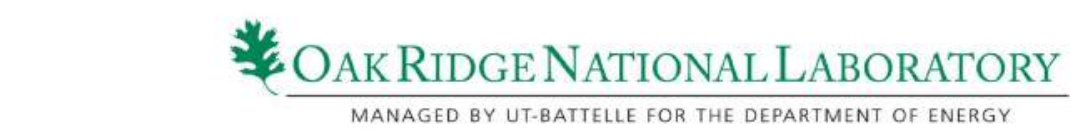

\begin{tabular}{l|cccc} 
Report Period Summary & Q1 & Q2 & Q3 & Q4 \\
\hline Average connection duration (hrs.) & 3.6 & 3.2 & - & - \\
\cline { 2 - 2 } & Average \% of battery filled per & 17.9 & 18.6 & - \\
$\quad \begin{array}{l}\text { Average } \\
\quad \text { charge event }\end{array}$ & $31.4 \%$ & $32.5 \%$ & -
\end{tabular}

EVSE Quarterly Load Profile

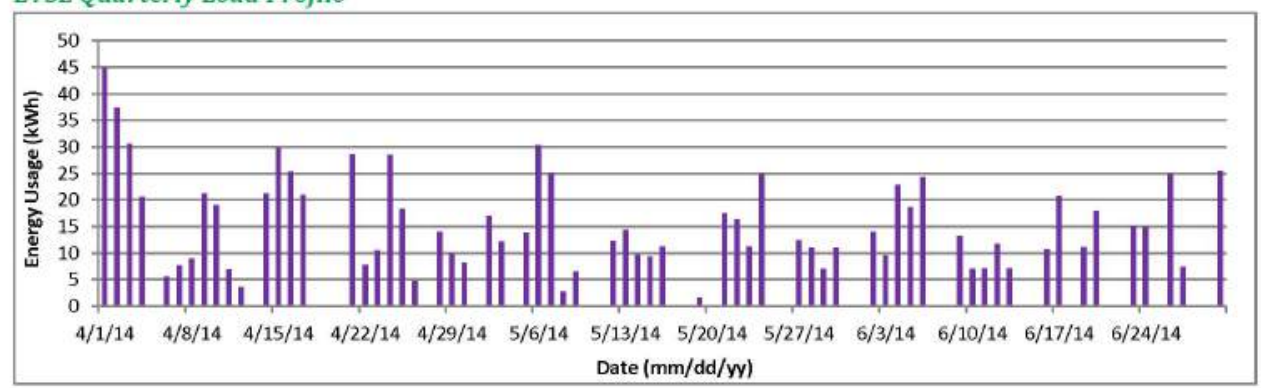

PV Array Quarterly Power Generation Profile

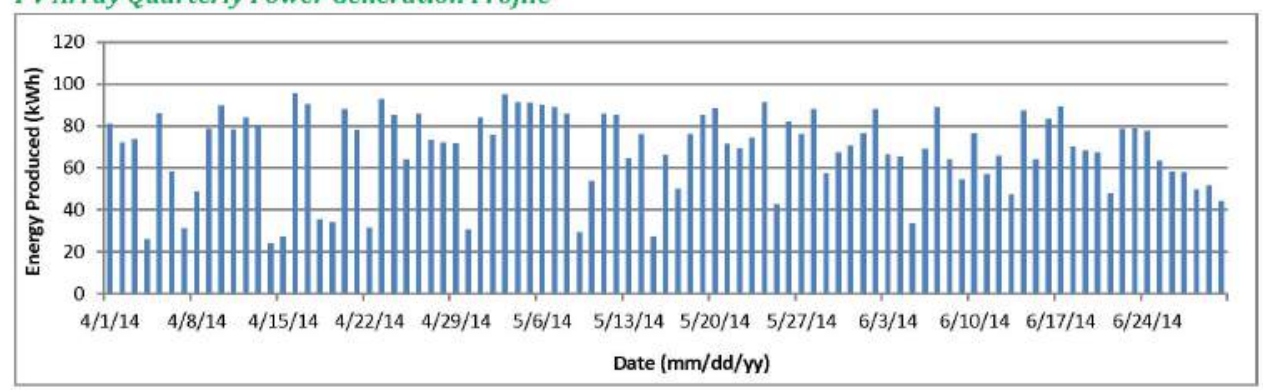

Based on the total energy consumption and an average of miles per $\mathrm{kWh}$ for the Nissan Leaf ( $2.94 \mathrm{mi} / \mathrm{kWh}$ ) and Chevy Volt $(2.78 \mathrm{mi} / \mathrm{kWh})$.

Values taken from http://www.fueleconomy.gov/.

"Based on energy consumption and size of battery for the Nissan Leaf ( $24 \mathrm{kWh}$ ) and Chevy Volt (16 kWh).

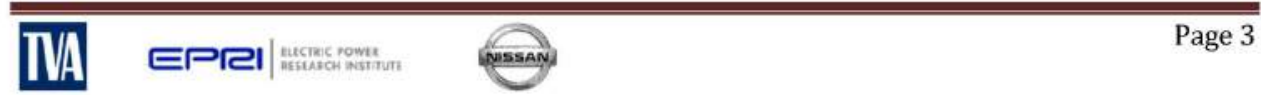




\section{A.8 LP Field, Nashville}

\section{$\frac{\text { OAK RIDGE NATIONAL LABORATORY }}{\text { MANAGED BY UT-BATTELLE FOR THE DEPARTMENT OF ENERGY }}$}

EV Project Solar-Assisted Charging Infrastructure Summary Report

EVSE Grouping/Region: LP Field

Report Period: October 1-December 31, 2012 (Quarter 4, 2012)

Number of EV Charging Stations: 8

\section{=1/Project}

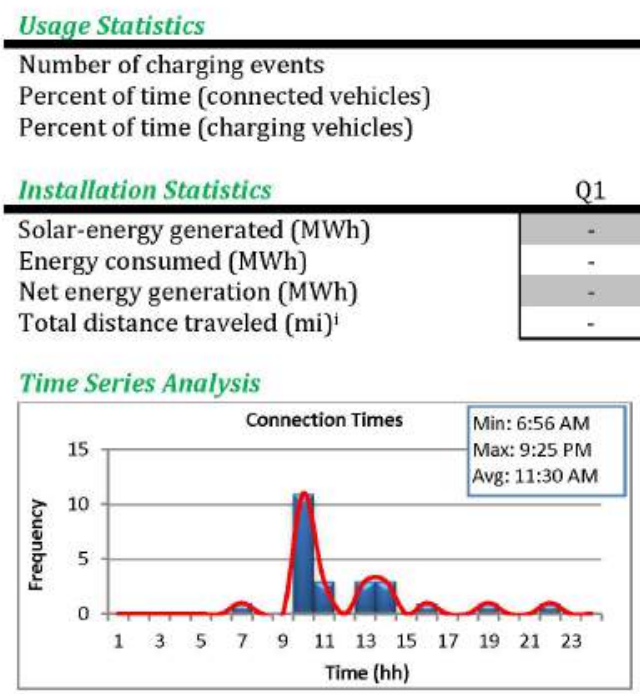

\begin{tabular}{cccc|}
$\mathrm{Q} 1$ & $\mathrm{Q} 2$ & $\mathrm{Q} 3$ & $\mathrm{Q} 4$ \\
\hline- & 15 & 13 & 24 \\
- & $0.1 \%$ & $0.2 \%$ & $0.5 \%$ \\
- & $0.0 \%$ & $0.1 \%$ & $0.2 \%$
\end{tabular}

\begin{tabular}{l|ccccc|} 
Installation Statistics & Q1 & Q2 & Q3 & Q4 & 2012 Totals \\
\hline Solar-energy generated (MWh) & - & 0.00 & 6.16 & 4.07 & 10.23 \\
Energy consumed $(\mathrm{MWh})$ & - & 0.04 & 0.09 & 0.12 & 0.25 \\
Net energy generation $(\mathrm{MWh})$ & - & -0.04 & 6.08 & 3.95 & 9.99 \\
Total distance traveled $(\mathrm{mi})^{\mathrm{i}}$ & - & 102 & 246 & 348 & 696 \\
\cline { 3 - 6 }
\end{tabular}

Time Series Analysis
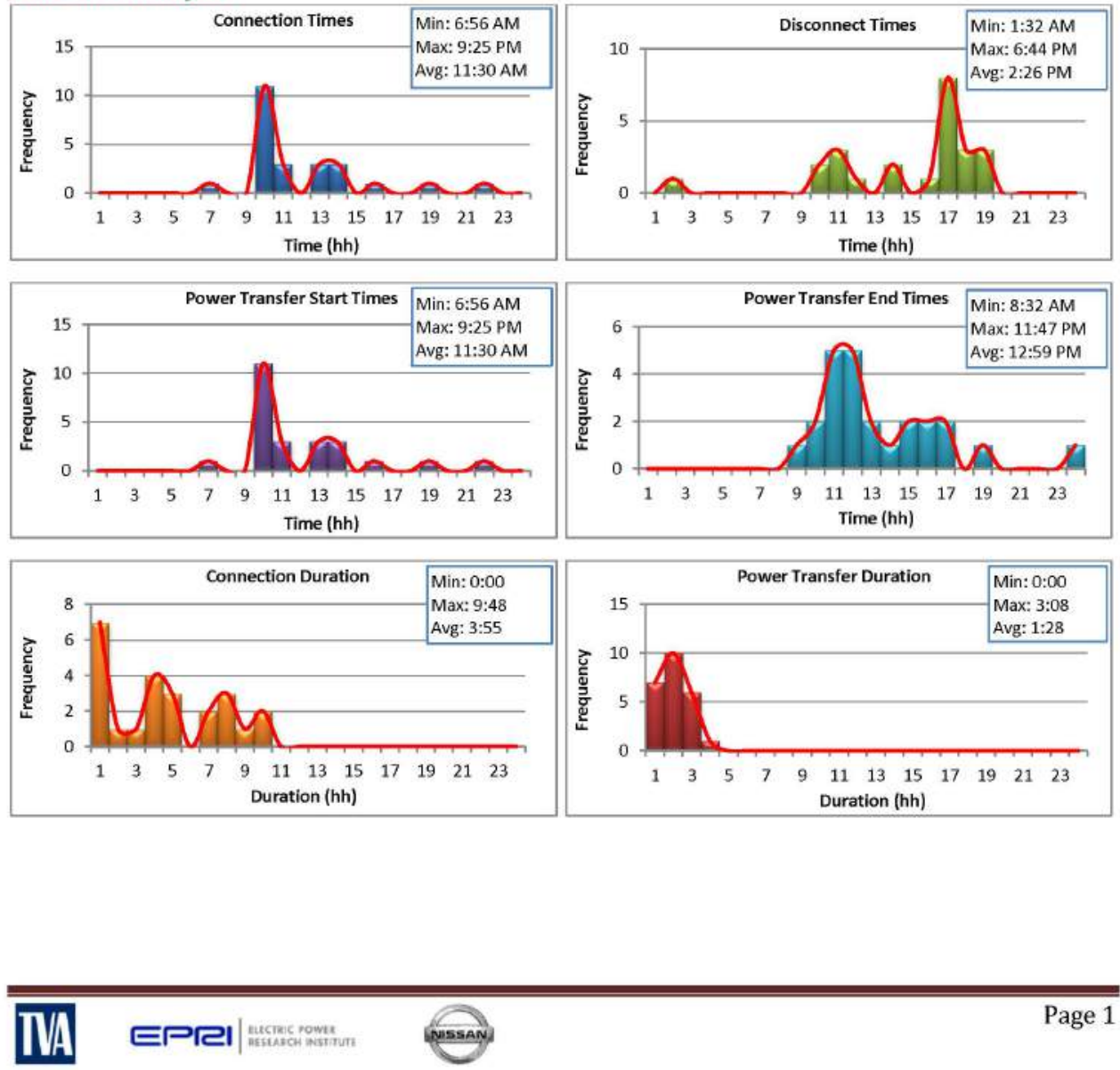


\section{OAK RIDGE NATIONAL LABORATORY}

Energy Consumption Analysis
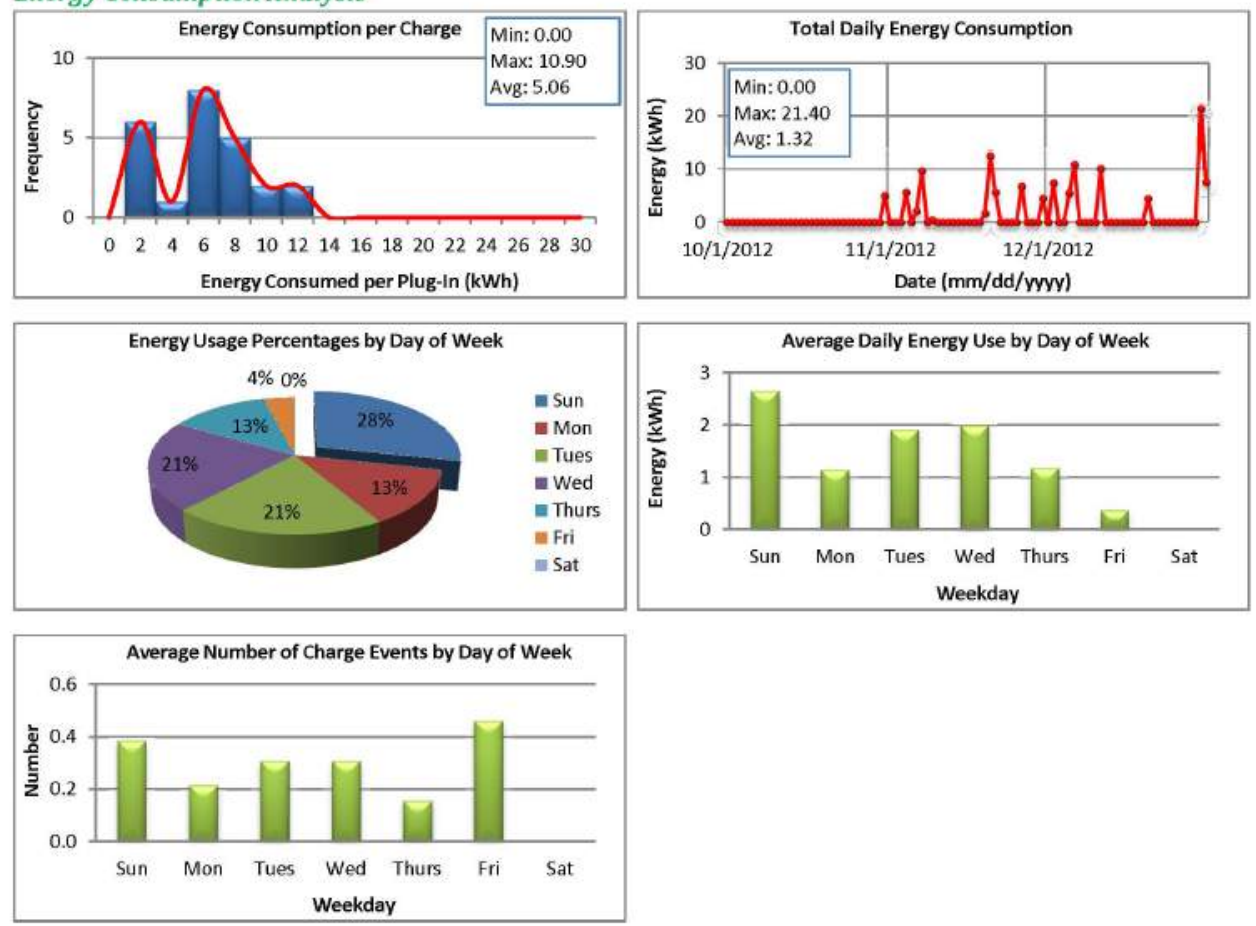

Charging Analysis
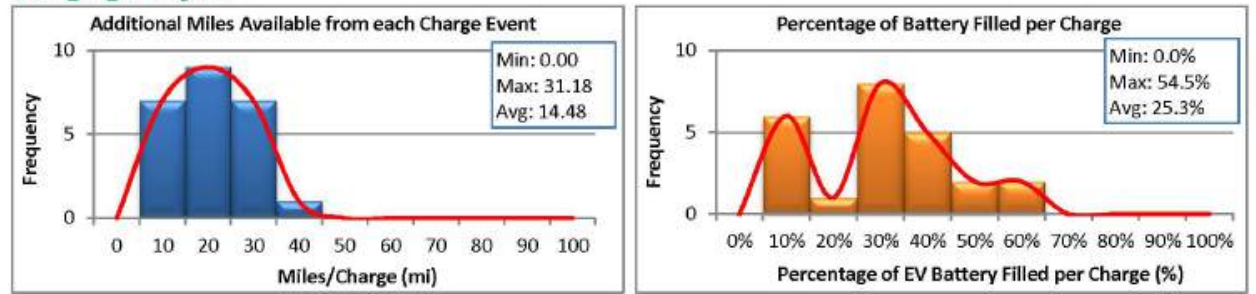

EVSE Analysís
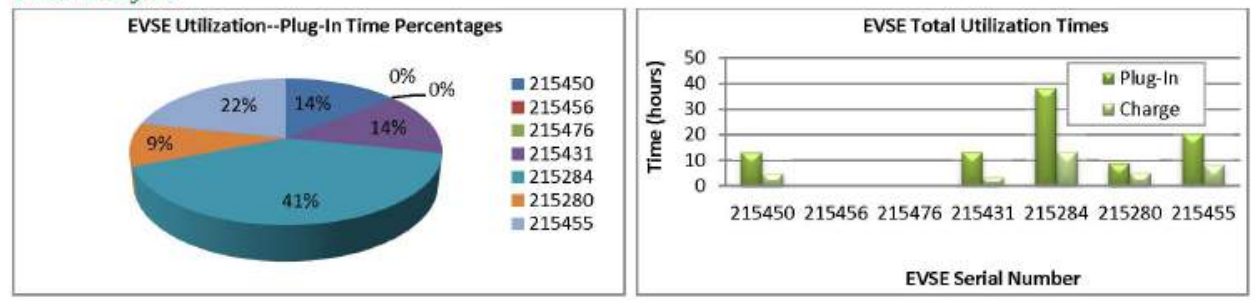

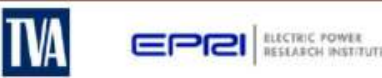

Page 2 


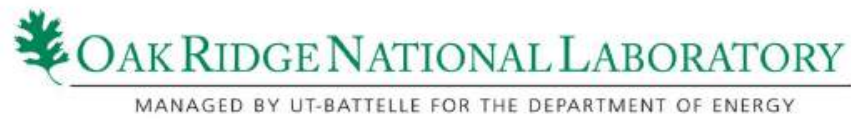

\begin{tabular}{|c|c|c|c|c|}
\hline Report Period Summary & Q1 & Q2 & Q3 & Q4 \\
\hline Average connection duration (hrs.) & - & 1.5 & 2.9 & 3.9 \\
\hline Average charge duration (hrs.) & - & 0.4 & 1.9 & 1.5 \\
\hline Average miles per charge & - & 6.8 & 18.9 & 14.5 \\
\hline $\begin{array}{l}\text { Average } \% \text { of battery filled per } \\
\text { charge event }{ }^{\mathrm{ii}}\end{array}$ & - & $11.9 \%$ & $33.0 \%$ & $25.3 \%$ \\
\hline
\end{tabular}

EVSE Quarterly Load Profile

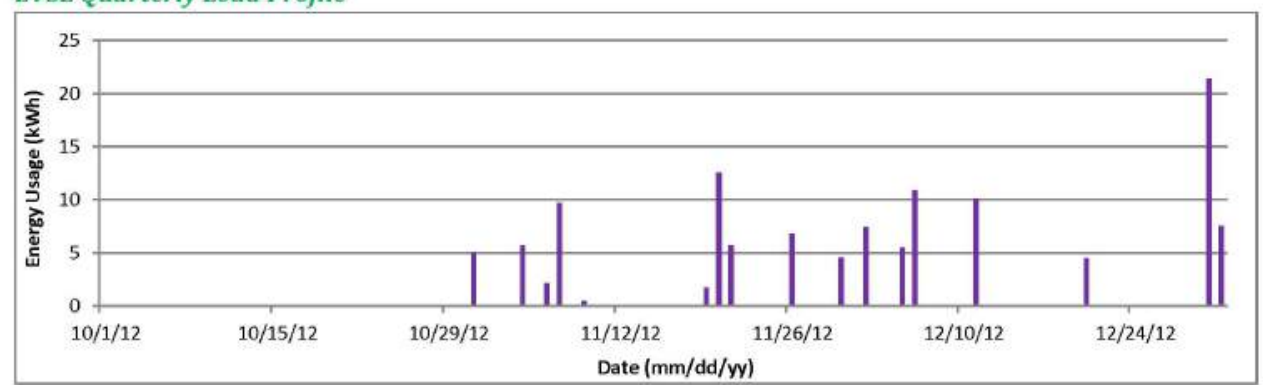

PV Array Quarterly Power Generation Profile

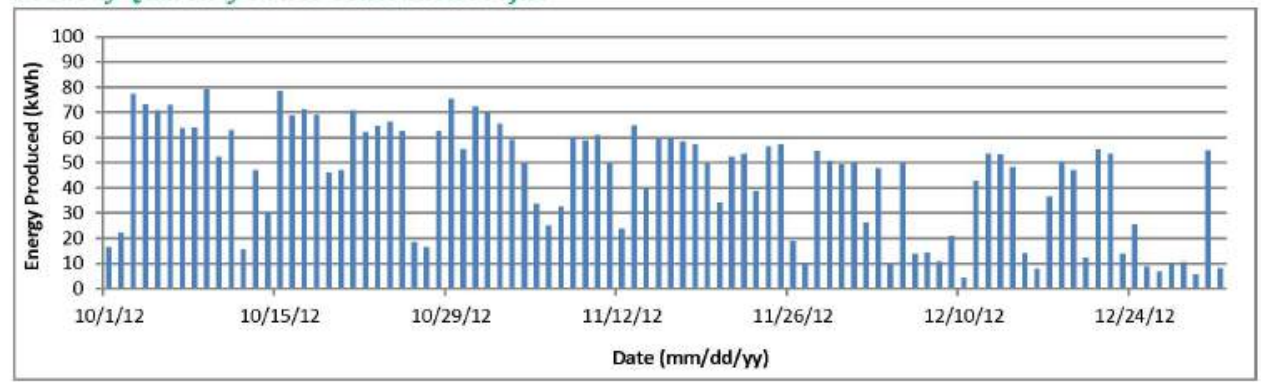

Based on the total energy consumption and an average of miles per $\mathrm{kWh}$ for the Nissan Leaf ( $2.94 \mathrm{mi} / \mathrm{kWh})$ and Chevy Volt $(2.78 \mathrm{mi} / \mathrm{kWh}$ ).

Values taken from http://www.fueleconomv.gov/.

"Based on energy consumption and size of battery for the Nissan Leaf ( $24 \mathrm{kWh}$ ) and Chevy Volt (16 kWh).

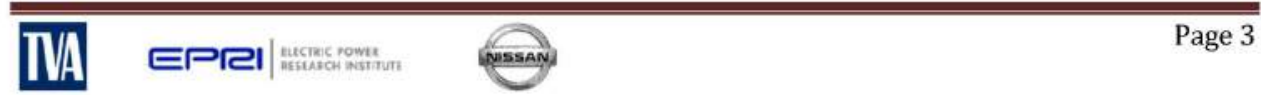




\section{Oak Ridge NaTiOnAL LabORATORY}

EV Project Solar-Assisted Charging Infrastructure Summary Report

EVSE Grouping/Region: LP Field

Report Period: July 1-September 30, 2013 (Quarter 3, 2013)

Number of EV Charging Stations: 8

F/y Project

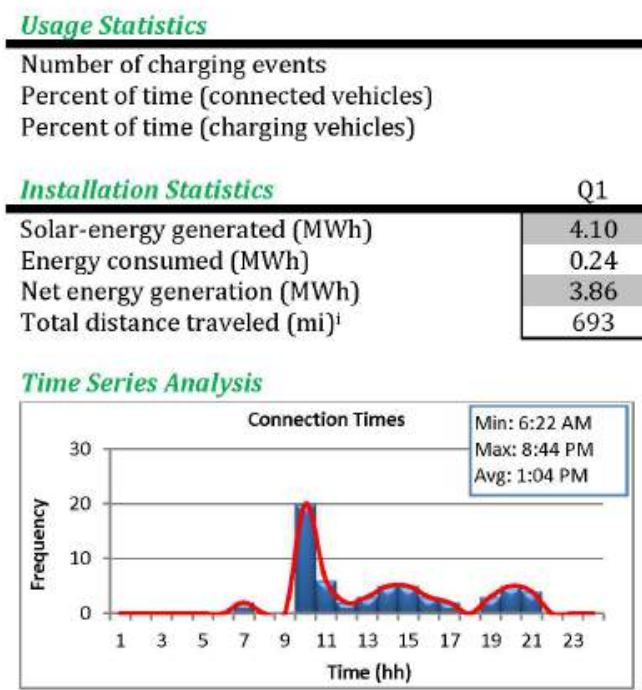

\begin{tabular}{|cccc|}
\hline $\mathrm{Q} 1$ & $\mathrm{Q} 2$ & $\mathrm{Q} 3$ & $\mathrm{Q} 4^{*}$ \\
\hline 32 & 61 & 60 & 0 \\
$0.9 \%$ & $1.5 \%$ & $1.7 \%$ & $0.0 \%$ \\
$0.4 \%$ & $0.7 \%$ & $0.9 \%$ & $0.0 \%$
\end{tabular}

\begin{tabular}{l|ccccc|} 
Installation Statistics & Q1 & Q2 & Q3 & Q4* & 2013 Totals \\
\hline Solar-energy generated (MWh) & 4.10 & 7.42 & 6.72 & 5.34 & 23.58 \\
Energy consumed (MWh) & 0.24 & 0.52 & 0.60 & 0.00 & 1.36 \\
Net energy generation (MWh) & 3.86 & 6.90 & 6.12 & 5.34 & 22.22 \\
Total distance traveled (mi) & 693 & 1482 & 1715 & 0 & 3890 \\
\cline { 3 - 6 }
\end{tabular}

Time Series Analysis
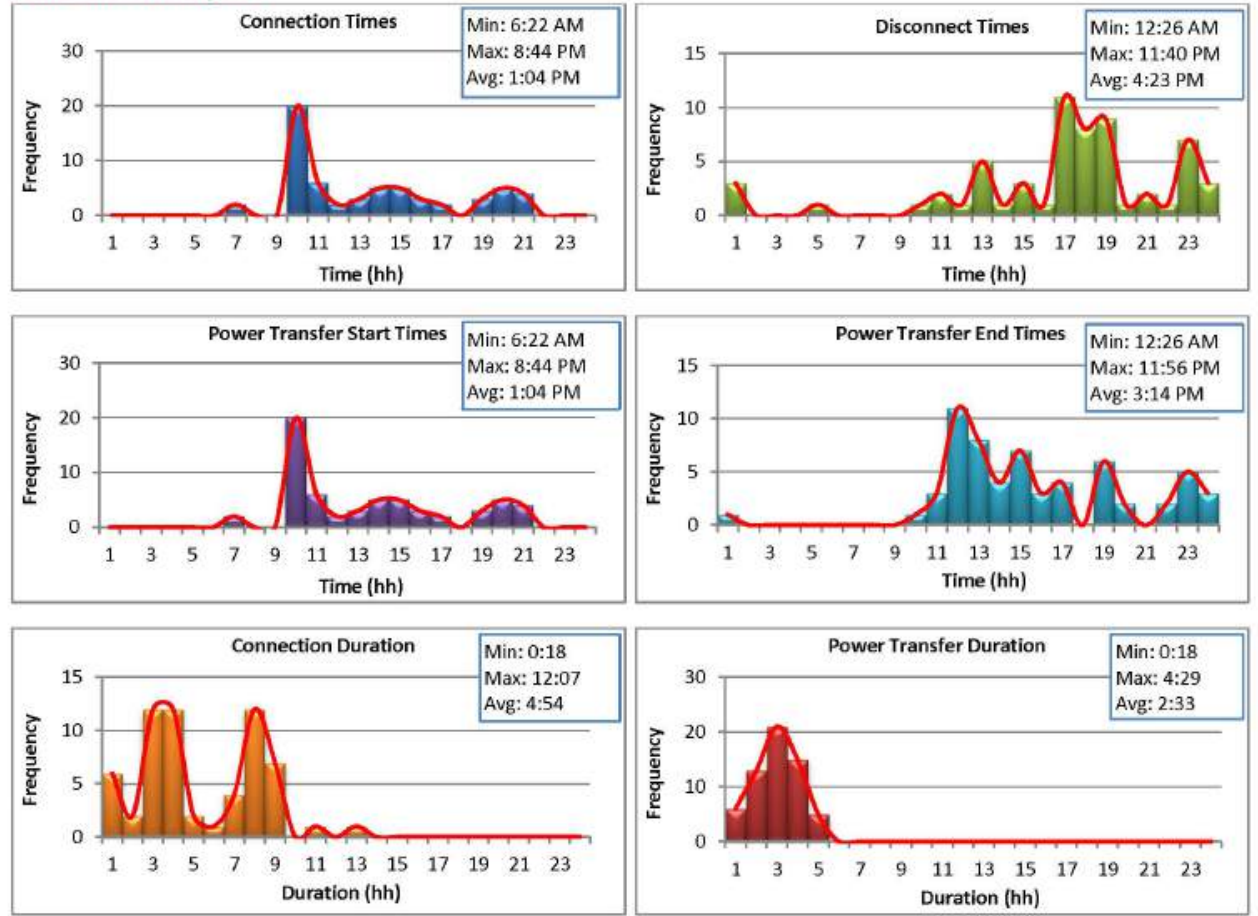

* There was no EVSE Charge data during the 4th quarter 2013 at LP Field since there was a system power outage during a 5 month period. The solar array did continue to produce power during part of this time.

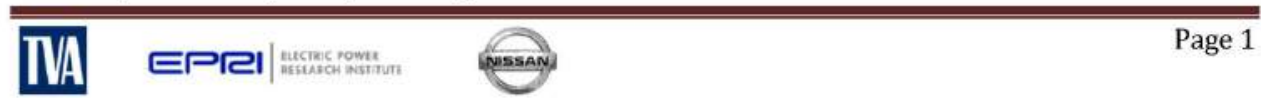




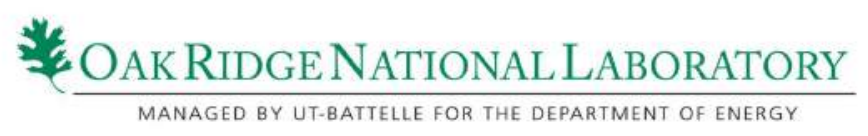

Energy Consumption Analysis
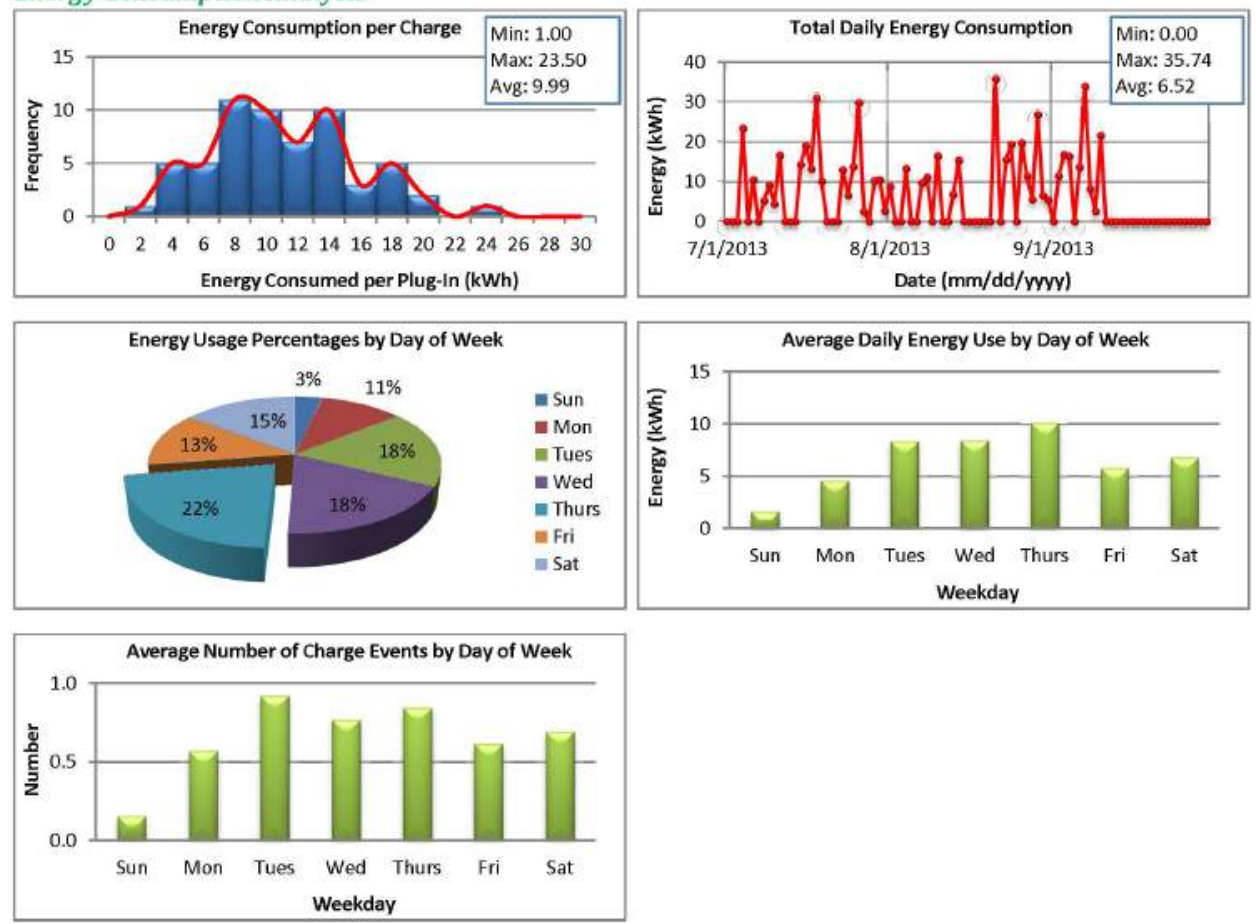

Charging Analysis
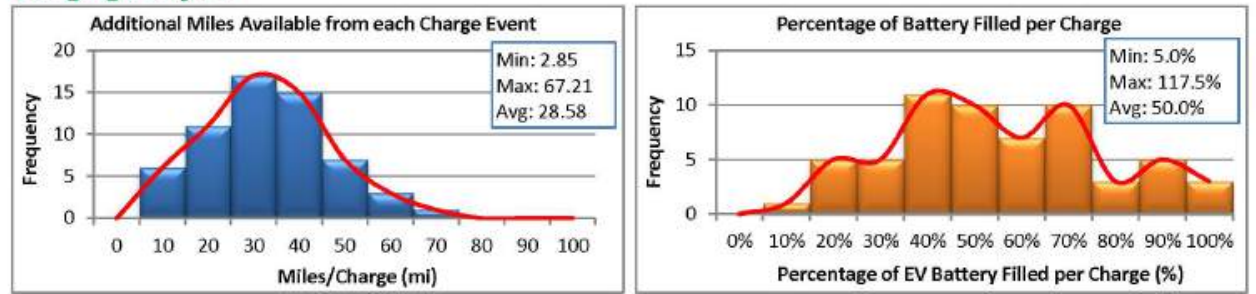

EVSE Analysís

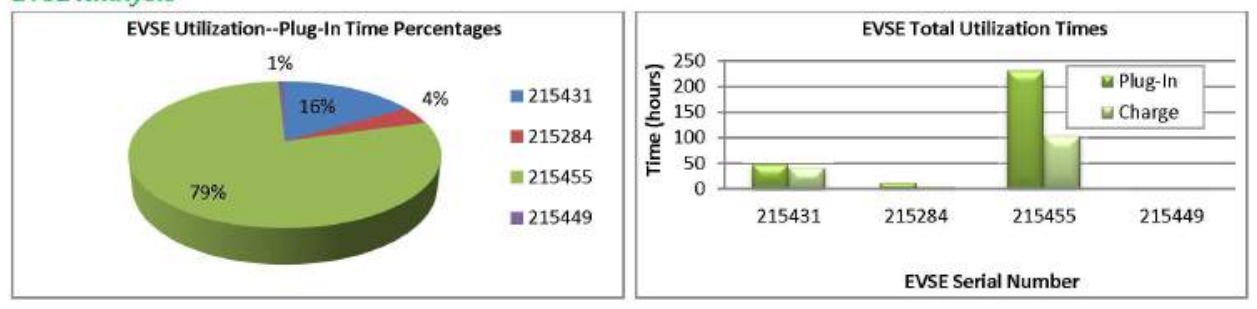

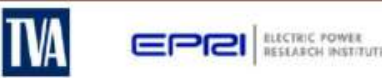

Page 2 


\section{OAK Ridge National Laboratory}

\begin{tabular}{|c|c|c|c|c|}
\hline Report Period Summary & Q1 & Q2 & Q3 & Q4* \\
\hline \multirow{4}{*}{$\begin{array}{l}\text { Average connection duration (hrs.) } \\
\text { Average charge duration (hrs.) } \\
\text { Average miles per charge } \\
\text { Average } \% \text { of battery filled per } \\
\quad{\text { charge event } t^{\mathrm{ii}}}^{\text {char }}\end{array}$} & 4.7 & 4.4 & 4.9 & 0.0 \\
\hline & 2.2 & 2.1 & 2.6 & 0.0 \\
\hline & 21.7 & 24.3 & 28.6 & 0.0 \\
\hline & $37.8 \%$ & $42.5 \%$ & $50.0 \%$ & $0.0 \%$ \\
\hline
\end{tabular}

EVSE Quarterly Load Profile

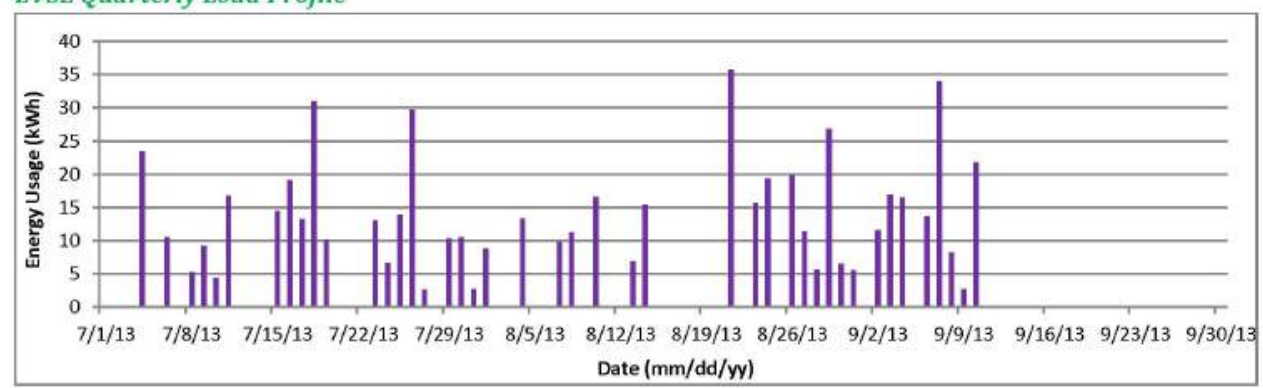

PV Array Quarterly Power Generation Profile

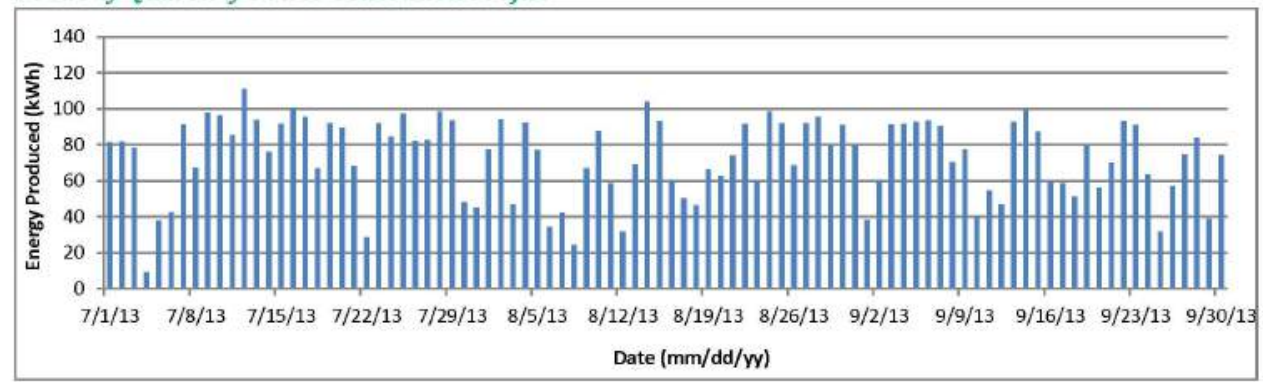

Based on the total energy consumption and an average of miles per $\mathrm{kWh}$ for the Nissan Leaf $(2.94 \mathrm{mi} / \mathrm{kWh})$ and Chevy Volt $(2.78 \mathrm{mi} / \mathrm{kWh})$.

Values taken from http://www.fueleconomy.gov/.

"Based on energy consumption and size of battery for the Nissan Leaf ( $24 \mathrm{kWh}$ ) and Chevy Volt (16 kWh).

* There was no EVSE Charge data during the 4th quarter 2013 at LP Field since there was a system power outage during a 5 month period.

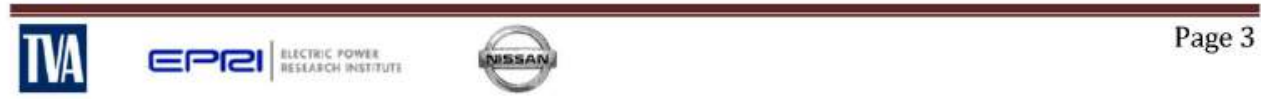




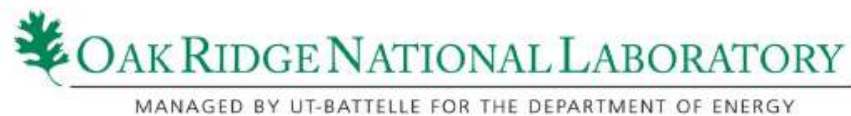

EV Project Solar-Assisted Charging Infrastructure Summary Report

EVSE Grouping/Region: LP Field

Report Period: April 1-June 30, 2014 (Quarter 2, 2014)

Number of EV Charging Stations: 8

$\Rightarrow \boldsymbol{y}$ Project

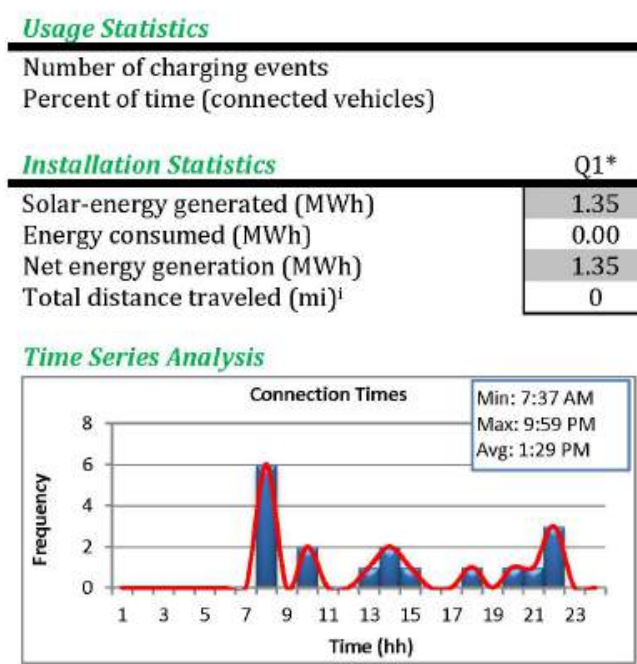

\begin{tabular}{cccc|}
$\mathrm{Q}^{*}$ & $\mathrm{Q} 2$ & $\mathrm{Q} 3$ & $\mathrm{Q} 4$ \\
\hline 0 & 18 & - & - \\
$0.0 \%$ & $0.4 \%$ & - & - \\
\hline
\end{tabular}

\section{Statistics}

Q1*

Q2

Q3 $\quad 04 \quad 2014$ Totals

Energy consumed (MWh

Net energy generation (MWh)

Total distance traveled (mi)

\begin{tabular}{llll|}
7.54 & - & - & 8.89 \\
0.12 & - & - & 0.12 \\
7.42 & - & - & 8.77 \\
333 & - & - & 333 \\
\hline
\end{tabular}

333

- $\quad 333$
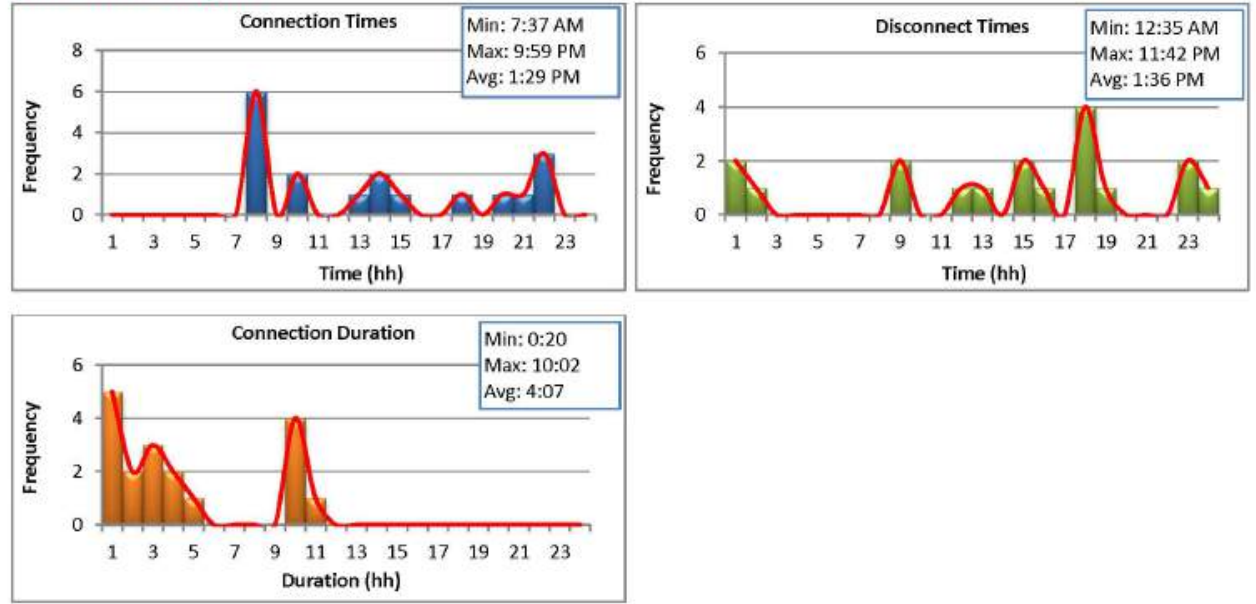

* There was no EVSE Charge data during the $1^{\text {st }}$ quarter 2014 at LP Field since there was a system power outage during a 5 month period. The solar array did continue to produce power during part of this time.

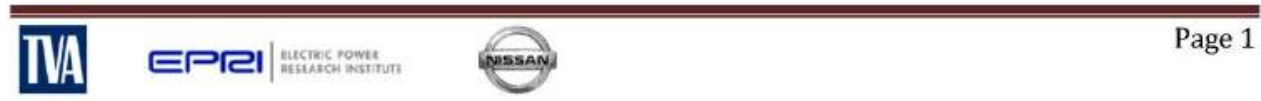




\section{OAK RIDGE NATIONAL LABORATORY}

Energy Consumption Analysis
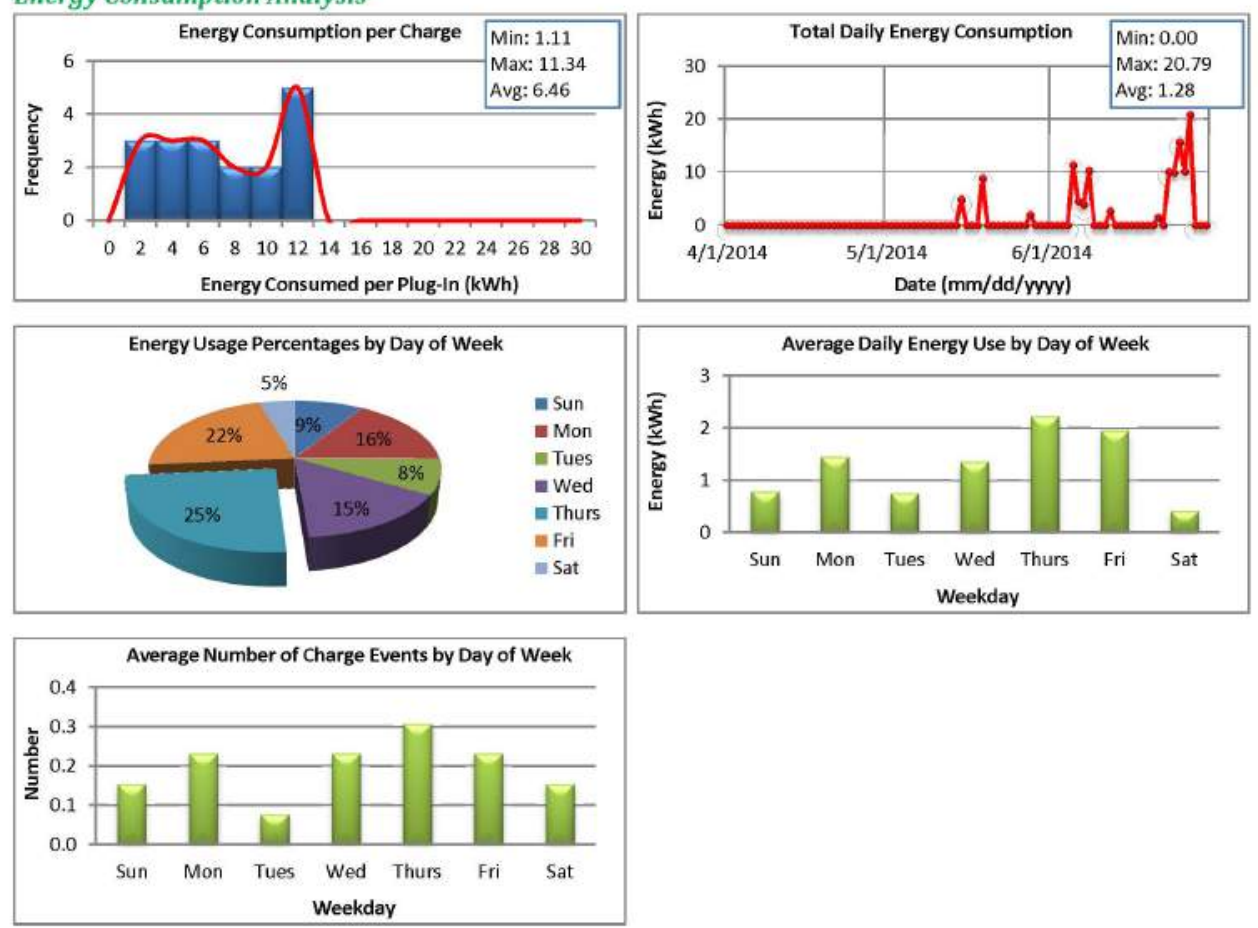

Charging Analysis
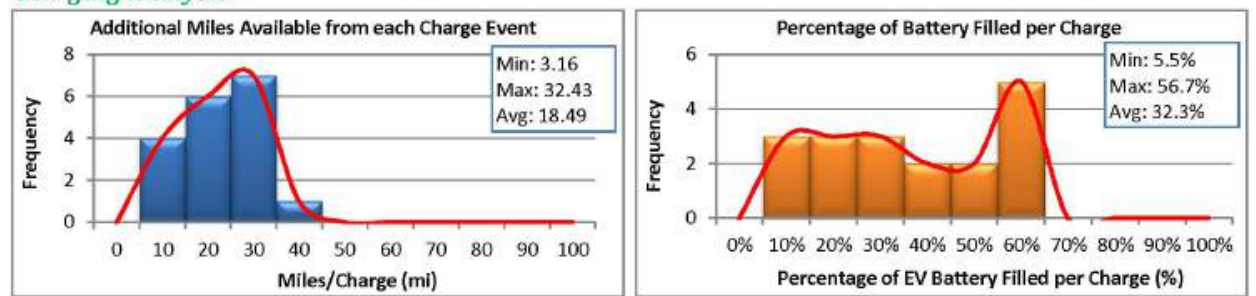

EVSE Analysis

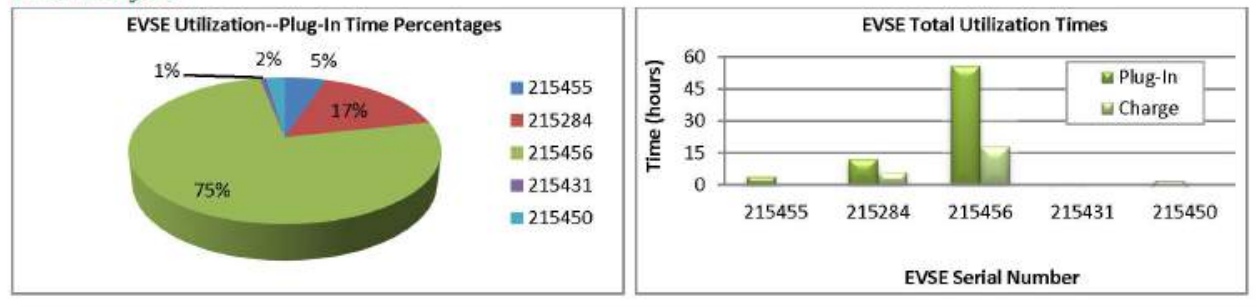

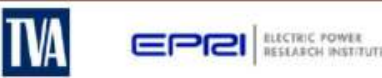

Page 2 


\section{8}

\begin{tabular}{|c|c|c|c|c|}
\hline Report Period Summary & Q1* & Q2 & Q3 & Q4 \\
\hline Average connection duration (hrs.) & 0.0 & 4.1 & - & - \\
\hline Average miles per charge ${ }^{i}$ & 0.0 & 18.5 & - & - \\
\hline $\begin{array}{l}\text { Average } \% \text { of battery filled per } \\
\text { charge event } \|\end{array}$ & $0.0 \%$ & $32.3 \%$ & - & - \\
\hline
\end{tabular}

EVSE Quarterly Load Profile

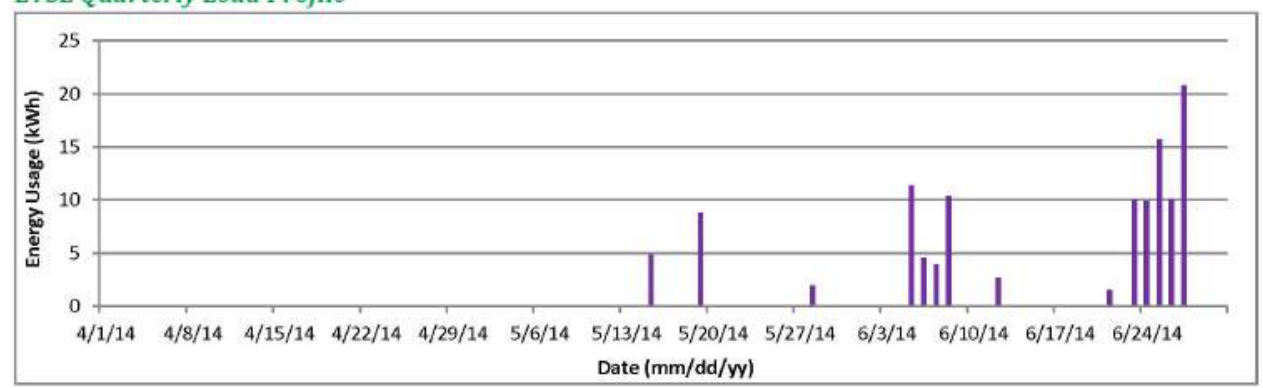

PV Array Quarterly Power Generation Profile

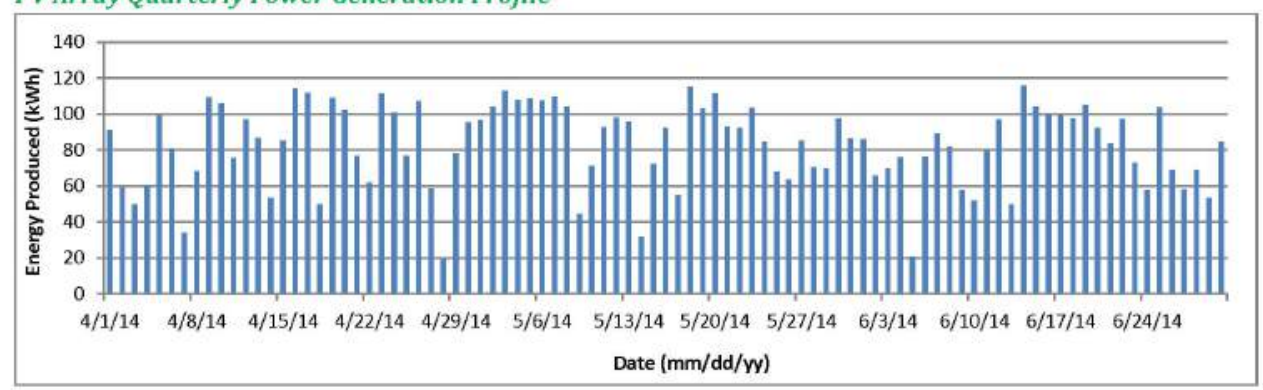

Based on the total energy consumption and an average of miles per $\mathrm{kWh}$ for the Nissan Leaf ( $2.94 \mathrm{mi} / \mathrm{kWh}$ ) and Chevy Volt $(2.78 \mathrm{mi} / \mathrm{kWh}$ )

Values taken from http://www.fueleconomy.gov/.

"Based on energy consumption and size of battery for the Nissan Leaf ( $24 \mathrm{kWh}$ ) and Chevy Volt ( $16 \mathrm{kWh}$ ).

* There was no EVSE Charge data during the $1^{\text {t }}$ quarter 2014 at LP Field since there was a system power outage during a 5 month period.

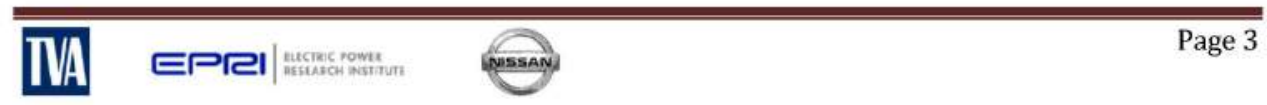




\section{$\frac{\text { OAK RIDGE NATIONAL LABORATORY }}{\text { MANAGED BY UT-BATtELLE For THE DEPARTMENT OF ENERGY }}$}

EV Project Solar-Assisted Charging Infrastructure Summary Report

EVSE Grouping/Region: TN State Lot

Report Period: October 1-December 31, 2012 (Quarter 4, 2012)

Number of EV Charging Stations: 4

F/y Project
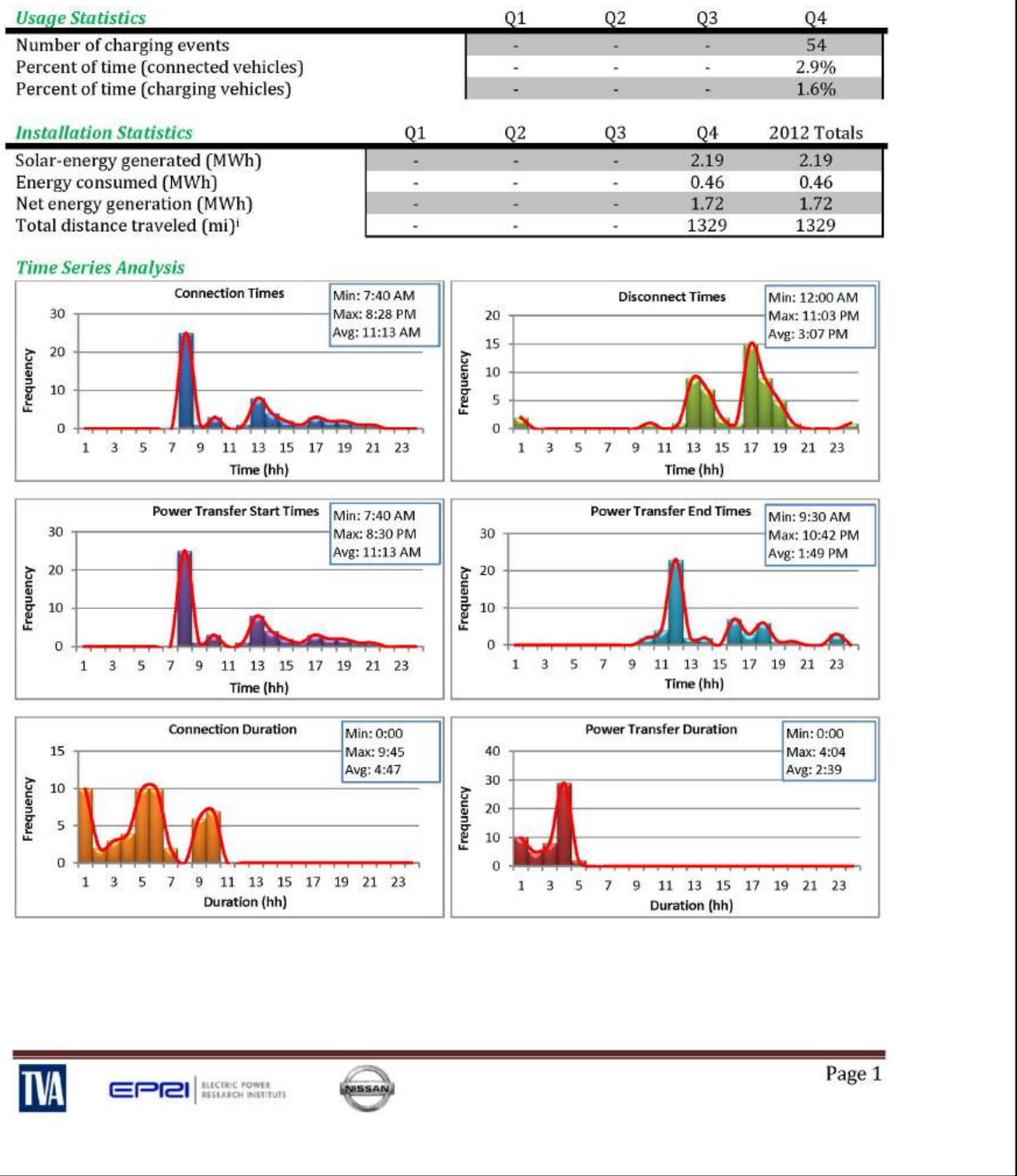


\section{OAK RIDGE NATIONAL LABORATORY}

Energy Consumption Analysis
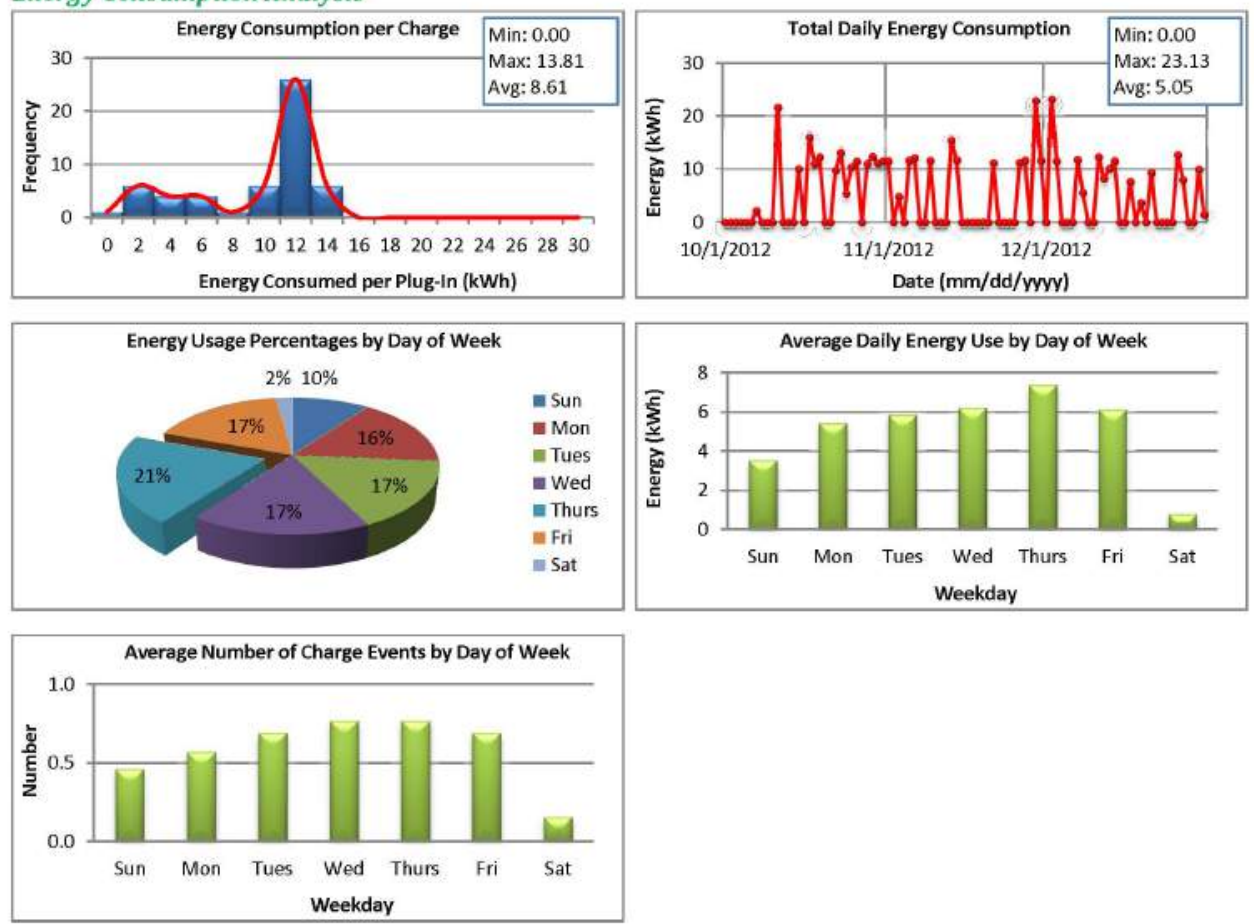

Charging Analysis
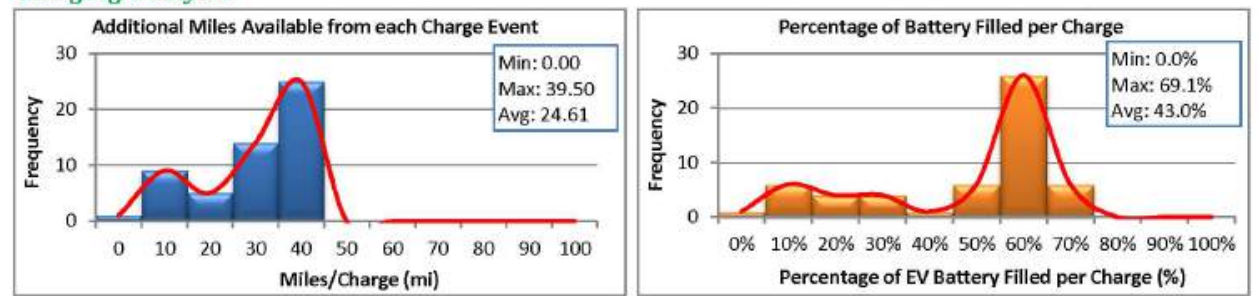

EVSE Analysís

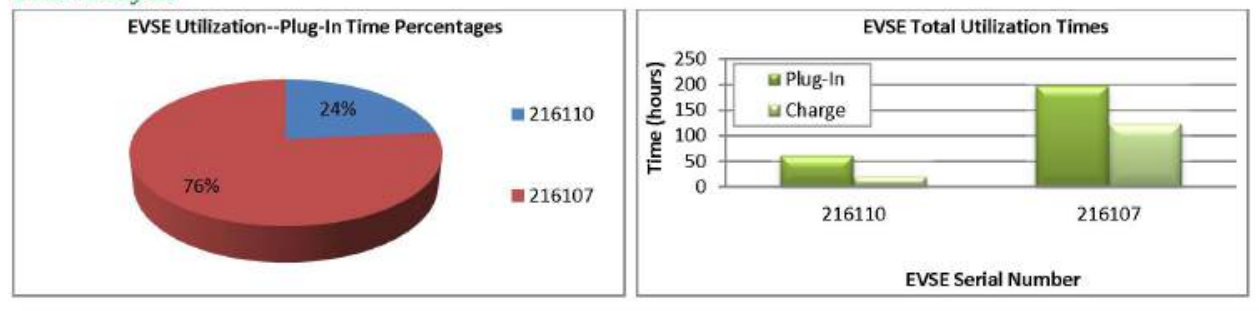

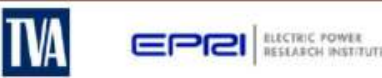

Page 2 


\section{OAK Ridge National Laboratory}

\begin{tabular}{|c|c|c|c|c|}
\hline Report Period Summary & Q1 & Q2 & Q3 & Q4 \\
\hline Average connection duration (hrs.) & - & - & - & 4.8 \\
\hline Average charge duration (hrs.) & - & - & - & 2.7 \\
\hline Average miles per charge & - & - & - & 24.6 \\
\hline $\begin{array}{l}\text { Average } \% \text { of battery filled per } \\
\text { charge event } t^{\mathrm{ii}}\end{array}$ & - & - & - & $43.0 \%$ \\
\hline
\end{tabular}

EVSE Quarterly Load Profile

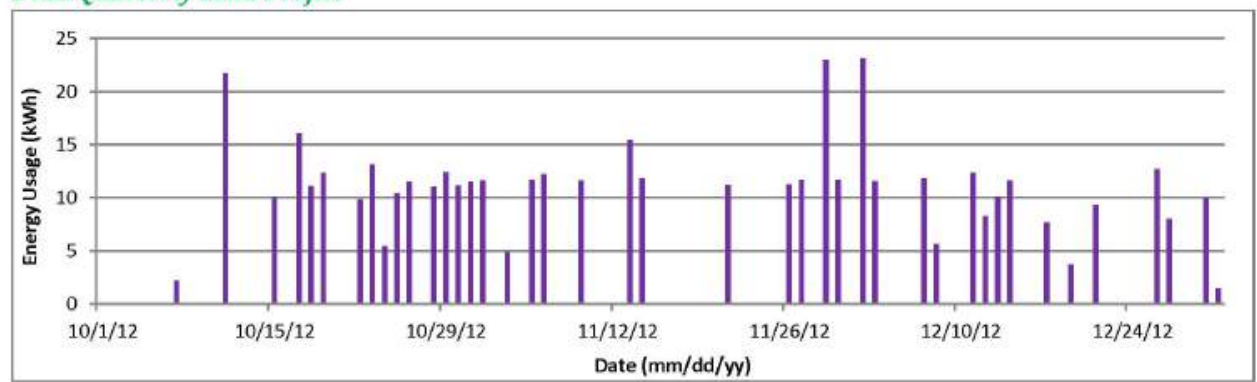

PV Array Quarterly Power Generation Profile

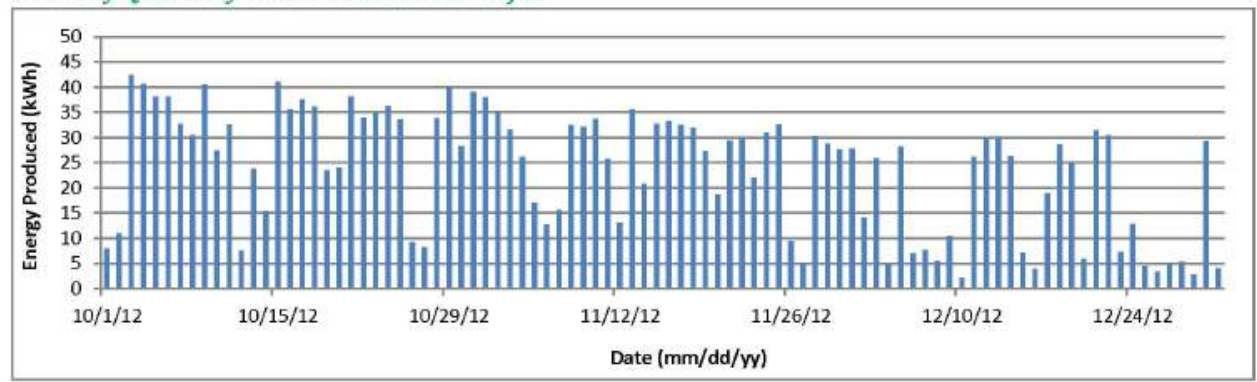

Based on the total energy consumption and an average of miles per $\mathrm{kWh}$ for the Nissan Leaf ( $2.94 \mathrm{mi} / \mathrm{kWh})$ and Chevy Volt $(2.78 \mathrm{mi} / \mathrm{kWh}$.

Values taken from htto://www.fueleconomy.gov/.

Based on energy consumption and size of battery for the Nissan Leaf (24 kWh) and Chevy Volt (16 kWh).

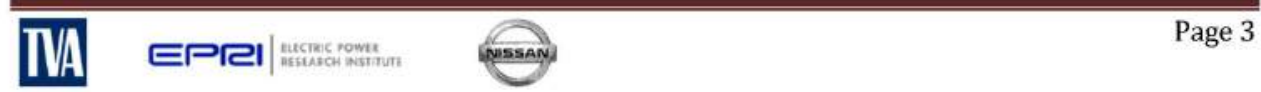




\section{Oak Ridge NaTiOnAL LabORATORY}

EV Project Solar-Assisted Charging Infrastructure Summary Report

EVSE Grouping/Region: TN State Lot

Report Period: October 1-December 31, 2013 (Quarter 4, 2013)

Number of EV Charging Stations: 4

F/y Project

\begin{tabular}{|c|c|c|c|c|c|}
\hline Usage Statistics & & Q1 & Q2 & Q3 & Q4 \\
\hline Number of charging events & & 89 & 124 & 135 & 141 \\
\hline Percent of time (connected vehicles) & & $5.2 \%$ & $6.5 \%$ & $9.1 \%$ & $7.0 \%$ \\
\hline Percent of time (charging vehicles) & & $3.1 \%$ & $3.8 \%$ & $3.8 \%$ & $4.2 \%$ \\
\hline Installation Statistics & Q1 & Q2 & Q3 & Q4 & 2013 Totals \\
\hline Solar-energy generated (MWh) & 2.15 & 3.76 & 3.42 & 2.03 & 11.36 \\
\hline Energy consumed (MWh) & 0.92 & 1.19 & 1.23 & 1.36 & 4.7 \\
\hline Net energy generation (MWh) & 1.23 & 2.58 & 2.19 & 0.67 & 6.67 \\
\hline Total distance traveled $(\mathrm{mi})^{\mathrm{i}}$ & 2642 & 3394 & 3515 & 3883 & 13434 \\
\hline
\end{tabular}

Time Series Analysis
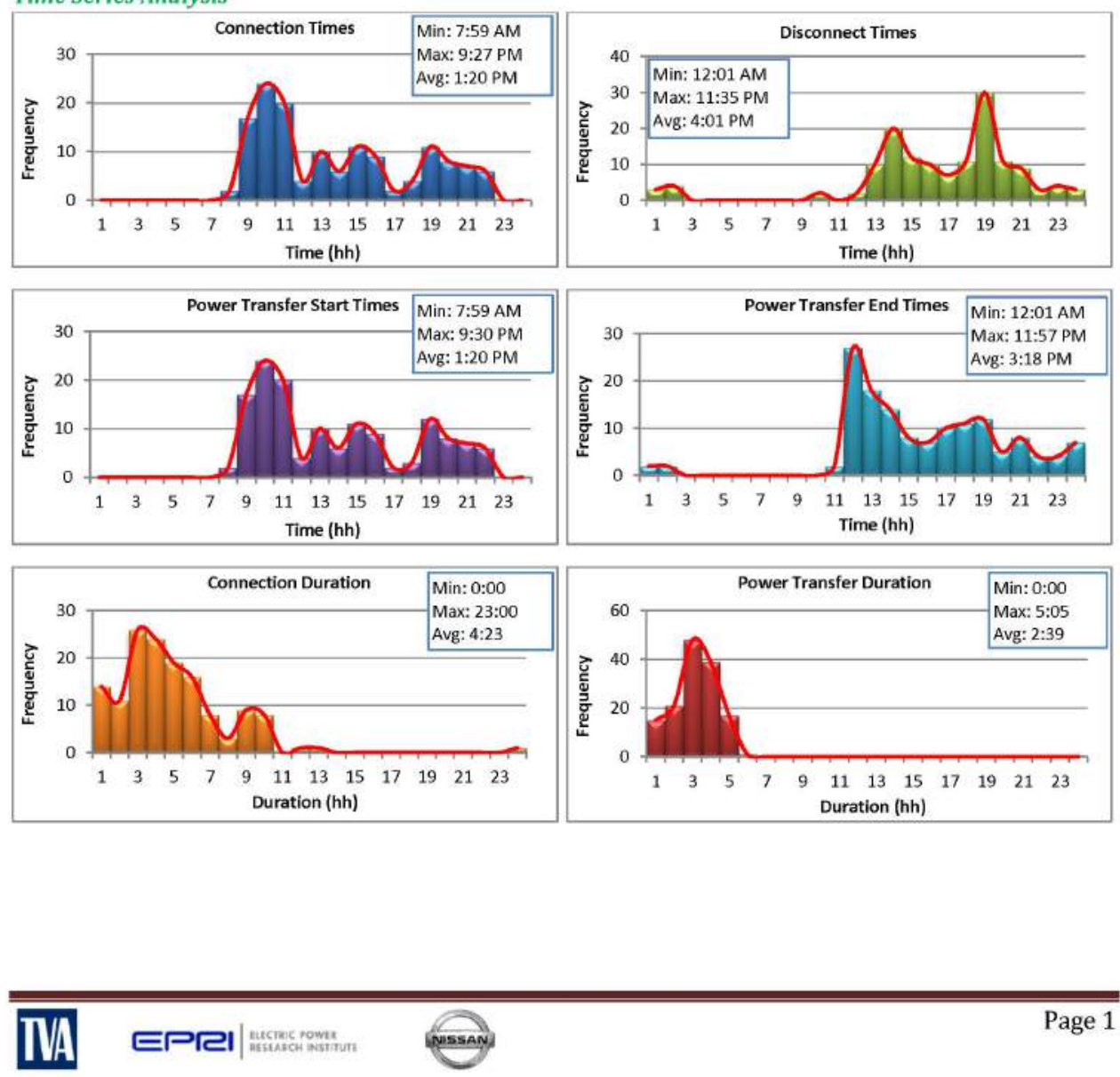


\section{$\frac{\text { OAK RIDGE NATIONAL LABORATORY }}{\text { ManAGED BY UT-BATtELE FOR ThE DEAARTMENT OF ENERGY }}$}

Energy Consumption Analysis
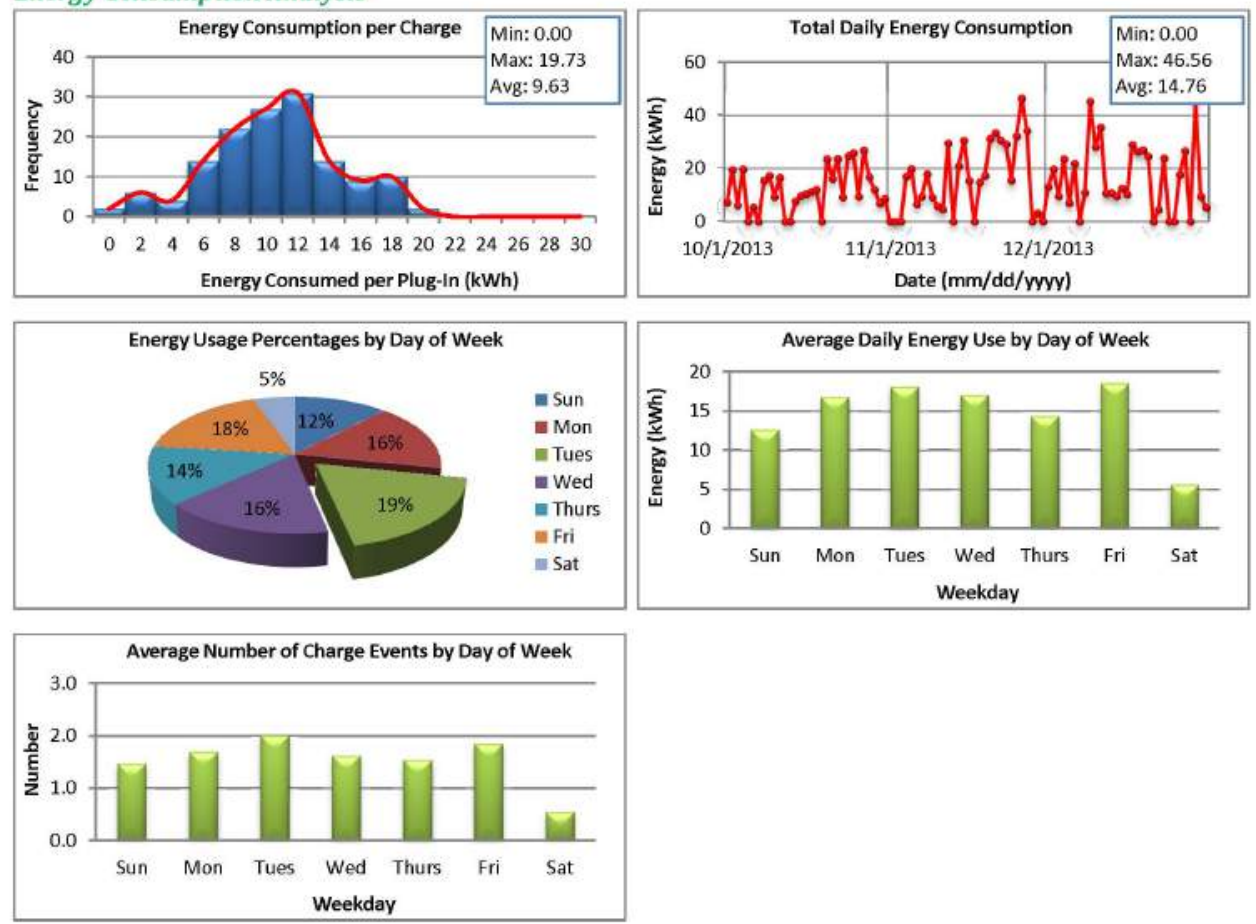

Charging Analysis
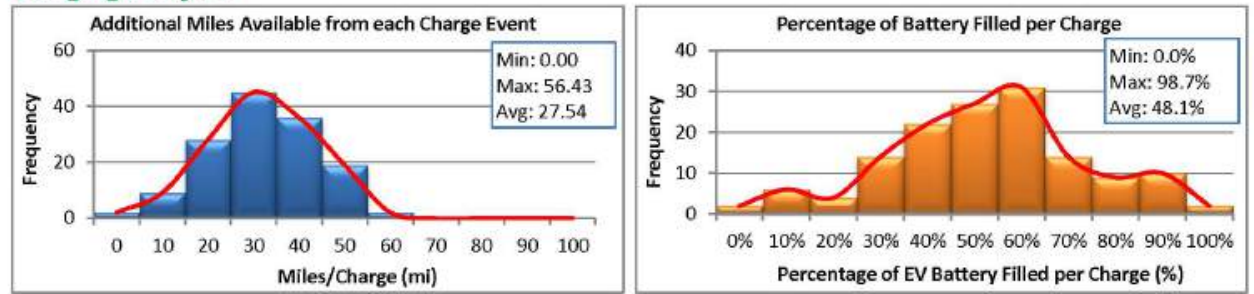

EVSE Analysís

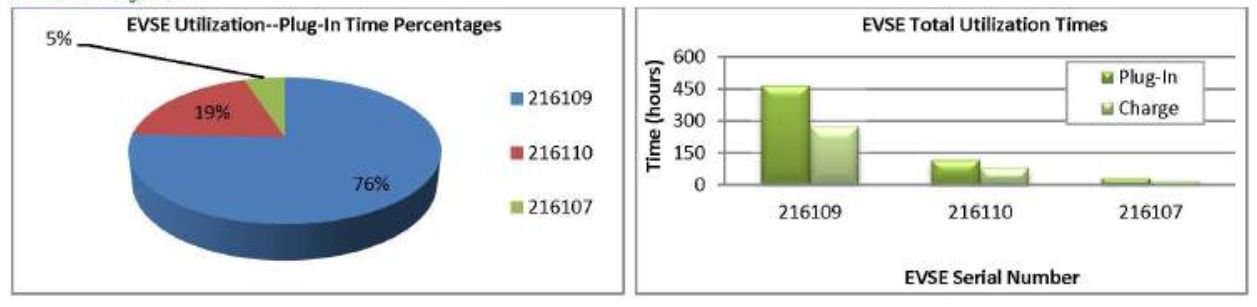

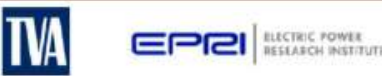

Page 2 


\section{$\frac{\text { OAK RIDGE NATIONAL LABORATORY }}{\text { MANAGED GY UT-BATtELE FOR THE DEAATMENT OF ENERGY }}$}

\begin{tabular}{|c|c|c|c|c|}
\hline \multirow{5}{*}{$\begin{array}{l}\text { Average connection duration (hrs.) } \\
\text { Average charge duration (hrs.) } \\
\text { Average miles per charge } \\
\text { Average } \% \text { of battery filled per }\end{array}$} & Q1 & Q2 & Q3 & Q4 \\
\hline & 5.0 & 4.6 & 6.0 & 4.4 \\
\hline & 3.0 & 2.7 & 2.5 & 2.7 \\
\hline & 29.7 & 27.4 & 26.0 & 27.5 \\
\hline & $51.9 \%$ & $47.8 \%$ & $45.5 \%$ & $48.1 \%$ \\
\hline
\end{tabular}

EVSE Quarterly Load Profile

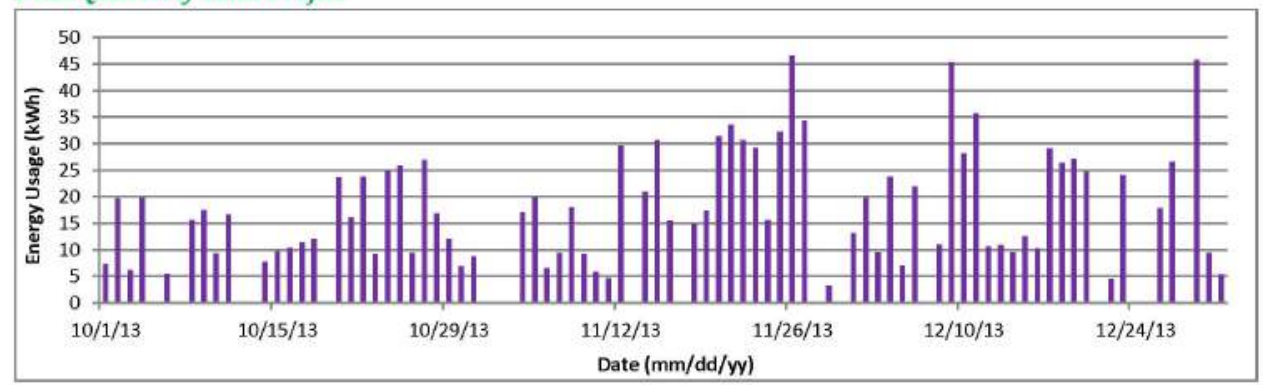

PV Array Quarterly Power Generation Profile

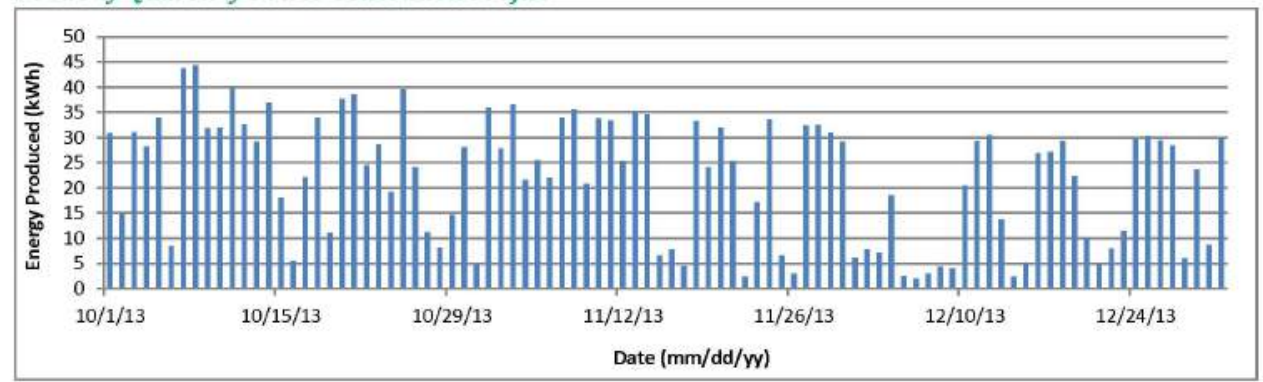

Based on the total energy consumption and an average of miles per $\mathrm{kWh}$ for the Nissan Leaf ( $2.94 \mathrm{mi} / \mathrm{kWh})$ and Chevy Volt $(2.78 \mathrm{mi} / \mathrm{kWh})$.

Values taken from http://www.fueleconomv.gov/.

Based on energy consumption and size of battery for the Nissan Leaf ( $24 \mathrm{kWh}$ ) and Chevy Volt ( $16 \mathrm{kWh}$ ).

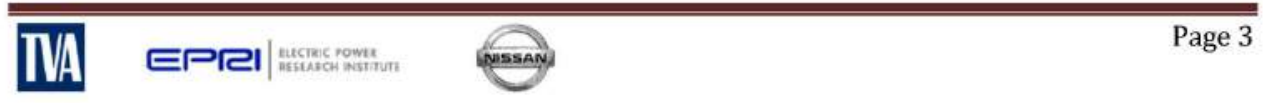




\section{Oak Ridge NaTiOnAL LabORATORY}

EV Project Solar-Assisted Charging Infrastructure Summary Report

EVSE Grouping/Region: TN State Lot

Report Period: January 1-March 31, 2014 (Quarter 1, 2014)

Number of EV Charging Stations: 4

$\exists \boldsymbol{F}$ Project

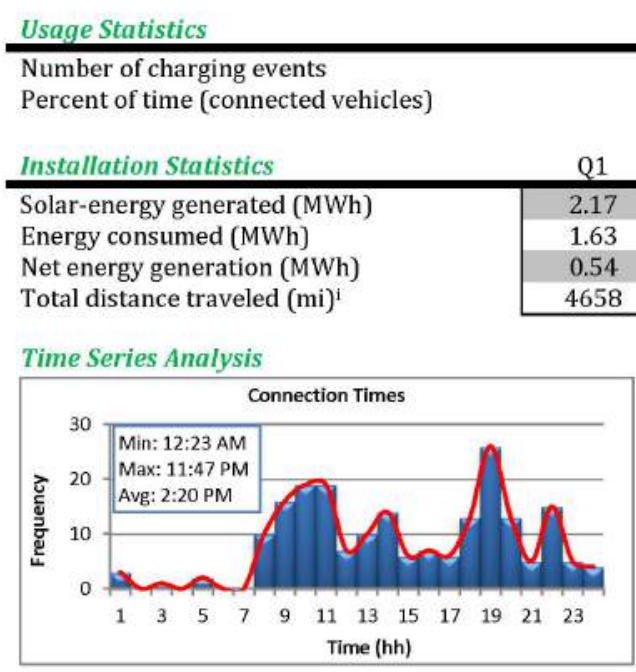

\begin{tabular}{cccc|} 
Q1 & $\mathrm{Q}^{*}$ & $\mathrm{Q} 3$ & $\mathrm{Q} 4$ \\
\hline 201 & - & - & - \\
$8.9 \%$ & - & - & - \\
\hline
\end{tabular}

\begin{tabular}{|c|c|c|c|c|c|}
\hline Installation Statistics & Q1 & Q2* & Q3 & Q4 & 2014 Totals \\
\hline Solar-energy generated (MWh) & 2.17 & - & $\cdot$ & - & 2.17 \\
\hline Energy consumed (MWh) & 1.63 & - & - & - & 1.63 \\
\hline Net energy generation (MWh) & 0.54 & - & - & - & 0.54 \\
\hline Total distance traveled $(\mathrm{mi})^{\mathrm{i}}$ & 4658 & - & - & - & 4658 \\
\hline
\end{tabular}

Time Series Analysis
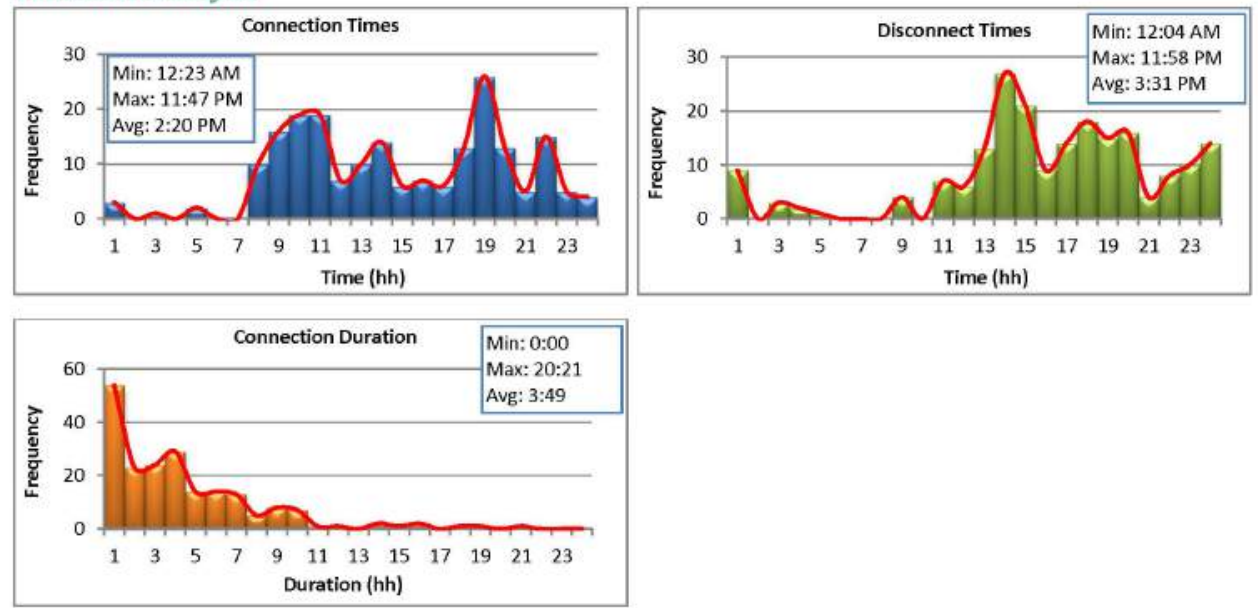

* There was no data during the 2 nd quarter 2014 at the TN State Lot since the system was decommissioned. All equipment will be reinstalled later at another location.

D/A EPर|




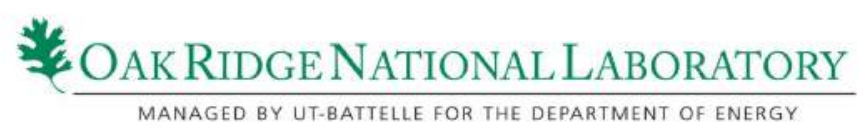

Energy Consumption Analysis
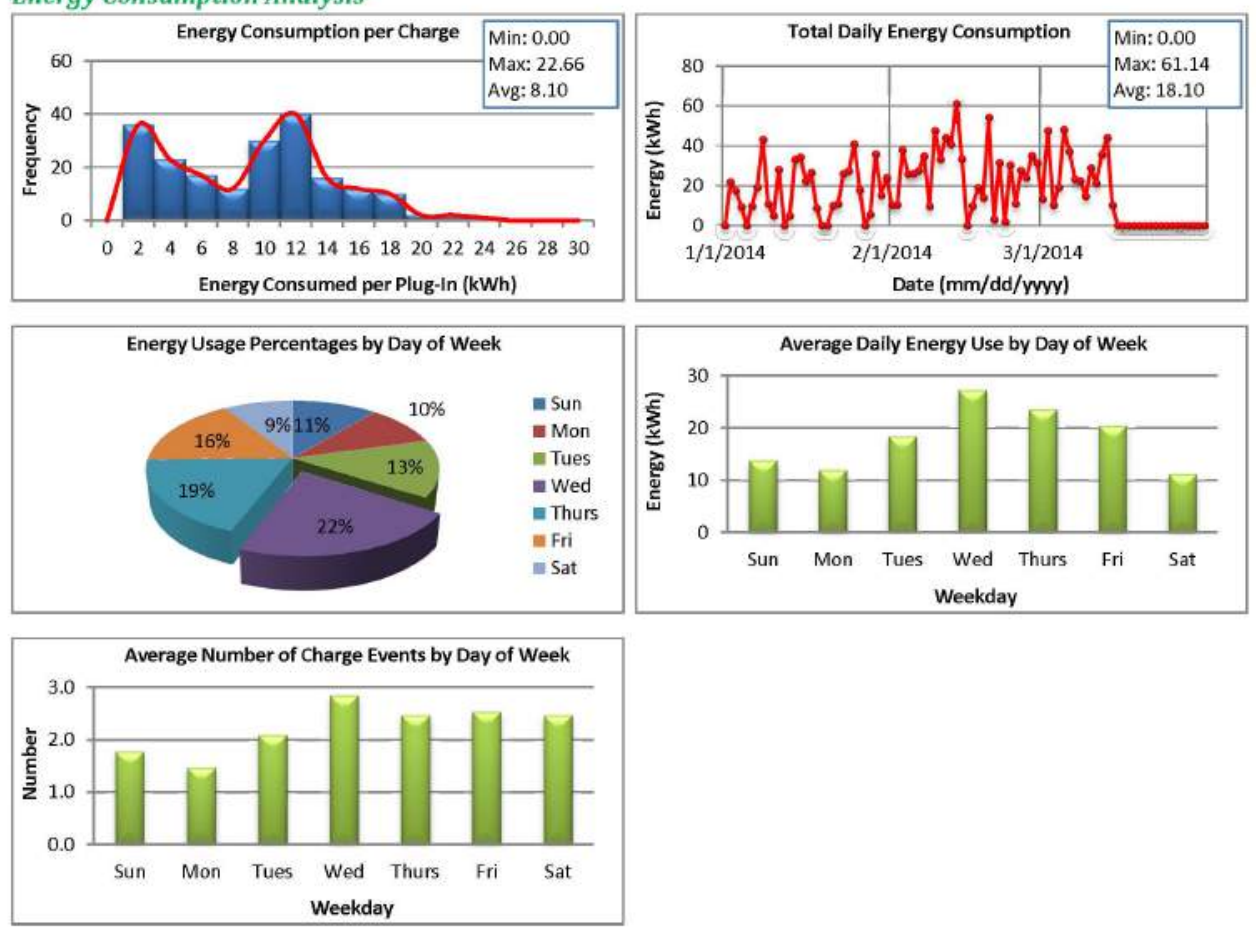

Charging Analysis
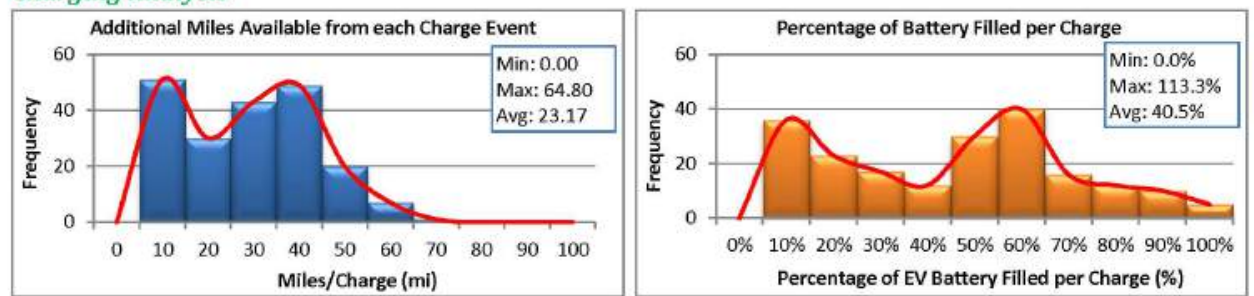

EVSE Analysís
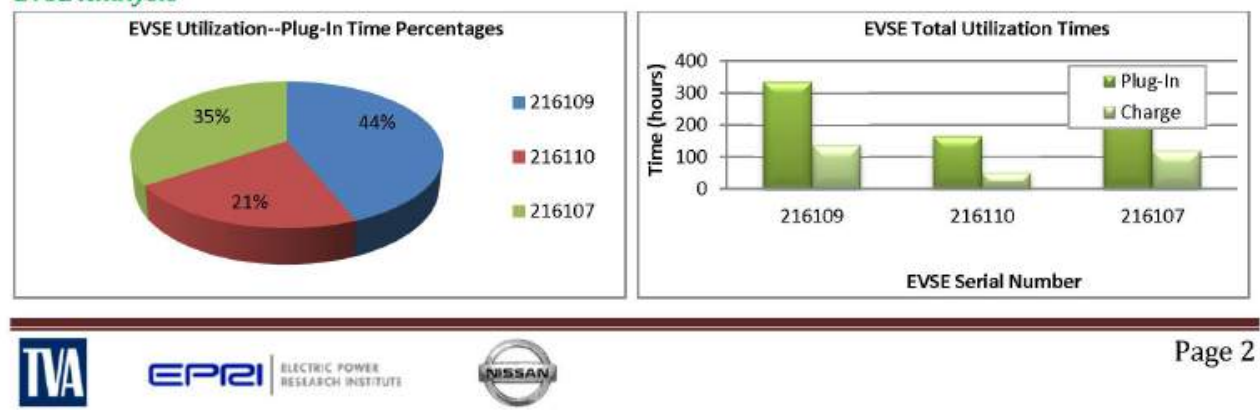

Page 2 


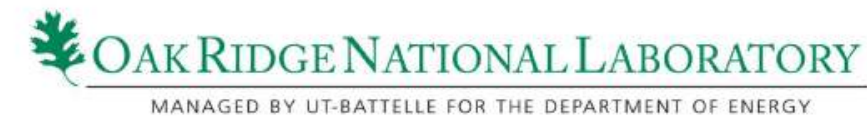

\begin{tabular}{|c|c|c|c|c|}
\hline Report Period Summary & Q1 & Q2 & Q3 & Q4 \\
\hline Average connection duration (hrs.) & 3.8 & - & - & - \\
\hline Average miles per charge ${ }^{i}$ & 23.2 & - & - & - \\
\hline $\begin{array}{l}\text { Average } \% \text { of battery filled per } \\
\text { charge event } \|\end{array}$ & $40.5 \%$ & - & - & - \\
\hline
\end{tabular}

EVSE Quarterly Load Profile

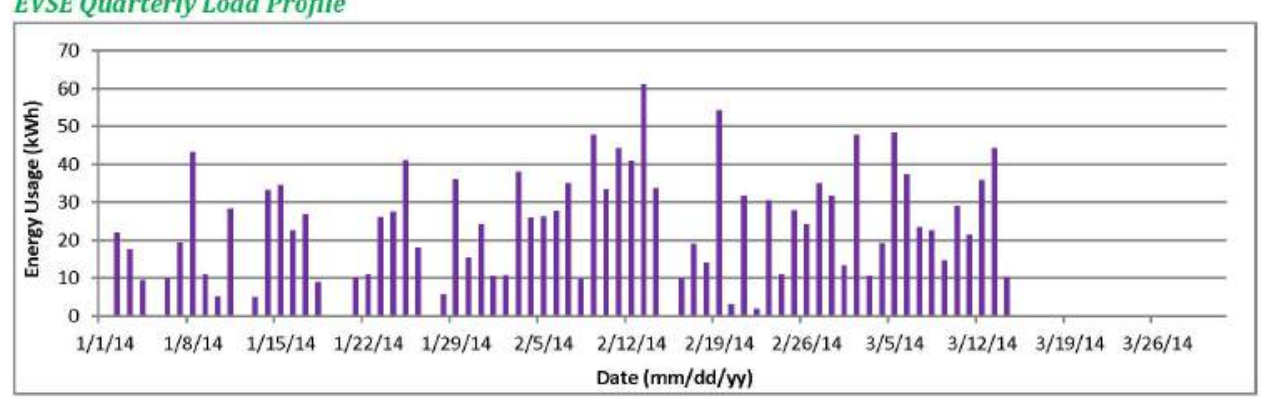

PV Array Quarterly Power Generation Profile

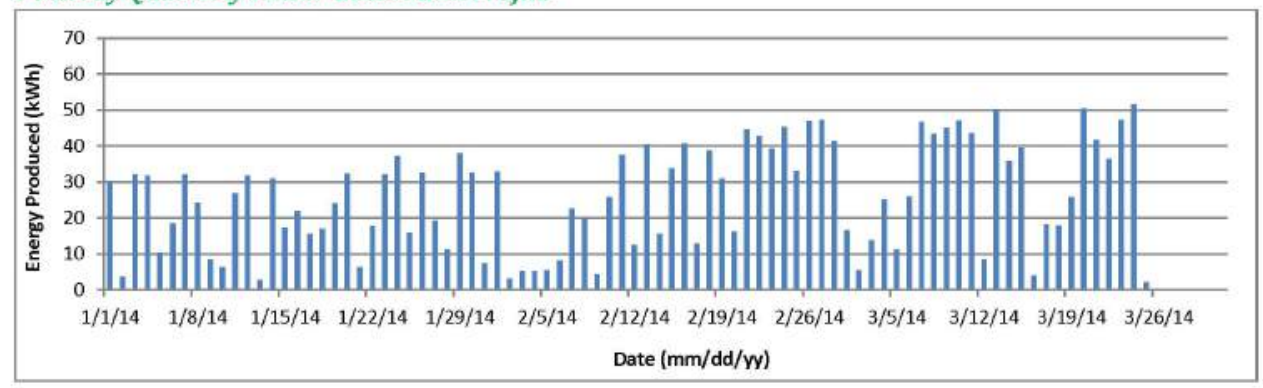

Based on the total energy consumption and an average of miles per $\mathrm{kWh}$ for the Nissan Leaf ( $2.94 \mathrm{mi} / \mathrm{kWh}$ ) and Chevy Volt ( $2.78 \mathrm{mi} / \mathrm{kWh}$ ).

Values taken from http://www.fueleconomy.gov/.

"Based on energy consumption and size of battery for the Nissan Leaf ( $24 \mathrm{kWh}$ ) and Chevy Volt (16 kWh).

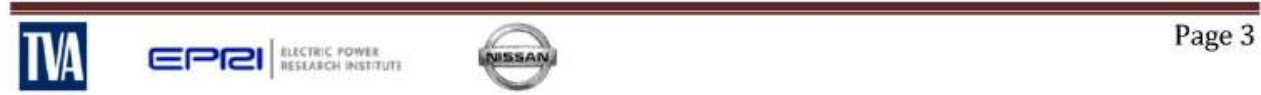




\section{A.10 EPRI Knoxville Laboratory}

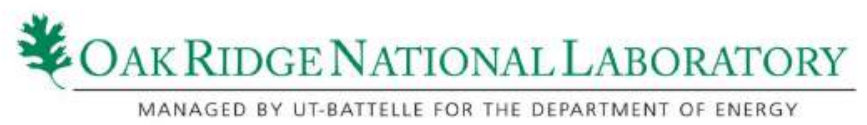

EV Project Solar-Assisted Charging Infrastructure Summary Report

EVSE Grouping/Region: EPRI Knoxville

Report Period: October 1-December 31, 2012 (Quarter 4, 2012)

Number of EV Charging Stations: 6

$\exists \mathbf{y}$ Project

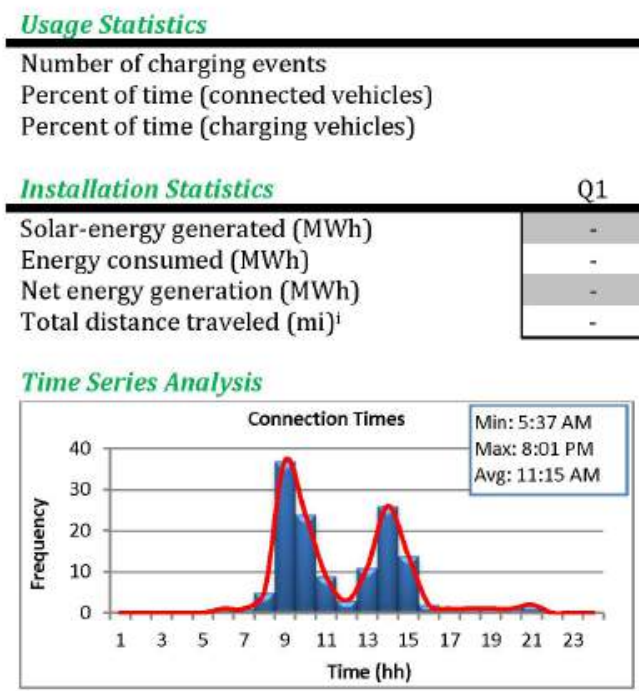

\begin{tabular}{|cccc|}
\hline Q1 & Q2 & Q3 & Q4 \\
\hline- & - & 296 & 138 \\
- & - & $40.7 \%$ & $26.7 \%$ \\
- & - & $5.0 \%$ & $2.4 \%$
\end{tabular}
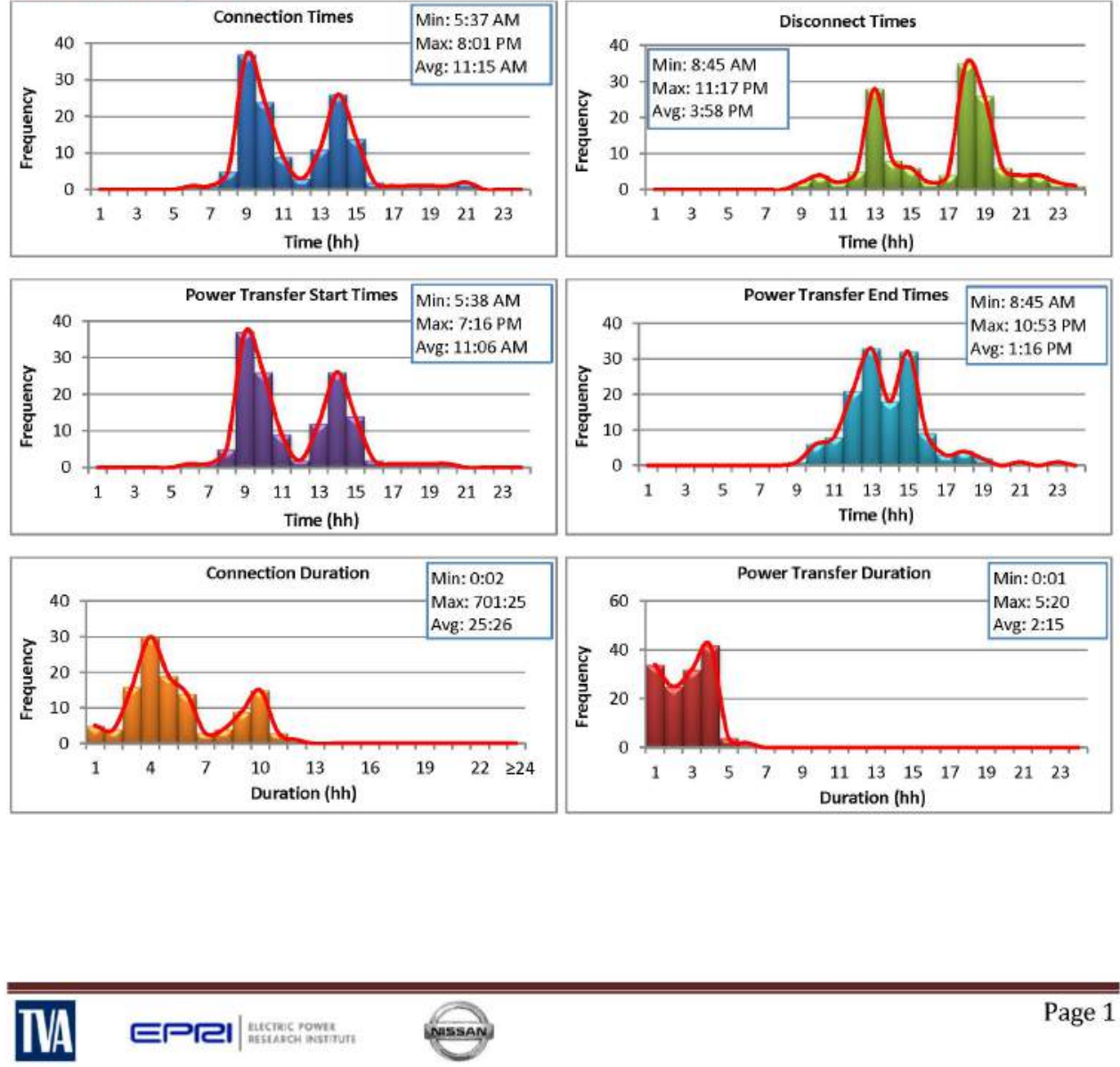


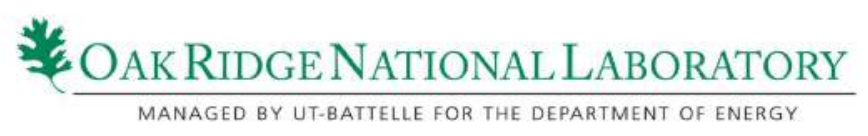

Energy Consumption Analysis
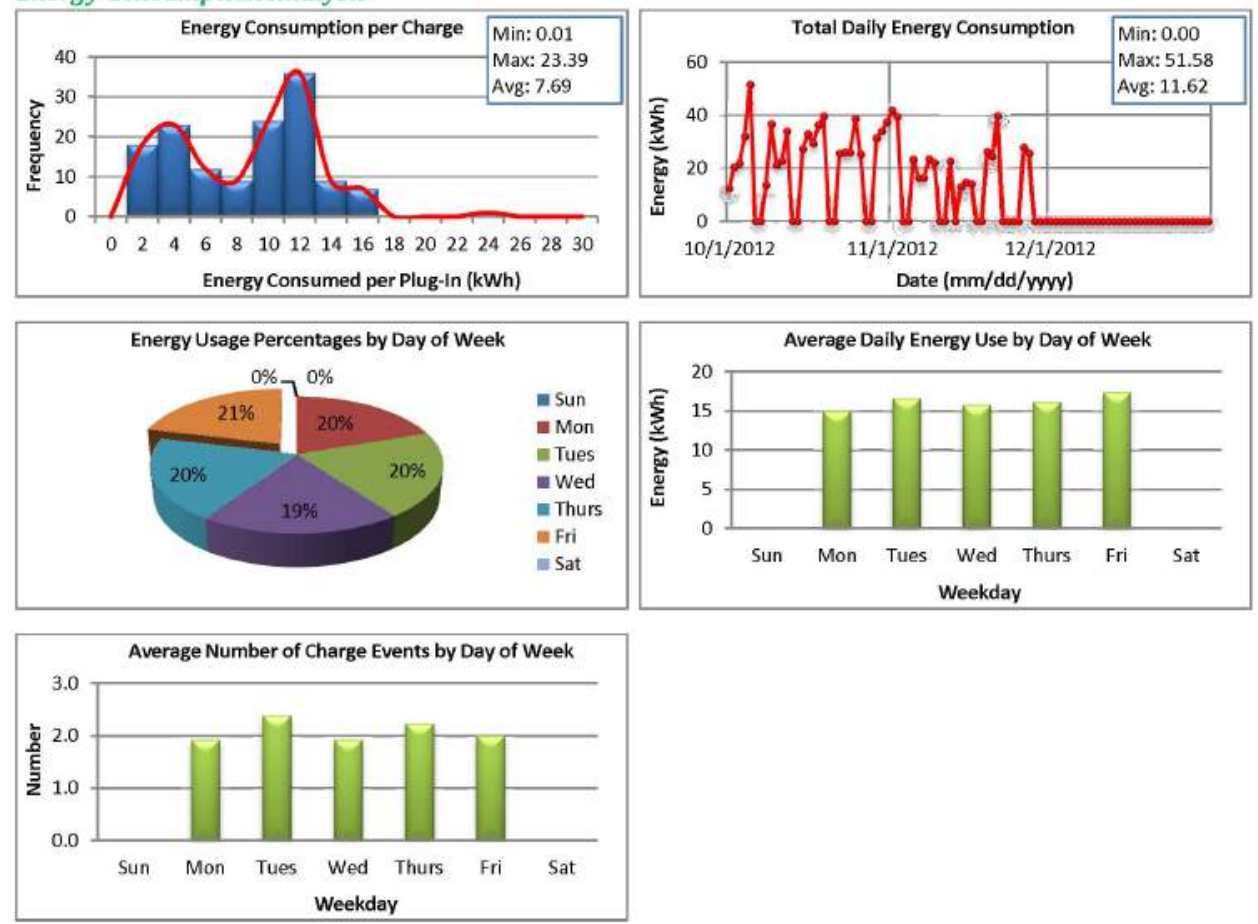

Charging Analysis
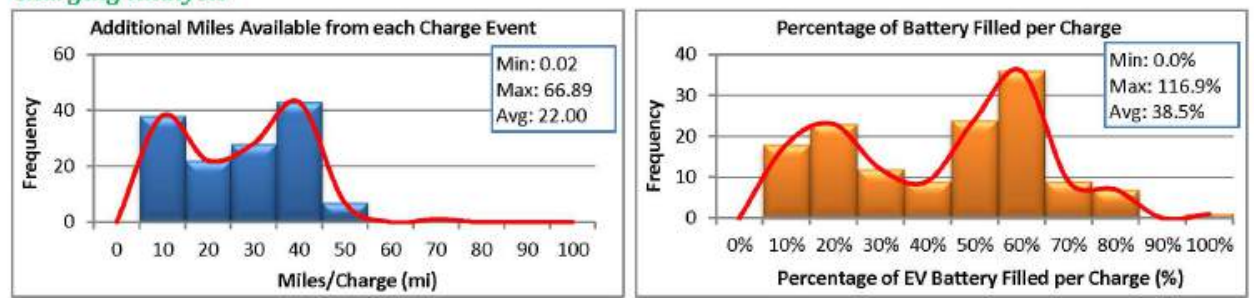

EVSE Analysis
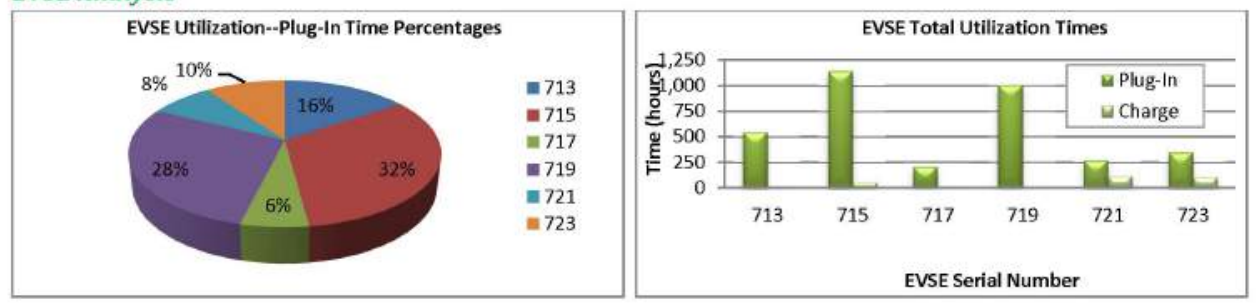

IVA Eहा|

Page 2 


\section{OAK Ridge NATIONAL LABORATORY}

\begin{tabular}{|c|c|c|c|c|}
\hline \multirow{5}{*}{$\begin{array}{l}\text { Average connection duration (hrs.) } \\
\text { Average charge duration (hrs.) } \\
\text { Average miles per charge } \\
\text { Average } \% \text { of battery filled per }\end{array}$} & Q1 & Q2 & Q3 & Q4 \\
\hline & - & - & 18.2 & 25.6 \\
\hline & - & - & 2.2 & 2.3 \\
\hline & - & - & 21.1 & 22.2 \\
\hline & - & - & $36.7 \%$ & $38.5 \%$ \\
\hline
\end{tabular}

EVSE Quarterly Load Profile

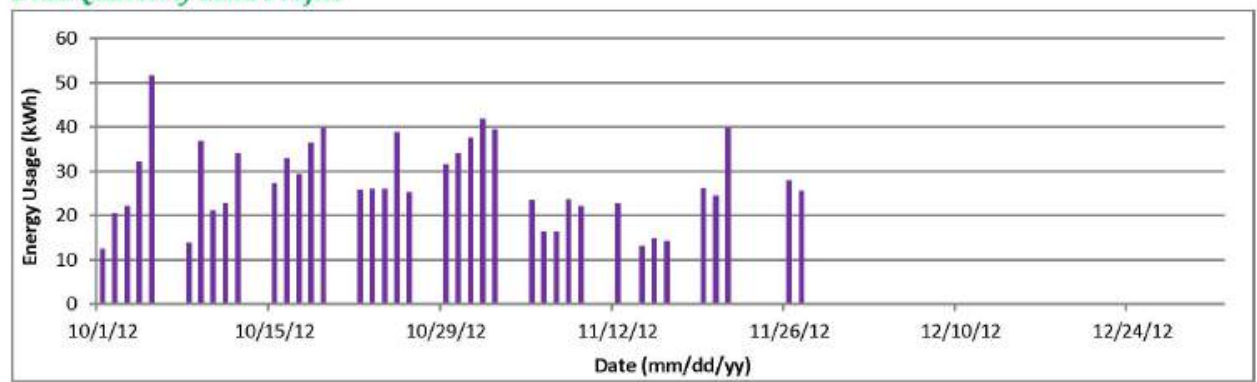

PV Array Quarterly Power Generation Profile

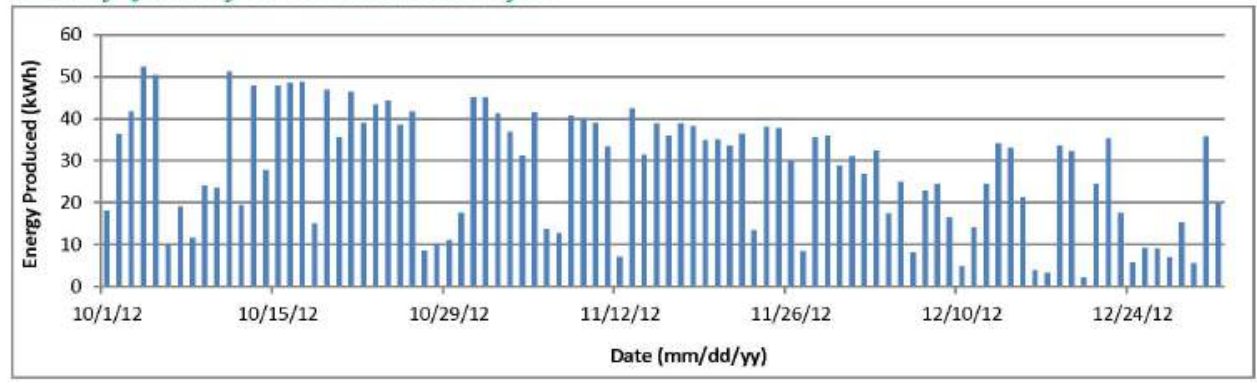

Based on the total energy consumption and an average of miles per $\mathrm{kWh}$ for the Nissan Leaf ( $2.94 \mathrm{mi} / \mathrm{kWh})$ and Chevy Volt $(2.78 \mathrm{mi} / \mathrm{kWh}$.

Values taken from htto://www.fueleconomy.gov/.

Based on energy consumption and size of battery for the Nissan Leaf (24 kWh) and Chevy Volt (16 kWh).

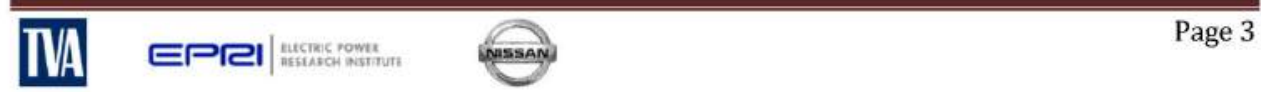




\section{Oak Ridge NaTiOnAL LabORATORY}

EV Project Solar-Assisted Charging Infrastructure Summary Report

EVSE Grouping/Region: EPRI Knoxville

Report Period: October 1-December 31, 2013 (Quarter 4, 2013)

Number of EV Charging Stations: 6

F/y Project

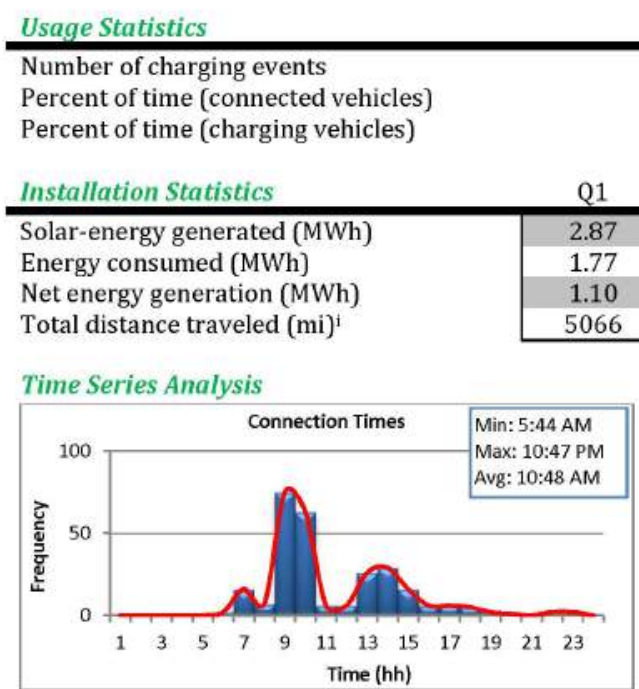

\begin{tabular}{cccc|}
\hline Q1 & Q2 & Q3 & Q4 \\
\hline 223 & 277 & 312 & 270 \\
$32.6 \%$ & $22.1 \%$ & $34.2 \%$ & $43.6 \%$ \\
$4.1 \%$ & $4.7 \%$ & $5.4 \%$ & $4.6 \%$
\end{tabular}
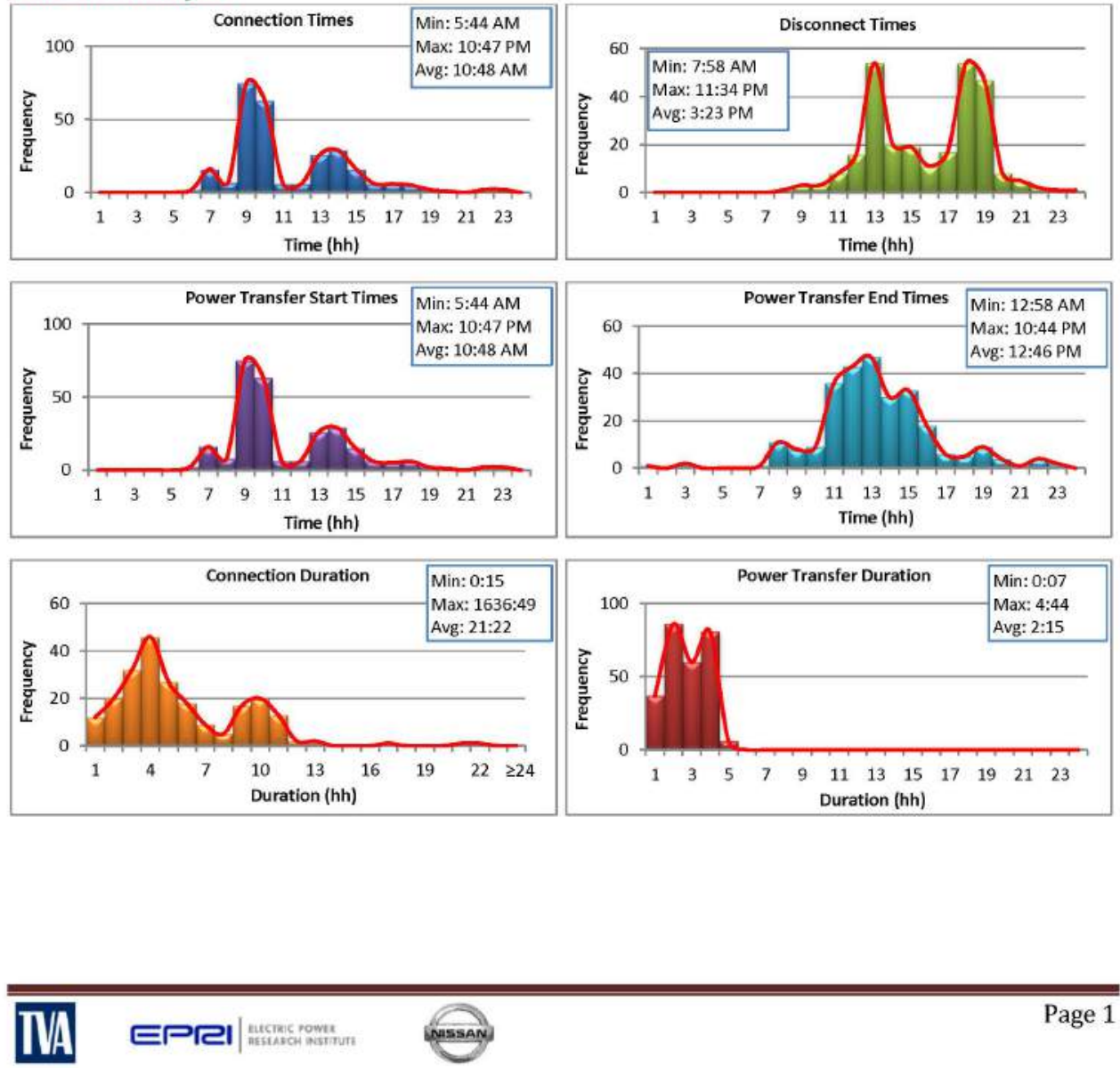


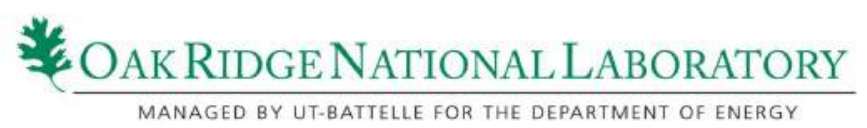

Energy Consumption Analysis
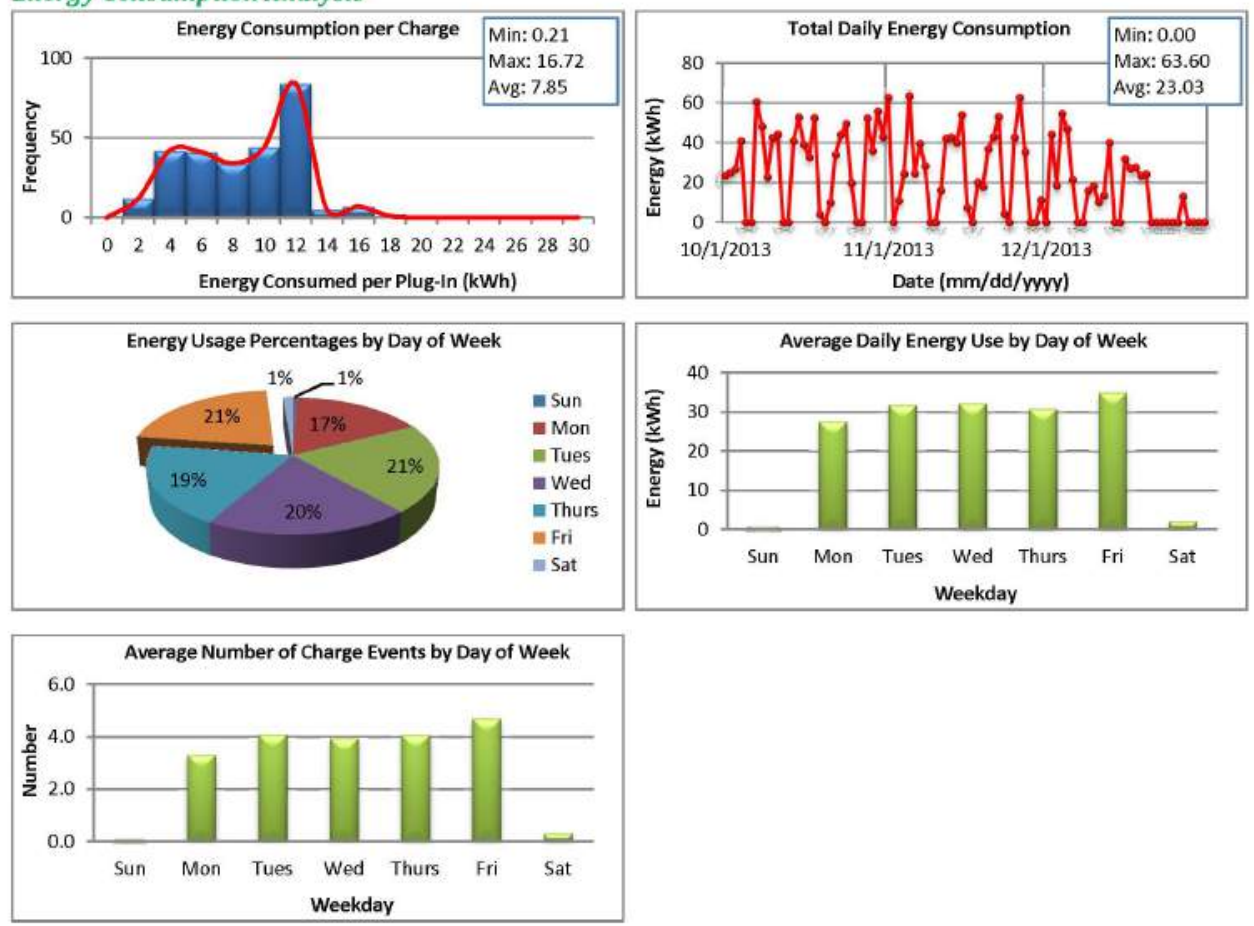

Charging Analysis
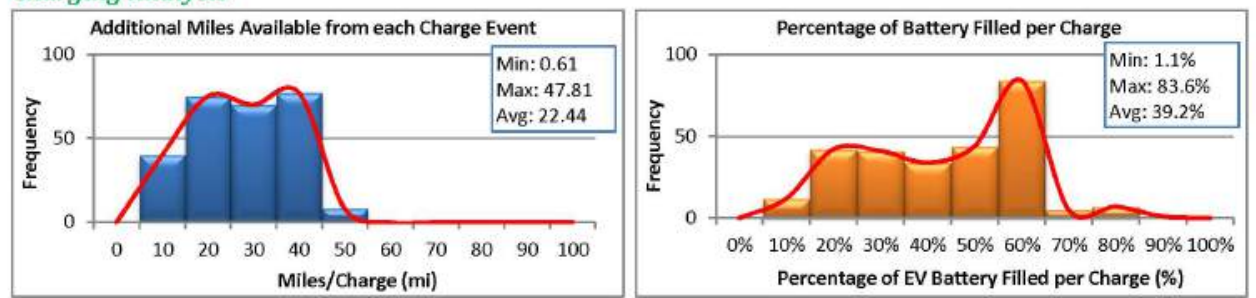

EVSE Analysis

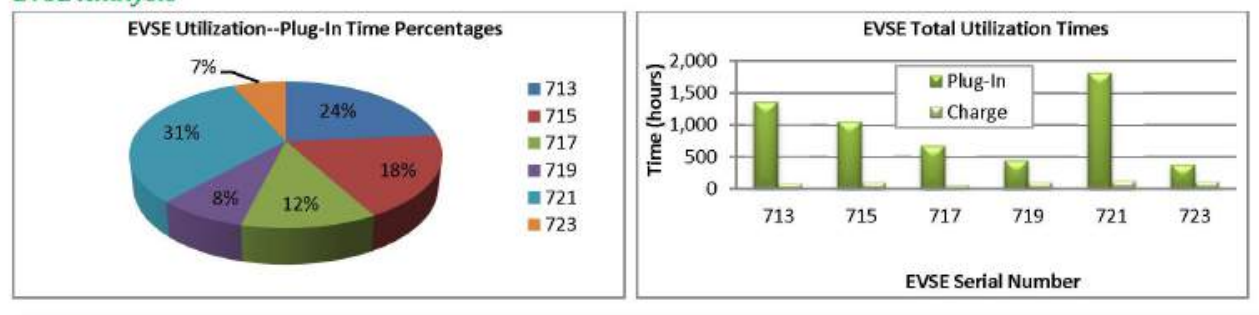

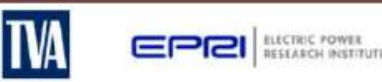

Page 2 


\section{OAK Ridge National Laboratory}

\begin{tabular}{|c|c|c|c|c|}
\hline \multirow{5}{*}{$\begin{array}{l}\text { Average connection duration (hrs.) } \\
\text { Average charge duration (hrs.) } \\
\text { Average miles per charge } \\
\text { Average } \% \text { of battery filled per }\end{array}$} & Q1 & Q2 & Q3 & Q4 \\
\hline & 18.9 & 10.4 & 14.5 & 21.4 \\
\hline & 2.4 & 2.2 & 2.3 & 2.3 \\
\hline & 22.7 & 19.9 & 21.4 & 22.4 \\
\hline & $39.7 \%$ & $34.8 \%$ & $37.5 \%$ & $39.2 \%$ \\
\hline
\end{tabular}

EVSE Quarterly Load Profile

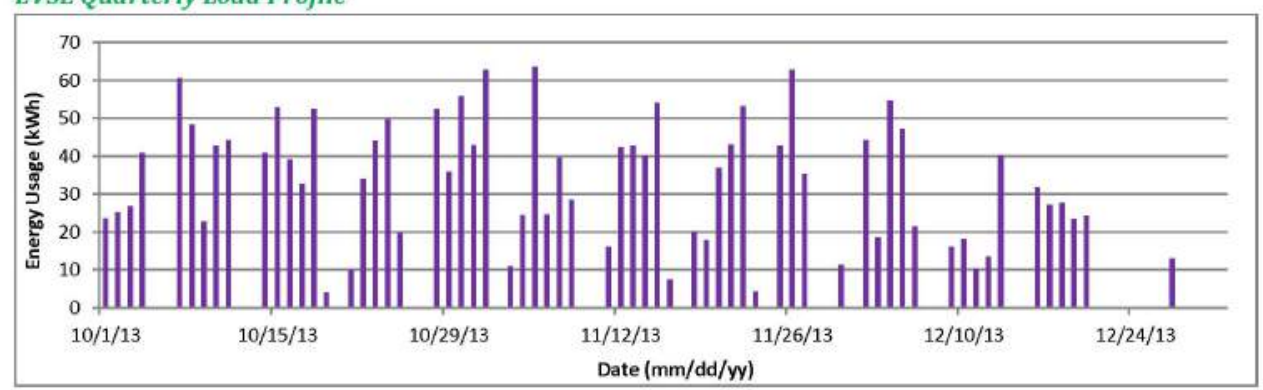

PV Array Quarterly Power Generation Profile

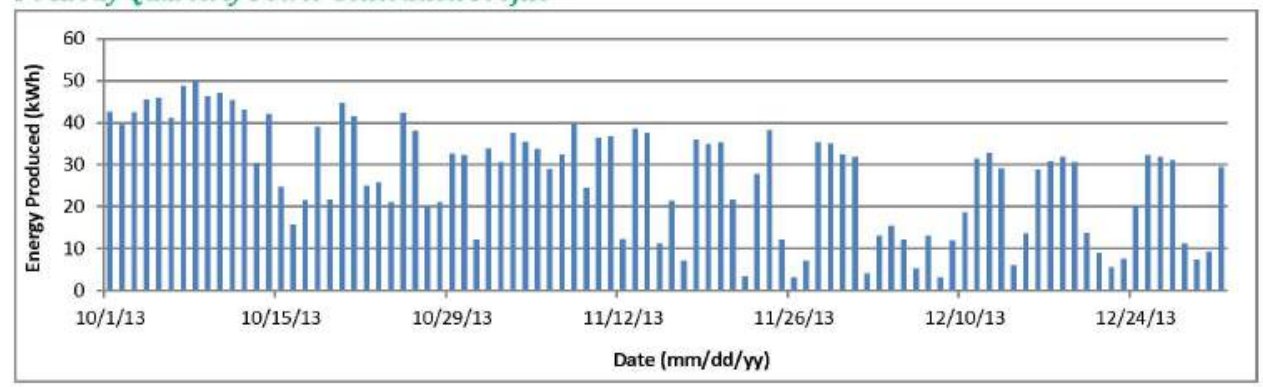

Based on the total energy consumption and an average of miles per $\mathrm{kWh}$ for the Nissan Leaf ( $2.94 \mathrm{mi} / \mathrm{kWh})$ and Chevy Volt $(2.78 \mathrm{mi} / \mathrm{kWh}$ ).

Values taken from http://www.fueleconomv.gov/.

Based on energy consumption and size of battery for the Nissan Leaf (24 kWh) and Chevy Volt (16 kWh).

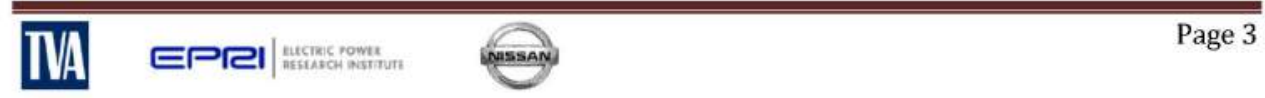




\section{A.11 Chattanooga Theatre Center}

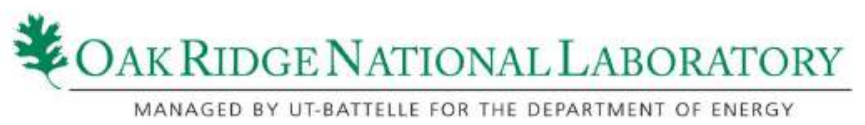

EV Project Solar-Assisted Charging Infrastructure Summary Report

EVSE Grouping/Region: EPRI Chattanooga-Theatre

Report Period: October 1-December 31, 2012 (Quarter 4, 2012)

Number of EV Charging Stations: 6

$\exists \mathbf{y}$ Project
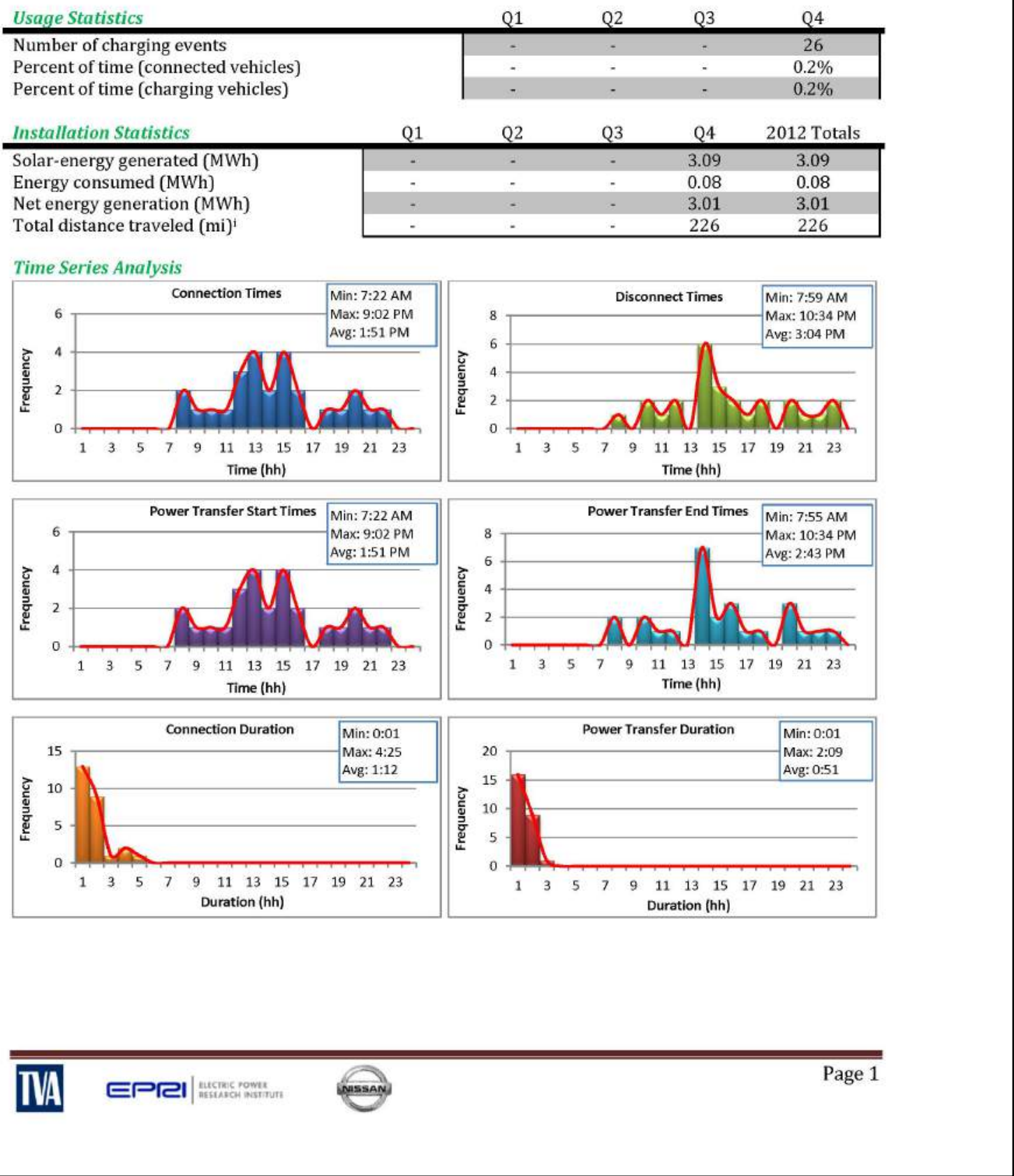


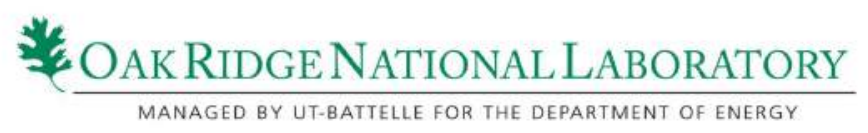

Energy Consumption Analysis
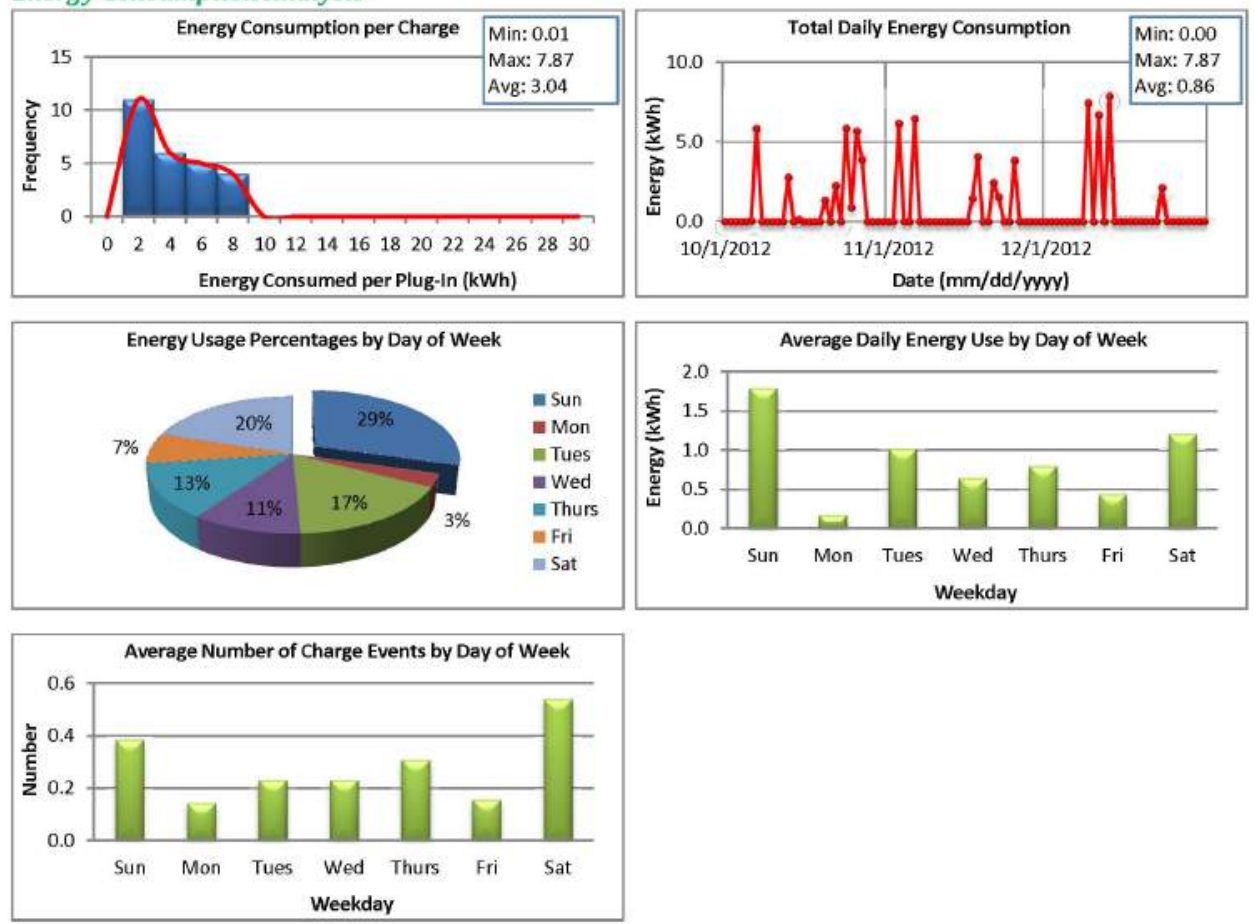

Charging Analysis
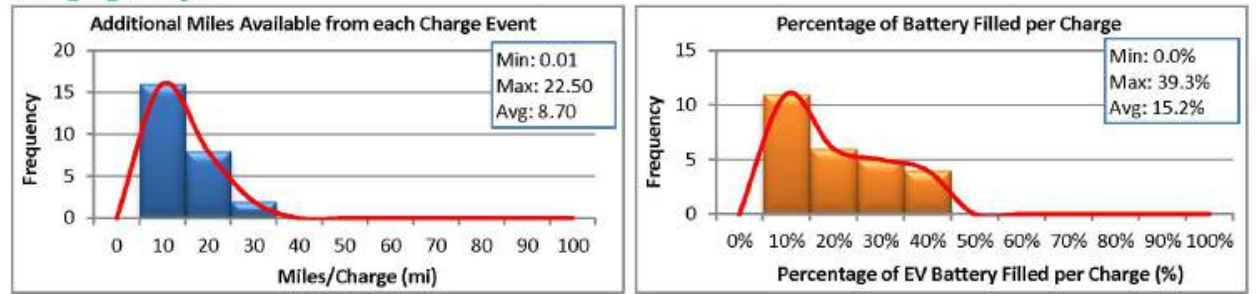

EVSE Analysis

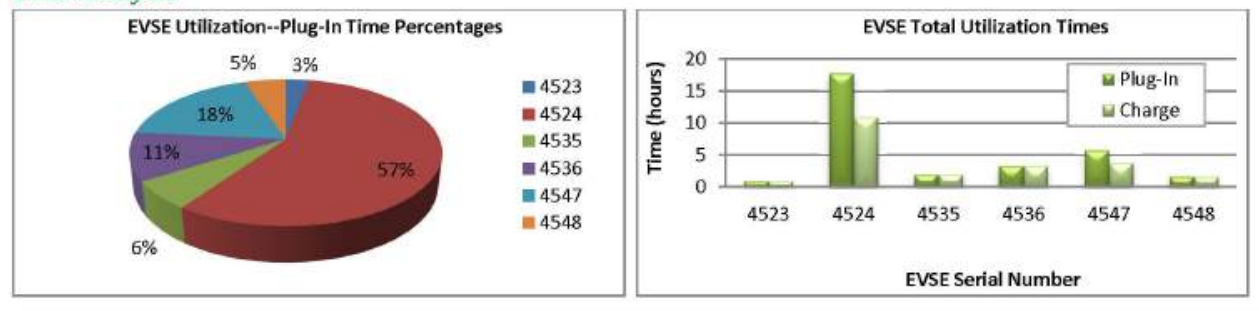

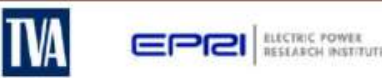

Page 2 

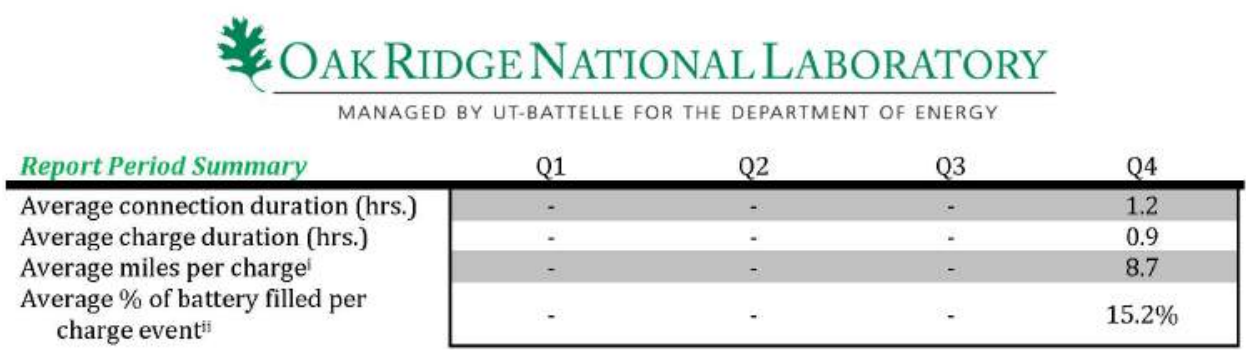

charge event

EVSE Quarterly Load Profile

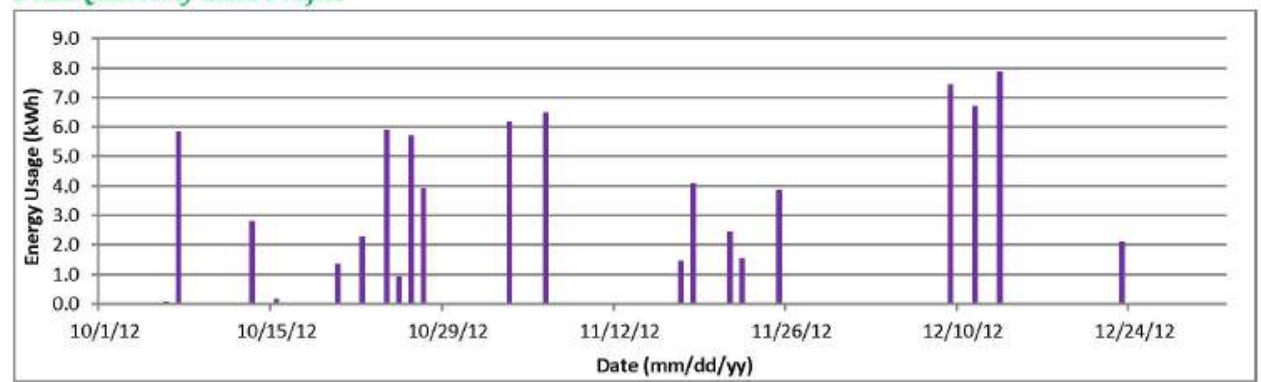

PV Array Quarterly Power Generation Profile

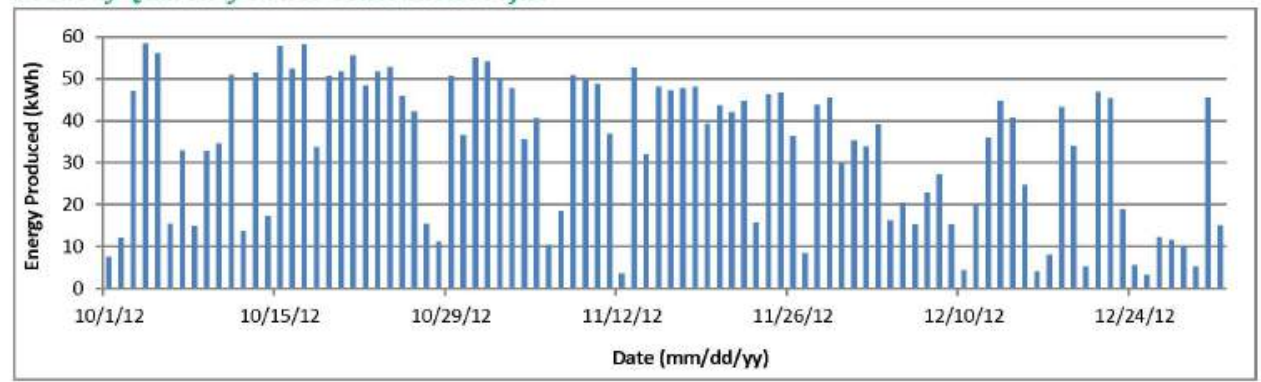

Based on the total energy consumption and an average of miles per $\mathrm{kWh}$ for the Nissan Leaf ( $2.94 \mathrm{mi} / \mathrm{kWh})$ and Chevy Volt $(2.78 \mathrm{mi} / \mathrm{kWh})$.

Values taken from htto://www.fueleconomy.gov/.

"Based on energy consumption and size of battery for the Nissan Leaf ( $24 \mathrm{kWh}$ ) and Chevy Volt (16 kWh).

IVA EPRI|




\section{Oak Ridge NaTiOnAL LabORATORY}

EV Project Solar-Assisted Charging Infrastructure Summary Report

EVSE Grouping/Region: EPRI Chattanooga-Theatre

Report Period: October 1-December 31, 2013 (Quarter 4, 2013)

Number of EV Charging Stations: 6

F/y Project

\begin{tabular}{|c|c|c|c|c|c|}
\hline Usage Statistics & & Q1 & Q2 & Q3 & Q4 \\
\hline Number of charging events & & 29 & 47 & 75 & 42 \\
\hline Percent of time (connected vehicles) & & $0.3 \%$ & $0.5 \%$ & $1.4 \%$ & $0.5 \%$ \\
\hline Percent of time (charging vehicles) & & $0.3 \%$ & $0.4 \%$ & $0.7 \%$ & $0.4 \%$ \\
\hline Installation Statistics & Q1 & Q2 & Q3 & Q4 & 2013 Totals \\
\hline Solar-energy generated (MWh) & 2.54 & 5.17 & 4.62 & 2.93 & 15.26 \\
\hline Energy consumed (MWh) & 0.14 & 0.20 & 0.37 & 0.22 & 0.93 \\
\hline Net energy generation (MWh) & 2.40 & 4.97 & 4.25 & 2.71 & 14.33 \\
\hline Total distance traveled $(\mathrm{mi})^{\mathrm{i}}$ & 407 & 576 & 1062 & 631 & 2676 \\
\hline
\end{tabular}

Time Series Analysis
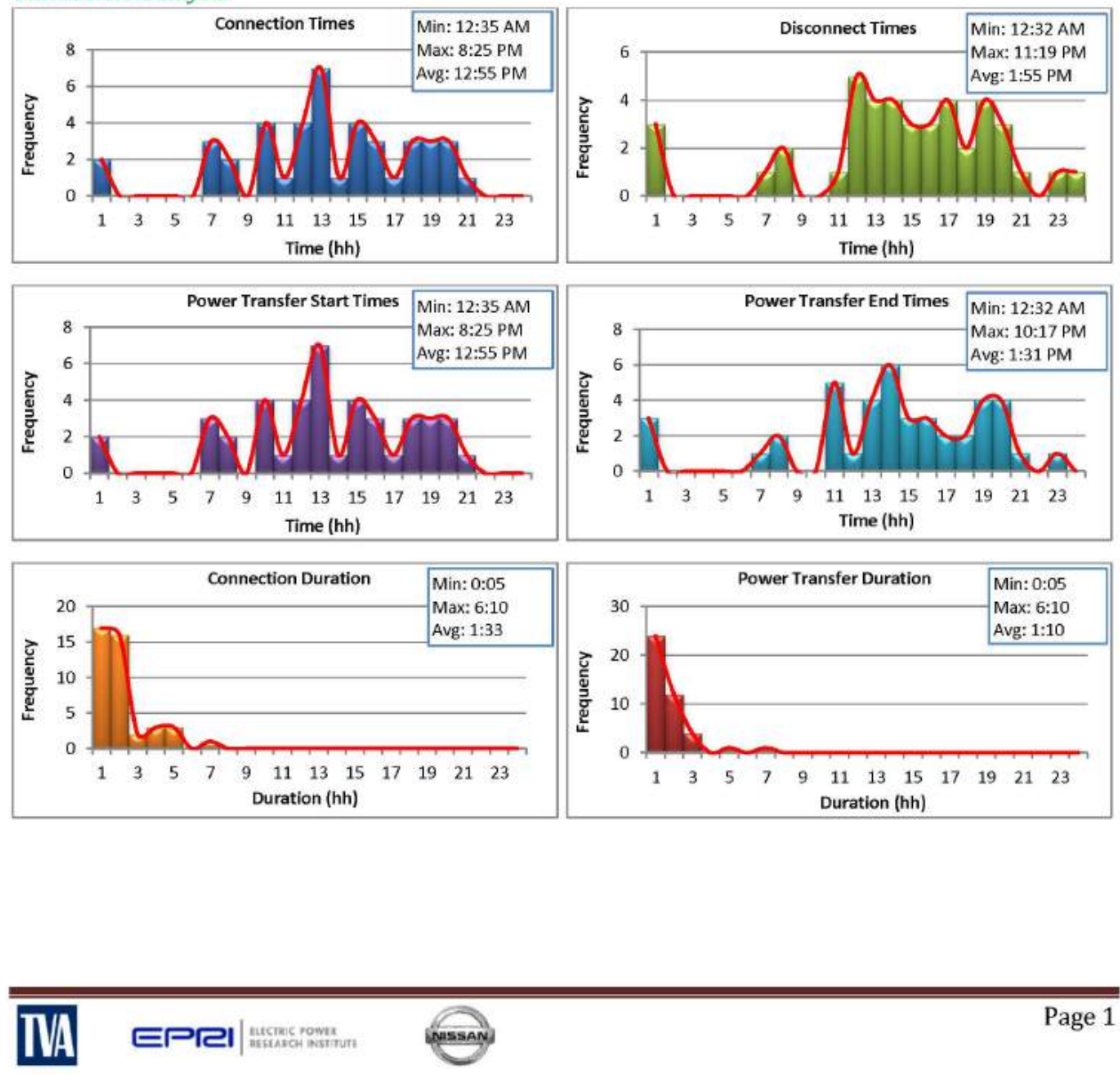


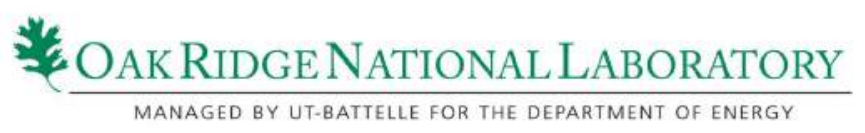

Energy Consumption Analysis
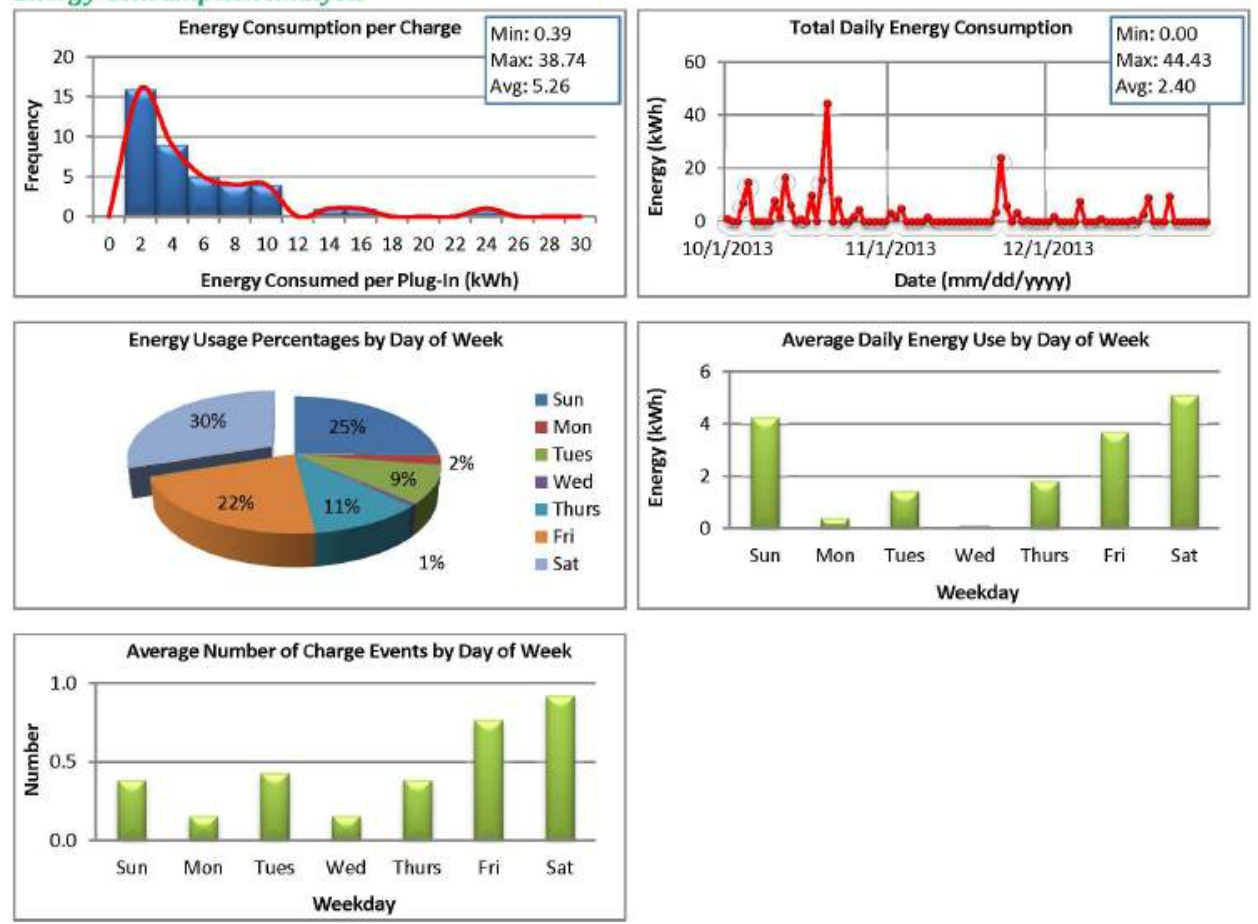

Charging Analysis
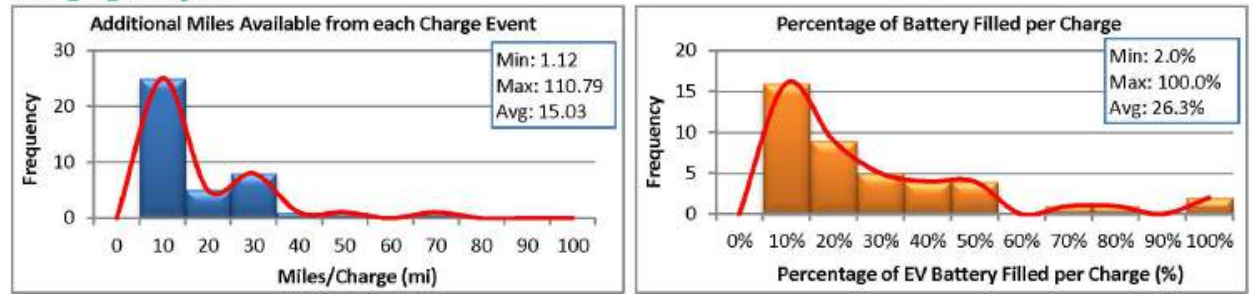

EVSE Analysis
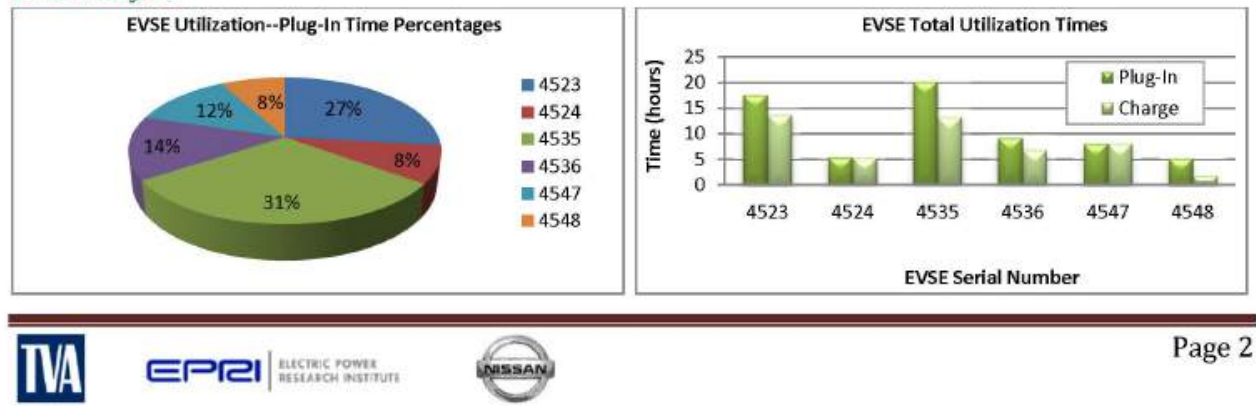

Page 2 


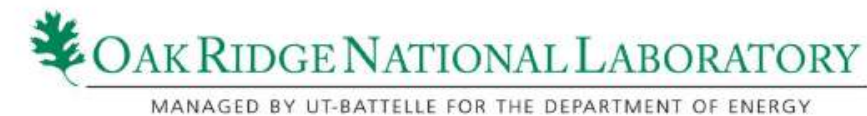

\begin{tabular}{|c|c|c|c|c|}
\hline Report Period Summary & Q1 & Q2 & Q3 & Q4 \\
\hline Average connection duration (hrs.) & 1.5 & 1.5 & 2.5 & 1.6 \\
\hline Average charge duration (hrs.) & 1.4 & 1.1 & 1.3 & 1.2 \\
\hline Average miles per charge ${ }^{i}$ & 14.0 & 12.3 & 14.2 & 15.0 \\
\hline $\begin{array}{l}\text { Average } \% \text { of battery filled per } \\
\text { charge event }{ }^{\mathrm{ti}}\end{array}$ & $24.5 \%$ & $21.4 \%$ & $24.4 \%$ & $26.3 \%$ \\
\hline
\end{tabular}

\section{EVSE Quarterly Load Profile}

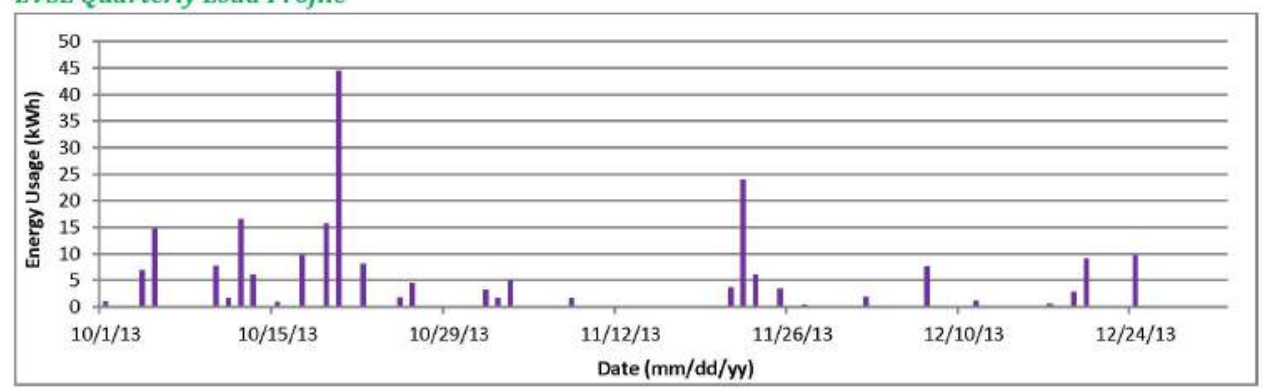

PV Array Quarterly Power Generation Profile

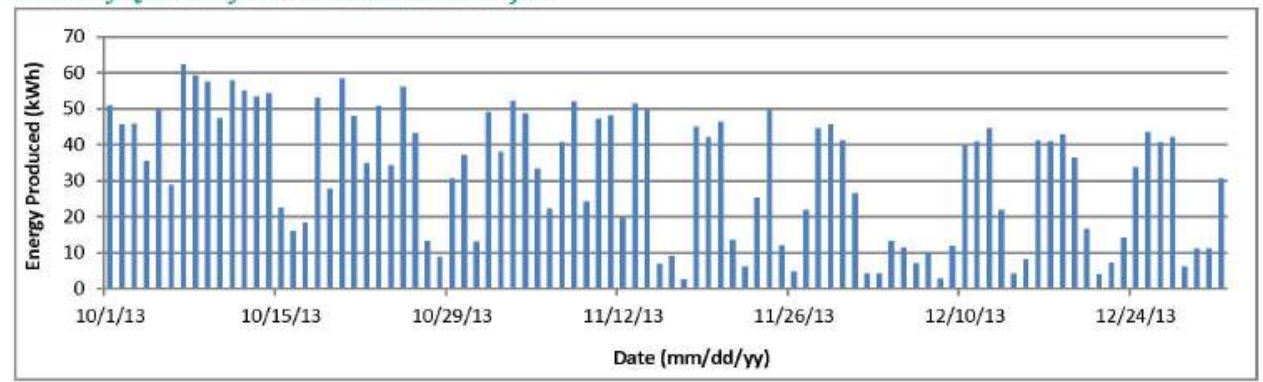

Based on the total energy consumption and an average of miles per $\mathrm{kWh}$ for the Nissan Leaf ( $2.94 \mathrm{mi} / \mathrm{kWh})$ and Chevy Volt ( $2.78 \mathrm{mi} / \mathrm{kWh})$.

Values taken from http://www.fueleconomy.gov/.

Based on energy consumption and size of battery for the Nissan Leaf ( $24 \mathrm{kWh})$ and Chevy Volt ( $16 \mathrm{kWh})$.

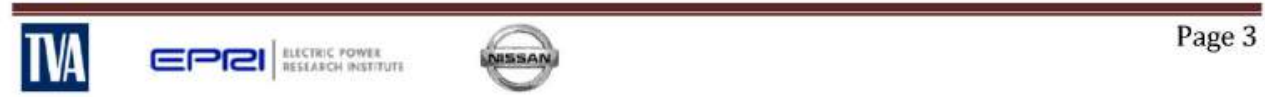




\section{A.12 TVA Advanced Vehicle Test Facility, Chattanooga}

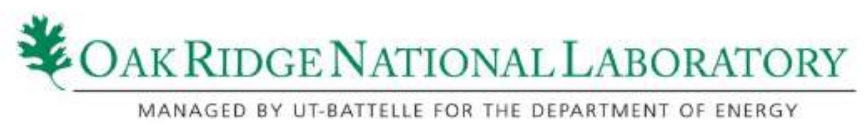

EV Project Solar-Assisted Charging Infrastructure Summary Report

EVSE Grouping/Region: EPRI Chattanooga-Vehicle

Report Period: October 1-December 31, 2012 (Quarter 4, 2012)

Number of EV Charging Stations: 4

$\exists \boldsymbol{\nabla}$ Project

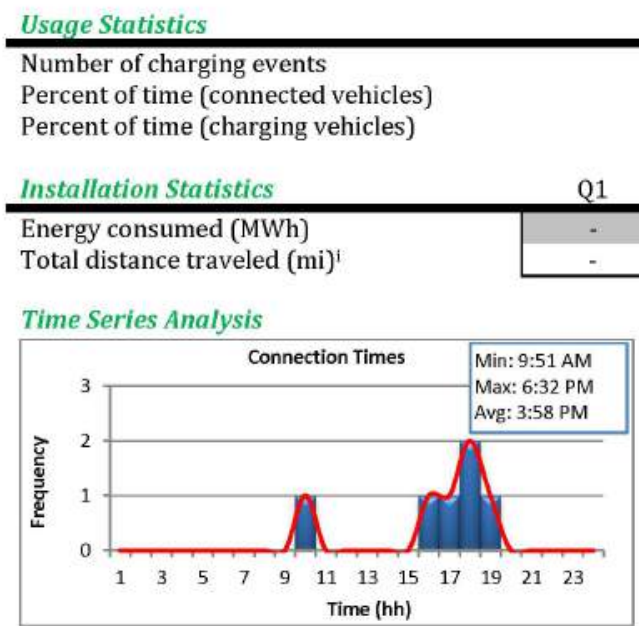

\begin{tabular}{|cccc|}
\hline $\mathrm{Q} 1$ & $\mathrm{Q} 2$ & $\mathrm{Q} 3$ & $\mathrm{Q} 4$ \\
\hline- & - & 1 & 6 \\
- & - & $2.7 \%$ & $10.1 \%$ \\
- & - & $0.0 \%$ & $0.2 \%$ \\
\hline
\end{tabular}
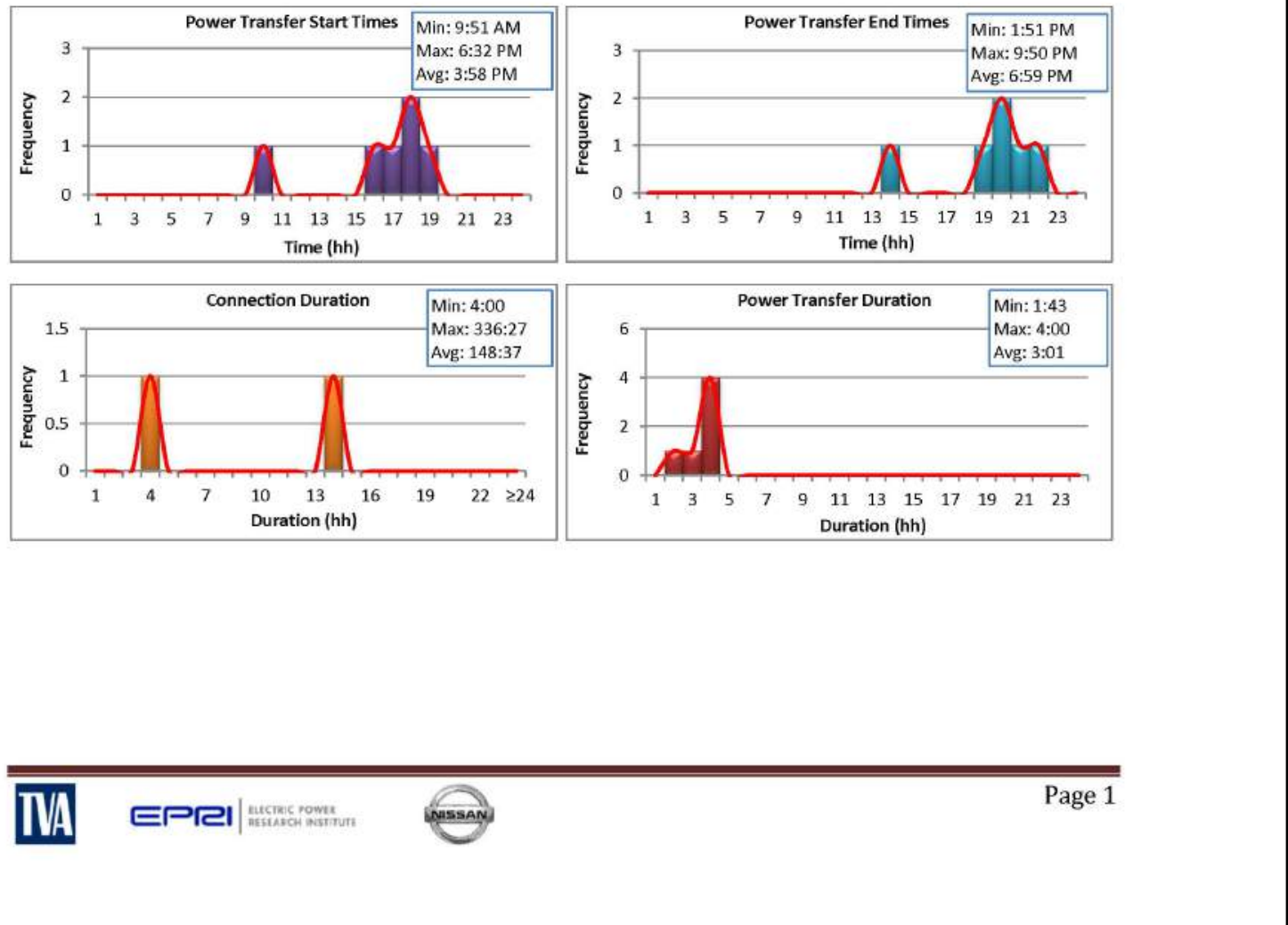


\section{OAK RIDGE NATIONAL LABORATORY}

Energy Consumption Analysis
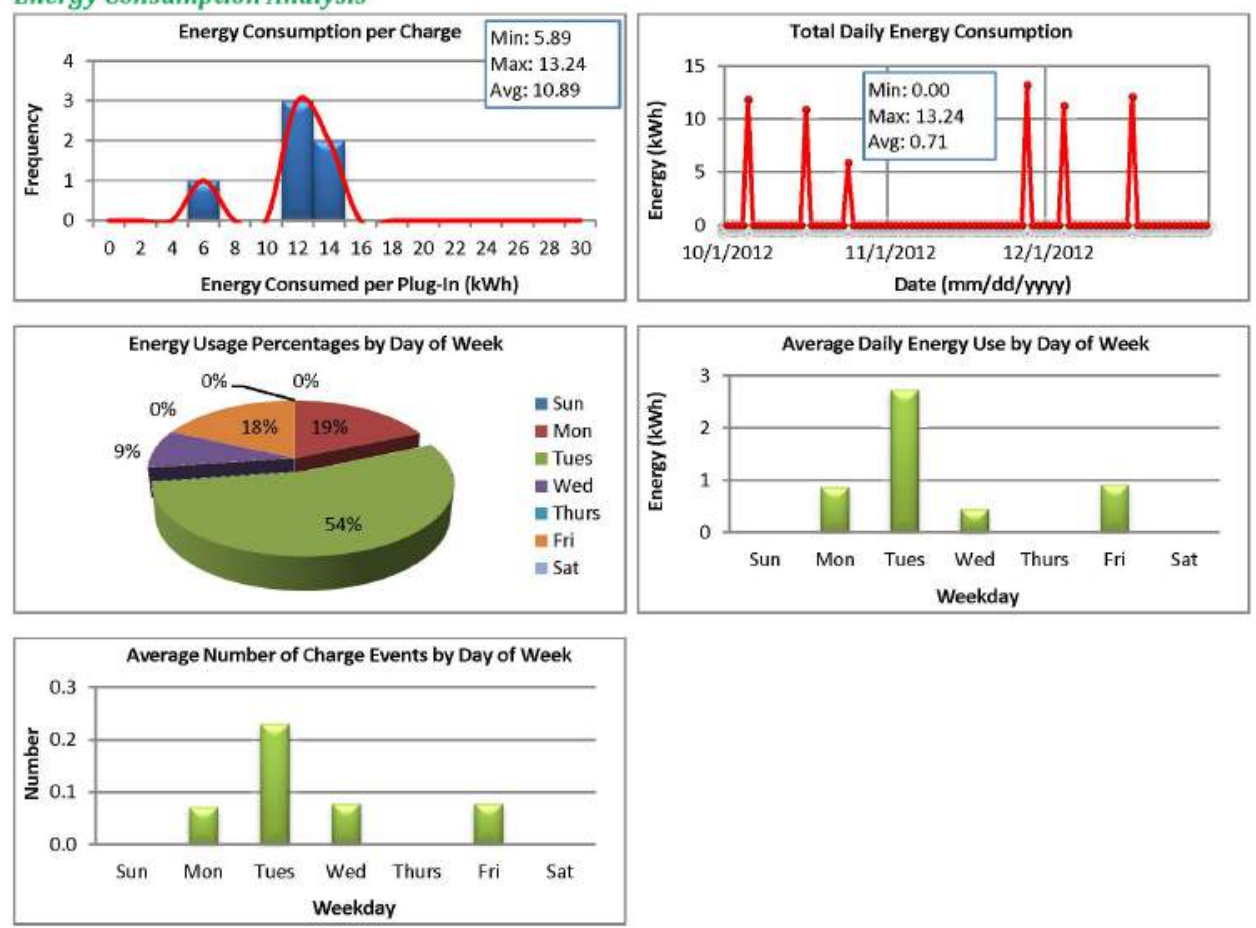

Charging Analysis
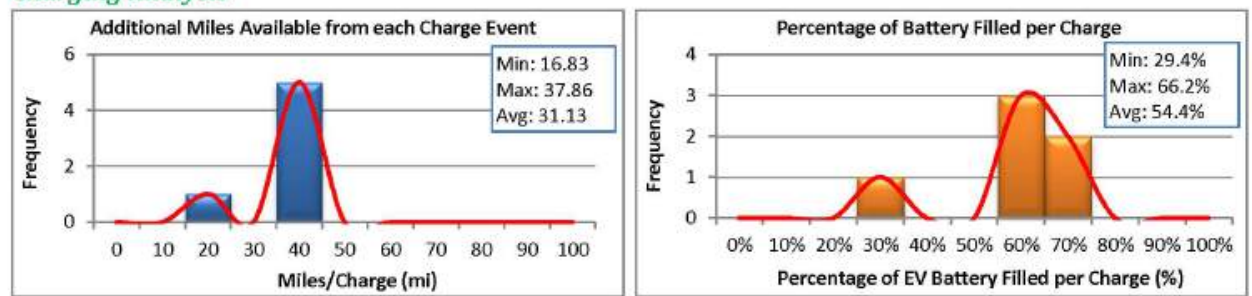

EVSE Analysis
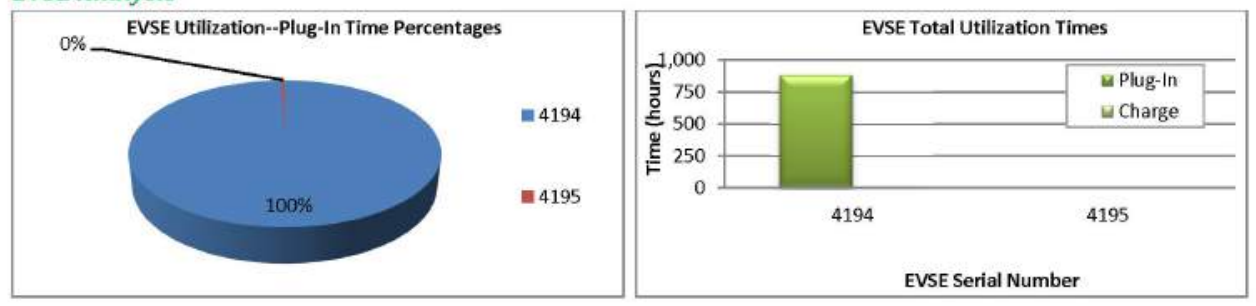

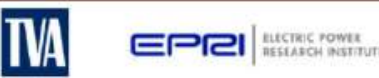

Page 2 


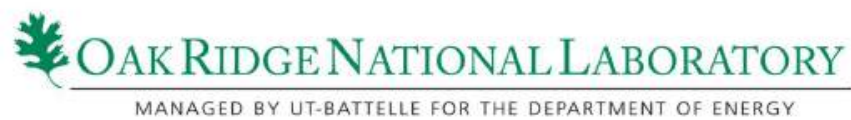

\begin{tabular}{|c|c|c|c|c|}
\hline Report Period Summary & Q1 & Q2 & Q3 & Q4 \\
\hline Average connection duration (hrs.) & - & - & 238.8 & 148.6 \\
\hline Average charge duration (hrs.) & - & - & 3.8 & 3.0 \\
\hline Average miles per charge ${ }^{i}$ & - & - & 40.5 & 31.1 \\
\hline $\begin{array}{l}\text { Average } \% \text { of battery filled per } \\
\text { charge event } t^{\mathrm{ii}}\end{array}$ & - & - & $70.8 \%$ & $54.4 \%$ \\
\hline
\end{tabular}

EVSE Quarterly Load Profile

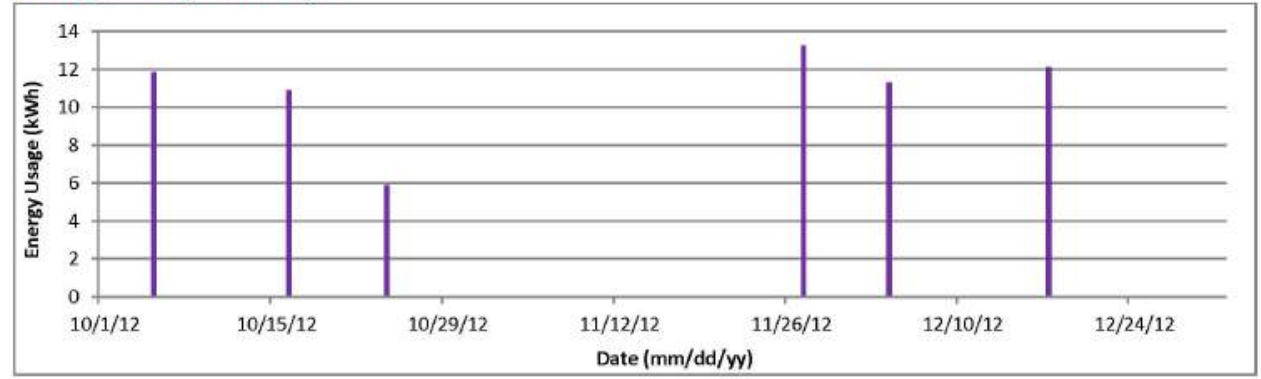

Note: Although this site includes a solar PV array, the daily solar energy generation data was not available.

Based on the total energy consumption and an average of miles per kWh for the Nissan Leaf ( $2.94 \mathrm{mi} / \mathrm{kWh}$ ) and Chevy Volt (2.78 mi/kWh). Values taken from http://www.fueleconomy.gov/.

Based on energy consumption and size of battery for the Nissan Leaf ( $24 \mathrm{kWh})$ and Chevy Volt (16 kWh).

IVA EPRI|




\section{Oak Ridge NaTiOnAL LabORATORY}

EV Project Solar-Assisted Charging Infrastructure Summary Report

EVSE Grouping/Region: EPRI Chattanooga-Vehicle

Report Period: October 1-December 31, 2013 (Quarter 4, 2013)

Number of EV Charging Stations: 4

F/y Project

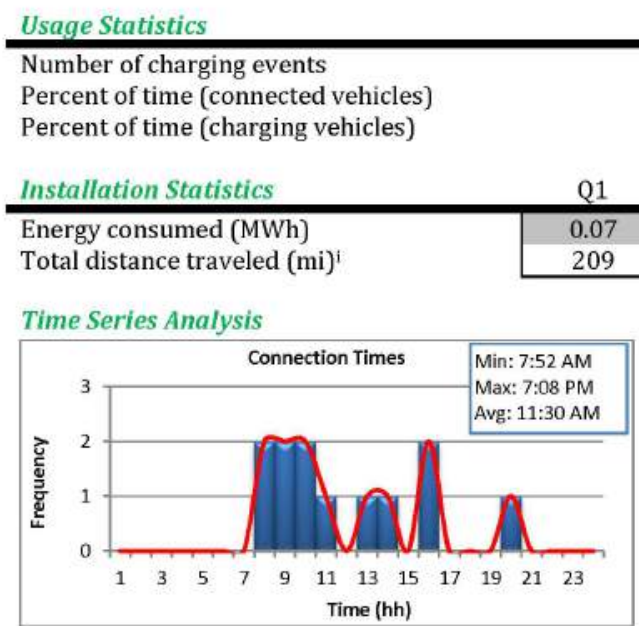

\begin{tabular}{cccc|}
\hline 1 & Q2 & Q3 & Q4 \\
\hline 6 & 13 & 17 & 12 \\
$9.2 \%$ & $27.9 \%$ & $2.6 \%$ & $0.1 \%$ \\
$0.2 \%$ & $0.3 \%$ & $0.3 \%$ & $0.1 \%$
\end{tabular}
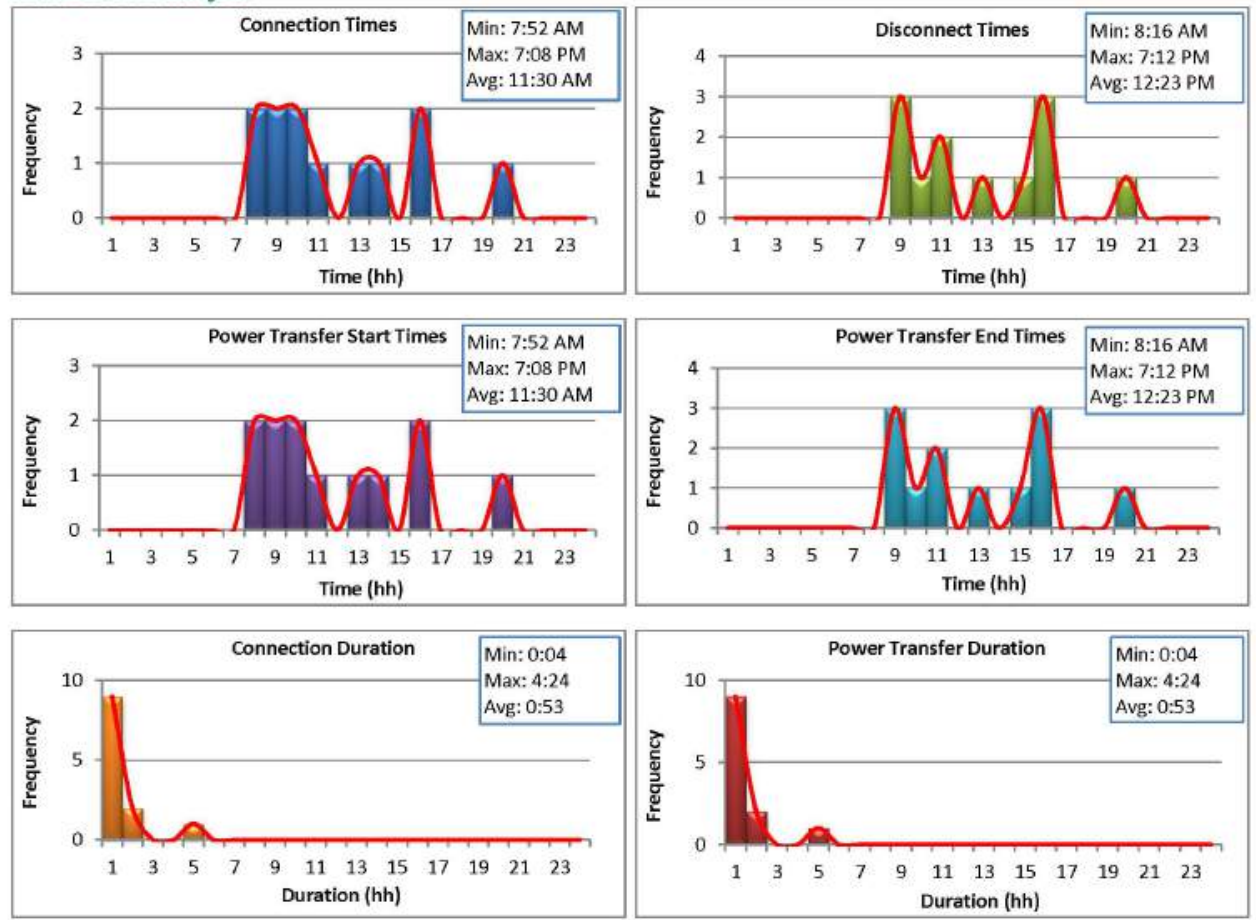

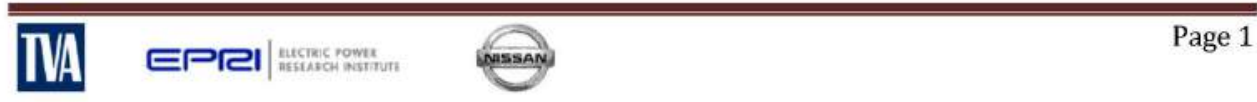




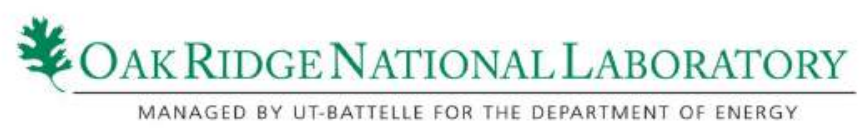

Energy Consumption Analysis
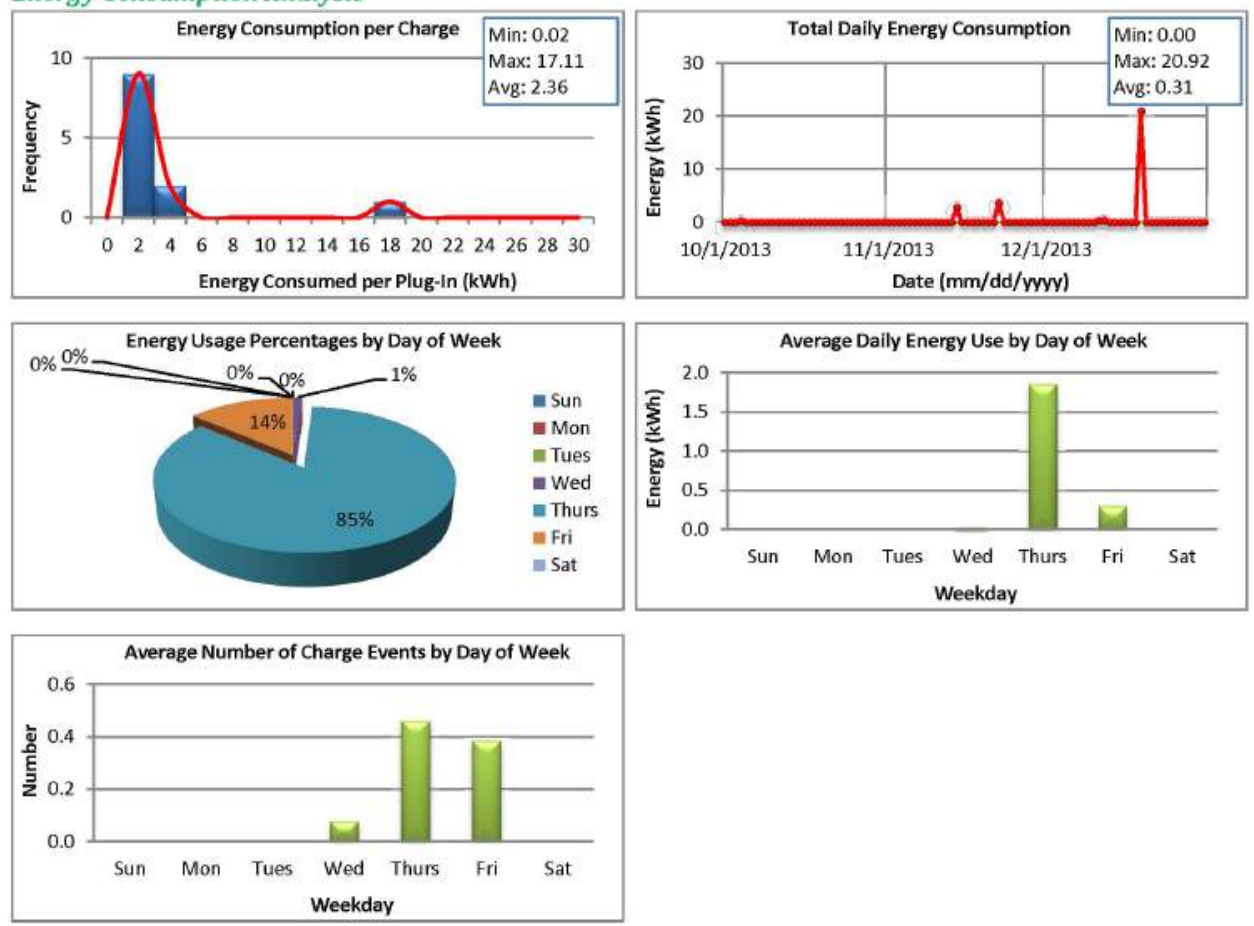

Charging Analysis
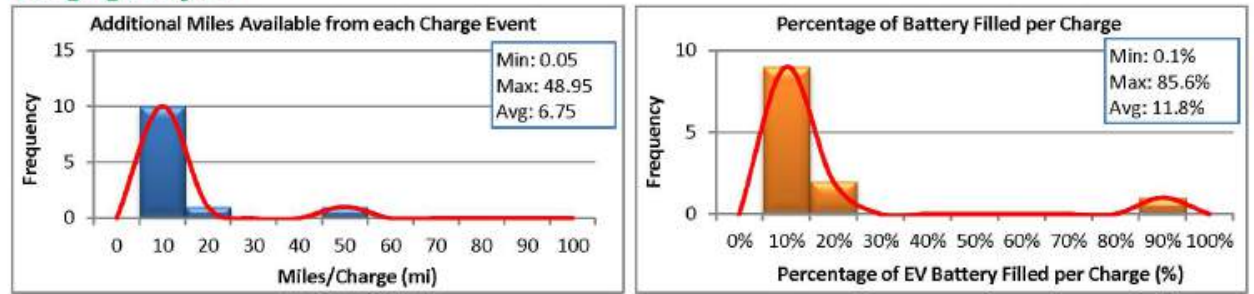

EVSE Analysis

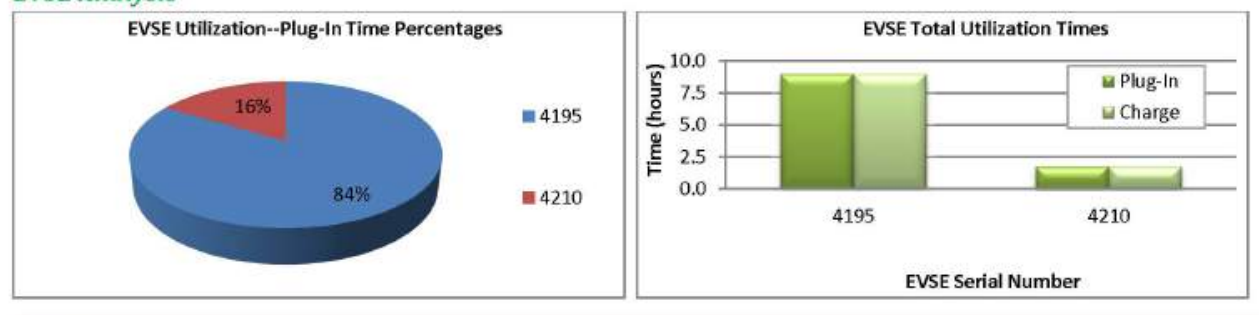

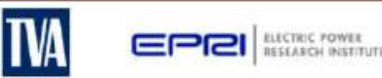

Page 2 


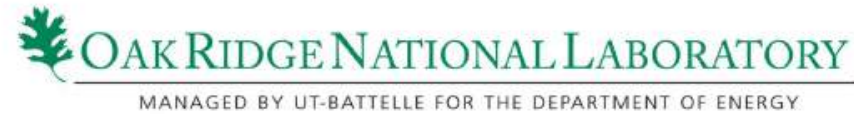

\begin{tabular}{|c|c|c|c|c|}
\hline Report Period Summary & Q1 & Q2 & Q3 & Q4 \\
\hline Average connection duration (hrs.) & 132.0 & 187.7 & 13.3 & 0.9 \\
\hline Average charge duration (hrs.) & 3.2 & 1.7 & 1.4 & 0.9 \\
\hline Average miles per charge & 34.8 & 16.5 & 11.4 & 6.8 \\
\hline $\begin{array}{l}\text { Average } \% \text { of battery filled per } \\
\text { charge event }{ }^{\mathrm{ii}}\end{array}$ & $60.8 \%$ & $28.8 \%$ & $20.0 \%$ & $11.8 \%$ \\
\hline
\end{tabular}

EVSE Quarterly Load Profile

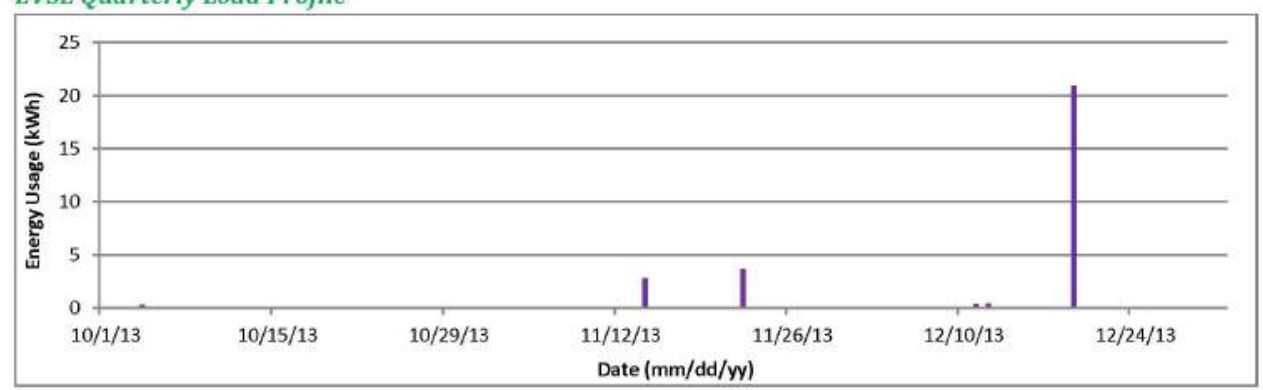

Note: Although this site includes a solar PV array, the daily solar energy generation data was not available.

Based on the total energy consumption and an average of miles per $\mathrm{kWh}$ for the Nissan Leaf ( $2.94 \mathrm{mi} / \mathrm{kWh}$ ) and Chevy Volt ( $2.78 \mathrm{mi} / \mathrm{kWh}$ ).

Values taken from http://www.fueleconomy.gov/.

"Based on energy consumption and size of battery for the Nissan Leaf ( $24 \mathrm{kWh}$ ) and Chevy Volt (16 kWh).

IVA EPRI|




\section{A.13 Shelby Farms Park, Memphis}

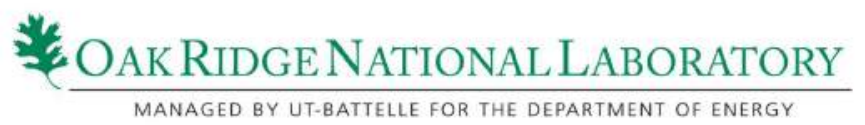

EV Project Solar-Assisted Charging Infrastructure Summary Report

EVSE Grouping/Region: EPRI Memphis

Report Period: October 1-December 31, 2012 (Quarter 4, 2012)

Number of EV Charging Stations: 10

$\exists \mathbf{y}$ Project

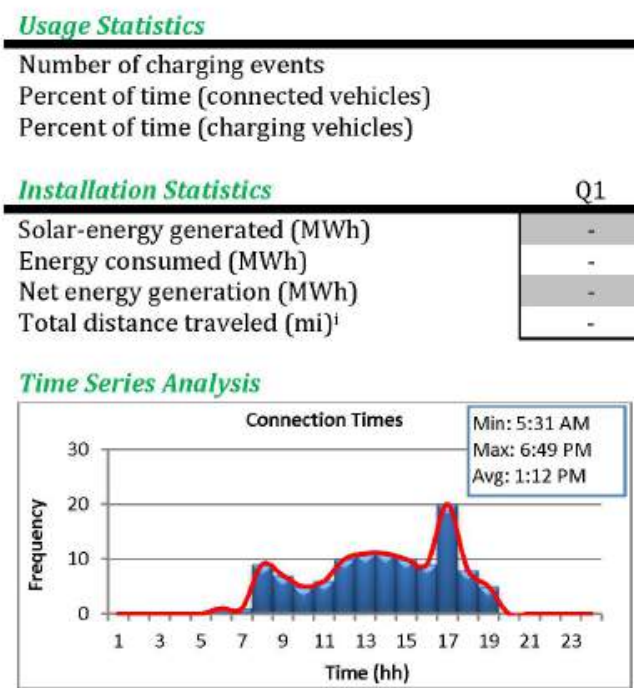

\begin{tabular}{|cccc|}
\hline Q1 & Q2 & Q3 & Q4 \\
\hline- & - & 2 & 113 \\
- & - & $0.0 \%$ & $1.2 \%$ \\
- & - & $0.0 \%$ & $0.7 \%$
\end{tabular}
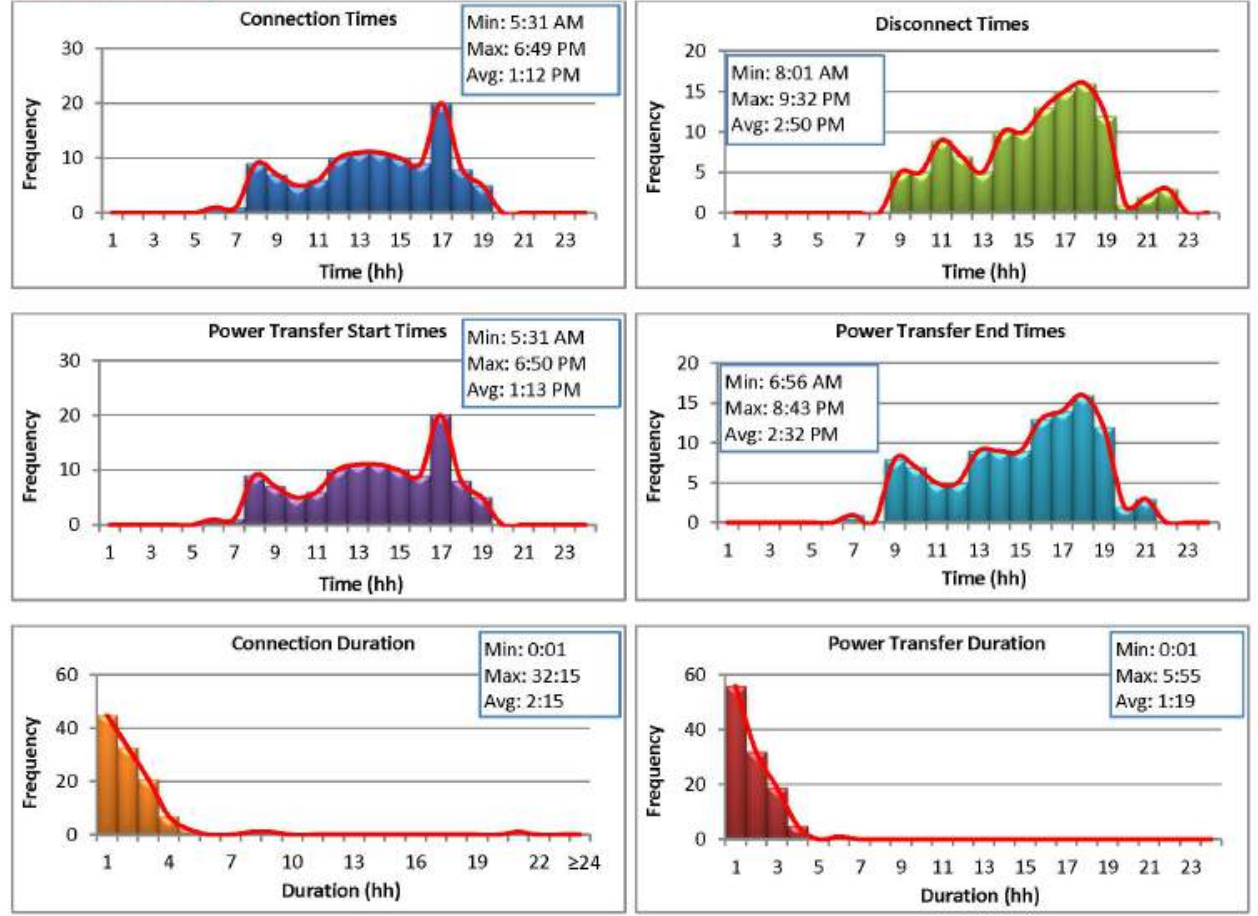

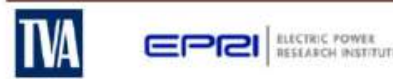

Page 1 


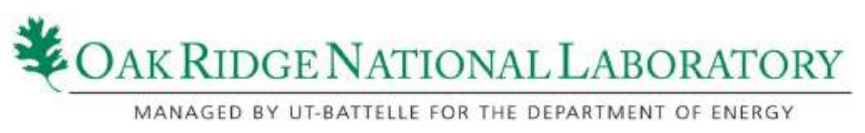

Energy Consumption Analysis
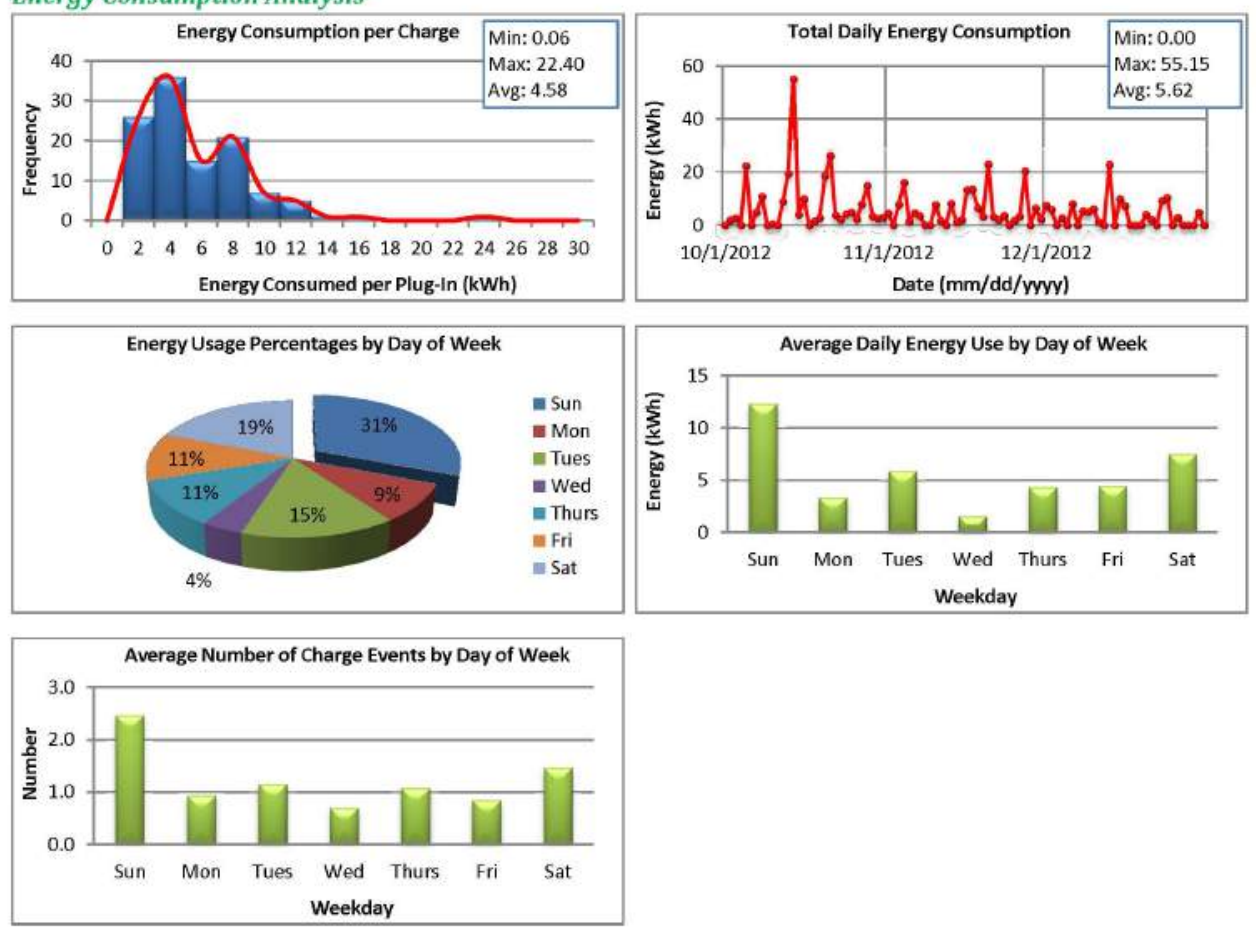

Charging Analysis
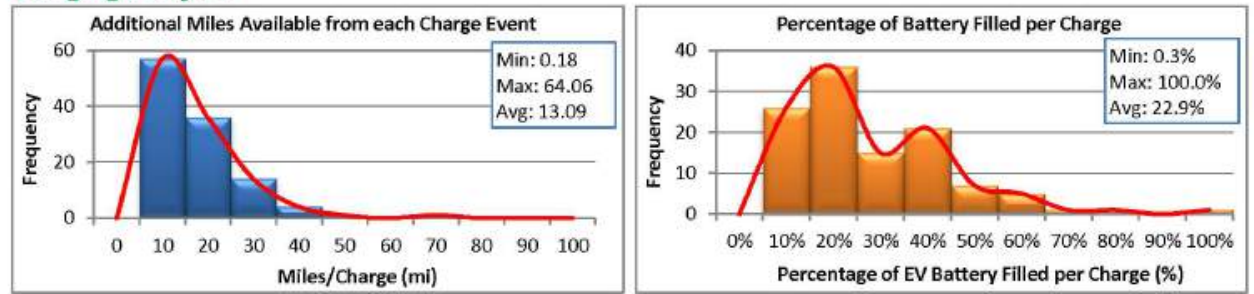

EVSE Analysís

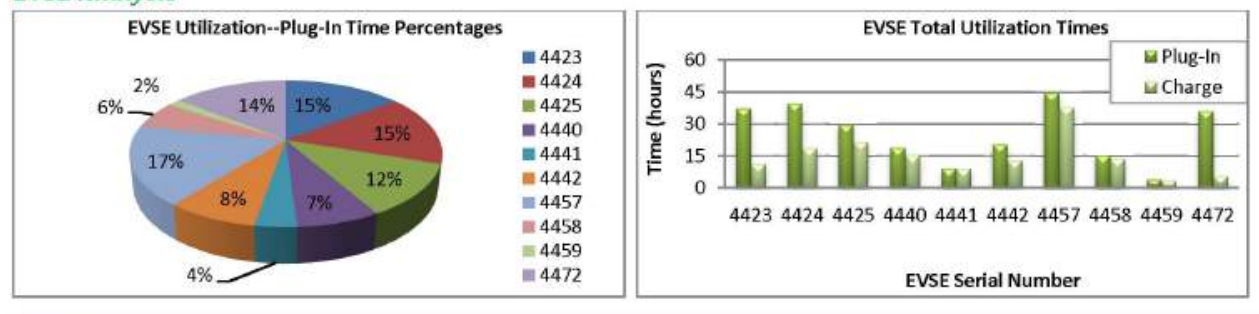

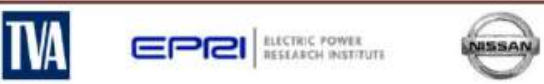

Page 2 


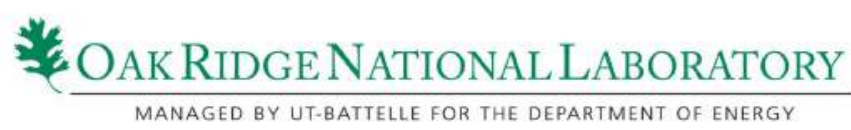

\begin{tabular}{|c|c|c|c|c|}
\hline \multirow{5}{*}{$\begin{array}{l}\text { Report Period Summary } \\
\text { Average connection duration (hrs.) } \\
\text { Average charge duration (hrs.) } \\
\text { Average miles per charge } \\
\text { Average } \% \text { of battery filled per }\end{array}$} & Q1 & Q2 & Q3 & Q4 \\
\hline & - & - & 2.8 & 2.3 \\
\hline & - & - & 1.5 & 1.3 \\
\hline & - & - & 16.1 & 13.1 \\
\hline & - & - & $28.1 \%$ & $22.9 \%$ \\
\hline
\end{tabular}

EVSE Quarterly Load Profile

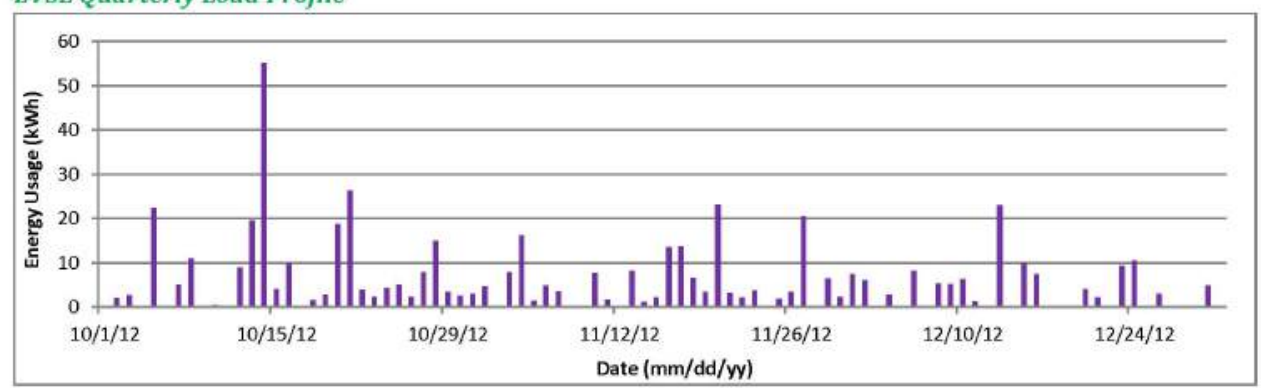

PV Array Quarterly Power Generation Profile

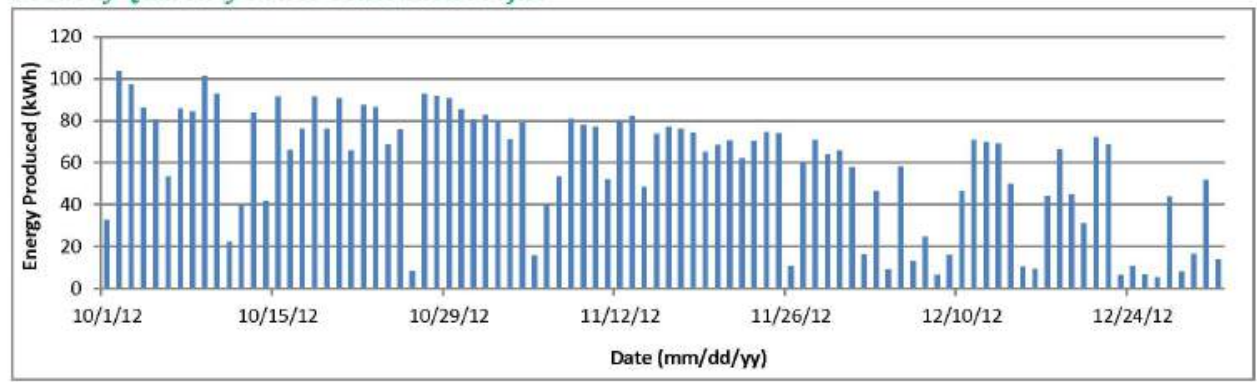

Based on the total energy consumption and an average of miles per $\mathrm{kWh}$ for the Nissan Leaf ( $2.94 \mathrm{mi} / \mathrm{kWh}$ ) and Chevy Volt ( $2.78 \mathrm{mi} / \mathrm{kWh}$.

Values taken from http://www.fueleconomv.gov/.

Based on energy consumption and size of battery for the Nissan Leaf (24 kWh) and Chevy Volt (16 kWh).

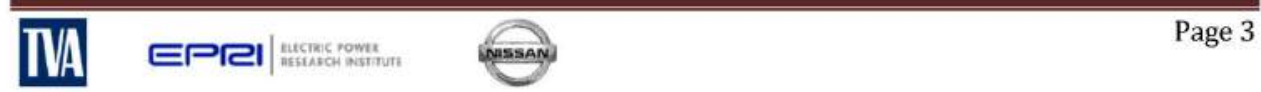




\section{Oak Ridge NaTiOnAL LabORATORY}

EV Project Solar-Assisted Charging Infrastructure Summary Report

EVSE Grouping/Region: EPRI Memphis

Report Period: October 1-December 31, 2013 (Quarter 4, 2013)

Number of EV Charging Stations: 10

F/V Project

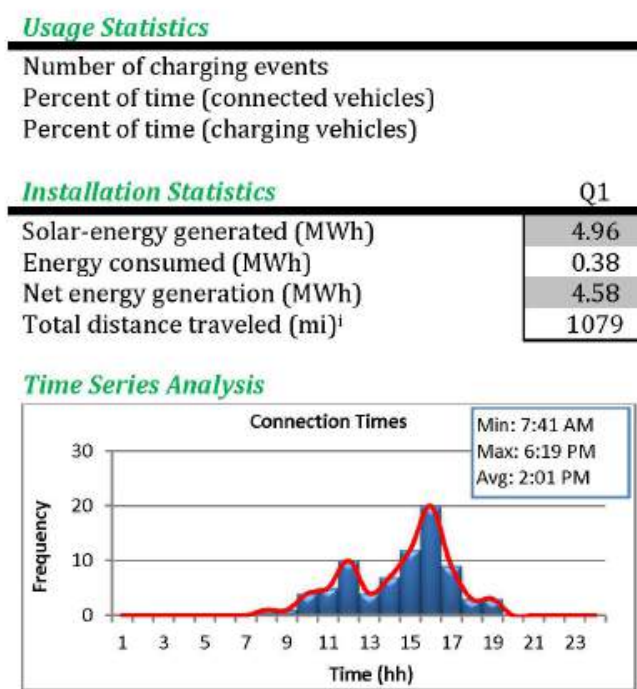

\begin{tabular}{cccc|} 
Q1 & Q2 & Q3 & Q4 \\
\hline 84 & 109 & 89 & 79 \\
$0.5 \%$ & $0.8 \%$ & $0.6 \%$ & $0.5 \%$ \\
$0.5 \%$ & $0.7 \%$ & $0.6 \%$ & $0.4 \%$
\end{tabular}
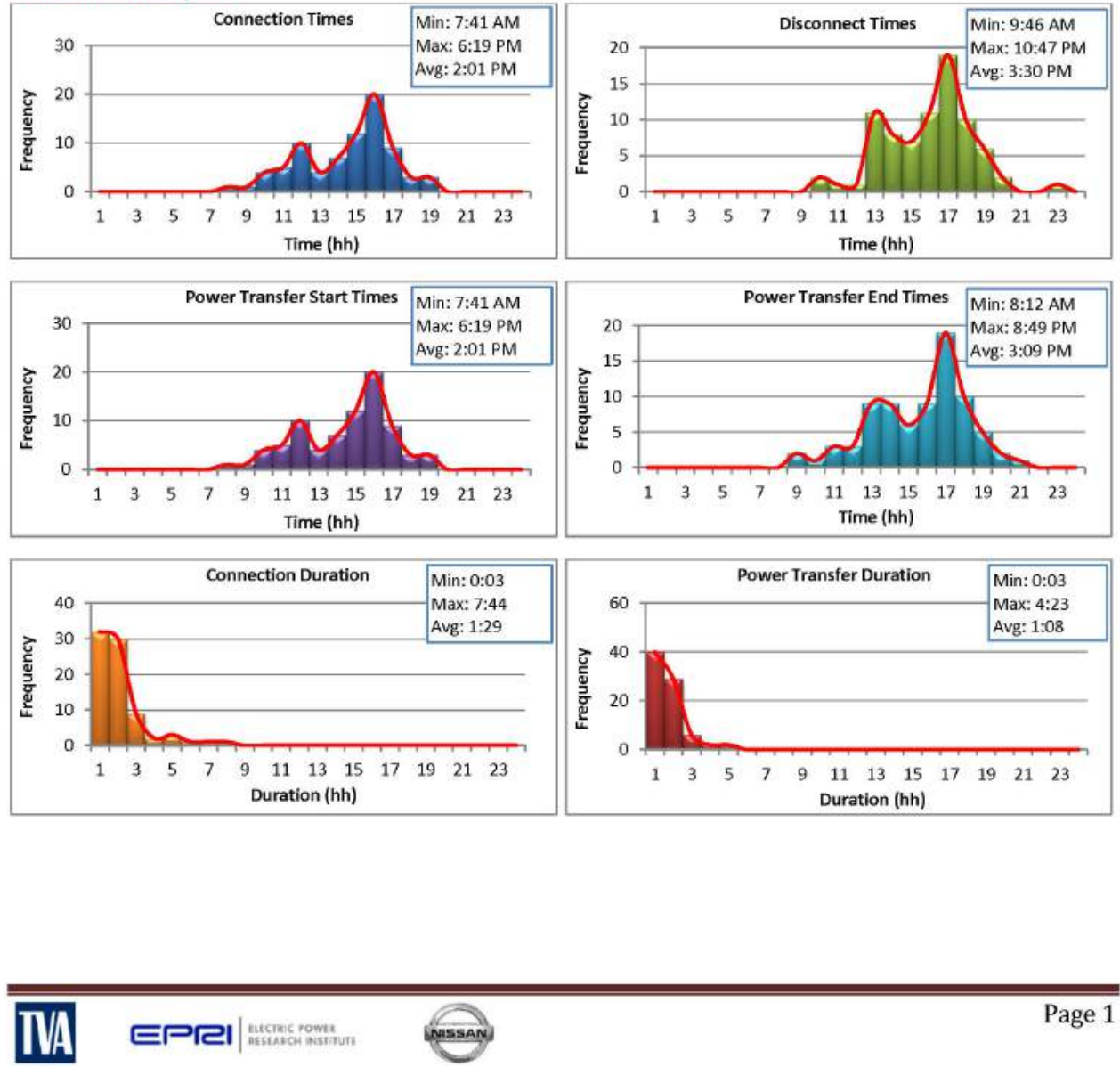


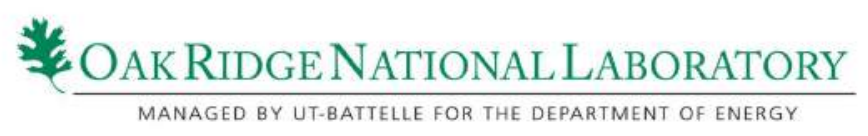

Energy Consumption Analysis
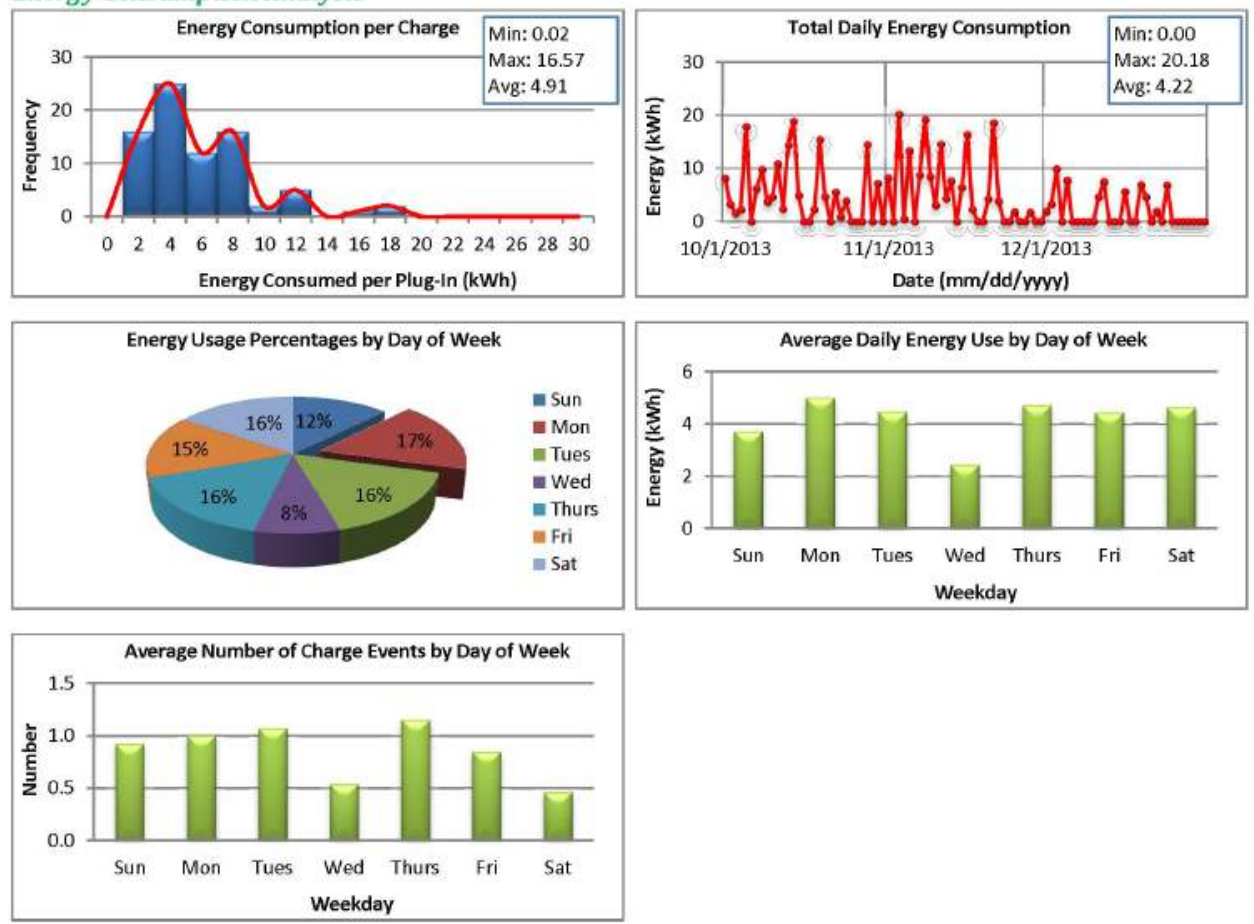

Charging Analysis
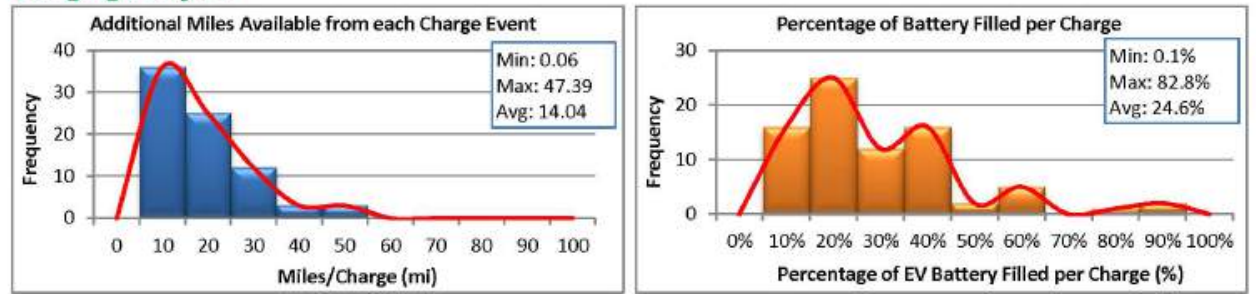

EVSE Analysis
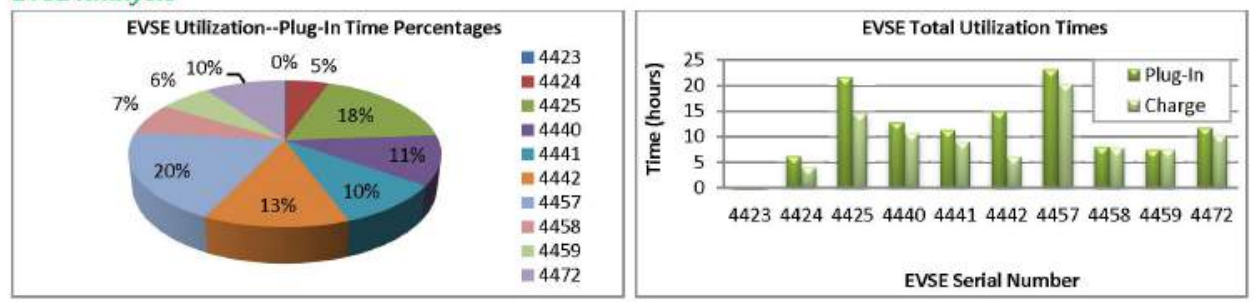

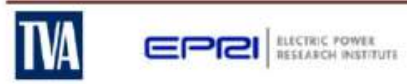

Page 2 


\section{Oak Ridge National Laboratory}

\begin{tabular}{|c|c|c|c|c|}
\hline Report Period Summary & Q1 & Q2 & Q3 & Q4 \\
\hline Average connection duration (hrs.) & 1.4 & 1.6 & 1.6 & 1.5 \\
\hline Average charge duration (hrs.) & 1.3 & 1.4 & 1.4 & 1.1 \\
\hline Average miles per charge & 12.8 & 14.5 & 15.3 & 14.0 \\
\hline $\begin{array}{l}\text { Average } \% \text { of battery filled per } \\
\text { charge event }{ }^{\mathrm{ii}}\end{array}$ & $22.5 \%$ & $25.3 \%$ & $26.8 \%$ & $24.6 \%$ \\
\hline
\end{tabular}

EVSE Quarterly Load Profile

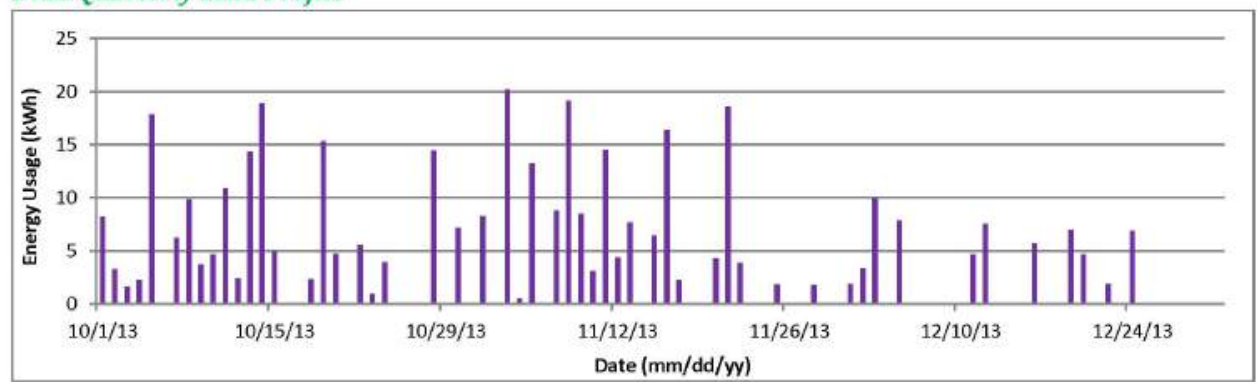

PV Array Quarterly Power Generation Profile

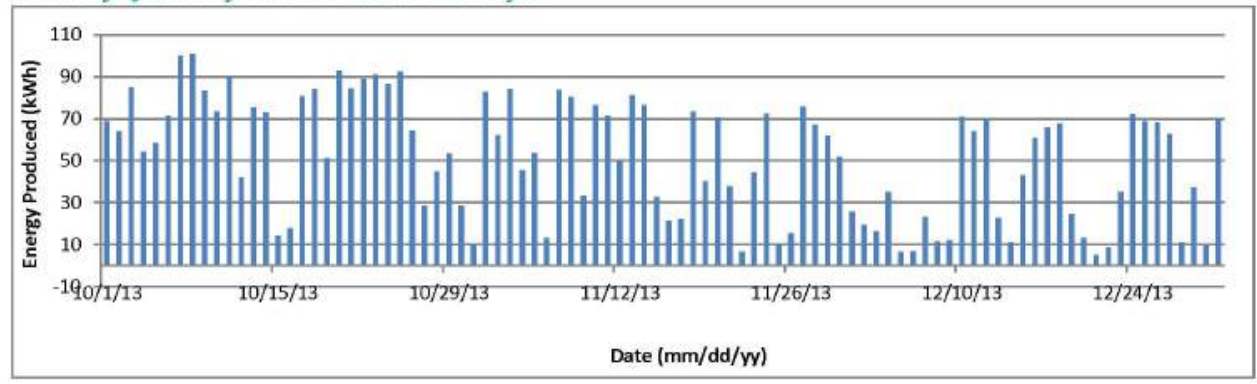

Based on the total energy consumption and an average of miles per $\mathrm{kWh}$ for the Nissan Leaf ( $2.94 \mathrm{mi} / \mathrm{kWh})$ and Chevy Volt $(2.78 \mathrm{mi} / \mathrm{kWh})$

Values taken from htto://www.fueleconomy.gov/.

Based on energy consumption and size of battery for the Nissan Leaf (24 kWh) and Chevy Volt (16 kWh).

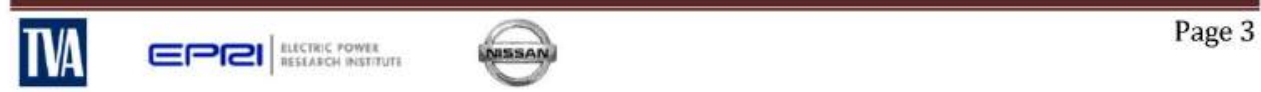




\section{A.14 Vanderbilt University, Nashville}

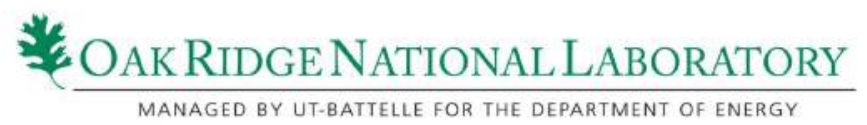

EV Project Solar-Assisted Charging Infrastructure Summary Report

EVSE Grouping/Region: EPRI Nashville-Vanderbilt

Report Period: October 1-December 31, 2012 (Quarter 4, 2012)

Number of EV Charging Stations: 10

$\exists \mathbf{y}$ Project
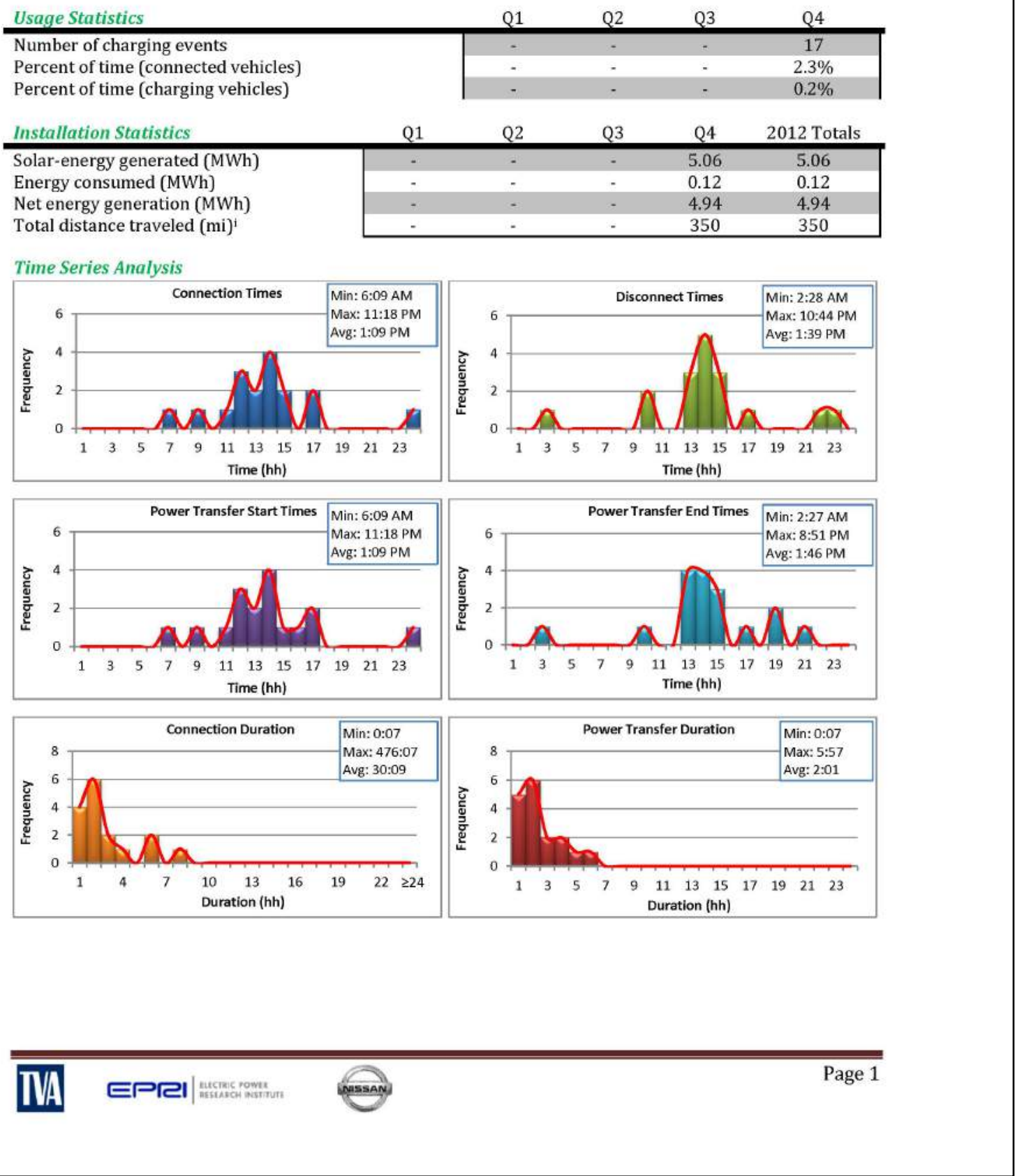


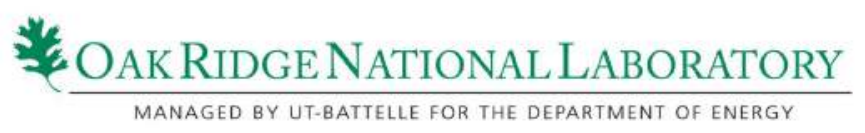

Energy Consumption Analysis
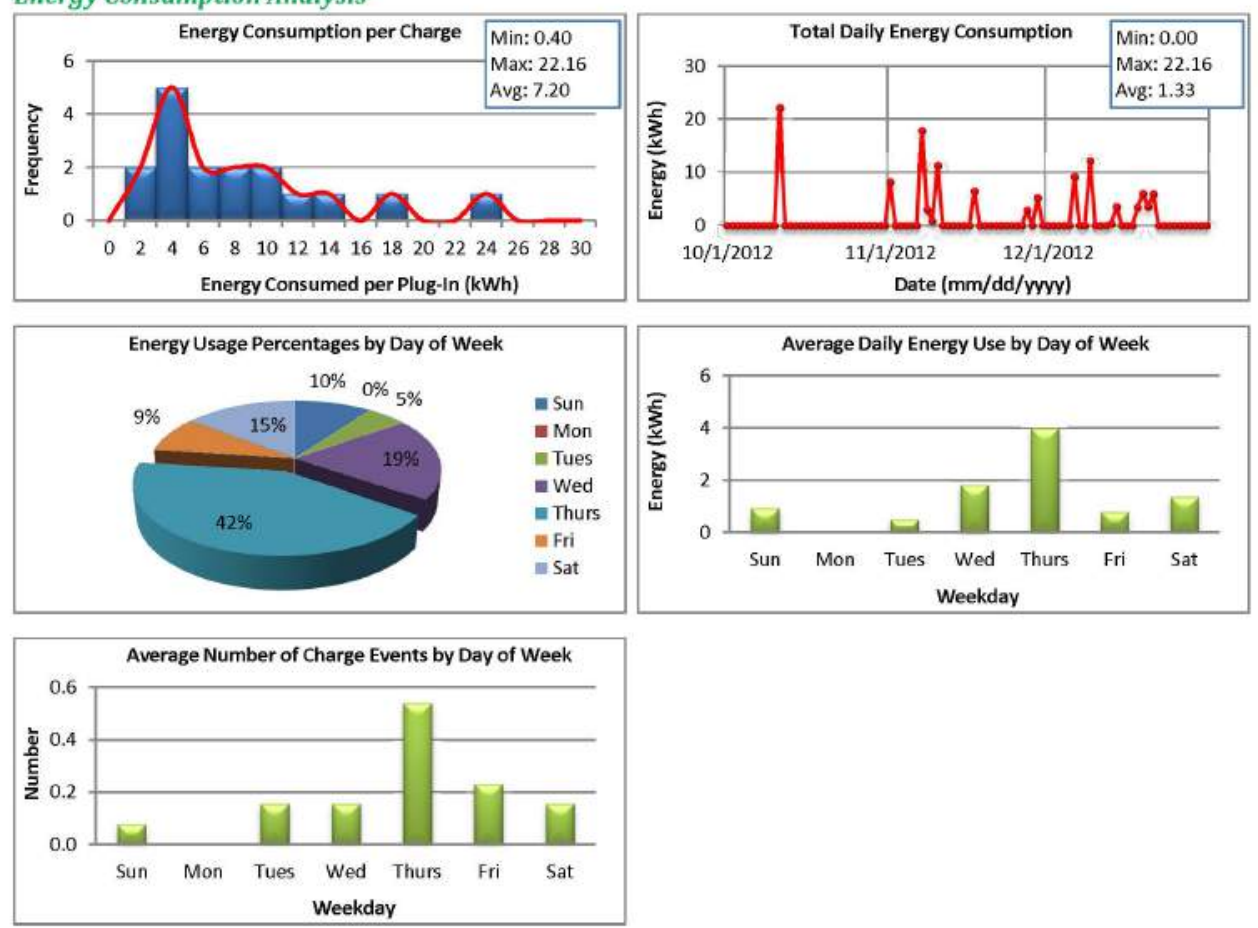

Charging Analysis
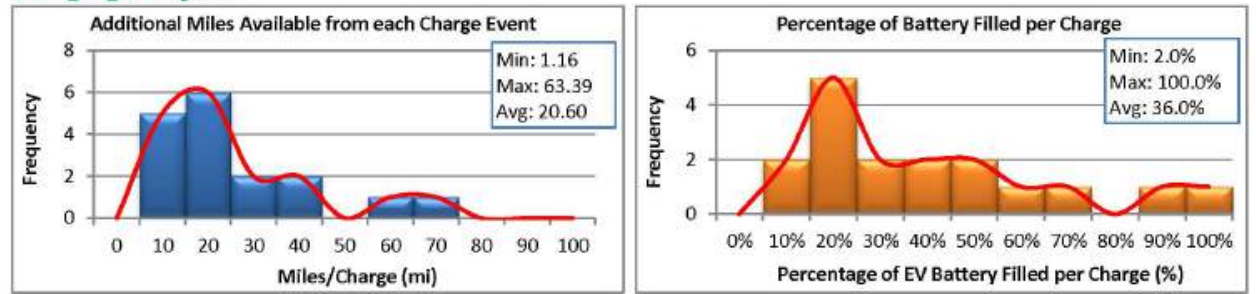

EVSE Analysís

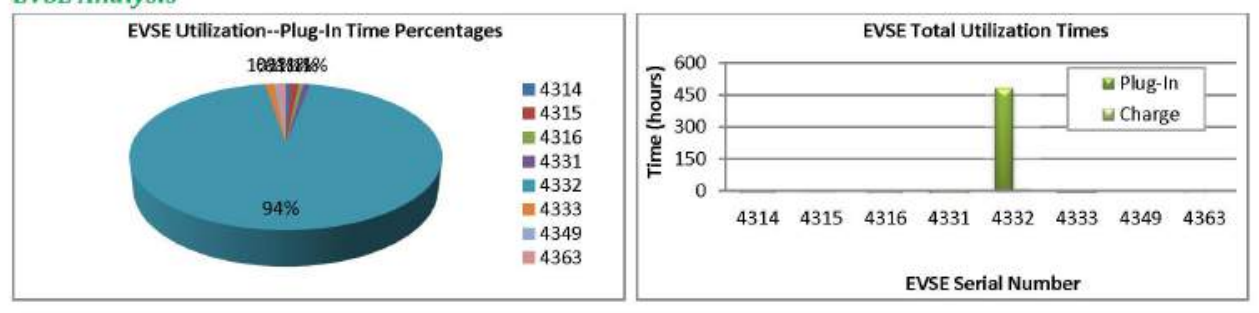

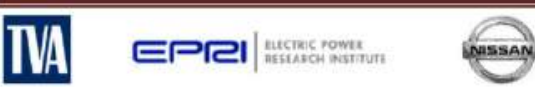

Page 2 


\section{OAK Ridge National Laboratory}

\begin{tabular}{|c|c|c|c|c|}
\hline Report Period Summary & Q1 & Q2 & Q3 & Q4 \\
\hline Average connection duration (hrs.) & - & - & - & 30.2 \\
\hline Average charge duration (hrs.) & - & - & - & 2.0 \\
\hline Average miles per charge & - & - & - & 20.6 \\
\hline $\begin{array}{l}\text { Average } \% \text { of battery filled per } \\
\text { charge event } t^{\mathrm{ii}}\end{array}$ & - & - & - & $36.0 \%$ \\
\hline
\end{tabular}

EVSE Quarterly Load Profile

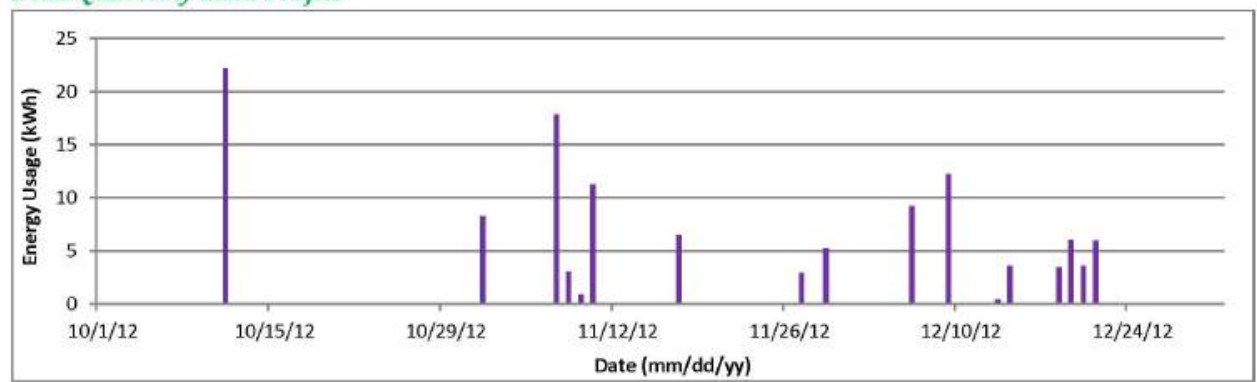

PV Array Quarterly Power Generation Profile

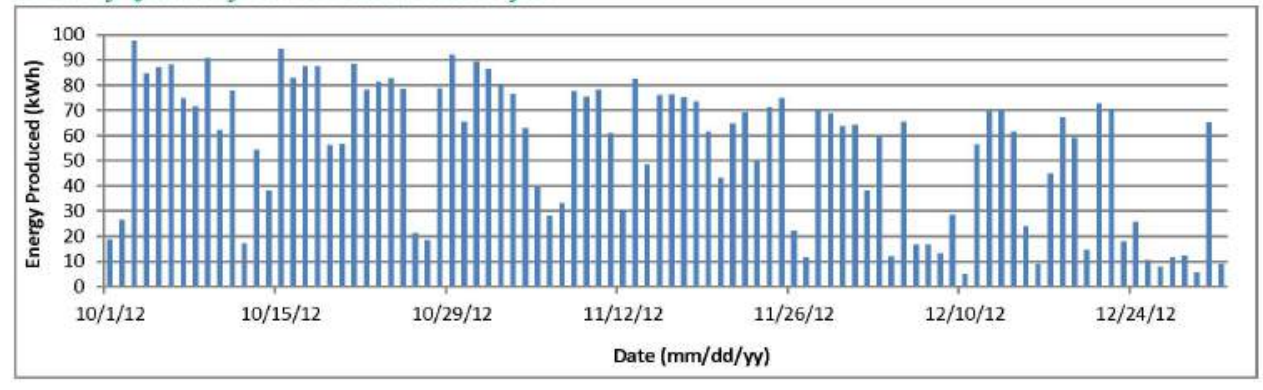

Based on the total energy consumption and an average of miles per $\mathrm{kWh}$ for the Nissan Leaf ( $2.94 \mathrm{mi} / \mathrm{kWh}$ ) and Chevy Volt ( $2.78 \mathrm{mi} / \mathrm{kWh}$.

Values taken from htto://www.fueleconomy.gov/.

Based on energy consumption and size of battery for the Nissan Leaf (24 kWh) and Chevy Volt (16 kWh).

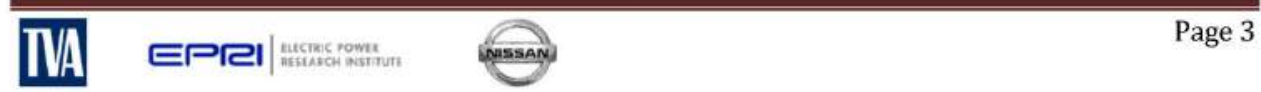




\section{Oak Ridge National LabORATORY}

EV Project Solar-Assisted Charging Infrastructure Summary Report

EVSE Grouping/Region: EPRI Nashville-Vanderbilt

Report Period: October 1-December 31, 2013 (Quarter 4, 2013)

Number of EV Charging Stations: 10

$\exists \boldsymbol{y}$ Project

\begin{tabular}{|c|c|c|c|c|c|}
\hline Usage Statistics & & Q1 & Q2 & Q3 & Q4 \\
\hline \multirow{3}{*}{$\begin{array}{l}\text { Number of charging events } \\
\text { Percent of time (connected vehicles) } \\
\text { Percent of time (charging vehicles) }\end{array}$} & & 22 & 86 & 121 & 84 \\
\hline & & $1.3 \%$ & $1.7 \%$ & $1.0 \%$ & $1.2 \%$ \\
\hline & & $0.2 \%$ & $0.6 \%$ & $0.7 \%$ & $0.6 \%$ \\
\hline Installation Statistics & Q1 & Q2 & Q3 & Q4 & 2013 Totals \\
\hline \multirow{4}{*}{$\begin{array}{l}\text { Solar-energy generated (MWh) } \\
\text { Energy consumed (MWh) } \\
\text { Net energy generation (MWh) } \\
\text { Total distance traveled }(\mathrm{mi})^{\mathrm{i}}\end{array}$} & 4.94 & 8.74 & 7.65 & 4.64 & 25.97 \\
\hline & 0.19 & 0.52 & 0.68 & 0.69 & 2.08 \\
\hline & 4.76 & 8.22 & 6.97 & 3.95 & 23.9 \\
\hline & 535 & 1483 & 1957 & 1976 & 5951 \\
\hline
\end{tabular}

Time Series Analysis
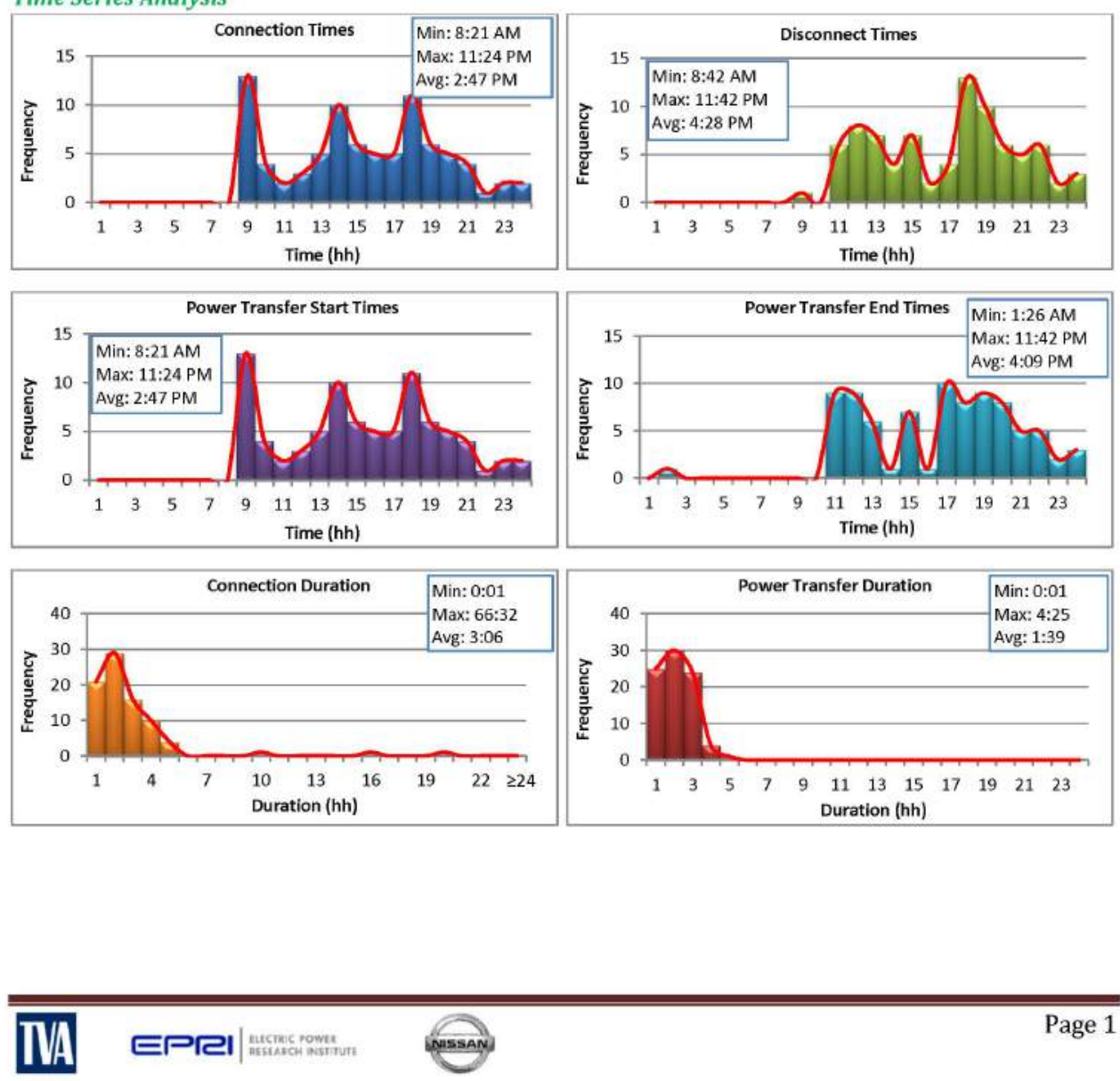


\section{OAK Ridge NATIONAL LABORATORY}

Energy Consumption Analysis
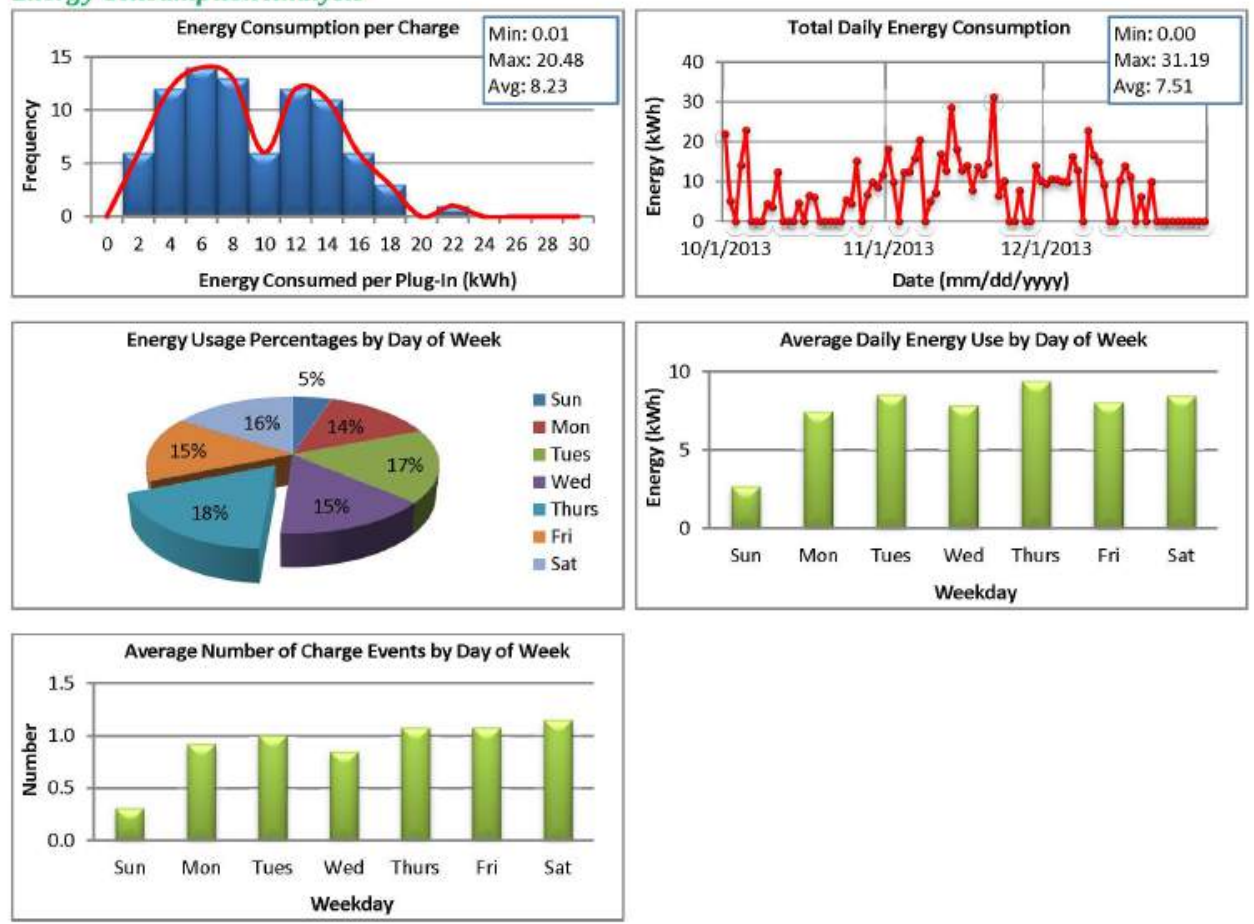

Charging Analysis
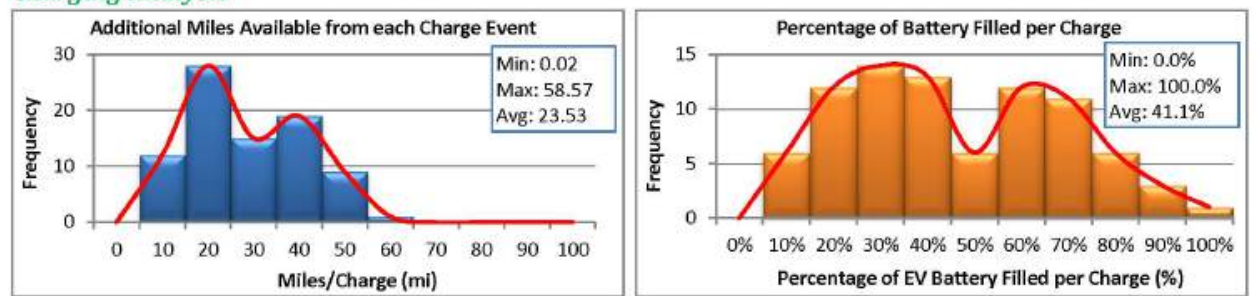

EVSE Analysis

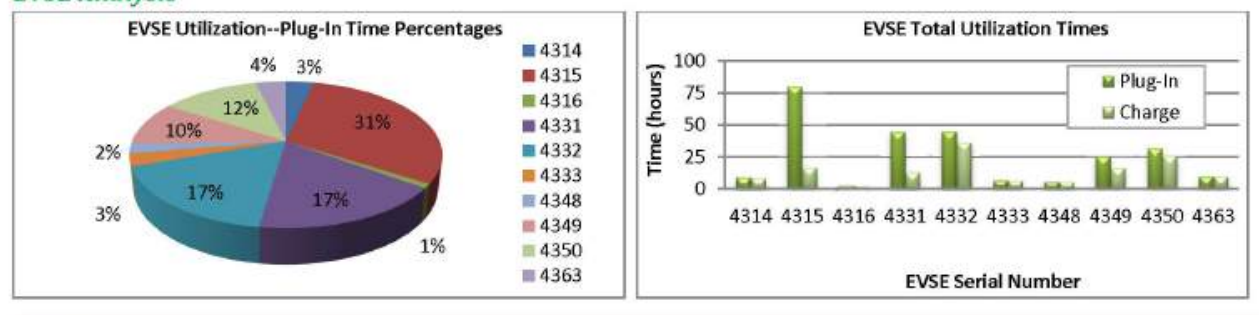

IVA EPR।

Page 2 


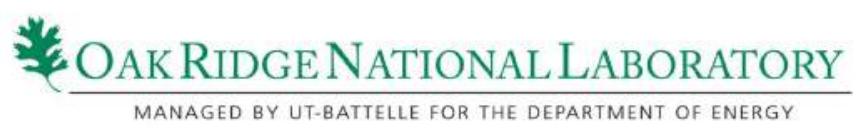

\begin{tabular}{|c|c|c|c|c|}
\hline Report Period Summary & Q1 & Q2 & Q3 & Q4 \\
\hline Average connection duration (hrs.) & 13.0 & 4.2 & 1.8 & 3.1 \\
\hline Average charge duration (hrs.) & 2.3 & 1.5 & 1.3 & 1.7 \\
\hline Average miles per charge & 24.3 & 17.2 & 16.2 & 23.5 \\
\hline $\begin{array}{l}\text { Average } \% \text { of battery filled per } \\
\text { charge event }{ }^{\mathrm{ii}}\end{array}$ & $42.6 \%$ & $30.2 \%$ & $28.3 \%$ & $41.1 \%$ \\
\hline
\end{tabular}

EVSE Quarterly Load Profile

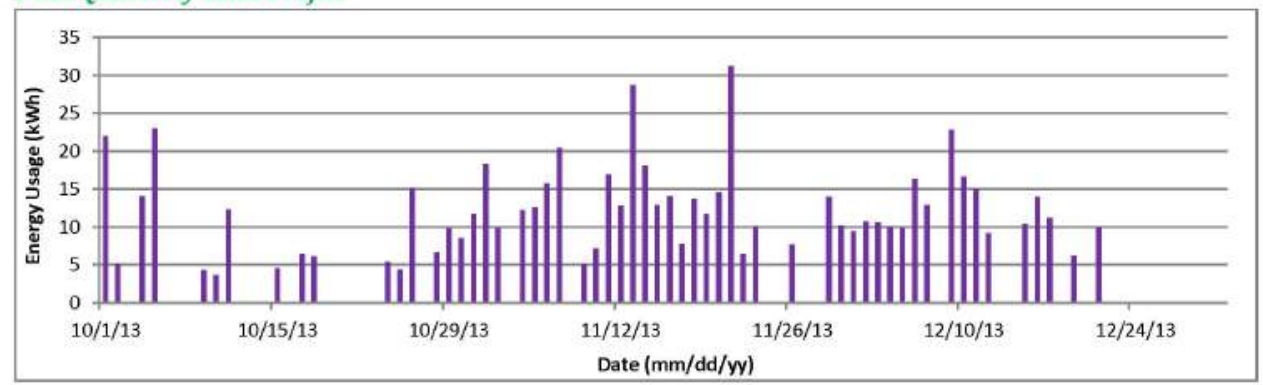

PV Array Quarterly Power Generation Profile

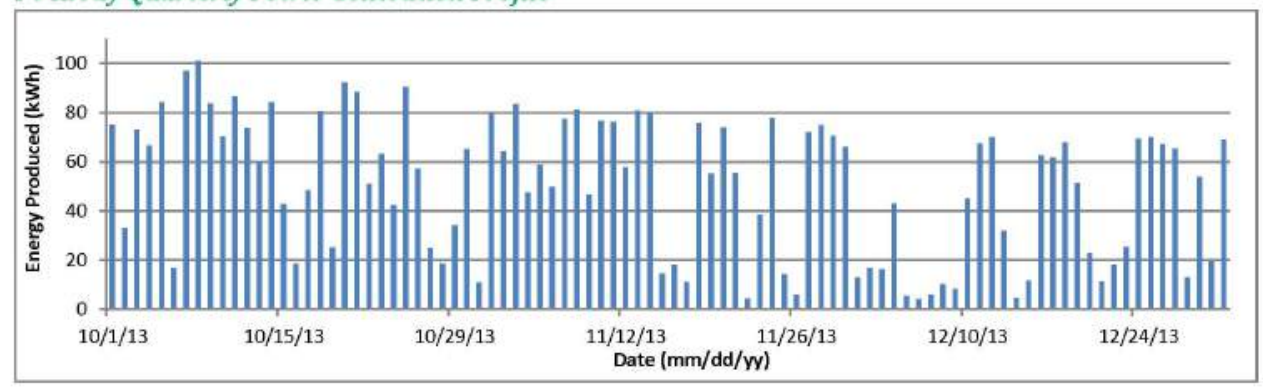

Based on the total energy consumption and an average of miles per $\mathrm{kWh}$ for the Nissan Leaf ( $2.94 \mathrm{mi} / \mathrm{kWh})$ and Chevy Volt $(2.78 \mathrm{mi} / \mathrm{kWh})$.

Values taken from http://www.fueleconomv.gov/.

Based on energy consumption and size of battery for the Nissan Leaf (24 kWh) and Chevy Volt (16 kWh).

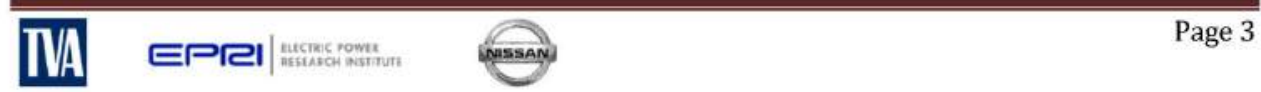




\section{A.15 Nissan, Administration Building, Smyrna, Tennessee, Assembly Plant}

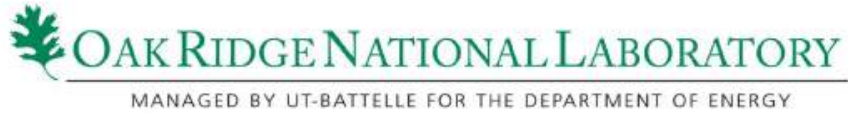

EV Project Solar-Assisted Charging Infrastructure Summary Report

EVSE Grouping/Region: Nissan Smyrna

Report Period: October 1-December 31, 2012 (Quarter 4, 2012)

Number of EV Charging Stations: 9

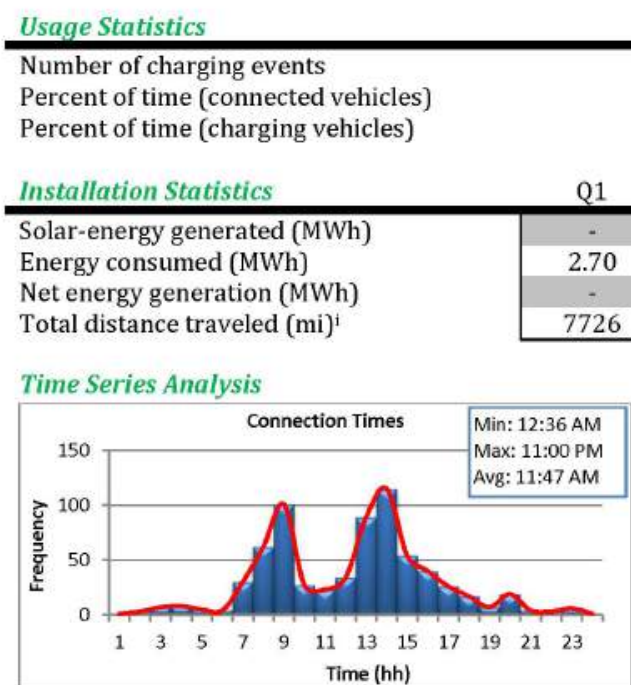

\begin{tabular}{|cccc|}
\hline $\mathrm{Q} 1$ & $\mathrm{Q} 2$ & $\mathrm{Q} 3$ & $\mathrm{Q} 4$ \\
\hline 407 & 636 & 615 & 686 \\
$9.9 \%$ & $16.3 \%$ & $13.6 \%$ & $14.0 \%$ \\
$3.9 \%$ & $6.6 \%$ & $7.5 \%$ & $9.9 \%$ \\
\hline
\end{tabular}
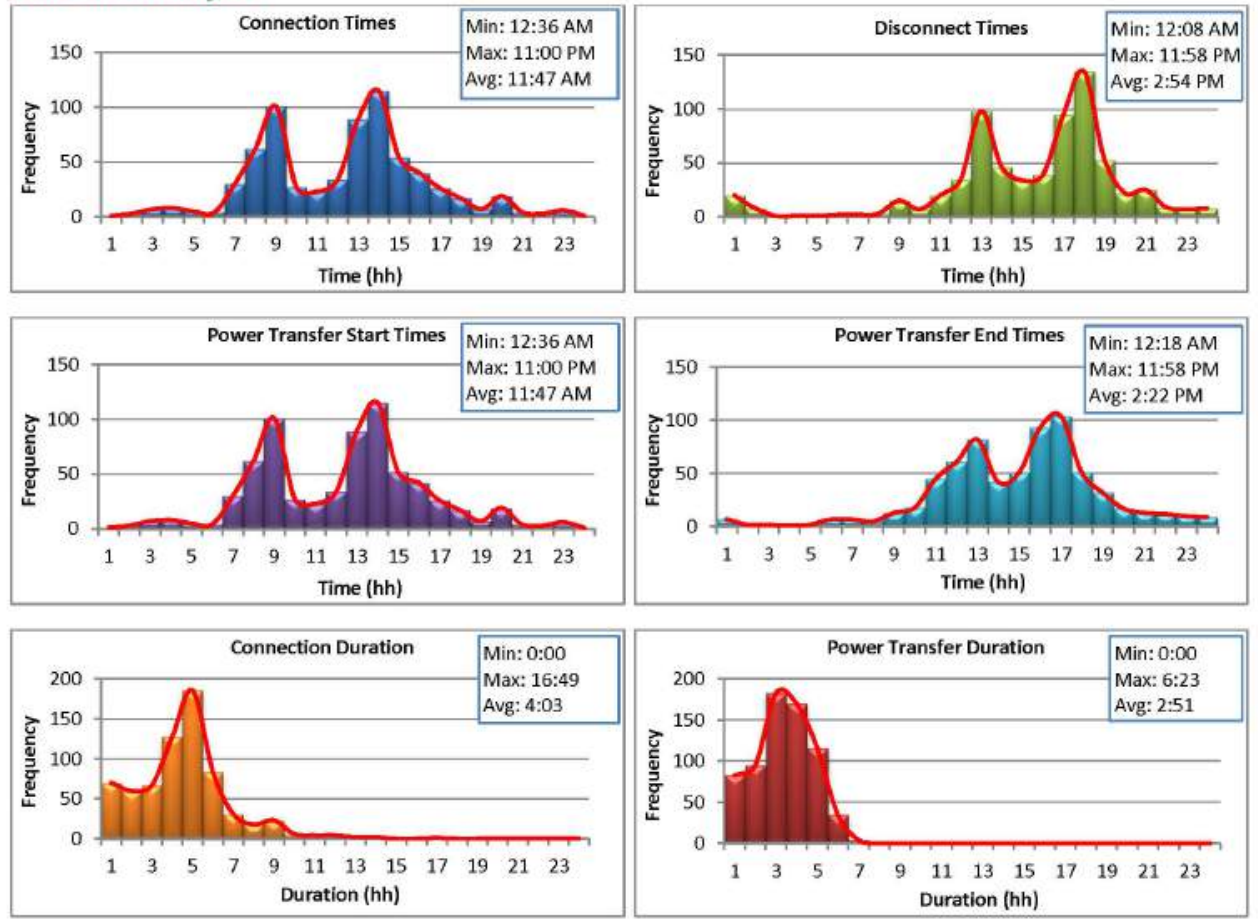

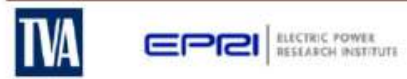

Page 1 


\section{OAK RIDGE NATIONAL LABORATORY}

Energy Consumption Analysis
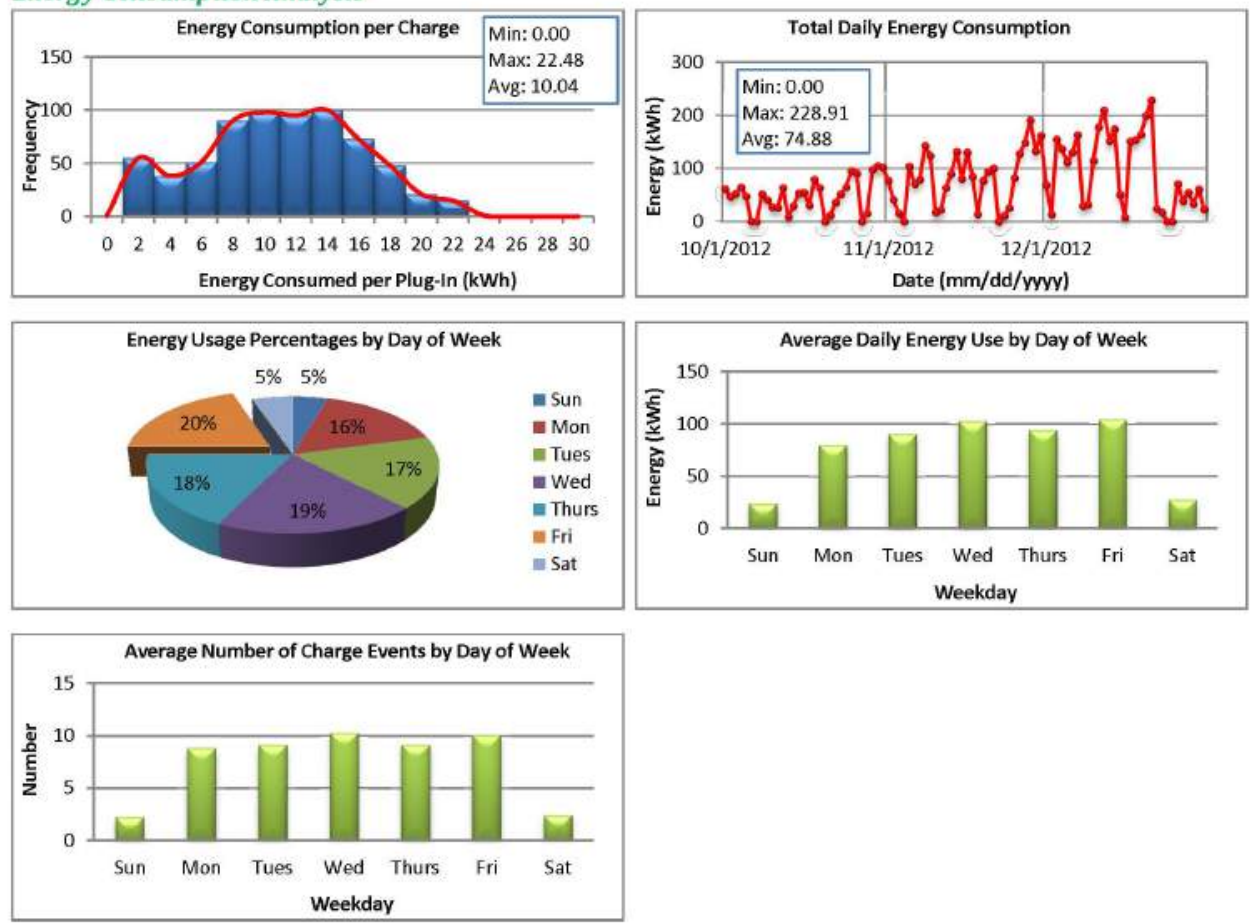

Charging Analysis
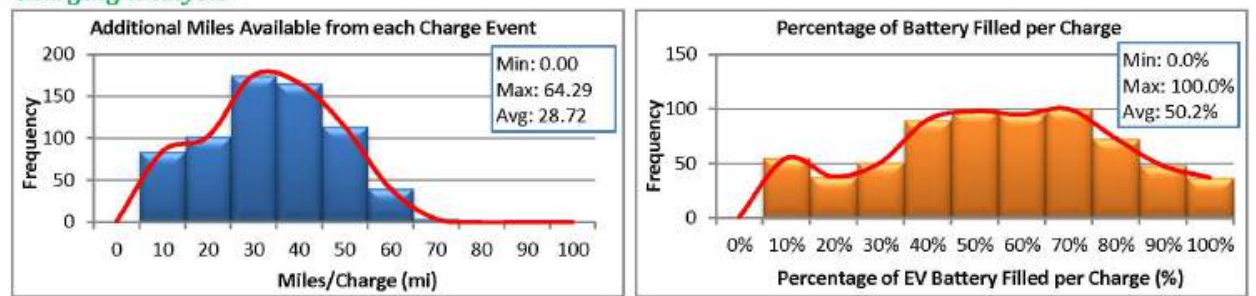

EVSE Analysís

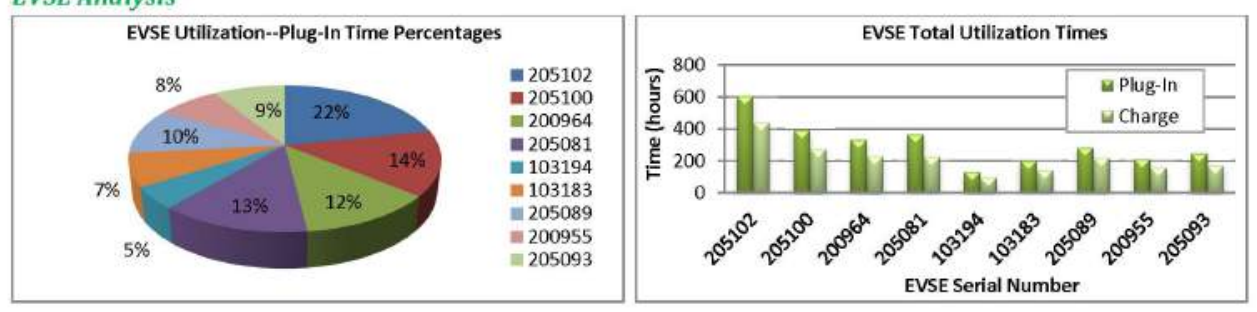

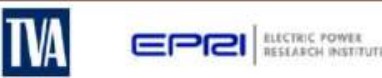

Page 2 


\section{OAK RIDGE NATIONAL LABORATORY}

\begin{tabular}{|c|c|c|c|c|}
\hline Report Period Summary & Q1 & Q2 & Q3 & Q4 \\
\hline Average connection duration (hrs.) & 4.8 & 5.0 & 4.4 & 4.1 \\
\hline Average charge duration (hrs.) & 1.9 & 2.0 & 2.4 & 2.9 \\
\hline Average miles per charge & 19.0 & 22.9 & 24.4 & 28.7 \\
\hline $\begin{array}{l}\text { Average } \% \text { of battery filled per } \\
\text { charge event }{ }^{\mathrm{ii}}\end{array}$ & $33.2 \%$ & $40.0 \%$ & $42.7 \%$ & $50.2 \%$ \\
\hline
\end{tabular}

EVSE Quarterly Load Profile

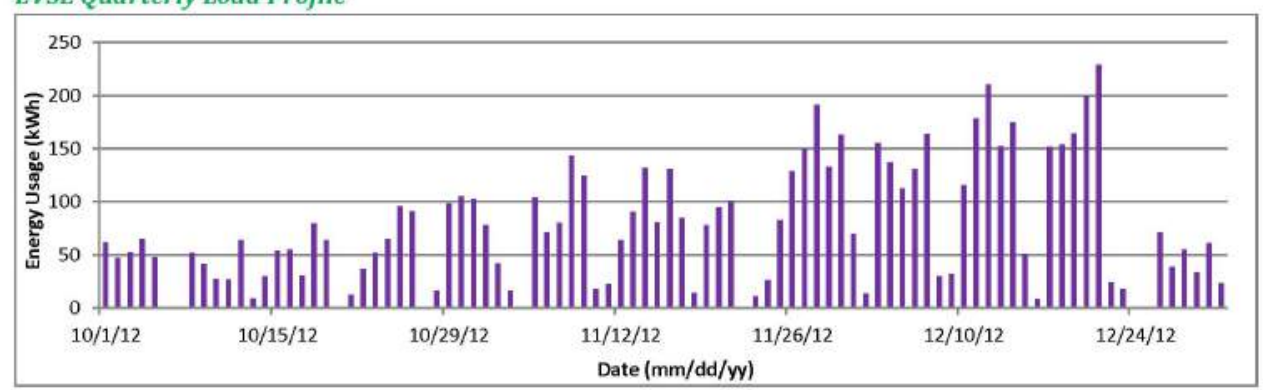

PV Array Quarterly Power Generation Profile

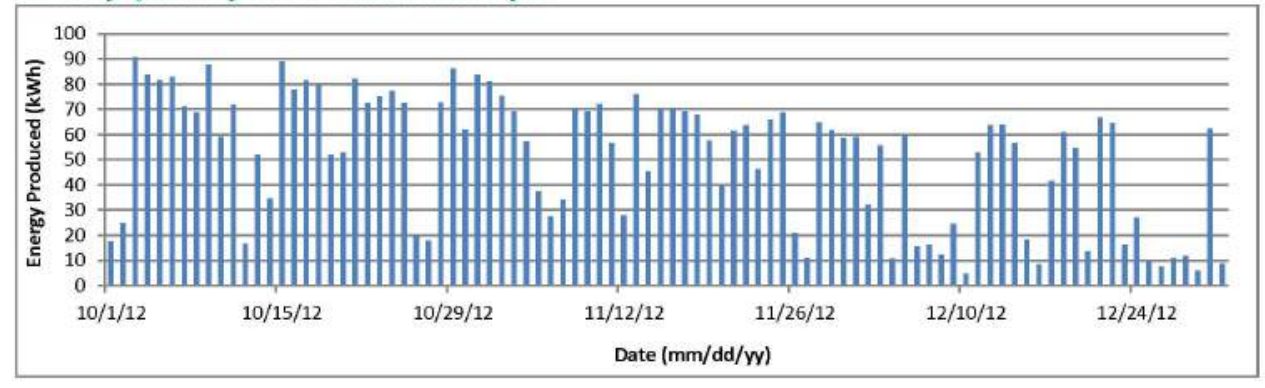

Note: Solar data was not provided for the site. Values shown are estimated based on power generation from other PV arrays in Nashville. No solar data was available during the $1^{\text {st }}$ and $2^{\text {nd }}$ quarters, 2012.

Based on the total energy consumption and an average of miles per $\mathrm{kWh}$ for the Nissan Leaf ( $2.94 \mathrm{mi} / \mathrm{kWh}$ ) and Chevy Volt (2.78 mi/kWh).

Values taken from http://www.fueleconomy.gov/.

"Based on energy consumption and size of battery for the Nissan Leaf ( $24 \mathrm{kWh}$ ) and Chevy Volt (16 kWh).

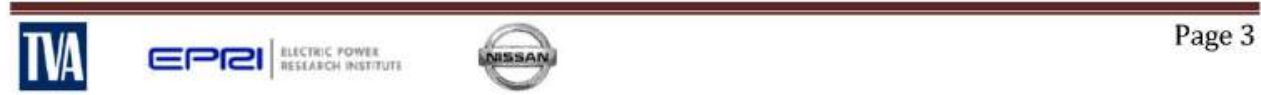




\section{Oak Ridge NaTiOnAL LabORATORY}

EV Project Solar-Assisted Charging Infrastructure Summary Report

EVSE Grouping/Region: Nissan Smyrna

Report Period: October 1-December 31, 2013 (Quarter 4, 2013)

Number of EV Charging Stations: 9

F/y Project

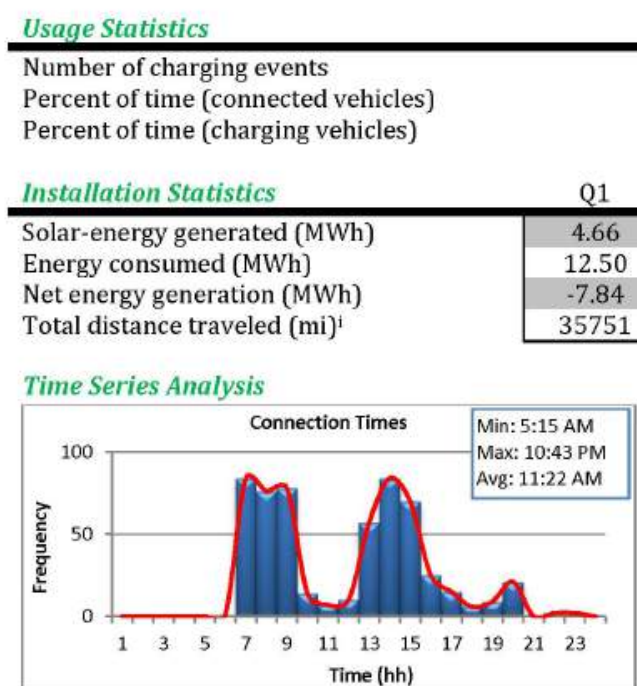

\begin{tabular}{cccc|}
\hline Q1 & Q2 & Q3 & Q4 \\
\hline 1163 & 1137 & 585 & 561 \\
$28.2 \%$ & $27.7 \%$ & $13.9 \%$ & $15.3 \%$ \\
$17.5 \%$ & $16.5 \%$ & $7.8 \%$ & $8.7 \%$
\end{tabular}
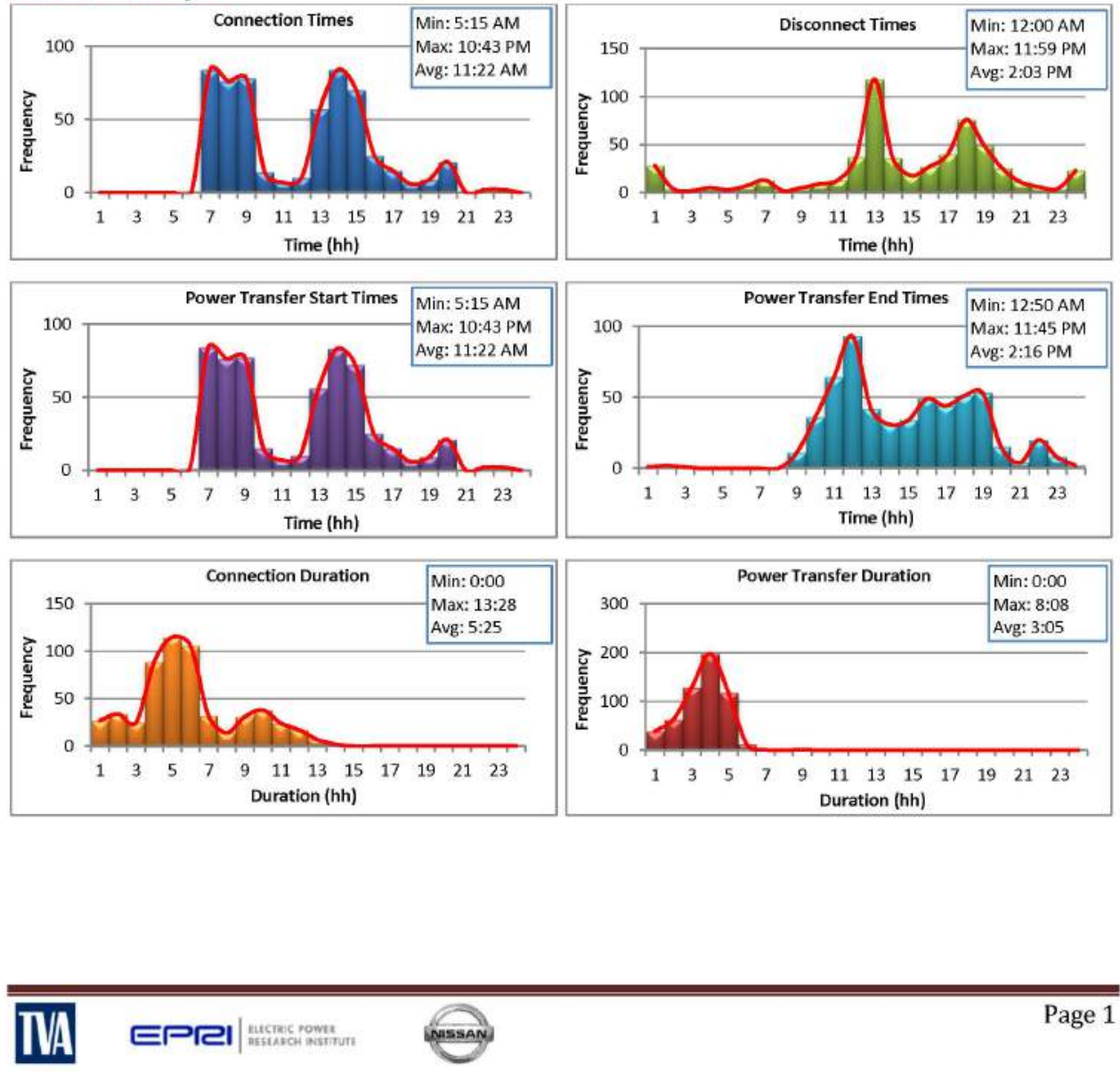


\section{OAK Ridge NATIONAL LABORATORY}

Energy Consumption Analysis
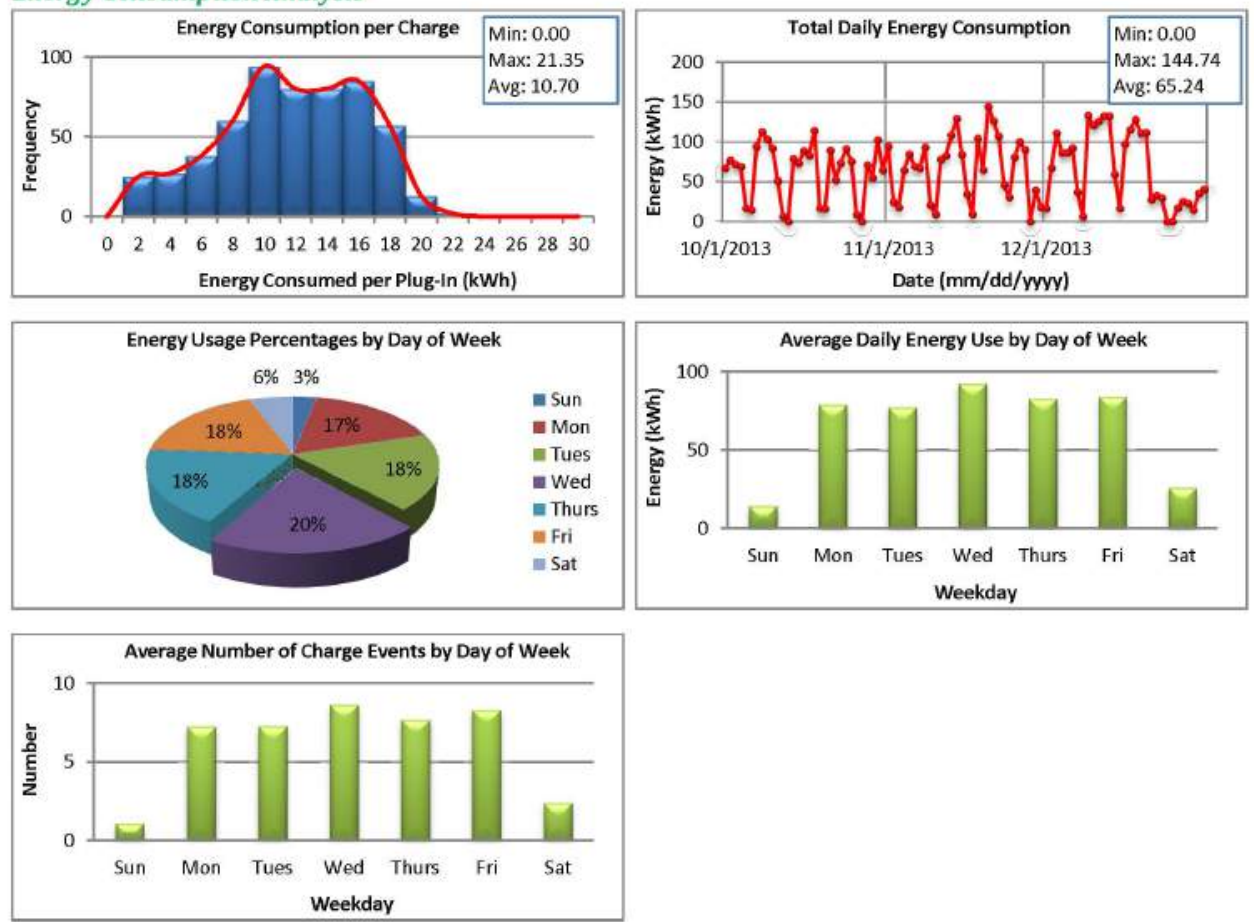

Charging Analysis
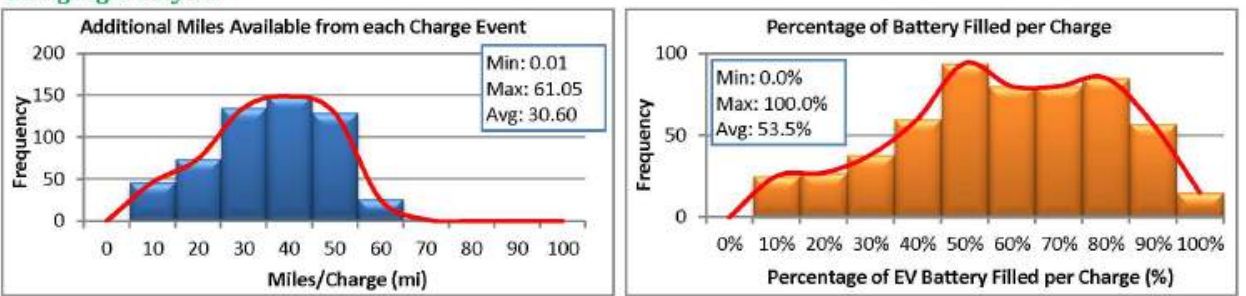

EVSE Analysis

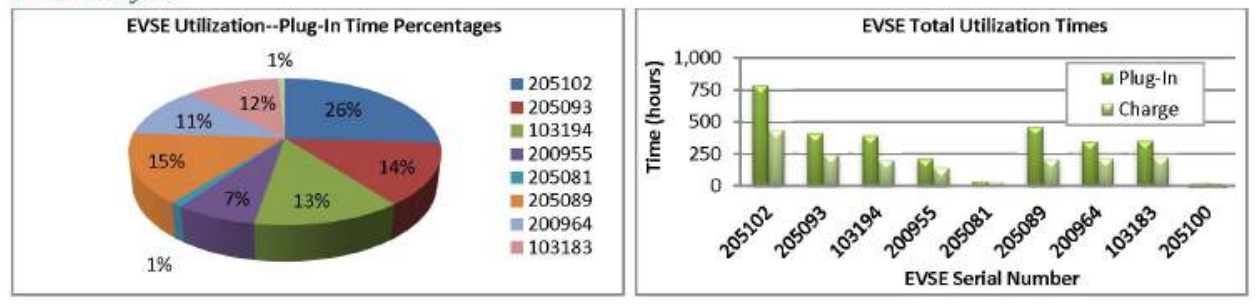

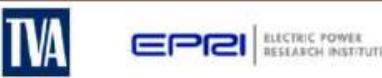

Page 2 


\section{OAK Ridge National Laboratory}

\begin{tabular}{|c|c|c|c|c|}
\hline \multirow{5}{*}{$\begin{array}{l}\text { Average connection duration (hrs.) } \\
\text { Average charge duration (hrs.) } \\
\text { Average miles per charge } \\
\text { Average } \% \text { of battery filled per }\end{array}$} & Q1 & Q2 & Q3 & Q4 \\
\hline & 4.7 & 4.8 & 4.7 & 5.4 \\
\hline & 2.9 & 2.8 & 2.7 & 3.1 \\
\hline & 30.7 & 30.5 & 27.2 & 30.6 \\
\hline & $53.7 \%$ & $53.3 \%$ & $47.6 \%$ & $53.5 \%$ \\
\hline
\end{tabular}

EVSE Quarterly Load Profile

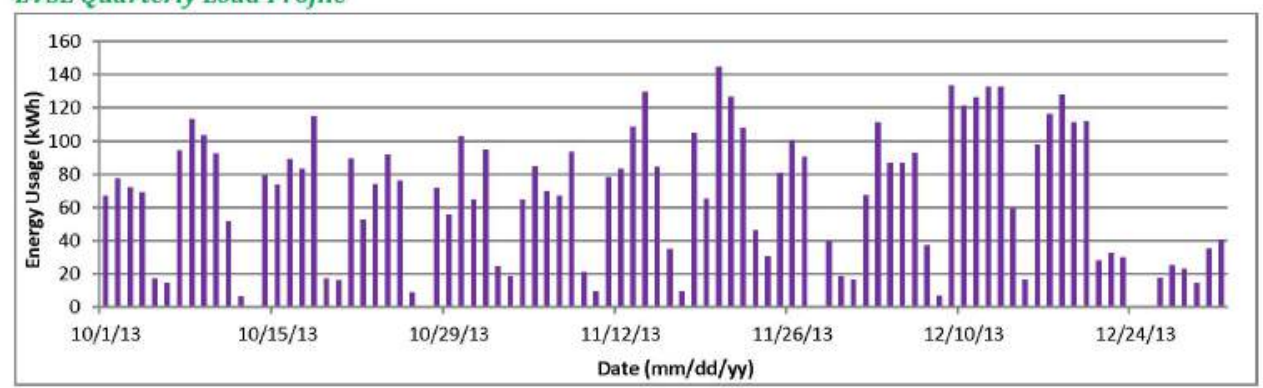

PV Array Quarterly Power Generation Profile

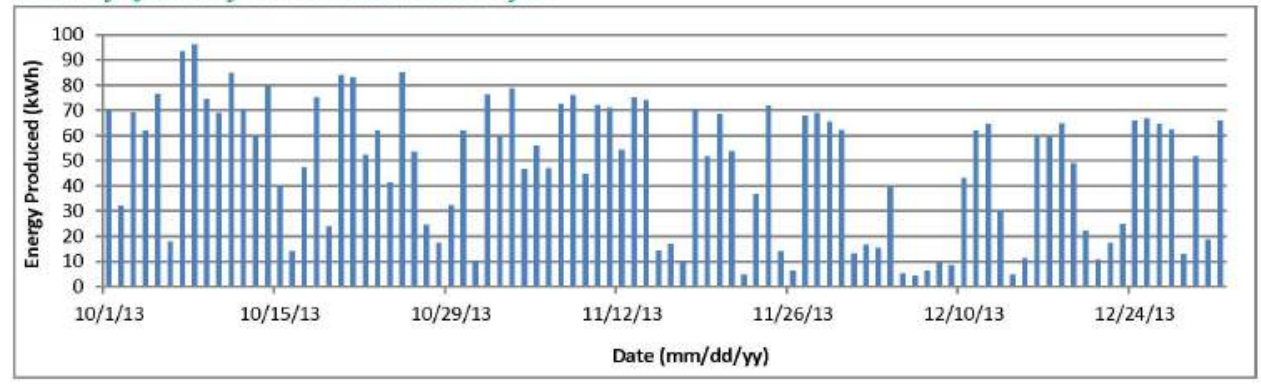

Note: Solar data was not provided for the site. Values shown are estimated based on power generation from other PV arrays in Nashville.

Based on the total energy consumption and an average of miles per $\mathrm{kWh}$ for the Nissan Leaf ( $2.94 \mathrm{mi} / \mathrm{kWh})$ and Chevy Volt $(2.78 \mathrm{mi} / \mathrm{kWh})$

Values taken from http://www.fueleconomy.gov/.

Based on energy consumption and size of battery for the Nissan Leaf ( $24 \mathrm{kWh}$ ) and Chevy Volt (16 kWh).

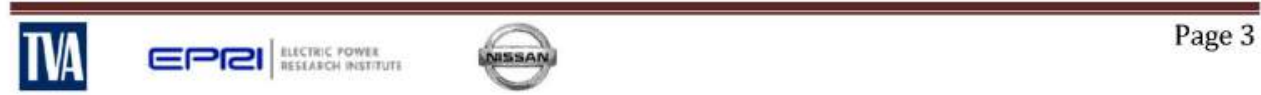




\section{Oak Ridge NaTiOnAL LabORATORY}

EV Project Solar-Assisted Charging Infrastructure Summary Report

EVSE Grouping/Region: Nissan Smyrna

Report Period: April 1-June 30, 2014 (Quarter 2, 2014)

Number of EV Charging Stations: 9

$\exists \boldsymbol{F}$ Project

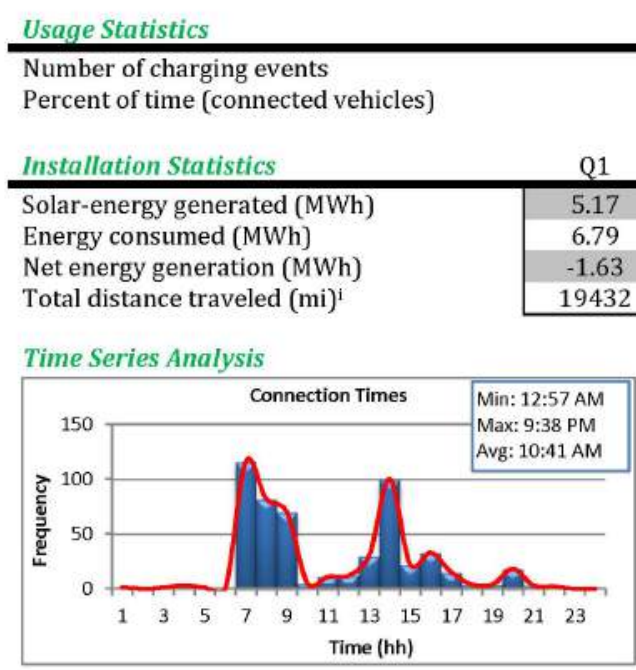

\begin{tabular}{cccc|}
\hline 1 & $Q 2$ & $Q 3$ & $Q 4$ \\
\hline 641 & 533 & - & - \\
$17.8 \%$ & $14.5 \%$ & - & - \\
\hline
\end{tabular}

$\begin{array}{lllll}\text { Q1 } & \text { Q2 } & \text { Q3 } & \text { Q4 } & \text { 2014 Totals }\end{array}$

Solar-energy generated (MWh)

Energy consumed (MWh

Net energy generation (MWh)

8.25

8.25

5.35
2.90

$\begin{array}{lllll}19432 & 15294 & - & - & 34726\end{array}$

Q3 $24 \quad 13.42$

- $\quad$ - $\quad 12.14$

$\begin{array}{lllll}-1.63 & 2.90 & - & - & 1.27\end{array}$

Time Series Analysis
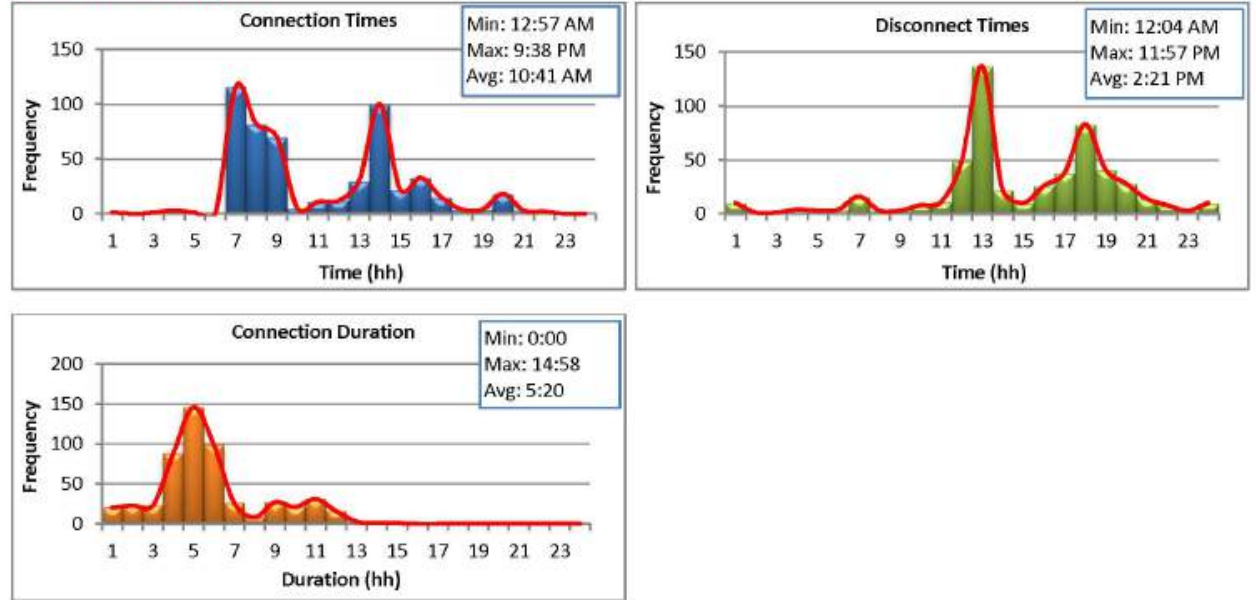


\section{OAK RIDGE NATIONAL LABORATORY}

Energy Consumption Analysis
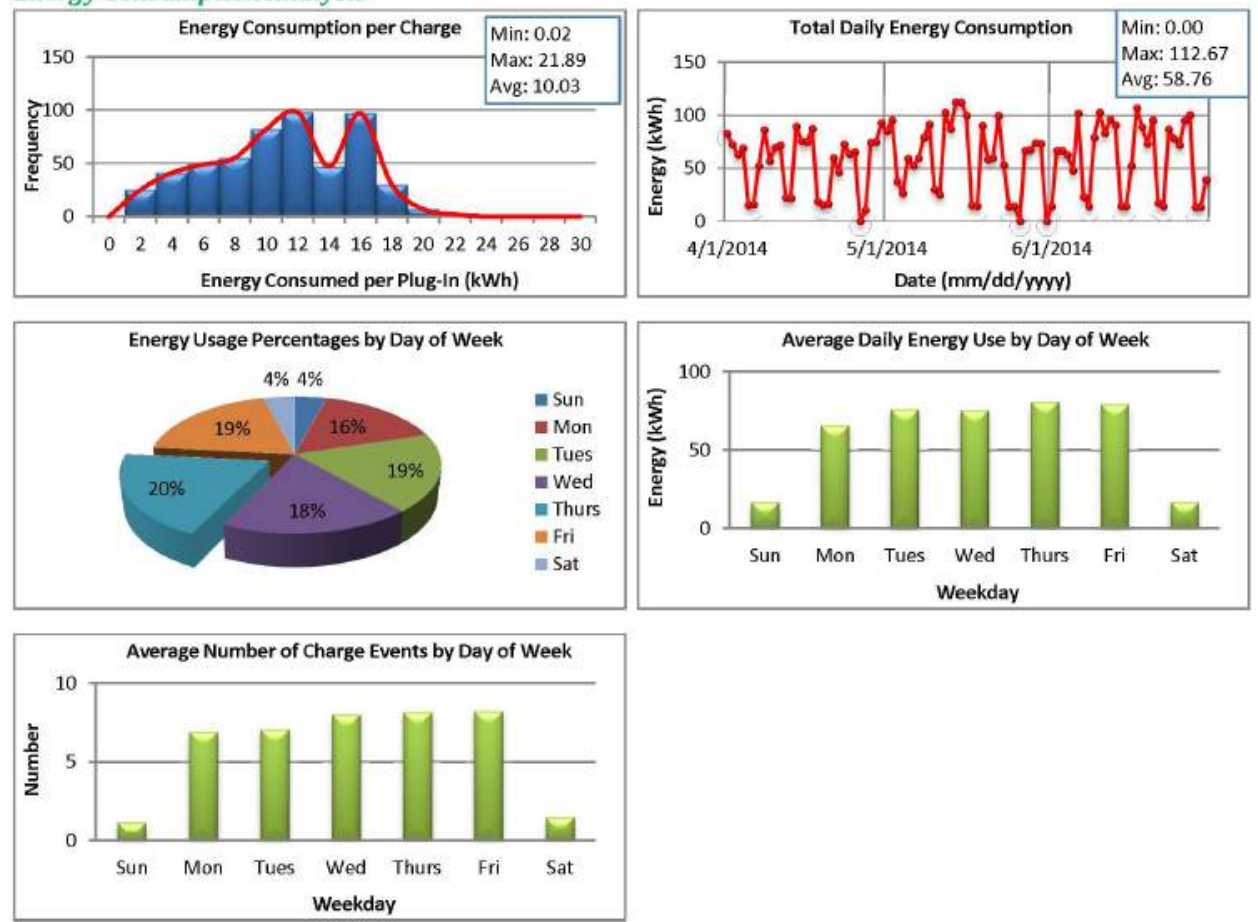

Charging Analysis
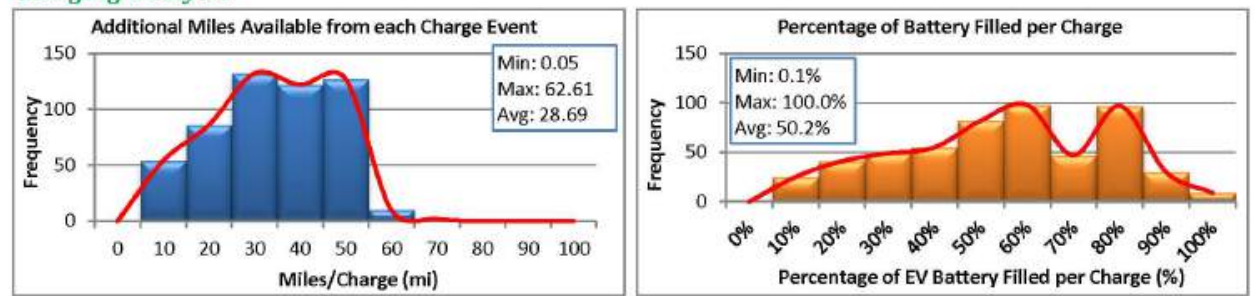

EVSE Analysis

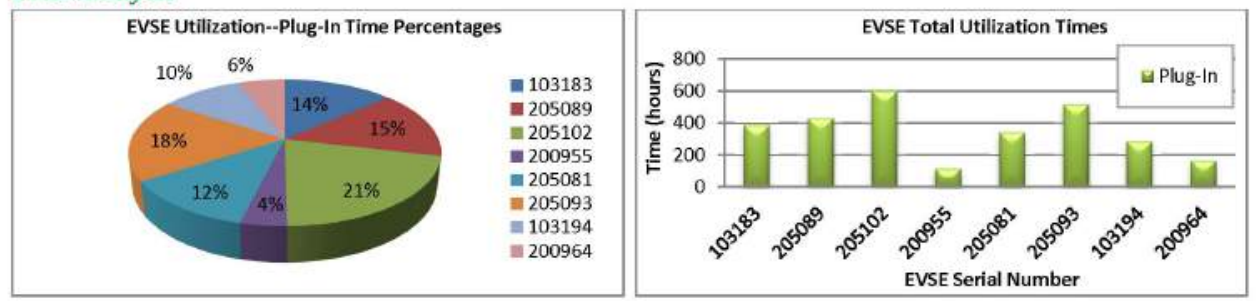

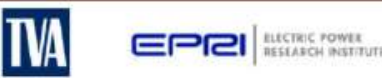

Page 2 


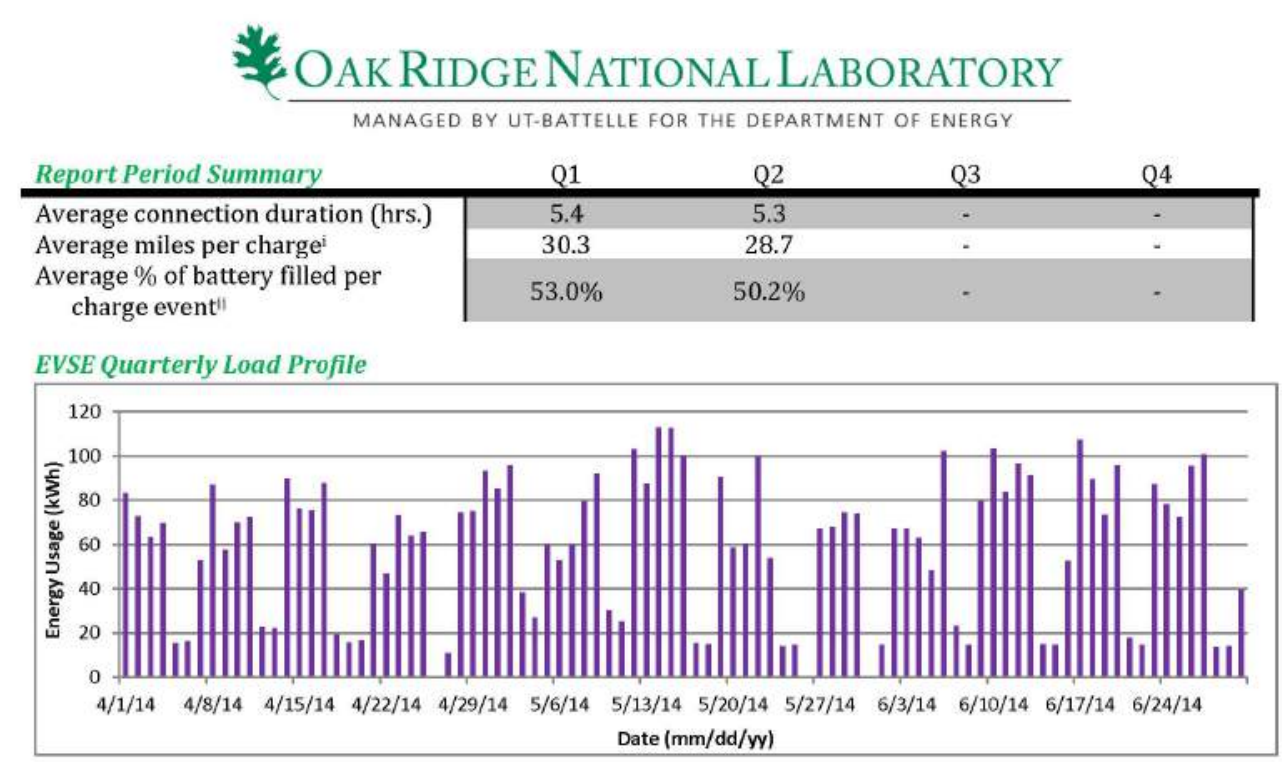

PV Array Quarterly Power Generation Profile

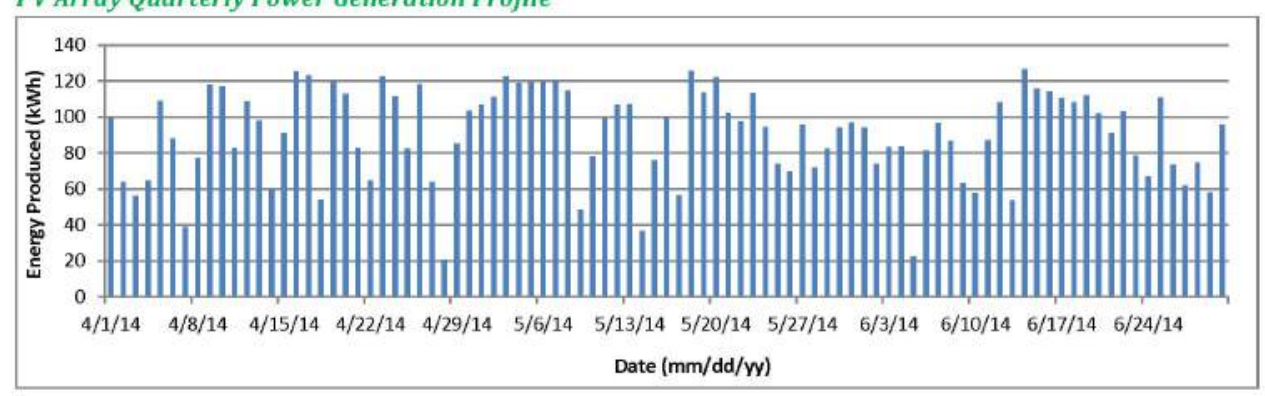

Note: Solar data was not provided for the site. Values shown are estimated based on power generation from other PV arrays in Nashville.

Based on the total energy consumption and an average of miles per $\mathrm{kWh}$ for the Nissan Leaf ( $2.94 \mathrm{mi} / \mathrm{kWh}$ ) and Chevy Volt (2.78 mi/kWh).

Values taken from http://www.fueleconomy.gov/.

"Based on energy consumption and size of battery for the Nissan Leaf ( $24 \mathrm{kWh}$ ) and Chevy Volt ( $16 \mathrm{kWh}$ ).

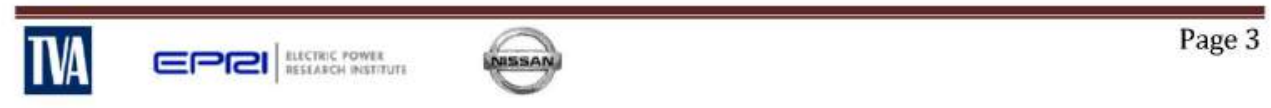




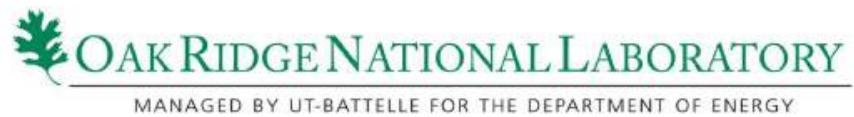

EV Project Solar-Assisted Charging Infrastructure Summary Report

EVSE Grouping/Region: Nissan Franklin

Report Period: October 1-December 31, 2012 (Quarter 4, 2012)

Number of EV Charging Stations: 18
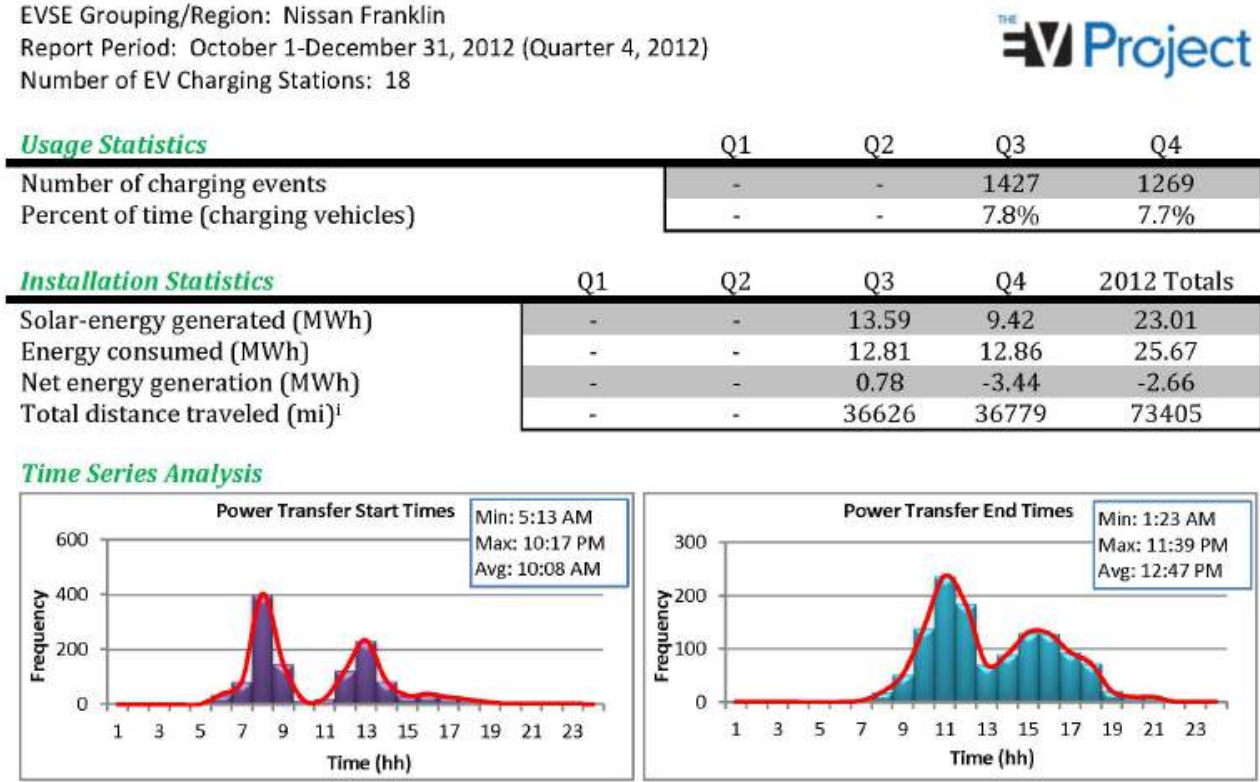

\begin{tabular}{cccc|} 
Q1 & Q2 & Q3 & Q4 \\
\hline- & - & 1427 & 1269 \\
- & - & $7.8 \%$ & $7.7 \%$ \\
\hline
\end{tabular}

\begin{tabular}{l|ccccc|} 
Installation Statistics & Q1 & Q2 & Q3 & Q4 & 2012 Totals \\
\hline Solar-energy generated (MWh) & - & - & 13.59 & 9.42 & 23.01 \\
Energy consumed (MWh) & - & - & 12.81 & 12.86 & 25.67 \\
Net energy generation $(\mathrm{MWh})$ & - & - & 0.78 & -3.44 & -2.66 \\
Total distance traveled $(\mathrm{mi})^{\mathrm{i}}$ & - & - & 36626 & 36779 & 73405 \\
\hline
\end{tabular}

Time Series Analysis
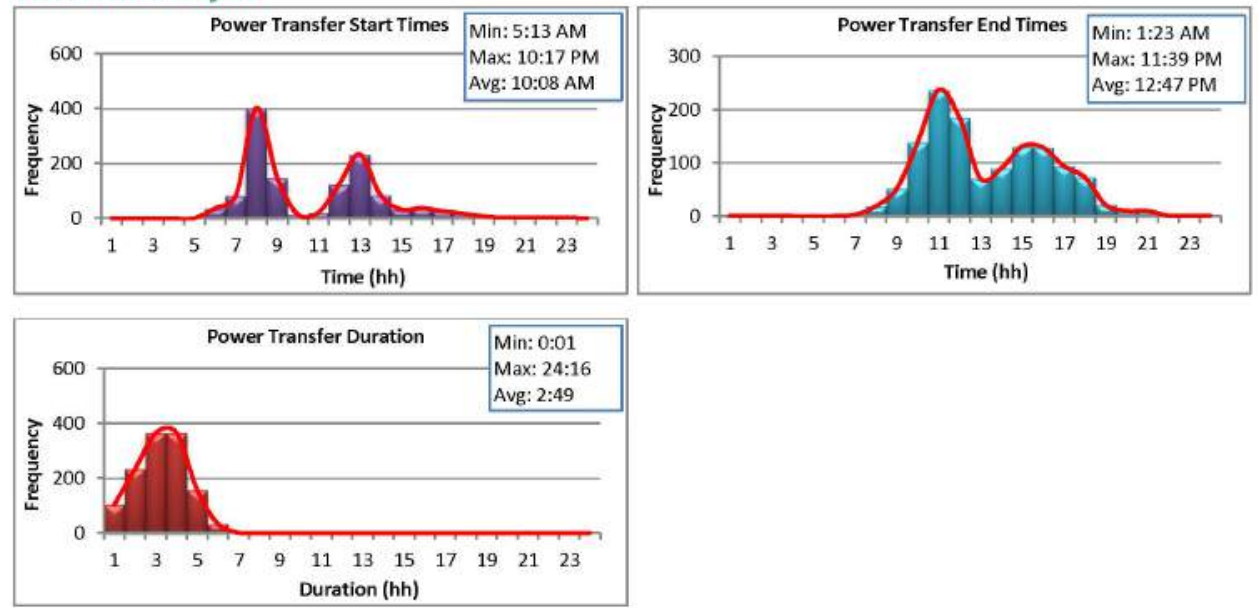

Page 1 


\section{OAK RIDGE NATIONAL LABORATORY}

Energy Consumption Analysis
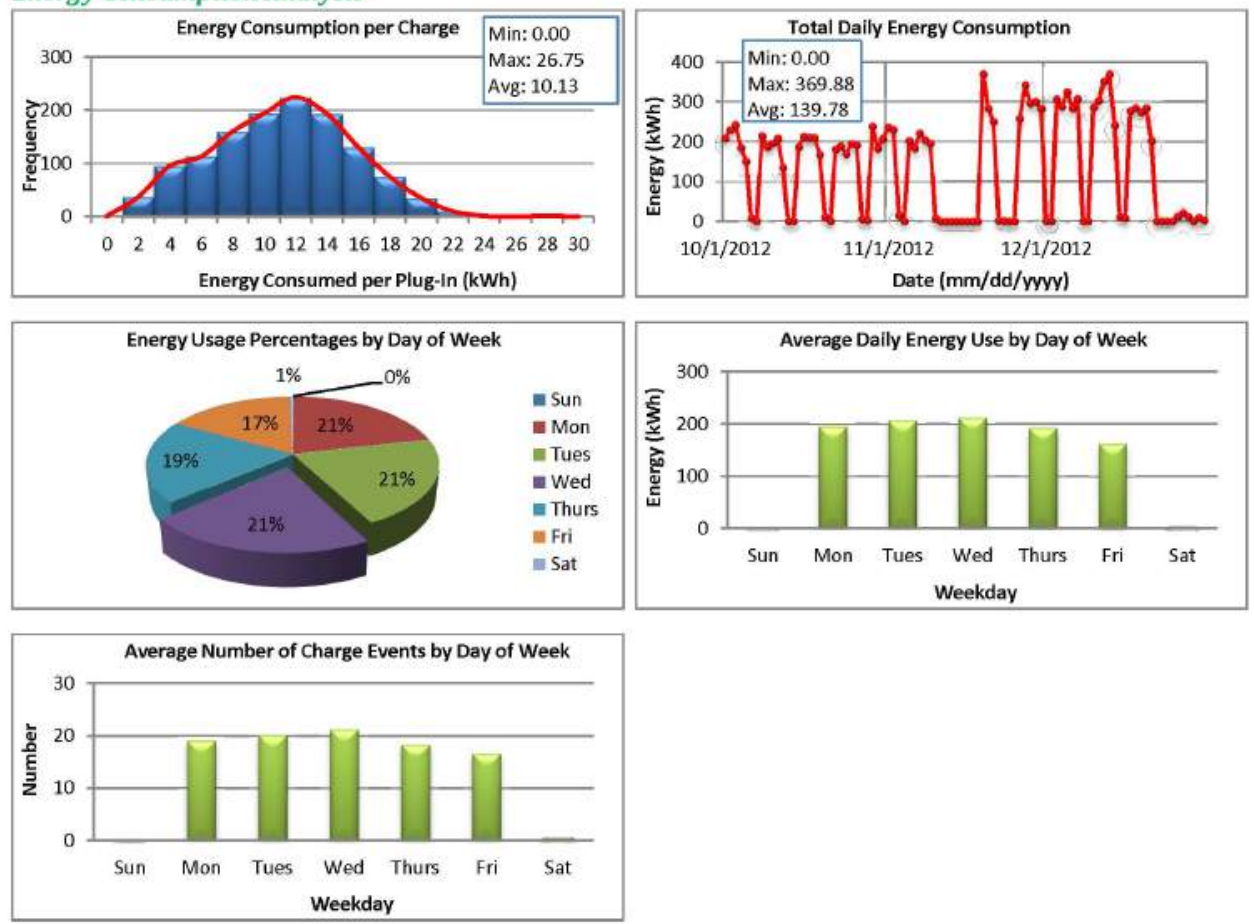

Charging Analysis
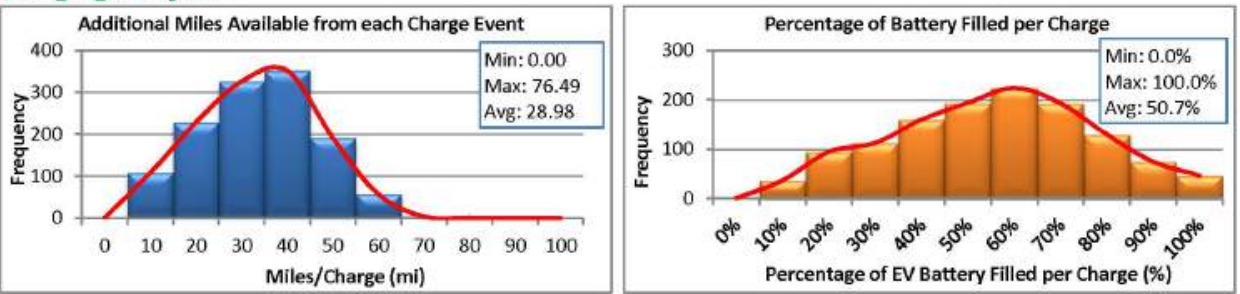

EVSE Analysis
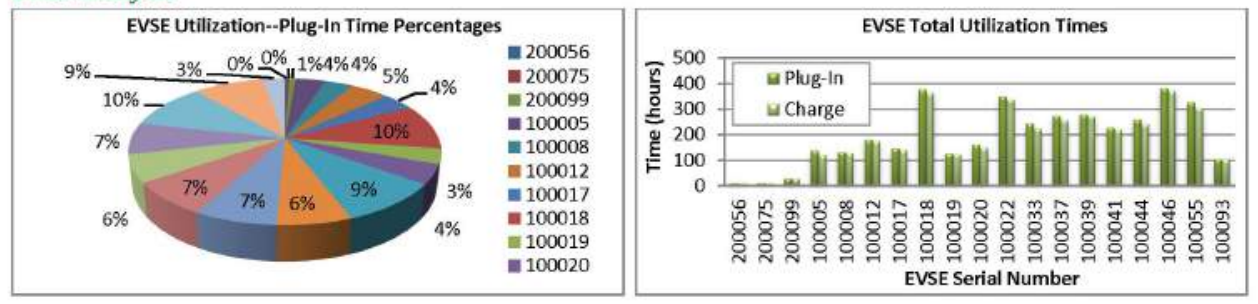

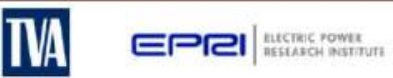

Page 2 


\section{OAK Ridge NaTional Laboratory}

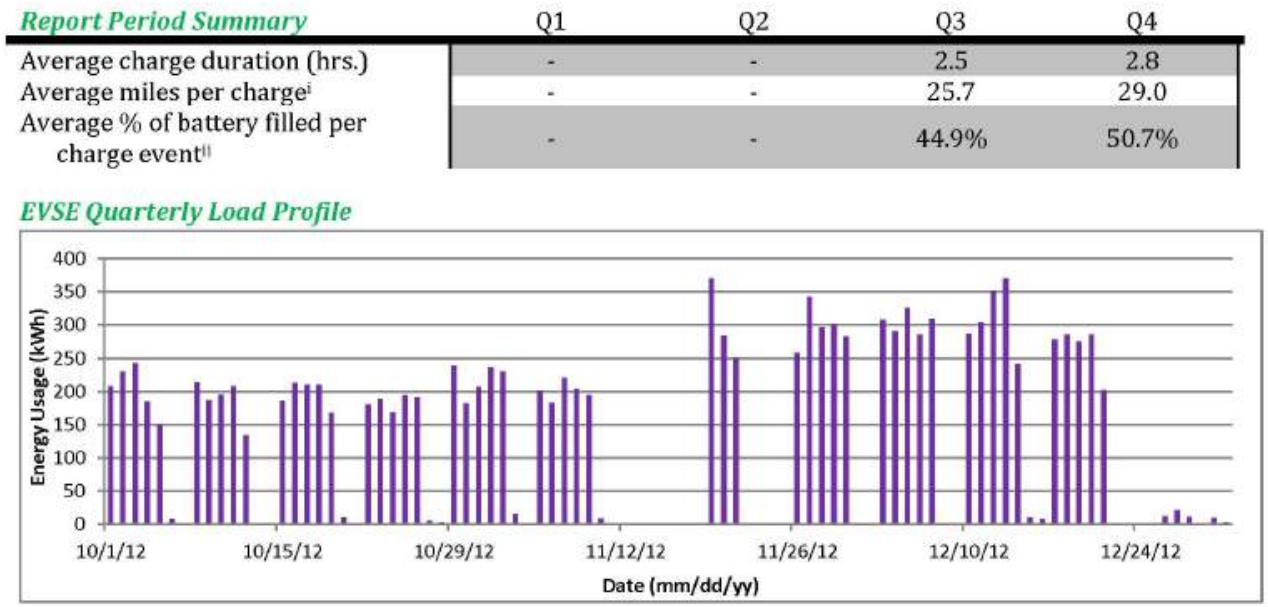

PV Array Quarterly Power Generation Profile

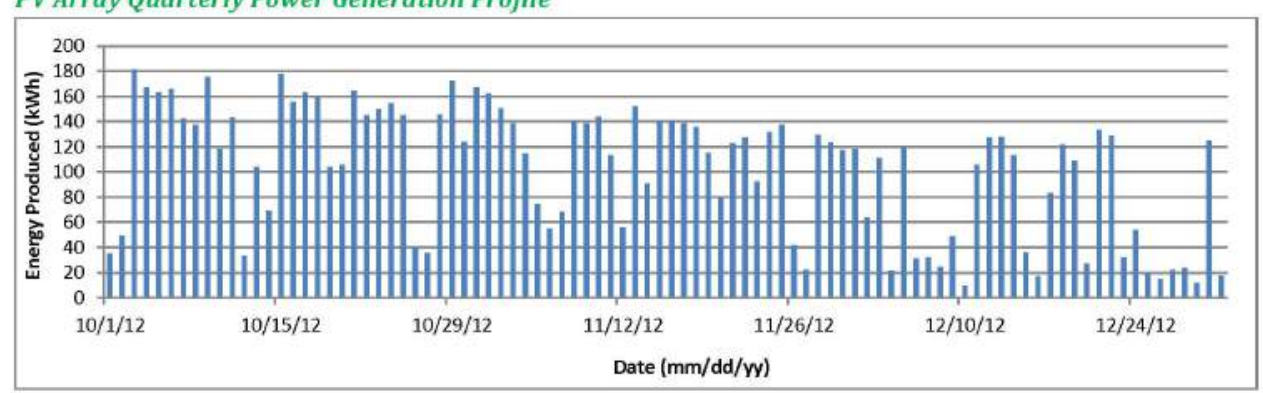

Notes:

1. Solar data was not provided for the site. Values shown are estimated based on power generation from other PV arrays in Nashville.

2. The AeroVironment EVSE data does not contain values for connect and disconnect times that are distinct from the power transfer times. Connection time data are therefore not presented for this site.

Based on the total energy consumption and an average of miles per $\mathrm{kWh}$ for the Nissan Leaf $(2.94 \mathrm{mi} / \mathrm{kWh})$ and Chevy Volt $(2.78 \mathrm{mi} / \mathrm{kWh})$

Values taken from htto://www.fueleconomy.gov/.

"Based on energy consumption and size of battery for the Nissan Leaf ( $24 \mathrm{kWh}$ ) and Chevy Volt (16 kWh).

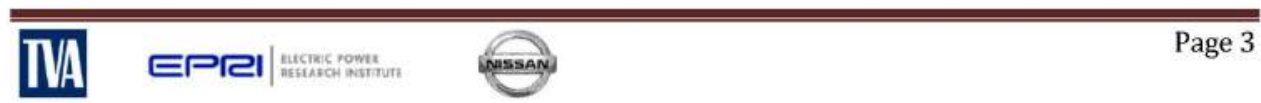




\section{Oak Ridge NaTiOnAL LabORATORY}

EV Project Solar-Assisted Charging Infrastructure Summary Report

EVSE Grouping/Region: Nissan Franklin

Report Period: October 1-December 31, 2013 (Quarter 4, 2013)

Number of EV Charging Stations: 18

$\exists \boldsymbol{F}$ Project

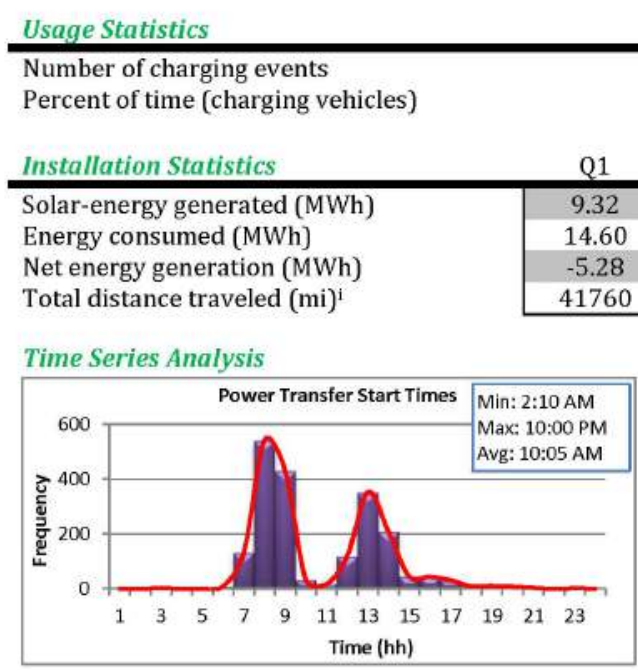

Q1

$9.0 \% \quad 10.5$

Q3 Q4

$10.5 \%$

1670

$12.4 \%$

Installation Statistics

Q2

Q4 2013 Totals

Energy consumed (MWh

Net energy generation (MWh)

16.54

14.83

$\begin{array}{llll}14.83 & 8.80 & 49.49\end{array}$

$\begin{array}{lllll}28 & -0.91 & -0.81 & -11.78 & -18.78\end{array}$

$\begin{array}{lllll}1760 & 49911 & 44729 & 58868 & 195268\end{array}$

Time Series Analysis
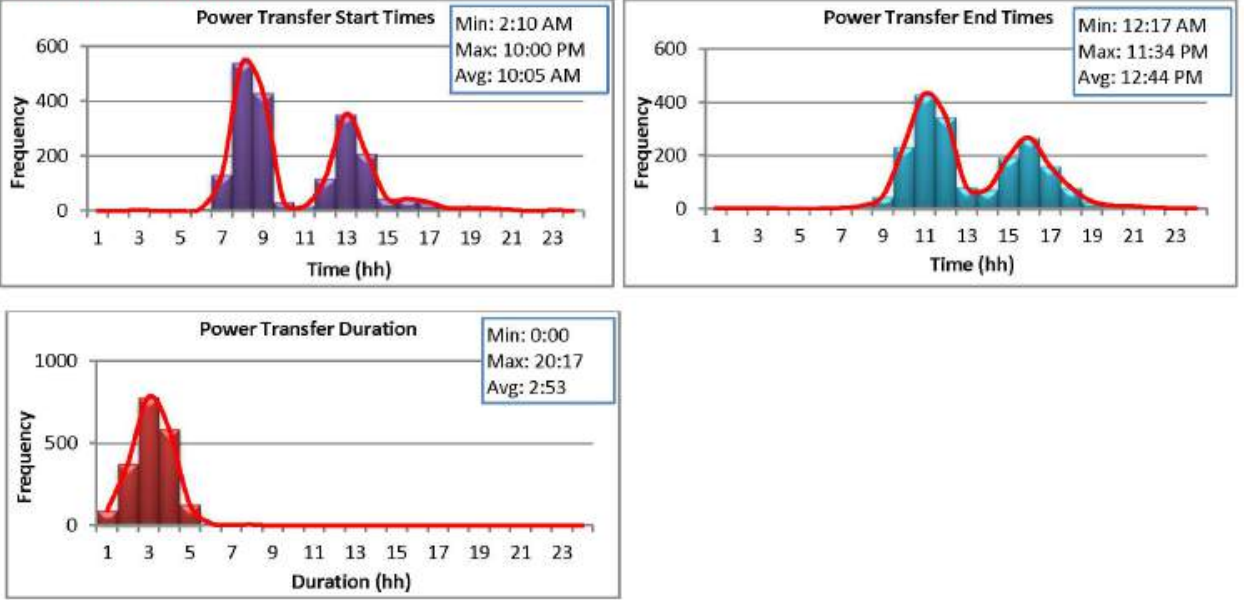

Page 1

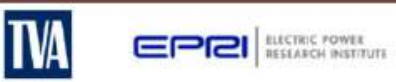




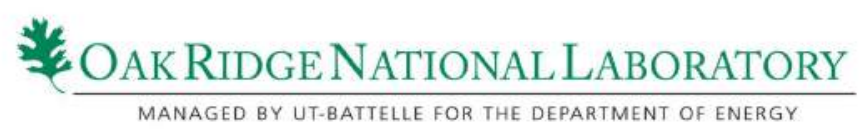

Energy Consumption Analysis
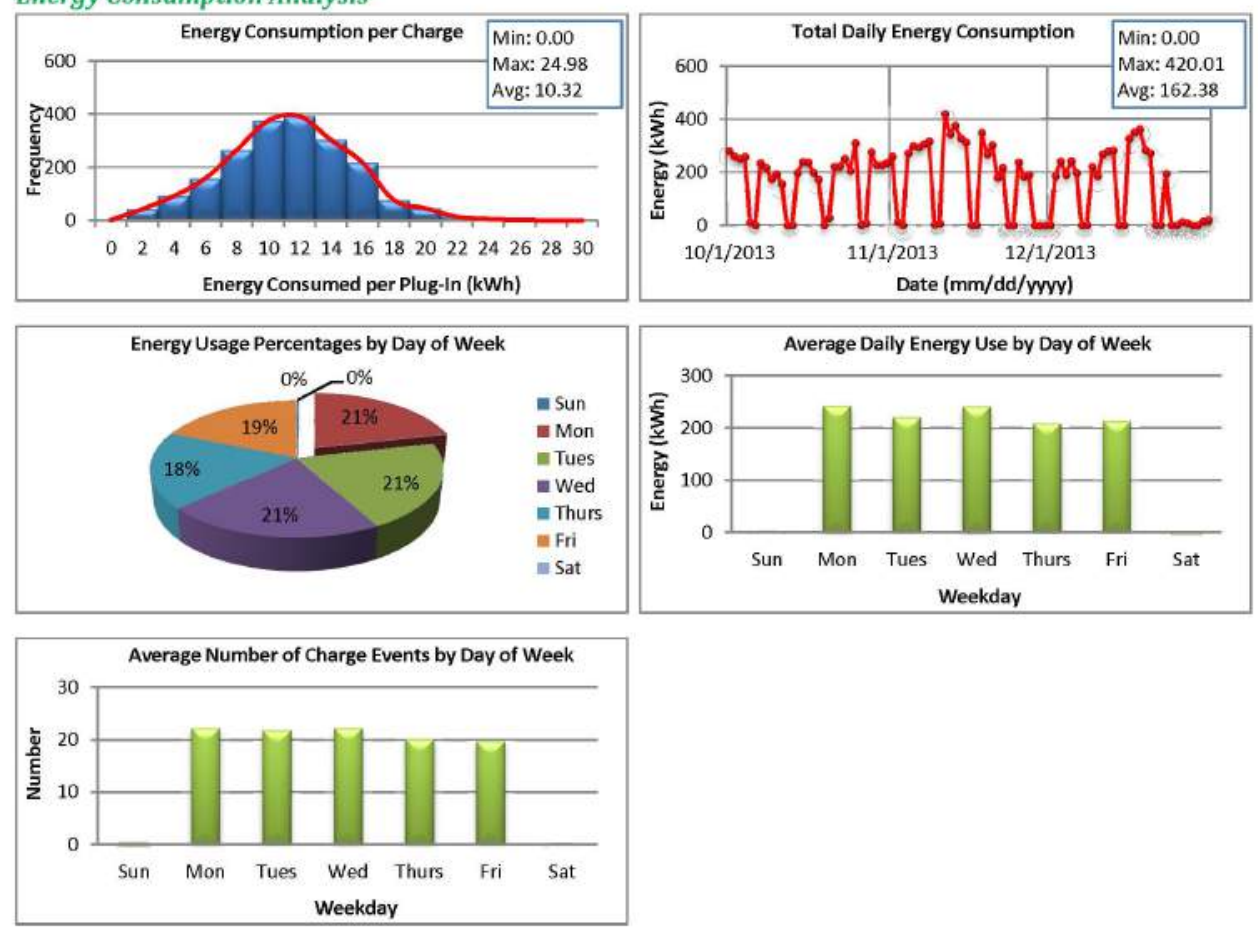

Charging Analysis
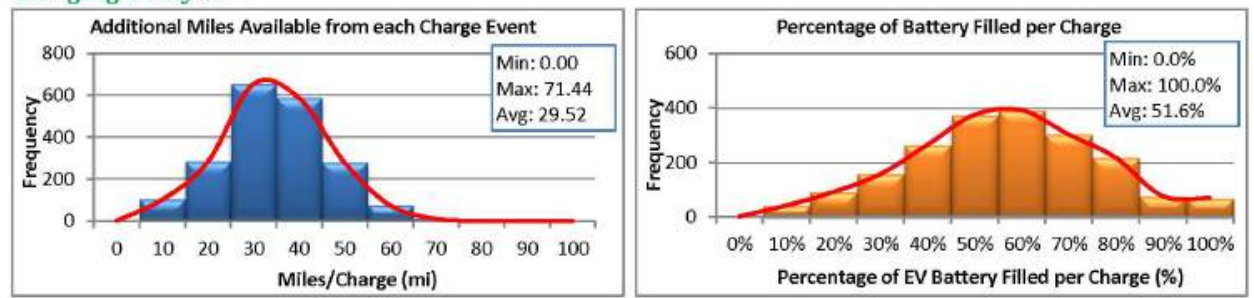

EVSE Analysís
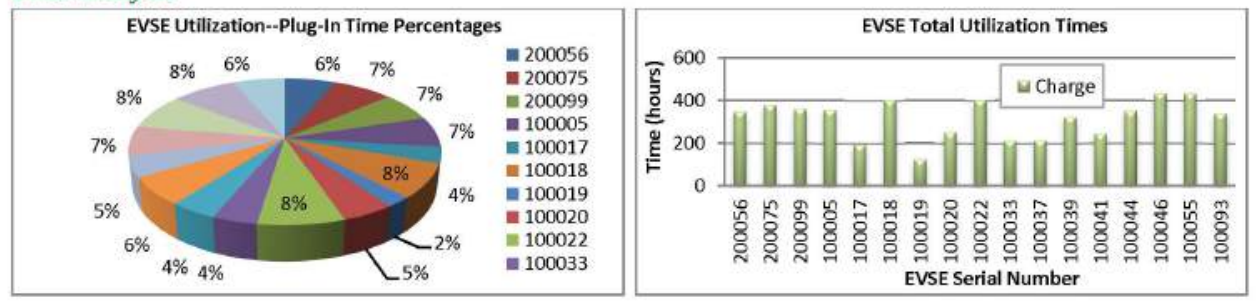

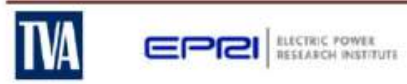

Page 2 


\section{OAK Ridge NATIONAL LABORATORY}

\begin{tabular}{l|cccc|} 
Report Period Summary & Q1 & Q2 & Q3 & Q4 \\
\hline $\begin{array}{l}\text { Average charge duration (hrs.) } \\
\begin{array}{l}\text { Average miles per charge } \\
\text { Average } \% \text { of battery filled per }\end{array}\end{array}$ & 3.0 & 2.6 & 2.6 & 4.1 \\
$\begin{array}{l}\text { charge event } \\
\text { ch }\end{array}$ & 30.3 & 27.3 & 26.8 & 41.8 \\
\end{tabular}

EVSE Quarterly Load Profile

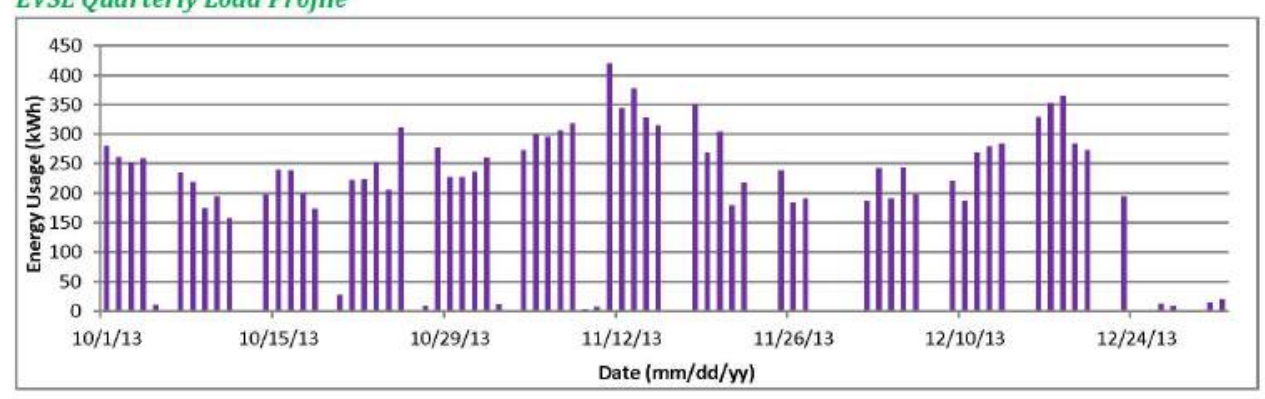

PV Array Quarterly Power Generation Profile

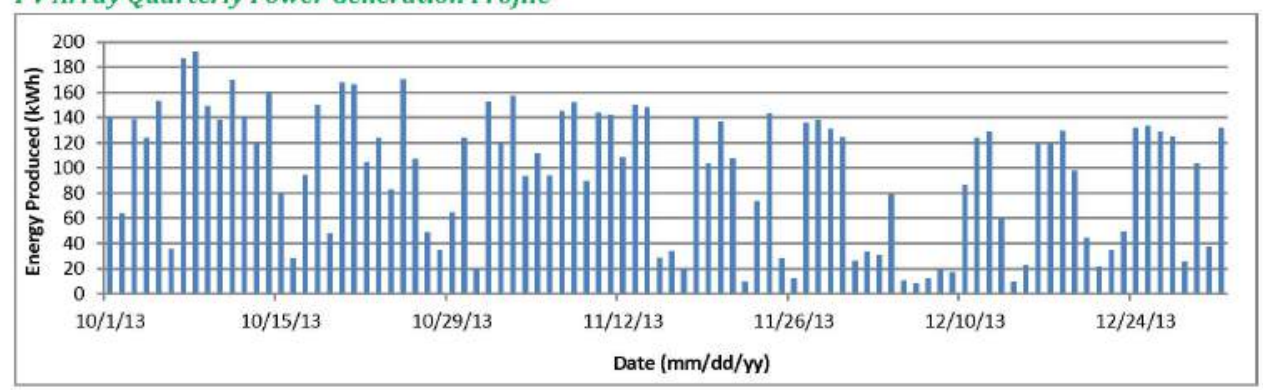

Notes:

1. Solar data was not provided for the site. Values shown are estimated based on power generation from other PV arrays in Nashville.

2. The AeroVironment EVSE data does not contain values for connect and disconnect times that are distinct from the power transfer times. Connection time data are therefore not presented for this site.

Based on the total energy consumption and an average of miles per $\mathrm{kWh}$ for the Nissan Leaf $(2.94 \mathrm{mi} / \mathrm{kWh})$ and Chevy Volt $(2.78 \mathrm{mi} / \mathrm{kWh})$.

Values taken from http://www.fueleconomy.gov/.

"Based on energy consumption and size of battery for the Nissan Leaf ( $24 \mathrm{kWh}$ ) and Chevy Volt (16 kWh).

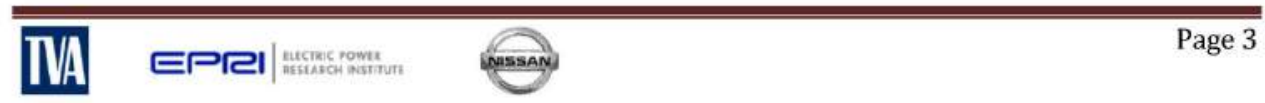




\section{Oak Ridge NaTiOnAL LabORATORY}

EV Project Solar-Assisted Charging Infrastructure Summary Report

EVSE Grouping/Region: Nissan Franklin

Report Period: April 1-June 30, 2014 (Quarter 2, 2014)

Number of EV Charging Stations: 18

$\exists \boldsymbol{F}$ Project

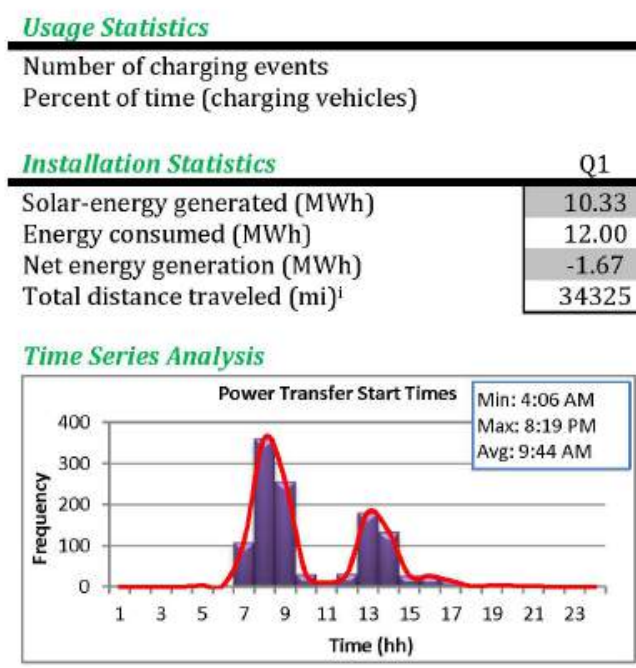

\begin{tabular}{cccc|} 
Q1 & Q2 & Q3 & Q4 \\
\hline 1103 & 1193 & - & - \\
$7.5 \%$ & $6.4 \%$ & - & - \\
\hline & & & \\
Q2 & Q3 & Q4 & 2014 Totals \\
\hline 16.50 & - & - & 26.83 \\
11.30 & - & - & 23.3 \\
5.20 & - & - & 3.53 \\
32328 & - & - & 66653 \\
\hline
\end{tabular}

Time Series Analysis
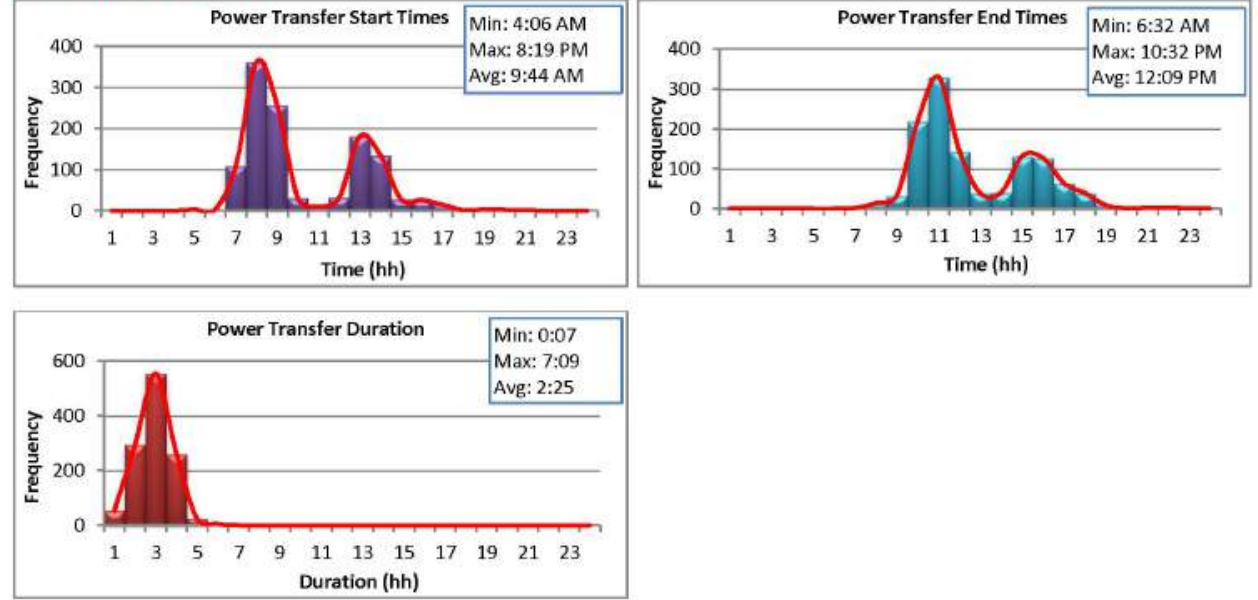

Page 1 


\section{OAK RIDGE NATIONAL LABORATORY}

Energy Consumption Analysis
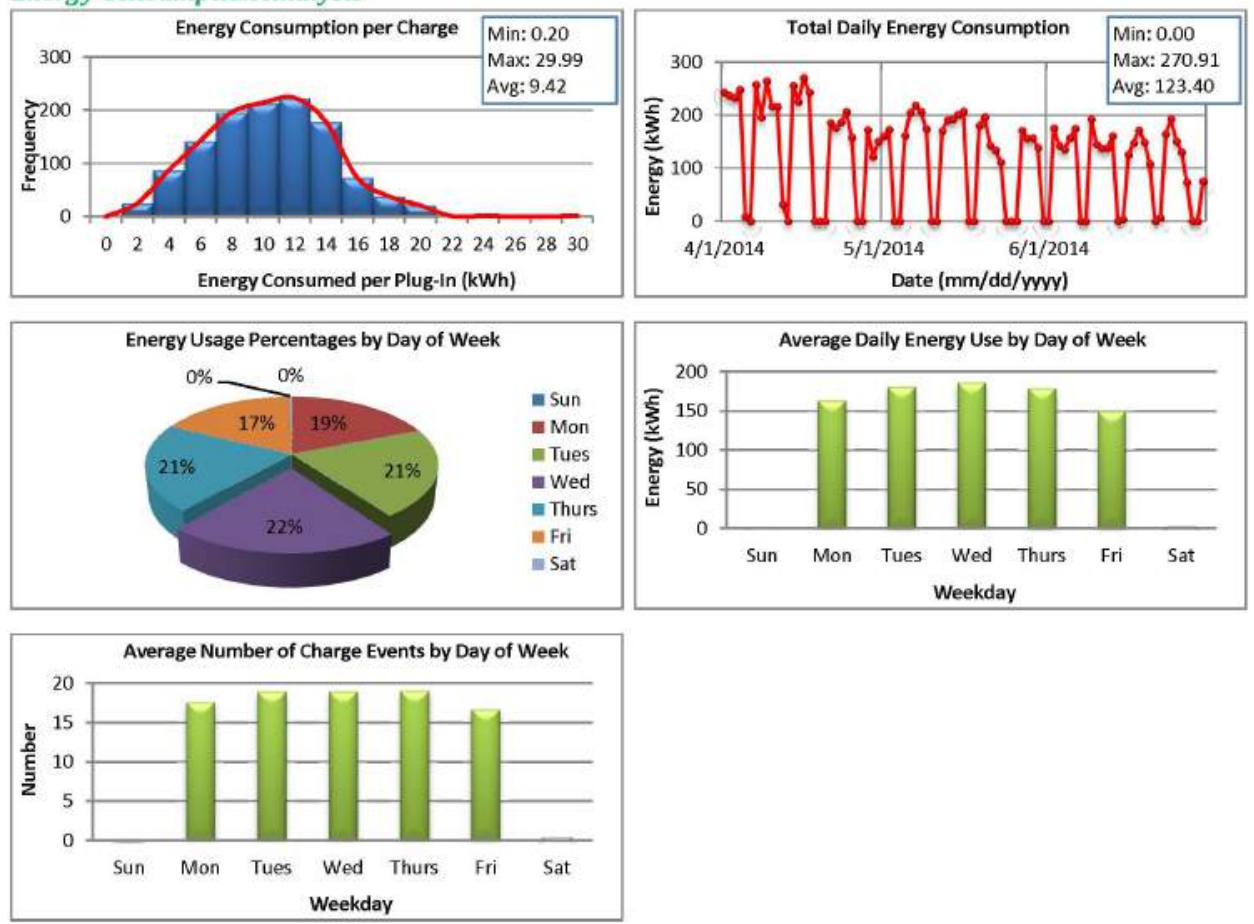

Charging Analysis
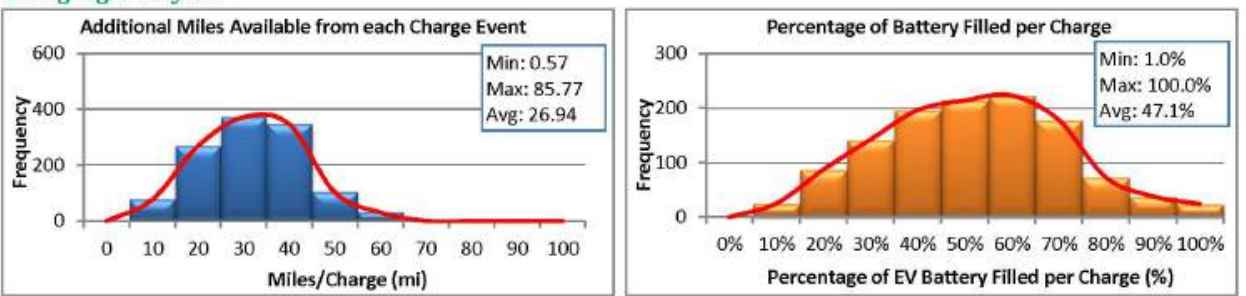

EVSE Analysís

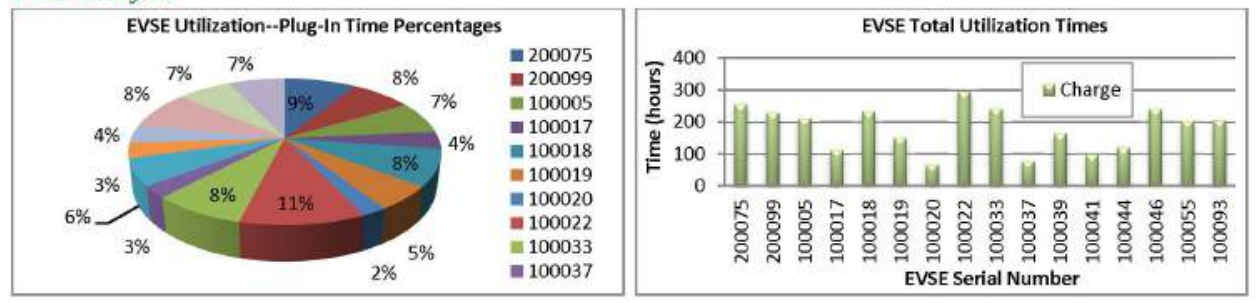

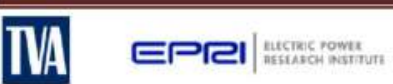

Page 2 


\section{$\frac{\text { OAK RIDGE NATIONAL LABORATORY }}{\text { MANAGED BY UT-BATTELLE FOR THE DEPARTMENT OF ENERGY }}$}

\begin{tabular}{l|cccc} 
Report Period Summary & Q1 & Q2 & Q3 & Q4 \\
\hline Average charge duration (hrs.) & 3.1 & 2.4 & - & - \\
$\begin{array}{l}\text { Average miles per charge } \\
\text { Average } \% \text { of battery filled per }\end{array}$ & 31.1 & 27.1 & - & - \\
$\quad$ charge event & $54.4 \%$ & $47.1 \%$ & -
\end{tabular}

EVSE Quarterly Load Profile

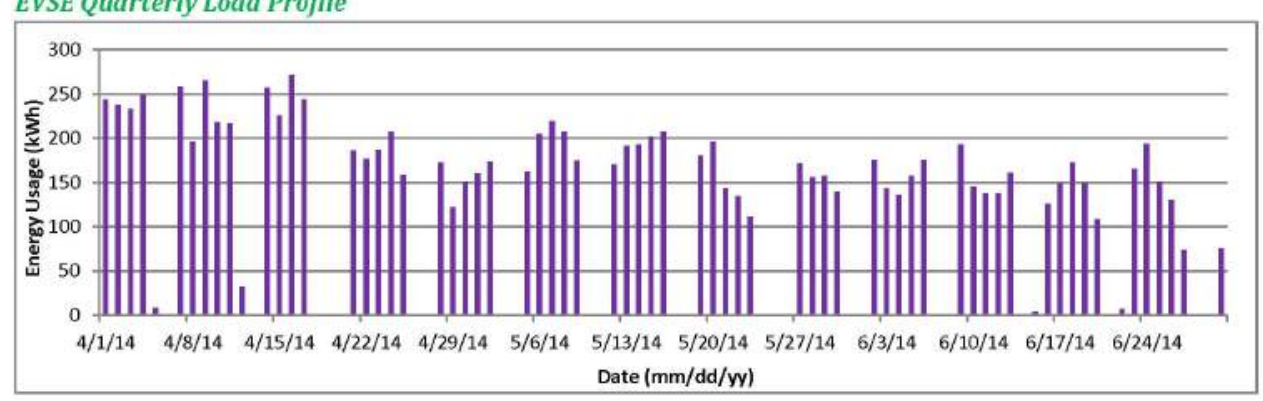

PV Array Quarterly Power Generation Profile

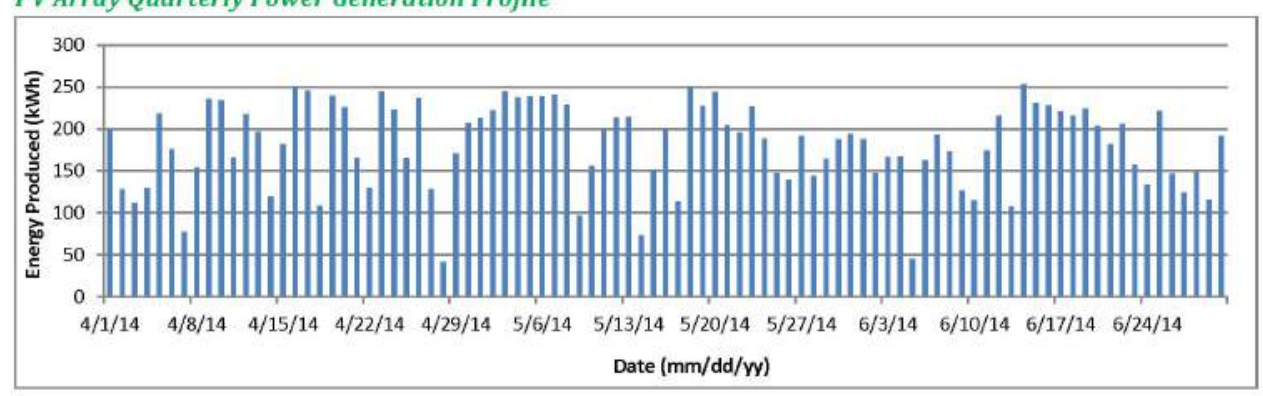

Notes:

1. Solar data was not provided for the site. Values shown are estimated based on power generation from other PV arrays in Nashville.

2. The AeroVironment EVSE data does not contain values for connect and disconnect times that are distinct from the power transfer times. Connection time data are therefore not presented for this site.

Based on the total energy consumption and an average of miles per kWh for the Nissan Leaf ( $2.94 \mathrm{mi} / \mathrm{kWh}$ ) and Chevy Volt $(2.78 \mathrm{mi} / \mathrm{kWh})$.

Values taken from htto://www.fueleconomy.gov/.

"Based on energy consumption and size of battery for the Nissan Leaf ( $24 \mathrm{kWh}$ ) and Chevy Volt (16 kWh).

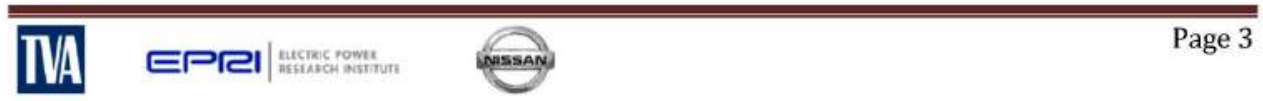




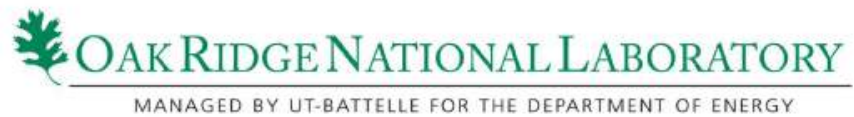

EV Project Solar-Assisted Charging Infrastructure Summary Report

EVSE Grouping/Region: Nissan Battery Plant

Report Period: October 1-December 31, 2012 (Quarter 4, 2012)

Number of EV Charging Stations: 3

$\exists \boldsymbol{F}$ Project

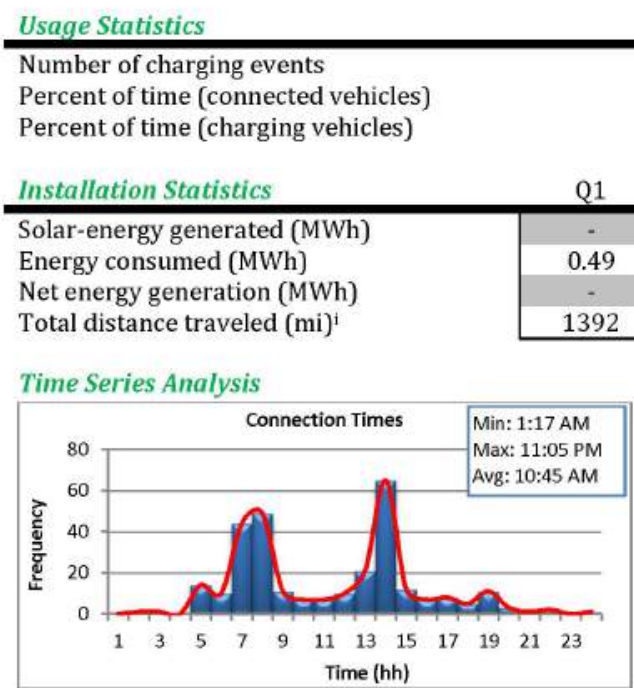

\begin{tabular}{|cccc|}
\hline $\mathrm{Q} 1$ & $\mathrm{Q} 2$ & $\mathrm{Q} 3$ & $\mathrm{Q} 4$ \\
\hline 64 & 144 & 167 & 290 \\
$5.6 \%$ & $15.2 \%$ & $13.7 \%$ & $20.9 \%$ \\
$2.2 \%$ & $6.0 \%$ & $6.2 \%$ & $13.3 \%$ \\
\hline
\end{tabular}
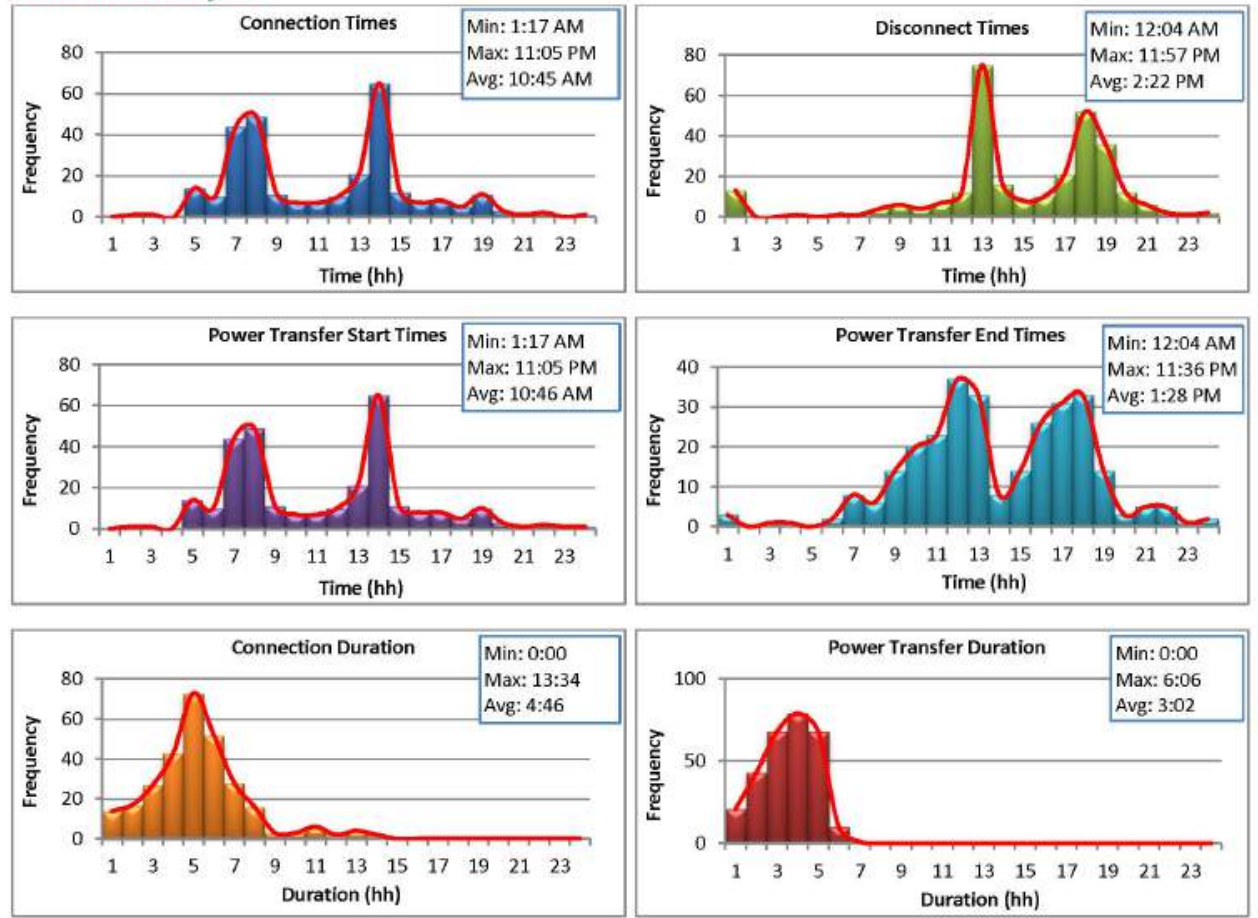

IVA ED展

Page 1 


\section{OAK RIDGE NATIONAL LABORATORY}

Energy Consumption Analysis
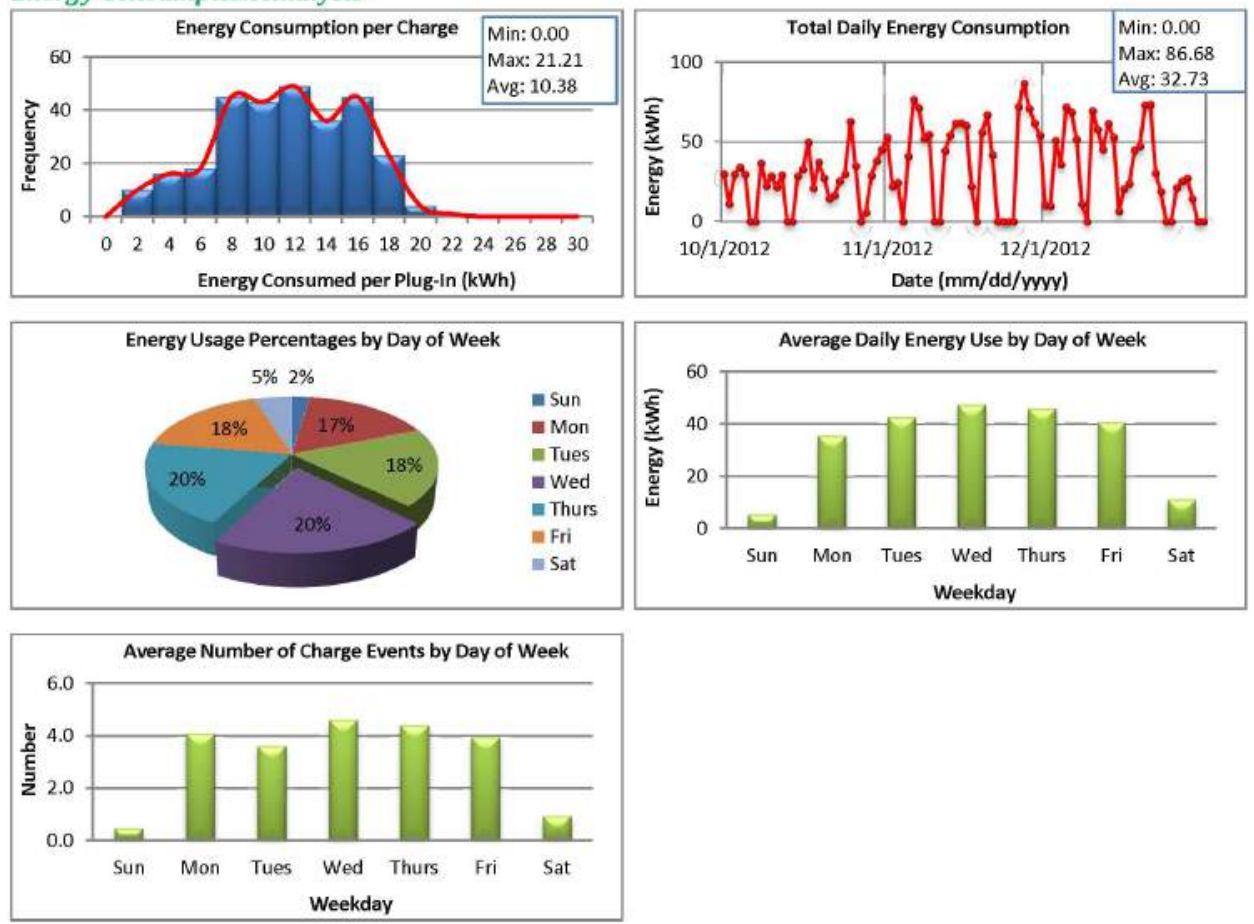

Charging Analysis
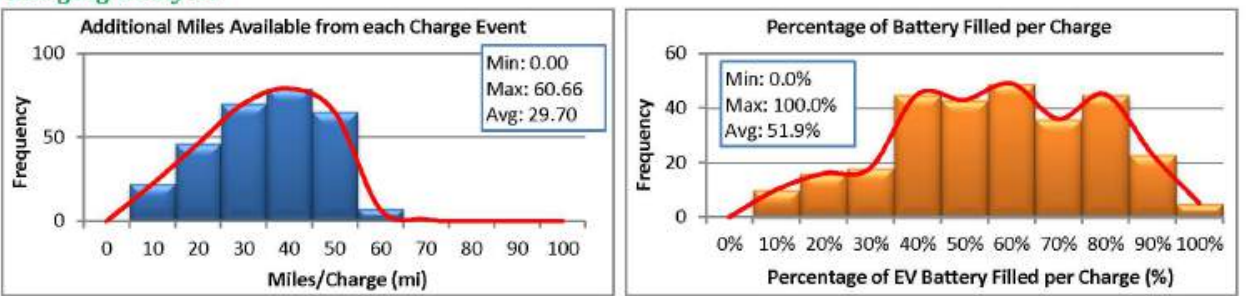

EVSE Analysís

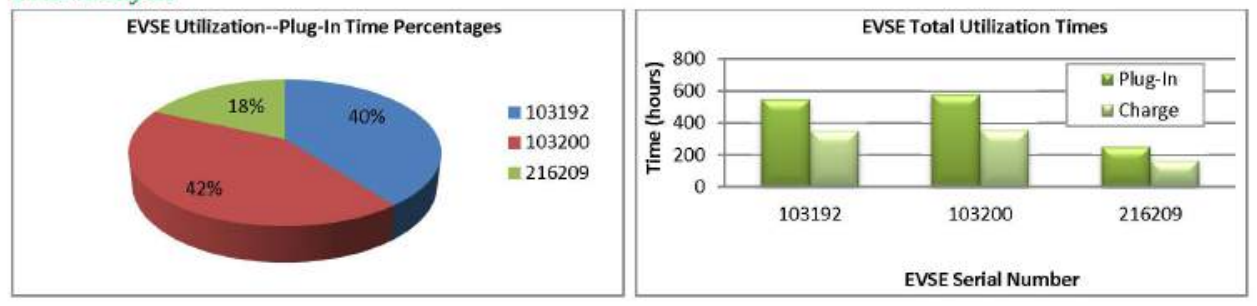

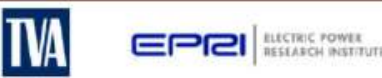

Page 2 


\section{OAK Ridge National Laboratory}

\begin{tabular}{|c|c|c|c|c|}
\hline \multirow{5}{*}{$\begin{array}{l}\text { Average connection duration (hrs.) } \\
\text { Average charge duration (hrs.) } \\
\text { Average miles per charge } \\
\text { Average } \% \text { of battery filled per }\end{array}$} & Q1 & Q2 & Q3 & Q4 \\
\hline & 5.7 & 6.9 & 5.4 & 4.8 \\
\hline & 2.2 & 2.7 & 2.4 & 3.0 \\
\hline & 21.8 & 23.4 & 24.1 & 29.7 \\
\hline & $38.0 \%$ & $40.9 \%$ & $42.1 \%$ & $51.9 \%$ \\
\hline
\end{tabular}

EVSE Quarterly Load Profile

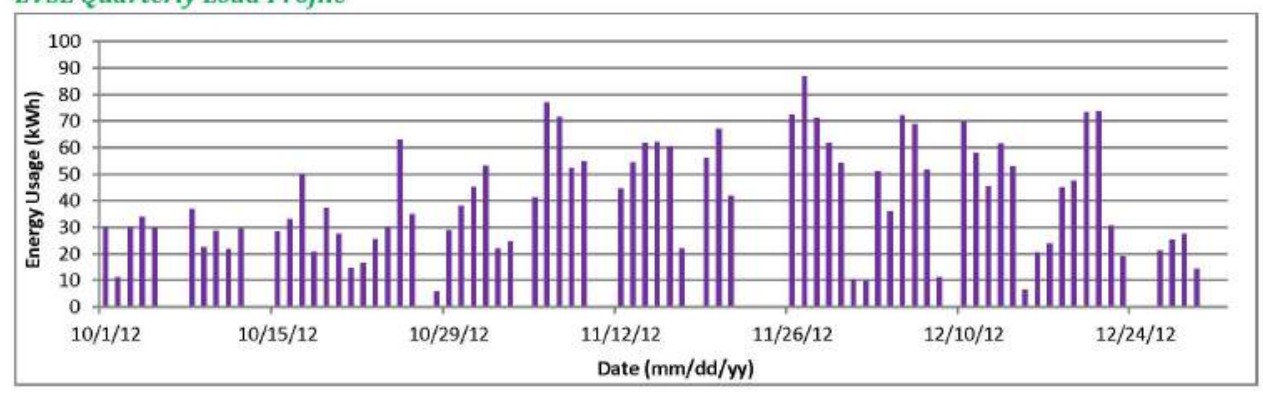

PV Array Quarterly Power Generation Profile

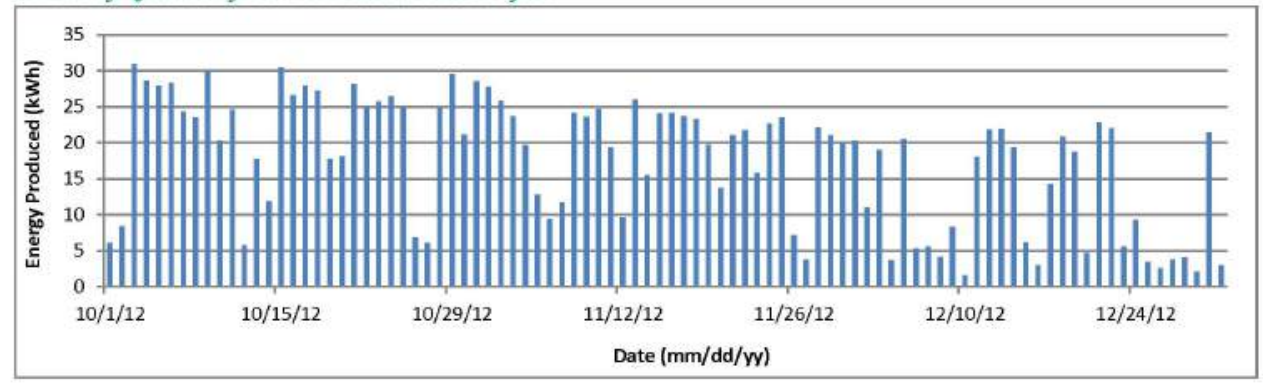

Note: Solar data was not provided for the site. Values shown are estimated based on power generation from other PV arrays in Nashville. No solar data was available during the $1^{\text {st }}$ and $2^{\text {nd }}$ quarters.

Based on the total energy consumption and an average of miles per $\mathrm{kWh}$ for the Nissan Leaf ( $2.94 \mathrm{mi} / \mathrm{kWh}$ ) and Chevy Volt $(2.78 \mathrm{mi} / \mathrm{kWh})$. Values taken from http://www.fueleconomy.gov/.

Based on energy consumption and size of battery for the Nissan Leaf ( $24 \mathrm{kWh}$ ) and Chevy Volt (16 kWh).

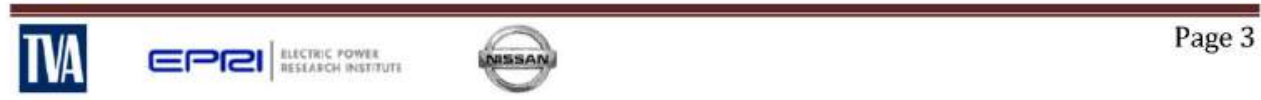




\section{Oak Ridge NaTiOnAL LabORATORY}

EV Project Solar-Assisted Charging Infrastructure Summary Report

EVSE Grouping/Region: Nissan Battery Plant

Report Period: October 1-December 31, 2013 (Quarter 4, 2013)

Number of EV Charging Stations: 3

F/y Project

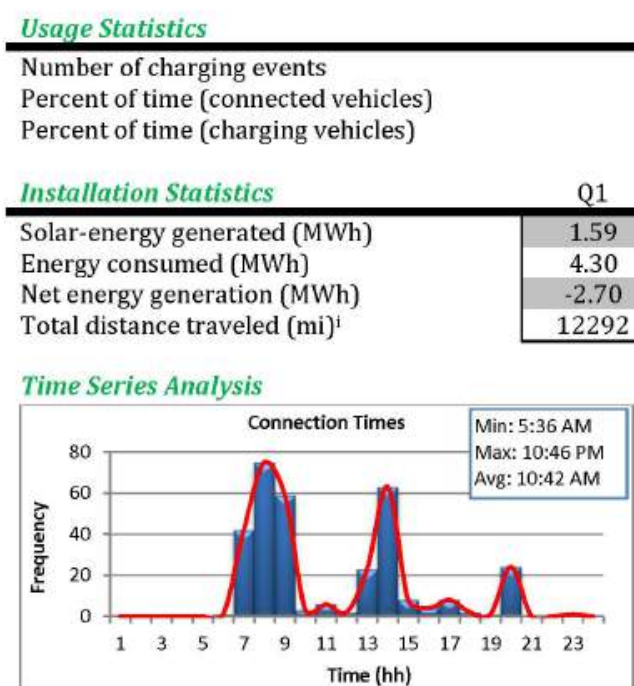

\begin{tabular}{cccc|}
\hline Q1 & Q2 & Q3 & Q4 \\
\hline 378 & 406 & 350 & 322 \\
$25.7 \%$ & $27.1 \%$ & $28.7 \%$ & $25.2 \%$ \\
$18.8 \%$ & $18.5 \%$ & $15.8 \%$ & $15.6 \%$
\end{tabular}
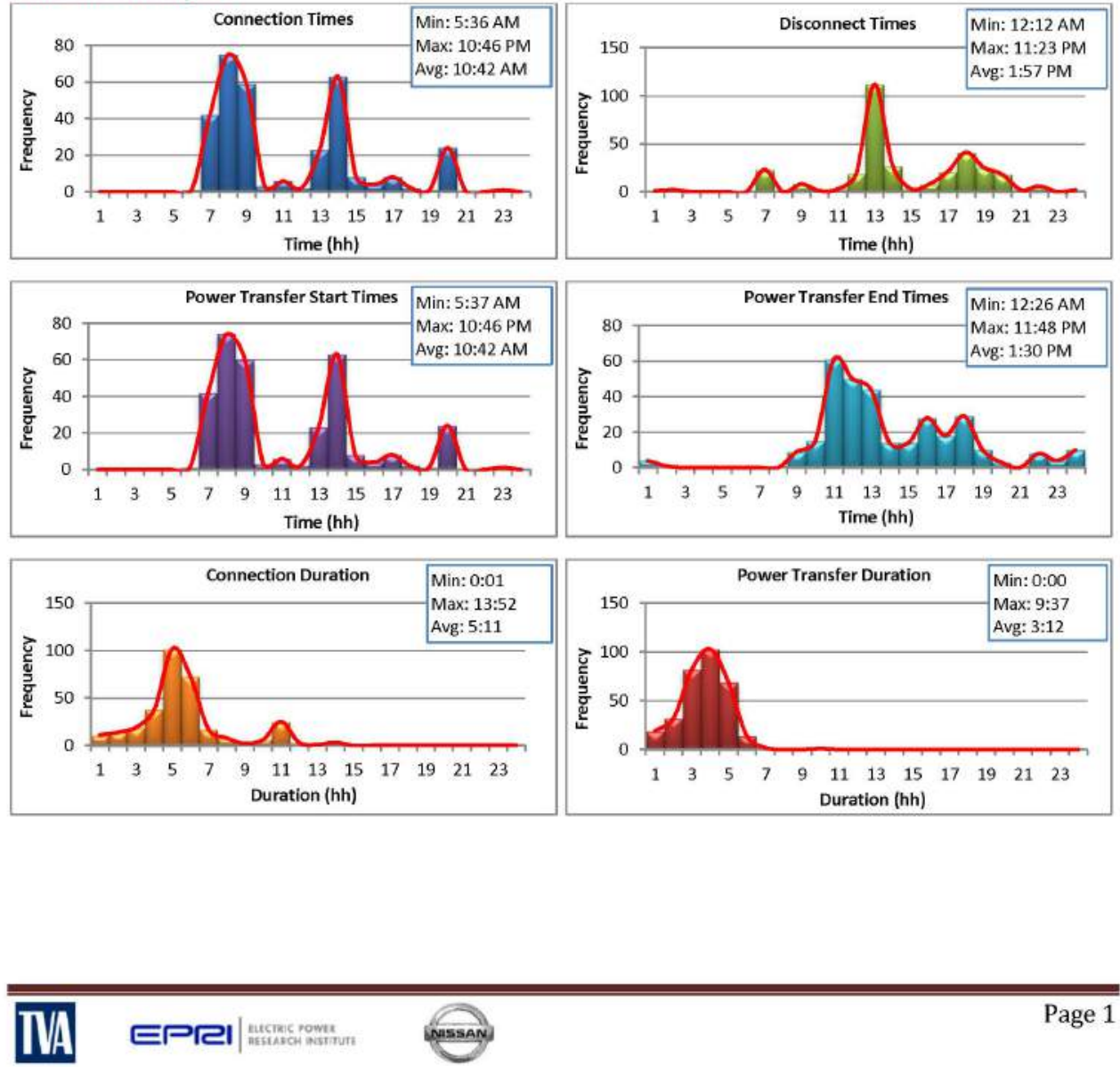


\section{OAK RIDGE NATIONAL LABORATORY}

Energy Consumption Analysis
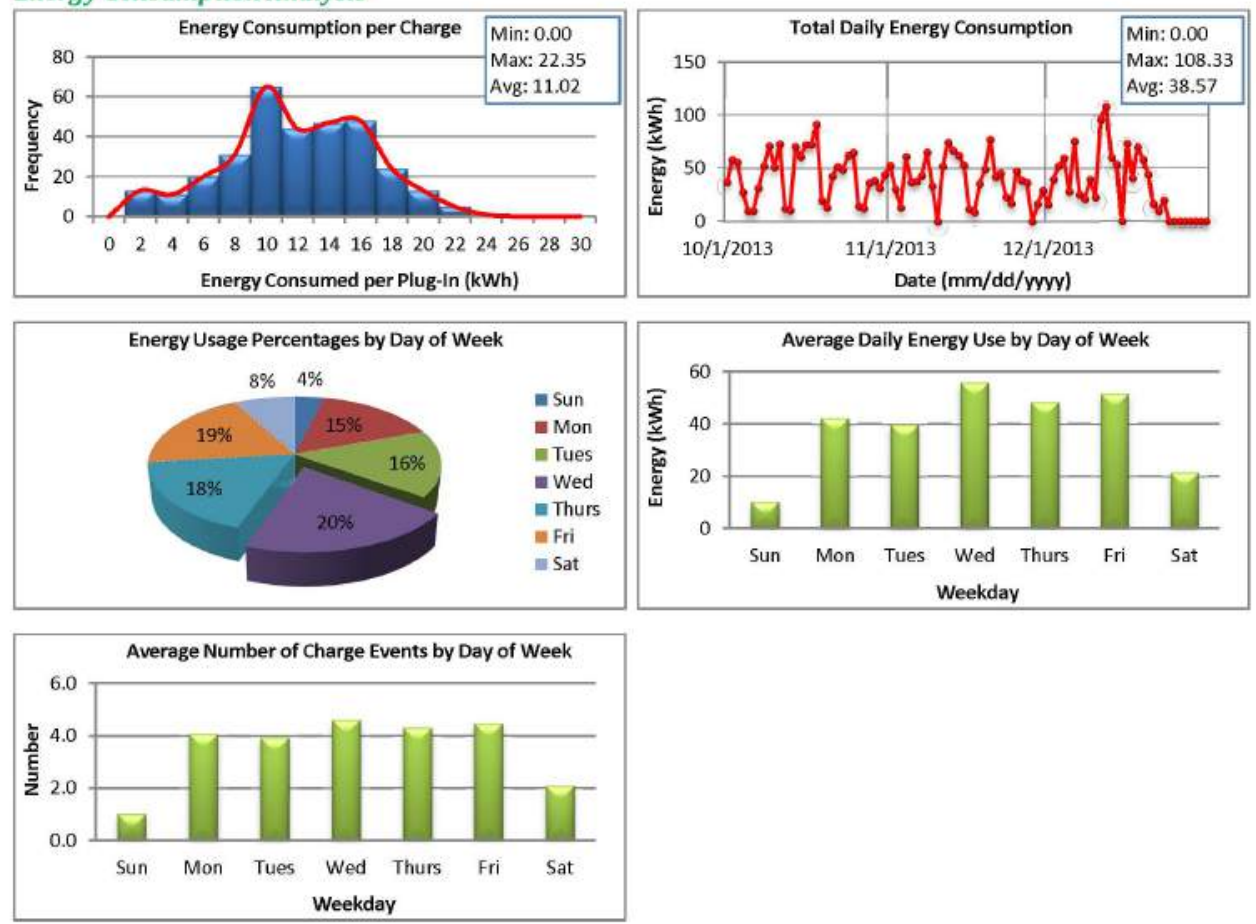

Charging Analysis
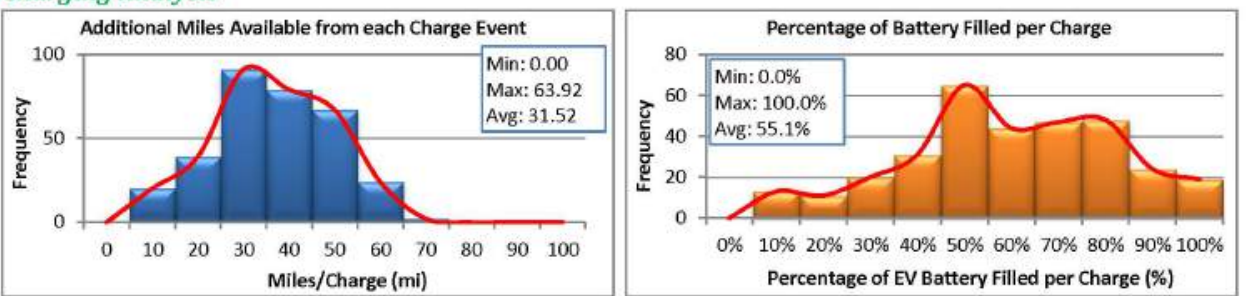

EVSE Analysis

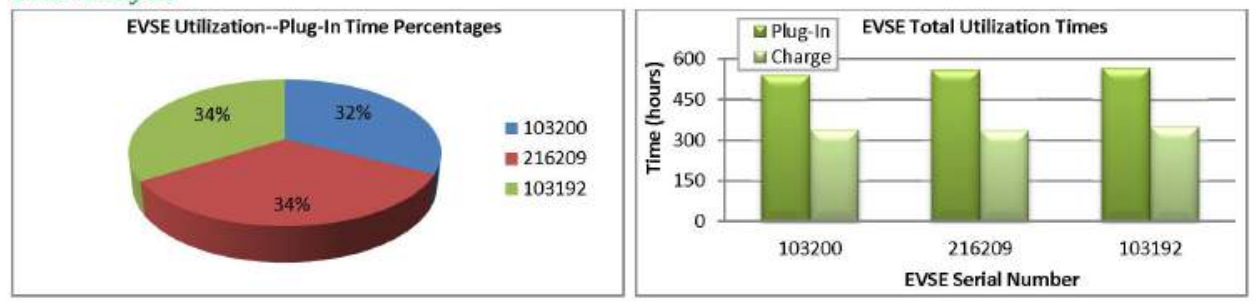

IVA EPR्|

Page 2 


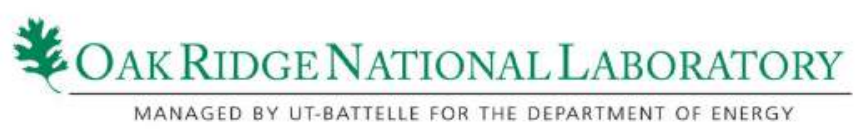

\begin{tabular}{|c|c|c|c|c|}
\hline Report Period Summary & Q1 & Q2 & Q3 & Q4 \\
\hline Average connection duration (hrs.) & 4.4 & 4.4 & 5.4 & 5.2 \\
\hline Average charge duration (hrs.) & 3.2 & 3.0 & 3.0 & 3.2 \\
\hline Average miles per charge & 32.5 & 29.9 & 30.0 & 31.5 \\
\hline $\begin{array}{l}\text { Average } \% \text { of battery filled per } \\
\text { charge event }{ }^{\mathrm{ii}}\end{array}$ & $56.9 \%$ & $52.3 \%$ & $52.5 \%$ & $55.1 \%$ \\
\hline
\end{tabular}

EVSE Quarterly Load Profile

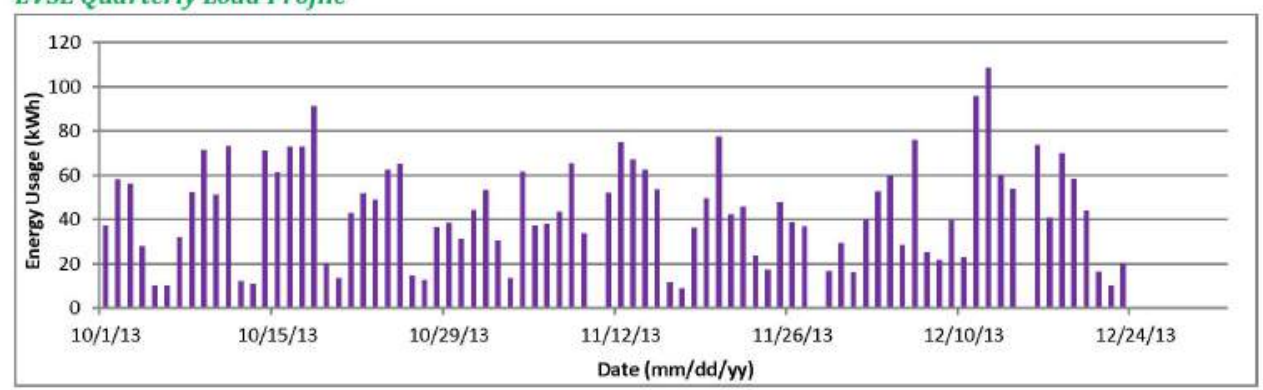

PV Array Quarterly Power Generation Profile

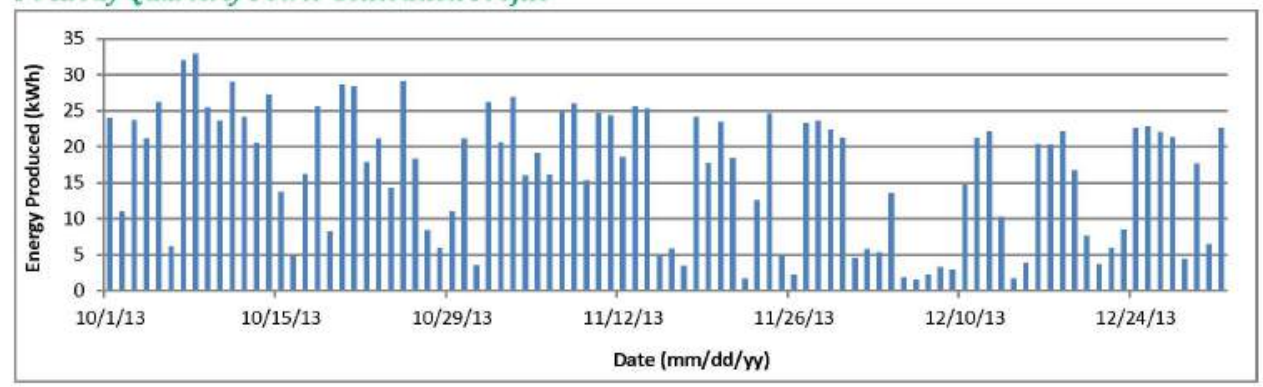

Note: Solar data was not provided for the site. Values shown are estimated based on power generation from other PV arrays in Nashville.

Based on the total energy consumption and an average of miles per $\mathrm{kWh}$ for the Nissan Leaf $(2.94 \mathrm{mi} / \mathrm{kWh})$ and Chevy Volt $(2.78 \mathrm{mi} / \mathrm{kWh}$ ).

Values taken from http://www.fueleconomy.gov/.

"Based on energy consumption and size of battery for the Nissan Leaf ( $24 \mathrm{kWh}$ ) and Chevy Volt (16 kWh).

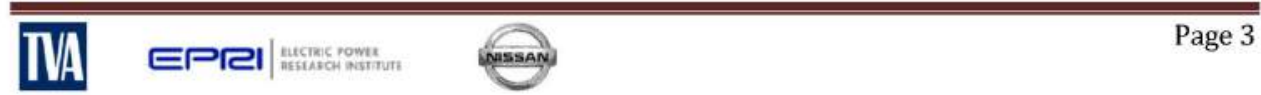




\section{Oak Ridge NaTiOnAL LabORATORY}

EV Project Solar-Assisted Charging Infrastructure Summary Report

EVSE Grouping/Region: Nissan Battery Plant

Report Period: April 1-June 30, 2014 (Quarter 2, 2014)

Number of EV Charging Stations: 3

$\exists \boldsymbol{F}$ Project

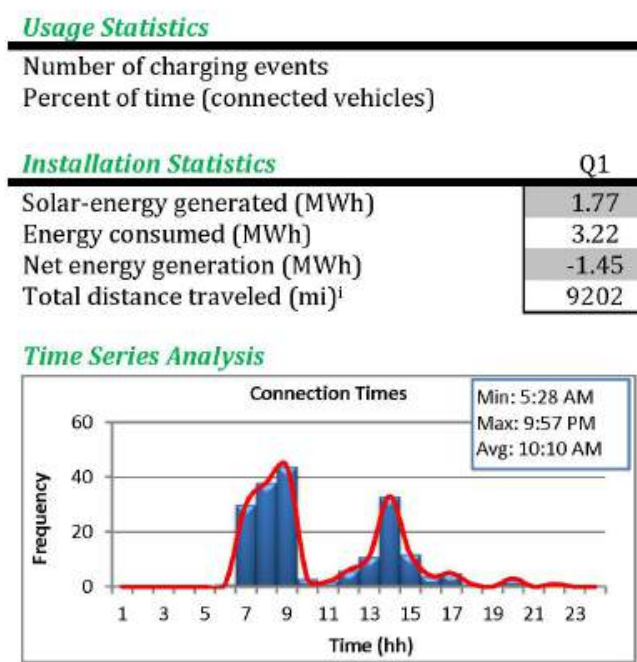

Q1

275

Q2

$21.4 \% \quad 14.1 \%$

$14.1 \%$

Q3 $\quad$ Q4

Q2 Q3 Q4 2014 Totals

$1.77 \quad 2.82$

1.99

0.83

5695

$\begin{array}{lr}\text { - } & 4.59\end{array}$

$\begin{array}{lll}- & - & 4.21\end{array}$

\begin{tabular}{ll}
- & -0.62 \\
\hline
\end{tabular}

$-$

14897
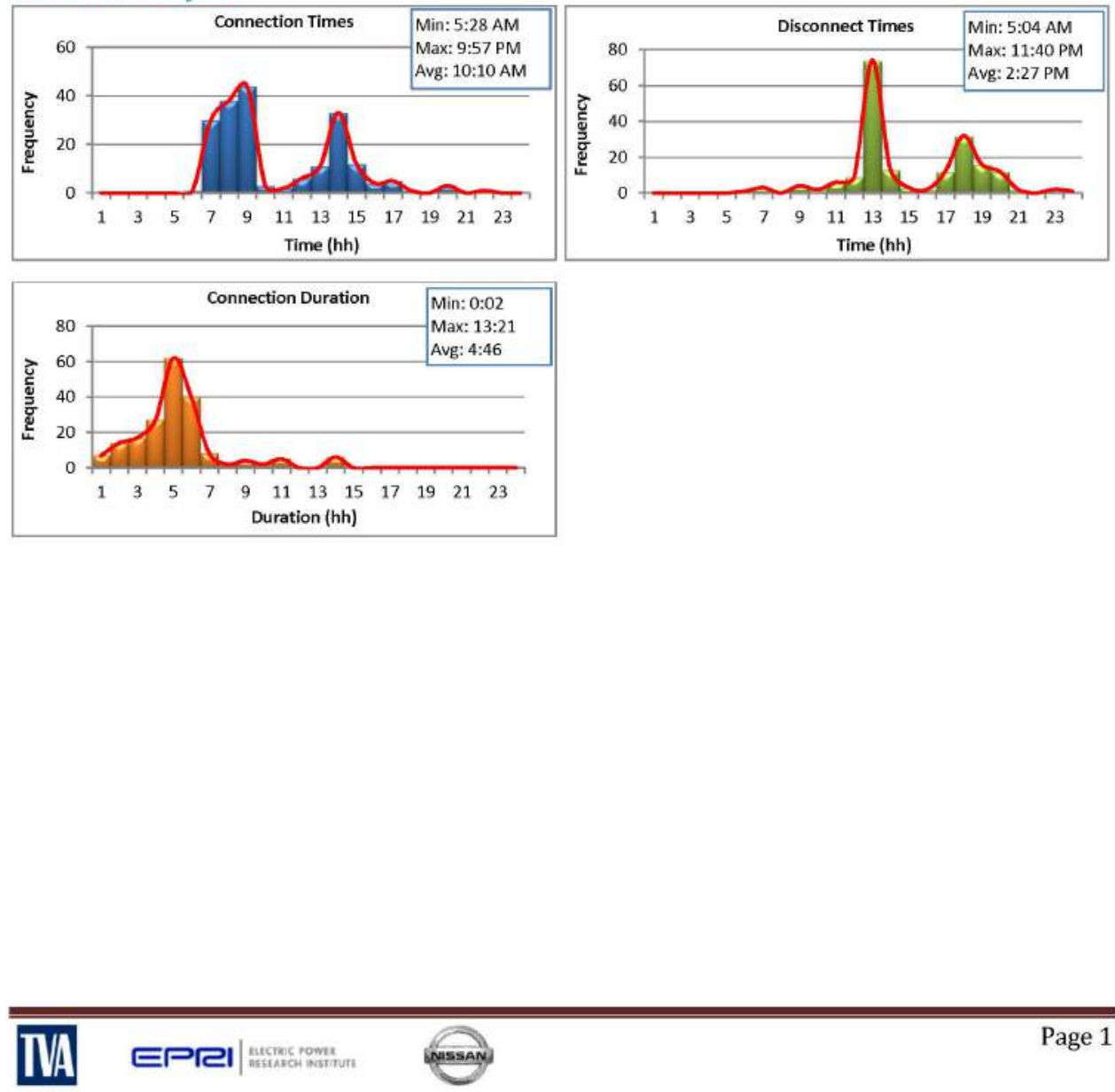

Page 1 


\section{$\frac{\text { OAK RIDGE NATIONAL LABORATORY }}{\text { ManAGED BY UT-BATtELE FOR ThE DEAARTMENT OF ENERGY }}$}

Energy Consumption Analysis
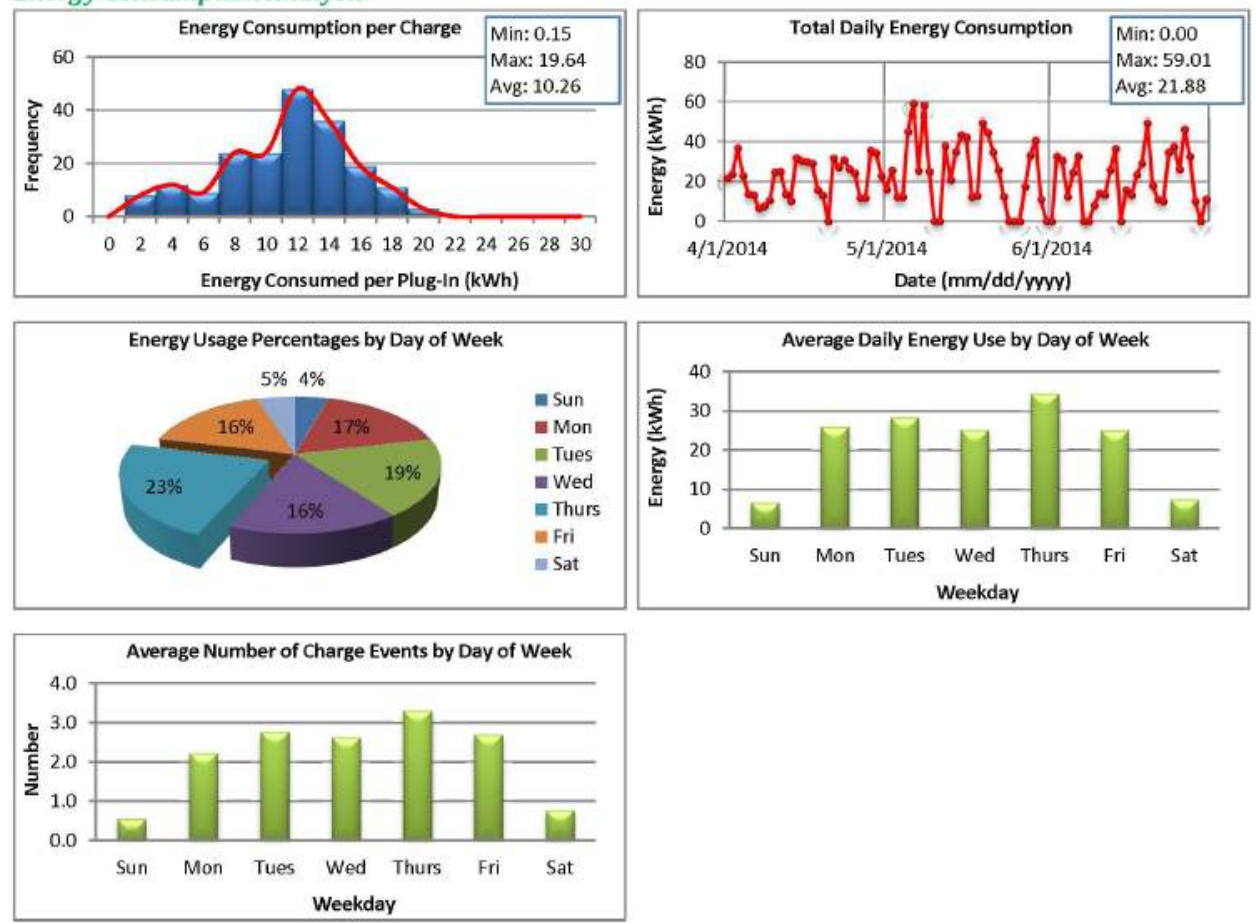

Charging Analysis
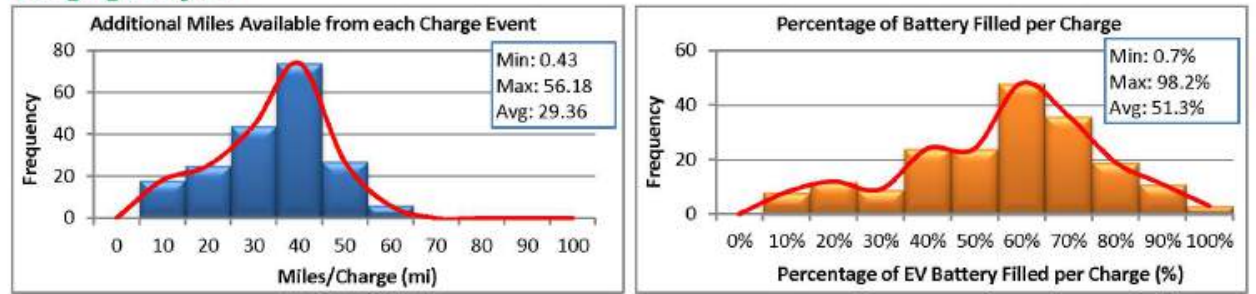

EVSE Analysís

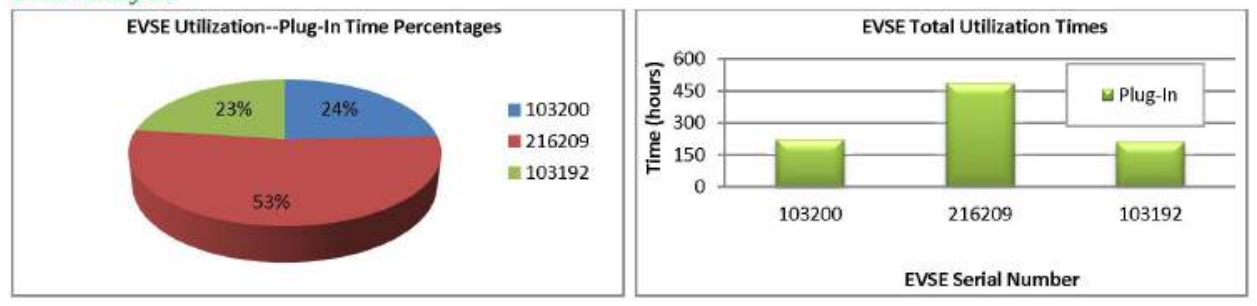

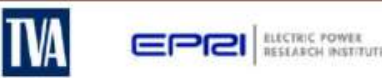

Page 2 


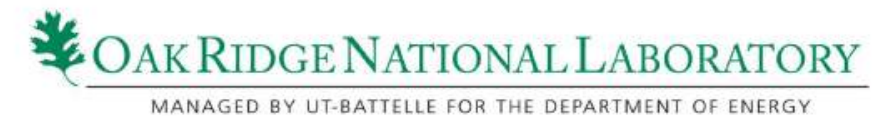

\begin{tabular}{l|cccc} 
Report Period Summary & Q1 & Q2 & Q3 & Q4 \\
\hline Average connection duration (hrs.) & 5.1 & 4.8 & - & - \\
$\begin{array}{l}\text { Average miles per charge } \\
\text { Average } \% \text { of battery filled per }\end{array}$ & 33.5 & 29.4 & - & - \\
$\quad$ charge event & $58.5 \%$ & $51.3 \%$ & -
\end{tabular}

EVSE Quarterly Load Profile

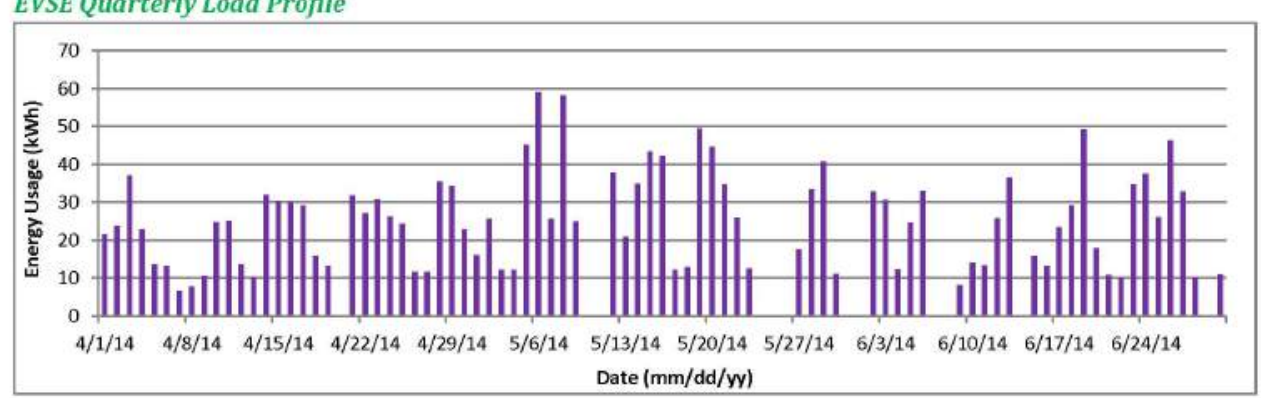

PV Array Quarterly Power Generation Profile

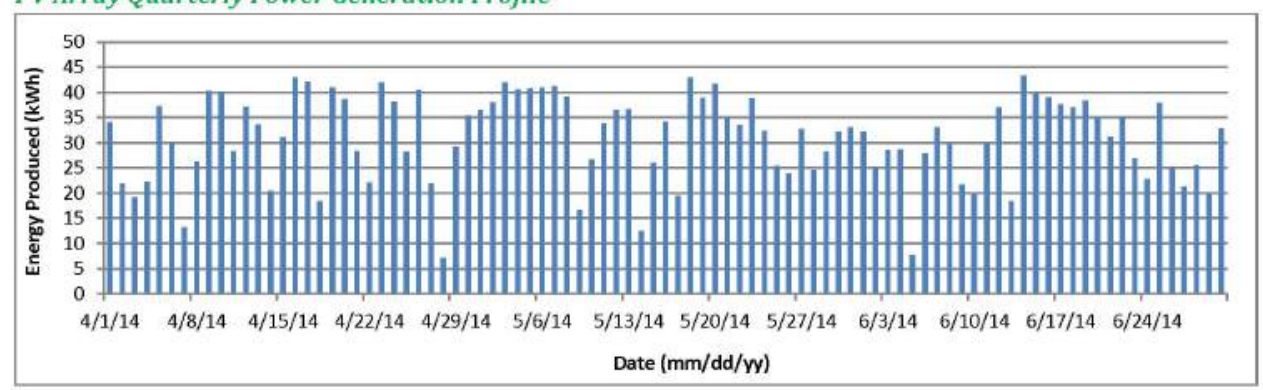

Note: Solar data was not provided for the site. Values shown are estimated based on power generation from other PV arrays in Nashville.

Based on the total energy consumption and an average of miles per $\mathrm{kWh}$ for the Nissan Leaf $(2.94 \mathrm{mi} / \mathrm{kWh})$ and Chevy Volt $(2.78 \mathrm{mi} / \mathrm{kWh})$. Values taken from http://www.fueleconomy.gov/.

Based on energy consumption and size of battery for the Nissan Leaf ( $24 \mathrm{kWh}$ ) and Chevy Volt (16 kWh).

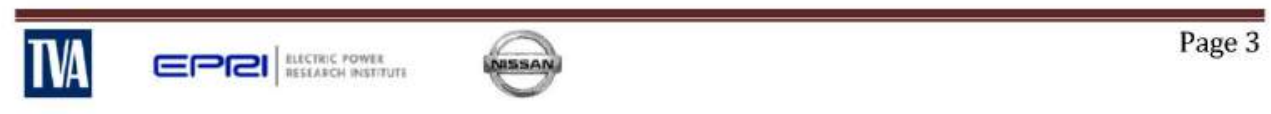


APPENDIX B. UTILIZATION SUMMARY REPORTS 



\section{APPENDIX B. UTILIZATION SUMMARY REPORTS}

\section{ORNL All Campus EVSEs}
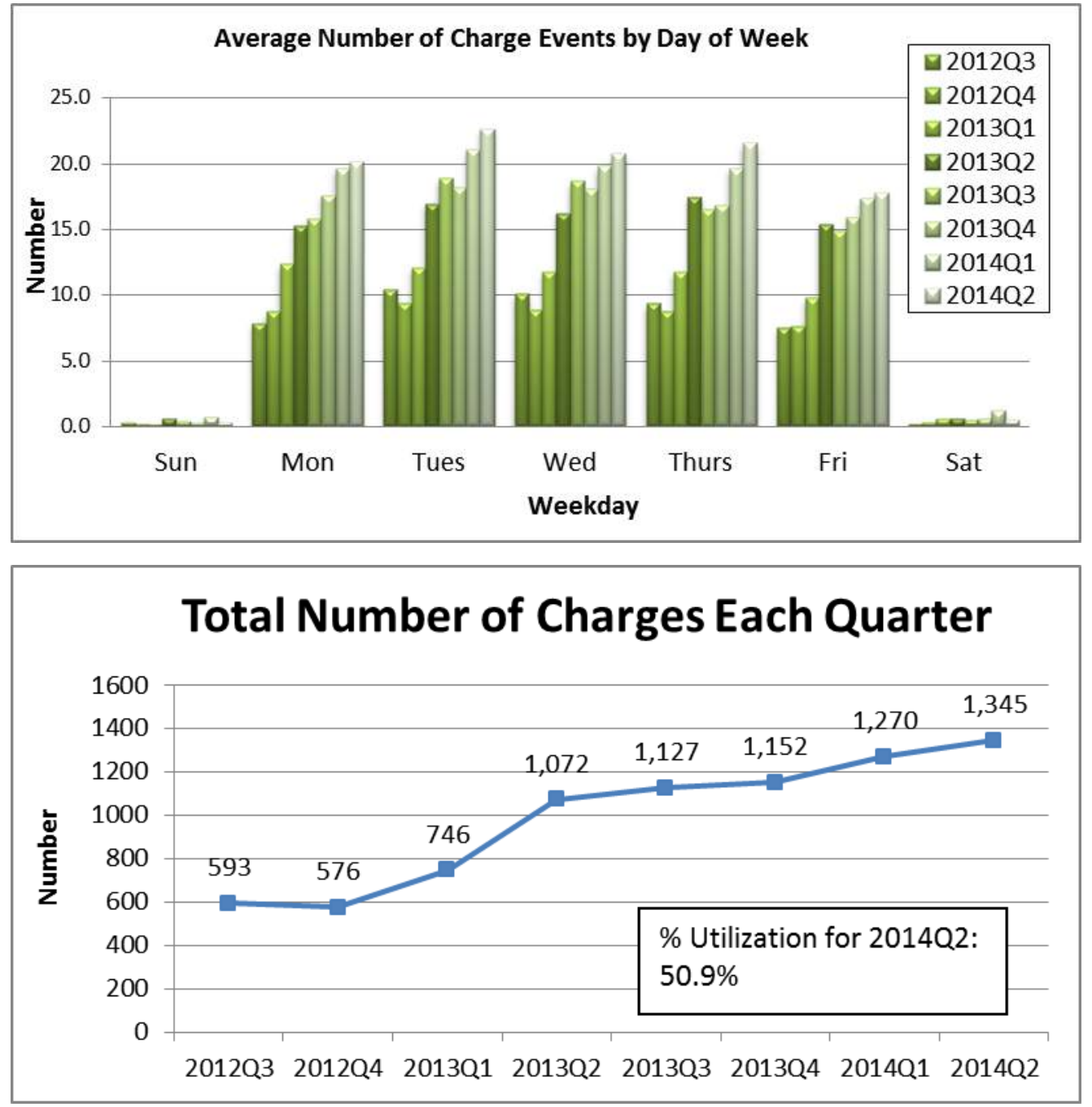
ORNL Solar-Assisted EVSEs
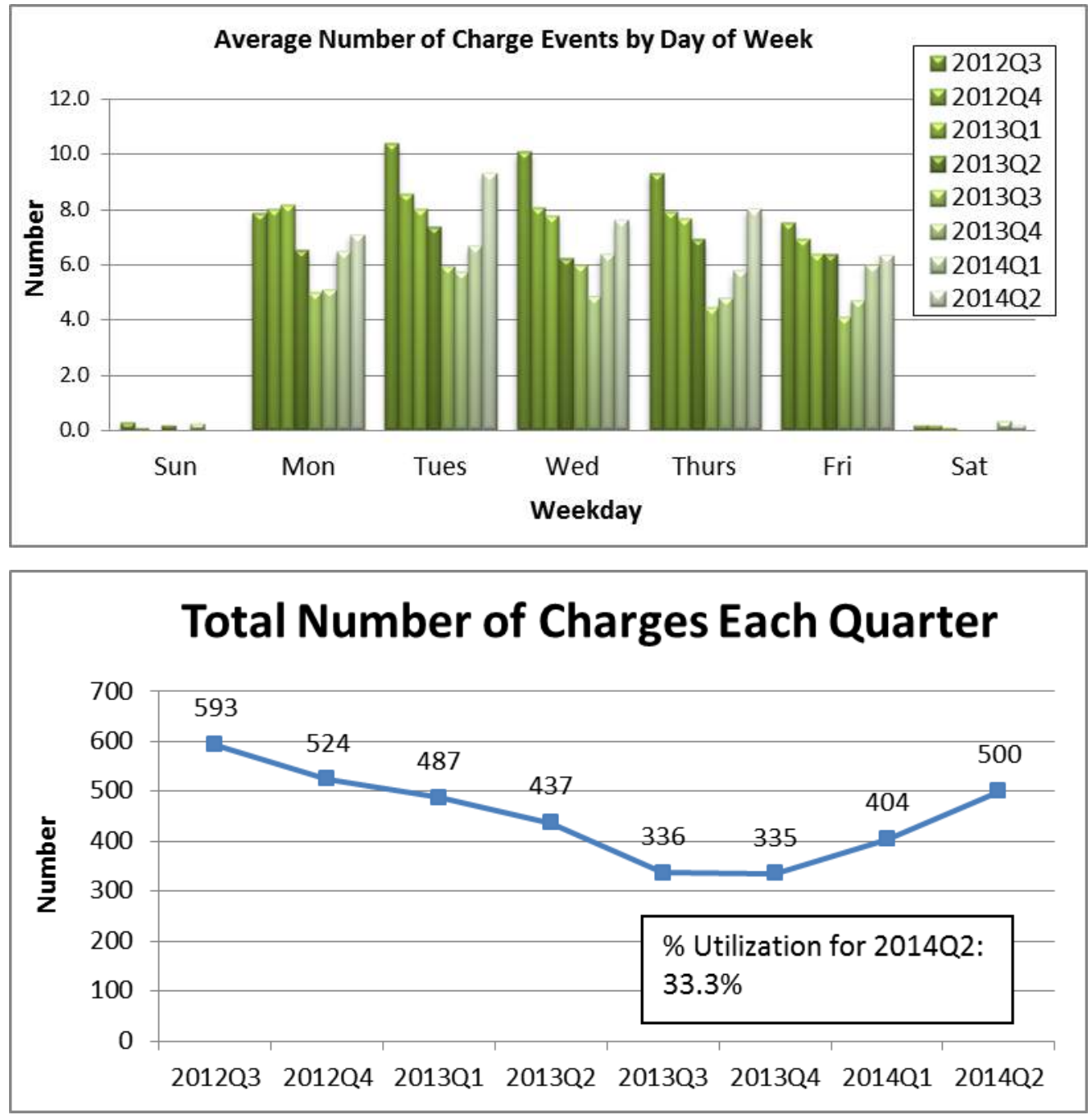


\section{ORNL Non-Solar EVSEs}
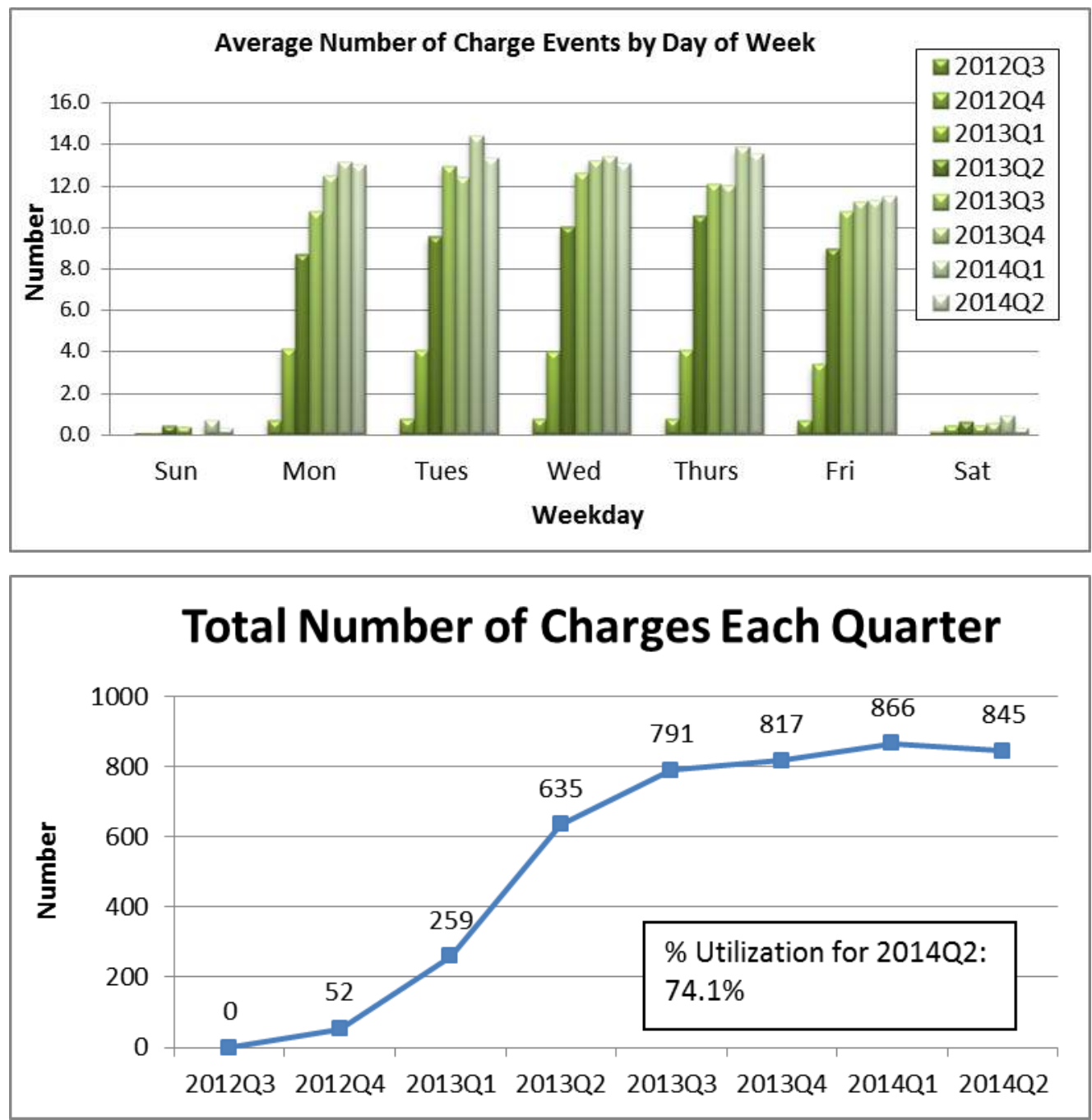


\section{UT-Knoxville Agriculture Campus}
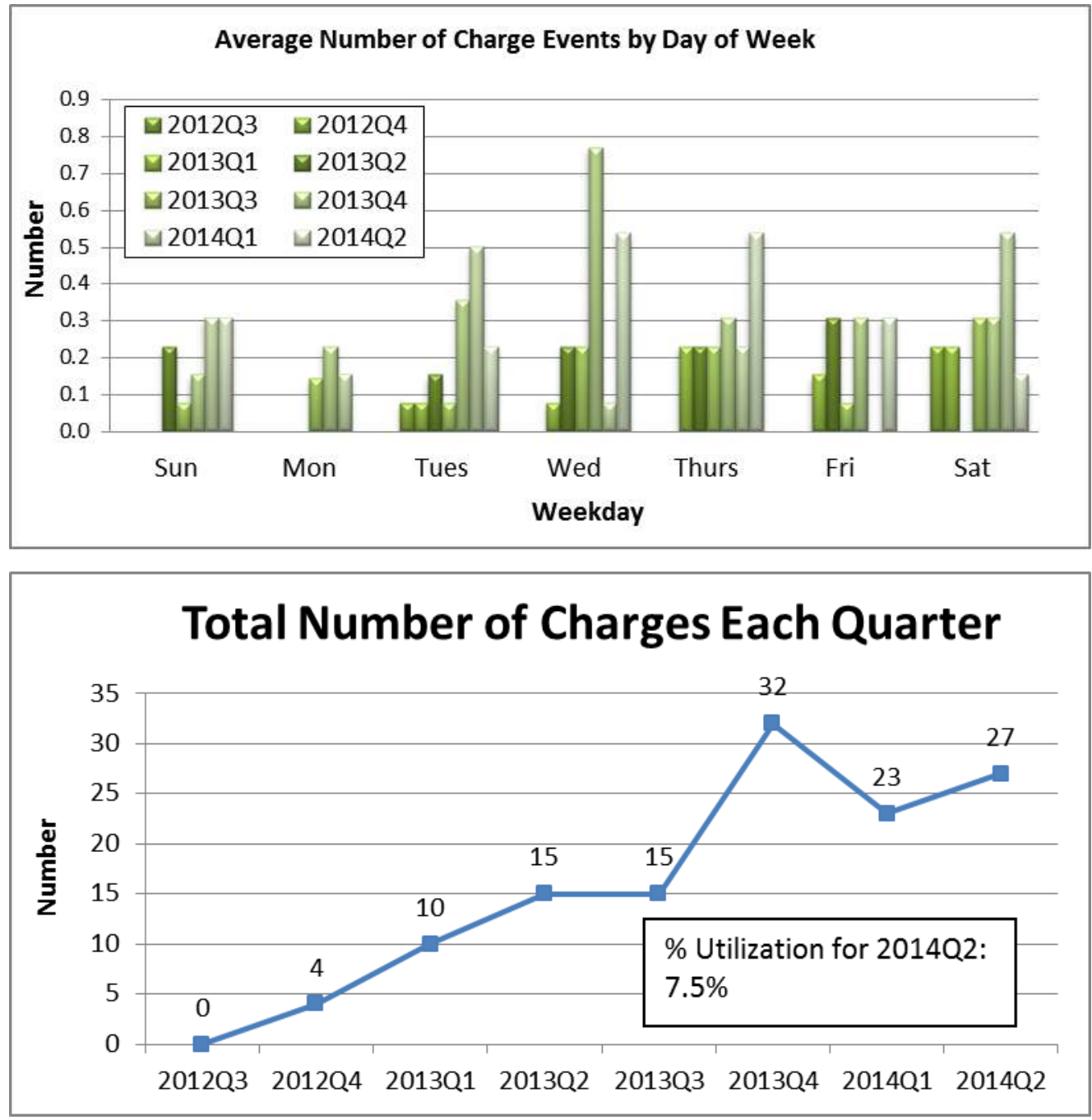


\section{UT-Knoxville Music Building}
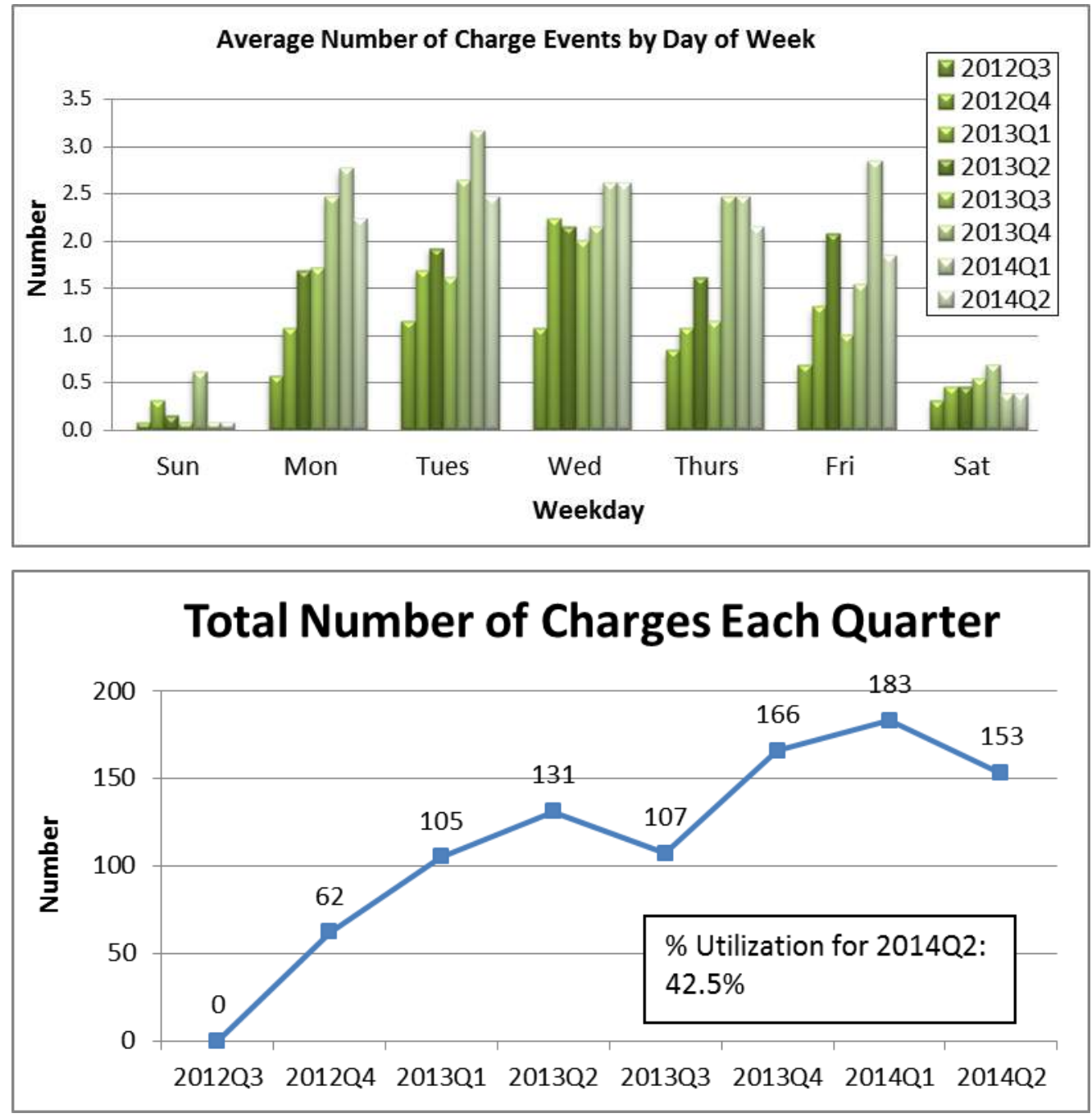


\section{LP Field, Nashville}
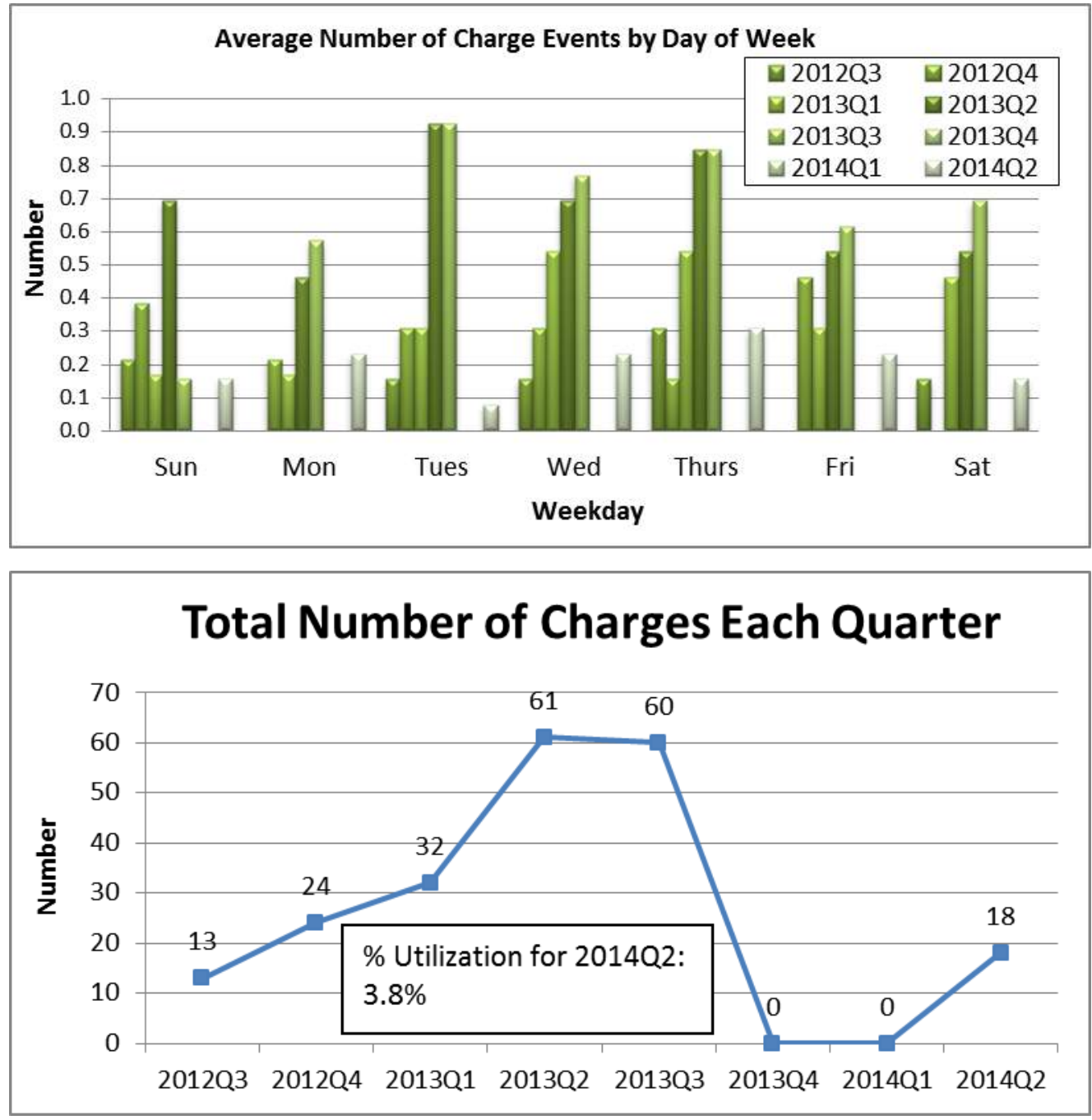

No data available 9/11/2013-5/14/2014 due to extended power outage. 
TN State Lot, Nashville
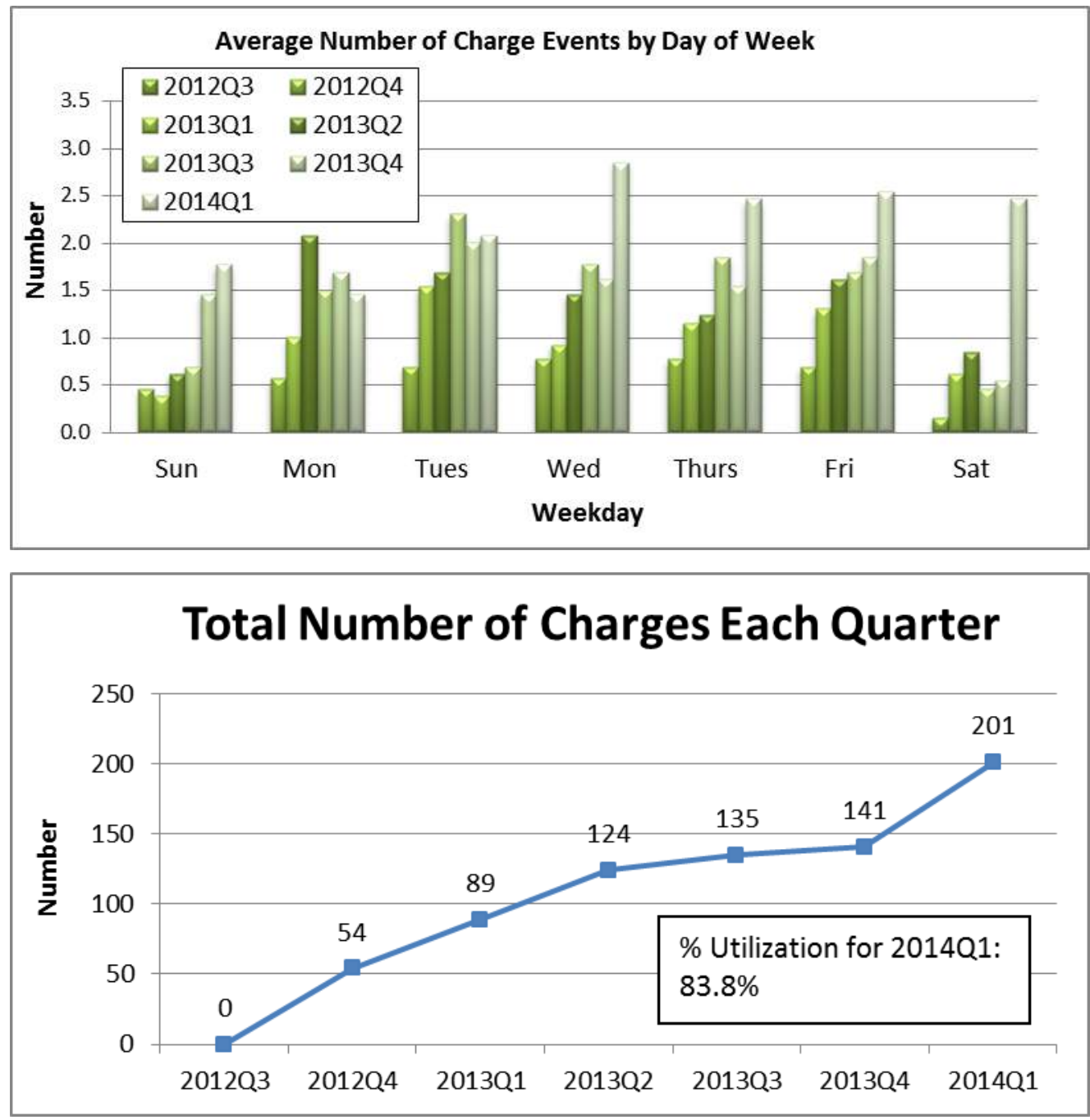

No data in 2014Q2 (The charging station was removed from service on 3/15/2014 and will be reinstalled at a later date). 
$\underline{\text { Knoxville Civic Coliseum }}$
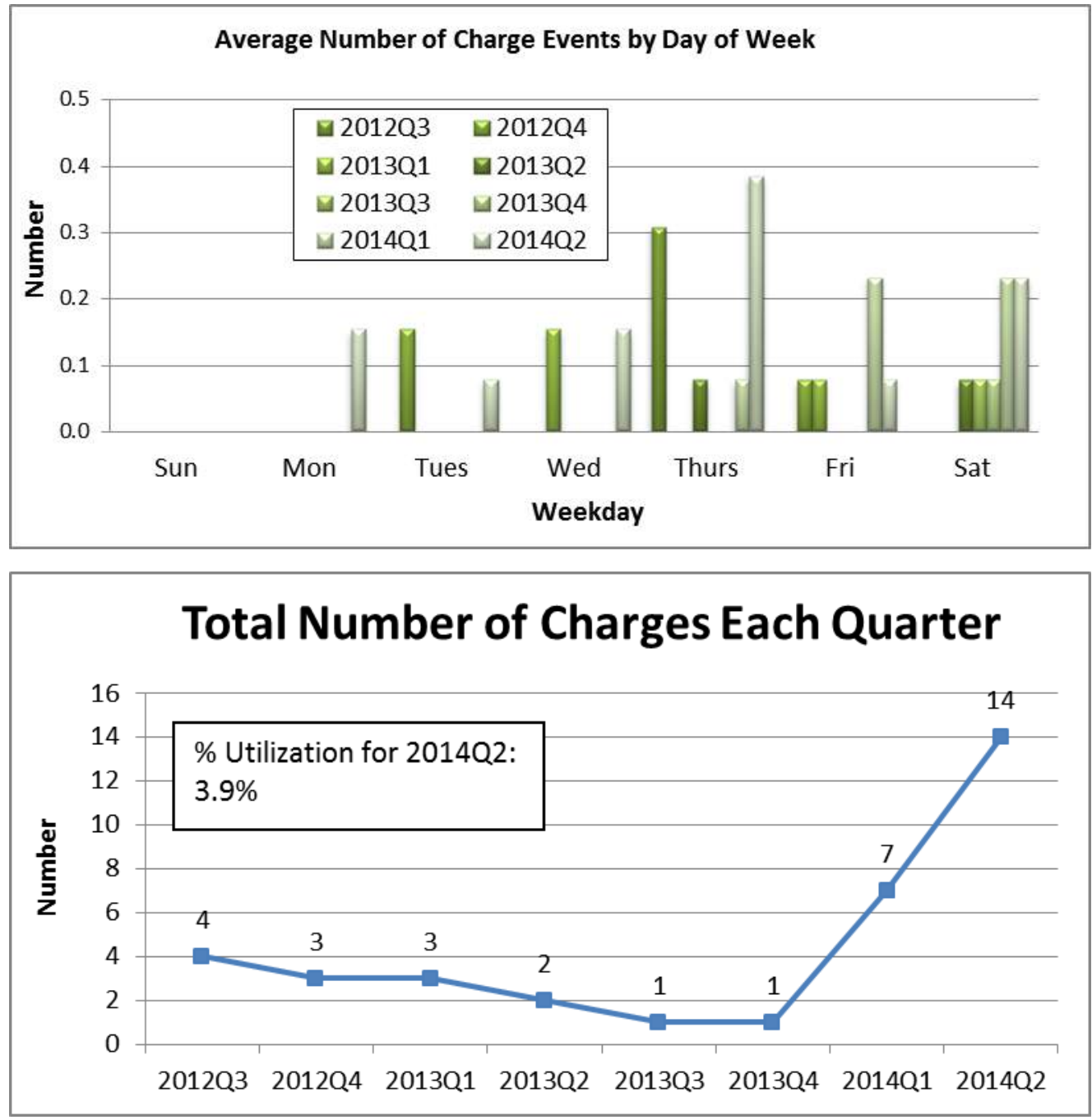
Knoxville Market Square
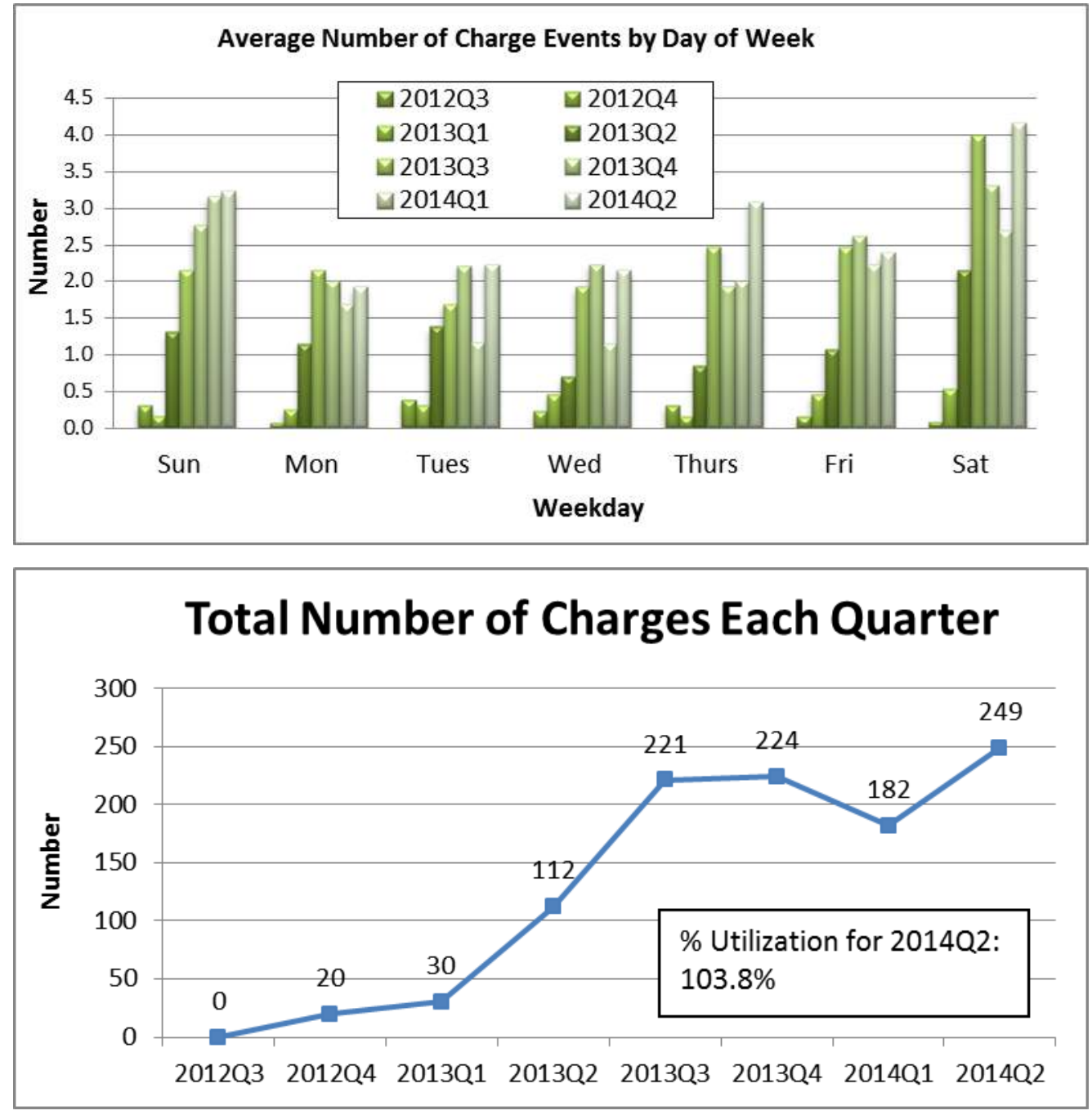
Nissan Battery Plant, Smyrna
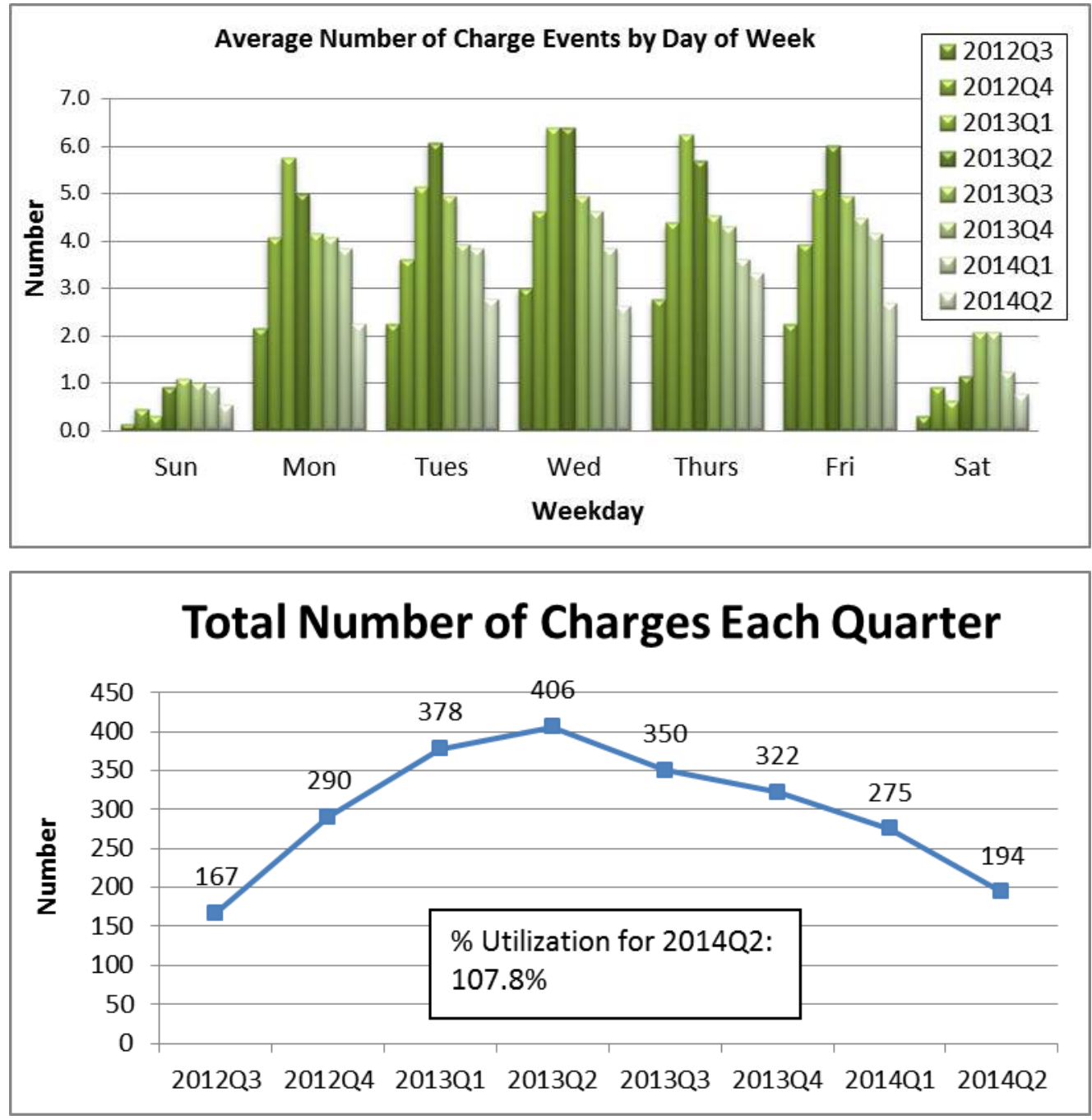
Nissan Smyrna Assembly Plant, Administration Building
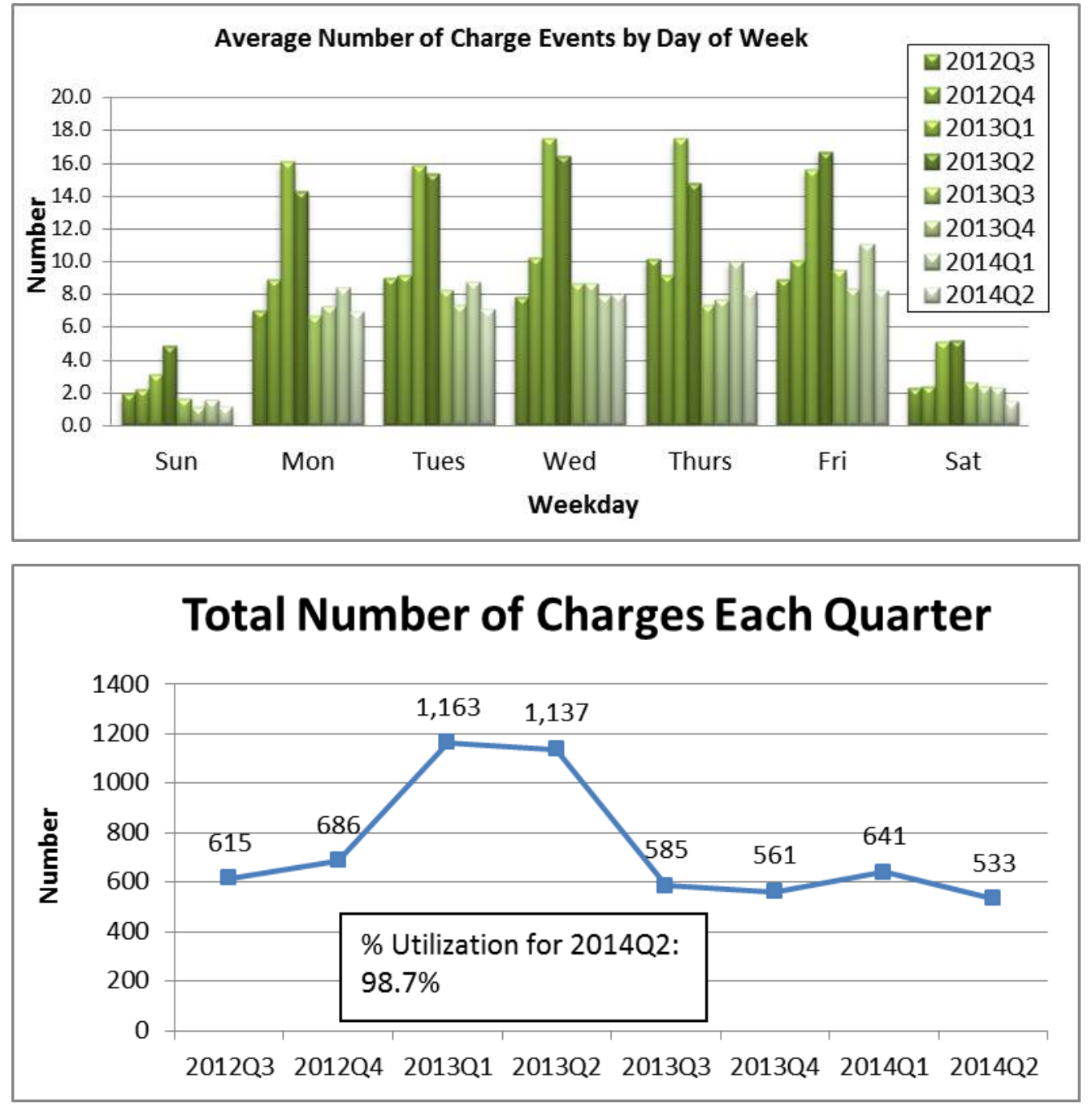
Nissan Headquarters, Franklin
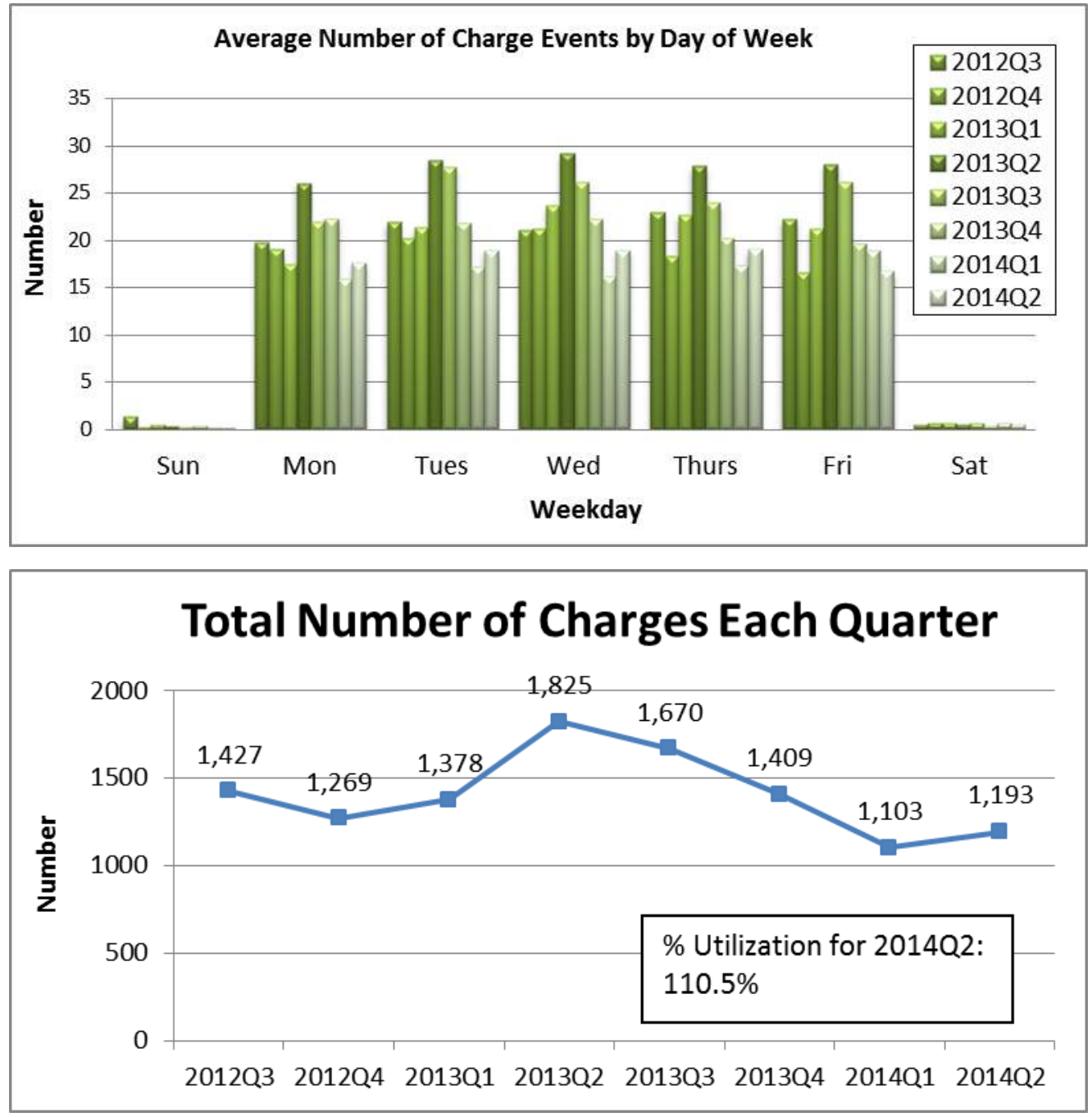
EPRI Knoxville
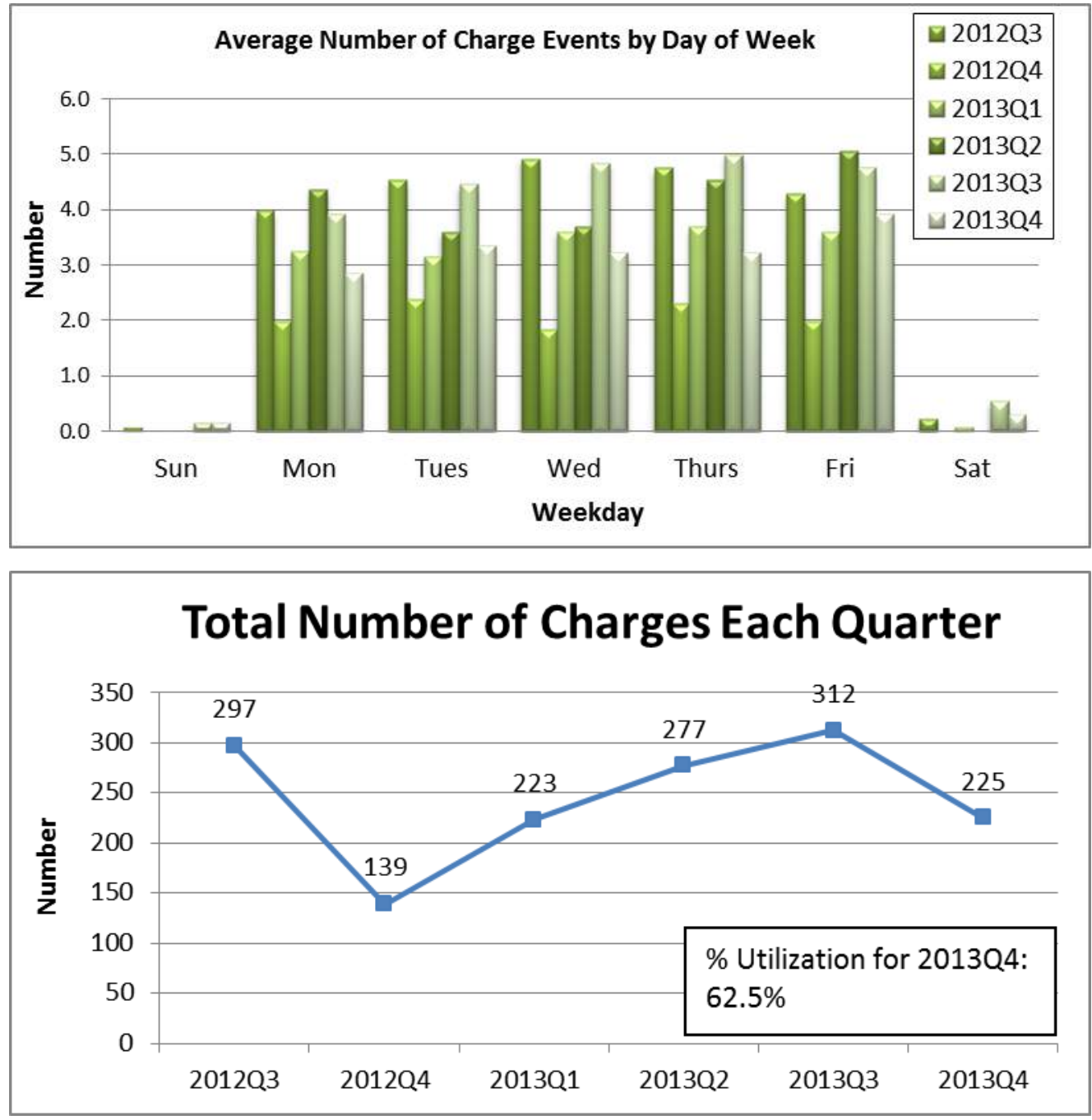

No data available in 2014 
TVA Advanced Vehicle Test Facility, Chattanooga
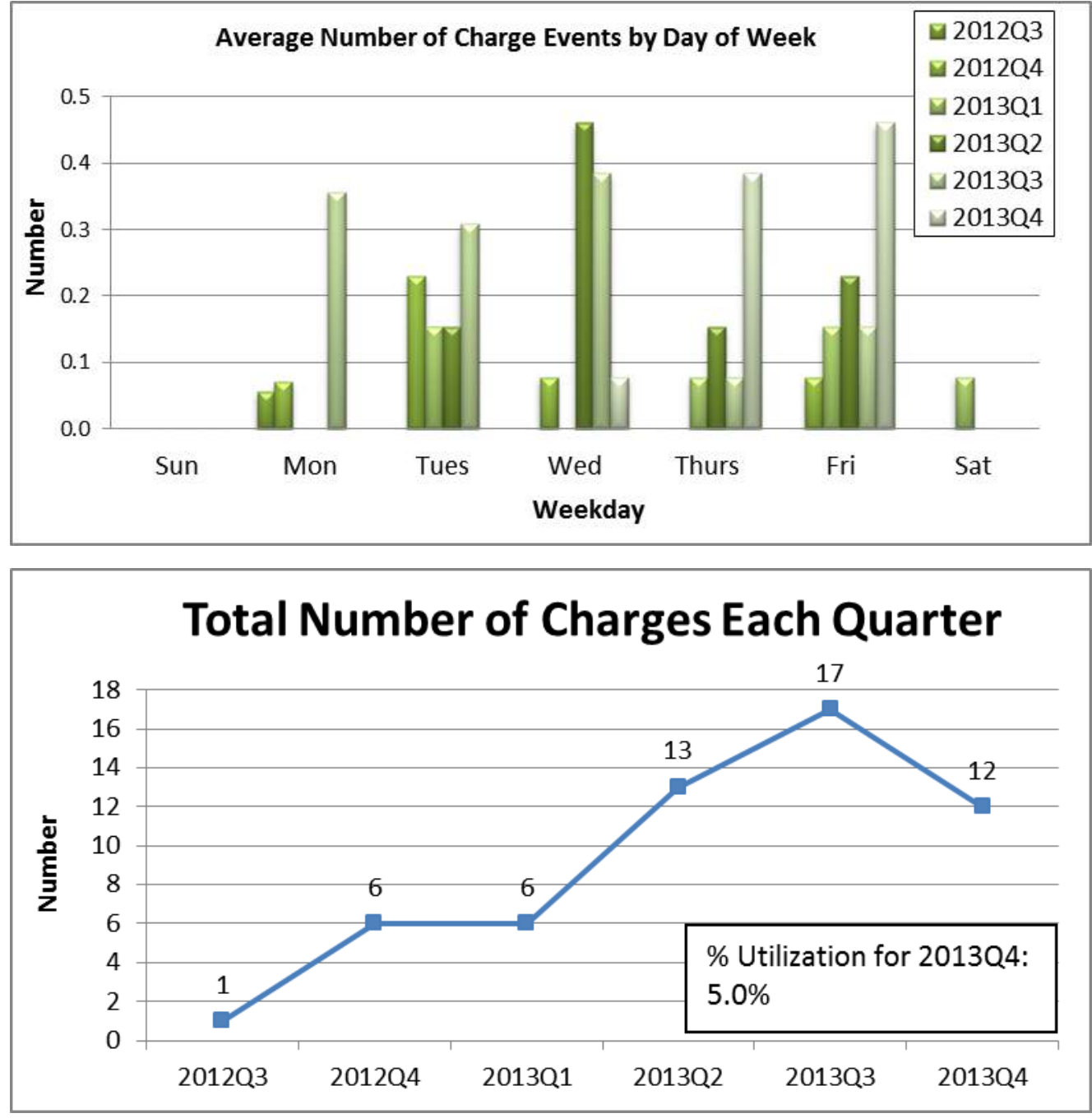

No data available in 2014 
Vanderbilt University, Nashville
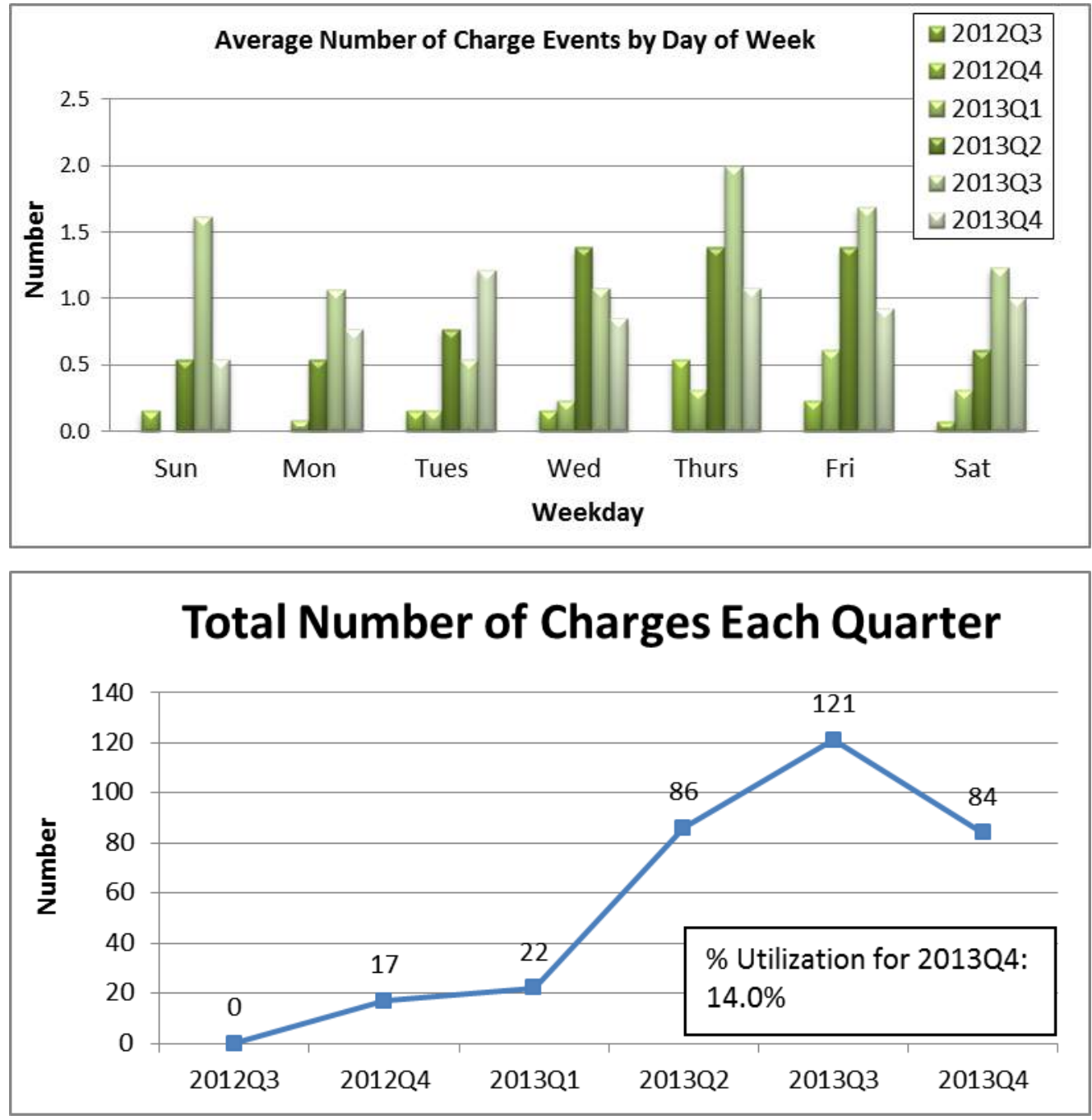

No data available in 2014 
Shelby Farms Park, Memphis
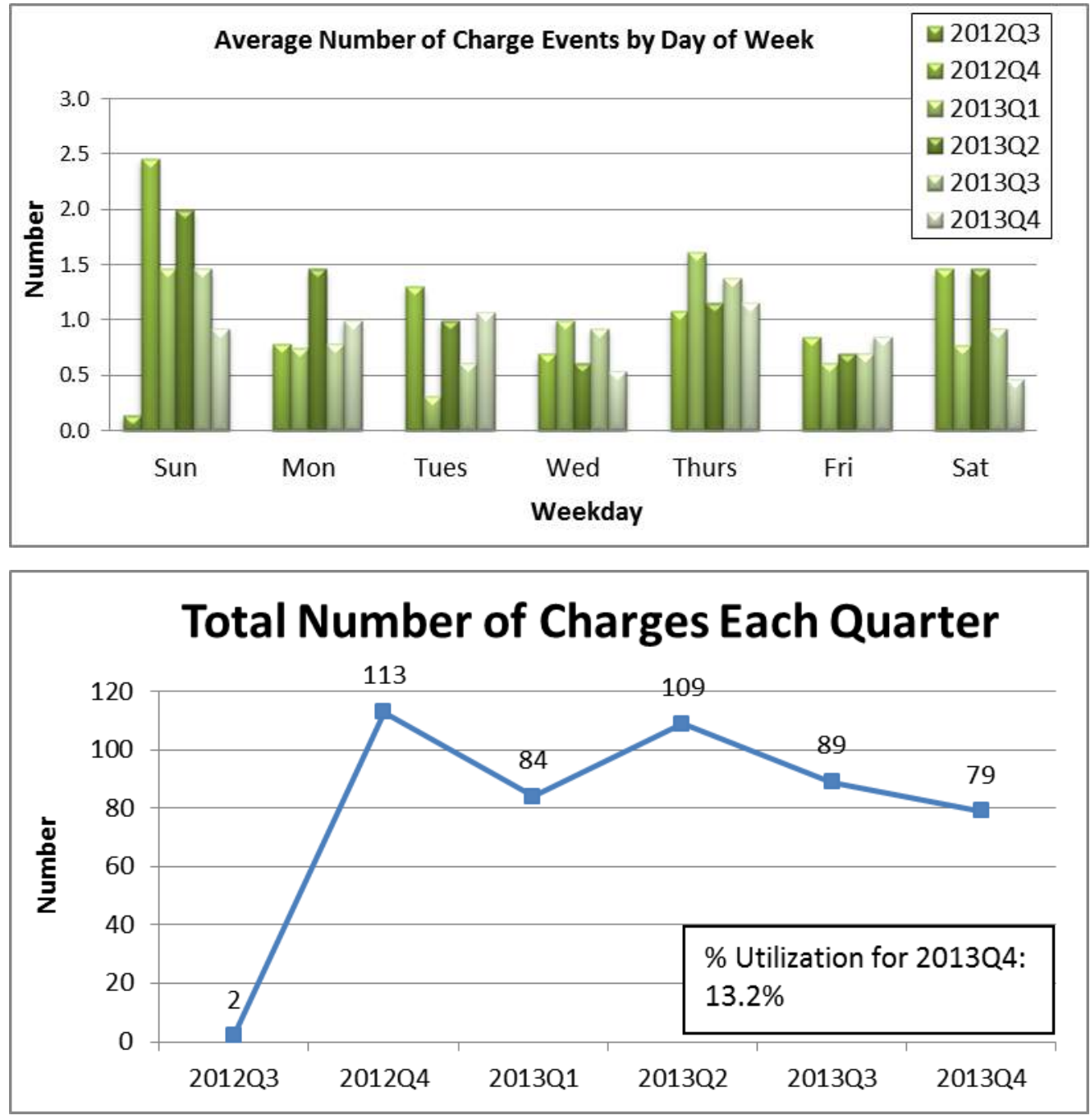

No data available in 2014 


\section{Chattanooga Theatre Center}
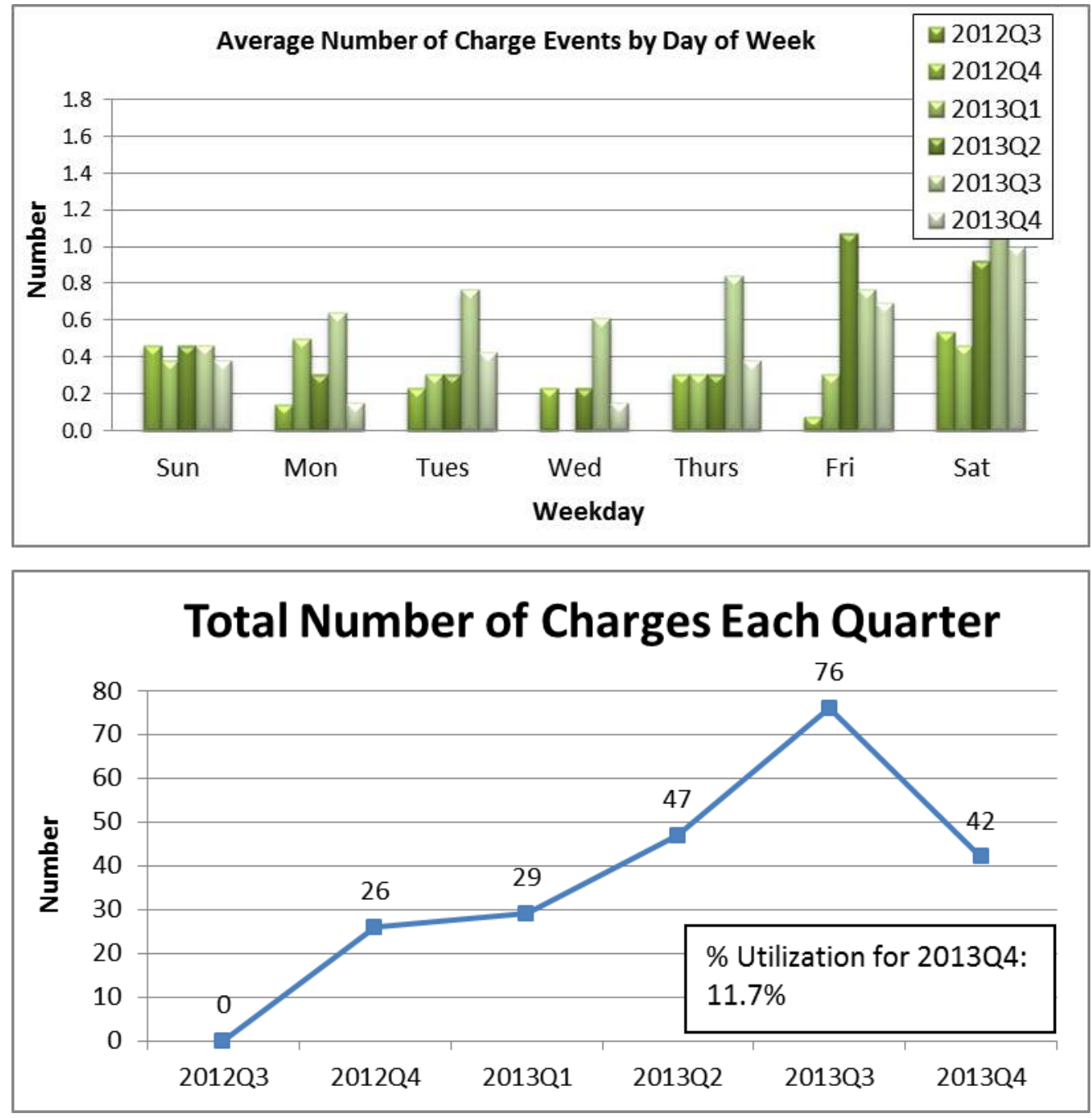

No data available in 2014 
Table B.1. Number of charge events By EVSE charging station site

\begin{tabular}{|c|c|c|c|c|c|c|c|c|}
\hline & $2012 Q 3$ & 2012Q4 & 2013Q1 & 2013Q2 & $2013 Q 3$ & $2013 Q 4$ & 2014Q1 & $2014 Q 2$ \\
\hline ORNL Solar-Assisted & 593 & 524 & 487 & 437 & 336 & 335 & 404 & 500 \\
\hline ORNL Non-Solar & 0 & 52 & 259 & 635 & 791 & 817 & 866 & 845 \\
\hline ORNL All EVSEs & 593 & 576 & 746 & 1072 & 1127 & 1152 & 1270 & 1345 \\
\hline $\begin{array}{l}\text { UTK Agriculture } \\
\text { Campus }\end{array}$ & 0 & 4 & 10 & 15 & 15 & 32 & 23 & 27 \\
\hline UTK Music Bldg & 0 & 62 & 105 & 131 & 107 & 166 & 183 & 153 \\
\hline LP Field & 13 & 24 & 32 & 61 & 60 & 0 & 0 & 18 \\
\hline TN State Lot & 0 & 54 & 89 & 124 & 135 & 141 & 201 & NA \\
\hline Knoxville Coliseum & 4 & 3 & 3 & 2 & 1 & 1 & 7 & 14 \\
\hline Market Square & 0 & 20 & 30 & 112 & 221 & 224 & 182 & 249 \\
\hline Nissan Battery Plant & 167 & 290 & 378 & 406 & 350 & 322 & 275 & 194 \\
\hline Nissan Smyrna & 615 & 686 & 1163 & 1137 & 585 & 561 & 641 & 533 \\
\hline Nissan Franklin & 1427 & 1269 & 1378 & 1825 & 1670 & 1409 & 1103 & 1193 \\
\hline EPRI Knoxville & 297 & 139 & 223 & 277 & 312 & 225 & - & - \\
\hline $\begin{array}{l}\text { Chattanooga Theatre } \\
\text { Center }\end{array}$ & 0 & 26 & 29 & 47 & 76 & 42 & - & - \\
\hline $\begin{array}{l}\text { TVA Vehicle Test } \\
\text { Facility }\end{array}$ & 1 & 6 & 6 & 13 & 17 & 12 & - & - \\
\hline Shelby Farms & 2 & 113 & 84 & 109 & 89 & 79 & - & - \\
\hline Vanderbilt & 0 & 17 & 22 & 86 & 121 & 84 & - & - \\
\hline All Blink EVSEs & 1392 & 1719 & 2556 & 3060 & 2601 & 2599 & 2782 & 2533 \\
\hline $\begin{array}{l}\text { All EPRI-installed } \\
\text { EVSEs }\end{array}$ & 300 & 301 & 364 & 532 & 615 & 442 & - & - \\
\hline Total All EVSEs & 3119 & 3289 & 4298 & 5417 & 4886 & 4450 & $3885 *$ & 3726* \\
\hline
\end{tabular}

* EPRI data were not available after 2013Q4, so the totals for 2014 do not include the utilization at the EPRIinstalled sites. 